SAND--86-0611

DE87 009350

SAND86-0611

Distribution

Unlimited Release

Category UC -70

Printed April 1987

\title{
Basic Data Report for Drilling and Hydrologic Testing of Drillhole DOE-2 at the Waste Isolation Pilot Plant (WIPP) Site
}

\author{
Jerry W. Mercer \\ Engineering Projects Division \\ Richard L. Beauheim \\ Earth Sciences Division \\ Sandia National Laboratories \\ Albuquerque, NM 87185 \\ Richard P. Snyder and George M. Fairer \\ US Geological Survey \\ Denver, CO 80225

This document is
PUBLICLY RELEASABLE
S Sleel
Authorizing Official
Date: $\quad 3 / 22 / 06$

\begin{abstract}
Drillhole DOE-2 was drilled to investigate a structural depression marked by the downward displacement of stratigraphic markers in the Salado Formation $\sim 2$ mi north of the center of the WIPP site. This depression was named informally after the shallow borehole FC-92 in which the structure was described. The presence of the depression was confirmed by drilling. Contrary to several hypotheses, halite layers were thicker in the lower part of the Salado, not thinner as a result of any removal of halite. The upper Castile anhydrite in Drillhole DOE-2 is anomalously thick and is strongly deformed relative to the anhydrite in adjacent drillholes. In contrast, the halite was $<8 \mathrm{ft}$ thick and significantly thinner than usually encountered. The lower Castile anhydrite appears to be normal. The depression within the correlated marker beds in the Salado Formation in Drillhole DOE-2 is interpreted as a result of gravity-driven deformation of the underlying Castile Formation.
\end{abstract}

Several stratigraphic units were hydrologically tested in Drillhole DOE-2. Testing of the unsaturated lower portion of the Dewey Lake Red Beds was unsuccessful because of exceptionally small rates of fluid intake. Drill-stem tests were conducted in five intervals in the Rustler Formation, over the Marker Bed 138-139 interval in the Salado Formation, and over three sandstone members of the Bell Canyon Formation. A pumping test was conducted in the Culebra Dolomite Member of the Rustler Formation. Pressure-pulse tests were conducted over the entire Salado Formation. Fluid samples were collected from the Culebra Dolomite Member and from the Hays Member of the Bell Canyon Formation. 


\section{DISCLAIMER}

This report was prepared as an account of work sponsored by an agency of the United States Government. Neither the United States Government nor any agency Thereof, nor any of their employees, makes any warranty, express or implied, or assumes any legal liability or responsibility for the accuracy, completeness, or usefulness of any information, apparatus, product, or process disclosed, or represents that its use would not infringe privately owned rights. Reference herein to any specific commercial product, process, or service by trade name, trademark, manufacturer, or otherwise does not necessarily constitute or imply its endorsement, recommendation, or favoring by the United States Government or any agency thereof. The views and opinions of authors expressed herein do not necessarily state or reflect those of the United States Government or any agency thereof. 


\section{DISCLAIMER}

Portions of this document may be illegible in electronic image products. Images are produced from the best available original document. 

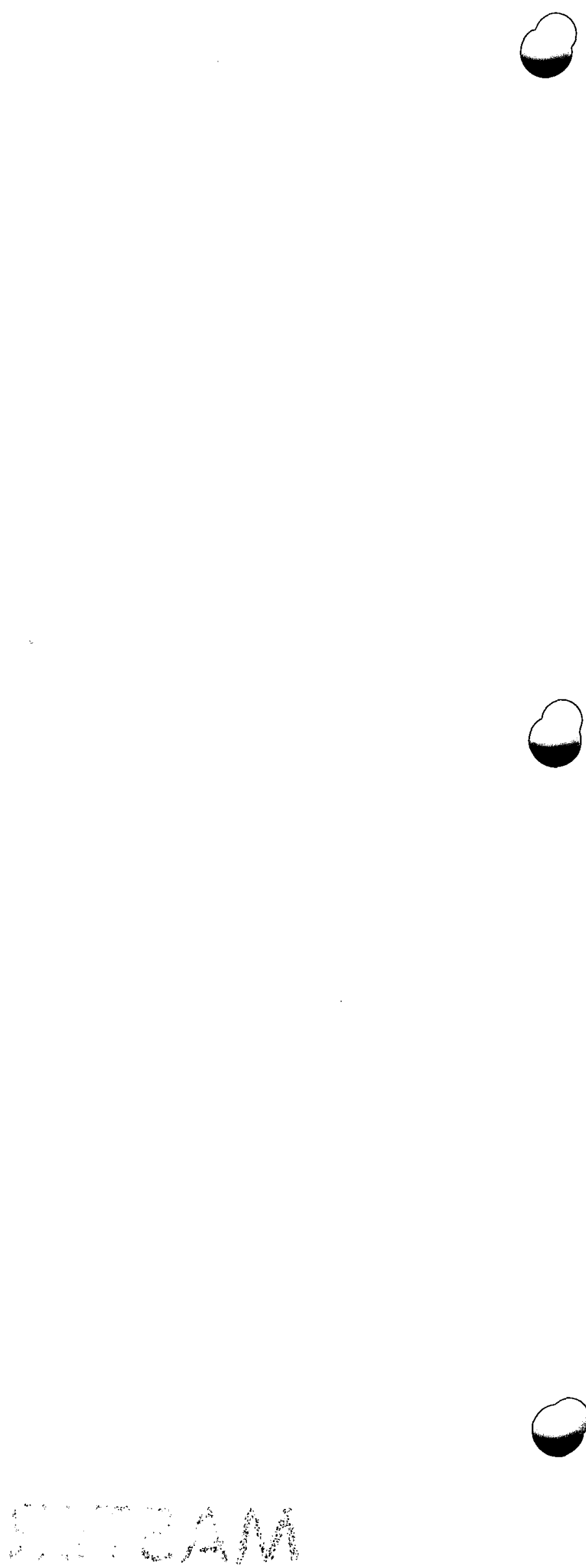


\section{Contents}

1. Executive Summary

2. Introduction

Jerry W. Mercer, Sandia National Laboratories ........................................................................................ 9

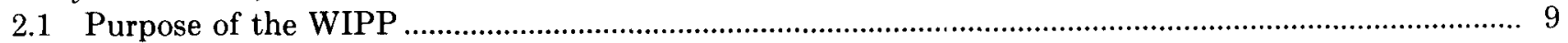

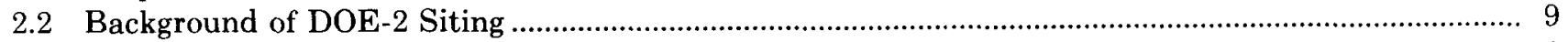

2.3 The Purpose of Drillhole DOE-2

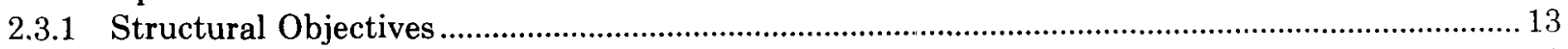

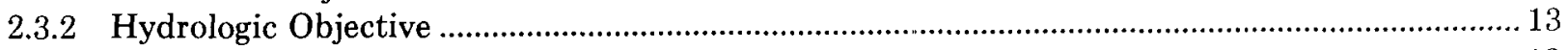

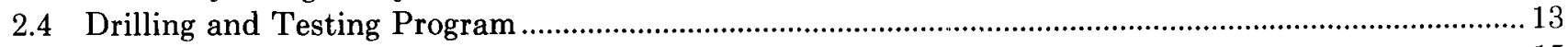

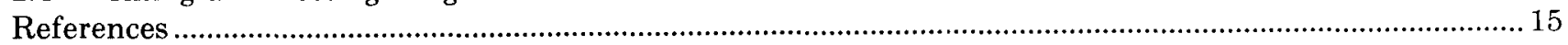

3. Geologic Data

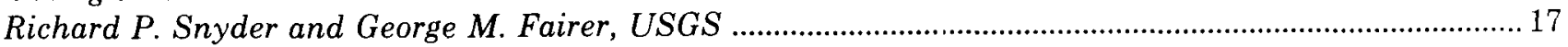

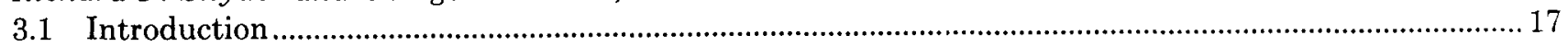

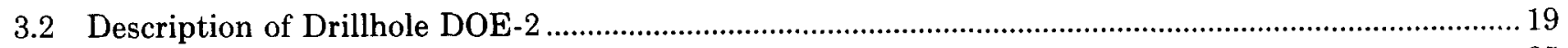

3.3 Description of Cuttings and Core

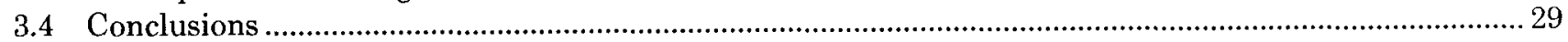

3.5 Structural Summary

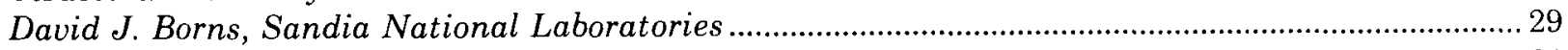

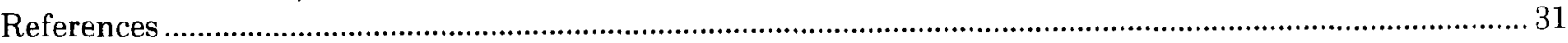

4. Hydrologic Testing

Richard L. Beauheim, Sandia National Laboratories ................................................................................... 33

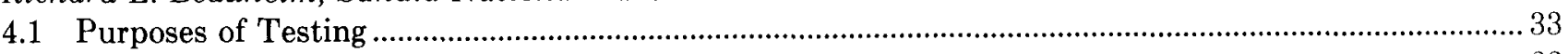

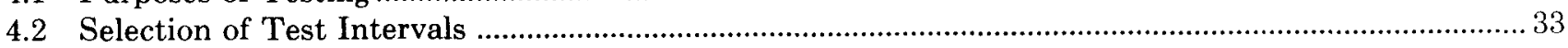

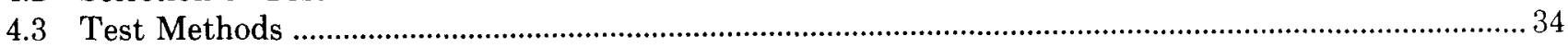

4.3.1 Constant-Head Borehole-Infiltration Tests ................................................................................ 34

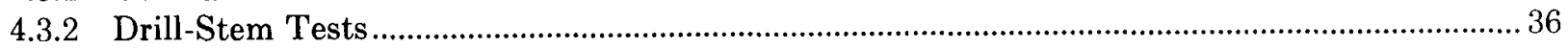

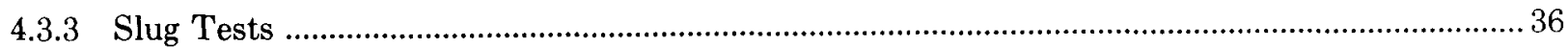

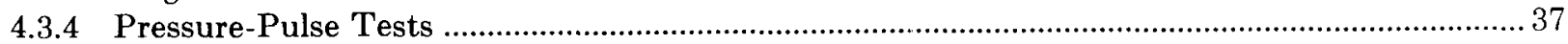

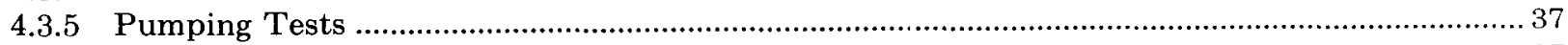

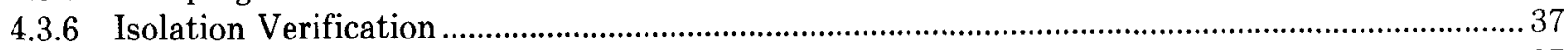

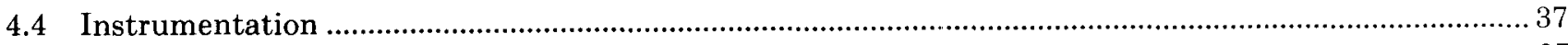

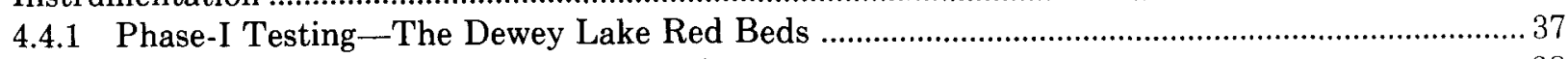

4.4.2 Phase-I Testing-The Rustler Formation ............................................................................... 38

4.4.3 Phase-Ia Testing-The Culebra Dolomite Member ........................................................................ 39

4.4.4 Phases-II and -III Testing-The Salado and Bell Canyon Formations .....................................4 41

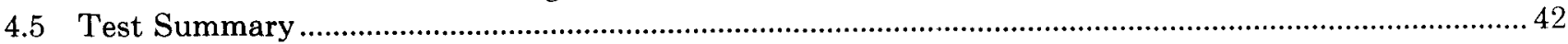

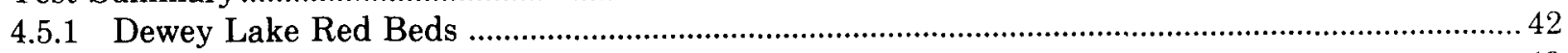

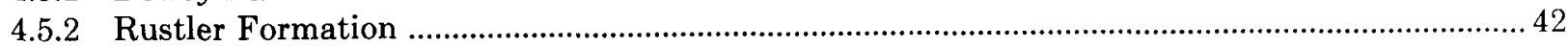

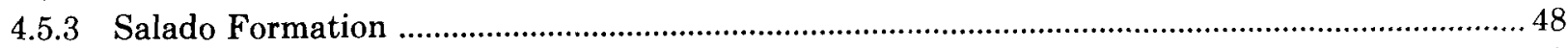

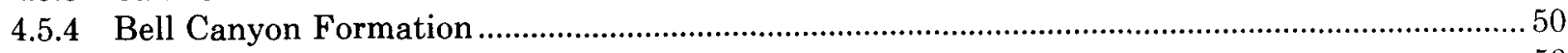

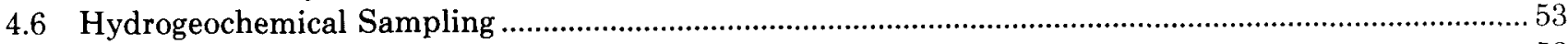

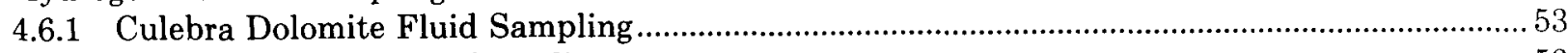

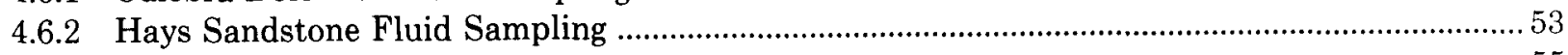

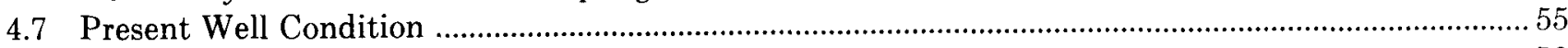

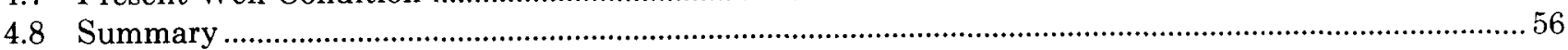

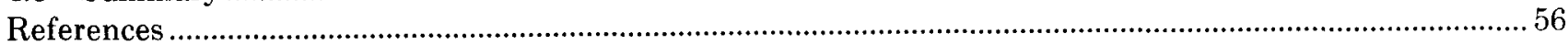




\section{Contents (continued)}

APPENDIX A-Field Operations Plan of Sandia National Laboratories for WIPP Site Investigations of Drillhole DOE-2, Phase I

APPENDIX B-Field Operations Plan of Sandia National Laboratories for WIPP Site Investigations of Drillhole DOE-2, Phases II and III ....

APPENDIX C-Abridged Hole History of Drillhole DOE-2: Phases I, II, and JII ....................................... 209

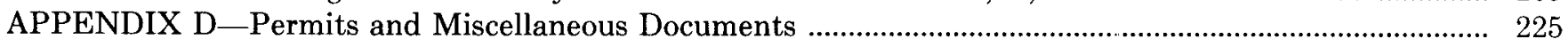

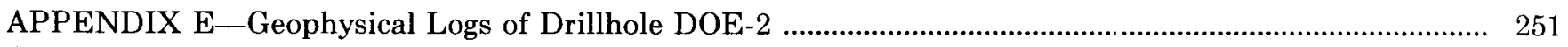

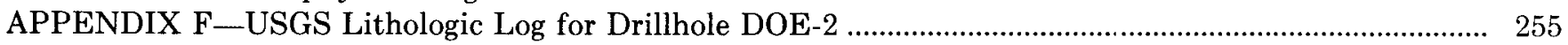

\section{Figures}

2-1 Location Map for Drillhole DOE-2, WIPP Site, Southeastern New Mexico ......................................... 9

2-2 Structure Contours for MB-124 in the Salado Formation .................................................................. 10

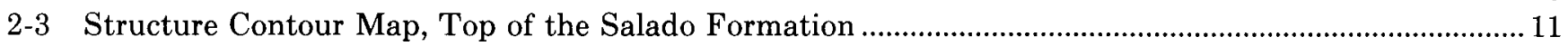

2-4 WIPP Drillhole DOE-2 As-Built Conditions After Hydrologic Tests, July 1985 ....................................14

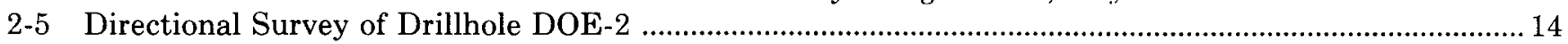

3-1 Location of WIPP Site and Drillholes DOE-2, W-11, W-12, and W-13 .................................................. 18

3-2 Lithologic and Geophysical Logs of Drillhole DOE-2 …......................................................plastic envelope

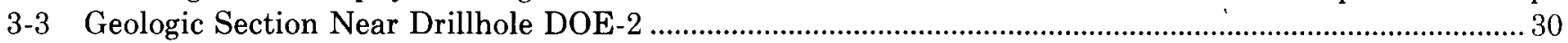

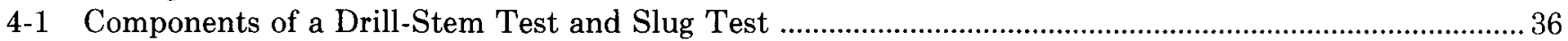

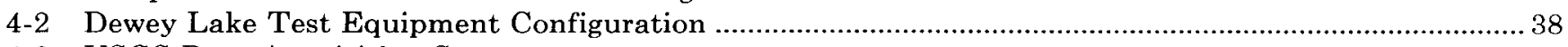

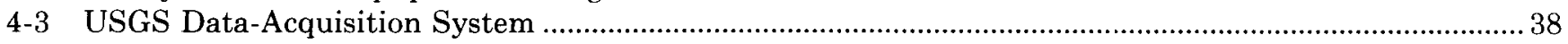

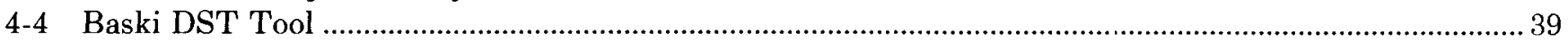

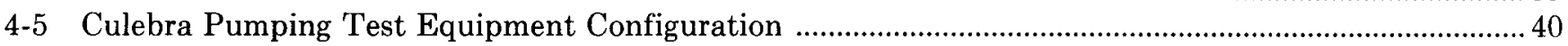

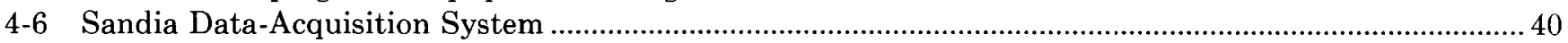

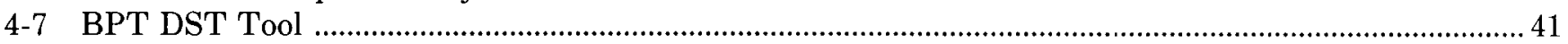

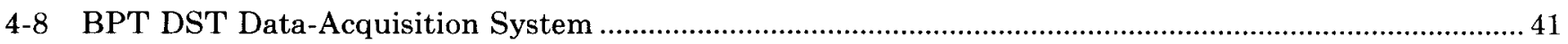

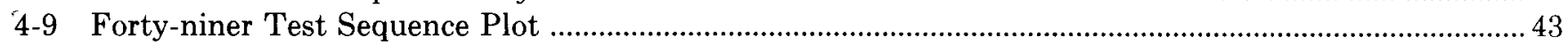

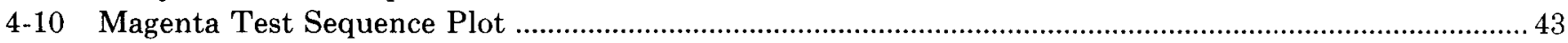

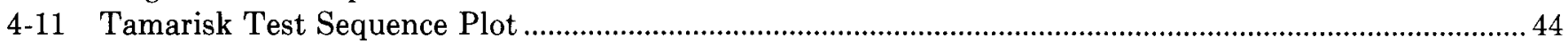

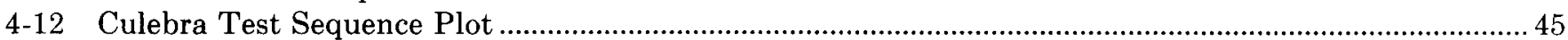

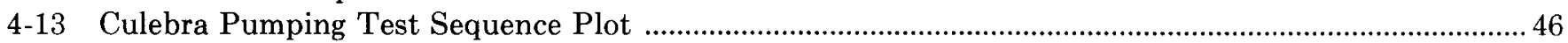

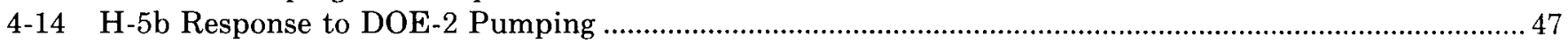

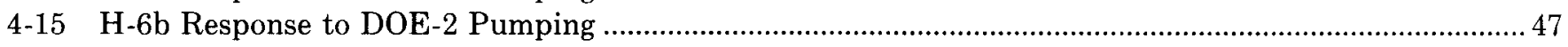

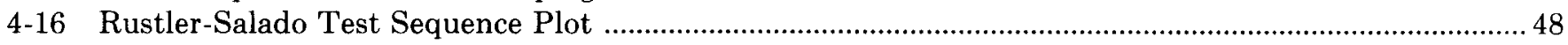

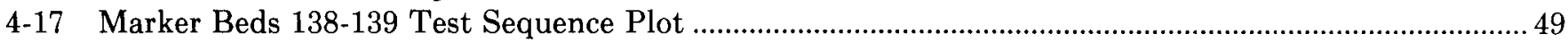

4-18 Bottom-Hole Temperature and Pressure During Marker Beds 138-139 Testing ...................................49

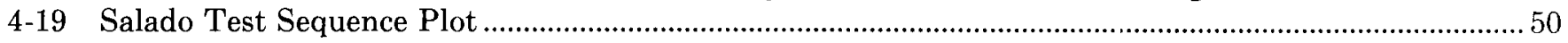

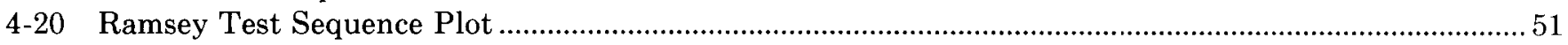

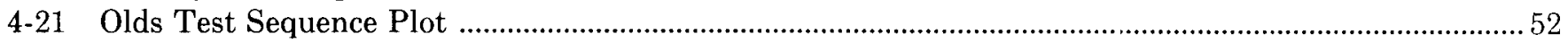

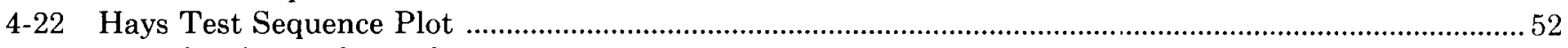

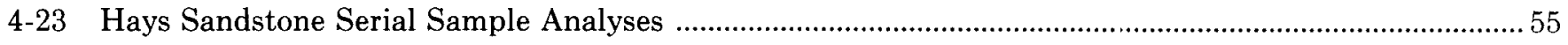

\section{Tables}

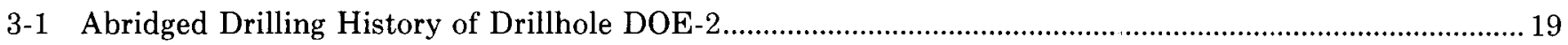

3-2 Stratigraphic Summary of Drillhole DOE-2

3-3 Interval Thicknesses of Salado Formation in Drillholes W-11, W-12, and DOE-2; and Differences

in Thickness of the Intervals in W-11 and W-12 Compared to Interval Thicknesses in DOE-2 ..............27

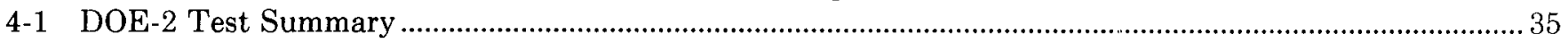

4-2 Solute Concentrations in Drillhole DOE-2 Groundwaters .................................................................5 


\section{Basic Data Report for Drilling and Hydrologic Testing of Drillhole DOE-2 at the Waste Isolation Pilot Plant (WIPP) Site}

\section{Executive Summary}

Geologic and hydrologic site characterization has progressed at the Waste Isolation Pilot Plant (WIPP) in southeastern New Mexico for more than 10 years. Although the major concentration of studies is ending, investigation into several questions continues. These questions, such as hydrologic variations within the evaporite sequence, and evaporite deformation within the Salado and Castile Formations, are being further evaluated to increase overall confidence in the reliability of WIPP performance.

One potentially significant area of interest lies 2 mi north of the center of the WIPP facility in an area called the "disturbed zone"; it consists of a stacked sequence of depressions in the Salado Formation. Drillhole DOE-2 (704FSL, 128FEL, Sec.8, T.22S., R.31E., Eddy County, NM) was drilled and hydrologically tested during 1984 and 1985 to investigate this depression. These studies are being done on behalf of the US Department of Energy (DOE) in response to their stipulated agreement with the State of New Mexico. C\&C item (1a) states: "Complete basic data report for Phases I, Ia, II, and III of DOE-2 drillhole." This report contains all basic geologic and hydrologic data obtained from the drilling and testing of Drillhole DOE-2.

Before DOE-2 was drilled, the depression, named informally after the shallow drillhole FC-92, was identified as circular and $\sim 0.5 \mathrm{mi}$ in diameter. Structural closure of the "FC-92 depression" was up to $25 \mathrm{ft}$ at the top of the Salado Formation. The structure was inferred to increase in diameter with increasing depth and to have $\sim 50 \mathrm{ft}$ of closure at Marker Bed 124, near the middle of the Salado. Structural data were not available below MB124. Such structures raise questions as to the processes that cause them; suggestions include the possible contributions of dissolution, gravity tectonics, and faulting in the evaporites.

Drillhole DOE-2 penetrated (from top to bottom) Pleistocene deposits, $13 \mathrm{ft}$, including fill material for the pad; Santa Rosa Sandstone, $120 \mathrm{ft}$; Dewey Lake Red Beds, $506 \mathrm{ft}$; the Rustler Formation, $322 \mathrm{ft}$; the Salado Formation, $2122 \mathrm{ft}$; the Castile Formation, 988 $\mathrm{ft}$; and the upper Bell Canyon Formation (Delaware Mountain Group), $254 \mathrm{ft}$. In addition to obtaining nearly continuous core ( $>99 \%$ recovery) from the surface to total depth (4325 ft), geophysical logs were taken to measure acoustic velocities, density, radioactivity, and formation porosities. The geophysical logs were used to help identify the stratigraphy, to verify formation tops, to verify depth measurements, and to provide physical property data on the various lithologies.

Drilling of DOE-2 confirmed the presence of a depression within the lower portion of the Salado. The halitic units between the anhydrite and polyhalite marker beds in the lower Salado, beginning at the Union anhydrite, were thickened up to two times the average thickness determined by previous drilling in the WIPP area. The base of the Salado was $\sim 300 \mathrm{ft}$ deeper in DOE-2 than extrapolated from nearby holes. Thus, the depression at DOE-2 does not result from halite removal from the lower Salado, as several workers in the area have suggested. 
The Castile Formation encountered in DOE-2 is also anomalous. Three anhydrites are usually present, interlayered with two thick halites. Anhydrite I, the lowest Castile anhydrite, appears to be intact and of normal thickness in DOE-2. Anhydrites II and III, however, are thickened by tight folding and are in direct contact. Three hundred feet or more of halite is expected in the average section of the Castile; in DOE2 the only halite present was $<8 \mathrm{ft}$ thick.

The depression within the Salado Formation at DOE-2 is interpreted as having formed in response to gravity-driven salt flowage within the Castile Formation. This is suggested by the distribution of salt structures within the Castile in adjacent holes. For example, the anomalously thin Castile halite in DOE2 is interpreted as having resulted from lateral flow of halite towards hole WIPP-11 to the north, in which Castile halite is anomalously thick. Some of the upper Castile anhydrite in DOE-2 apparently deformed very soon after deposition. In addition, the absence of dissolution residues or relicts in the lower Salado or Castile suggests that evaporite dissolution did not contribute to forming the structure.

Several stratigraphic units were hydrologically tested in DOE-2, including drill-stem tests, pressurepulse tests, and a pumping test of the Culebra Dolomite. Units tested included (with increasing depth) the lower portion of the Dewey Lake Red Beds, five members of the Rustler Formation (including the Rustler-Salado contact), the WIPP facility horizon and bounding anhydrite marker beds within the Salado Formation, the bulk of the Salado Formation, and three zones in the upper portion of the Bell Canyon Formation. Water samples were collected from the Culebra Dolomite Member of the Rustler Formation and from the Hays sandstone of the Bell Canyon Formation. 


\title{
2. Introduction
}

\author{
Jerry W. Mercer, Sandia National Laboratories
}

This report describes the data collected during the drilling and hydrologic testing of exploration Drillhole DOE-2. Chapter 2 gives detailed background information on development of the technical objectives and siting of the drillhole. Consistent with the usual format of a basic data report, individual technical sections are by separate authors, with references listed separately for each section.

\subsection{Purpose of the WIPP}

The DOE is developing the WIPP for underground disposal of transuranic waste from defenserelated programs. The site selected for this facility is in eastern Eddy County, 25 mi east of Carlsbad, NM (Figure 2-1).

The underground disposal facility of the WIPP will be placed at a depth of $\sim 2150 \mathrm{ft}$ in the bedded salts of the Permian Salado Formation, which is contained in an evaporite sequence $>3200 \mathrm{ft}$ thick. After a period of "pilot" operation in a waste-retrievable mode, it is expected that the WIPP will be converted into a permanent disposal facility. The WIPP also includes an underground research facility for in situ experiments to address technical issues related to interactions between bedded salt and high-level defense wastes.

Sandia National Laboratories, as scientific advisor to the DOE, supports the WIPP project in site characterization, including continuing evaluation of the geologic and hydrologic processes that may affect the WIPP site both now and in the future.

\subsection{Background of DOE-2 Siting}

Geologic and hydrologic site characterization has progressed at the site for more than 10 years, and the major effort is drawing to a close. Several questions will continue to be investigated, such as hydrologic variations within the entire evaporite sequence and evaporite deformation within the Salado and Castile Formations.

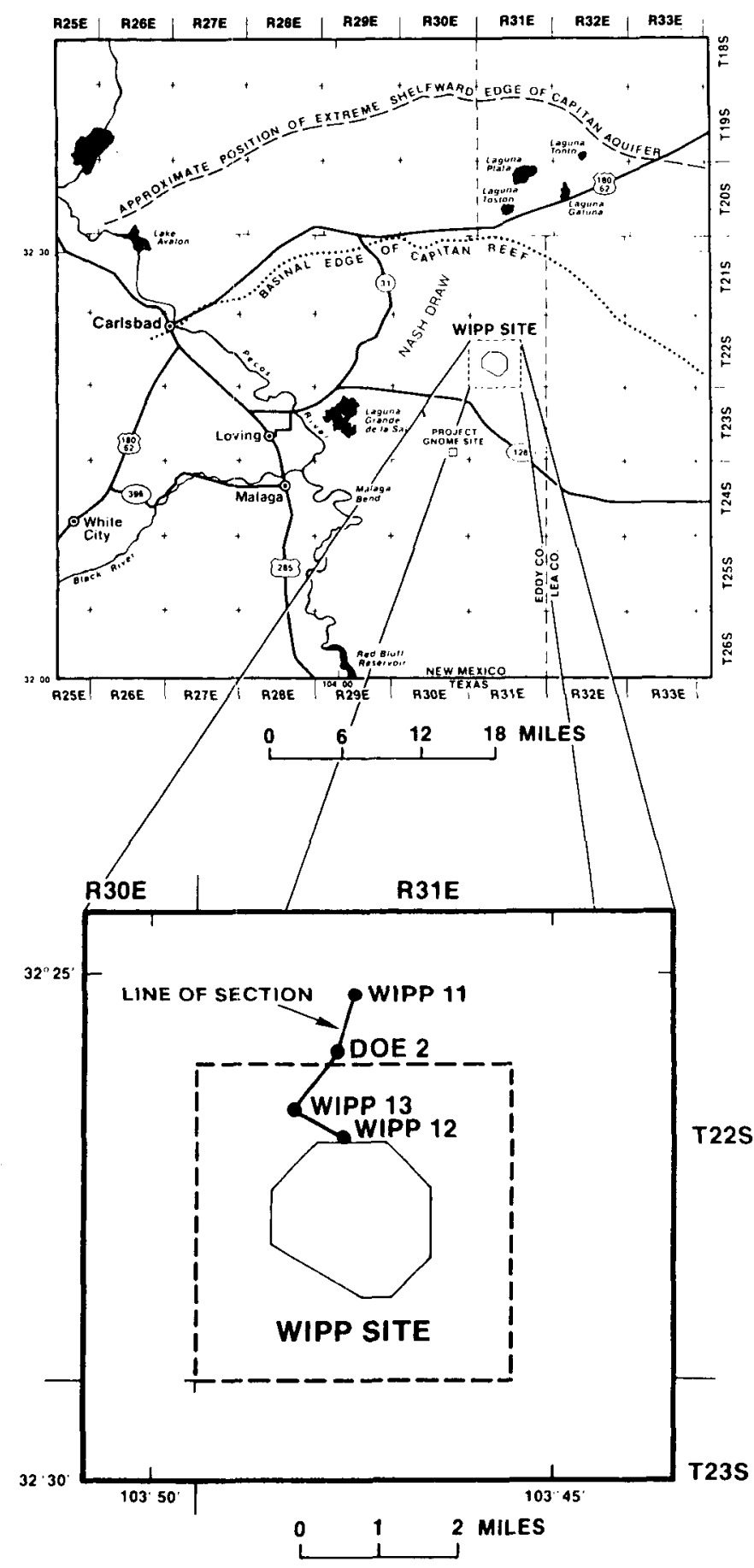

Figure 2-1. Location Map for Drillhole DOE-2, WIPP Site, Southeastern New Mexico 
One area of interest lies $2 \mathrm{mi}$ north of the WIPP site in the "disturbed zone" (defined by Borns et al., 1983) and consists of a stacked sequence of depressions in the Salado Formation. This anomalous feature, a structural depression $\sim 0.5 \mathrm{mi}$ in diameter, was found centered near a potash test hole called FC-92 located in the SE corner of Sec.8, T.22S., R.31E., and first described by Griswold (1977). This structure, often referred to as the "FC-92 depression," was also discussed in reports by Powers et al. (1978) and Borns, et al. (1983). Davies discussed this feature (Figure 2-2) in a paper given to the State of New Mexico Environmental Evaluation Group (EEG) in 1983. Before DOE-2 was drilled, the structural closure of the FC-92 depression appeared to be $\sim 25 \mathrm{ft}$ at the top of the Salado (Figure 2-3), increasing to $\sim 50 \mathrm{ft}$ at Marker Bed 124 (Figure 2-2). The stratigraphic extent of the depression was unknown. However, based on data from several shallow drillholes (in particular, WIPP34 and FC-92), it was concluded that the structure extended at least to Marker Bed 126 in the middle of the Salado Formation. In most of the potash exploration holes, Marker Bed 126 is the deepest and most consistent horizon penetrated. Such structures as the "FC-92 depression" raise questions regarding the processes that could have formed them and are important in understanding the evolution of the Delaware Basin.

R31E

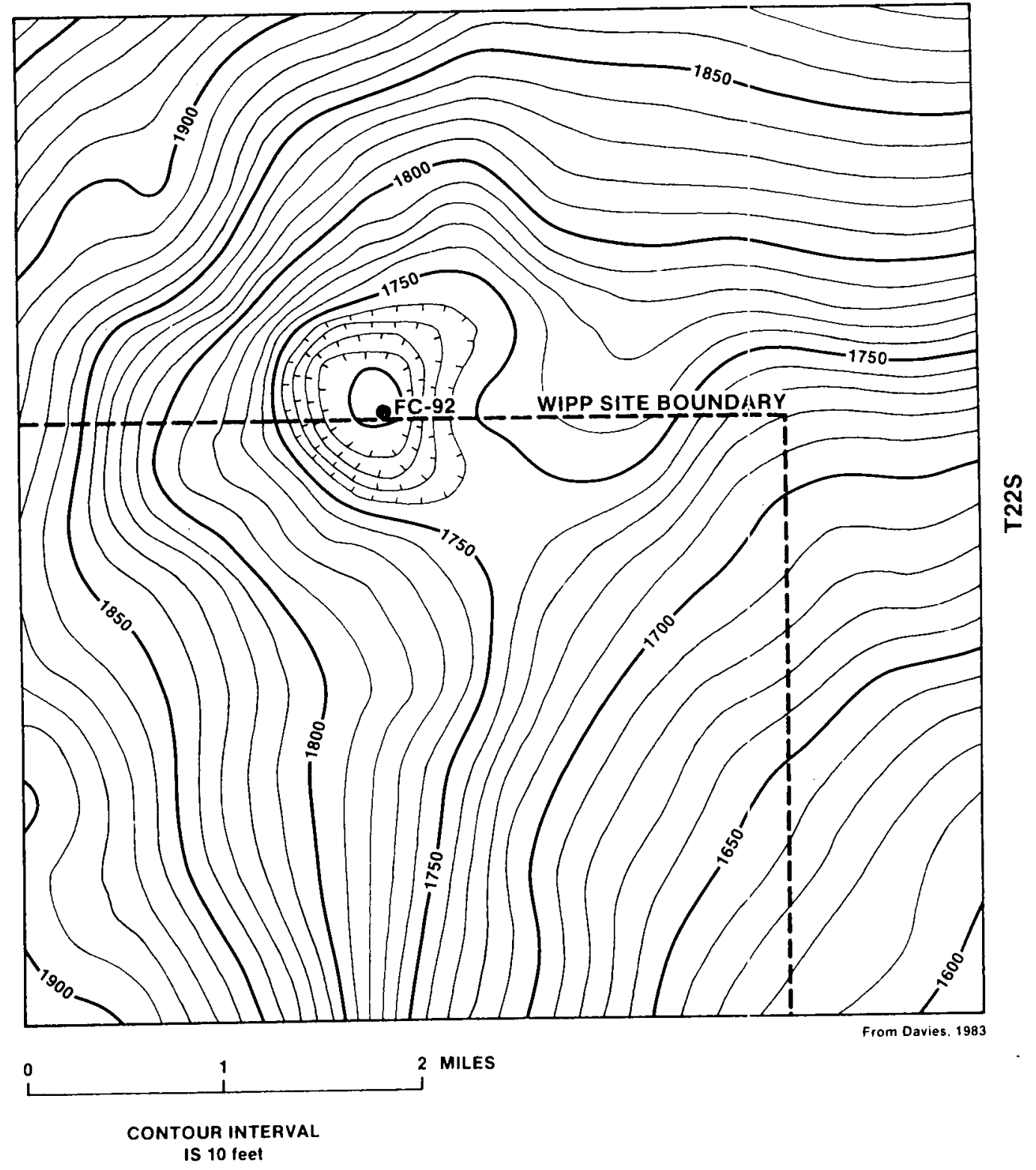

Figure 2-2. Structure Contours for MB-124 in the Salado Formation 


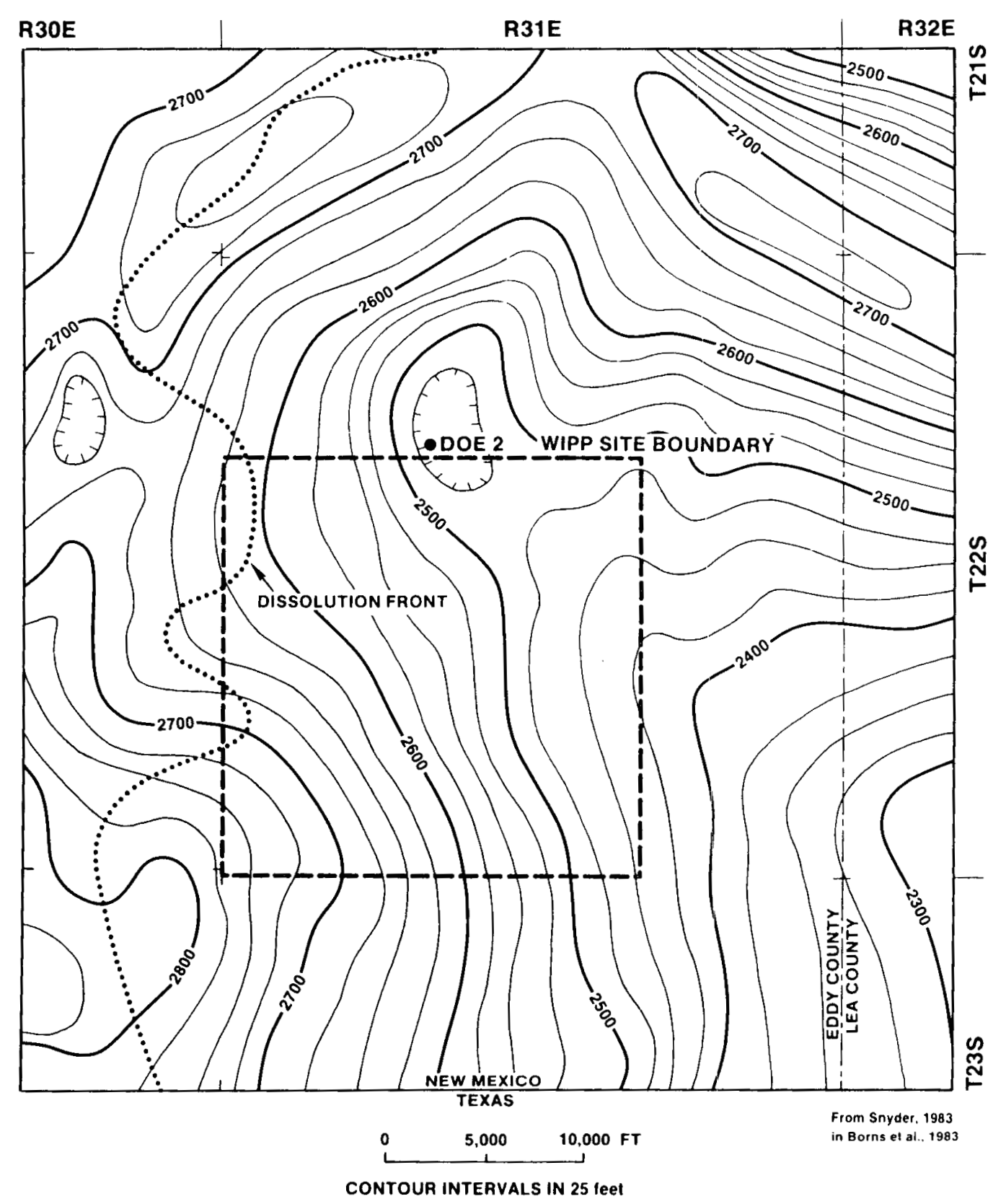

Figure 2-3. Structure Contour Map, Top of the Salado Formation

Davies (1983) proposed that the FC-92 depression could be evidence of deep dissolution near the WIPP site, resulting from input of unsaturated brines from or below the Castile Formation and moving into the lower portion of the Salado. Such dissolution, he said, could occur at a rate that would induce lateral and vertical ductile flow in the overlying halite units towards a point of dissolution and/or removal at the base of the Salado.
Processes discussed by other workers in the area that could cause such an anomaly include irregular sedimentation, gravity tectonics, and/or basement faulting of the rocks near the base of or immediately below the evaporite section. As discussed by Borns et al. (1983), the extensive deformation structures that do occur are usually restricted to the "disturbed zone" that is mostly confined to the Castile Formation. The 
Salado Formation is usually structurally smooth except in local areas such as the FC-92 depression. This observation led Snyder (in Borns et al., 1983) to suggest that changes in thickness of the sedimentation in the Salado were a result of deposition of the Salado on an already deforming Castile surface. The Castile deformation and resultant Salado features such as the FC-92 depression could be a result either of gravity tectonics within the Castile or of faulting associated with the lower Castile or in the Delaware Mountain Group that forms the floor for the evaporite sequence. In this case, the FC-92 depression may be restricted to the Salado Formation, although the "cause" may be in the Castile or below.

However, if the FC-92 structure (1) would continue or extend into the Castile Formation, and (2) would appear to result from deep dissolution and to be still active, it would raise questions about the project's ability to assure no breaching of the WIPP facility by dissolution from below during the containment period. On the other hand, if the structure was a result of irregular sedimentation or of inactive or active gravity tectonics or basement faulting, it would probably not jeopardize facility development. Irregular sedimentation could have occurred more than 200 million years ago when the Salado Formation was being deposited; in that case, the process would now be inactive and would have no effect on facility development. Gravity tectonics and basement faulting may have led to the irregular sedimentation discussed above and would be inactive today, but the rates of deformation would be very slow even if these processes were still active. Borns et al. (1983) calculate that, even if deformation was ongoing and regional, it would not jeopardize the facility over the next 10,000 yr (the time frame for facility containment).

A formal meeting was convened January 19, 1984, after a recommendation by the New Mexico EEG to the DOE to investigate the genesis of the "FC-92 depression." Attendees included personnel from EEG, Sandia, the DOE, D'Appolonia (now IT Corporation), the US Geological Survey, and the University of New Mexico. After lengthy discussions, a tentative site for a drillhole (DOE-2) was selected, and a set of technical objectives and a preliminary drilling plan were agreed upon. Another issue was the possible encounter of a pressurized brine reservoir in the Castile Formation. It was concluded that minimal testing should be conducted if a brine reservoir was encountered, although this was not a primary technical objective of the drilling plan.

Multiple lines of evidence were used in siting Drillhole DOE-2. Several seismic reflection surveys were conducted near the proposed DOE- 2 site because the site is within the "disturbed zone" (Powers et al., 1978; Borns et al., 1983). However, interpretation of these surveys is not definitive in outlining the FC-92 depression or the structure that may be causing it.

In 1984, Sandia conducted a controlled-source, audio-frequency magnetotelluric (CSAMT) survey specifically to investigate the FC-92 depression and to evaluate the potential for an associated brine reservoir in the Castile Formation. The experimental CSAMT survey method consists of laying out several lines of data stations that use two orthogonal, groundeddipole, primary field-transmitting antennas. For both antennas, the electric field was measured parallel to the grounded dipole, and the magnetic field was measured perpendicular to the electric field in the plane of the earth (Bartel and Jacobson, in preparation). Results of this survey yield a resistivity value as a function of frequency for each data station. There are limitations in this method, but it does provide another tool for noninvasive evaluation of structures.

Preliminary da'ta analyses from earlier CSAMT surveys had identified low electrical resistivities (conductors) in the subsurface described as possibly characteristic of brine. One such area was near WIPP-12, a known occurrence of a brine reservoir in the Castile Formation. Based on these surveys, it was proposed that the CSAMT survey might provide a method to define the structure near FC-92, and possibly to determine if a brine reservoir was present within the Castile. Preliminary results from these CSAMT surveys, when compared to the WIPP-12 surveys, strongly suggested no anornalously low resistivities (conductors) near the proposed DOE-2 site. Consequently, the potential was considered minimal for the occurrence of any brine reservoir.

Also of concern in the hole siting was the presence of possible faulting in the lower part of the Castile Formation and the upper part of the Bell Canyon Formation. Davies (1983) suggested that the possible presence of faults should be considered in the recommendation for the final hole location. The significance of this faulting is that, if faults do intersect the lower Castile and upper Bell Canyon Formations, they may provide a hydrologic pathway to the evaporites. Such deep structures wire originally inferred by Powers et al. (1978) and were interpreted from seismic lines as faults extending NiW-SE. However, using higher resolution seismic lines, Barrows (in Borns et al., 1983) did not maintain this interpretation. Another set of faults was postulated by Snyder (in Borns et al., 1983) to occur in Anhydrite I of the Castile Formation and to trend NE-SW, the trace of which would intersect the faults proposed by Davies near the FC-92 depression. During hole selection, it was determined that because 
the presence of these faults was suspect and because their delineation was constrained both by limited borehole data and by a preliminary interpretation of geophysical data, it would be almost impossible to locate a drillhole precisely at the intersection of these faults. Although the suspected presence of these faults was used in the evolution of the drillhole location, it was decided by the New Mexico EEG and the WIPP project staff that the final hole location would still be determined basically by the shape of the FC-92 depression and the geophysical CSAMT surveys.

Several meetings were held early in 1984 between the WIPP project staff and the New Mexico EEG to finalize the hole location and to refine the drilling and testing plan to be used for drilling DOE-2. The final hole location recommended by the New Mexico EEG and the WIPP project staff was in the SE $1 / 4$ of Sec.8, T.22S., R.31E. The final hole location resulted from many discussions concerning siting criteria and included moving the hole to accommodate the final expected geometry of the depression and the final CSAM'T surveys. The scope of work and the field operations plans developed from these meetings are included in Appendixes A and B of this report. The abridged hole history of DOE-2 is included in Appendix C, permits and miscellaneous documents are contained in Appendix D, and listings of the geophysical logs are in Appendix E. The USGS Lithologic Log for Drillhole DOE-2 is contained in Appendix F.

\subsection{The Purpose of Drillhole DOE-2}

The presence of the FC-92 depression raised questions about the processes that formed it and whether these processes, if active, could threaten the long-term containment of wastes in the WIPP facility. Because of the strong interest in the anomaly, and based on a recommendation of the New Mexico EEG through the stipulated agreement and $\mathrm{C} \& \mathrm{C}$ item (1-b) to "evaluate the depression near FC-92 drill hole," DOE drilled a hole (DOE-2) to investigate this feature.

Although DOE-2 was primarily a structural investigation, the proposed hole location provided an opportunity for collecting added information on the hydrology of the evaporite and associated lithologies.

The stated structural and hydrologic objectives resulting from various meetings and the recommendations of the EEG are as follows:

\subsubsection{Structural Objectives}

- Evaluate the extent of the FC-92 depression in the Salado Formation, and characterize (if present) the deformation and flow structures in the Salado and Castile Formations, specifically at the base of the Salado evaporite section. The stratigraphic extent of the depression is described in Chapter 3 of this report. Detailed description of structures and interpretation of the origin of the structures will be described in a separate report (Borns, 1986).

- Determine the origin of the FC-92 depression.

\subsubsection{Hydrologic Objective}

Perform hydrologic tests in the Rustler, Salado, Castile, and Bell Canyon Formations. If funded, perform a "whole-hole" test in which the Rustler and Bell Canyon fluid-producing zones are intentionally interconnected and in which directions of fluid movement can be monitored. All hydrologic testing in Drillhole DOE-2 is described in Chapter 4 of this report. The raw data collected during these tests are reported in INTERA Technologies (1986).

As stated, the hydrologic tests were conducted as tests of opportunity in an area of limited available hydrologic data. The units in the Rustler Formation, particularly the Magenta and Culebra Dolomite Members, were considered critical for hydrologic site characterization. In this location, the proposed hole would fill a void in defining the potentiometric surface map for the WIPP site. The hole also provides an opportunity to conduct hydrologic tests in the SaladoCastile Formations to add to the hydrologic data base characterizing the evaporite section (Mercer, 1987). Additional hydrologic data from the Bell Canyon Formation were also needed; in particular, data from the Hays, Olds, and Ramsey sandstone members. If brine was encountered in the Castile Formation, it was decided to conduct minimal testing.

\subsection{Drilling and Testing Program}

The drilling and testing program at Drillhole DOE-2 was divided into three phases. This division accommodates budget cycles and differences in primary scientific interest for (1) different sections of the stratigraphy in the Dewey Lake, Rustler, and Bell Canyon Formations, and (2) different structures and hydrologies in the Salado and Castile Formations. 
Phase I of the DOE-2 investigation included coring to the top of the Salado Formation and preliminary hydrologic testing of the Rustler Formation and the overlying Dewey Lake Red Beds.

Hydrologic "retesting" of the Culebra Dolomite Member of the Rustler was carried out before deepening the hole into the Salado; it was included as Phase Ia. Phase II completed the hole to the total depth, coring the evaporite section (Salado and Castile Formations) and the upper part of the underlying Bell Canyon Formation. The primary focus of this phase was to delimit the structural depression and to conduct hydrologic tests on the Salado and Castile Formations. Phase III included hydrologic characterization of the Ramsey, Olds, and Hays sandstones of the Bell Canyon Formation. The Phase III program was also considered to include the operation of a "wholehole" test intentionally interconnecting the Bell Canyon and Rustler Formations. However, a whole-hole test has not yet been approved or funded by the DOE. An abridged drilling and testing history for DOE-2 is contained in Appendix C. Legal permitting and asbuilt documentation is contained in Appendix $D$. Drillhole DOE-2 is located 704FSL (from south line) and 128FEL (from east line) in Sec.8, T.22S., R.31E., in Eddy County, NM: The borehole penetrated, from top to bottom, Pleistocene deposits (13 ft with fill material for pad), Santa Rosa Sandstone (120 ft), Dewey Lake Red Beds (506 ft), Rustler Formation $(322 \mathrm{ft})$, Salado Formation (2122 ft), Castile Formation (988 ft), and $254 \mathrm{ft}$ of the upper Bell Canyon Formation (Delaware Mountain Group). In addition to obtaining nearly continuous core ( $>99 \%$ recovery) from the surface to total depth $(4325 \mathrm{ft})$, geophysical logs were taken to measure acoustic velocities, density, radioactivity, and formation porosities (Appendix E).

Following all testing, the hole configuration included a packer set at $4051 \mathrm{ft}$ with $2-3 / 8$-in. tubing to the surface (Figure 2-4). This configuration allowed the Salado-Castile hydrostatic heads to be monitored in the annulus and the Bell Canyon hydrostatic heads to be monitored in the tubing.

In April 1986, the packer and tubing were removed, and a retrievable-bridge plug was set in the casing from 868.6 to $873.2 \mathrm{ft}$ below ground level. The casing across the Culebra Dolomite test interval was perforated from 822 to $848 \mathrm{ft}$ using 0.5 -in. bullets at 4 shots/ft. This configuration allows DOE- 2 to serve as a hydrologic observation well monitoring heads within the Culebra Dolomite.

A directional survey of Drillhole DOE-2 showing borehole departure from vertical is shown in Figure 25 . The deviation at the bottom of the hole is $\sim 185 \mathrm{ft}$ east and $50 \mathrm{ft}$ to the north relative to the hole collar at the surface.

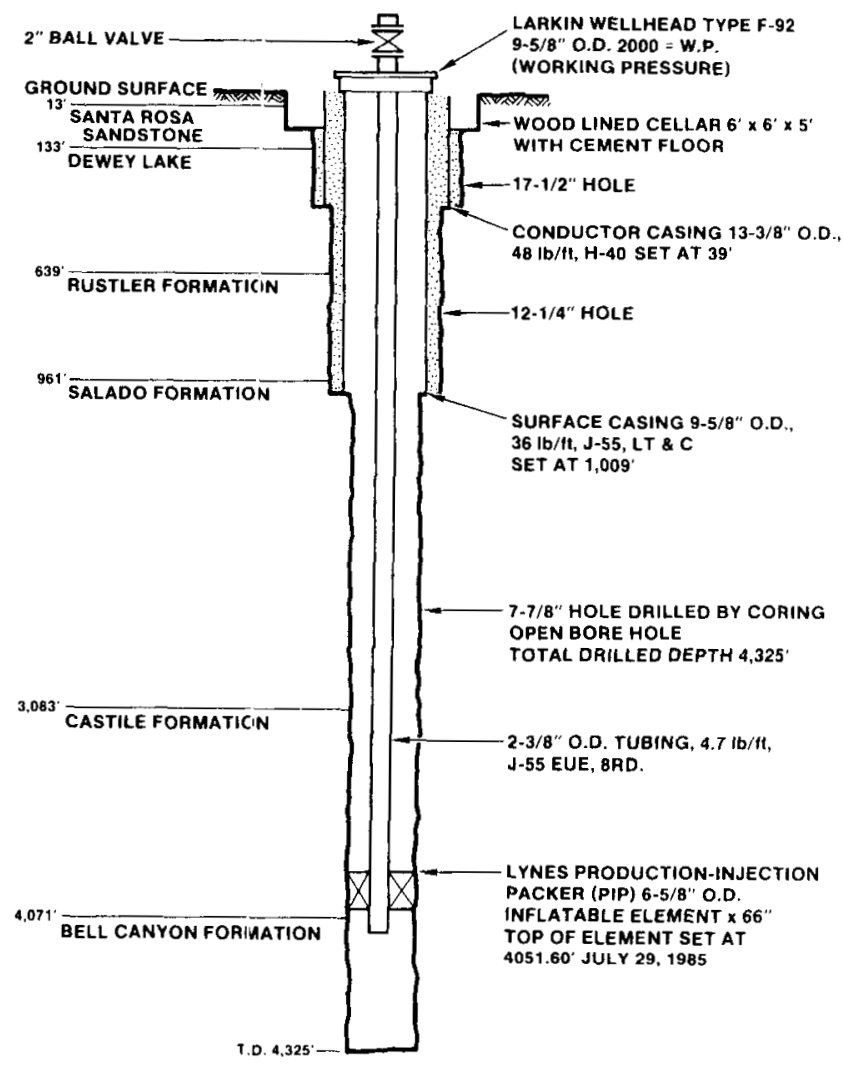

Figure 2-4. WIPP Drillhole DOE-2 As-Built Conditions After Hydrologic Tests, July 1985

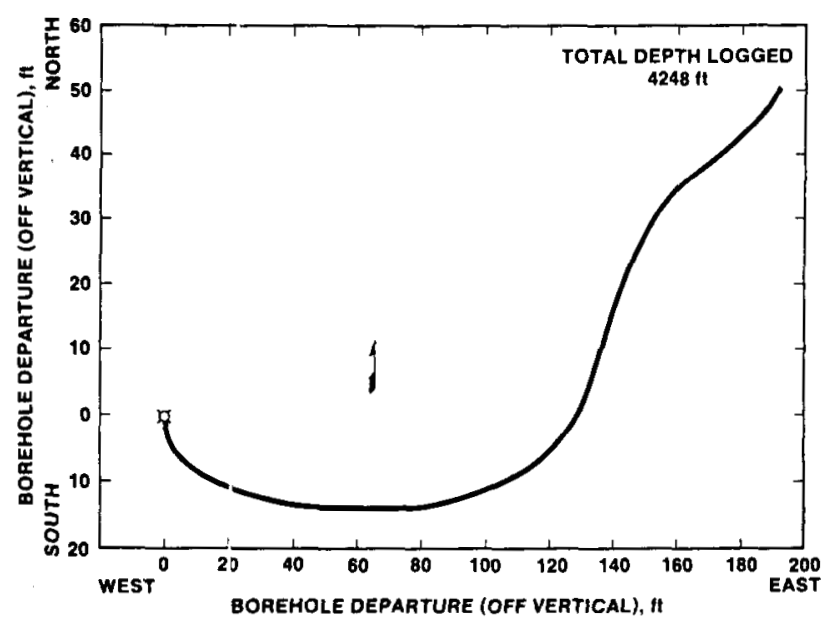

Figure 2-5. Directional Survey of Drillhole DOE-2 


\section{References}

Bartel, L. C.; and Jacobson, R. D. In preparation. Preliminary Interpretation of the Results from the CSAMT Survey to Site the DOE-2 Borehole (Albuquerque, NM: Sandia National Laboratories).

Borns, D. J. 1986. The Geologic Structures Observed in Drillhole DOE-2 and Their Possible Origins, SAND861495 (Albuquerque, NM: Sandia National Laboratories).

Borns, D. J.; Barrows, L. J.; Powers, D. W.; and Snyder, R. P. 1983. Deformation of Evaporites Near the Waste Isolation Pilot Plant (WIPP) Site, SAND82-1069 (Albuquerque, NM: Sandia National Laboratories).

Davies, P. B. 1983. Assessing the Potential for Deep-Seated Salt Dissolution and Subsidence at the Waste Isolation Pilot Plant (WIPP). Presentation prepared for the State of New Mexico Environmental Group Conference on WIPP Site Suitability for Radioactive Waste Disposal, May 12 and 13, Carlsbad, NM.
Griswold, G. B. 1977. Site Selection and Evaluation Studies of the Waste Isolation Pilot Plant (WIPP), Los Medaños, Eddy County, New Mexico, SAND77-0946 (Albuquerque, NM: Sandia National Laboratories).

INTERA Technologies. 1986. WIPP Hydrology Program, Waste Isolation Pilot Plant, Southeastern New Mexico, Hydrologic Data Report \#3, SAND86-7109 (Albuquerque, NM: Sandia National Laboratories).

Mercer, J. W. 1987. Compilation of Hydrologic Data from Drilling the Salado and Castile Formations Near the Waste Isolation Pilot Plant (WIPP) Site in Southeastern New Mexico, SAND86-0954 (Albuquerque, NM: Sandia National Laboratories).

Powers, D. W.; Lambert, S. J.; Shaffer, S. E.; Hill, L. R.; and Weart, W. D. 1978. Geological Characterization Report, Waste Isolation Pilot Plant (WIPP) Site, Southeastern New Mexico, SAND78-1596 (Albuquerque, NM: Sandia National Laboratories). 


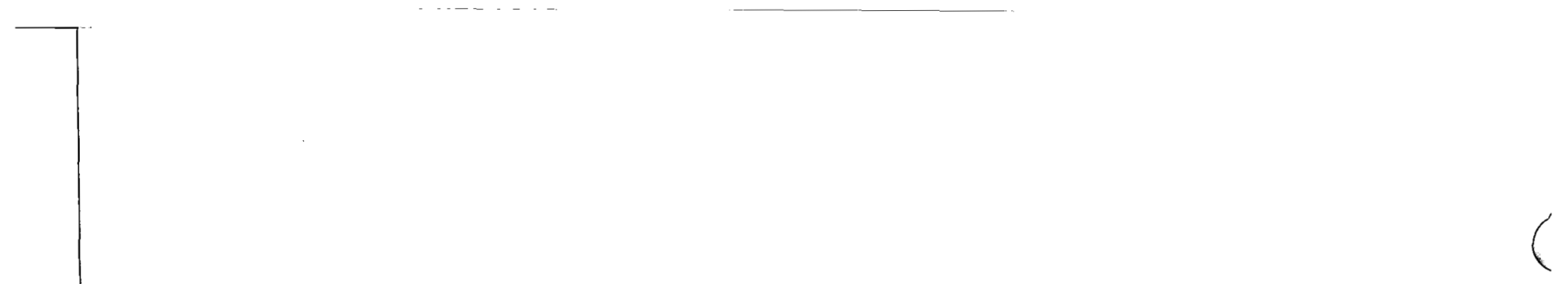

(

( 


\title{
3. Geologic Data
}

\author{
Richard P. Snyder and George M. Fairer, USGS
}

\section{Abstract}

Drillhole DOE-2, in the north-central part of the WIPP site, southeastern New Mexico, was drilled and cored to a depth of $4325 \mathrm{ft}$ below ground level to investigate a structural depression in this part of the site. The hole penetrated surficial Holocene sand, the Mescalero caliche of Pleistocene age, Santa Rosa Sandstone of Triassic age, and the Dewey Lake Red Beds, Rustler Formation, Salado Formation, Castile Formation, and upper $254 \mathrm{ft}$ of the Bell Canyon Formation, all of Permian age.

The Dewey Lake Red Beds contain numerous veins of secondary selenite, most of which are parallel to the nearly horizontal bedding, but the dip of some selenite-filled fractures is between $30^{\circ}$ and vertical.

Data obtained from core show that halite, formerly present in the Forty-niner and Tamarisk Members of the Rustler Formation, has been removed by dissolution, but that most of the halite in the unnamed lower member of the Rustler is still present. The Magenta Dolomite Member of the Rustler Formation does not appear to be sufficiently fractured to be a suitable aquifer, but the Culebra Dolomite Member of the Rustler Formation is highly fractured and probably is a very good aquifer. The contact between the Rustler and the underlying Salado Formation shows no evidence of ground-water movement.

The Salado Formation is approximately $300 \mathrm{ft}$ thicker than projected from nearby drillholes. All the increased thickness occurs in the unnamed lower member, and is caused by a combination of constantly downward thickening of the halite layers (or beds) between anhydrite and polyhalite marker beds and by beds which were more steeply dipping than were projected.

A typical section of the Castile Formation was not penetrated by DOE-2. Instead of the expected three anhydrite units separated by two halite units, the Castile Formation at DOE-2 consists of an upper excessively thick anhydrite unit, a very thin halite unit, and a typical lower anhydrite unit. Instead of an average thickess of about $1330 \mathrm{ft}$, only $989 \mathrm{ft}$ of Castile were penetrated and even some of this thickness is due to dipping strata. The thinner Castile section is probably the result of halite having flowed northward slowly enough to allow the overlying anhydrite to move southward and downward by pressure recrystallization; almost no fracturing was observed in the core.

The Bell Canyon Formation in DOE-2 is nearly horizontal and includes a typical section to the bottom of the hole. Units of the Bell Canyon penetrated include the Lamar Limestone Member, and the Ramsey sand, Ford shale, Olds sand, and Hays sand (informal units of local usage).

\subsection{Introduction}

Drillhole DOE-2 is an exploratory hole drilled to investigate a structural depression about 2 miles north of the center of the WIPP site in southeastern New Mexico (Figure 3-1). Starting on August 28, 1984, Drillhole DOE-2 was cored from a depth of $48.1 \mathrm{ft}$ below G.L. (ground level) to $981 \mathrm{ft}$ on September 18, 1984. From May 5 to June 8,1985 , the hole was deepened to $4325 \mathrm{ft}$ (drilling and coring). 


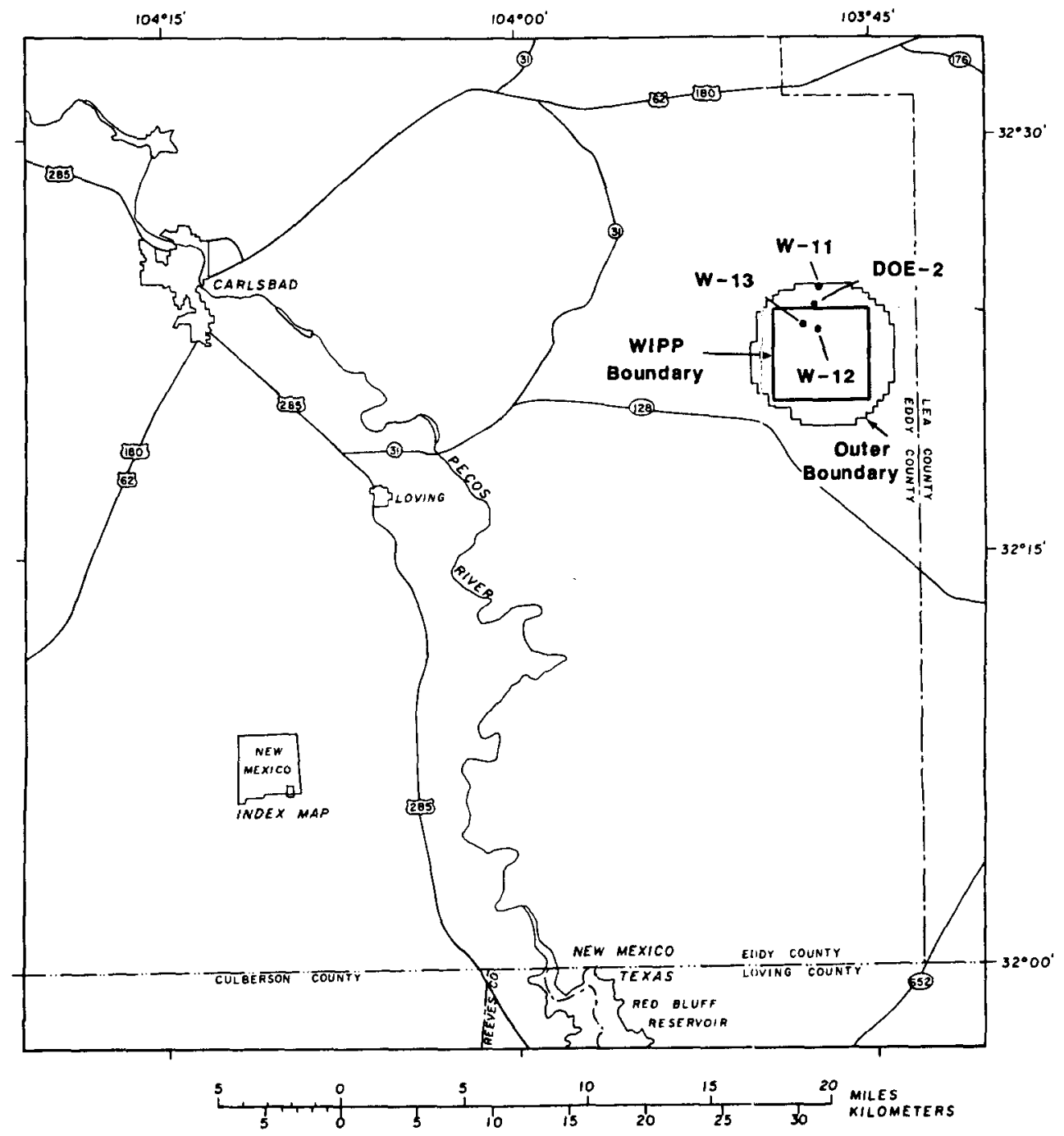

Figure 3-1. Location of WIPP Site and Drillholes DOE-2, W-11, W-12, and W-13

A southeast-trending syncline is evident on structure maps drawn on the top of the Dewey Lake Red Beds, on the tops of the various members of the Rustler Formation, and on the top of the Salado Formation (Snyder, 1983, Figures 2-17, 2-19, 2-21, 224, and 2-26). Earlier maps by Griswold (1977, Figures 8 and 12), constructed when less information was available, also show the syncline.

All measurements related to the drill site are in English units. The measurements include: the horizontal and vertical location survey of the drill hole, the drilling depths furnished by the driller, and the wire line log furnished by the logger. If metric units are desired, the following conversion factors should be used.

\begin{tabular}{lll}
$\begin{array}{c}\text { Multiply } \\
\text { English } \\
\text { Unit }\end{array}$ & \multicolumn{1}{c}{ By } & \multicolumn{1}{c}{$\begin{array}{c}\text { To Obtain } \\
\text { Metric } \\
\text { Unit }\end{array}$} \\
\hline mile (mi) & 1.6093 & kilometer $(\mathrm{km})$ \\
foot (ft) & 0.3048 & meter $(\mathrm{m})$ \\
$\begin{array}{l}\text { inch (in.) } \\
\text { inch (in.) }\end{array}$ & 25.4 & millimeter $(\mathrm{mm})$ \\
$\begin{array}{c}\text { pounds per square } \\
\text { inch (lb/in. }{ }^{2} \text { ) }\end{array}$ & 2.54 & centimeter $(\mathrm{cm})$ \\
& 0.006895 & megapascal $(\mathrm{MPa})$
\end{tabular}




\subsection{Description of Drillhole DOE-2}

Drillhole DOE-2 is located in eastern Eddy County, New Mexico, approximately $700 \mathrm{ft}$ north of the south line, $130 \mathrm{ft}$ west of the east line, Sec.8, T.22S., R.31E., nearly 2 miles north of the center of the WIPP site (Figure 3-1 and Table 3-1). DOE-2 was drilled and cored to a depth of $981 \mathrm{ft}$ from August 28 to September 18, 1984, and deepened by drilling and coring to $4325 \mathrm{ft}$ from May 5 to April 8, 1985. During the 1984 drilling, surface casing was set to a depth of $39 \mathrm{ft}$ prior to coring. During 1985, the hole was drilled and reamed and casing was set to a depth of $1009 \mathrm{ft}$. Continuous core was taken from 48.1 to $981 \mathrm{ft}$ and from 1011.2 to $4325 \mathrm{ft}$. No description of cuttings is available from 981 to $1011.2 \mathrm{ft}$. Core was logged at the site by R. P. Snyder and G. M. Fairer of the U.S. Geological Survey from 48.1 to $981 \mathrm{ft}$, and by R. P. Snyder, and R. M. Holt, K. L. Pittman, and Rey Corrasco of International Technology, and D. J. Borns of Sandia National Laboratories from 1011.2 to 4325 ft. A stratigraphic summary (Table 3-2) and a detailed lithologic $\log$ (Figure 3-2 and Appendix F) were prepared.
Drillhole DOE-2 penetrated loose sand of Holocene age and the Mescalero caliche of Pleistocene age; sandstone and siltstone of the Santa Rosa Sandstone of Triassic age; siltstone, claystone, and sandstone of the Dewey Lake Red Beds of Permian age; and an evaporite sequence of the Rustler Formation of Permian age, consisting of anhydrite, gypsum, dolomite, claystone, siltstone, and halite. Below the Rustler Formation the hole penetrated additional rocks of Permian age as follows: the Salado Formation, which predominately consists of halite and lesser amounts of anhydrite, polyhalite, siltstone, and potash minerals; the Castile Formation, nearly all anhydrite; and the upper part of the Bell Canyon Formation, consisting of shale, limestone, and sandstone.

Geophysical logs were run by the Water Resources Division of the U.S. Geological Survey and by Dresser Atlas Co. The Dresser Atlas logs, reproduced on Figure 3-2, include: (1) a gamma log recording natural gamma radiation; (2) a gamma-gamma log recording rock density; and (3) a neutron log recording hydrogen (water) in the rock. Caliper, dual laterolog, temperature, 4-arm caliper and directional survey logs were run below $1000 \mathrm{ft}$, but are not included in this report.

\section{Table 3-1. Abridged Drilling History of Drillhole DOE-2}

LUCATION: SeC. 8, T. 22 S., R. 31 E.

$704.07 \mathrm{ft}$ from south line

$128.19 \mathrm{ft}$ from east line

ELEVATION (land surface): $3418.35 \mathrm{ft}$. Datum for depth measurements in drilling and logging operations.

LITHOLOGIC LOG PREPARED BY: R. P. Snyder and G. M. Fairer, USGS: 0 to $981 \mathrm{ft}$.

R. P. Snyder, USGS, and R. M. Holt, Kate L. Pittman, Rey Carrasco, IT Corp., and D. J. Borns, SNL: 981 to $4325 \mathrm{ft}$.

DRILLING CONTRACTOR: Pennsylvania Drilling Co. $0-981 \mathrm{ft}$

Verna Drilling Co. $\quad 981-4325 \mathrm{ft}$

DRILLING RECURD: 0-981 ft. Commenced drilling on Aug. 28, 1984, and completed on Sept. $18,1984$.

13-3/8-in. casing set at $39 \mathrm{ft}$ below surface. Rock bit 39 to $48.1 \mathrm{ft}$, core 48.1 to

$981 \mathrm{ft}$. Lost circulation below $200 \mathrm{ft}$. Drilling medium, air and air mist above

$477 \mathrm{ft}$, brine below $477 \mathrm{ft}$. Hole ready for reaming to $4-3 / 4 \mathrm{in}$. prior to water

tests in Rustler Formation and Rustler/Salado Formation contact.

981-4325 ft:. April 29, 1985, reamed hole from $43 / 4$ in. to $12 \mathrm{in.}$, deepened hole.

(rock bit) to $1011.1 \mathrm{ft}$, set $10 \mathrm{in}$. casing from surface to $1008 \mathrm{ft}$. May 5 to

May 16, cored from 1011.1 to $3095.6 \mathrm{ft}$. May 17 to 22, geophysical logging and

hydraulic testing. May 23 to June 8 coring from 3095.6 to $4325.0 \mathrm{ft}$. Hole rearly

for logging and additional hydraulic testing. 
Table 3-1. (continued)

\begin{tabular}{|c|c|c|c|c|c|c|}
\hline Core & Depth & RPM & Weight & Circulating & Interval & Percent \\
\hline №. & $\begin{array}{c}\text { Interval (feet) } \\
\text { From / to }\end{array}$ & & $\begin{array}{l}\text { on bit } \\
\text { (lbs) }\end{array}$ & $\begin{array}{l}\text { pressure } \\
\left(10 / \text { in }^{2}\right)\end{array}$ & $\begin{array}{cc}\text { Feet } & \text { Feet } \\
\text { cired recovered }\end{array}$ & \\
\hline
\end{tabular}

\begin{tabular}{|c|c|c|c|c|c|c|c|c|}
\hline $\begin{array}{l}2 \\
3\end{array}$ & $\begin{array}{l}55.6 \\
61.0\end{array}$ & $\begin{array}{l}61.0 \\
69.0\end{array}$ & & & Air & 5.4 & $\begin{array}{r}2.5 \\
\end{array}$ & $\begin{array}{r}46 \\
\end{array}$ \\
\hline 4 & 690 & 79.0 & 60 & NA & Air & 13.0 & 10.0 & $\begin{array}{r}125 \\
07\end{array}$ \\
\hline 5 & $\begin{array}{l}59.0 \\
79.0\end{array}$ & 89.2 & 60 & NA & Air & 10.0 & $\begin{array}{r}9.7 \\
10 ?\end{array}$ & 97 \\
\hline 6 & 89.2 & 98.8 & 60 & NA & Air & $\begin{array}{r}0.6 \\
9.6\end{array}$ & 9.6 & 100 \\
\hline 7 & 98.8 & 108.8 & 60 & NA & Air & 10.0 & 10.0 & 100 \\
\hline 8 & 108.8 & 118.5 & 60 & NA & Air & 9.7 & 9.7 & 100 \\
\hline 9 & 118.5 & 121.2 & 60 & NA & Air & 2.7 & 2.7 & 100 \\
\hline 10 & 121.2 & 131.0 & 60 & NA & Air & 9.8 & 9.6 & Q8 \\
\hline 11 & 131.0 & 141.0 & 60 & NA & Air & 10.0 & 9.5 & 95 \\
\hline 12 & 141.0 & 151.0 & 60 & NA & Air & 10.0 & 9.3 & 93 \\
\hline 13 & 151.0 & 161.0 & 60 & NA & Air & 10.0 & 7.8 & 78 \\
\hline 14 & 161.0 & 168.0 & 60 & NA & Air & 7.0 & 9.3 & 133 \\
\hline 15 & 168.0 & 178.0 & 60 & NA & Air & 10.0 & 2.9 & 29 \\
\hline 16 & 178.0 & 180.0 & 60 & NA & Air & 2.0 & 2.8 & 140 \\
\hline 17 & 180.0 & 190.0 & 60 & NA & Air & 10.0 & 10.2 & 102 \\
\hline 18 & 190.0 & 200.0 & 60 & NA & Air & 10.0 & 10.0 & inn \\
\hline 19 & 200.0 & 210.0 & 60 & NA & Air & 10.0 & 8.0 & 80 \\
\hline 20 & 210.0 & 220.0 & 60 & NA & Air & 10.0 & 10.1 & 101 \\
\hline 21 & 220.0 & 230.0 & 60 & NA & Air & 1.0 .0 & 9.2 & $9 ?$ \\
\hline 22 & 230.0 & 240.0 & 60 & NA & Air & 10.0 & 9.3 & 93 \\
\hline 23 & 240.0 & 250.0 & 60 & NA & Air & 10.0 & 9.5 & 95 \\
\hline 24 & 250.0 & 260.0 & 60 & NA & Air & 10.0 & 9.1 & 91 \\
\hline 20 & 260.0 & 270.0 & 60 & NA & Air & 10.0 & 10.0 & 100 \\
\hline 26 & 270.0 & 280.0 & 60 & NA & Air & 10.0 & 10.0 & $10 n$ \\
\hline 27 & 280.0 & 290.0 & 60 & NA & Air & 10.0 & 10.0 & 100 \\
\hline 28 & 290.0 & 300.0 & 60 & NA & Air & 10.0 & 10.2 & 102 \\
\hline 29 & 300.0 & 310.2 & 60 & NA & Air-Mist & 10.2 & 10.2 & 100 \\
\hline 30 & 310.2 & 320.0 & 60 & NA & Air-Mist & 9.8 & 9.8 & $10 n$ \\
\hline 31 & 320.0 & 330.0 & 60 & NA & $200-300$ & 10.0 & 10.0 & $10 n$ \\
\hline 32 & 330.0 & 339.0 & 60 & NA & $200-300$ & 9.0 & 8.4 & 93 \\
\hline 33 & 339.0 & 341.0 & 60 & $N A$ & $200-300$ & 2.0 & 2.6 & 130 \\
\hline 34 & 341.0 & 351.0 & 60 & NA & $200-300$ & 10.0 & 9.4 & 94 \\
\hline 35 & 351.0 & 361.0 & 60 & NA & $200-300$ & 10.0 & 10.0 & 100 \\
\hline 36 & 361.0 & 371.5 & 60 & NA & $200-300$ & 10.5 & 10.5 & 100 \\
\hline 37 & 371.5 & 381.0 & 60 & NA & $200-300$ & 9.5 & 8.5 & 89 \\
\hline 38 & 381.0 & 382.5 & 60 & NA & $200-300$ & 1.5 & 2.5 & 157 \\
\hline 39 & 382.5 & 392.0 & 60 & NA & $200-300$ & 9.5 & 9.7 & in? \\
\hline 40 & 392.0 & 401.0 & 60 & NA & $200-300$ & 9.0 & 9.0 & 100 \\
\hline 41 & 401.0 & 411.0 & 60 & NA & $200-300$ & 10.0 & 10.0 & $10 n$ \\
\hline 42 & 411.0 & 421.0 & 60 & NA & $200-300$ & 10.0 & 9.8 & 98 \\
\hline 43 & 421.0 & 431.0 & 60 & NA & 250 & 10.0 & 9.6 & 96 \\
\hline 44 & 431.0 & 441.0 & 60 & NA & 250 & 10.0 & 10.1 & 101 \\
\hline 45 & 441.0 & 451.1 & 60 & NA & 250 & 10.1 & 10.2 & 102 \\
\hline 46 & 451.1 & 461.0 & 60 & NA & 250 & 9.9 & 9.8 & 99 \\
\hline 47 & 461.0 & 471.0 & 60 & NA & 250 & 10.0 & 10.0 & 100 \\
\hline 48 & 471.0 & 478.0 & 60 & NA & 250 & 7.0 & 5.8 & 83 \\
\hline 49 & 478.0 & 481.1 & 30 & NA & 100 & 3.1 & 3.1 & $10 n$ \\
\hline 50 & 481.1 & 491.0 & 60 & NA & 100 & 9.9 & 9.8 & 99 \\
\hline 51 & 491.0 & 501.0 & 60 & NA & 100 & 10.0 & 9.9 & 99 \\
\hline 52 & 501.0 & 511.0 & 60 & $N A$ & 100 & 10.0 & 9.5 & 95 \\
\hline 53 & 511.0 & 516.5 & 60 & NA & 100 & 5.5 & 5.9 & 107 \\
\hline 54 & 516.5 & 521.0 & 45 & NA & 100 & 4.5 & 4.5 & $10 n$ \\
\hline 55 & 521.0 & 531.0 & 80 & NA & 100 & 10.0 & 9.9 & 99 \\
\hline 56 & 531.0 & 541.0 & 80 & NA & 100 & 10.0 & 9.8 & 98 \\
\hline 57 & 541.0 & 551.0 & 80 & NA & 100 & 10.0 & 9.8 & 98 \\
\hline 58 & 551.0 & 561.0 & 80 & NA & 150 & 10.0 & 10.0 & 100 \\
\hline $\begin{array}{l}50 \\
59\end{array}$ & 561.0 & 571.0 & 80 & NA & 100 & 10.0 & 9.5 & 95 \\
\hline 60 & 571.0 & 581.0 & 80 & NA & 100 & 10.0 & 10.0 & 100 \\
\hline 61 & 581.0 & 591.0 & 80 & NA & 100 & 10.0 & 9.5 & 95 \\
\hline 62 & 591.0 & 601.0 & 80 & NA & 100 & 10.0 & 9.9 & 99 \\
\hline \multicolumn{9}{|c|}{ (continued) } \\
\hline
\end{tabular}


Table 3-1. (continued)

\begin{tabular}{|c|c|c|c|c|c|c|c|c|}
\hline \multirow{2}{*}{$\begin{array}{l}\text { Core } \\
\text { No. }\end{array}$} & \multirow{2}{*}{\multicolumn{2}{|c|}{$\begin{array}{l}\text { Depth } \\
\text { Interval (feet) }\end{array}$}} & \multirow[t]{2}{*}{ RPM } & \multirow{2}{*}{$\begin{array}{l}\text { Weight } \\
\text { on bit } \\
\text { (1bs) }\end{array}$} & \multirow{2}{*}{$\begin{array}{l}\text { Circulating } \\
\text { pressure } \\
\left(1 b / i n^{2}\right)\end{array}$} & \multicolumn{2}{|c|}{ Interval } & \multirow{2}{*}{$\begin{array}{l}\text { Percent } \\
\text { recovered }\end{array}$} \\
\hline & & $\begin{array}{l}\text { (feet) } \\
\text { to }\end{array}$ & & & & $\begin{array}{l}\text { Feet } \\
\text { cored }\end{array}$ & $\begin{array}{l}\text { Feet } \\
\text { recovered }\end{array}$ & \\
\hline $\begin{array}{r}63 \\
64 \\
65 \\
66 \\
67 \\
68 \\
69 \\
70 \\
71 \\
72 \\
73 \\
74 \\
75 \\
76 \\
77 \\
78 \\
79 \\
80 \\
81 \\
82 \\
83 \\
84 \\
85 \\
86 \\
87 \\
88 \\
89 \\
90 \\
91 \\
92 \\
93 \\
94 \\
95 \\
96 \\
97 \\
98 \\
99 \\
100 \\
101 \\
102\end{array}$ & $\begin{array}{l}601.0 \\
611.0 \\
621.0 \\
631.0 \\
641.0 \\
651.0 \\
661.0 \\
671.0 \\
681.0 \\
691.0 \\
701.0 \\
711.0 \\
721.0 \\
731.0 \\
741.0 \\
751.0 \\
761.0 \\
771.0 \\
781.2 \\
791.2 \\
801.2 \\
811.0 \\
821.0 \\
831.0 \\
841.0 \\
849.0 \\
851.0 \\
858.5 \\
861.0 \\
871.0 \\
881.0 \\
891.0 \\
901.0 \\
911.2 \\
921.4 \\
931.0 \\
941.0 \\
951.0 \\
961.0 \\
971.0\end{array}$ & $\begin{array}{l}611.0 \\
621.0 \\
631.0 \\
641.0 \\
651.0 \\
661.0 \\
671.0 \\
681.0 \\
691.0 \\
701.0 \\
711.0 \\
721.0 \\
731.0 \\
741.0 \\
751.0 \\
761.0 \\
771.0 \\
781.2 \\
791.2 \\
801.2 \\
811.0 \\
821.0 \\
831.0 \\
841.0 \\
849.0 \\
851.0 \\
858.5 \\
861.0 \\
871.0 \\
881.0 \\
891.0 \\
901.0 \\
911.2 \\
921.4 \\
931.0 \\
941.0 \\
951.0 \\
961.0 \\
971.0 \\
981.0\end{array}$ & $\begin{array}{l}100 \\
100 \\
100 \\
100 \\
80 \\
80 \\
80 \\
80 \\
60 \\
60 \\
60 \\
60 \\
60 \\
60 \\
60 \\
60 \\
60 \\
75 \\
75 \\
75 \\
75 \\
75 \\
75 \\
75 \\
75 \\
75 \\
75 \\
75 \\
75 \\
75 \\
75 \\
75 \\
75 \\
75 \\
75 \\
75 \\
75 \\
75 \\
75 \\
75\end{array}$ & $\begin{array}{l}\text { NA } \\
\text { NA } \\
\text { NA } \\
\text { NA } \\
N A \\
\text { NA } \\
\text { NA } \\
\text { NA } \\
\text { NA } \\
\text { NA } \\
\text { NA } \\
\text { NA } \\
\text { NA } \\
\text { NA } \\
\text { NA } \\
\text { NA } \\
\text { NA } \\
\text { NA } \\
\text { NA } \\
\text { NA } \\
\text { NA } \\
\text { NA } \\
\text { NA } \\
\text { NA } \\
\text { NA } \\
\text { NA } \\
\text { NA } \\
\text { NA } \\
\text { NA } \\
\text { NA } \\
\text { NA } \\
\text { NA } \\
\text { NA } \\
\text { NA } \\
\text { NA } \\
\text { NA } \\
\text { NA } \\
\text { NA } \\
\text { NA } \\
\text { NA }\end{array}$ & $\begin{array}{r}100 \\
100 \\
100 \\
100 \\
50 \\
50 \\
100 \\
250 \\
100 \\
150 \\
200 \\
150 \\
100 \\
100 \\
100 \\
100 \\
100 \\
150 \\
150 \\
150 \\
300 \\
300 \\
175 \\
200 \\
200 \\
175 \\
150 \\
100 \\
100 \\
100 \\
100 \\
275 \\
175 \\
175 \\
175 \\
175 \\
275 \\
100 \\
100 \\
100\end{array}$ & $\begin{array}{r}10.0 \\
10.0 \\
10.0 \\
10.0 \\
10.0 \\
10.0 \\
10.0 \\
10.0 \\
10.0 \\
10.0 \\
10.0 \\
10.0 \\
10.0 \\
10.0 \\
10.0 \\
10.0 \\
10.0 \\
10.0 \\
10.0 \\
10.0 \\
9.8 \\
10.0 \\
10.0 \\
10.0 \\
8.0 \\
2.0 \\
7.5 \\
2.5 \\
10.0 \\
10.0 \\
10.0 \\
10.0 \\
10.2 \\
10.2 \\
9.6 \\
10.0 \\
10.0 \\
10.0 \\
10.0 \\
10.0\end{array}$ & $\begin{array}{r}9.6 \\
9.9 \\
10.0 \\
9.6 \\
10.0 \\
10.0 \\
9.5 \\
8.2 \\
10.1 \\
10.0 \\
9.1 \\
10.1 \\
10.0 \\
10.0 \\
10.0 \\
9.5 \\
10.0 \\
10.2 \\
10.0 \\
9.7 \\
10.3 \\
10.0 \\
8.6 \\
10.0 \\
6.5 \\
1.8 \\
7.5 \\
2.5 \\
9.8 \\
10.0 \\
9.8 \\
10.2 \\
10.2 \\
10.2 \\
9.6 \\
10.0 \\
10.0 \\
10.0 \\
10.0 \\
10.0\end{array}$ & $\begin{array}{r}96 \\
99 \\
10 n \\
96 \\
100 \\
100 \\
95 \\
82 \\
101 \\
100 \\
91 \\
101 \\
100 \\
100 \\
100 \\
95 \\
100 \\
102 \\
100 \\
97 \\
105 \\
100 \\
96 \\
100 \\
83 \\
90 \\
100 \\
10 n \\
98 \\
100 \\
98 \\
10 ? \\
100 \\
100 \\
100 \\
100 \\
100 \\
100 \\
100 \\
100\end{array}$ \\
\hline
\end{tabular}

* Note: core numbers 1 through 58 were repeated when coring was resumed in May 1985.

\begin{tabular}{|c|c|c|c|c|c|c|c|c|}
\hline $\begin{array}{r}1 \\
2 \\
3 \\
4 \\
5 \\
6 \\
7 \\
8 \\
9 \\
10 \\
11 \\
12 \\
13 \\
14 \\
15 \\
16 \\
17 \\
18\end{array}$ & $\begin{array}{l}1011.2 \\
1042.7 \\
1102.6 \\
1162.9 \\
1222.3 \\
1282.0 \\
1342.0 \\
1402.0 \\
1427.0 \\
1487.0 \\
1547.0 \\
1607.0 \\
1667.0 \\
1700.0 \\
1760.9 \\
1821.0 \\
1881.0 \\
1941.0\end{array}$ & $\begin{array}{l}1042.7 \\
1102.6 \\
1162.9 \\
1222.3 \\
1282.0 \\
1342.0 \\
1402.0 \\
1427.0 \\
1487.0 \\
1547.0 \\
1607.0 \\
1667.0 \\
1700.0 \\
1760.9 \\
1821.0 \\
1881.0 \\
1941.0 \\
2001.0\end{array}$ & $\begin{array}{l}60 \\
44 \\
44 \\
44 \\
44 \\
44 \\
44 \\
48 \\
48 \\
44 \\
44 \\
44 \\
44 \\
44 \\
44 \\
44 \\
44 \\
44\end{array}$ & $\begin{array}{l}15,000 \\
15,000 \\
15,000 \\
15,000 \\
15,000 \\
15,000 \\
10,000 \\
15-18,000 \\
15-18,000 \\
15,000 \\
15,000 \\
15,000 \\
15,000 \\
15,000 \\
15,000 \\
15,000 \\
15,000 \\
15,000\end{array}$ & $\begin{array}{l}300 \\
150-200 \\
150-200 \\
150-200 \\
150-200 \\
150-200 \\
150-200 \\
200 \\
200 \\
200 \\
200 \\
200 \\
200 \\
200 \\
200 \\
200 \\
200 \\
200\end{array}$ & $\begin{array}{l}31.5 \\
59.9 \\
60.3 \\
59.4 \\
59.7 \\
60.0 \\
60.0 \\
25.0 \\
60 \\
60 \\
60 \\
60 \\
33 \\
60.9 \\
60.1 \\
60.0 \\
60.0 \\
60.0\end{array}$ & $\begin{array}{l}31.5 \\
58.3 \\
61.4 \\
61.0 \\
59.0 \\
60.0 \\
60.0 \\
25.7 \\
59.4 \\
59.5 \\
57.0 \\
58.0 \\
32.6 \\
60.9 \\
59.6 \\
60.0 \\
60.0 \\
60.0\end{array}$ & $\begin{array}{r}100 \\
97 \\
10 ? \\
103 \\
99 \\
100 \\
100 \\
103 \\
99 \\
99 \\
95 \\
97 \\
99 \\
100 \\
99 \\
100 \\
100 \\
100\end{array}$ \\
\hline
\end{tabular}


Table 3-1. (concluded)

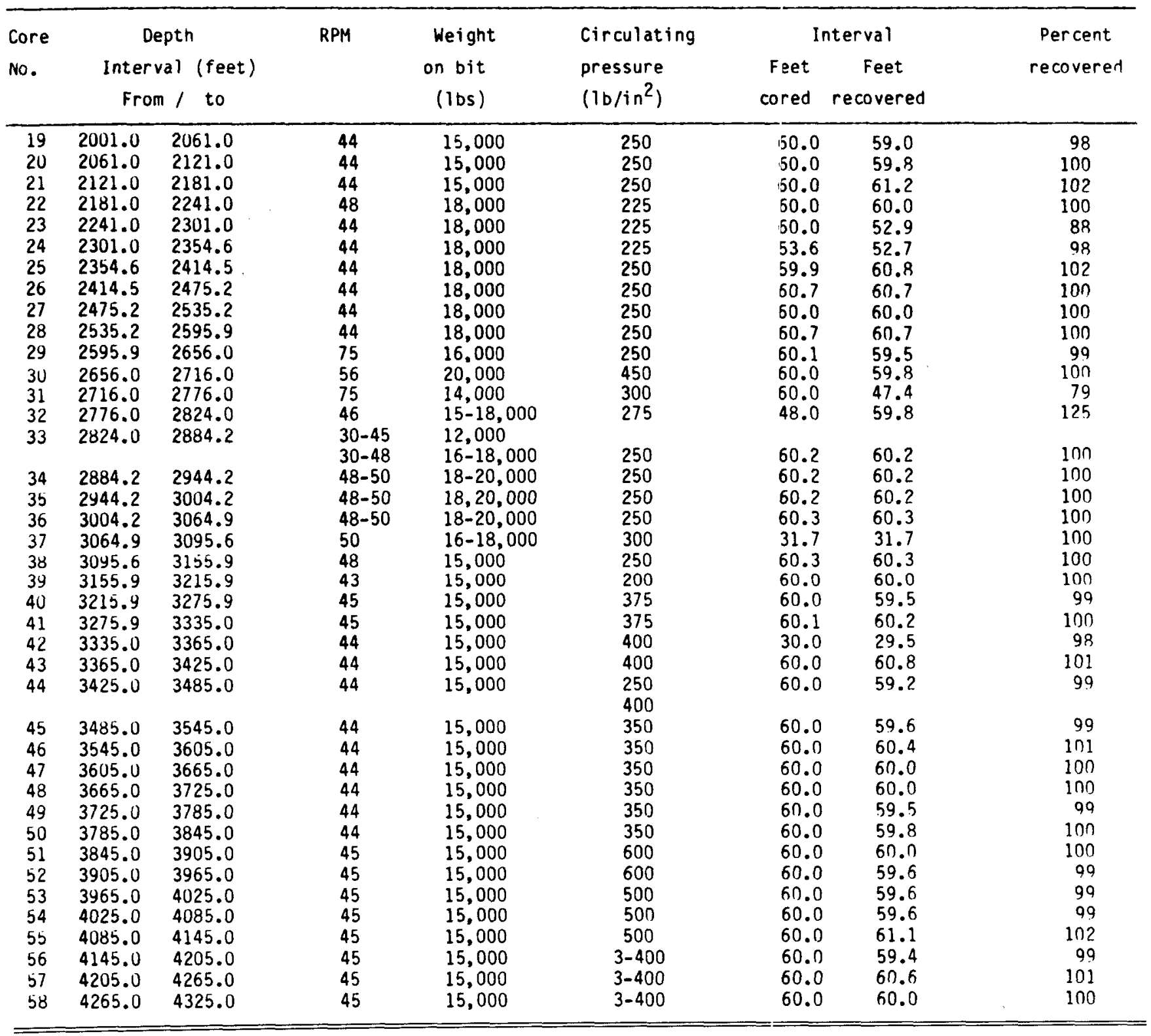


Table 3-2. Stratigraphic Summary of Drillhole DOE-2

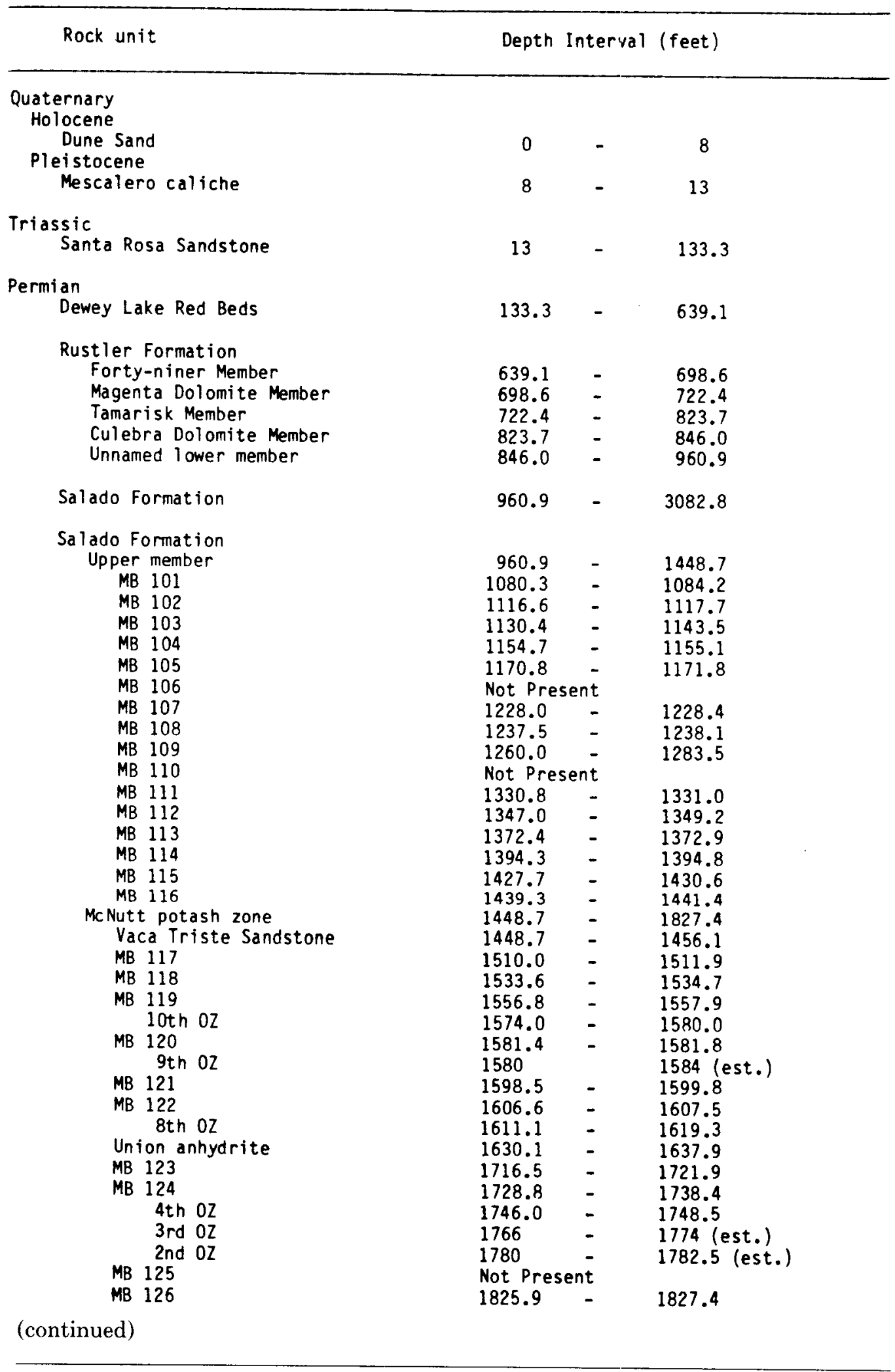


Table 3-2. (concluded)

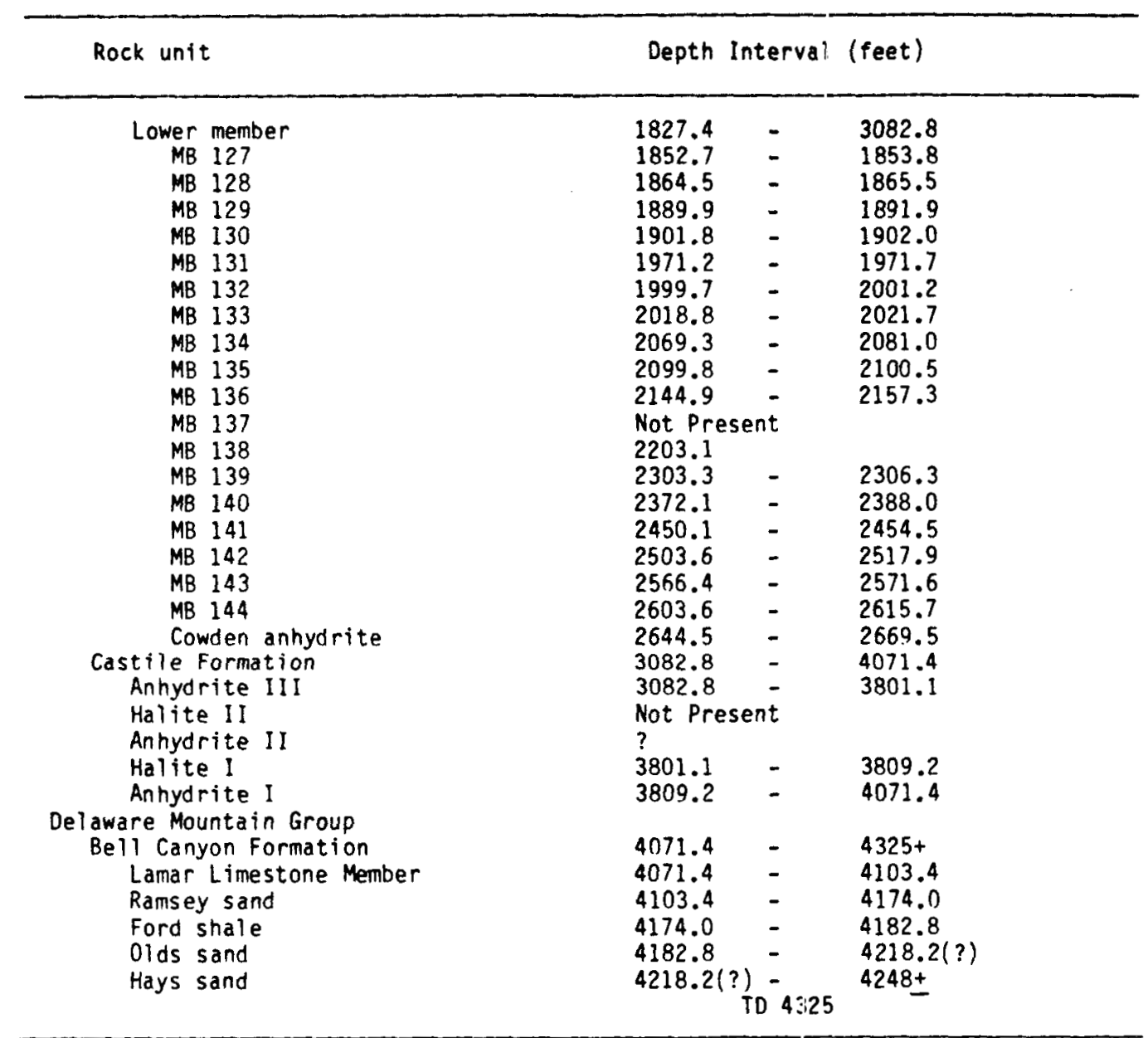

Depth interval interval estimated during auguring hole for surface pipe. All other depths from core measurements. 


\subsection{Description of Cuttings and Core}

The surface units at the DOE-2 site consist of yellowish-brown dune sand approximately $8 \mathrm{ft}$ thick overlying the Mescalero Caliche, a light-gray carbonate soil approximately $5 \mathrm{ft}$ thick. Depth and thickness of these two units were estimated by observing material recovered by augering prior to setting the surface casing.

The Santa Rosa Sandstone (at a depth of 13 to 133 $\mathrm{ft}$ ) consists of $120 \mathrm{ft}$ of moderately to well-indurated, moderate-reddish-brown and yellowish-brown sandstone interbedded with dark-reddish-brown siltstone and claystone. The rocks are laminated to thinly bedded; sandstones range from fine to coarse grained. Some beds contain clay galls indicating periods during deposition when the surface was dry enough for desiccation cracks to form. Some units are cross-bedded, but most are thinly bedded.

The 506-ft-thick Dewey Lake Red Beds were penetrated from 133 to $639 \mathrm{ft}$. Most of the formation consists of dark-reddish-brown siltstone, but sandstones and especially claystones are interspersed at irregular intervals. The rock contains grayish-green blebs and streaks, resulting from the reduction of iron-bearing minerals in the rock.

Secondary gypsum (selenite) occurs as veins and fracture fillings in most of the Dewey Lake Red Beds in the subsurface at the WIPP site area. In Drillhole DOE-2 the selenite was first observed at a depth of $144 \mathrm{ft}$ ( $11 \mathrm{ft}$ below the top of the formation), but is common in beds below $178 \mathrm{ft}(45 \mathrm{ft}$ below top of formation). Most veins occur along nearly horizontal bedding planes and are as much as $5 \mathrm{~cm}$ thick. The thicker veins occur in the section down to about $541 \mathrm{ft}$ (408 $\mathrm{ft}$ below top of formation). From $541 \mathrm{ft}$ to the base of the formation at $639 \mathrm{ft}$, the numerous selenite veins are very thin and commonly form a box-work pattern. Selenite also fills fractures that occur at various angles to the bedding. Most selenite veins show a median suture and contain straight crystals normal to the wall rock, despite variations in dip of the fracture. Presence of a median suture identifies the vein filling as antitaxial. At a depth of $420 \mathrm{ft}$, a vein filling shows crystal curvature near the center of the vein. Nearly all vein fillings show no crystal curvature; therefore, shear stress was probably absent during formation of the selenite crystals. For a comprehensive discussion of vein fillings, median sutures, and curved crystals, the reader is referred to Durney and Ramsey (1973).
Clay galls and desiccation-crack fillings are disseminated throughout the Dewey Lake Red Beds, indicating deposition of sediment in a very shallow or ephemeral lake. Cross-bedding of some thin-bedded sandstones and siltstones indicates current movement from various directions. Soft sediment deformation (convoluted bedding) also occurs throughout strata of the Dewey Lake. The contact of the Dewey Lake Red Beds with the underlying Rustler Formation is marked by a 0.1 -ft-thick grayish-green claystone that appears to have been deposited on partially eroded anhydrite. There is no indication of ground-water movement along the contact.

The Rustler Formation is divided into five members; from top to bottom, (1) Forty-niner Member; (2) Magenta Dolomite Member; (3) Tamarisk Member; (4) Culebra Dolomite Member; and (5) the unnamed lower member. The Forty-niner and Tamarisk Members were named by W. B. Lang (Adams, 1944) and the two dolomite members by Vine (1963). The Rustler Formation is $321.8 \mathrm{ft}$ thick (639.1 to $960.9 \mathrm{ft}$ ) in DOE-2.

The Forty-niner Member (639.1 to $698.6 \mathrm{ft}$ ) is composed of two thick anhydrite/gypsum units (639.1 to 670.0 and 680.9 to $698.6 \mathrm{ft}$ ) separated by a $10.9-\mathrm{ft}$ thick $(670.0$ to $680.9 \mathrm{ft})$ claystone and gypsumfragment unit. At other locations in the subsurface on and near the WIPP site and to the west, the calcium sulfate units have been completely hydrated to gypsum. Eastward, where the Forty-niner is more deeply buried, the units are totally anhydrite. Density and neutron logs were used together with core descriptions to distinguish anhydrite from gypsum in Drillhole DOE-2. "Chicken-wire" and nodular structure in the anhydrite of the lower unit indicate the complex alteration history of the Forty-niner. The geophysical logs indicate gypsum in portions of both the upper and lower anhydrites, mostly in the lower halves of each (Figure 3-2). The claystone unit between the two anhydrites, which has been identified as a dissolution residue, remaining after removal of halite (Jones and others, 1960, Figure 1), contains recemented rounded siltstone fragments and broken secondary gypsum beds. The rock varies from soft to very well indurated. Washout during coring is common in this soft unit.

The Magenta Dolomite Member, approximately $24 \mathrm{ft}$ thick $(698.7$ to $722.4 \mathrm{ft}$ ), underlies the Fortyniner Member. The Magenta is a pale-yellowishbrown to light-olive-gray, thinly laminated to thickly bedded dolomite containing several 2- to 6-mm-thick selenite veins that are parallel to nearly horizontal 
bedding. The dolomite also commonly contains crossbeds and small-scale lenses. Laminae in the lower 1.4 $\mathrm{ft}$ of the member are wavy and may be the result of soft sediment deformation. No open fractures were observed in the core, but the selenite vein fillings attest to possible postdepositional vertical tension on the unit.

Underlying the Magenta Dolomite is the Tamarisk Member, approximately $101 \mathrm{ft}$ thick (722.4 to $823.7 \mathrm{ft}$ ), which consists of two light- to dark-gray and brownish-gray gypsum and anhydrite units separated by $6.6 \mathrm{ft}$ of reddish-brown, light-bluish-gray, paleyellowish-brown, and olive-gray gypsiferous siltstone and claystone residue containing pods of gypsum and bladed selenite.

The upper gypsum and anhydrite unit (722.4 to $798.3 \mathrm{ft}$ ), approximately $76 \mathrm{ft}$ thick, consists mainly of gypsum and gypsiferous anhydrite and minor anhydrite. Nearly all of the core of this member exhibits "chicken-wire" and nodular structures. From 782 to $798.3 \mathrm{ft}$ most of the unit consists of large-bladed crystals of gypsum. Crenulated, nodular laminae of gypsum are common between depths of 768 and 783.5 $\mathrm{ft}$, and soft sediment deformation structures occur from 796.0 to $797.1 \mathrm{ft}$.

The lower gypsum and anhydrite unit, approximately $19 \mathrm{ft}$ thick ( 804.9 to $823.7 \mathrm{ft}$ ), also contains gypsiferous anhydrite and minor clayey gypsum. Swallow-tail, twinned gypsum crystals occur in the upper one-third of the unit, which is mostly gypsum; anhydrite constitutes most of the lower half of the unit. Clay seams occur throughout.

Underlying the Tamarisk Member is the Culebra Dolomite Member, $22.3 \mathrm{ft}$ thick (823.7 to $846.0 \mathrm{ft}$ ). The Culebra consists of commonly clayey dolomite of a light-olive-gray and moderate-yellowish-brown color. Numerous vugs, generally less than $1 \mathrm{~mm}$ in diameter, occur near the top and bottom of the member, but the central part contains vugs as large as 5 $\mathrm{mm}$. The rock is highly fractured in the central portion, and only a few fractures are healed with gypsum.

Below the Culebra Dolomite Member is the 124.9ft-thick unnamed lower member of the Rustler Formation ( 846.0 to $960.9 \mathrm{ft}$ ). The uppermost part of the
Iower member consists of $3.8 \mathrm{ft}$ of black, plastic clay and $6.0 \mathrm{ft}$ of reddish-brown clay residue containing bladed selenite crystals and gypsum nodules. The remainder of the member consists of thin to thick, alternating beds of reddish-brown halitic claystone, argillaceous halite clear halite, reddish-orange polyhalitic halite, gypum, anhydrite, and grayish-green siltstone and claysitone. Minor amounts of anhydrite and gypsum containing halite pseudomorphs are disseminated throughiout the member. In the basal part, siltstone and claystone units contain halite-healed, high-angle fractures. An 0.8-ft, dark-reddish-brown and pale-red anhydrite(?) occurs at the base of the member. No evidence of halite dissolution occurs below $864.4 \mathrm{ft}$.

The Salado Formation, named by Lang (1935, p 267), includes the upper halite-rich part of the Castile Gypsum of Richardson (1904, p 43). The Salado contains $85 \%$ to $90 \%$ halite or rock salt and lesser amounts of anhydrite, polyhalite, potassimumrich rocks, and minor amounts of sandstone, and claystone. The formation has been divided into three informal members (Jones, 1973, p 14). All three members contain similar amounts of halite, anhydrite, and polyhalite; the middle member, the McNutt potash zone, contains nineable quantities of potassiumbearing minerals, chiefly sylvite and langbeinite. The upper and middle members are generally more silty and clayey than the lower member. The detailed description of the Sialado Formation is given in Jones (1973).

The unnamed upper member of the Salado Formation consists of halite containing alternating units of disseminated polyhalite, clay, and anhydrite, 15 marker beds (Jones and others, 1960) of either polyhalite or anhydrite and several unnumbered, very thin beds of polyhalite. The thickness of the unnamed upper member at DOE-2 (488 ft) compares favorably with thickness of this unit in Drillholes W-11 (463 ft) and W-12 (478 ft). Distances between tops of marker beds (Table 3-3) are quite similar. These two factors suggest that the upper member at these three sites has not been affected by dissolution or flowage of halite. 
Table 3-3. Interval Thicknesses of Salado Formation in Drillholes W-11, W-12, and DOE-2; and Differences ( + or - ) in Thickness of the Intervals in W-11 and W-12 Compared to Interval Thicknesses in DOE-2 (rounded to nearest foot)

\begin{tabular}{|c|c|c|c|c|c|}
\hline Interval ${ }^{1}$ & $\begin{array}{c}W-12 \\
\text { Thickness } \\
(f t)\end{array}$ & $\begin{array}{l}W-11 \\
\text { Thickness } \\
(\mathrm{ft})\end{array}$ & $\begin{array}{l}\text { DOE-2 } \\
\text { Thickness } \\
\quad(\mathrm{ft})\end{array}$ & $\begin{array}{l}\text { Difference in thickness } \\
\text { DOE- }-2 \text { vs } W-12 \\
+=\text { more, }-=\text { less }\end{array}$ & $\begin{array}{l}\text { Difference in thickness } \\
\text { DnE-2 vs } W-11 \\
+=\text { more, }-=\text { less }\end{array}$ \\
\hline 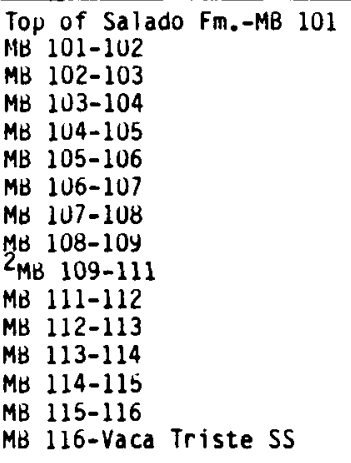 & $\begin{array}{r}113 \\
36 \\
15 \\
20 \\
16 \\
21 \\
35 \\
9 \\
23 \\
69 \\
17 \\
26 \\
22 \\
34 \\
12 \\
10\end{array}$ & $\begin{array}{r}113 \\
34 \\
14 \\
22 \\
15 \\
22 \\
36 \\
7 \\
25 \\
65 \\
14 \\
25 \\
19 \\
34 \\
11 \\
9\end{array}$ & $\begin{array}{r}120 \\
36 \\
13 \\
25 \\
16 \\
22 \\
35 \\
10 \\
22 \\
71 \\
16 \\
25 \\
22 \\
34 \\
11 \\
10\end{array}$ & $\begin{array}{r}+7 \\
0 \\
-2 \\
+5 \\
0 \\
+1 \\
0 \\
+1 \\
-1 \\
+2 \\
-1 \\
-1 \\
0 \\
0 \\
-1 \\
0\end{array}$ & $\begin{array}{r}+7 \\
+2 \\
-1 \\
+3 \\
+1 \\
0 \\
-1 \\
+3 \\
-3 \\
+6 \\
+2 \\
+0 \\
+3 \\
0 \\
0 \\
+1\end{array}$ \\
\hline Upper nember & 478 & 465 & 488 & +10 & +23 \\
\hline 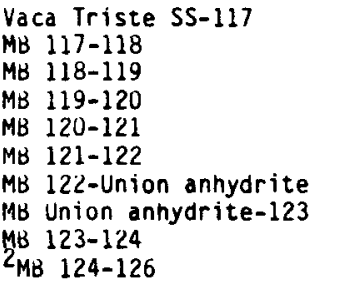 & $\begin{array}{r}62 \\
22 \\
24 \\
22 \\
12 \\
8 \\
23 \\
78 \\
13 \\
90\end{array}$ & $\begin{array}{r}59 \\
21 \\
18 \\
25 \\
16 \\
8 \\
22 \\
71 \\
12 \\
75\end{array}$ & $\begin{array}{r}61 \\
24 \\
23 \\
24 \\
18 \\
8 \\
23 \\
87 \\
12 \\
98\end{array}$ & $\begin{array}{r}-1 \\
+2 \\
-1 \\
+2 \\
+6 \\
0 \\
0 \\
+9 \\
-1 \\
+8\end{array}$ & $\begin{array}{r}+2 \\
+3 \\
+5 \\
-1 \\
+7 \\
0 \\
+1 \\
+16 \\
n \\
+23\end{array}$ \\
\hline McNutt potash zone & 354 & 327 & 378 & +24 & +51 \\
\hline $\begin{array}{l}\text { MB } 126-127 \\
\text { MB } 127-128 \\
\text { MB } 128-129 \\
\text { MB } 129-130 \\
\text { MB } 130-131 \\
\text { MB } 131-132 \\
\text { MB } 132-133 \\
\text { MB } 133-134 \\
\text { MB } 134-135 \\
\text { MB } 135-136 \\
2 \text { MB } 136-138 \\
\text { MB } 138-139 \\
\text { MB } 139-140 \\
\text { MB } 140-141 \\
\text { MB } 141-142 \\
\text { MB } 142-143 \\
\text { MB } 143-144 \\
\text { MB } 144-\text { Cowden anhydrite } \\
\text { Cowden anhydrite- } \\
\text { Top Castile Fm. }\end{array}$ & $\begin{array}{r}23 \\
12 \\
22 \\
10 \\
62 \\
29 \\
18 \\
41 \\
23 \\
34 \\
63 \\
47 \\
44 \\
64 \\
44 \\
49 \\
30 \\
34 \\
\\
292\end{array}$ & $\begin{array}{r}18 \\
9 \\
18 \\
8 \\
47 \\
21 \\
12 \\
37 \\
20 \\
32 \\
48 \\
36 \\
31 \\
41 \\
28 \\
30 \\
36 \\
98 \\
17\end{array}$ & $\begin{array}{l}26 \\
12 \\
25 \\
12 \\
69 \\
29 \\
19 \\
50 \\
31 \\
45 \\
89 \\
70 \\
68 \\
78 \\
54 \\
62 \\
38 \\
41 \\
438\end{array}$ & $\begin{array}{r}+3 \\
0 \\
+3 \\
+2 \\
+7 \\
0 \\
+1 \\
+9 \\
+8 \\
+11 \\
+26 \\
+23 \\
+24 \\
+14 \\
+10 \\
+13 \\
+8 \\
+7 \\
+146\end{array}$ & $\begin{array}{r}+8 \\
+3 \\
+7 \\
+4 \\
+22 \\
+8 \\
+7 \\
+13 \\
+11 \\
+13 \\
+41 \\
+34 \\
+37 \\
+37 \\
+26 \\
+32 \\
+? \\
-57 \\
+4 ? \\
+4\end{array}$ \\
\hline Lower member & 941 & 587 & 1256 & +315 & +669 \\
\hline Total Salado Fm. & 1773 & 1379 & 2122 & +349 & +743 \\
\hline
\end{tabular}

Theasurement from top of marker bed to top of next lower marker bed, includes halite interval between.

2 Marker bed not identified, next lower marker bed used. 
The Vaca Triste Sandstone (Adams, 1944) marks the top of the McNutt potash zone; the base of Marker Bed 126 marks the base. The McNutt potash zone differs in one important aspect from the upper and lower members; it contains as many as 11 separate potash-mineral bearing zones numbered from the bottom up. Not all strata contain mineable amounts of potash in all areas. Some minor amounts of the potash mineral (sylvite) were identified in the core, but most of the potash was dissolved by the drilling fluid during coring, and there is no direct evidence as to the amount of potash minerals the 11 zones contain at DOE-2. Indirect evidence (lost core and partially dissolved core, wash-out zones shown by the caliper log, and high gamma readings matched to very low density readings) shows where the soluble potash zones (mostly sylvite) are located. Potash is present at DOE-2 in the 11th, 10th, 9th, 8th, 4th, and probably the 3 rd and 2 nd ore zones. The 4 th ore zone contains about $2.5 \mathrm{ft}$ of langbeinite, a potassium-magnesium sulfate that is not soluble in the brine drilling fluid.

Table 3-3 shows the footage intervals between tops of marker beds in the McNutt. The intervals do not vary much when comparing DOE-2 and W-11 and $\mathrm{W}-12$, except below the Union anhydrite, where the intervals in DOE-2 begin to increase in thickness.

The unnamed lower member of the Salado consists mainly of halite, some of which is argillaceous, polyhalitic, and anhydritic, and irregularly spaced anhydrite and polyhalite beds. Some of the halite exhibits evidence of recrystallization that includes halite free of foreign material and of intervals that are very coarsely crystalline.

The halite intervals in the lower member in W-11 (Table 3-3) are believed to have been thinned by flowage of halite from between marker beds caused by upward flowage of halite and anhydrite beds in the underlying Castile Formation (Snyder, 1982). With $\mathrm{W}-12$ as a guide, a thickness of about $940 \mathrm{ft}$ was projected for the lower member in DOE-2; instead a thickness of $1256 \mathrm{ft}$ was penetrated. Some of this apparent thickness is caused by dipping strata. Because the marker beds themselves do not vary in thickness very much from one drillhole to the next, the majority of the thickness change from the top of one marker bed to the top of the next is due to thickening of the intervening halite. Table $3-3$ illustrates the thickened intervals of halite between marker beds in DOE-2 as compared with W-11 and W-12.

The Castile Formation, in the area of DOE-2, generally consists of three anhydrite units separated by two halite units. Anderson and others, (1972) identify these units from the top downward as AIII, HII,
AII, HI, and AI. Estimates of total Castile thickness from oil and gas holes in the WIPP site vicinity ranged from about 1350 to $1400 \mathrm{ft}$. DOE-2 penetrated $989 \mathrm{ft}$ of the Castile; from top to bottom, $719 \mathrm{ft}$ of anhydrite, $8 \mathrm{ft}$ of halite, and $262 \mathrm{ft}$ of anhydrite. Dipping and repeated beds (sometimes inverted sections) cause AIII to appear much thicker than typical, HII may be missing, AII is posibibly incorporated in the thickened upper anhydrite, $\mathrm{HI}$ is only $9.1 \mathrm{ft}$ thick $(7.6$ to $7.8 \mathrm{ft}$ of true thickness), and AI is typical and nearly flat lying. The upper anhydrite showed no macroscopic evidence of fracturing excepit for rare verticle rehealed fractures visible only on artificially broken surfaces. Laminations directly above and below $3387 \mathrm{ft} \operatorname{dip} 25^{\circ}$ to $30^{\circ}$ in opposing direction's, and one lamination can be seen to enter into and exit from the core in the same direction over a length of less than $2 \mathrm{ft}$. The $9.1 \mathrm{ft}$ of halite penetrated just below the thick upper anhydrite consists of nearly transparent bands alternating with translucent bands containing finely disseminated crystals of anhydilite. The faint banding dips, $15^{\circ}$ to $20^{\circ}$ and the haliti is very coarsely crystalline.

The basal anhydrite dips $15^{\circ}$ to $20^{\circ}$ in the upper part and $0^{\circ}$ to $10^{\circ}$ in the lower part. These dips do not take into consideration the $5^{\circ}$ to $7^{\circ}$ deviation of the drillhole. The true dip may be $0^{\circ}$ to more than $20^{\circ}$. Future work with portions of the core that were oriented will define the true dip and strike of the upper part of the basal anhydrite. Most of the basal anhydrite consists of cyclic deposits of relatively thick anhydrite, thinner dolomite, and laminated anhydrite/dolomite. These cycles range in thickness from a few inches to several feet. At the base of the anhydrite is a 1.7-ft-thick dolomite/anhydrite bed containing hydrocarbon that oozes from nearly vertical open fractures. The Castile Formation conformably overlies the Bell Canyon Formation.

DOE-2 penetrated the upper part of the Bell Canyon Formation of the Delaware Mountain Group. From the top downward, units penetrated are the Lamar Limestone, the Ramsey sand, the Ford shale, the Olds sand, and the Hays sand. The Lamar Limestone was first clescribed by Lang (1935); the other units are informal units of local usage.

Dip angles rneasured were nearly normal to the core, but the directional survey indicated that the drillhole deviated about $5^{\circ}$. The actual dip of the formation could range from $5^{\circ}$ to $10^{\circ}$.

The Lamar limestone consists of an upper $2.4 \mathrm{ft}$ of grayish-and dark-black calcareous shale and $29.6 \mathrm{ft}$ of similar colored limestone containing pelecypod shell fragments and corals as large as $0.02 \mathrm{ft}$ in diameter. 
The Ramsey sand, $70.6 \mathrm{ft}$ thick, is light to olive gray and fine to medium grained. The unit is fairly well indurated with calcareous cement. Underlying the Ramsey sand is the $8.8 \mathrm{ft}$-thick, dusky-yellowishbrown, calcareous Ford shale. The Ford contains numerous white pelecypod shells, both fragmental and whole.

The Olds sand, $35.4 \mathrm{ft}$ thick, is fine to medium grained olive-black and olive-gray sandstone; where well indurated, the sandstone contains a noncalcareous cement. Discontinuous claystone laminae are disseminated throughout.

The basal contact of the Hays sand was not identified but is believed to be at about $4248 \mathrm{ft}$, making the unit about $44 \mathrm{ft}$ thick. The Hays sand is marked by an upper shaley sandstone nearly $1 \mathrm{ft}$ thick and by sandstone similar to the Olds sand above. Like the Olds, the Hays has noncalcareous cement but is more indurated. Below the Hays, the unnamed sandstones contain thin ( 3 to $9 \mathrm{~mm}$ thick) black shale beds in sharp contact with the sandstone. Contacts between the named units are generally gradational.

\subsection{Conclusions}

The purpose of Drillhole DOE-2 was to investigate a known structural depression in rocks of Salado and younger age. The depression is a southeasttrending, doubly plunging syncline. Previous drilling in the area has defined the syncline as to size, and has shown that there is about $20 \mathrm{ft}$ of closure generally centered on the DOE-2 site. Control of mappable units is excellent from the surface downward to the top of the unnamed member of the Salado Formation, and the syncline is apparent to this depth. Three holes, W-11 about $4000 \mathrm{ft}$ north of DOE-2, W-12 about $1 \mathrm{mi}$ south, and $\mathrm{W}-13$ about $4500 \mathrm{ft}$ southwest, yielded some indication that the Castile-Bell Canyon contact might not conform to a generally eastwarddipping uninterrupted surface; the contact in W-11 appears at too shallow a depth.

From the surface to as deep as the unnamed lower member (MB126), of the Salado Formation, depths to rock units and formation tops were within a few feet of projections using previously published structure maps. From the unnamed lower member, marker beds and identifiable units consistently occurred at greater depths than predicted. It appears that downward salt flowage has increased thicknesses of halite between marker beds from MB126 to the base of the Salado Formation. The unnamed lower member of the Salado is about $315 \mathrm{ft}$ thicker than predicted.
The Castile Formation underlying the Salado Formation was not a typical section as is found in this area. A typical section consists of three anhydrite units separated by two halite units. In descending order, the Castile should consist of about 300 to $450 \mathrm{ft}$ of AIII, 225 to $275 \mathrm{ft}$ of HII, $120 \pm \mathrm{ft}$ of AII, 320 to 370 $\mathrm{ft}$ of $\mathrm{HI}$, and about $265 \mathrm{ft}$ of AI. The uppermost anhydrite was $719 \mathrm{ft}$ thick, but some of this thickness is caused by dipping and overturned beds. Only about $7.5 \mathrm{ft}$ (corrected for dips of $15^{\circ}$ to $20^{\circ}$ ) of halite was penetrated below the uppermost anhydrite. The lowermost anhydrite, $262 \mathrm{ft}$ thick, identified as AI, appeared to be undisturbed. The laminations dipped from $0^{\circ}$ to $10^{\circ}$, but considering the hole deviation of $5^{\circ}$, the true dip of AI could be as much as $15^{\circ}$.

The portion of the Bell Canyon Formation cored in DOE-2 showed no unusual structure and no fracturing. Dips of bedding planes were similar to AI in the Castile Formation.

It appears as if Castile halite, probably all of HII, and most of HI moved northward by flowage toward the $\mathrm{W}-11$ drill site where nearly $1000 \mathrm{ft}$ of halite (HI and HII) was penetrated. As the halite moved northward, AIII and possibly AII subsided, and moved southward from drill site W-11 toward drill site DOE2 slowly enough to allow pressure recrystallization of the thick anhydrite units. This slow movement precluded formation of fractures. It is possible that AII was pulled apart by tensional forces as HI flowed outward from beneath AII, and no AII is present at the DOE-2 site. No evidence of solution, such as residue, was observed in the core from either Salado or Castile Formations.

\subsection{Structural Summary}

\section{David J. Borns, Sandia National Laboratories}

The following discussion is an abridged summary of the structural data as interpreted by D. J. Borns. A more detailed interpretation will be made available in a report of DOE-2 to be released later (Borns, 1986).

Dissolution and gravity-driven deformation are two processes that are mentioned prominently as possibly producing the structural depression at DOE-2. Dissolution, if it occurred at DOE-2 in the last million years, would be significant relative to the adjacent $(3-\mathrm{km})$ WIPP site. Dissolution is marked by the removal of salt, but the Salado section at DOE-2 exhibits thickening. Therefore, it is unlikely that the depression was formed by dissolution in the Salado. The near absence of halite in the Castile suggests that the 
dissolution hypothesis be examined. In Halite I and especially Halite II in nearby holes, there are many anhydrite stringers $1 \mathrm{~cm}$ to $1 \mathrm{~m}$ wide. These stringers occur with consistent stratigraphic position within the halites. If dissolution of Halite II and I occurred, these stringers should remain. In examining the core from DOE-2, we have not observed such relict stringers within the upper anhydrite nor at the contact with halite. The only evidence for dissolution is the thinned halite section.

Halite can, however, also be thinned by deformation. The cross section of Salado and Castile stratigraphy (Figure 3-3) from DOE-2 and adjacent holes shows that the Castile salt is anomalously thickened at borehole WIPP-11, $1.6 \mathrm{~km}$ north of DOE-2. Within this portion of the Delaware Basin, the Castile Formation deforms into a series of antiforms and synforms (Snyder, in Borns et al, 1983). Salt flowage accompa- nies such deformation. The thickening of salt at WIPP-11 will be accompanied by thinning elsewhere. In some cases, the area of removal is called a salt removal basin or a peripheral sink (Seni and Jackson, 1980). The structure at DOE-2 may represent a salt removal basin. Sialt flowage is consistent with the strongly lineated fabric exhibited by the halite remaining at DOE-2. The elongation of the halite grains may represent the direction of flowage.

In summary, the structural depression intersected at the DOE-2 borehole probably formed in response to gravity-driven salt flowage, as suggested by distribution of salt structures within adjacent holes and the distribution of structures within the Castile. Dissolution is not favored due to the thickening of salt in the Salado and the nonobservation of residues or relicts in the Castile.

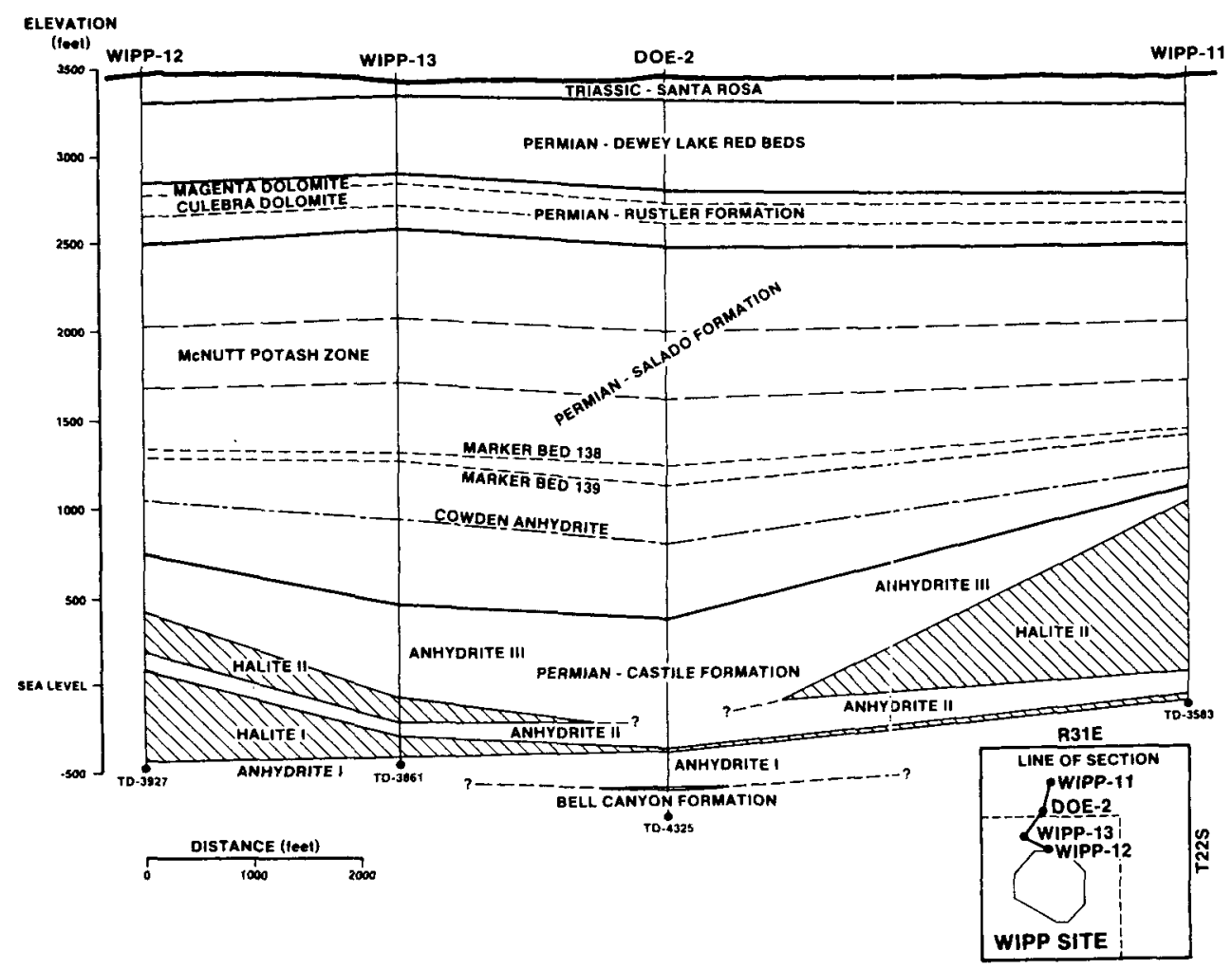

Figure 3-3. Geologic Section Near Drillhole DOE-2 


\section{References}

Adams, J. E., 1944, Upper Permian Ochoan Series of Delaware Basin. West Texas and Southeast New Mexico: American Association of Petroleum Geologists Bulletin, vol. 28 , no. 11 , p. $1596-1625$.

Anderson, R. Y., Dean, W. E., Jr., Kirkland, D. W., and Snider, H. 1., 1972, Permian Castile varved evaporite sequence, west Texas and New Mexico: Geological Society of America Bulletin, v. 83, no. 1, p. 59-86.

Borns, D. J., 1986, The geologic structures observed in drillhole DOE-2 and their possible origins, Waste Isolation Pilot Plant (WIPP): Sandia National Laboratories Report SAND86-1495.

Durney, D. W., and Ramsey, J. G., 1973, Incremented strains measured by syntectonic crystal growths, in Gravity and Tectonics, DeJong, K. A., and Scholten, Robert, eds., New York, John Wiley and Sons, p. 67-96.

Freeland, M. H., and Dadourian, P. P., 1982, Geologic data for borehole WIPP-12, Eddy County, New Mexico, in Basic data report for drillhole WIPP-12 (Waste Isolation Pilot Plant-WIPP): Sandia National Laboratories Report SAND82-2336, p. 4-68.

Goddard, E. N., Chairman, and others, 1948, Rock-Color Chart: Washington, National Research Council (reprinted by Geological Society of America, 1975).

Gonzalez, J. L., and Jones, C. L., 1979, Geologic data, in Basic data report on drillhole WIPP-25 (Waste Isolation Pilot Plant-WIPP): Sandia Laboratories Report SAND79-0279, p. 4-26.

Griswold, G. B., 1977, Site selection and evaluation studies of the Waste Isolation Pilot Plant (WIPP), Los Medanos, Eddy County, New Mexico: Sandia Laboratories Report SAND77-0946, 48 p.

Jones, C. L., 1973, Salt deposits of Los Medanos area, Eddy and Lea Counties, New Mexico, with sections on Ground water hydrology by M. E. Cooley and Surficial geology by G. O. Bachman: U.S. Geological Survey Open-File Report USGS-4339-7, 67 p.
1978, Test drilling for potash resources, Waste Isolation Pilot Plant site, Eddy County, New Mexico: U.S. Geological Survey Open-File Report 78-592, v. 2, 431 p.

Jones, C. L., Bowles, C. G., Bell, K. G., 1960, Experimental drill hole logging in potash deposits of the Carlsbad district, New Mexico: U.S. Geological Survey Open-File Report 502, $25 \mathrm{p}$.

Lang, W. B., 1935, Upper Permian Formation of Delaware Basin of Texas and New Mexico: American Association of Petroleum Geologists Bulletin, v. 19, p. 262-270.

1937, The Fermian Formations of the Pecos Valley of New Mexico and Texas: American Association of Petroleum Geologists Bulletin, v. 21, p. 874-875.

Richardson, G. B., 1904, Report of a reconnaissance in Trans-Pecos Texas, north of Texas and Pacific Railway: Texas University Mineralogical Survey Bulletin, and Texas University Bulletin 23, $119 \mathrm{p}$.

Seni, S. J., and Jackson, M. P. A., 1983, "Evolution of Salt Structures, East Texas Diapir Province, Part 2: Patterns and Rates of Halokinesis." American Association of Petroleum Geologists Bulletin 67, 1245.

Snyder, R. P., 1982, Geologic Data for borehole WIPP-11, in Basic data report for drillhole WIPP-11; (Waste Isolation Pilot Plant-WIPP): Sandia National Laboratories Report SAND79-0272, p. 5-23.

1983, General site geology, in Borns, D. J., Barrows, L. J., Powers, D. W., and Snyder, R. P., Deformation of evaporites near the Waste Isolation Pilot Plant (WIPP) site: Sandia National Laboratories Report SAND821069, p. 13-51.

Snyder, R. P., and McIntyre, A. F., 1981, Geologic data for borehole WIPP 33, in Basic data report for drillhole WIPP 33 (Waste Isolation Pilot Plant-WIPP): Sandia National Laboratories Report SAND80-2011, p. 4-22.

Vine, J. D., 1963, Surface Geology of the Nash Draw Quadrangle, Eddy County, New Mexico: U.S. Geological Survey Bulletin 1141-B, 46 p. 


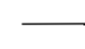




\title{
4. Hydrologic Testing
}

\author{
Richard L. Beauheim, Sandia National Laboratories
}

The hydrologic testing program for Drillhole DOE-2 was developed through consultation between Sandia National Laboratories, the US Department of Energy (DOE), the US Geological Survey (USGS), and Westinghouse/IT. The program was outlined for the New Mexico Environmental Evaluation Group (EEG) for their information and to solicit their comments.

\subsection{Purposes of Testing}

Various breach consequence scenarios have been hypothesized for the WIPP that involve interconnection of the WIPP facility with overlying and/or underlying aquifers through one or more boreholes. To evaluate these scenarios requires characterization of the aquifers overlying and underlying the facility with respect to their relative head potentials, permeabilities, storativities, and water qualities. The intent of the DOE-2 testing program was to characterize hydrologically all zones in a single borehole that could potentially play a significant role in any breach event. The information gathered from each zone would also assist in regional characterization of the different aquifers.

\subsection{Selection of Test Intervals}

During the drilling of DOE-2, four stop points were scheduled, to allow for hydraulic testing of the most recently penetrated strata. The first stop point was at the top of the Rustler Formation, to allow for testing the overlying Dewey Lake Red Beds. Although a water table exists in the Dewey Lake locally south of the WIPP site, no evidence of saturation of the Dewey Lake at DOE-2 was observed. Nevertheless, the Dewey Lake is permeable, as evidenced by a loss of circulation at a depth of $\sim 245 \mathrm{ft}$, and it could conceivably provide a flow path in the event of a breach.
The original Field Operations Plan for the PhaseI investigations (Appendix A) called for three tests in the Dewey Lake: one in the Dewey Lake sandstone estimated to lie between $\sim 200$ and $250 \mathrm{ft}$ deep, one in the Dewey Lake gypsiferous zone between $\sim 250$ and $400 \mathrm{ft}$ deep, and one in the lower Dewey Lake from $\sim 400 \mathrm{ft}$ to just below the Dewey Lake-Rustler contact. Unfavorable drilling conditions, however, required reaming the upper Dewey Lake to too large a diameter for testing with the available equipment. Hence, the decision was made to try to test only the lower Dewey Lake from a depth of $490 \mathrm{ft}$ to the bottom of the hole at $641 \mathrm{ft}$ deep, $\sim 2 \mathrm{ft}$ below the contact with the Rustler Formation. When a reliable packer seat could not be obtained at $490 \mathrm{ft}$, the top of the test interval was moved down to $539 \mathrm{ft}$.

The second stop point, at the top of the Salado Formation, coincided with the end of Phase-I drilling and allowed for testing the overlying Rustler Formation. Portions or all of the five members of the Rustler were selected for testing, with the test intervals and major rock types of interest being as follows: the lower claystone part of the unnamed member and the Rustler-Salado contact, from 945 to $967 \mathrm{ft}$ deep; the Culebra Dolomite Member, from 824 to $846 \mathrm{ft}$ deep; the claystone/siltstone portion of the Tamarisk Member, from 796 to $817 \mathrm{ft}$ deep; the Magenta Dolomite Member, from 700 to $722 \mathrm{ft}$ deep; and the claystone/ siltstone portion of the Forty-niner Member, from 664 to $686 \mathrm{ft}$ deep (refer to Appendix $\mathrm{F}$ for relationship between test intervals and detailed lithology). The untested portions of the Tamarisk and Forty-niner Members are comprised of unfractured anhydrite and gypsum; the untested portion of the lower unnamed member is comprised of clay, anhydrite, gypsum, and halite. These zones were judged to have permeabilities too low for measuring with the available equipment.

Phase-Ia testing of the Culebra dolomite also occurred at the second stop point, albeit after the hole was reamed. The results of the Phase-I testing of the Culebra, discussed later, indicated the need for additional testing before Phase-II drilling. 
The third stop point was at the top of the Castile Formation, to allow for testing the overlying Salado Formation. The first zone tested in the Salado Formation extended from 2196 to $2308 \mathrm{ft}$ deep and included Marker Beds 138 and 139 as well as the WIPP facility horizon (see Table 3-2). This zone was selected because of the pressurized gas and brine occurrences noted in the 50-ft coreholes into the roof and floor of the facility (US DOE, 1983). The bulk of the Salado and the Salado-Castile contact was also tested over the interval from 1041 to $3095 \mathrm{ft}$ deep. This interval was tested to determine whether there were significant pressure-producing zones within the Salado. Because no such zones were detected, no further tests were performed in the Salado.

The fourth stop point was at the final total depth of the hole $(4325 \mathrm{ft}), \sim 254 \mathrm{ft}$ into the Bell Canyon Formation; it allowed for testing portions of the upper Bell Canyon and the Castile Formation. This stopping point was selected because it was beneath the typical stopping point for gas exploration drilling in the Bell Canyon and extended about the same distance into the Bell Canyon as Hole Cabin Baby-1 (Beauheim et al., 1983). Hence, the same Bell Canyon zones that were tested in Cabin Baby-1 could be tested in DOE- 2 . Evaluation of core and geophysical logs indicated a total lack of open fractures in the Castile and very low permeability. Thus, testing in the Castile was deemed unwarranted. The Bell Canyon test intervals and units of interest in DOE-2 were: the Hays sandstone, from 4220 to $4325 \mathrm{ft}$ deep; the Olds sandstone, from 4177 to $4218 \mathrm{ft}$ deep; and the Ramsey sandstone, from 4138 to $4180 \mathrm{ft}$ deep (see Appendix F for relationship between test intervals and detailed lithology). The Lamar limestone, which was tested in Cabin Baby-1, was not tested in DOE-2 because examination of the core indicated very low permeability.

All intervals listed above and in Table 4-1 are actual, tested intervals, i.e., the intervals between straddle packers or between a single packer and the bottom of the hole. As the individual tests are summarized in Section 4.5, differences between the estimated producing thicknesses and the total tested thicknesses will be discussed.

\subsection{Test Methods}

A variety of testing methods were used at DOE-2 because both saturated and unsaturated media were tested and because permeabilities ranging over six orders of magnitude were encountered. A constanthead borehole-infiltration test was attempted in the unsaturated Dewey Lake Red Beds. For the saturated intervals to be tested, drill-stem tests (DSTs), risinghead "slug" tests: pressure-pulse tests, and pumping tests were selected as the most appropriate means of quantifying hydraulic properties.

\subsubsection{Constant-Head Borehole- Infiltration Tests}

Constant-hecid borehole-infiltration tests, as described by Stephens and Neuman (1980), involve isolating a zone to be tested above a water table with inflatable packers, then applying a constant fluid pressure to the zone and monitoring the rate of water flow into the forrnation. Where the unsaturated strata to be tested overlie a relatively impermeable layer rather than a water table, the same type of test may be suitable, depending on whether steady-state flow conditions are reached before boundary effects from the impermeable layer come into play. If boundary effects begin to influence the data before steady-state conditions are reached, observation wells are required to interpret the response.

When a constant-head borehole-infiltration test begins, the flow rate into the formation will be relatively high as the rock around the borehole begins to saturate. At this time, flow is largely horizontal because the strongest gradient is oriented normal to the axis of the borehole. With increasing time and saturation, the flow rate decreases and downward vertical flow becomes increasingly important. As the horizontal area of saturation widens, the area over which vertical flow occurs also increases. When the downward vertical flow balances the horizontal flow, steady state is reached and the flow rate stabilizes. The stabilized flow rate can then, in theory, be used to calculate the saturated permeability of the formation.

In practice, complete stabilization of the flow rate can take an unreasonably long time. Stephens and Neuman (1980) determined that when flow rate was plotted vs the inverse of the square root of flow time, a straight line would eventually develop that could be extrapolated to infinite time. The flow-rate intercept at infinite time corresponds to the saturated flow rate within $\sim 10 \%$. In the field, this plotting technique can be used to determine when a valid extrapolation can be made and the test terminated, reducing total test time by one or more orders of magnitude. 


\section{Table 4-1. DOE-2 Test Summary}

\begin{tabular}{|c|c|c|c|c|c|c|c|c|c|c|c|}
\hline Zone & Lithology & $\begin{array}{c}\text { Depth } \\
\text { (ft) }\end{array}$ & $\begin{array}{c}\text { Test } \\
\text { Interval } \\
\text { Transducer } \\
\text { Depth (ft) }\end{array}$ & Test & $\begin{array}{l}\text { Test } \\
\text { Date }\end{array}$ & $\begin{array}{l}\text { Start } \\
\text { Time }\end{array}$ & $\begin{array}{l}\text { End } \\
\text { Time } \\
\end{array}$ & $\begin{array}{l}\text { Pressure } \\
\text { Before } \\
\text { Test (psia) }\end{array}$ & $\begin{array}{c}\text { Start } \\
\text { Pressure } \\
\text { (psia) } \\
\end{array}$ & $\begin{array}{c}\text { End } \\
\text { Pressure } \\
\text { (psia) }\end{array}$ & $\begin{array}{c}\mathrm{q}_{\mathrm{f}}^{*} \\
(\mathrm{BPD})\end{array}$ \\
\hline Dewey Lake & $\begin{array}{l}\text { siltstone/ } \\
\text { claystone }\end{array}$ & $539-641$ & 53.8 & $\begin{array}{l}\text { Constant- } \\
\text { Head }\end{array}$ & $9 / 14 / 84$ & 02:08 & 03:08 & - & - & - & 0.009 \\
\hline Forty-niner & $\begin{array}{l}\text { siltstone/ } \\
\text { claystone/ } \\
\text { anhydrite/ } \\
\text { gypsum }\end{array}$ & $664-686$ & 644.4 & $\begin{array}{l}\text { FFL }^{1} \\
\text { FBU }^{2} \\
\text { Slug }\end{array}$ & $\begin{array}{l}10 / 15 / 84 \\
10 / 15 / 84 \\
10 / 15-16 / 84\end{array}$ & $\begin{array}{l}10: 37: 54 \\
11: 38: 18 \\
21: 12: 05\end{array}$ & $\begin{array}{l}\text { 11:38:10 } \\
\text { 21:07:00 } \\
\text { 08:15:019 }\end{array}$ & $\begin{array}{c}176.3^{\dagger} \\
-\overline{175.2^{\dagger}}\end{array}$ & $\begin{array}{r}7.3^{\dagger} \\
17.4^{+} \\
14.7^{+}\end{array}$ & $\begin{array}{r}8.4^{\dagger} \\
175.2^{\dagger} \\
31.8^{\dagger}\end{array}$ & $\begin{array}{c}0.16 \\
- \\
-\end{array}$ \\
\hline Magenta & dolomite & $700-722$ & 680.9 & $\begin{array}{l}\text { FFL } \\
\text { FBU } \\
\text { Slug }\end{array}$ & $\begin{array}{l}10 / 13 / 84 \\
10 / 13-14 / 84 \\
10 / 14-15 / 84\end{array}$ & $\begin{array}{c}16: 29: 08 \\
17: 22: 29 \\
09: 18: 40\end{array}$ & $\begin{array}{l}17: 22: 20 \\
05: 15: 00 \\
08: 45: 00\end{array}$ & $\begin{array}{c}184.1^{\dagger} \\
- \\
174.7^{\dagger}\end{array}$ & $\begin{array}{r}7.0^{\dagger} \\
18.8^{\dagger} \\
6.9^{\dagger}\end{array}$ & $\begin{array}{r}9.1^{\dagger} \\
188.9^{\dagger} \\
41.8^{\dagger}\end{array}$ & $\begin{array}{c}0.08 \\
- \\
-\end{array}$ \\
\hline Tamarisk & $\begin{array}{l}\text { clay/ } \\
\text { siltstone/ } \\
\text { anhydrite/ } \\
\text { gypsum }\end{array}$ & $796-817$ & 776.3 & $\begin{array}{l}\text { FFL/Slug } \\
\text { FBU }\end{array}$ & $\begin{array}{l}10 / 12-13 / 84 \\
10 / 13 / 84\end{array}$ & $\begin{array}{l}22: 09: 40 \\
09: 39: 10\end{array}$ & $\begin{array}{l}\text { 09:38:30 } \\
12: 35: 00\end{array}$ & $271.4^{\dagger}$ & $\begin{array}{l}122.0^{\dagger} \\
136.2^{+}\end{array}$ & $\begin{array}{l}112.2^{+} \\
133.7^{\dagger}\end{array}$ & - \\
\hline Culebra(I) & dolomite & $824-846$ & 804.8 & $\begin{array}{l}\text { FFL } \\
\text { FBU } \\
\text { SFL }^{3} \\
\text { SBU }^{4} \\
\text { Slug }\end{array}$ & $\begin{array}{l}10 / 12 / 84 \\
10 / 12 / 84 \\
10 / 12 / 84 \\
10 / 12 / 84 \\
10 / 12 / 84\end{array}$ & $\begin{array}{l}12: 32: 05 \\
12: 39: 15 \\
13: 01: 10 \\
13: 08: 30 \\
16: 01: 17\end{array}$ & $\begin{array}{c}12: 39: 00 \\
13: 00: 40 \\
13: 08: 25 \\
16: 00: 35 \\
16: 52: 00\end{array}$ & $\begin{array}{c}178.0^{\dagger} \\
- \\
175.6^{\dagger} \\
- \\
187.2^{\dagger}\end{array}$ & $\begin{array}{r}61.6^{\dagger} \\
103.9^{\dagger} \\
107.1^{\dagger} \\
142.0^{\dagger} \\
47.3^{\dagger}\end{array}$ & $\begin{array}{l}102.0^{\dagger} \\
175.6^{\dagger} \\
140.0^{\dagger} \\
187.2^{\dagger} \\
186.4^{\dagger}\end{array}$ & $\begin{array}{r}54.0 \\
- \\
41.8 \\
- \\
-\end{array}$ \\
\hline Culebra(Ia) & dolomite & $824-846$ & $810^{\ddagger}$ & $\begin{array}{l}\text { Pumping } \\
\text { Recovery }\end{array}$ & $\begin{array}{l}2 / 19-3 / 12 / 85 \\
3 / 12-13 / 85\end{array}$ & $\begin{array}{r}17: 00: 00 \\
17: 00: 00\end{array}$ & $\begin{array}{l}17: 00: 00 \\
10: 00: 00\end{array}$ & $\begin{array}{c}197.1^{\dagger} \\
-\end{array}$ & $\begin{array}{r}197.1^{\dagger} \\
65.6^{\dagger}\end{array}$ & $\begin{array}{r}65.6^{\dagger} \\
196.6^{\dagger}\end{array}$ & $\begin{array}{l}213 \\
-\end{array}$ \\
\hline $\begin{array}{l}\text { Rustler- } \\
\text { Salado }\end{array}$ & $\begin{array}{l}\text { claystone/ } \\
\text { siltstone/ } \\
\text { halite }\end{array}$ & $945-967$ & 925.6 & $\begin{array}{l}\text { FFL/Slug } \\
\text { FBU }\end{array}$ & $10 / 11-12 / 84$ & $\begin{array}{l}19: 00: 55 \\
09: 20: 00\end{array}$ & $\begin{array}{l}09: 00: 001 \\
09: 30: 00\end{array}$ & $\begin{array}{c}384.7^{\dagger} \\
-\end{array}$ & $\begin{array}{l}103.9^{\dagger} \\
348.8^{\dagger}\end{array}$ & $\begin{array}{r}93.6^{\dagger} \\
347.2^{\dagger}\end{array}$ & - \\
\hline MB 138-139 & $\begin{array}{l}\text { halite/ } \\
\text { anhydrite/ } \\
\text { clay }\end{array}$ & $\begin{array}{l}2195- \\
2309\end{array}$ & 2176.94 & $\begin{array}{l}\text { FFL } \\
\text { FBU }\end{array}$ & $\begin{array}{l}5 / 19 / 85 \\
5 / 19-20 / 85\end{array}$ & $\begin{array}{l}10: 20: 15 \\
10: 41: 00\end{array}$ & $\begin{array}{l}10: 41: 00 \\
10: 00: 09\end{array}$ & $\begin{array}{c}988.4 \\
-\end{array}$ & $\begin{array}{l}241.0 \\
243.1\end{array}$ & $\begin{array}{l}243.1 \\
445.6\end{array}$ & $\begin{array}{c}0.37 \\
-\end{array}$ \\
\hline Salado & $\begin{array}{l}\text { halite/ } \\
\text { anhydrite }\end{array}$ & $\begin{array}{l}1040- \\
3095\end{array}$ & 1022.33 & $\begin{array}{l}\text { Pulse 1 } \\
\text { Pulse } 2\end{array}$ & $\begin{array}{l}5 / 21 / 85 \\
5 / 22 / 85\end{array}$ & $\begin{array}{l}14: 18: 15 \\
00: 12: 30\end{array}$ & $\begin{array}{l}23: 55: 00 \\
14: 00: 02\end{array}$ & $\begin{array}{l}308.8 \\
267.1\end{array}$ & $\begin{array}{l}181.9 \\
405.7\end{array}$ & $\begin{array}{l}266.2 \\
309.3\end{array}$ & - \\
\hline Ramsey & $\begin{array}{l}\text { sandstone/ } \\
\text { shale }\end{array}$ & $\begin{array}{l}4138- \\
4180\end{array}$ & 4120.57 & $\begin{array}{l}\text { FFL } \\
\text { FBU } \\
\text { SFL } \\
\text { SBU } \\
\text { Slug }\end{array}$ & $\begin{array}{l}7 / 12 / 85 \\
7 / 12 / 85 \\
7 / 12 / 85 \\
7 / 12 / 85 \\
7 / 12-14 / 85\end{array}$ & $\begin{array}{c}08: 55: 38 \\
09: 19: 50 \\
12: 12: 04 \\
13: 27: 10 \\
19: 02: 10\end{array}$ & $\begin{array}{c}09: 19: 50 \\
12: 11: 38 \\
13: 27: 10 \\
19: 01: 44 \\
07: 10: 07\end{array}$ & $\begin{array}{c}1825.0 \\
- \\
1783.3 \\
- \\
1765.0\end{array}$ & $\begin{array}{l}270.5 \\
285.1 \\
287.7 \\
343.3 \\
326.0\end{array}$ & $\begin{array}{r}285.1 \\
1783.3 \\
324.1 \\
1765.0 \\
1114.0\end{array}$ & $\begin{array}{c}5.31 \\
- \\
4.49 \\
- \\
-\end{array}$ \\
\hline Olds & $\begin{array}{l}\text { sandstone/ } \\
\text { shale }\end{array}$ & $\begin{array}{l}4177- \\
4218\end{array}$ & 4159.19 & $\begin{array}{l}\text { FFL } \\
\text { FBU } \\
\text { SFL } \\
\text { SBU } \\
\text { Slug }\end{array}$ & $\begin{array}{l}7 / 26 / 85 \\
7 / 26 / 85 \\
7 / 26 / 85 \\
7 / 26-27 / 85 \\
7 / 27-29 / 85\end{array}$ & $\begin{array}{l}08: 14: 55 \\
08: 29: 50 \\
12: 30: 15 \\
13: 00: 13 \\
08: 48: 22\end{array}$ & $\begin{array}{l}08: 29: 50 \\
12: 29: 52 \\
13: 00: 13 \\
08: 47: 50 \\
07: 10: 23\end{array}$ & $\begin{array}{c}1875.6 \\
- \\
1848.7 \\
- \\
1843.0\end{array}$ & $\begin{array}{l}127.5 \\
141.6 \\
143.2 \\
164.1 \\
165.6\end{array}$ & $\begin{array}{r}141.6 \\
1848.7 \\
164.1 \\
1843.0 \\
980.4\end{array}$ & $\begin{array}{c}6.60 \\
- \\
5.51 \\
- \\
-\end{array}$ \\
\hline Hays & sandstone & $\begin{array}{l}4220- \\
4325\end{array}$ & 4206.31 & $\begin{array}{l}\text { FFL } \\
\text { FBU } \\
\text { SFL } \\
\text { SBU } \\
\text { Slug }\end{array}$ & $\begin{array}{l}7 / 18 / 85 \\
7 / 18-19 / 85 \\
7 / 19 / 85 \\
7 / 19 / 85 \\
7 / 19 / 85\end{array}$ & $\begin{array}{c}18: 04: 00 \\
18: 15: 06 \\
07: 38: 07 \\
07: 58: 25 \\
12: 24: 30\end{array}$ & $\begin{array}{l}18: 15: 06 \\
07: 37: 39 \\
07: 58: 25 \\
12: 24: 06 \\
16: 40: 11\end{array}$ & $\begin{array}{c}1872.2 \\
- \\
1846.8 \\
- \\
1838.7\end{array}$ & $\begin{array}{r}198.9 \\
832.9 \\
581.8 \\
1175.9 \\
194.2\end{array}$ & $\begin{array}{r}564.2 \\
1846.8 \\
1011.4 \\
1838.7 \\
1775.8\end{array}$ & $\begin{array}{c}277 \\
- \\
165 \\
- \\
-\end{array}$ \\
\hline
\end{tabular}

${ }^{*} q_{\mathrm{f}} \quad=$ final flow rate, in barrels per day

†psig; psig $\approx$ psia -10.5

tbelow top of casing

${ }^{1}$ FFL = first flow period

${ }^{2} \mathrm{FBU}=$ first buildup period

${ }^{3} \mathrm{SFL}=$ second flow period

${ }^{4} \mathrm{SBU}=$ second buildup period 


\subsubsection{Drill-Stem Tests (DSTs)}

DSTs (and slug and pressure-pulse tests) require mounting a packer assembly at the bottom of a tubing string in the hole to isolate the interval to be tested. For a test of the lower portion of the hole, a single packer may be used. To test a discrete zone in a hole requires a straddle-packer arrangement. Other necessary equipment includes a shut-in tool to isolate the test interval from the tubing, transducers reading pressures above, between, and below the packers, and a data-acquisition system (DAS). Instrumentation specifications are discussed below.

The first step in a DST is to select the interval to be tested. The packer separation, or straddle, is then adjusted to correspond to the interval thickness. Next, the packer assembly, including transducers, is run into the hole to the desired depth and the packers are inflated. The test interval is then shut in (isolated from the tubing above), and the fluid in the tubing above the tool is swabbed out while the pressure in the test interval stabilizes.

The various phases of a drill-stem test described below are depicted schematically in Figure 4-1. The actual DST begins with opening the shut-in tool, which allows the water in the isolated interval to enter the tubing. Because of the large pressure differential normally existing between the evacuated tubing and the isolated interval, water under the initial static formation pressure flows toward the borehole and up the tubing string. This is the first flow (FFL) period (Figure 4-1). This period begins with a drop in pressure from static (shut-in tool closed) to a pressure corresponding to the weight of the water remaining in the tubing (after swabbing) above the transducer. As water rises up the tubing string, the pressure exerted downward on the isolated interval increases, reducing the pressure differential and thus the flow rate.

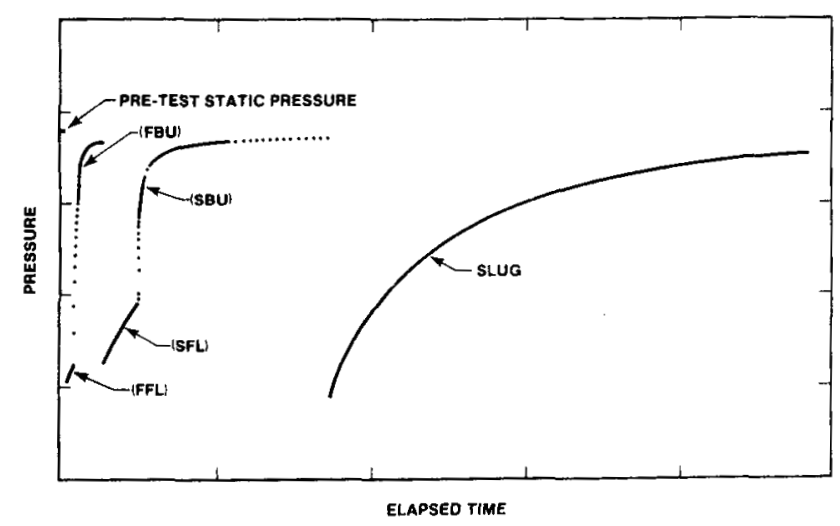

Figure 4-1. Components of a Drill-Stem Test and Slug Test
When the flow rate has decreased by $\sim 10 \%$ to $20 \%$ from its initial value, the shut-in tool is closed, stopping the flow of water up the tubing. This is the beginning of the firsit pressure buildup (FBU) period. The pressure in the test interval, which had dropped because of the FFL, builds back up toward the static formation pressure now that the interval is once again isolated. Initially, the pressure builds up rapidly because of the differential between the pressure in the test interval at the end of the FFL and that in the surrounding formation. As this pressure differential decreases, the rate of pressure buildup decreases. On an arithmetic plot of pressure vs time, the pressure "bends over" and starts to level out (Figure 4-1). The longer the FBU is allowed to run, the more definitive the data become, and conditions become more ideal for the start of the second flow period. In practical terms, the FBU should generally last at least four times as long as the FFL. In very low permeability formations, an FBU duration more than 10 times as long as the FFL may be necessary.

Following the $\mathrm{FBU}$, the shut-in tool is reopened to initiate the second flow (SFL) period. Because the water level in the tubing will not have changed since the end of the FF:L, a pressure differential will exist between the test interval and the tubing. The SFL typically lasts longer than the FFL, again until the flow rate decreases by $10 \%$ to $20 \%$. At the conclusion of the SFL, the shut-in tool is closed and the second buildup (SBU) period begins. Like the FBU, the SBU continues until the pressure starts to "level out." As with the FBU, the data become more definitive the longer the SBU continues, and conditions improve for the next phase of testing. These four periods - the FFL, FBU, SFL, and SBU-generally constitute a single complete DST.

\subsubsection{Slug Tests}

After the second buildup of the DST, and while the shut-in tool is still closed, the fluid is swabbed out of the tubing to allow a rising-head slug test. A risinghead slug test is performed in exactly the same manner as the DST flow periods, except that the test is not terminated after the flow rate changes by $10 \%$ to $20 \%$. Ideally, the slug test should continue until the initial pressure differential has decreased by $80 \%$ to $90 \%$. Practically, $40 \%$ recovery is generally adequate to define the shape of the recovery curve, particularly if $\log$-log plotting techniques are used (Ramey et al., 1975). 


\subsubsection{Pressure-Pulse Tests}

Pressure-pulse tests come in two varieties: pulsewithdrawal and pulse-injection. For either type, the test interval is first shut in and the pressure allowed to stabilize. The tubing string is either swabbed for a pulse-withdrawal test or filled to the surface (or otherwise pressurized) for a pulse-injection test. The shutin tool is then opened only long enough to transmit the underpressure (pulse-withdrawal) or overpressure (pulse-injection) to the test zone. In practical terms, it typically takes $\sim 1 \mathrm{~min}$ to open the tool, to verify over several pressure readings that the pressure pulse has been transmitted, and to close the tool. The dissipation of the resultant pressure differential between the test zone and the formation is then monitored for the actual test. As with a slug test, the pressure differential should be allowed to decrease by $80 \%$ to $90 \%$. However, pressure-pulse tests proceed much more rapidly than slug tests because equilibration is caused by compression of fluid rather than by filling a volume of tubing. Hence, attaining $80 \%$ to $90 \%$ recovery is generally practical during a pressure-pulse test.

\subsubsection{Pumping Tests}

Pumping tests are performed by isolating the interval to be tested in a borehole, lowering a pump into the hole, and pumping water from the formation at a nominally constant rate while monitoring the decline in water level or pressure in the pumped well and in any nearby available observation wells. Durations of pumping periods vary greatly, primarily as a function of what volume (or areal extent) of the aquifer one wishes to test. Following the pumping period, the recovery (rise) of water levels or pressures in the wells is monitored, typically through at least $95 \%$ recovery.

\subsubsection{Isolation Verification}

Pressures above and below the tested interval are monitored during all tests to detect any leakage around packers or other types of flow into or out of the test interval from/to above or below. Slow, uniform pressure changes of a few psi above and below the test interval are not uncommon because borehole fluids may seep into the adjacent formations or formation fluids may flow into relatively underpressurized intervals of the borehole. Abrupt, higher magnitude pressure changes may indicate faulty packer seats or other malfunctions.

Even when inflated to 2000 psi above ambient pressures, however, packers exhibit a degree of compliance, or "give." Because some shut-in tools require an up-or-down movement of the tubing string with several tons of force, packers may shift very slightly upward or downward during these movements. In an isolated interval of the borehole, such as below the bottom packer, the increase or decrease in volume caused by the packer compliance is translated into a detectable pressure change. Packer-compliance effects should not be confused with pressure changes having other causes. Differentiation is possible because packer compliance typically causes abrupt pressure changes at the time of tool movements $\rho r$ after packer inflation, followed by a return to the predisturbance pressure, whereas packer leaks or bad seals usually result in continuous pressure changes or equilibration between test-interval pressure and annulus or bottomhole pressure.

\subsection{Instrumentation}

Four different sets of instrumentation were used during DOE-2 testing: one set during the Phase-I testing of the Dewey Lake Red Beds, a second set during the Phase-I testing of the Rustler Formation, a third set during the Phase-Ia testing of the Culebra dolomite, and a fourth set during the Phase-II and Phase-III testing of the Salado and Bell Canyon Formations. The fourth set of instrumentation, which used quartz-crystal transducers, produced the highest quality (high-resolution, low-noise) data.

NOTE: The use of brand names in this report is for identification only, and does not imply endorsement of specific products by Sandia National Laboratories.

\subsubsection{Phase-l Testing- The Dewey Lake Red Beds}

The downhole equipment for the Phase-I constant-head borehole-infiltration testing of the Dewey Lake Red Beds consisted of a Baski airinflatable packer with a feed-through line for a transducer on 2.375-in. tubing. Two Bell and Howell CEC 1000 strain-gauge transducers were strapped to the tubing, one connected to the zone below the packer by means of the feed-through line and the other measuring the pressure in the borehole annulus above the packer. The uphole equipment consisted of a positivedisplacement Bean pump to supply pressure to the tubing, a CertainTeed water meter to measure the flow rate, an Ashcroft 0- to 100-psi pressure gauge to measure the injection pressure, a ball valve to control the backpressure, and a bypass line to divert the water 
produced by the pump in excess of that which the formation could accept. Figure 4-2 is a schematic drawing of the downhole and uphole instrumentation.

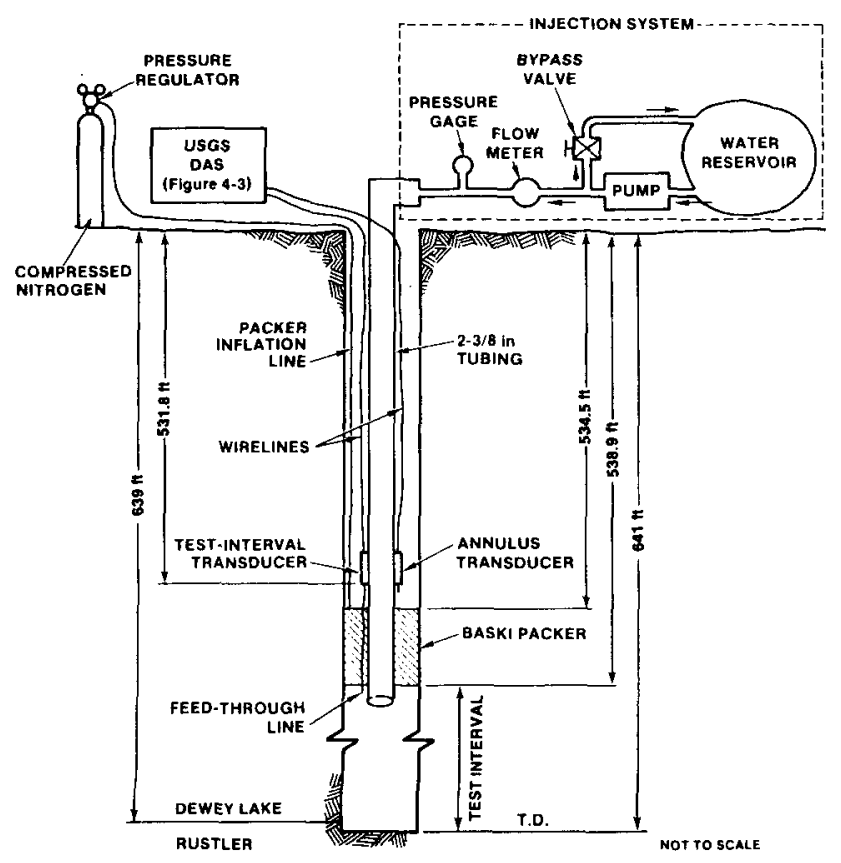

Figure 4-2. Dewey Lake Test Equipment Configuration

The transducers and other data-acquisition equipment for the Phase-I Dewey Lake and Rustler testing were provided by the USGS and are described in detail by Basler (1983). A Validyne CD-19 carrier demodulator amplifier provided ac excitation and a variable high-level output for the transducers. Data were recorded with a Soltec VP-6723S strip-chart recorder and an Esterline Angus PD2064 digital data logger. A Validyne DB-199 digital barometer was used to monitor and record barometric pressure. The USGS DAS is shown schematically in Figure 4-3. A Datel DVC- 8500 voltage calibrator was used to verify calibration of recorders and digital meters. Transducer calibration was performed before and after each installation with a Chandler 23-1 dead-weight tester.

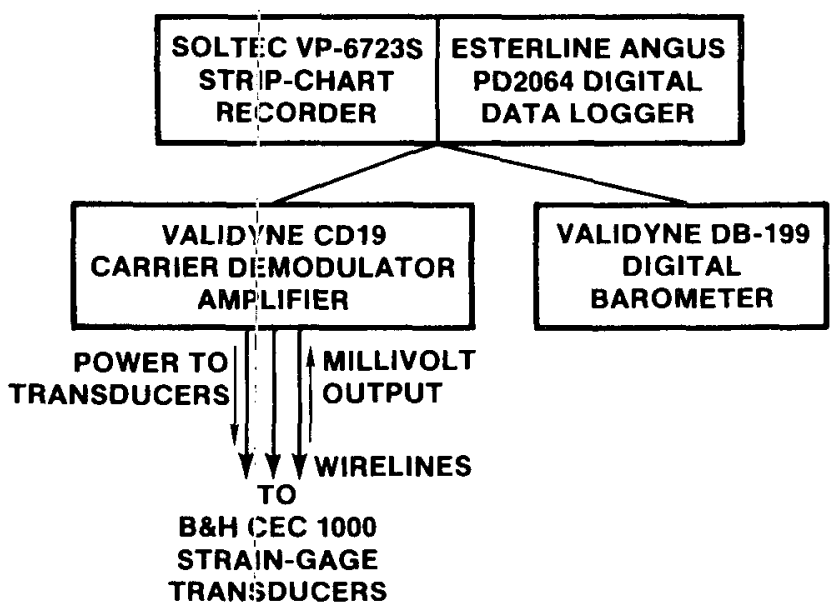

Figure 4-3. USGS Data-Acquisition System

\subsubsection{Phase-I Testing- The Rustler Formation}

For the Phasse-I drill-stem testing of the Rustler Formation, the downhole equipment consisted of a Baski straddle-packer DST tool and three Bell and Howell CEC 1000 strain-gauge transducers. The DST tool consisted of two air-inflatable packers separated by a perforated spacing shroud, with a section of blank pipe containing an air-inflatable shut-in packer set above the upper straddle packer (Figure 4-4). This entire assembly was lowered to the desired test depth on 2.375-in. tubing. The DST tool has feed-through fittings for inflation lines for the three packers, and for pressure-trarismittal lines from the zone beneath the lower packel: and from the straddled interval to the transducers, which were strapped to the tubing just above the I)ST tool. A third transducer, which measured the wellbore annulus pressure above the upper packer, was also strapped to the tubing. Each transducer was connected to the DAS at the surface (described in Section 4.4.1) with a separate wireline. 


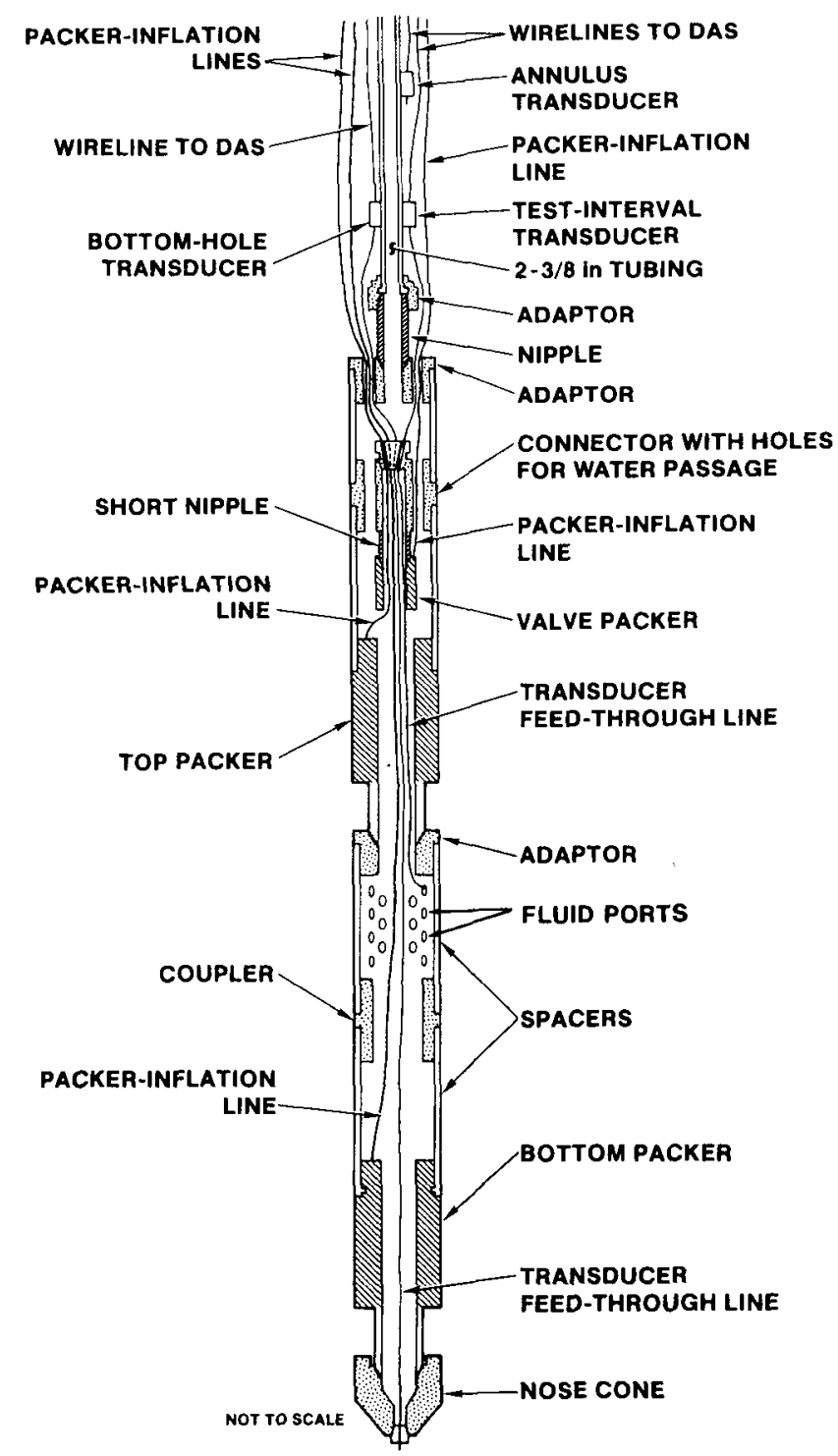

Figure 4-4. Baski DST Tool

\subsubsection{Phase-la Testing- The Culebra Dolomite Member}

For the Phase-Ia pumping test of the Culebra dolomite, the downhole equipment consisted of a 3-hp Red Jacket 32BC pump suspended below a Baski airinflatable packer on 2.375-in. tubing, with two Druck
PDCR-10 strain-gauge transducers strapped to the tubing above the packer (Figure 4-5). One transducer measured the pressure below the packer by means of a feed-through line through the packer; the second measured the pressure in the wellbore above the packer. A 0.25 -in. nylon line for collecting fluid samples was teed off from the main discharge line just above the pump and fed through the packer to the surface. A Lynes water-inflatable resettable bridge plug was set below the Culebra to seal off the lower portion of the hole. The uphole equipment consisted of a Rockwell flow meter, and of a pressure gauge and a ball valve to maintain adequate backpressure on the flow meter.

The DAS at the surface for the Phase-Ia testing consisted of Tektronix PS503A dual power supplies to provide power to the transducers, a Hewlett Packard (HP) 3495A signal scanner for channel switching, an HP3456A digital voltmeter (DVM) to measure the transducer output, an EDC-501J programmable voltage standard to verify the accuracy of the DVM, an HP9845B desktop computer for system control, and HP9885M and $\mathrm{S}$ floppy disk drives for data storage (Figure 4-6). The HP3456A DVM and the EDC-501J are calibrated by the Sandia Standards Laboratory every 6 months. The transducers were calibrated in the field using a Heise gauge before installation in the well. The data-acquisition software was written and is maintained by Sandia. Additional information on this DAS can be found in INTERA Technologies and HydroGeoChem (1985).

At the $\mathrm{H}-5 \mathrm{~b}$ and $\mathrm{H}-6 \mathrm{~b}$ observation wells (Figure 2-1), Baski air-inflatable packers were set in the well casing above the Culebra to minimize wellborestorage effects during the testing. Druck PDCR-10 strain-gauge transducers measured pressures in the Culebra intervals by means of feed-through lines through the packers. Additional transducers measured pressures in the wellbores above the packers. The DASs used were identical to that at DOE-2, except that at $\mathrm{H}-5 \mathrm{~b}$, no HP9845B computer was available. Millivolt output from the $\mathrm{H}-5 \mathrm{~b}$ transducers was read manually from the HP3456A DVM and entered into log books. The data were converted to pressures after hand-entry into computer files. 


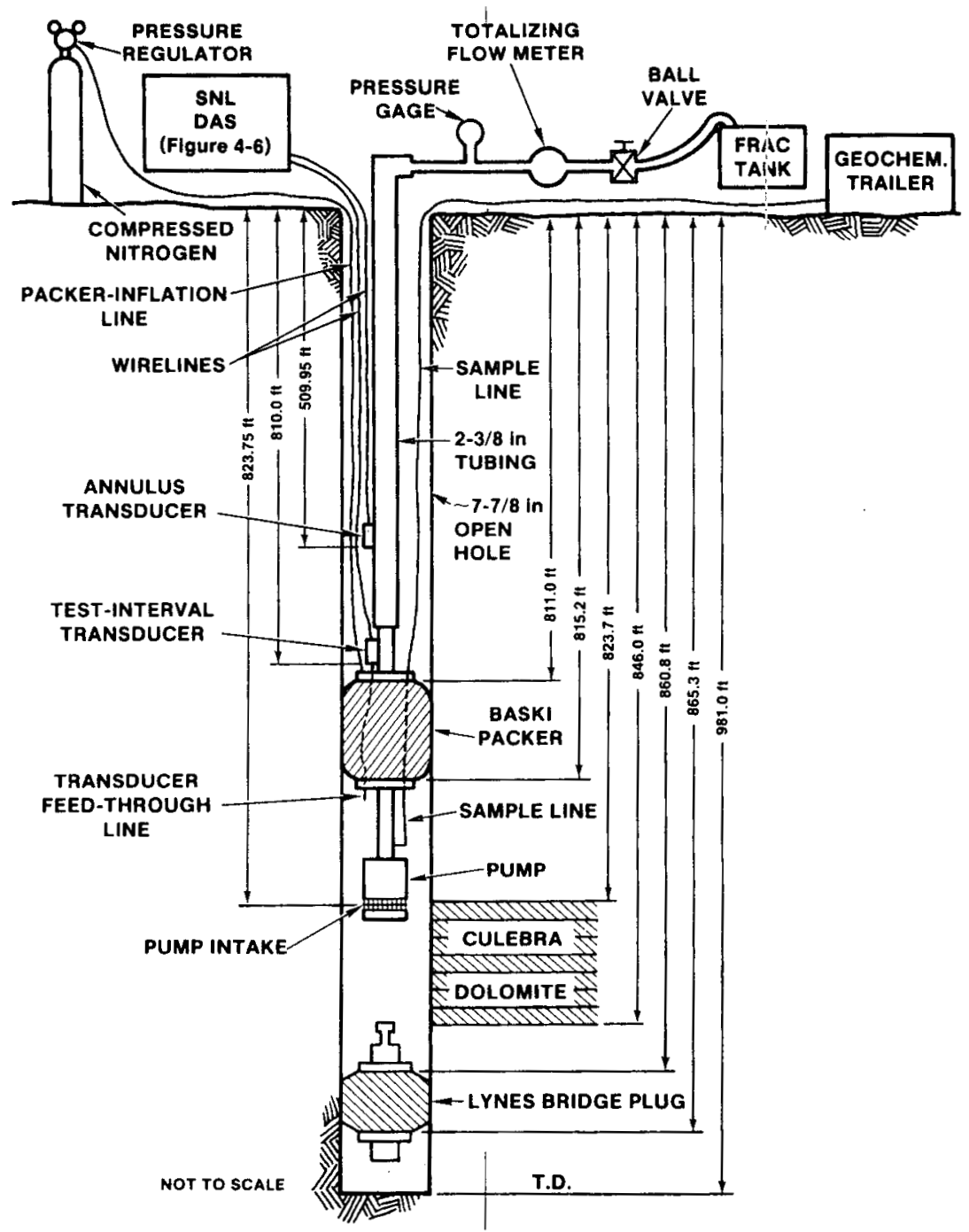

Figure 4-5. Culebra Pumping Test Equipment Configuration

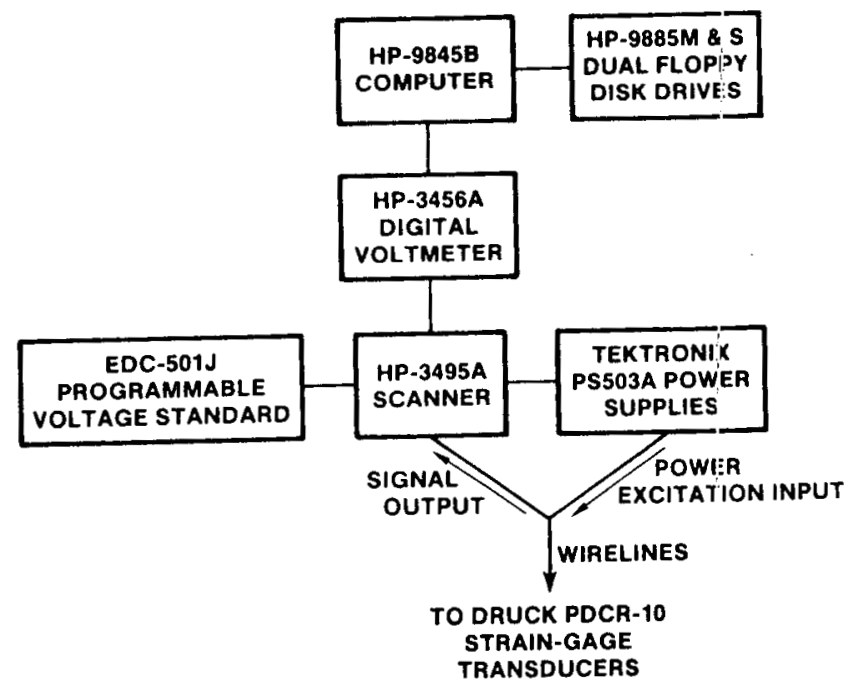

Figure 4-6. Sandia Data-Acquisition System 


\subsubsection{Phases-II and -III Testing- The Salado and Bell Canyon Formations}

For the Phase-II and Phase-III drill-stem, slug, and pressure-pulse testing of the Salado and Bell Canyon Formations, the downhole equipment was supplied by Baker Production Technology (BPT; formerly Lynes, Inc.). This consisted of a BPT hydrological test tool comprised of two water-inflatable straddle packers, spacers, a circulating valve, a shut-in tool, a J-slot tool used for packer inflation and deflation, various crossovers, and a sensor carrier containing three quartz-crystal pressure-temperature transducers (Figure 4-7). The transducers are ported through the tool to the hole below, between, and above the packers. A seamless, stainless-steel wireline connected

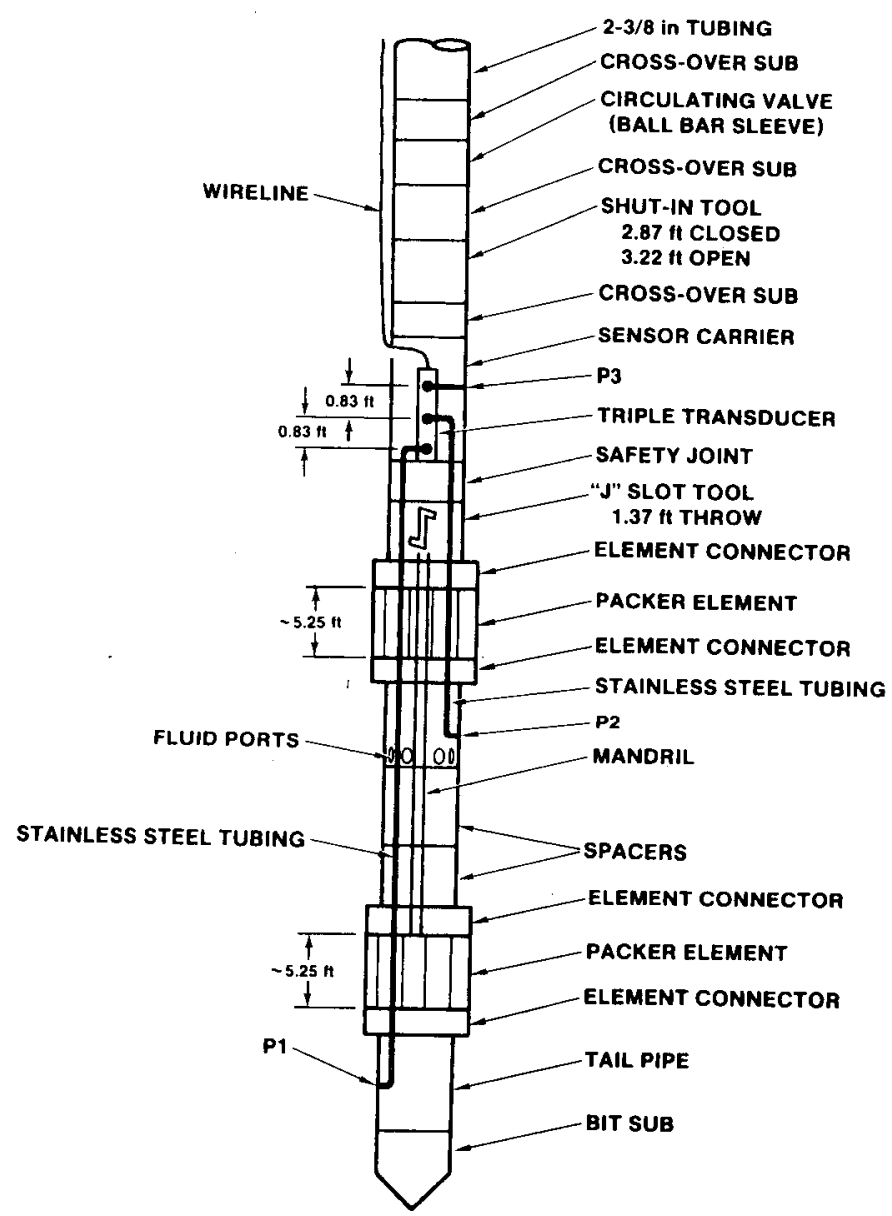

NOTE:

P1 IS PRESSURE BELOW THE TESTED INTERVAL;

P2 IS PRESSURE IN THE TESTED INTERVAL:

P3 IS PRESSURE IN THE WELL ANNULUS ABOVE

THE TESTED INTERVAL.

Figure 4-7. BPT DST Tool the transducers to the DAS at the surface. For tests of the lower portion of the hole, the bottom packer was removed and the tool was run in a single-packer configuration. The hydrological test tool was lowered to the desired test depth on 2.375-in. tubing.

The DAS used with the BPT tool consisted of a BPT SC-2 interface unit linking the transducers with the rest of the system, an HP5316A universal counter that measured the frequencies of the current pulses sent by the transducers, an HP59306A relay actuator or an HP3497A data acquisition/control unit for channel switching, an HP85 computer with tape drive for system control and data recording, an Epson LX-80 or HP2225A printer for real-time listing of the data, and an HP9872 plotter for real-time plotting of the data (Figure 4-8). The quartz-crystal transducers were calibrated by BPT before being sent to the field. The transducer calibration coefficients were entered into the data-acquisition program for automatic data conversion to pressure and temperature before recording. The data-acquisition software was written and is maintained by G-Tech Corp. of Houston.

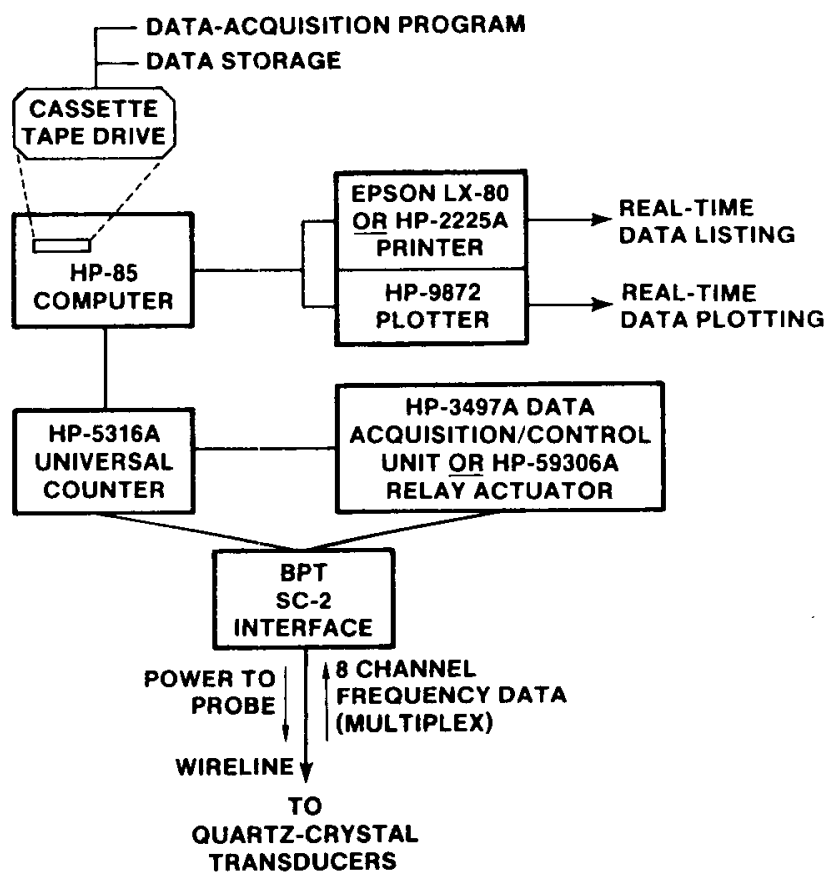

Figure 4-8. BPT DST Data-Acquisition System 


\subsection{Test Summary}

Portions of four formations were tested in DOE-2: the Dewey Lake Red Beds and the Rustler, Salado, and Bell Canyon Formations. A summary of the tests performed is presented in Table 4-1. All test data are contained in INTERA Technologies (1986).

\subsubsection{Dewey Lake Red Beds}

Testing of the Dewey Lake Red Beds began September 13, 1984, and concluded September 14, 1984 (Table 4-1). The original test zone selected was the lower Dewey Lake from $490 \mathrm{ft}$ deep to the bottom of the hole at $641 \mathrm{ft}, \sim 2 \mathrm{ft}$ into the Rustler Formation. When a good packer seat could not be obtained at 490 $\mathrm{ft}$, the packer was moved down to where the hole became slightly smaller. The final test interval was from 539 to $641 \mathrm{ft}$.

The Dewey Lake constant-head boreholeinfiltration test was originally set up with a pump to supply a constant pressure and a totalizing flow meter to measure the flow rate into the formation (Figure 4-2). This meter required a minimum of $0.25 \mathrm{gal} / \mathrm{min}$ (gpm) of flow to make the internal turbine turn. When it became apparent that the formation would not accept fluid at that rate, the pump and flow meter were removed from the system. The injection-system connections were removed from the tubing string, and the tubing was filled to the top, $\sim 7 \mathrm{ft}$ above ground surface. As the fluid level dropped in the tubing, water was added from a graduated cylinder every 10 to 20 min to maintain a constant head on the system.

After one hour, a total of $58 \mathrm{~mL}$ of water had been added to the tubing. The test was terminated at this time for two reasons: (1) at an apparent inflow rate of $\sim 1 \mathrm{~mL} / \mathrm{min}$, even a very small leak somewhere in the system could introduce a very large error in the flow measurement; and (2) because of the low observed initial infiltration rate, the difficulty of saturating an unknown volume of rock, and an anticipated declining infiltration rate as saturation approached, continuing the test until reaching steady-state conditions was deemed impractical.
The observed low inflow rate was taken as an indication that the permeability of the lower Dewey Lake is low enough to rule out the lower Dewey Lake at DOE-2 as a significant transport pathway in the event of a repository breach. Further quantification of the lower Dewey Lake hydraulic properties was deemed unwarranted.

\subsubsection{Rustler Formation}

Six sets of tests were conducted in the Rustler Formation in two phases: (1) the Phase-I testing of the Forty-niner Member, the Magenta Dolomite Member, the Tamarisk Member, the Culebra Dolomite Member, and the unnamed member and RustlerSalado contact; and (2) the Phase-Ia testing of the Culebra.

Forty-niner Member (DST 664-686) — The Fortyniner Member was tested between the depths of 664 and $686 \mathrm{ft}$, an interval containing all the clay and siltstone within the Forty-niner $(670.0-680.9 \mathrm{ft})$ as well as gypsum and anhydrite above and below. Testing of the Forty-uniner was performed October 15 and 16, 1984 (Table 4-1), and comprised one flow period lasting $60 \mathrm{~min}$, one buildup period lasting $569 \mathrm{~min}$, and a slug test lassting $663 \mathrm{~min}$ (Figure 4-9).

The apparent pressure response to testing was somewhat erratic. A relatively high degree of noise is superimposed on the pressure trends for all three transducers shown in Figure 4-9. The noise is significant because the low permeability of the unit did not always allow incremental changes in the pressure signal to be of a magnitude greater than that of the noise.

Magenta Dolomite Member (DST 700-722)-The Magenta Dolomite Member was tested between the depths of 700 and $722 \mathrm{ft}$. In total, the Magenta extends from 698.7 to $72: .4 \mathrm{ft}$ deep (Table 3-2). Testing of the Magenta began October 13, 1984, and concluded October 15, 1985 (Table 4-1). The testing consisted of one flow period lasting $53 \mathrm{~min}$, one buildup period lasting $713 \mathrm{~min}$, and a slug test lasting $1406 \mathrm{~min}$ (Figure 4-10). 


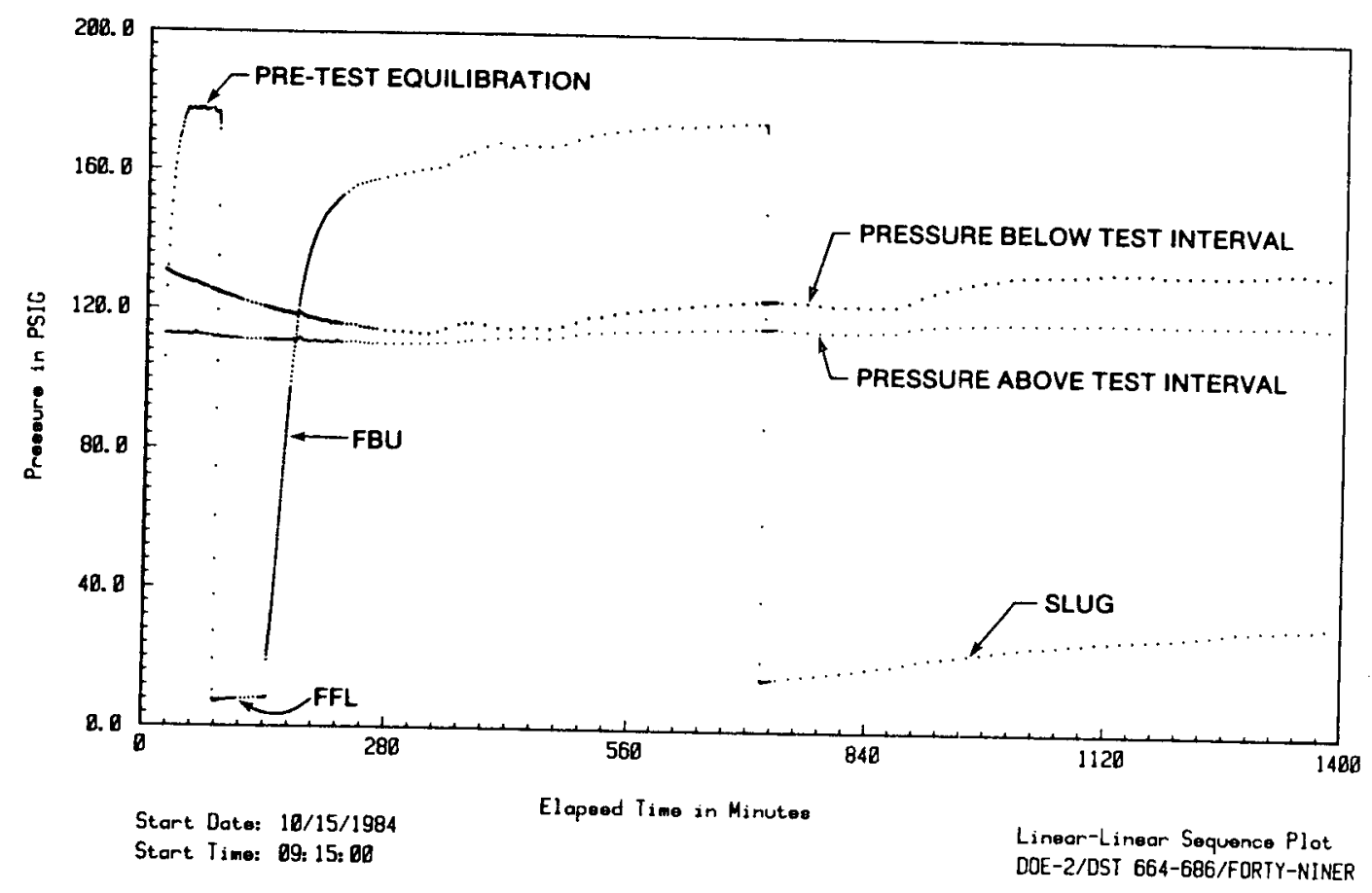

Figure 4-9. Forty-niner Test Sequence Plot

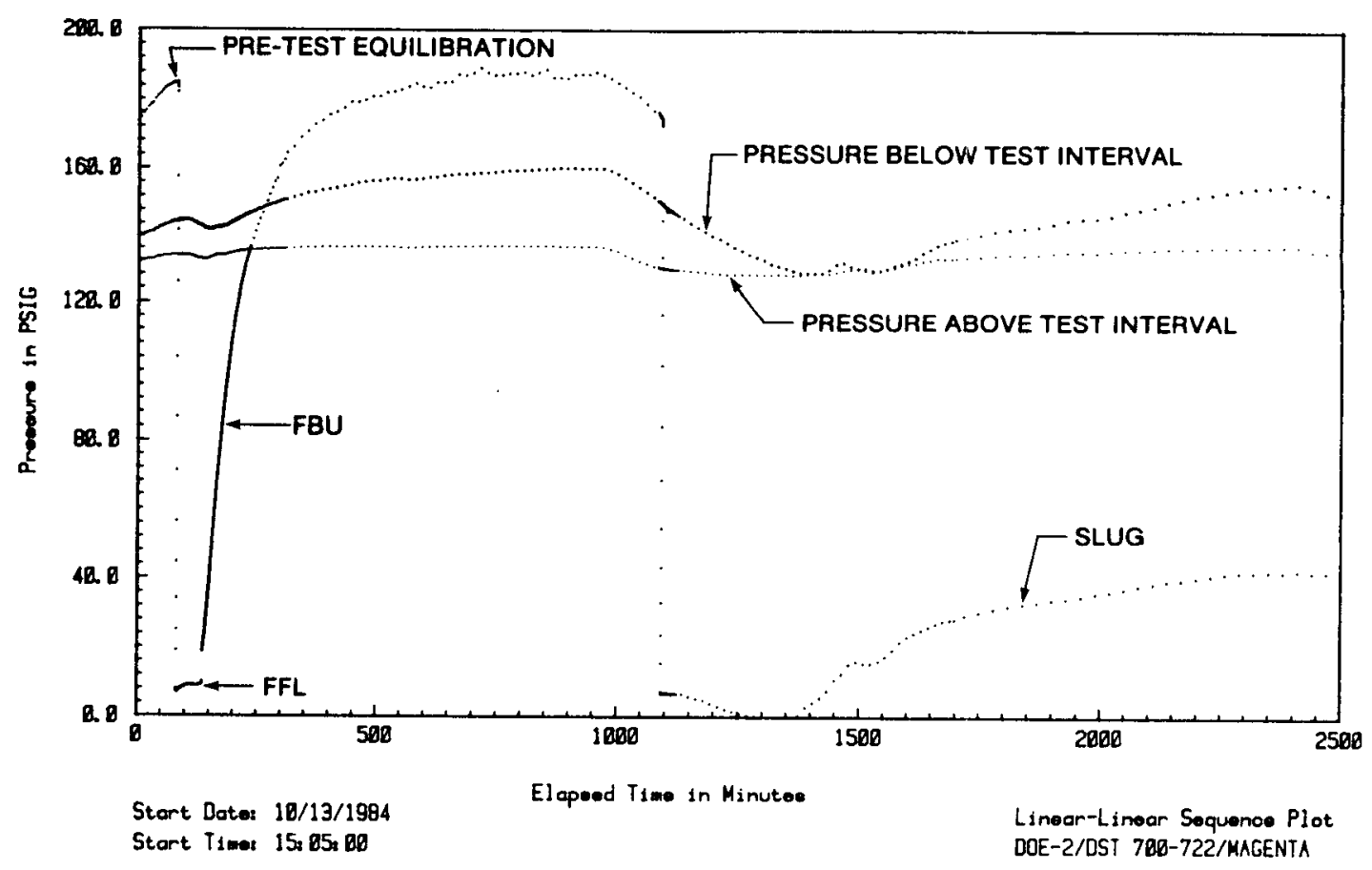

Figure 4-10. Magenta Test Sequence Plot 
All three transducers exhibited pressure trends during the Magenta testing that seemed to bear no relationship to the tests themselves (Figure 4-10). Often, these trends seemed to be parallel for all the transducers. The last four hours of the buildup period, for example, were marked by declines in the pressures measured by the transducers. These trends were probably caused by transducer "drift," i.e., a non-constant relationship between pressure-induced strain and transducer output. This drift could be caused by several factors. The fact that the drift of all three transducers was nearly parallel indicates that the drift may have had a source in an overall system problem, perhaps in the power supply, rather than in the individual transducers.

Tamarisk Member (DST 796-817)-The Tamarisk Member was tested between the depths of 796 and $817 \mathrm{ft}$, an interval containing all of the clay and siltstone within the Tamarisk $(798.3-804.9 \mathrm{ft}, 811.3$ $811.9 \mathrm{ft}$ deep), sandwiched between layers of gypsum and anhydrite. Testing of the Tamarisk began October 12, 1984, and concluded October 13, 1984 (Table
4-1). A drill-stem teit comprising one flow period and one buildup period vias attempted (Figure 4-11). With the test interval isolated from the tubing by a valve (shut-in) packer (Figure 4-4), the fluid was bailed from the tubing. The valve packer was deflated to initiate the flow period, but no fluid entered the tubing. After $11.5 \mathrm{hr}$, the pressure had not risen steadily but had oscillated slightly and had suffered a net loss of $\sim 10$ psi. Reinflating the valve packer to begin the "buildup" period caused an immediate 24-psi rise in pressure as the fluid in the test interval was compressed slightly. Over the subsequent 3 -hr "buildup" period, the pressure again oscillated with a net loss of $\sim 2.5$ psi.

\section{Culebra Dolonite Member, Phase-I (DST 824-}

846)-_The Culebral Dolomite Member was tested between the depths of 824 and $846 \mathrm{ft}$, which includes all but a fraction of the upper foot of the unit. Culebra testing took place October 12, 1984 (Table 4-1), and comprised two flow periods of 7 min duration each, two buildup periocls of 21 and $172 \mathrm{~min}$ duration, and one slug test lastirig $51 \mathrm{~min}$ (Figure 4-12).

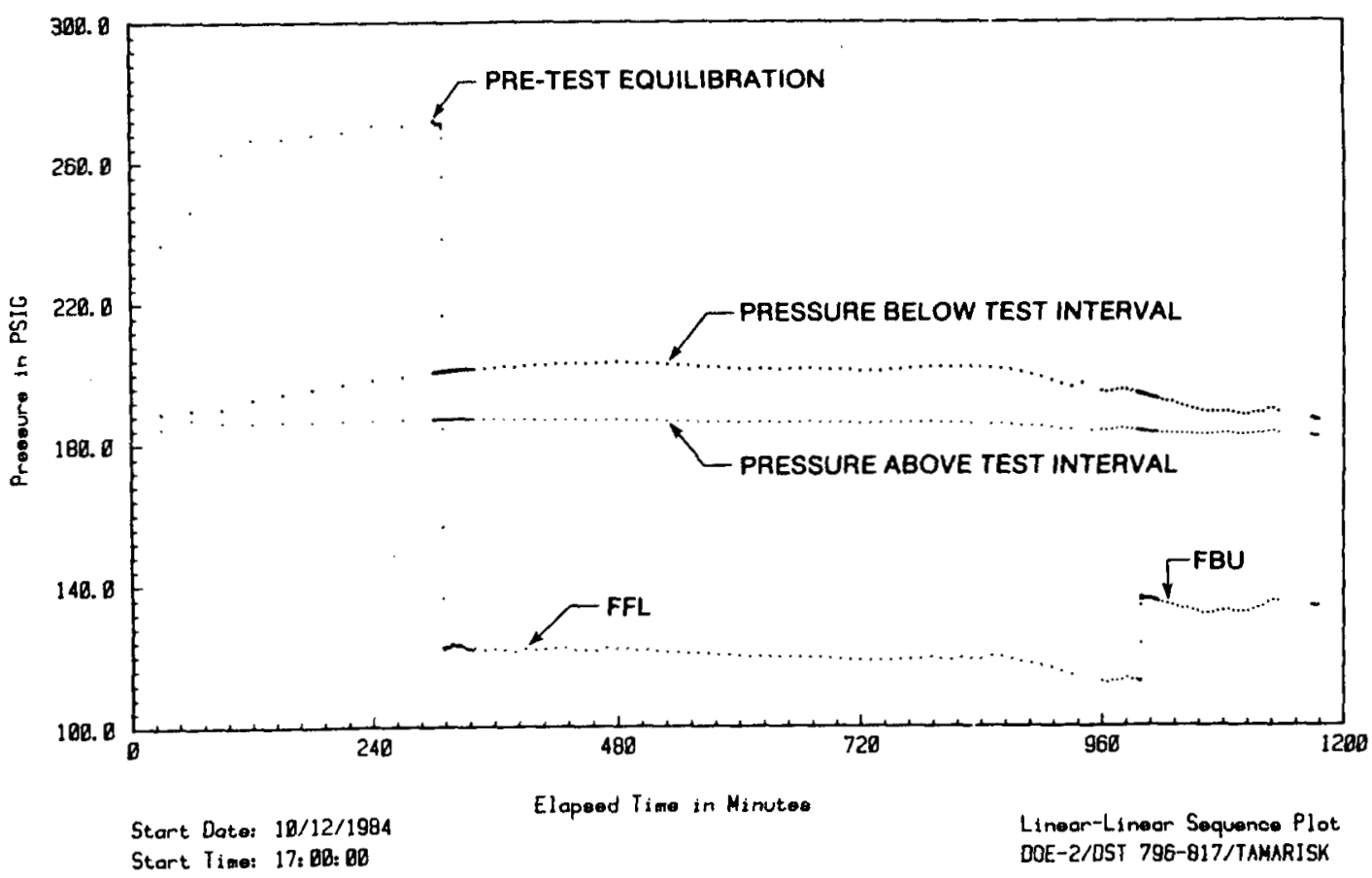

Figure 4-11. Tamarisk Test Sequence Plot 


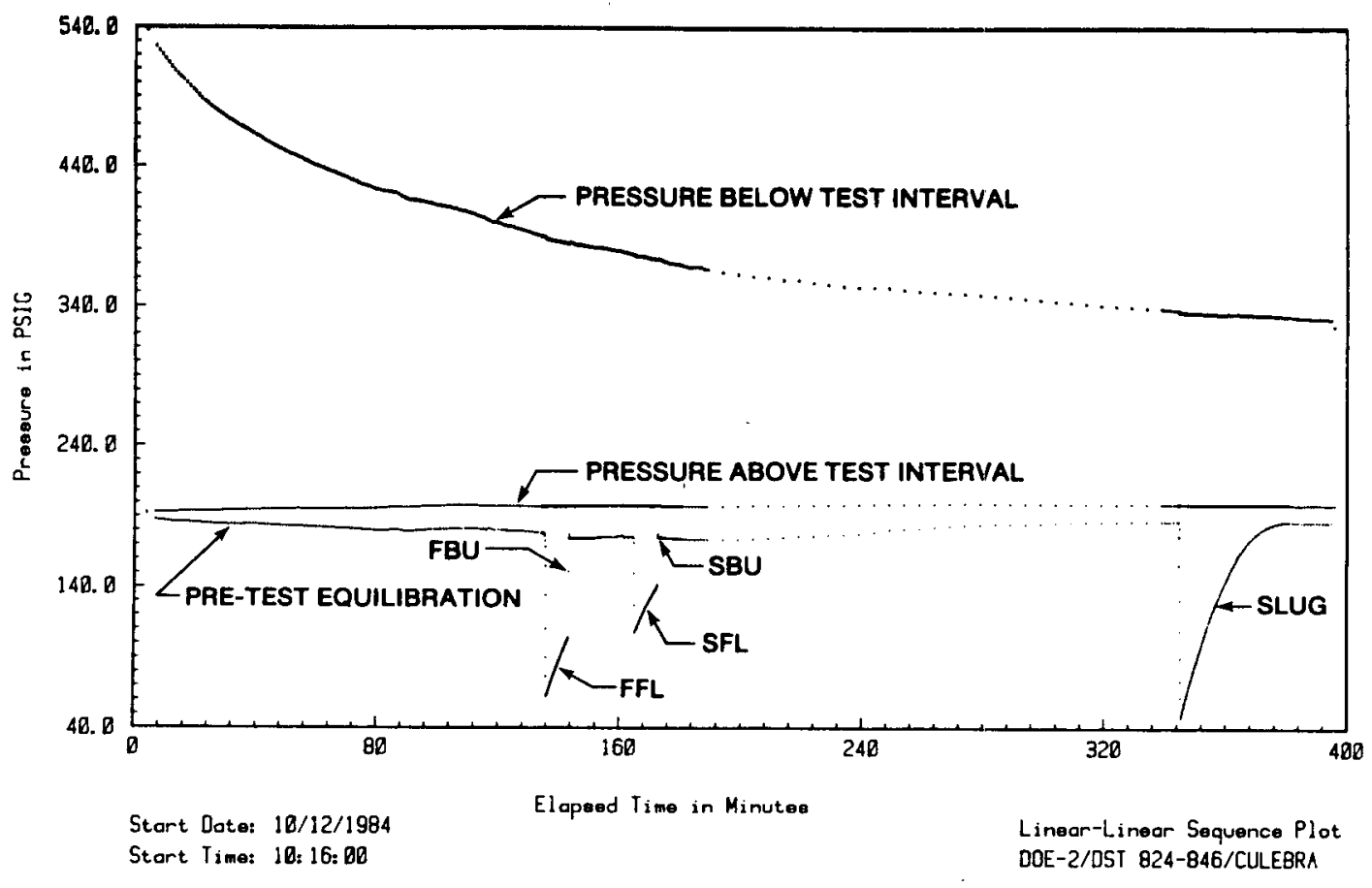

Figure 4-12. Culebra Test Sequence Plot

The pressure response during the Culebra testing was very rapid. Following the flow periods, $99 \%$ recovery was attained within 10 seconds. During the slug test, the pressure reached $100 \%$ recovery after $\sim 35$ min.

When the bottom straddle packer was inflated below the Culebra as the test equipment was being set up, the packer expansion compressed the fluid below. This caused an immediate pressure rise, which decayed steadily during the Culebra testing (Figure 4-12). This bottom-hole pressure decline neither influenced, nor was influenced by, the Culebra testing.

The pressure behavior exhibited during these tests indicated that the well was closely connected to a very high-permeability and/or high-storage zone within the Culebra. Further testing, of a type capable of placing a larger stress on the Culebra, was warranted. A long-term pumping test was selected as the most appropriate method of stressing the Culebra. This became the Phase-Ia testing, described in the following section.
Culebra Dolomite Member, Phase-la-A Culebra pumping test lasting exactly three weeks was conducted at DOE-2 from February 19 to March 12, 1985. About $187900 \mathrm{gal}$ were pumped over this period, at an average rate of $\sim 6.21 \mathrm{gpm}$ (213 bpd). Pressures were also monitored during the pumping period, and for 28 days of recovery, at the nearest other Culebra wells, $\mathrm{H}-5 \mathrm{~b}$ and H-6b. H-5b is $\sim 10590 \mathrm{ft}$ slightly south of east of DOE-2 , and H-6b is $\sim 10150 \mathrm{ft}$ slightly south of west of DOE-2.

\section{DOE-2 Response}

During the pumping period, the Culebra fluid pressure at DOE-2 drew down for the first several hours and then oscillated between $\sim 60$ and 65 psig for the remainder of the test (Figure 4-13). The oscillation was caused largely by flow-rate fluctuations, particularly early in the test, between $\sim 5.1$ and $6.6 \mathrm{gpm}$. Following the pumping period, pressure recovery was monitored at DOE-2 for $17 \mathrm{hr}$, by which time $99.6 \%$ recovery had occurred. 


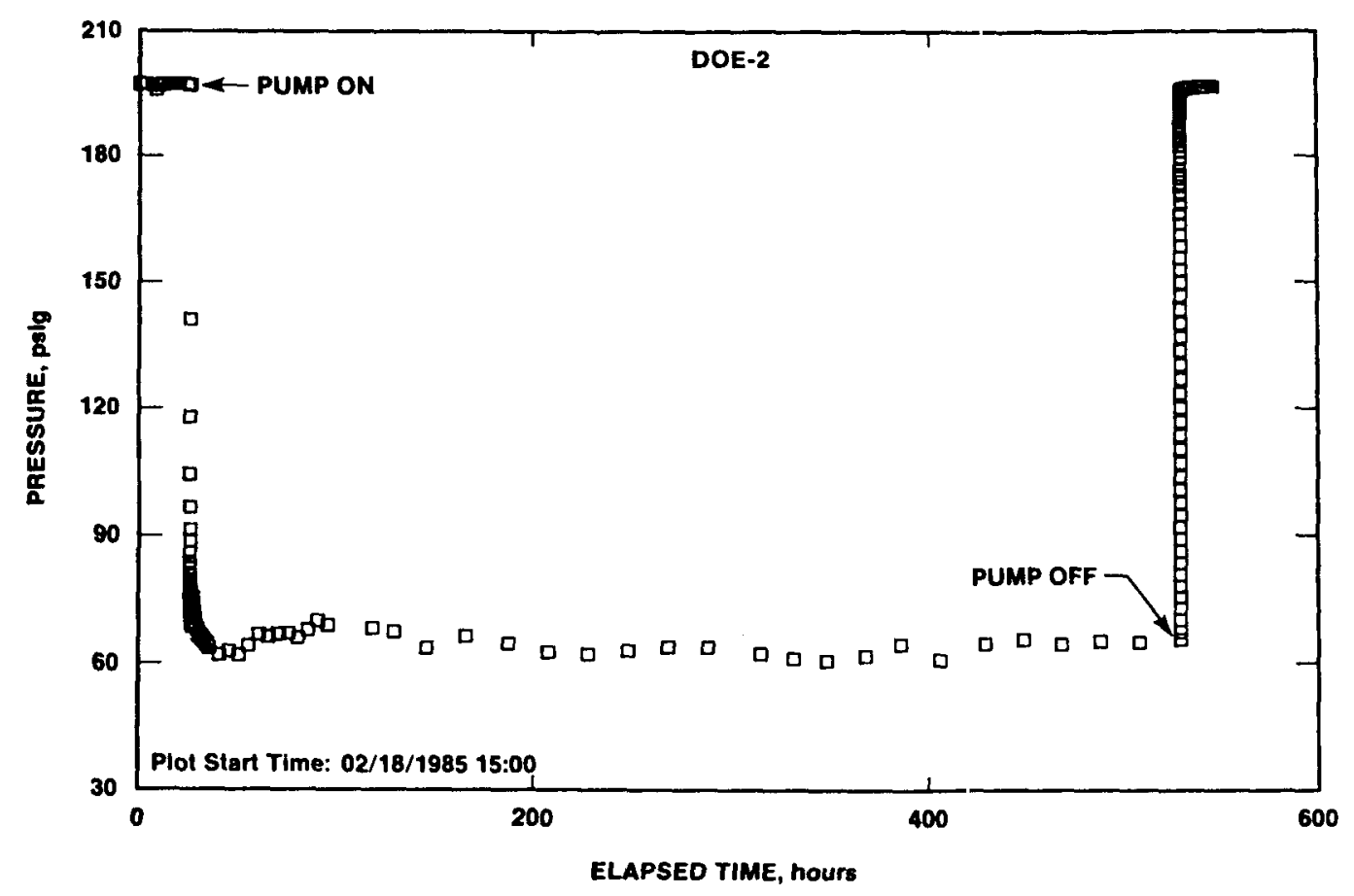

Figure 4-13. Culebra Pumping Test Sequence Plot

\section{H-5b Response}

A plot of the pressure at $\mathrm{H}-5 \mathrm{~b}$ during the DOE-2 pumping test is presented in Figure 4-14. Noise in the data obscures any uniform pressure trend and also makes it difficult to define a precise static pressure before the test. Additionally, while the pressure appears to have dropped during the pumping period, the maximum drawdown is only $\sim 0.4$ psi. Furthermore, no actual recovery of pressure is evident after the pump was turned off.

\section{$H$-6b Response}

A log-log plot of the H-6b drawdown and recovery response to the DOE-2 pumping test is presented in Figure 4-15. The maximum drawdown recorded was only 1.2 psi. With such a small magnitude of pressure change, transducer noise "smeared" the pressure response visibly.
Unnamed Nlember and Rustler-Salado Contact (DST 945-967)--The unnamed member of the Rustler, and the Rustler-Salado contact, were tested between 945 and $967 \mathrm{ft}$ deep. The Rustler-Salado contact is at $960.9 \mathrm{ft}$ (Table 3-2). The bottom $16 \mathrm{ft}$ of the Rustler Formation consist of claystone, while the upper $6 \mathrm{ft}$ of the Salado consist of siltstone and halite. Testing of this zone began October 11, 1984, and ended October 12, 1984 (Table 4-1).

Testing began by deflating the valve packer with the tubing partially bailed to initiate a flow period (Figure 4-16). Aiter one hour, no appreciable fluid had entered the tubing, and the test was converted to a long-term slug test. The flow period/slug test lasted a total of 14 hours. The pressure oscillated slightly during this period, with a net loss of $\sim 11$ psi. The valve packer was then reinflated to isolate the interval and to see whether the pressure would build up. The valve-packer in lation caused an immediate pressure increase of $\sim 255 \mathrm{psi}$ as the water in the test interval was compressed. This pressure began to decay slowly, and the test was terminated. 


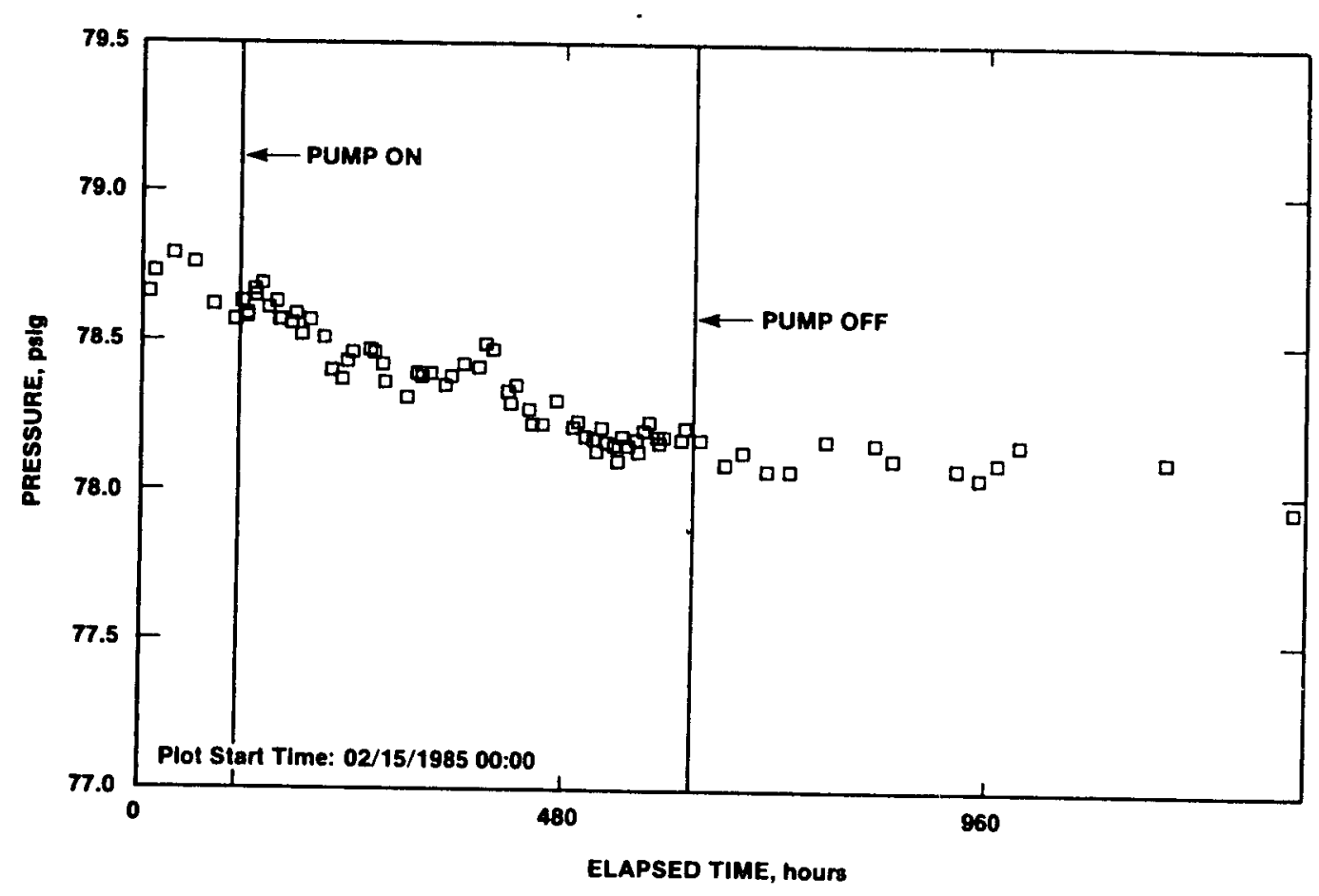

Figure 4-14. H-5b Response to DOE-2 Pumping

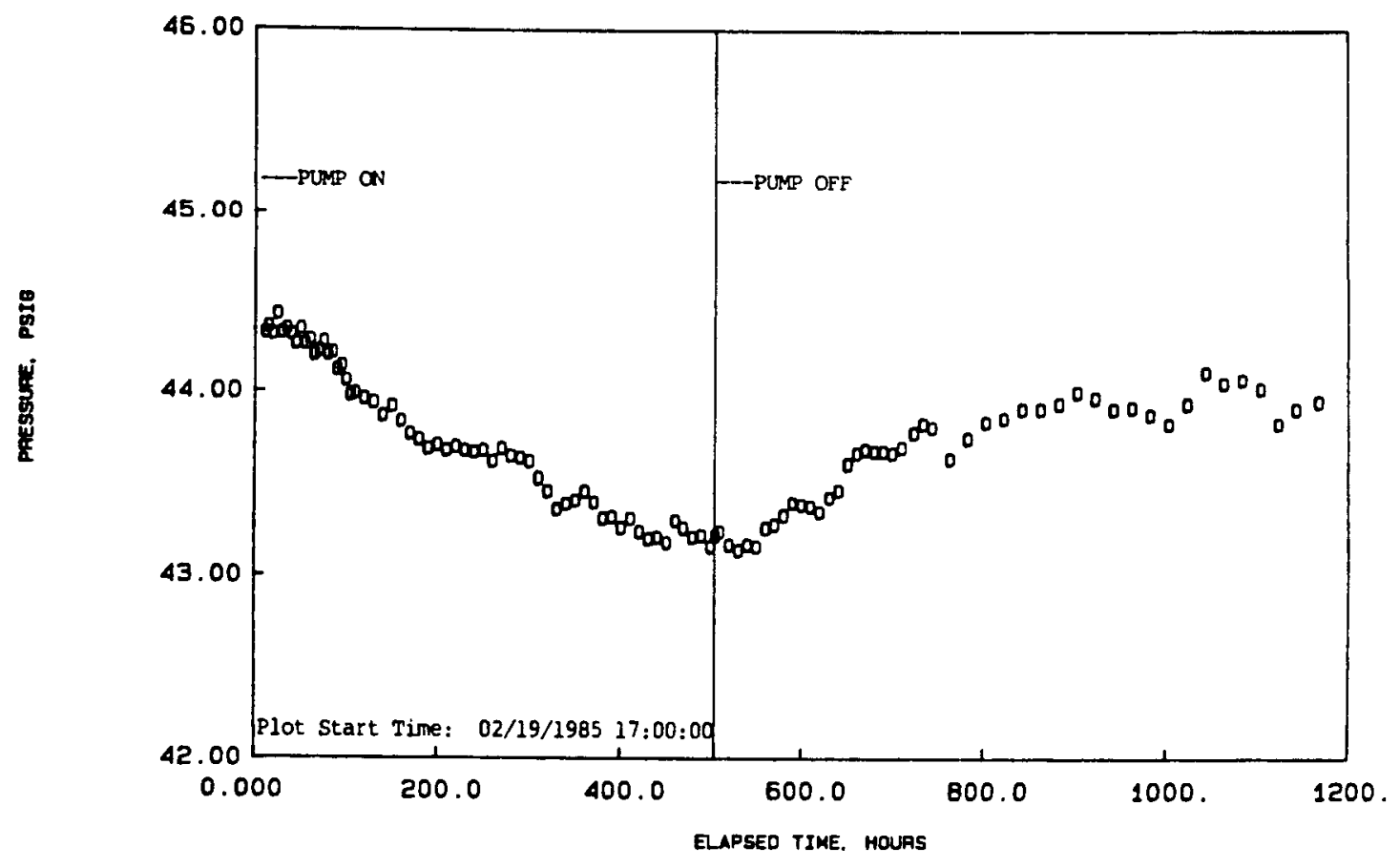

Figure 4-15. H-6b Response to DOE-2 Pumping 


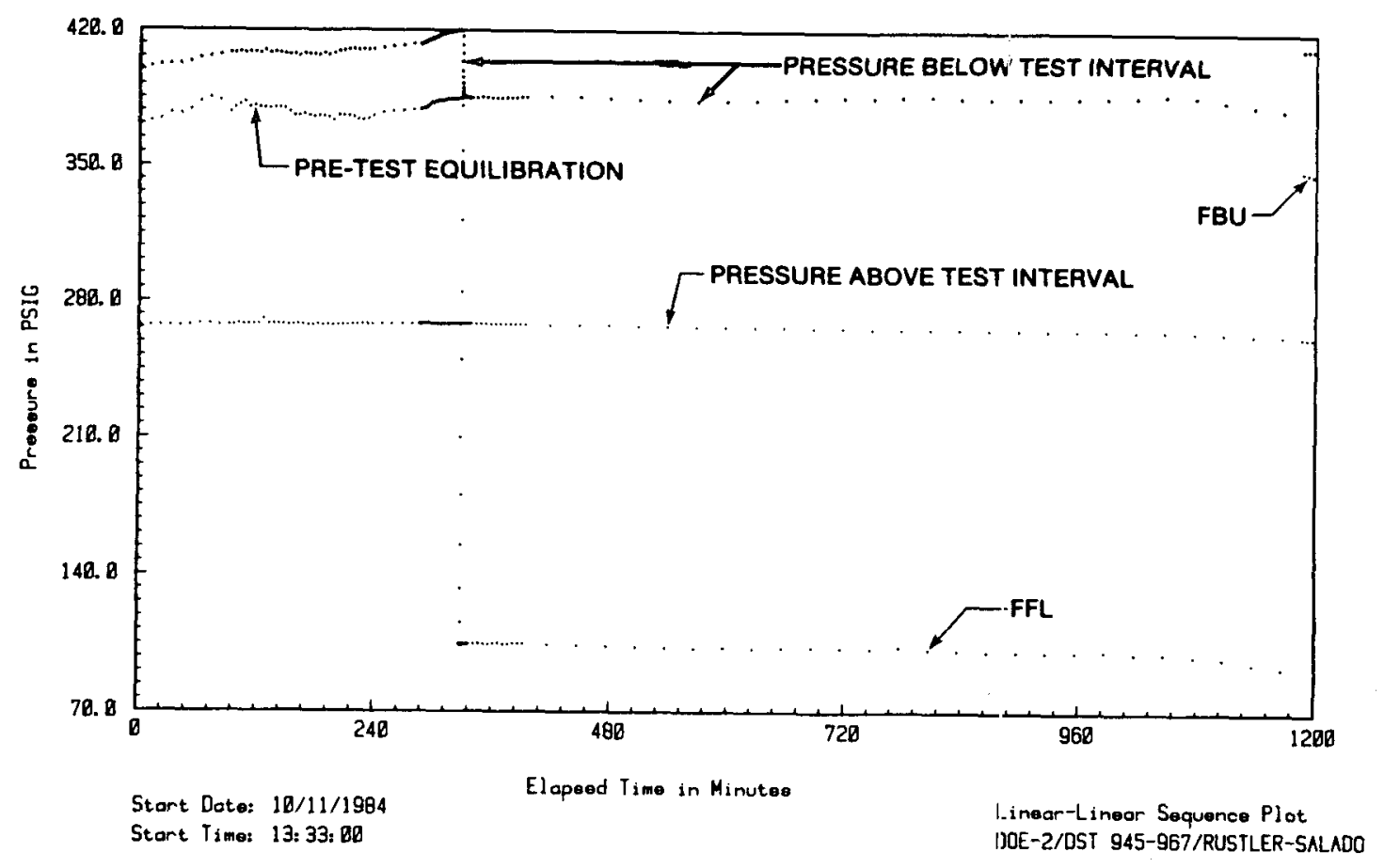

Figure 4-16. Rustler-Salado Test Sequence Plot

\subsubsection{Salado Formation}

Two sets of tests were conducted in the Salado Formation, one set covering the interval from slightly above Marker Bed 138 to slightly below Marker Bed 139 , which includes the repository horizon, and another set spanning essentially the entire Salado.

Marker Beds 138 to 139 (DST 2195-2309)-A section of the mid-Salado from 2195 to $2309 \mathrm{ft}$ deep was tested on May 19 and 20, 1985 (Table 4-1). This interval included Marker Beds 138 and 139 and the intervening WIPP facility horizon. The testing consisted of a 21 -min flow period followed by a $23.3-\mathrm{hr}$ buildup period (Figure 4-17).

During the testing of Marker Beds 138 to 139, the bottom-hole pressure initially dropped and then rose almost 50 psi (Figure 4-17). This pressure response was probably not related to formation pressure because later testing of the entire Salado did not detect pressures of this magnitude. Instead, the pressure response was probably caused by temperature changes that exactly paralleled the pressure changes in the isolated interval (Figure 4-18). The drilling fluid and the test equipment; used in drilling DOE-2 were probably not in thermal equilibrium with the formation rock and fluid. A shut-in borehole interval in an extremely low-permeability medium such as halite behaves, in the short term, as a closed system. Hence, when the temperature of the fluid dropped initially, probably as the fluid cooled the DST tool, the pressure dropped. Later, as the formation heated the drilling fluid, the fluid pressure rose. Over a longer period of time, the pressure would have dissipated through the lower Salado. Similar thermally induced pressure responses; have also been observed in testing low-permeability crystalline rocks (Grisak et al., 1985). No temperature trends were evident in the testinterval (i.e., Marker Beds 138 to 139) data. 


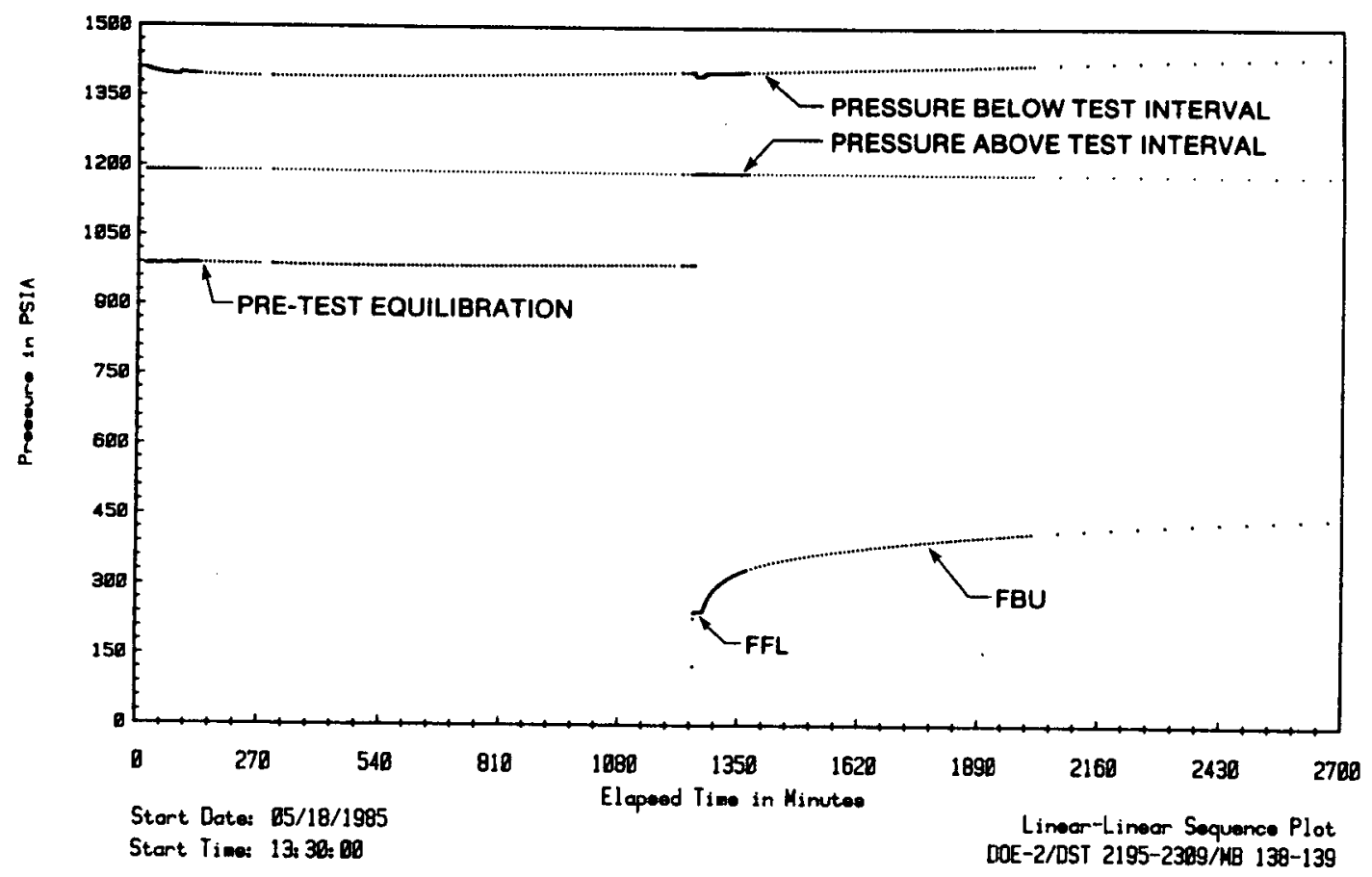

Figure 4-17. Marker Beds 138-139 Test Sequence Plot

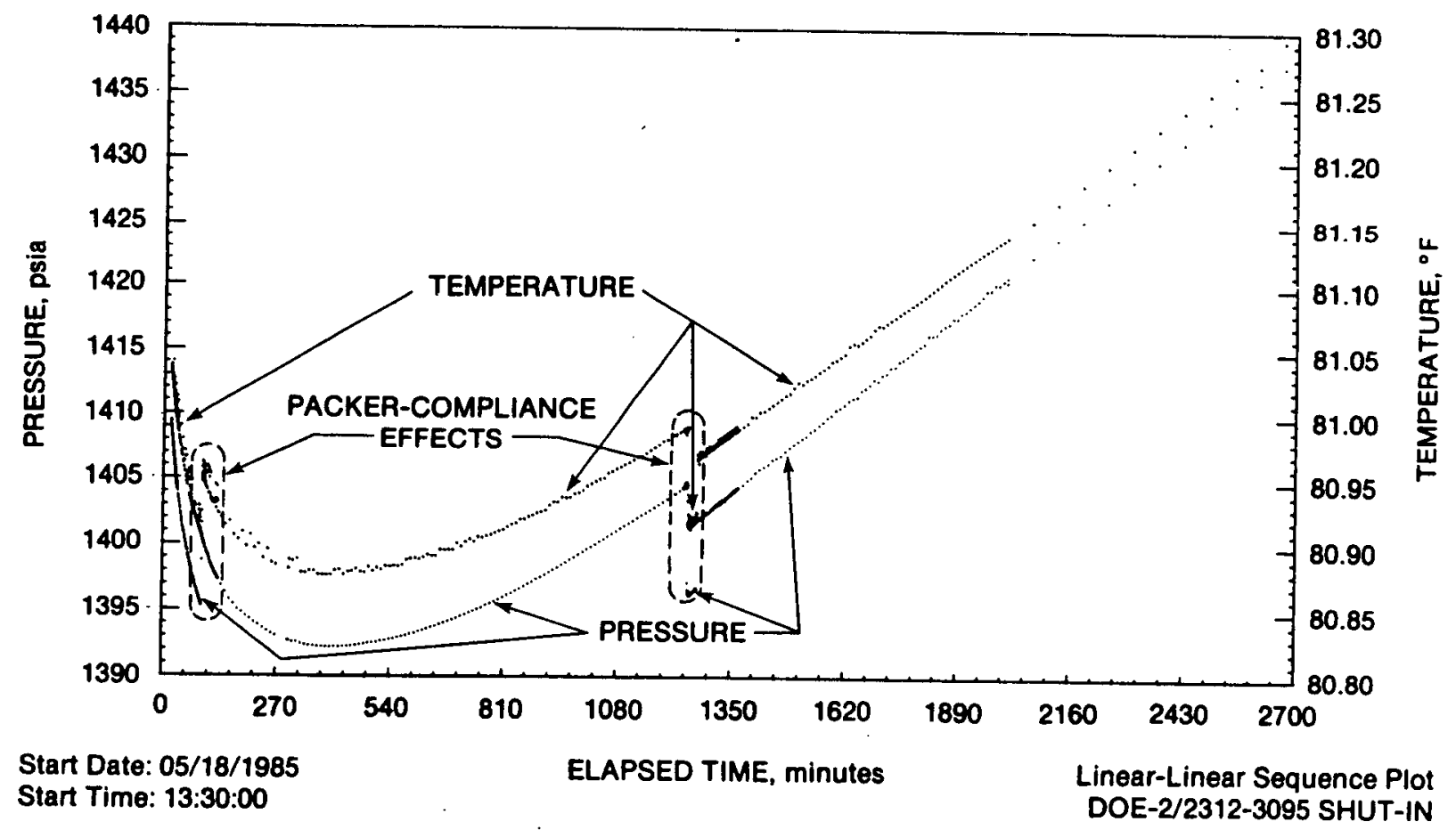

Figure 4-18. Bottom-Hole Temperature and Pressure During Marker Beds 138-139 Testing 
Salado Formation (DST 1040-3095) - The entire Salado Formation (except for the upper $79 \mathrm{ft}$ ) and the upper $12 \mathrm{ft}$ of the Castile Formation were tested in an interval extending from a single packer at $1040 \mathrm{ft}$ to the bottom of the hole, $3095 \mathrm{ft}$ deep. The tests were performed from May 21 to 22, 1985 (Table 4-1), and consisted of a 9.5-hr pulse-withdrawal test followed by a 13.8-hr pulse-injection test (Figure 4-19). The primary objective of the tests was to determine whether zones existed in the Salado that could cause pressure buildups at the wellhead such as those observed at Cabin Baby-1 and WIPP-12 (Mercer, 1987). The secondary objective of the tests was to obtain information on bulk Salado hydraulic properties.

When the packer was inflated and the Salado interval shut in, the interval was overpressurized relative to any expected Salado pressure. To relieve this overpressure, we partially swabbed the tubing, opened the interval briefly to the tubing to drop the pressure, and shut the interval back in. In response, the test interval pressure built up rapidly, then rolled over and began a slow, steady drop (Figure 4-19). This rollover effect was caused by the dissipation of the pressure skin imparted to the Salado while the hole was open and filled with fluid. Formal testing began after the rate of pressure decline had dropped to $\sim 2 \mathrm{psi} / \mathrm{hr}$.

\subsubsection{Bell Canyon Formation}

Three sets of tests were conducted in the Bell Canyon Formation: tests of the Ramsey sandstone, the Olds sandstone, and the Hays sandstone. These sandstones are separated by siltstones/claystones of lower permeability that served as packer seats.

Ramsey Sandstone (DST 4138-4 180)_Based on an examination of geophysical logs, the most permeable portion of the Ramsey sandstone appears to be a 28 -ft section fron 4144 to $4172 \mathrm{ft}$ deep. This zone was tested in a stradilled interval extending from 4138 to $4180 \mathrm{ft}$ deep. Tests were conducted from July 12 to 14 , 1985 (Table 4-1), and consisted of two flow periods of 24 and 75 min duration, two buildup periods of 172 and 335 min duration, and a 36 -hr slug test (Figure 4-20). The Ramsey tests were hindered by a partial short circuit in the wireline connecting the transducers to the DAS. The short circuit led to occasional periods of meaningless data. This "noise" was filtered out, leaving visible gaps in the data presented in Figure 4-30. The analysis of the data, however, is not affected by the rnalfunction.

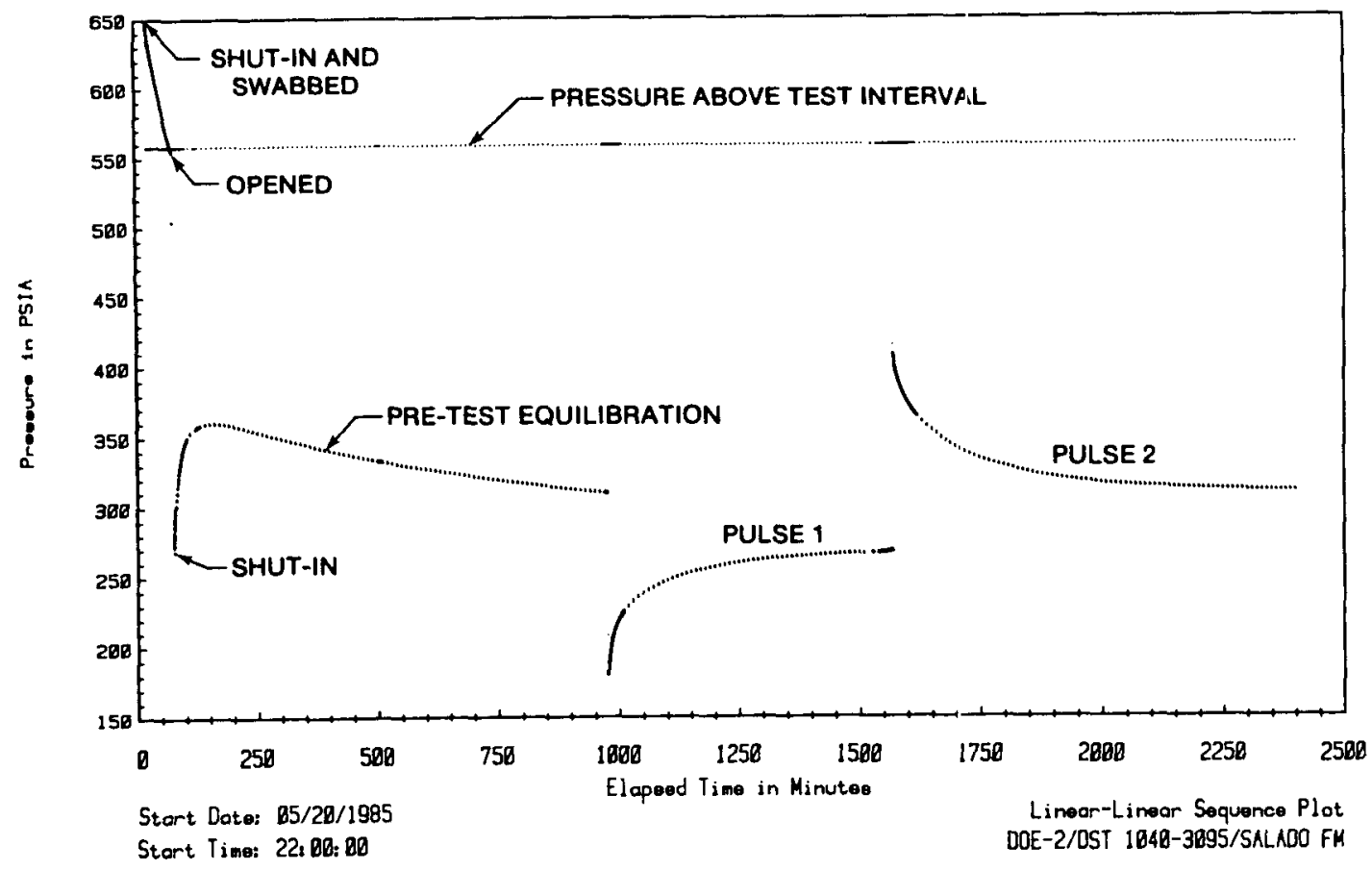

Figure 4-19. Salado Test Sequence Plot 


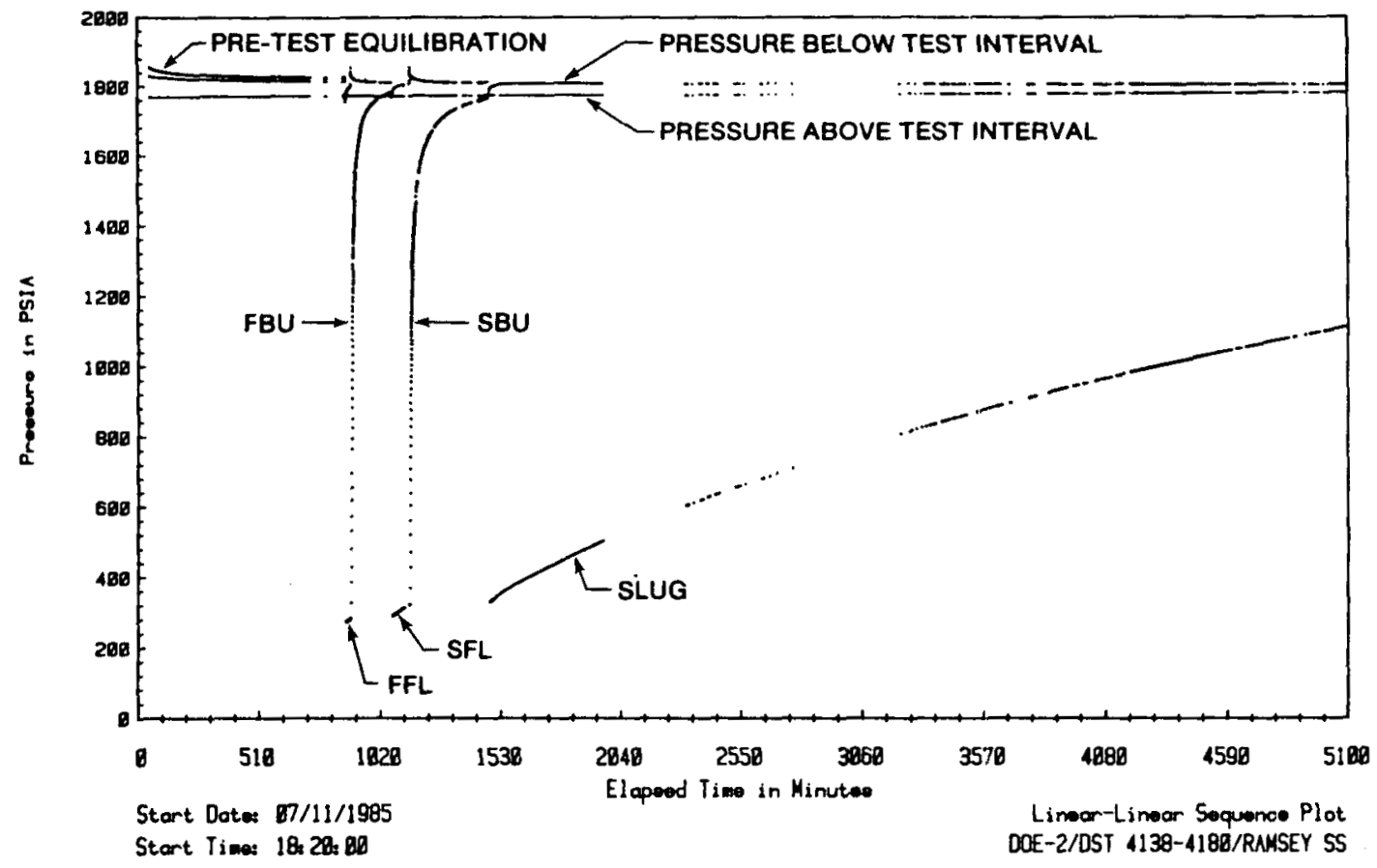

Figure 4-20. Ramsey Test Sequence Plot

Olds Sandstone (DST 4177-4218)—Based on an examination of geophysical logs, the most permeable portion of the Olds sandstone appears to be a $30-\mathrm{ft}$ section from 4187 to $4217 \mathrm{ft}$ deep. This zone was tested in a straddled interval extending from 4177 to $4218 \mathrm{ft}$ deep. Tests were conducted from July 26 to 29, 1985 (Table 4-1), and consisted of two flow periods of 15 and $30 \mathrm{~min}$ duration, two buildup periods of 240 and $1188 \mathrm{~min}$ duration, and a 46.4 -hr slug test (Figure 4-21).
Hays Sandstone (DST 4220-4325)-Based on an examination of geophysical logs, the most permeable portion of the Hays sandstone exposed in DOE-2 appears to be the lower $100 \mathrm{ft}$, from 4225 to $4325 \mathrm{ft}$ deep. This zone was tested in a bottom-hole test using a single packer set at $4220 \mathrm{ft}$, with the bottom of the hole at $4325 \mathrm{ft}$. Tests were conducted July 18 and 19 , 1985 (Table 4-1), and consisted of two flow periods of 11 and 20 min duration, two buildup periods of 803 and 266 min duration, and a 256 -min slug test (Figure 4-22). 


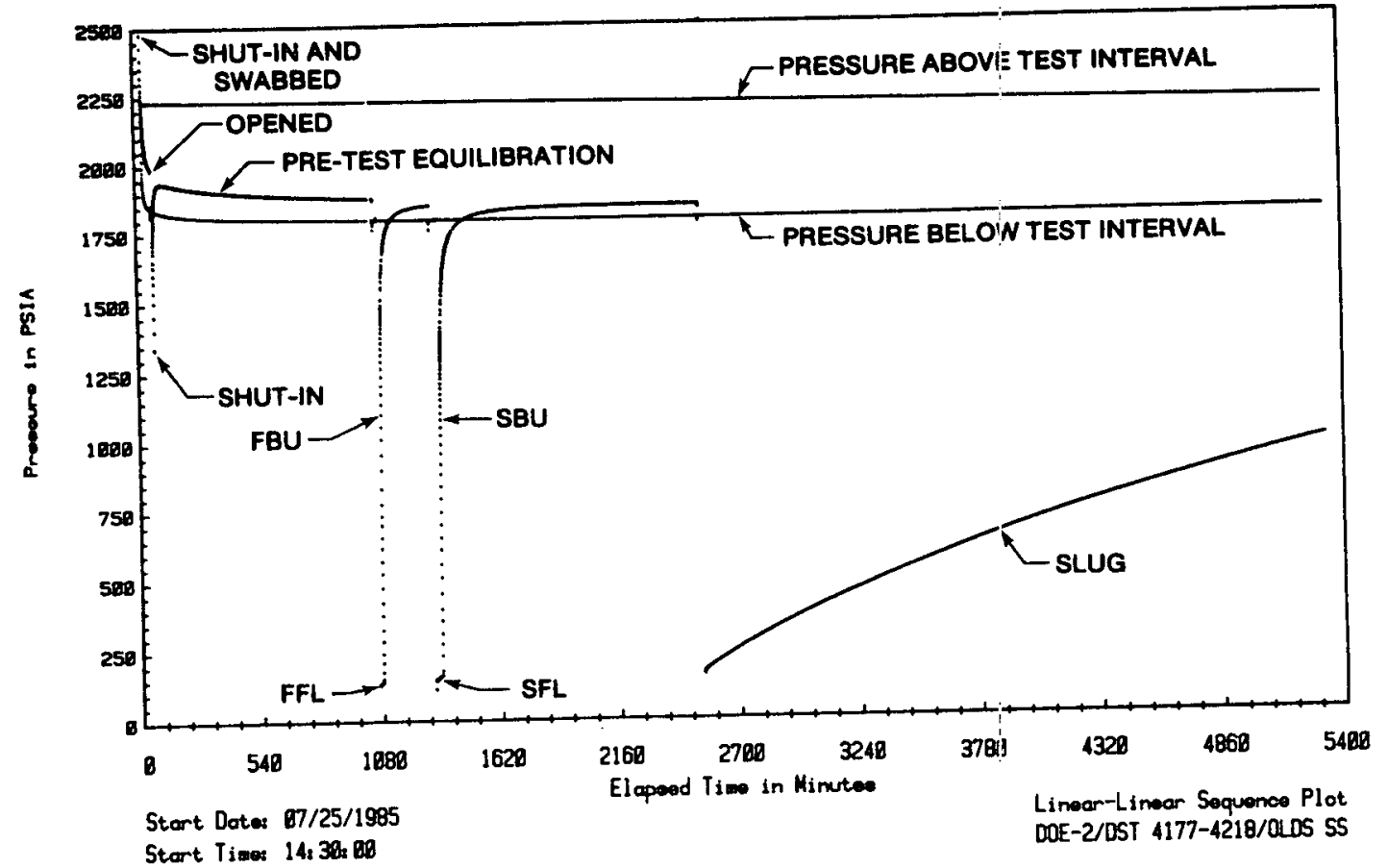

Figure 4-21. Olds Test Sequence Plot

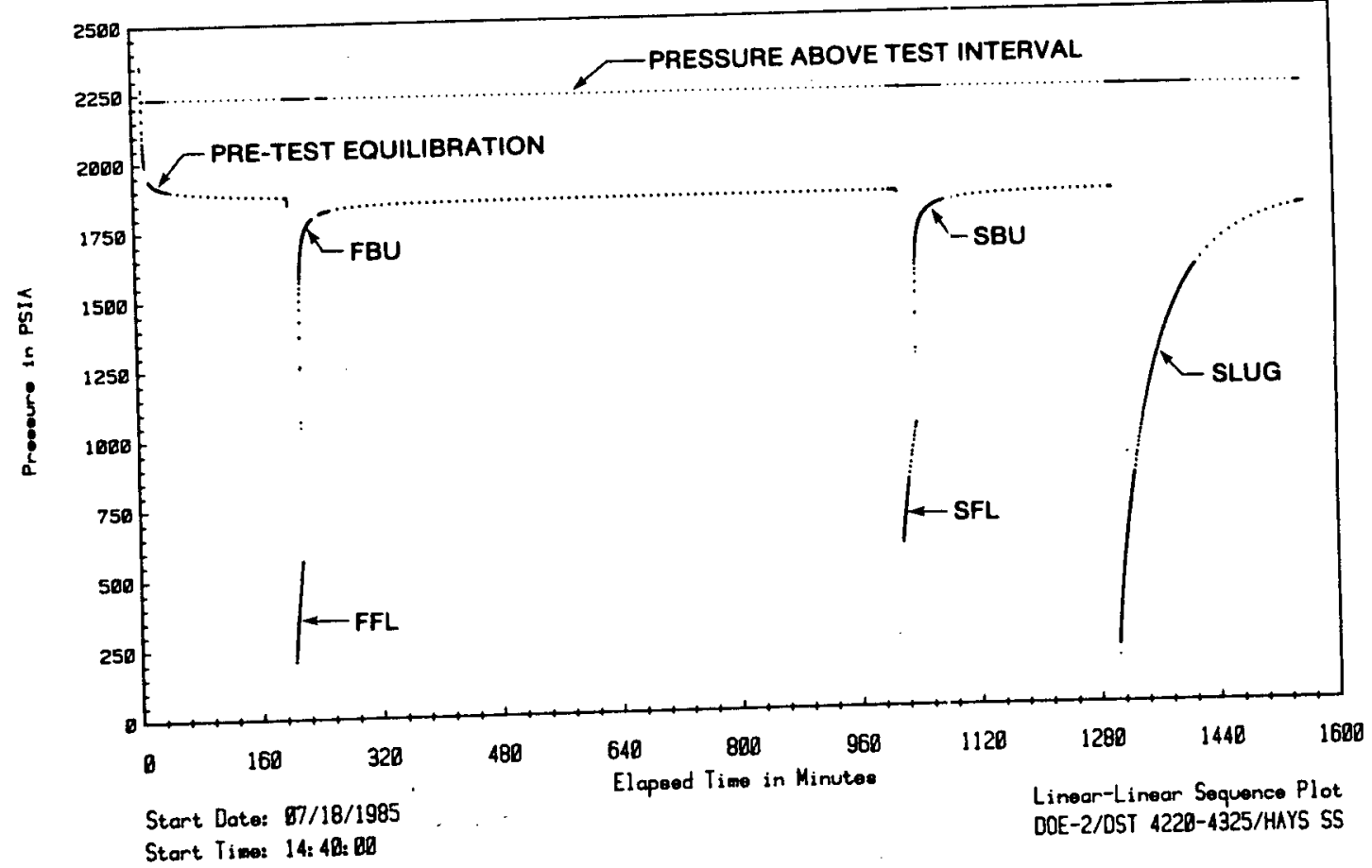

Figure 4-22. Hays Test Sequence Plot 


\subsection{Hydrogeochemical Sampling}

A major objective of the DOE-2 testing program was to obtain reliable fluid samples from the most significant water-bearing units (units that could affect the movement of radionuclides in the event of a repository breach). The fluid samples were to provide information on the fluid properties affecting flow, particularly specific gravity, as well as data on the major and minor element chemistries of the fluids.

Fluid samples were ultimately collected from two horizons in DOE-2: the Culebra Dolomite Member of the Rustler Formation, and the Hays sandstone of the Bell Canyon Formation, the only two units encountered that possessed adequate permeability to make sampling practicable. The Culebra samples were collected by pumping; the Hays samples were collected by swabbing. Other details of the sampling, and the results, follow.

When sampling through steel tubing, some degree of metals contamination of the samples is unavoidable. To lessen this contamination, all tubing was thoroughly steam-cleaned with detergent to remove rust scale before its introduction into the hole. A Teflon-based pipe dope was also used to lubricate all connections.

\subsubsection{Culebra Dolomite Fluid Sampling}

Ten sets of fluid samples were collected serially during the Culebra dolomite pumping test, which lasted from February 19 to March 12, 1985. The first samples were collected February 20, 1985; the final samples were collected March 12, 1985, after $\sim 184000$ gal had been pumped. The samples were collected at the surface through a 0.25 -in. nylon sample line, which was teed off from the main discharge line just above the pump (Figure 4-5).
Each set of serial samples was analyzed in a field laboratory trailer for some or all of the following parameters: $\mathrm{pH}, \mathrm{Eh}$, temperature, specific gravity, alkalinity, chloride, divalent cations, ferrous iron, and ferric iron. The final set of samples was collected near the end of the pumping test after alkalinity, chloride, and divalent cation concentrations had stabilized. The final samples were sent to the laboratories of Bendix Field Engineering Corp. in Grand Junction, Colorado, for more complete analyses. Additional information on sampling procedures, instrumentation, and serial analyses is presented in Colton and Morse (1985), and Fischer (1985).

Results of the final field and laboratory analyses of the Culebra water are presented in Table 4-2. The terminology of Back (1961) was used to classify the Culebra water as a sodium-calcium chloride-sulfate brine. The water has a total dissolved solids (TDS) concentration of $\sim 60500 \mathrm{mg} / \mathrm{L}$, a pH of 7.0 , a specific conductance of $\sim 61000 \mu \mathrm{mhos} / \mathrm{cm}$, and a specific gravity of $\sim 1.04$ at a temperature of $22^{\circ} \mathrm{C}$.

\subsubsection{Hays Sandstone Fluid Sampling}

After completion of the Hays sandstone slug test, the Hays interval was cleaned by swabbing. A total of 43 swabs, representing $\sim 11000$ gal, was pulled from July 19 to 23 , 1985. Eight sets of serial samples, plus the final samples, were collected during swabbing. For each set of serial samples, some or all of the following parameters were measured in the field: temperature, specific gravity, specific conductance, chloride, and divalent cations. The final samples were collected on the last swab, after specific gravity, chloride, and divalent cation concentrations had stabilized according to the criteria established in Colton and Morse (1985), and were shipped to the laboratories of Bendix Field Engineering Corp. for more complete analyses. 
Table 4-2. Solute Concentrations in Drillhole DOE-2 Groundwaters

\begin{tabular}{|c|c|c|c|}
\hline & \multirow[b]{2}{*}{ Units } & \multicolumn{2}{|c|}{ Såmple } \\
\hline & & $\begin{array}{l}\text { Hays Sandstone } \\
\text { DST } 4220-4325^{6}\end{array}$ & $\begin{array}{c}\text { Culebra Dolomite } \\
\text { Pumping Test }{ }^{\mathrm{b}}\end{array}$ \\
\hline \multicolumn{4}{|l|}{ Field Determinations } \\
\hline $\begin{array}{l}\text { Temperature } \\
\text { Eh } \\
\text { pH } \\
\text { Specific gravity } \\
\text { Specific conductance } \\
\text { Alkalinity (as } \mathrm{HCO}_{3} \text { ) } \\
\text { Chloride } \\
\text { Divalent cations }\end{array}$ & $\begin{array}{c}{ }^{\circ} \mathrm{C} \\
\mathrm{mV} \\
\text { std units } \\
\mu \mathrm{mhos} / \mathrm{cm} \\
\mathrm{mg} / \mathrm{L} \\
\mathrm{mg} / \mathrm{L} \\
\mathrm{meq} / \mathrm{L}\end{array}$ & $\begin{array}{c}32.5^{\mathrm{c}} \\
- \\
- \\
1.10^{\mathrm{d}} \\
120000^{\mathrm{d}} \\
- \\
89800^{\mathrm{f}} \\
397^{\mathrm{f}}\end{array}$ & $\begin{array}{r}20.7 \\
443 \\
7.01 \\
1.04^{\mathrm{e}} \\
61000 \\
67 \\
32300 \\
186\end{array}$ \\
\hline \multicolumn{4}{|l|}{ Laboratory Determinations } \\
\hline $\begin{array}{l}\text { Cations } \\
\text { Calcium } \\
\text { Cesium } \\
\text { Lithium } \\
\text { Magnesium } \\
\text { Potassium } \\
\text { Sodium } \\
\text { Strontium }\end{array}$ & $\begin{array}{l}\mathrm{mg} / \mathrm{L} \\
\mathrm{mg} / \mathrm{L} \\
\mathrm{mg} / \mathrm{L} \\
\mathrm{mg} / \mathrm{L} \\
\mathrm{mg} / \mathrm{L} \\
\mathrm{mg} / \mathrm{L} \\
\mathrm{mg} / \mathrm{L}\end{array}$ & $\begin{array}{r}5910 \\
<0.01 \\
5.8 \\
1330 \\
880 \\
49600 \\
145\end{array}$ & $\begin{array}{r}1960 \\
<0.007 \\
0.47 \\
1060 \\
410 \\
18400 \\
37.7\end{array}$ \\
\hline $\begin{array}{l}\text { Anions } \\
\left.\text { Alkalinity (as } \mathrm{CaCO}_{3}\right) \\
\text { Bromide } \\
\text { Chloride } \\
\text { Fluoride } \\
\text { Iodide } \\
\text { Sulfate }\end{array}$ & $\begin{array}{c}\mathrm{mg} / \mathrm{L} \\
\mathrm{mg} / \mathrm{L} \\
\mathrm{mg} / \mathrm{L} \\
\mathrm{mg} / \mathrm{L} \\
\mu \mathrm{g} / \mathrm{L} \\
\mathrm{mg} / \mathrm{L}\end{array}$ & $\begin{array}{r}39 \\
251 \\
89700 \\
1.12 \\
6390 \\
2020\end{array}$ & $\begin{array}{r}54 \\
33.5 \\
34600 \\
1.7 \\
225 \\
3950\end{array}$ \\
\hline $\begin{array}{l}\text { Other Elements } \\
\text { Boron } \\
\text { Iron } \\
\text { Manganese } \\
\text { Silicon (as } \mathrm{SiO}_{2} \text { ) }\end{array}$ & $\begin{array}{l}\mathrm{mg} / \mathrm{L} \\
\mathrm{mg} / \mathrm{L} \\
\mathrm{mg} / \mathrm{L} \\
\mathrm{mg} / \mathrm{L}\end{array}$ & $\begin{array}{r}53.8 \\
10.8 \\
2.84 \\
2.5\end{array}$ & $\begin{array}{l}15.6 \\
0.36 \\
0.30 \\
17.4\end{array}$ \\
\hline
\end{tabular}

${ }^{\mathrm{a}}$ Final sample collected on $43 \mathrm{rd}$ swab after $\sim 11000$ gal removed

'Sample collected after pumping $\sim 184000 \mathrm{gal}$

${ }^{c}$ Measured downhole

${ }^{\mathrm{d}}$ Measurement made on sample from 31 st swab; water temperature $=27^{\circ} \mathrm{C}$

${ }^{e}$ Water temperature $=22^{\circ} \mathrm{C}$

'Measurement made on sample from 41 st swab 
Results of the serial sample measurements are presented in Figure 4-23. Final field and laboratory analyses are presented in Table $4-2$. The terminology of Back (1961) was used to classify the Hays water as a sodium-calcium chloride-sulfate brine. The water has a TDS of $\sim 150000 \mathrm{mg} / \mathrm{L}$, a specific conductance of $\sim 120000 \mu \mathrm{mhos} / \mathrm{cm}$, and a specific gravity of $\sim 1.10$ at a temperature of $27^{\circ} \mathrm{C}$.
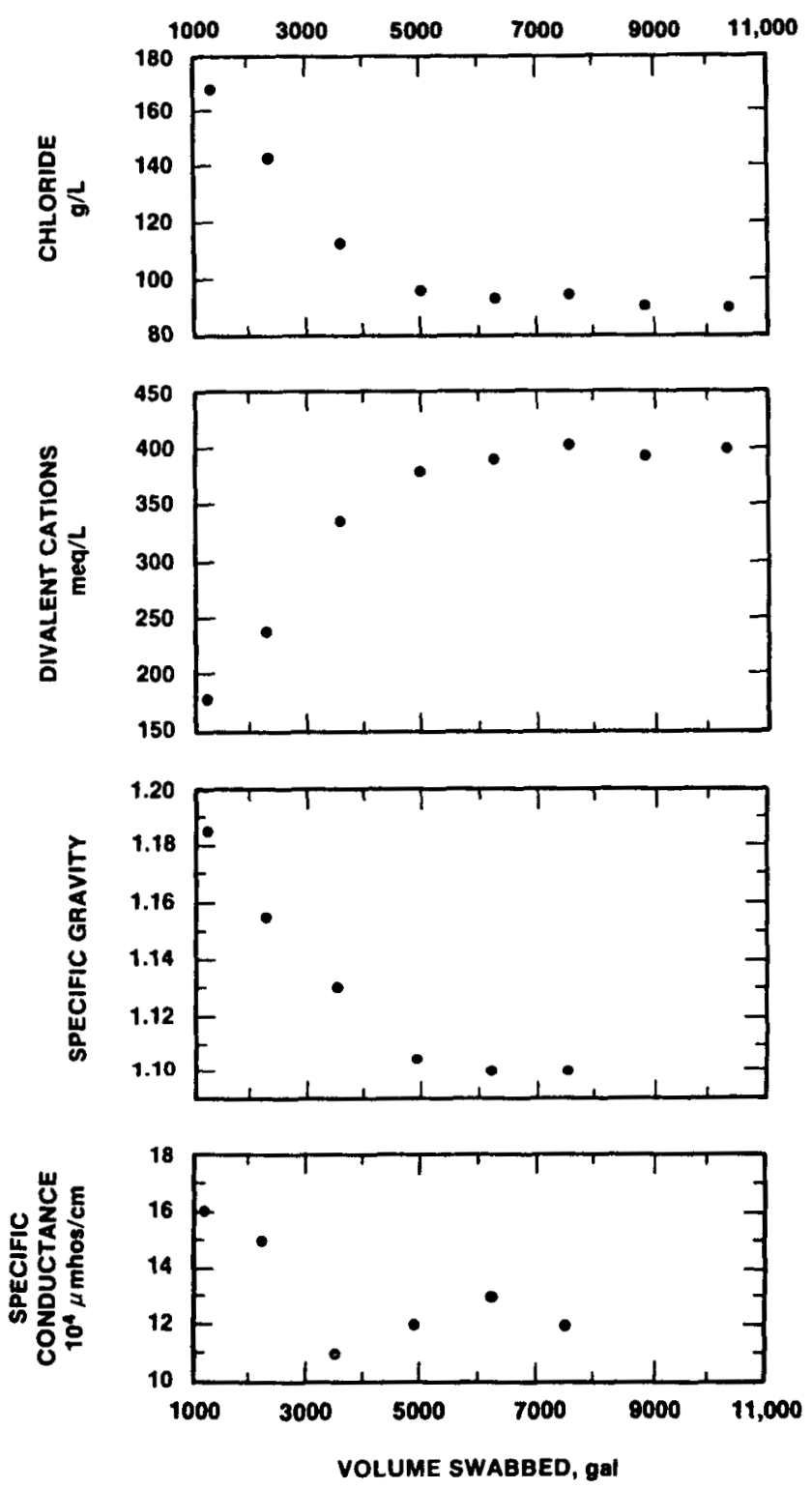

Figure 4-23. Hays Sandstone Serial Sample Analyses

\subsection{Present Well Condition}

After completion of all Bell Canyon testing in DOE-2, a production-injection packer (PIP) was set near the base of the Castile Formation from 4051.6 to $4057.1 \mathrm{ft}$ deep. The 2.375-in. drill tubing was left attached to the PIP and open to the interval below, forming an observation well completed through the upper Bell Canyon (Figure 2-4).

The Bell Canyon interval was cleaned by pulling 22 swabs, representing almost 5800 gal, between July 29 and 31, 1985. The specific gravity of the fluid removed was monitored during swabbing, and swabbing was terminated when the specific gravity stabilized at 1.1. Over the subsequent months, the Bell Canyon fluid rose up the tubing as a recovery response to the swabbing. From November 1985, through March 1986, the fluid level in the tubing changed very little, apparently stabilizing $\sim 384 \mathrm{ft}$ below ground surface, at an elevation of $\sim 3034 \mathrm{ft}$ above sea level. The PIP was removed from DOE-2 on April 1, 1986. When the PIP was removed, a tight spot in the hole in the upper Salado apparently stripped the rubber gland from the packer. The rubber remains in the hole. Complete recovery records for the Bell Canyon interval were published in INTERA Technologies and HydroGeoChem (1985) and INTERA Technologies (1986).

While the PIP was in the hole, the annular space between the tubing and the borehole wall functioned as an observation well completed across the entire Salado and Castile Formations. When the wellhead was installed on DOE-2 on July 31,1985 , the annulus was filled with brine to near the surface. When the wellhead was disassembled on April 1, 1986, the fluid level in the annulus was below the $200-\mathrm{m}$ limit of a water-level probe, having apparently infiltrated into the Salado and/or Castile.

After removal of the PIP, a BPT resettable bridge plug was set in the casing from 868.6 to $873.2 \mathrm{ft}$ deep. On April 2, 1986, the casing across the Culebra interval in DOE-2 was perforated with 0.5 -in. bullets, using four shots/ft between the depths of 822 and $848 \mathrm{ft}$. Henceforth, DOE-2 will serve as a Culebra observation well. 


\subsection{Summary}

Eleven stratigraphic intervals were hydrologically tested in Drillhole DOE-2, using four different sets of instrumentation and three different data-acquisition systems. The highest-quality data were obtained by using the BPT DST tool with quartz-crystal transducers. Test methods included constant-head boreholeinfiltration tests, drill-stem tests, slug tests, pressurepulse tests, and a pumping test. Units tested included (with increasing depth) the lower portion of the Dewey Lake Red Beds, five members of the Rustler Formation (including the Rustler-Salado contact), the WIPP facility horizon and bounding anhydrite marker beds within the Salado Formation, the bulk of the Salado Formation, and three zones in the upper portion of the Bell Canyon Formation.

Water-quality samples were collected from the Culebra Dolomite Member of the Rustler Formation by pumping, and from the Hays sandstone of the Bell Canyon Formation by swabbing. Both waters are sodium-calcium chloride-sulfate brines.

\section{References}

Back, W. 1961. Techniques for Mapping of Hydrochemical Facies. USGS Prof Paper 424-D (Washington, DC: US GPO), pp 380-82.

Basler, J. A. 1983. Instrumentation Used for Hydraulic Testing of Potential Water-Bearing Formations at the Waste Isolation Pilot Plant Site in Southeastern New Mexico. USGS Open-File Report 83-144 (Washington, DC: US GPO), 29 pp.

Beauheim, R. L.; Hassinger, B. W; and Klaiber, J. A. 1983. Basic Data Report for Borehole Cabin Baby-1 Deepening and Hydrologic Testing, WTSD-TME-020 (Albuquerque, NM: US DOE).
Colton, I. D., and Morse, J. G. 1985. Water Quality Sampling Plan, WIPP-DOE-215. (Carlsbad, NM: US DOE, WIPP Froject Office).

Fischer, N. T., ed. 1985. Ecological Monitoring Program Semiannual Report, January-June 1985, DOE/WIPP-85-002 (Carlsbad, NM: Waste Isolation Pilot Plaint).

Grisak, G. E.; Pi kens, J. F.; Avis, J. D.; Belanger, D. W.; Thury, M.; and Schneider, A. 1985. "Principles of Hydrogeologic Investigations at Depth in Crystalline Rock," Proc Int Assn of Hydrogeologists Memoires 17(1):52-71 (Tucson, AZ, January 7-12, 1985).

INTERA Technologies and HydroGeoChem. 1985. WIPP Hydrology Program, Waste Isolation Pilot Plant, Southeastern New Mexico, Hydrologic Data Report \#2, SAND85-7263 (Albuquerque, NM: Sandia National Laboratories).

INTERA Techncilogies. 1986. WIPP Hydrology Program, Waste Isolation Pilot Plant, Southeastern New Mexico, Hydrologic Data Report \#3, SAND86-7109 (Albuquerque, NM: Sandia National Laboratories).

Mercer, J. W. 1937. Compilation of Hydrologic Data From Drilling the Salado and Castile Formations Near the Waste Isolation Pilot Plant (WIPP) Site in Southeastern New Mexico, SAND86-0954 (Albuquerque, NM: Sandia National Laboratories).

Ramey, H. J., Jr.; Agarwal, R. G.; and Martin, I. 1975. "Analysis of 'Slug Test' or DST Flow Period Data," $J$ Can Pet Tech 14(3):37-47.

Stephens, D. B., and Neuman, S. P. 1980. Analysis of Borehole Infiltration Tests Above the Water Table, Reports on Natural Resources Systems, No. 35 (Tucson, AZ: U of Arizona), 211 pp.

US Department of Energy. 1983. Quarterly Geotechnical Field Data Report, October 1983, WIPP. DOE-177 (A.lbuquerque, NM: WIPP Project Office). 


\section{APPENDIX A}

Field Operations Plan of Sandia National Laboratories for WIPP Site Investigations of Drillhole DOE-2, Phase I 


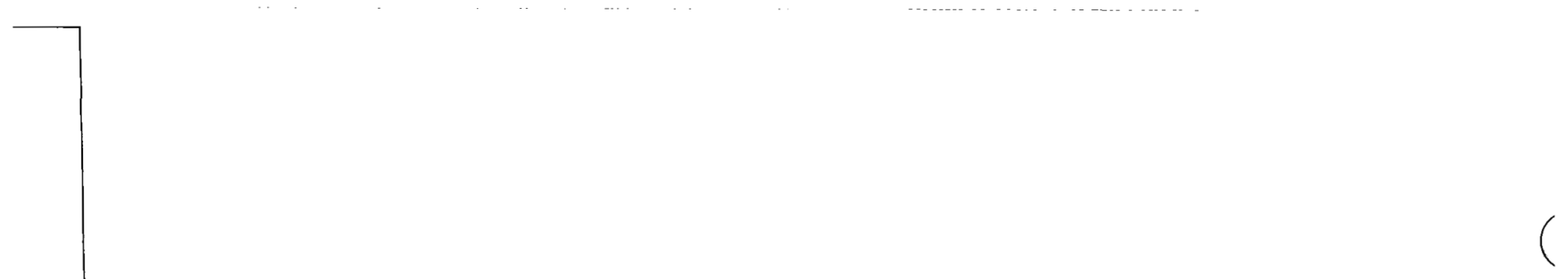


Field Operations Plan of Sandia National Laboratories

WIPP Site Investigation:

DOE-2 Phase I

Exploratory Hole: DOE-2 Phase I

Purpose: $\quad$ To define the work necessary for

investigating a depression in distinct

stratigraphic markers, to gather additional

stratigraphic information, and characterize

hydrogeochemically potential water-bearing

zones in the Dewey Lake and Rustler

Formations, including the Rustler-salado

contact.

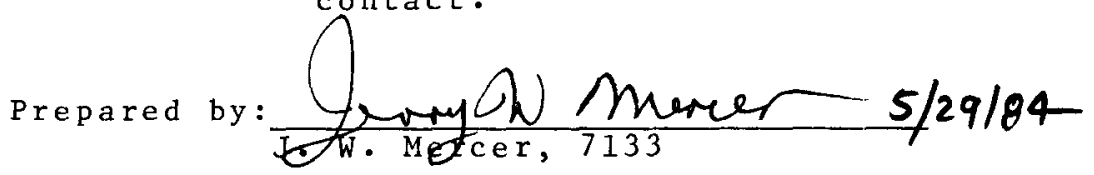

Reviewed by: $\frac{R . D \text {. Statter gnum } 6 / 7 / 84}{\text { R. D. Statier, 713 }}$

(

Hoted. Biness 6/7784

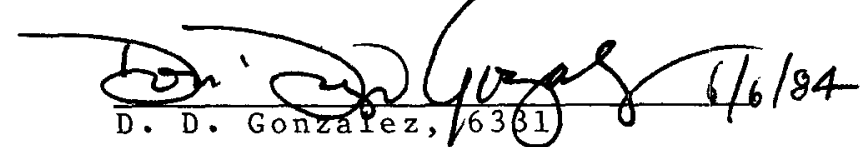

Approved by:
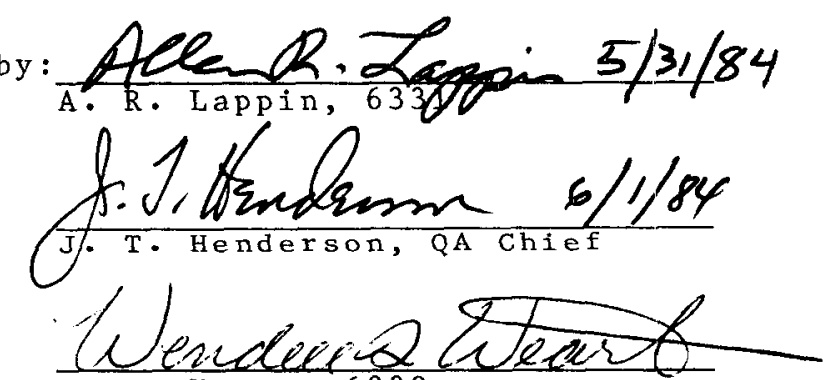

W. D. Weart, 6330

WIPP Project Manager 


\section{$\underline{\text { Page }}$}

INTRODUCTION

1. FIELD OPERATIONS CRITERIA

2. FIELD OPERATIONS PLAN

2.1 Organization and Responsibilities 2

2.2 Supporting Data

2.3 Drilling Program

3. FIELD OPERATING PROCEDURES FOR QIJALITY CONTROL REQUIREMENTS

$\begin{array}{lll}3.1 & \text { Surface Location and Depth } & \\ & \text { Measurements } & 14 \\ 3.2 & \text { Coring } & 18 \\ 3.3 & \text { Testing } & 24 \\ 3.4 & \text { Water Sampling } & 32 \\ 3.5 & \text { Geophysical Logging } & 37 \\ 3.6 \text { Cementing } & 47\end{array}$

4. REPORTS

4.1 Daily Report

50

4.2 Daily Time Log

50

4.3 Hole History

50

4. 4 Miscellaneous Records

51 


\section{INTRODUCTION}

This document contains plans, procedures, and spectfications for the Phase I drilling and testing of an exploratory drill hole, DOE-2. The recommended location for DOE-2 is $130^{\prime} \mathrm{FEL}$, $700^{\prime}$ FSL, Section 8, T22S, R31E. The hole is located $700^{\prime}$ north of the WIPP site northern boundary.

The Phase I program for the exploratory hole will include taking continuous core from a depth of 40 feet to a point to include the Rustler-Salado contact at about 940 feet. Formation tests, water sampling, and geophysical logs will be conducted. The core will be logged, photographed, and packaged at the well site, then retained in the WIPP core library.

\section{FIELD OPERATIONS CRITERIA}

This operations plan is based on scopes of work written by D. J. Borns, 6331, to A. R. Lappin, 6331, on May 8, 1984, and by D. D. Gonzalez, 6331, to W. D. Weart, 6330, on Apri1 27, 1984. Those scopes are reproduced in their entirety herein. 
STATEMENT OF WORK FDR DOE-2:

PHASE II (STRATIGRAPHY AND STRUCTURE)

Sandia National Laboratories Albuquerque, New Mexico

Prepared by:

Reviewed by s

Reviewed by:

Reviewed by:

Revile awed by s
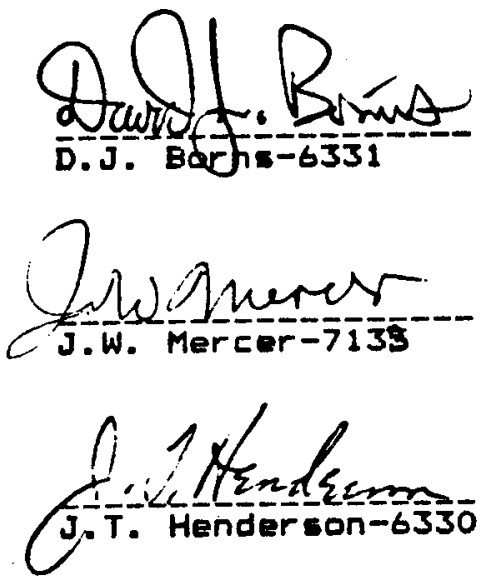

A.R. Lapplin-63i1

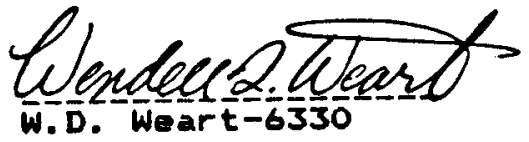

$4 / 25 / 84$

$\frac{4}{1}=\frac{1}{2}=184$

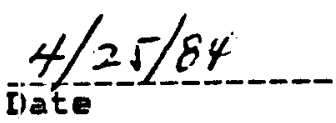

$4 / 25 / 84$

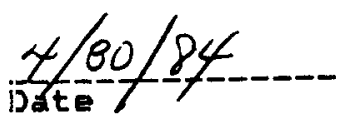

62 


\section{Sandia National Laboratories}

date: $\quad$ Kay 8,1984

Albuquerque. New Mexico 87185

to: A. R. Lappin -6331

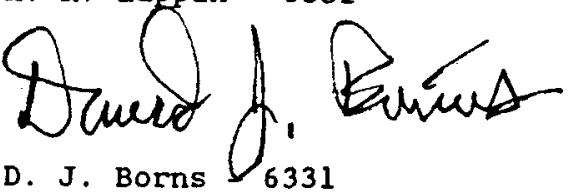

subject: Statement of Work for DOE 2

\section{References}

Borns, J.D., L.J. Barrows, and D.W. Powers, 1983, Deformation of Evaporites Near the Waste Isolation Pilot Plant (WIPP) Site. With a section by R.P. Snyder, USGS, SAND82-1069 (Albuquerque, NM: Sandia National Laboratories, February 1983).

Davies, P.B., 1983 (June 13), letter to L. Chaturvedi regarding the FC-92 depression.

Gonzalez, D.D., 1983 (June 14), letter to A.R. Lappin regarding Bell Canyon Hydro Test in the WIPP Vicinity.

Powers, D.W., S.J. Lambert, S.-E. Shaffer, L.R. Hill and W.D. Weart, ed., 1978, Geological Characterization Report, Waste Isolation Pilot Plant (WIPP) Site, Southeastern New Mexico, SAND78-1596, Vol. I and II (Albuquerque, NH: Sandia National Laboratories, 1978).

\section{Introduction}

Herein, we state the objectives, siting requirements, justification and methods of study for a proposed drillhole. This document supplants two earlier draft statements of work, July and september 1983. The purposes of this hole are to:

1. investigate a depression in distinct stratigraphic markers;

2. gather additional information on the hydrology of the Rustler Formation, Salado Formation, and the Delaware Mountain Group (DMG).

Hence, drilling will extend through the Castile. Also, since the proposed hole location is within the Disturbed Zone (Borns et al, 1983), there is a possibility that a brine reservoir will be encountered in the upper Castile anhydrites. There may be an opportunity for further testing of another brine reservoir in addition to ERDA 6 and WIPP 12 . 


\section{Objectives}

- Determine the origin of the LB-139 depression as indicated by the WIPP 34 and FC-92 drillholes. Processes that may/have produced this structure are irregular sedimentation, dissolution or gravity-driven tectonics, e.g., halokinesis and gravity sliding.

- Evaluate the MB-139 depression and characterize, if present, the deformation and flow structures in the Salado.

- Perform hydro-tests in the Rustler and Bell Canyoji aquifers and produce a "whole-hole" test in which the Rustler and Eell Canyon aquifers are interconnected.

\section{Siting Requirements}

The recommended location for DOE 2 is as follows: 130'FEL; 700'FSL; Sec.8, R31ET22S (see Figure 1). Only the $N-S$ coordinate may be varied $\pm 100^{\circ}$ to accomodate pad siting and safety considerations. Such a decision may be made in the field. This location is in the Sw corner of the intersection of the new North Access Road and the section boundary. All configurations of the MB 124 depression, Powers et al (2978), Snyder (in Borns et al, 1983) and Davies (1983), and FC-92 drilleore data are accommodated by this location (see Figure $2 \mathrm{~A}-2 \mathrm{~F}$ ).

Davies (1983) has suggested that the possible presence of faults within the lower Castile and upper DMG in MB 124 depression area should be considered in hole location (see Figure 2A). Such cleep structures were originally inferred by Powers et al (1978) within the Bell Canyon sands, and were interpreted as being faults trending NW-iSE. However, using higher resolution seismic lines, Barrows (in Borns et al, 1983) does not maintain this interpretation. Another set of faults: which trend NE-SW, in Anhydrite I are inferred from borehole data by Snyder (in Borns et al, 1983). The postulated trace of one crosses the MB 124 depression.

The trace of this "fault" and the Bell Canyon "fault" apparently intersect within the MB-124 depression near FC-92. However, this intersection does not alone justify a specific hole location. The original structures within Bell Canyon sands disappear in the later and nore detailed seismic interpretation. The postulated faults in Anhydrite $I$ can only have approximated positions ( \pm 100 's of feet). Therefore, it would be impossible to locate a hole precisely at a projected fault intersection, even if such existed. Conversely, if these faults are not intersected, this cannot be taken as justification for additional drilling in the area. The hole location is still determined basically by the shape of the MB-124 depression and geophysical CSAMT constraints.

\section{Justification of Hole}

- Deformation and Deep Dissolution

Peter Davies (1983) has proposed that the MB 12.4 depression is evidence of deep dissolution in the WIPP vicinity. Such dissolution is assumed to occur at a rate that induces ductile flow in the halite 
towards the point of dissolution/removal. Drill-core taken through the salado will provide evidence for the presence or absence of such flow structures. The removal of beds by dissolution can also be verified by observation of the core. Important features to observe are:

a. The presence or absence of dissolution residues (anomalously thick clay zones) and breccias.

b. Departures from normal stratigraphic section.

c. Association of residues with fractured and water-bearing units.

- Hydrology of the Rustler Formation.

The Rustler aquifers and the Magenta and Culebra dolomites are critical units for the hydrogeologic characterization of the WIPP site. In this crucial area, a hole at the proposed location would allow us to quantify and define the potentiometric surfaces for fluid-bearing zones in the Rustler.

- Additional justifications as the hole is deepened through Castile and completed in the DKG.

a. Additional hydraulic characterization of the Bell canyon in the area is needed. The hole would be used to obtain static heads, hydrologic parameters and water quality data from the Bell Canyon, namely, its Hayes, 0lds and Ramsey sands and Lamar Limestone.

b. The hole would allow a "whole-hole" test, in which the Bell Canyon and Rustler aquifers are intentionally interconnected and directions of fluid movement monitored (also see statement of work for Cabin Baby recompletion, Gonzalez, 1983.)

c. The proposed site is within the disturbed zone (Borns et al, 1983). Oriented core in Castile structures will permit determination of flow directions. Such data aid the ongoing study of deformation mechanisms, i.e., halokinesis vs. gravity sliding.

Also, there is a possibility of encountering a brine reservoir in the Castile. Brine reservoirs have been studied at WIPP 12 and ERDA 6 . Since this data base exists, it may be argued that further tests on a possible reservoir are not a primary purpose of the proposed hole. Still, the level of sampling/testing of a brine reservoir that could be encountered must be defined in advance. A brine-producing zone could be cased or packed of $f$ as was done at WIPP 12 as drilling was completed to Anhydrite $I$. Provisions, however, should be considered to allow nobilization for a reservoir test program, as contained in the WIPP 12 statement of work (Powers, 1981). Since a brine reservoir contingency testing plan is being developed by J. Mercer (SNL, 1133), a detailed test plan for a brine reservoir encounter is not developed in this document. still, during the deepening of DOE 2, provisions should be made for: 
a. Drillers should be prepared for $\mathrm{H}_{2} \mathrm{~S}$ and pressurized flow.

b. Comparison of DOE 2 brine reservoie to WIPP 12 and ERDA 6 occurrences through determination of flow rate, downhole pressure and major element chemistry, e.g., TDS.

c. Hole should be maintained in a configuration that permits longer term hydraulic testing during thase III, but some short-term testing, e.g., may be required in the brine reservoir contingency plan at the time of encounter.

\section{Methods}

The tasks essential to this program are divided into three phases (in order of completion):

I) Rustler Hydrology and Drilling

II) Drilling and core recovery from base of the Rustler into the DMG.

III) Perform hydrology and other related tests in the whole-hole.

This document is primarily a statement of work for Phase II. D.D. Gonzalez (6331) and J. Mercer (7133) will produce statements for Phase I and Phase III respectively. The proposed orilling for Fhase II is (2-1/2" or greater core acceptable, 4-1/2"' preferred):

1. Drill continuous core across the salado ( $945-2515^{\prime}$ below ground level) with oriented core at the following intervals:

- one barrel oriented core at MB 124 ( $1705^{\circ}$ below G.L.)

- one barrel oriented core across Cowden Anhydrite-Infra Cowden contact at $\sim 2355^{\prime}$ below G.L.

2. Drill continuous core across the Castile) $\left(\sim 2515^{\circ}-3800^{\circ}\right.$ below G.L.) with oriented core from the following intervals:

- Anhydrite III-Halite II contact at $\sim 285^{\circ}$ below G.L.

- middle of Anhydrite II at $\sim 2880^{\circ}$ below (a.l.

2a. If a brine reservoir is encountered, some minimal time of testing will be required, and the brine reservoir contingency plan (see Justification section above) will be enacted before orilling is continued.

3. Drill continuous core from the base of the Castile into the DMG, including the Ramsey, Ford, 01ds and Hayes nembers $\left(\sim 3800^{\prime}-4040^{\prime}\right.$ below G.L.) 
4. Perform geophysical logging of hole, including acoustilog, natural gamna, temperature, resistivity, 4-arm calipher for borehole geometry, neutron (limestone-compensated) and televiewer.

5. Set production packer, on 2-3/8" tubing, above the Bell Canyon to monitor fluid stabilization.

6. Photograph and preserve core according to WIPP standard practice.

7. Prepare hole as required for Phase III.

\section{Responsibilities}

statements of Work:

$\begin{array}{r}\text { Phase I - D. D. Gonzalez } \\ \text { Phase II - D. J. Borns } \\ \text { Phase III - J. Mercer }\end{array}$ (SNL, 6331)
Brine Reservoir Contingency Plan - J. Mercer 7133)
Field Operations Plan
Field Operations
Duty Geologist

\section{Quality Assurance}

Sandia Laboratories will implement this document in accordance with its established QA procedures. Operational QA will be performed by Fenix and Scisson and contractors in accordance with their established procedures to meet the objectives of the program. The QA level of this program in minor; unless a brine reservoir is encountered, then the level for portions of the testing is major.

DJB : $6331: \mathrm{cds}(03711)$

Distribution:

6330 W. D. Weart

6331 Personnel

6332 L. D. Tyler

7133 R. D. Statler

7133 J. Hercer

USGS R. P. Snyder 


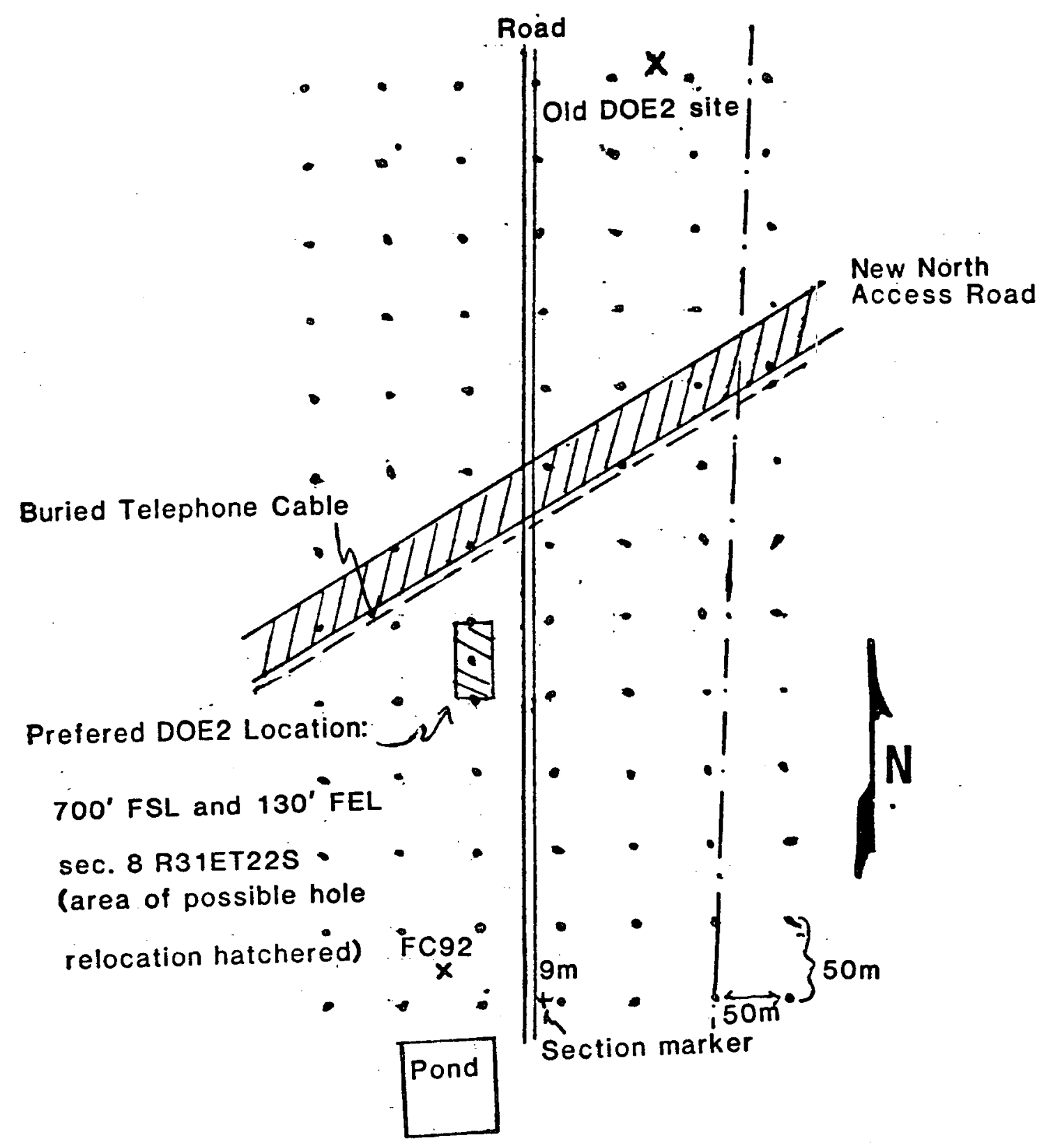

FIGURE I

Civilization Effects from L. Bartell 


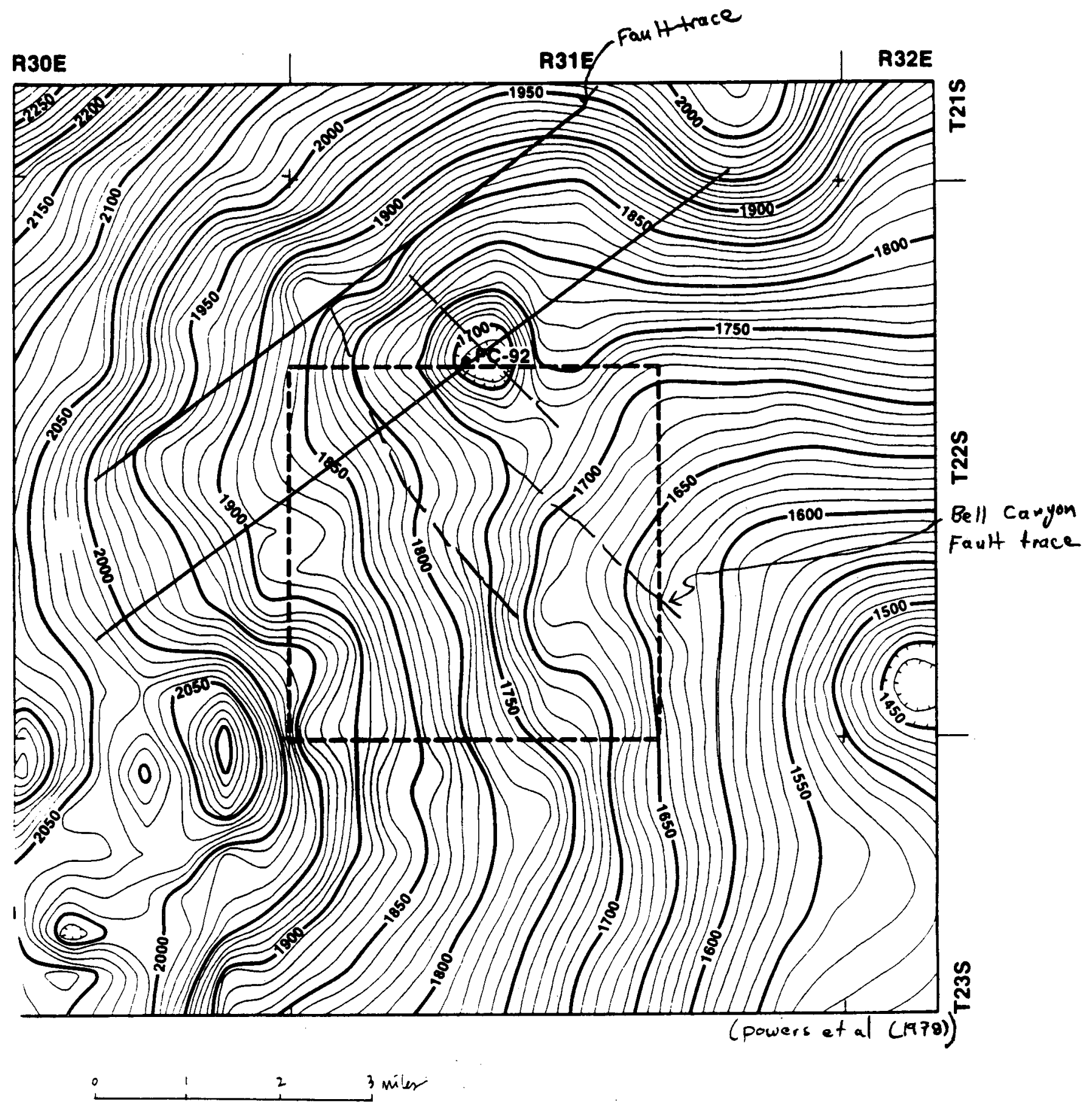

Figure 2A. Marker Bed 124 Depression and Projected Fault Trace 


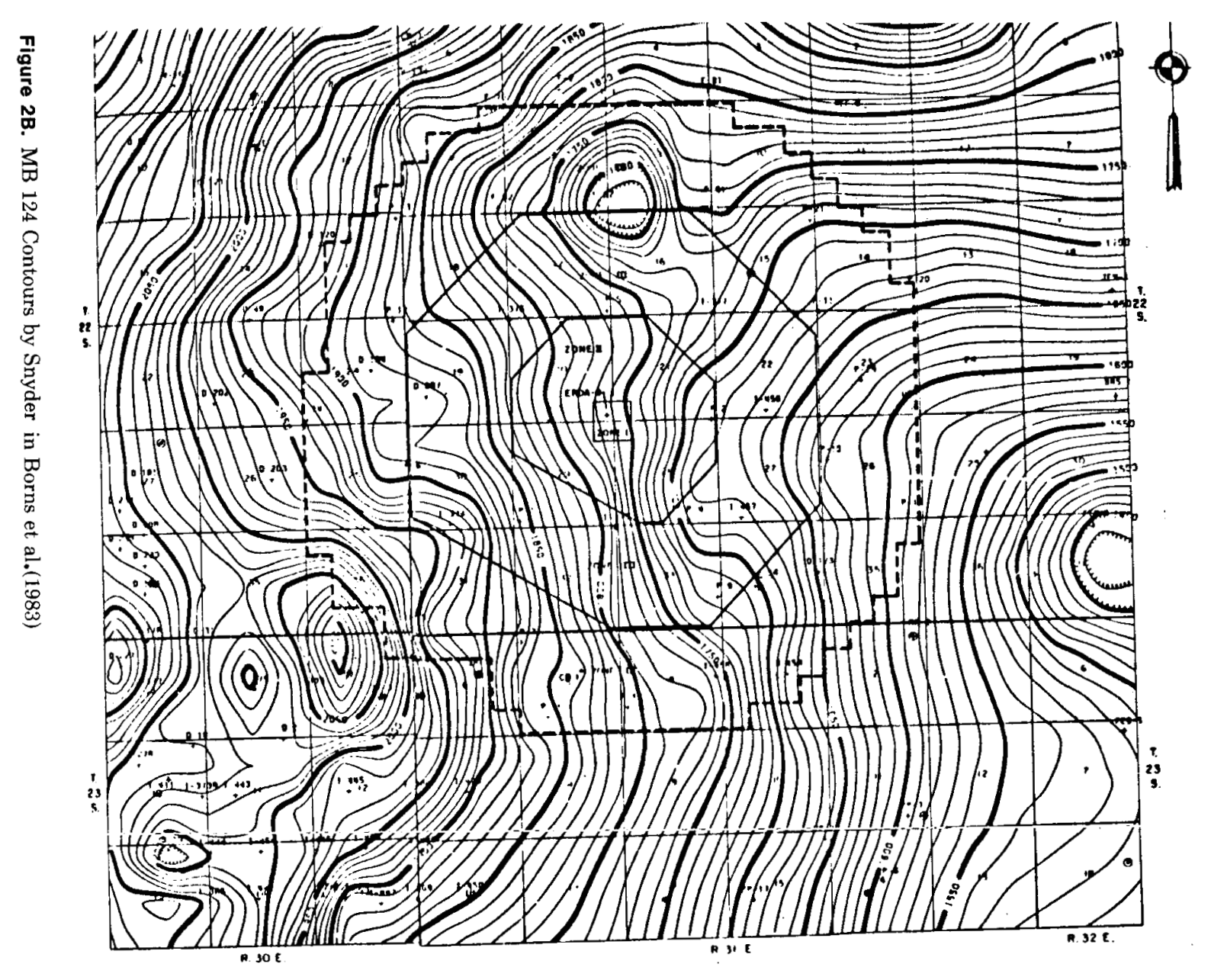

Noter

Gerehole sourcess of doto are stoos

REFERENCE

Grismold. 1977. 1.qurels

Contour morerval,

SCALE WI MLE

STRUCTURE C ON 124-MARI

FIGURE 


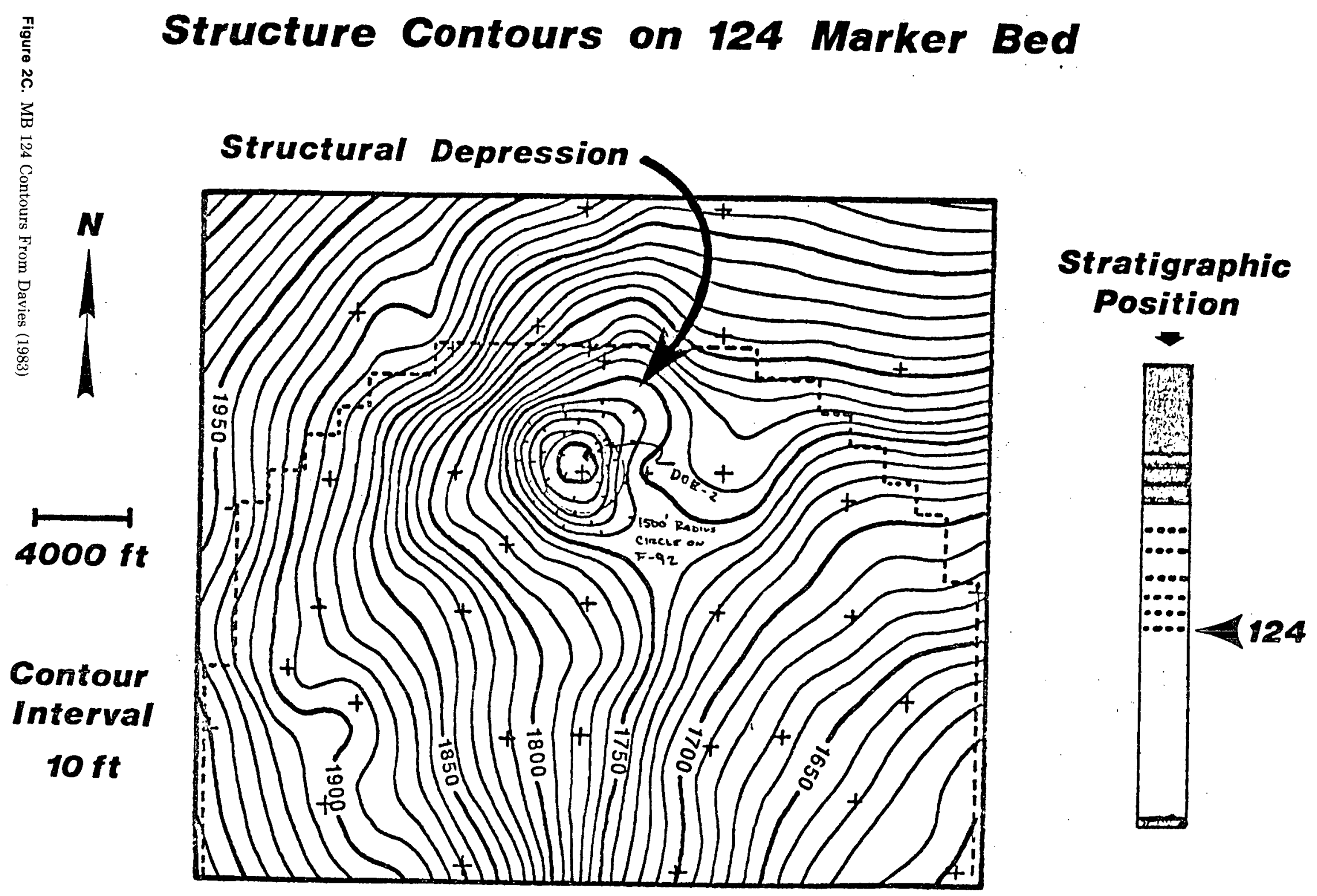




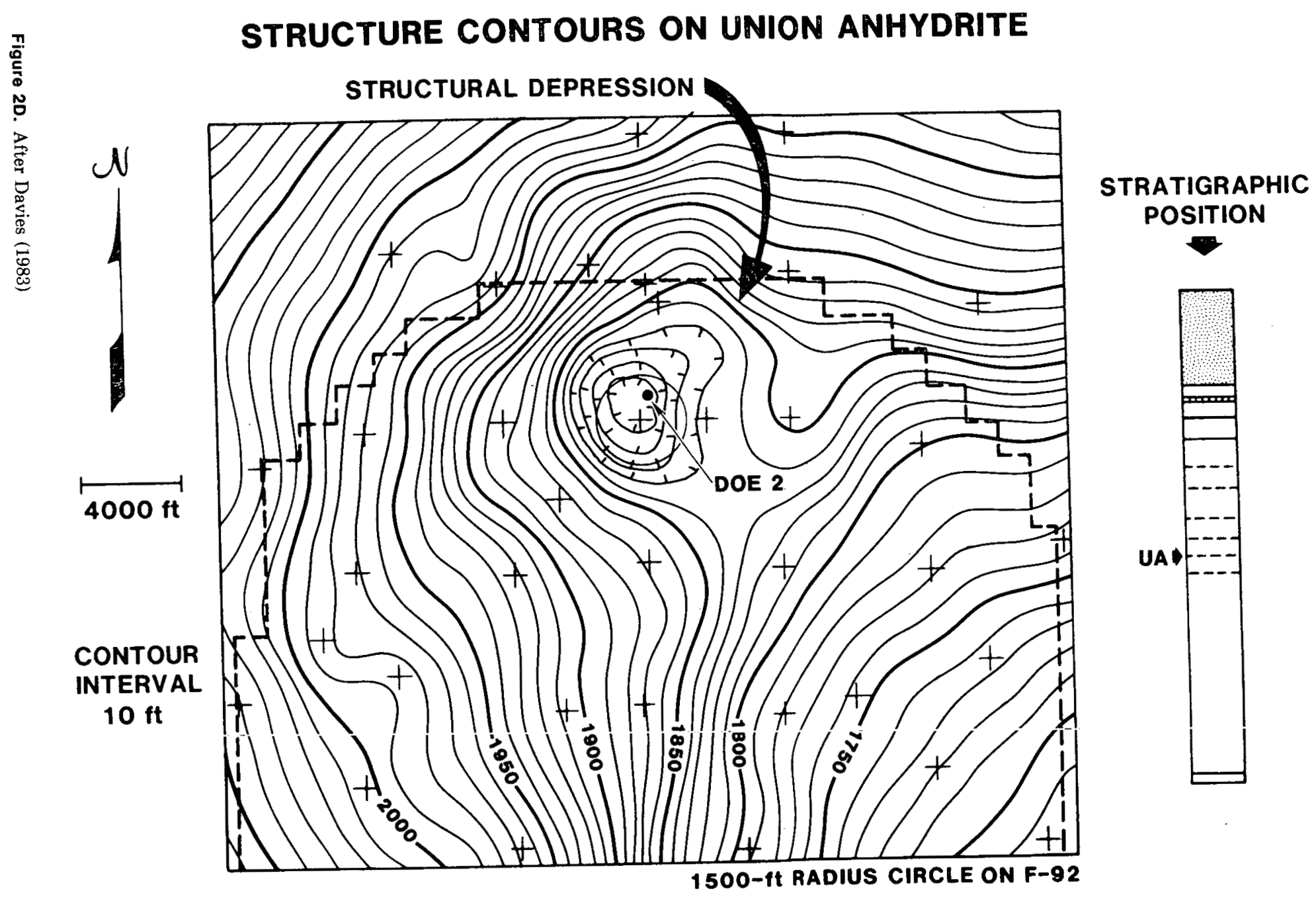




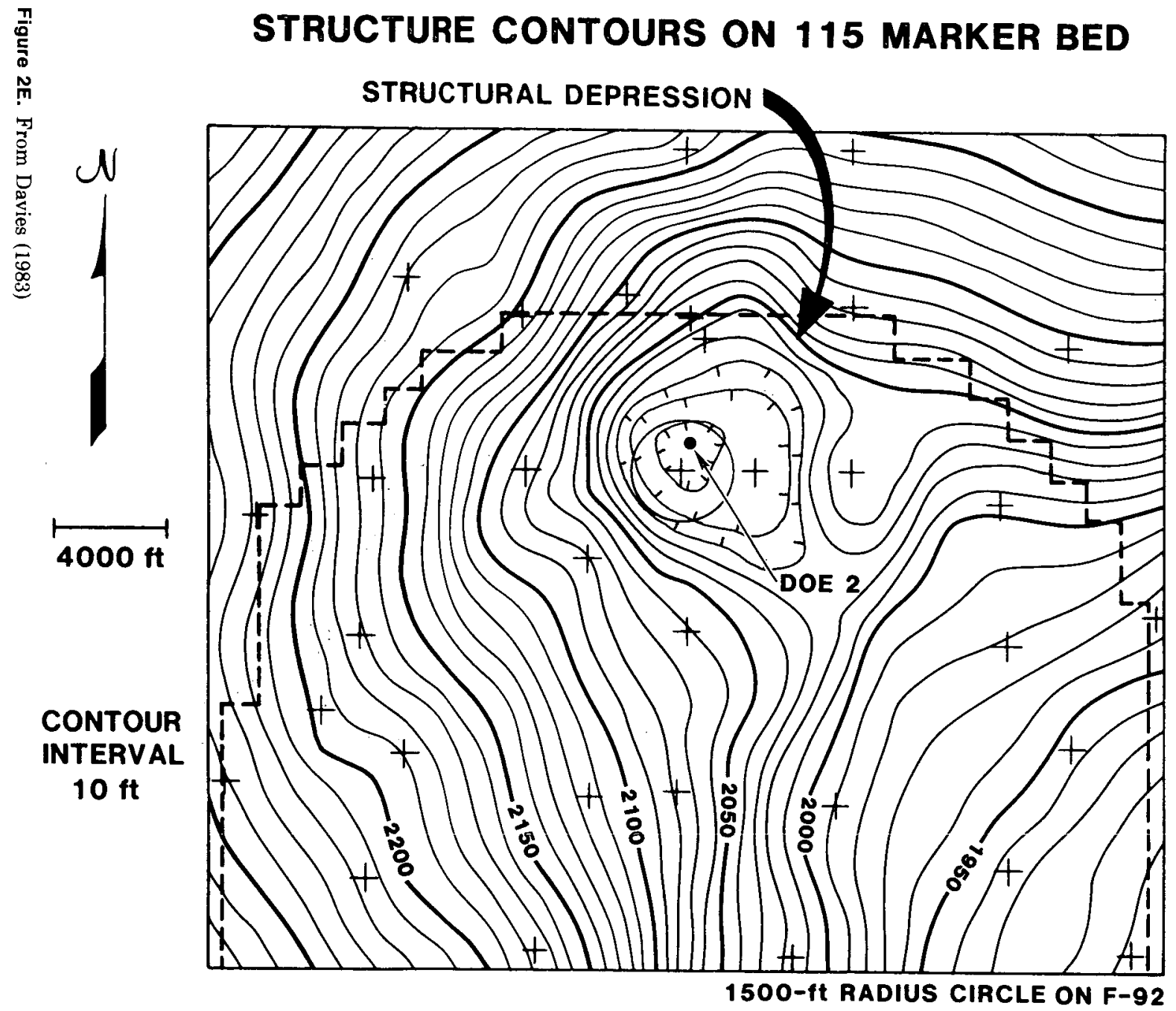

\section{STRATIGRAPHIC} POSITION

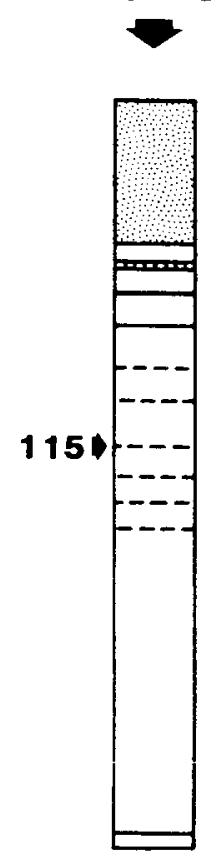



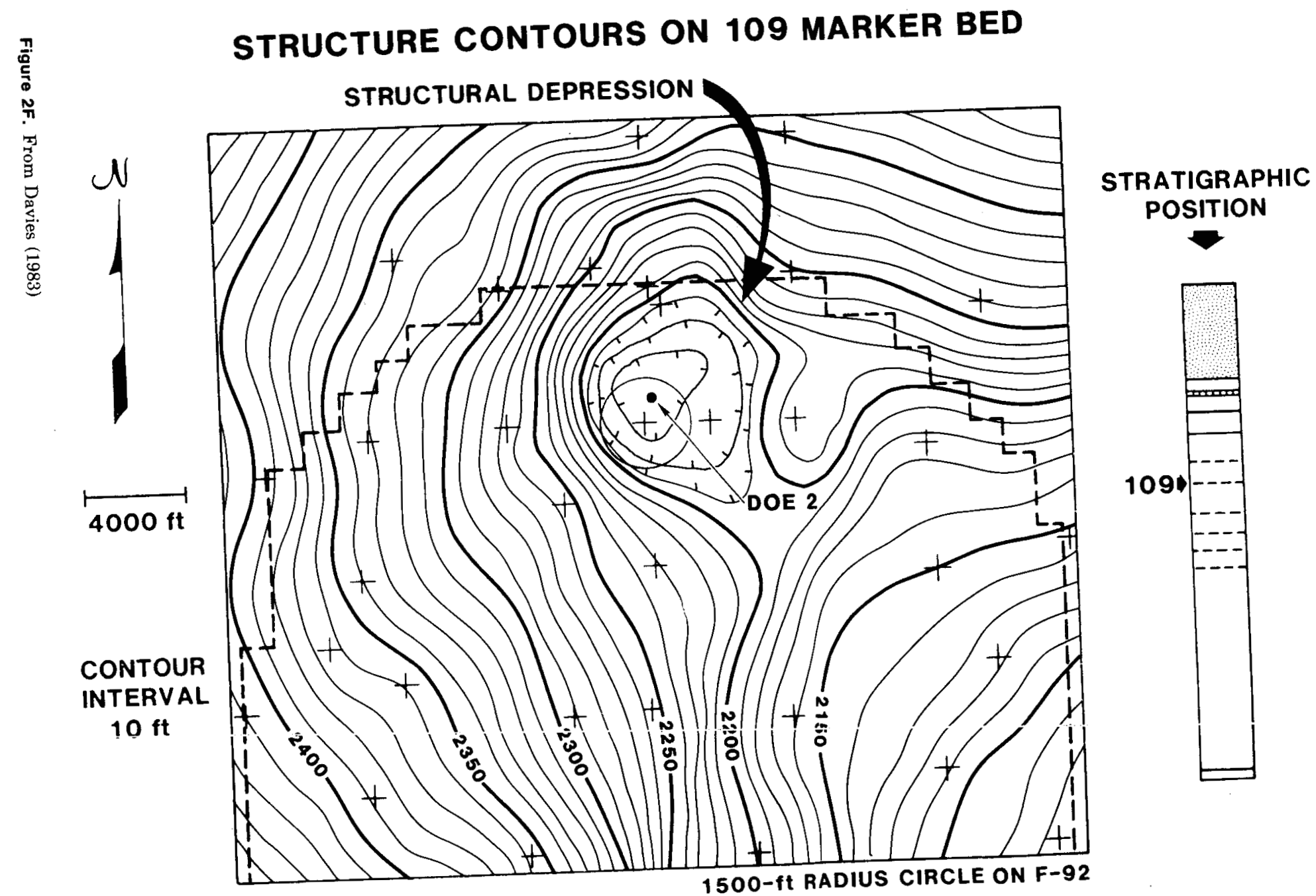
STATEMENT OF WORK FOR DOE-2: WISP HYDROLOGY (RUSTLER)

Sandia National Laboratories Albuquerque, NM

Prepared by:

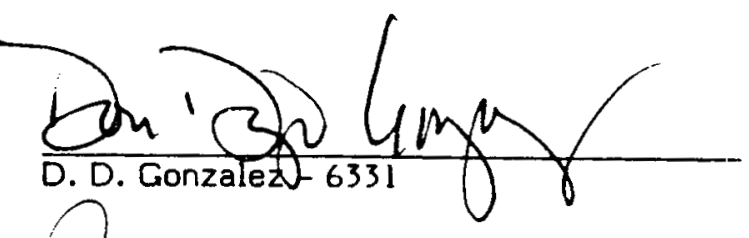

Reviewed by:

Reviewed by:

Approved by: ) 


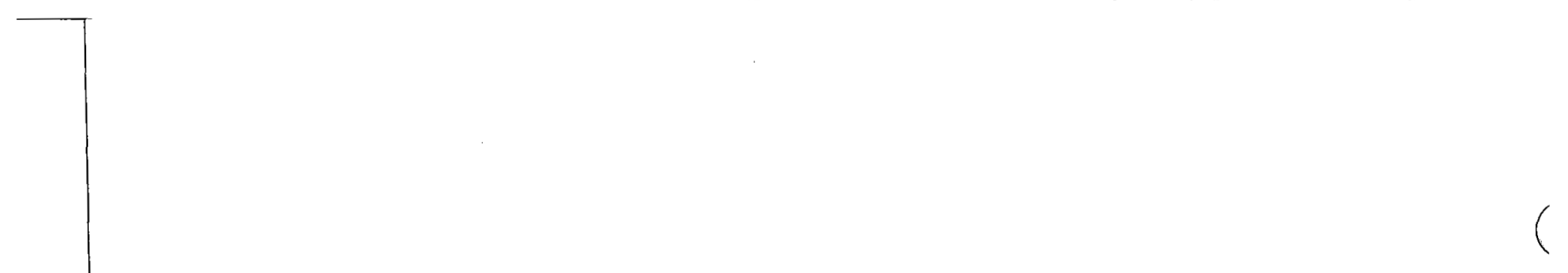

( 
This memo provides the scope of work (SOW) for hydrologic testing in the Dewey Lake and Rustler Formations in hole DOE-2. Included are specifics on the core retrieval, hydro-tests and water sampling necessary to allow completion of the field operations plan (FOP) by 7130.

OBJECTIVES - The objectives of work in DOE-2 to the base of the Rustler are:

a. To take continuous core from near the land surface to the Rustler-Salado contact.

b. To take the standard suite of geophysical logs in an open-hole condition.

c. To characterize hydrogeochemically the following potentially water-bearing zones:

- Dewey Lake (3 horizons controlled by internal stratigraphic subdivisions)

- Magenta Dolomite ( 740-770 ft)

- 49'r Member (transition zone)

- Culebra Dolomite ( 830-860 ft)

- Tamarisk Member (transition zone)

- Rustler-Salado Contact ( $\sim 945 \mathrm{ft}$ )

d. To retrieve representative samples of water and/or gas from water-yielding zones in conjunction with aquifer/reservoir testing.

\section{JUSTIFICATIONS}

a. Core

Coring will involve the taking of nearly 950 feet of core, 2.4 to 4 -inch diameter, from land surface to the Rustler-Salado contact. The method of drilling may be either conventional or wire-line; the choice between these two methods will be made to maximize core recovery. The core from DOE-2 will be correlated with core previously taken from the Rustler and Salado Formations in other drillholes. Core observations will be used to evaluate:

- Permeabilities and porosity observations in the water-bearing zones.

- Salt removal processes

- Diagenetic alteration

- Depositional history of the Rustler and Dewey Lake Formations

- Isotopic studies

- Paragenesis studies

- Matrix diffusion studies

\section{b. Geophysical Logging}

Geophysical logging will include the running of a standard suite of geophysical logs to identify stratigraphic picks to estimate basic rock properties such as density, porosity, permeability and saturation. Geophysical logs should include 
formation density, resistivity, porosity (limestone-compensated), acoustic, natural gamma, and temperature. The intent is that triese logs need only be run once. However, minimal logging may be required to select packer locations for hydrologic testing of individual intervals.

\section{c. Hydraulic Characterization}

Hydraulic characterization will include characterization of each water-bearing zone as it is encountered, to determine hydraulic parameters essential in the evaluation of solute transport with respect to several primary breach scenarios. Hydraulic parameters of prime interest are:

- Hydraulic conductivity

- Transmissivity

- Storativity

- Porosity/Dispersivity

- Hydraulic potential

\section{d. Water and/or Gas Sampling}

Water and gas sampling will provide support necessary; to add to the expanding base of general chemistry, isotopic studies and age ldating of aquifer fluids. These samples should be taken during the course of aquifer pump tests in water-bearing zones. The results of these analyses will be useful in helping to interpret flow patterns, areas of recharge and discharcje, and different episodes of fluid movement.

METHODS - Following are the methods and tests recommended to achieve the objectives outlined above. The exact details of each are not given; they will be given in detail in the field operations plan and during actual testing.

a. Core

It is anticipated that no oriented core will be necessiary during the drilling of DOE-2 to the Rustler-Salado contact. Justification for oriented core would need to be developed by Division 6331 and amended to the SOW and FOP. Core will be taken using conventional or wire-line coring mel:hods. Additional caution and control should be used when drilling across the Culebra Dolomite, in anticipation of coring across a fractured/vuggy matrix.

b. Geophysical Logs

It is recommended that the U.S. Geological Survey provide the geophysical support as required. The geophysical capability and response to need which the USGS possess are superior to local commercial service ciompanies.

c. Hydraulic Characterization

The testing of 9 intervals in the Dewey Lake and Rustler Formations is proposed and recommended to be accomplished as the core-drilling progresses to the bottom of each test interval. This technique would lend more credibility to the tests and would require only one packer setting to isolate each test interval. 
In very low-permeability zones pressure-pulse, slug withdrawal or injection and modified drill-stem tests are recommended. In those zones where fluid inflow is $\geq 0.5 \mathrm{gpm}$, pump tests should be performed. Either submersible or volume-displacement pumps can be utilized in an open-hole situation. It is anticipated that only the Culebra Dolomite and possibly the Magenta Dolomite would be transmissive enough to conduct aquifer pump tests. This stage of DOE -2 will be drilled and cased only to the Rustler-Salado contact. At some later date, the hole will be completed to the Bell Canyon. The interruption in drilling will be caused by a limitation in funding.

Since this will be a two-phase drilling program, detailed testing and sampling of the Culebra Dolomite could be deferred until after casing is set, alleviating excessive rig standby time and avoiding possible complications while pumping in an open hole. By delaying the Culebra test, more time could be allotted to testing, water sampling, and the observation of natural head buildup. It would, however, be necessary to perforate the casing across the Culebra Dolomite.

The following is a proposed coring and testing schedule, with approximate drilling and testing depth intervals and anticipated qualitative permeabilities in each zone.

- Surface casing set to $40 \mathrm{ft}$

- Core drilling 40-250 ft

1. Test Dewey Lake sandstone

- $\phi$ at about $200 \mathrm{ft}$, TD at $250 \mathrm{ft}$ ( $\Phi$ packer setting)

- should anticipate some appreciable permeability

- Core drilling 250-400 ft

2. Test Dewey Lake gypsiferous zones

- $\Phi$ at about $250 \mathrm{ft}$, TD at $400 \mathrm{ft}$

- Very low permeability

- Core drilling 400-645 ft

3. Test Dewey Lake clay/gypsiferous zone, including the Dewey Lake-Rustler contact

- $\phi$ at about $400 \mathrm{ft}, T D$ at $645 \mathrm{ft}$

- Very low permeability

- Core drilling 645-730 ft

4. Test the 49' $r$ member

- $\phi$ dependent on core evaluation

- Very low permeability

- Core drilling 730-780 ft

5. Test the magenta Dolomite

- $\$$ at about $740 \mathrm{ft}$

- Probably very low permeability, however, there is a chance that this unit may be productive enough to be pumped.

- Core drilling 780-800 ft

6. Test the transition zone

- $\Phi$ at about $770 \mathrm{ft}$

- Very low permeability 
- Core drilling 800-830 ft

7. Test the clay zone

- $\$$ at about $820 \mathrm{ft}$

- Very low permeability

- Core drilling 830-860 ft

8. Test the Culebra Dolomite

- $\$$ at about $830 \mathrm{ft}$

- Moderate permeability, pump test

- Core drilling 860-950 ft

9. Test the Rustler/Salado contact

- $\$$ at about $940 \mathrm{ft}$

- Very low permeability

- Completion of the testing and sampling of the Culebra may follow completion and casing of the hole to the Rustler/Salado contact.

\section{d. Water Sampling}

These samples will be taken according to guidelines set by SNL, and sampling procedures should be included in the field operation's plan. Field sampling procedures and distribution of samples must be documented and on file before this stage of work begins. Splits to interested personnel will be made accordingly.

\section{RESPONSIBILITIES}

Principal Investigators (Statement of Work)

D. D. Conzalez, 6331

J. W. Mercer, 7133

J. W. Mercer, 7133

D. J. Borns, 6331

Field Operations Plan

Field Operations

Duty Geologist
Dewey Lake/Rustler Hydrology

Bell Canyon and Whole-hole Hydrology

Brine Reservoir Contingency

Stratigraphic \& Structural Investigation

Org. $7133 /$ Fenix \& Scisson

Org. $7133 /$ Fenix \& Scisson

R. P. Snyder, USGS-Denver

\section{QUALITY ASSURANCE}

Sandia Laboratories will implement this document in accordance with its established QA procedures. Operational QA will be performed by Fenix and Scisson and contractors in accordance with their established procedures to meet the objectives of the program. The QA level of this program in minor. Note, however, that collection of water/gas samples should not begin without a fully documented set of procedures and agreement concerning variables to be analyzed in the field for purposes of determining stability with respect to fluid composition. This is especially important, given that the quality of samples and times allowed for sample collection are likely to be different in an open versus a cased and perforated hole.

Att.

4-12-84 (Rev. 5-2-84) (7211) 


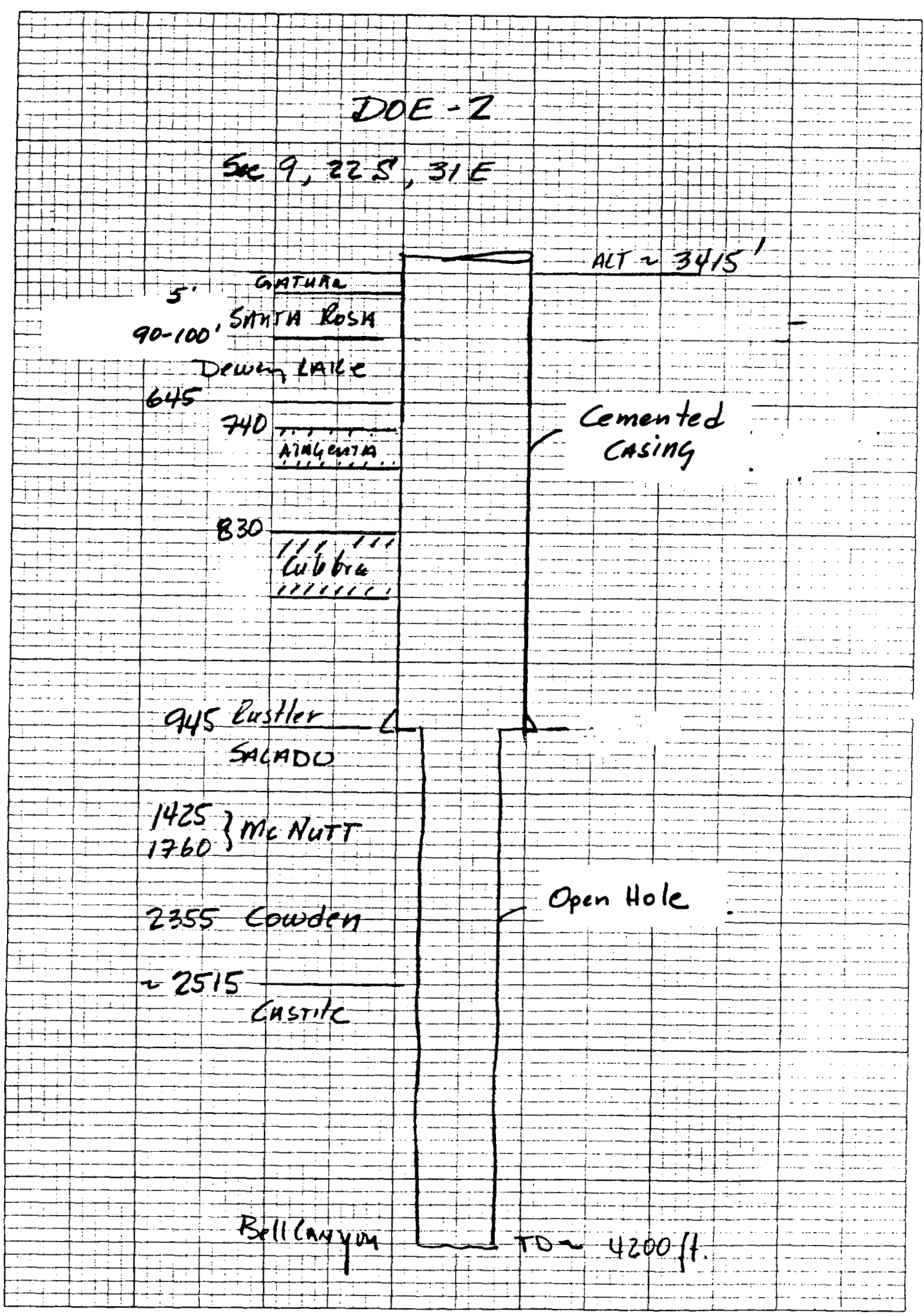

81 


\section{FIELD OPERATIONS PLAN}

\subsection{Organization and Responsibilities}

2.1.1 The technical program for Phase I in this operation is the responsibility of Earth Sciences Division 6331. D. J. Borns is responsible for the geological programs and D. D. Gonzalez is responsible for hydrology programs. Field decisions affecting the technical objectives will be made with full concurrence of Division 6331 .

$2 \cdot 1 \cdot 2$ The U. S. Geological Survey (Regional Geology and Water Resources Division) will be responsible for core description and are expected to provide their expertise and recommendations throughout the geophysical logging program.

$2 \cdot 1 \cdot 3$ The direction of field operations described in this plan is the responsibility of J. W. Mercer, Division 7133. 
2.1.4 Arrangements have been made with the DOE/NVO

for services of Fenix \& Scisson, a DOE/NVO

drilling engineering contractor. F\&S will

plan, contract for, and administer the

drilling, coring, logging, testing, and

other associated services on a 24-hour basis

and according to the technical criteria

provided by Sandia and according to the F\&S

WIPP Quality Assurance Manual.

2.1.5 The quality of Phase I of this program is

categorized as "minor". Appropriate Quality

Assurance measures on work performed by

Division 7133 will conform to the general

requirements of the "Field Engineering

Directorate Quality PIan", Issue B, dtd.

Dec., 1983

\section{2 Supporting Data}

This field operations plan covers the tasks essential

to the first phase of a three-phase program:

$\begin{array}{ll}\text { Phase I) } & \text { Rustler hydrology and coring } \\ \text { Phase II) } & \text { Drilling and core recovery from } \\ & \text { the base of the Rustler into the } \\ & \text { Delaware Mountain Group }\end{array}$




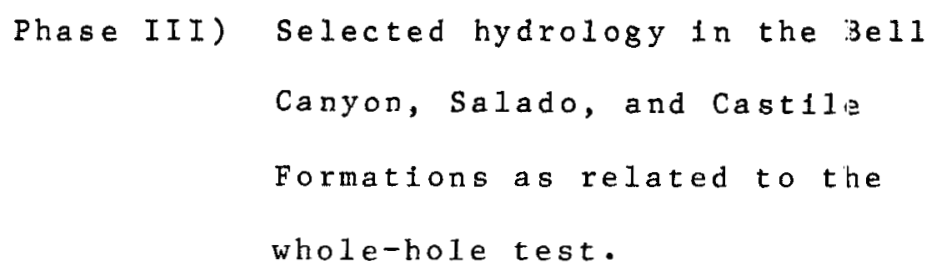

Phase II and III will be covered under a separate field operations plan.

\subsection{Drilling Program - Phase I}

It should be recognized that the primary objective of Phase $I$ is to hydrologica $11 y$ characterize the water-bearing zones encountered. If unusuel hole conditions develop, the drilling program maly have to be modified accordingly.

2.3.1 Construct a dri11 pad and access roads to the site. The pad size and design should follow API recommended practices for the estimated drilling depth for Phase II, (4040 feet) and the potential for encountering brine flows with associated $\mathrm{H}_{2} \mathrm{~S}$ gas.

2.3.2 Excavate ce1lar and construct a timber wall to accommodate the BOP (blow-out preventor) required for Phase II. 
2.3.3 Machine auger a sufficientiy large hole to

set about $40^{\prime}$ of $13-3 / 8^{\prime \prime}, \mathrm{H}-40,48$ \#

conductor pipe or appropriate casing for an

exploratory hole that may be drilled to

about 4040 feet. Land casing and cement to

surface. WOC (wait on cement) as directed.

2.3.4 Excavate mud pit and reserve pits as

required for the proposed drilling depths.

Line pits with suitable material.

2.3.5 Implement rig on a 24-hour operation to core

by wireline using the rotary method and air

or air/foam as a circulating media to

optimize core recovery. Use of all

additives to the circulating media will be

documented. If hole conditions or core

recovery dictate changing the circulating

media from air to a mud system, the mud

system should be compatible with the

hydrologic objectives of the exploratory

hole. A brine-based polymer mud or even

brine may be acceptable. Because the

potential exists for formation water samples

to be contaminated with drilling fluid, the

drilling fluid shall be "spiked" with a

tracer to determine the concentration of

drilling fluid in the sample. As a tracer

has not been selected, 
the type of tracer and procedures to be used will be added later as a supplement to the field operation plan.

2.3.6 Pick up core bit with a $10^{\prime}$ split core barrel capable of providing a nciminal 2.4 " core and proceed to take continuous core to about $250^{\circ}$ or to the Dewey Lake sandstone, documenting core recovery. See Section 3.2 for core handing procedures.

2.3.7 Lay down core barrel and pick up 7-7/8" bit and ream hole to total depth.

2.3.8 Load the hole with brine or polymer-mud spiked with tracer of known concentration and run USGS gamma log and califier in preparation for hydrologic testing.

2.3.9 Run hydrologic tests in the Dewey Lake sandstone interval between a packer set at about $200^{\circ}$ and the bottom of the hole (Test 1). Packer assembly should include an open-hole inflatable packer, trăınsducers below and above packer, a real-time surface readout of downhole pressures, ind the capability of opening and closing the tubing string from the zone to be tested. Time for 
the hydrologic tests could run from 24 up to 120 hours, depending on hole conditions.

See Section 3.3 for testing procedures.

2.3.10 Water samples will be collected by swabbing

from the test intervals. Sample collection

should be conducted during the hydrologic.

testing and prior to any injection tests.

See Section 3.4 covering water sampling

procedures.

2.3.11 Upon completion of testing and sampling, evacuate the borehole of fluids (if applicable) and resume coring with air from $250^{\prime}$ to about $400^{\prime}$.

2.3.12 Lay down core barrel and pick up 7-7/8" bit and ream hole to total depth.

2.3.13 Load the hole with brine or polymer-mud spiked with tracer and run USGS gamma $10 \mathrm{~g}$ and caliper in preparation for hydrologic testing.

2.3.14 Run hydrologic tests in the Dewey Lake gypsiferous zone between a packer set at about $250^{\prime}$ and the bottom of the hole (Test 2). Repeat procedures as described in Section $2 \cdot 3 \cdot 9$ and $2 \cdot 3 \cdot 10$. 
2.3.15 Upon completion of testing and sampling, evacuate the borehole of fluids if applicable) and resume coring with air from $400^{\prime}$ to about $645^{\prime}$.

2.3.16 Lay down core barrel and pick up 7-7/8" bit and ream hole to total depth.

2.3.17 Load the hole with brine or polymer-mud spiked with tracer and run USGS gamm log and caliper in preparation for hydrologic testing

2.3.18 Run hydrologic tests in the Dewey Lake c1ay/gypsiferous zone, including, the Dewey Lake-Rustler contact interval, between a packer set at about 400' and the bottom of the hole (Test 3 ). Repeat procedures as described in Section 2.3 .9 and ?.3.10.

2.3.19 Upon completion of testing and sampling, evacuate borehole of fluids (if applicable) and resume coring with air from 645' to about $730^{\circ}$.

2.3.20 Lay down core barrel and pick up 7-7/8" bit and ream hole to total depth. 
2.3.21 Load the hole with brine or polymer-mud spiked with tracer and run USGS gamma log and caliper in preparation for hydrologic testing .

2.3.22 Run hydrologic tests in the $49^{\prime} \mathrm{r}$ member.

Packer seat will depend on core evaluation. The test will include the interval between the packer seat and the bottom of the hole (Test 4). Repeat procedures as described in Section $2 \cdot 3 \cdot 9$ and $2 \cdot 3 \cdot 10$

2.3.23 Upon completion of testing and sampling, evacuate borehole of fluids (if applicable)

and resume coring with air from $130^{\prime}$ to $780^{\prime}$.

2.3.24 Lay down core barrel and pick up 7-7/8" bit and ream hole to total depth.

2.3.25 Load the hole with brine or polymer-mud spiked with tracer and run USGS gamma log and caliper in preparation for hydrologic testing.

2.3.26 Run hydrologic tests in the Magenta Dolomite Member between a packer set at about $740^{\circ}$ and the bottom of the hole (Test 5). Repeat procedures as described in Section 2.3 .9 and $2 \cdot 3 \cdot 10$ 
2.3 .27 It is presumed at this point that the borehole conditions will dictate using a mud system (brine or polymer-mud) sfiked with a tracer throughout the rest of the Phase I coring program. Upon completion of testing and sampling, resume coring with mud from 780' to $800^{\prime}$.

2.3.28 Lay down core barrel and pick up 7-7/8" bit and ream hole to total depth.

2.3.29 Run USGS gamma log and caliper in preparation for hydrologic testing.

2.3.30 Run hydrologic tests in the transition zone between a packer set at about $770^{\circ}$ and the bottom of the hole (Test 6). Repeat procedures as described in section 2.3 .9 and $2 \cdot 3 \cdot 10$

2.3.31 Upon completion of testing and sampling, resume coring with mud from 800' to $830^{\circ}$.

2.3.32 Lay down core barrel and pick up 7-7/8" bit and ream hole to total depth. 


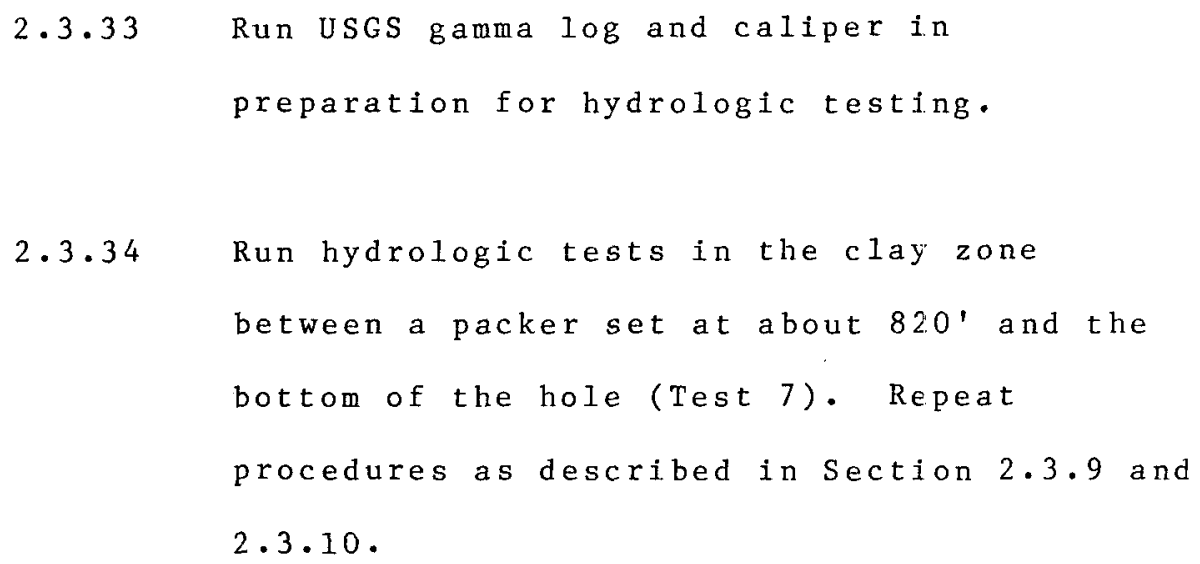


accommodated after the hole is cased.

Repeat procedures as described in Section

$2 \cdot 3 \cdot 9$ and $2 \cdot 3 \cdot 10$.

2.3.39 Upon completion of testing and sampling, resume coring with mud from about $860^{\prime}$ to $950^{\prime}$ or until good Salado salt has been recovered.

2.3.40 Lay down core barrel and pick uF 7-7/8" bit and ream hole to total depth.

2.3.41 Run USGS gamma $10 \mathrm{~g}$ and caliper $n$ preparation for hydrologic testing.

2.3.42 Run hydrologic tests at the Rustler-salado contact between a packer set at about $940^{\prime}$ and the bottom of the hole (Test 9). Repeat procedures as described in Section 2.3 .9 and $2 \cdot 3 \cdot 10$

2.3.43 After completion of hydrologic testing, pick up 7-7/8" bit and condition the hole and run geophysical logs. The logging program is required to provide information on acoustic velocities, porosity, density, natural 
radioactivity, formation resistivities and fracture geometry (acoustic televiewer).

See Section 3.5 on geophysical logging.

2.3.44 After logging has been completed, pick up 12-1/4" bit and ream hole to TD (about $40 \mathrm{ft}$ into Salado salt).

2.3.45 Run USGS gamma $10 \mathrm{~g}$ and caliper to calculate proper amount of cement.

2.3 .46 Inspect and set $9-5 / 8^{\prime \prime}$ (industry standard) casing to preselected depth. Install centralizers in optimum position, usually $60^{\prime}$ to $90^{\prime}$ apart.

2.3.47 Select a 70-30 poz mix cement slurry mixed with salt to saturation and $2 \%$ bentonite ge1. Circulate a minimum of $50 \%$ excess above volume calculated to fill annulus. See Section 3.6 on cementing procedures.

2.3.48 Following cementing, rig down and demobilize. Install a removable cap on wellhead and temporarily abandon until Phase II program is instituted. 
3. FIELD OPERATING PROCEDURES FOR QUALITY CONTROL REQUIREMENTS

Portions of this field activity are considered to be of sufficient significance that quality control measures have been established. These activities are:

3.1 Surface Location and Depth Measurement

3.2 Coring operations

3.3 Hydrologic Testing

3.4 Water Sampling

3.5 Geophysica1 Logging

3.6 Cementing

3.1 Surface Location and Depth Measurement Procedure of Sandia National Laboratories - WIPP Site Investigations

$3 \cdot 1 \cdot 1$

Introduction

This procedure is prepared by the Field

Engineering Division 7133 for use in Sandia

Laboratories WIPP Program. The objective is

to establish the methods and techniques to

be used in measurement of the surface

location and wel1 depth of exploratory well

DOE -2 . 
$3 \cdot 1 \cdot 2$

are to be done as part of the exploratory

program of drilling DOE-2. The nature of

the location of DOE-2, to accomodate

structural considerations and to investigate

potential depression in stratigraphic

markers, requires unusual accuracy in

surface location and depth control.

\subsubsection{Organization}

Sandia National Laboratories is conducting

this field work under technical direction

from Earth Sciences Division 6331. The

Sandia Field Engineering Division 7133 will

manage the field operations.

Fenix \& Scisson will be responsible for maintaining depth control on the drilling and testing operations. 


\subsubsection{Surface Location Measurements}

The general location will be:

established by Division 633]. following

a review of resistivity surveys,

surface features, accessibility and

other geo-political considerations. A

preliminary land survey shall be

conducted by a Registered Land Surveyor

to establish access routes and set

stakes for drill location and pad

boundaries. Dimension of the location

will be established with nearest

section boundaries and nearest marked

section corners to provide data

necessary for obtaining land use

permits. Drawings or sketches suitable

for constructon use shall bie

submitted. After pad construction is

complete and at the time of: hole

spudding, a concrete monument with a

brass cap will be set in the immmediate

vicinity of the borehole at ground

level such that it can be used as the

datum point for all borehole vertical 


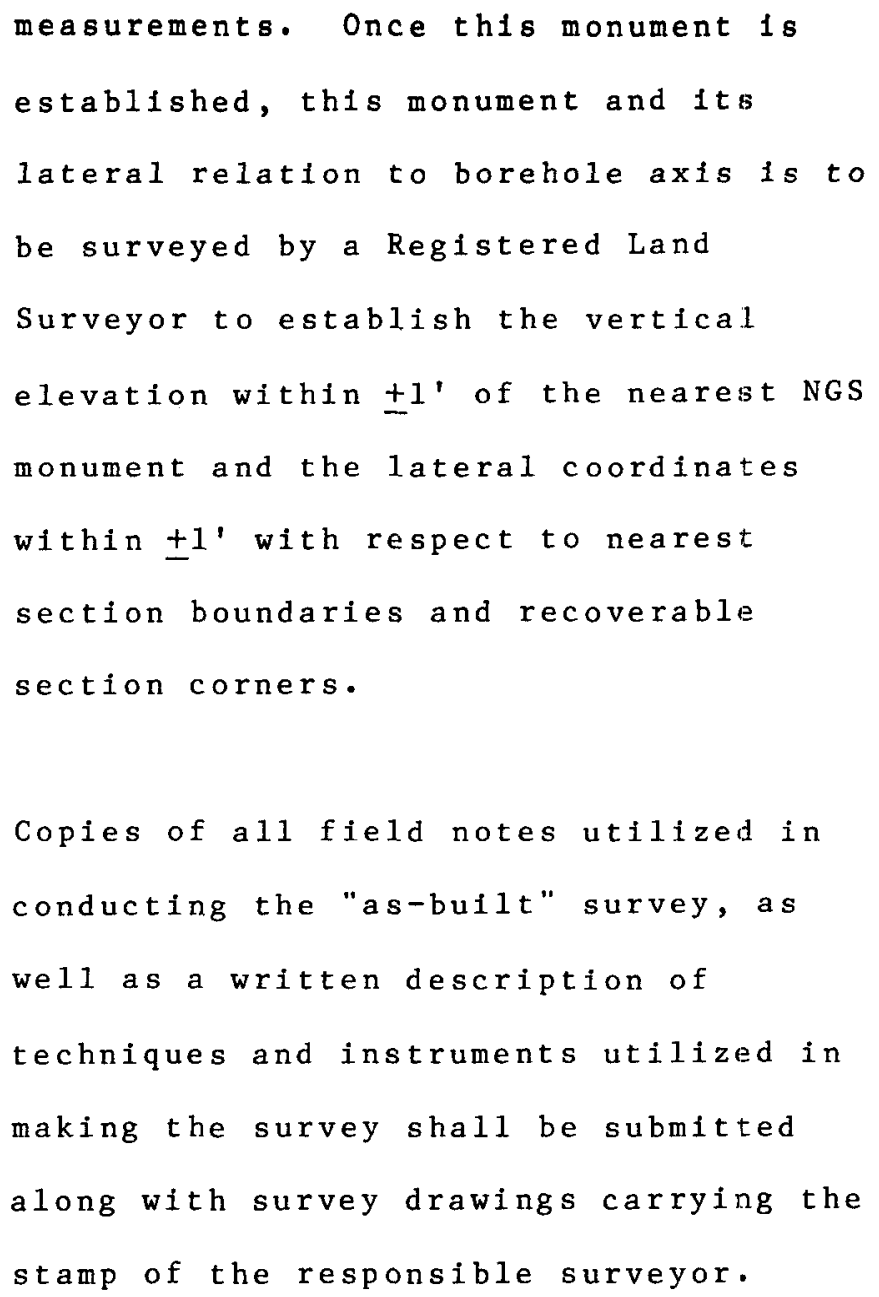

\subsubsection{Depth Measurements}

The nature of the drilling of exploratory we11 DOE-2 requires unusual accuracy in determining the depth of the core intervals and the depths for hydrologic testing. The depths shall be referenced to the concrete monument at ground level and the measurement procedures should be developed with a known accuracy and following standard API (American Petroleum Institute) procedures. 


\subsection{Coring Operations Procedure of Sandia National}

Laboratories - WIPP Site Investigations

\subsubsection{Introduction}

This procedure is prepared by the Field Engineering Division 7133 for use in Sandia National Laboratories' WIPP Program. The objective is to establish the methods and techniques to be used in coring operations in order to obtain reliable samples in a uniform manner.

\subsubsection{Scope of Work}

This coring operation is to be done as a part of exploratory drilling of Phase I Rustler Hydrology. Coring operation will consist of taking approximately $900^{\prime}$ of $2.4^{\prime \prime}$ diameter core to a TD of approximately 940'. Core is to be removed from the core barrel, logged, measured, cleaned, marked, photographed and packaged, transported and stored according to the procedures presented in this document. 
Sandia National Laboratories is conducting this field work under technical direction from Earth Science Division 6331. The Sandia Field Engineering Division 7133 will manage the field operations.

Fenix \& Scisson will prepare and administer a drilling program from criteria provided by Sandia that includes the taking of core" The drilling contractor, the coring contractor and the roustabout contractor are under contract to F\&S. USGS will provide the duty geologist for logging and identifying the core and supervision of core handling to the filed.

Sandia National Laboratories will provide core photography and arrange for core storage.

\subsubsection{Operations}

3.2.4.1 Coring ( $F \& S$ and their contractors)

Coring with core bit and a nominal $10^{\prime}$ split core barrel is required. 
other equipment and material such as

drill-collars and stabilizers, drilling

fluid (air or mud) should be vilized

according to best judgment to match the

formation and produce optimum core recovery.

Select and use drilling weight, rotary speed

and circulation rates that will produce

optimum core recovery.

The duty geologist shall maintain a daily

record which shows date, tour and operating

personnel, sequence of core interval, depth

of core interval, drilling time of core

interval, drilling weight, rotary speed and

circulation rate, and type circulating fluid

using the Core Logging Record (sample

fol1ows).

\title{
3.2.4.2 Removal from Barre1 (F\&S and their contractors)
}

\begin{abstract}
Core should be removed from core barrel as gently as possible to cause rinimum alteration of the core. Light hammering or jarring is permissible when using a standard
\end{abstract}


DAIIY CORE LOGGING RECORD

Date

DUTY GEOLOGIST

LOG HEADINGS:

Corpany

Well Number

WIPP No.

Field.

County

State New Mexico

Location

Section

Township

Range

Peranen: Datur.

Drilling Neasured frod
Elevarions: K.B.

D.F.

G.L.

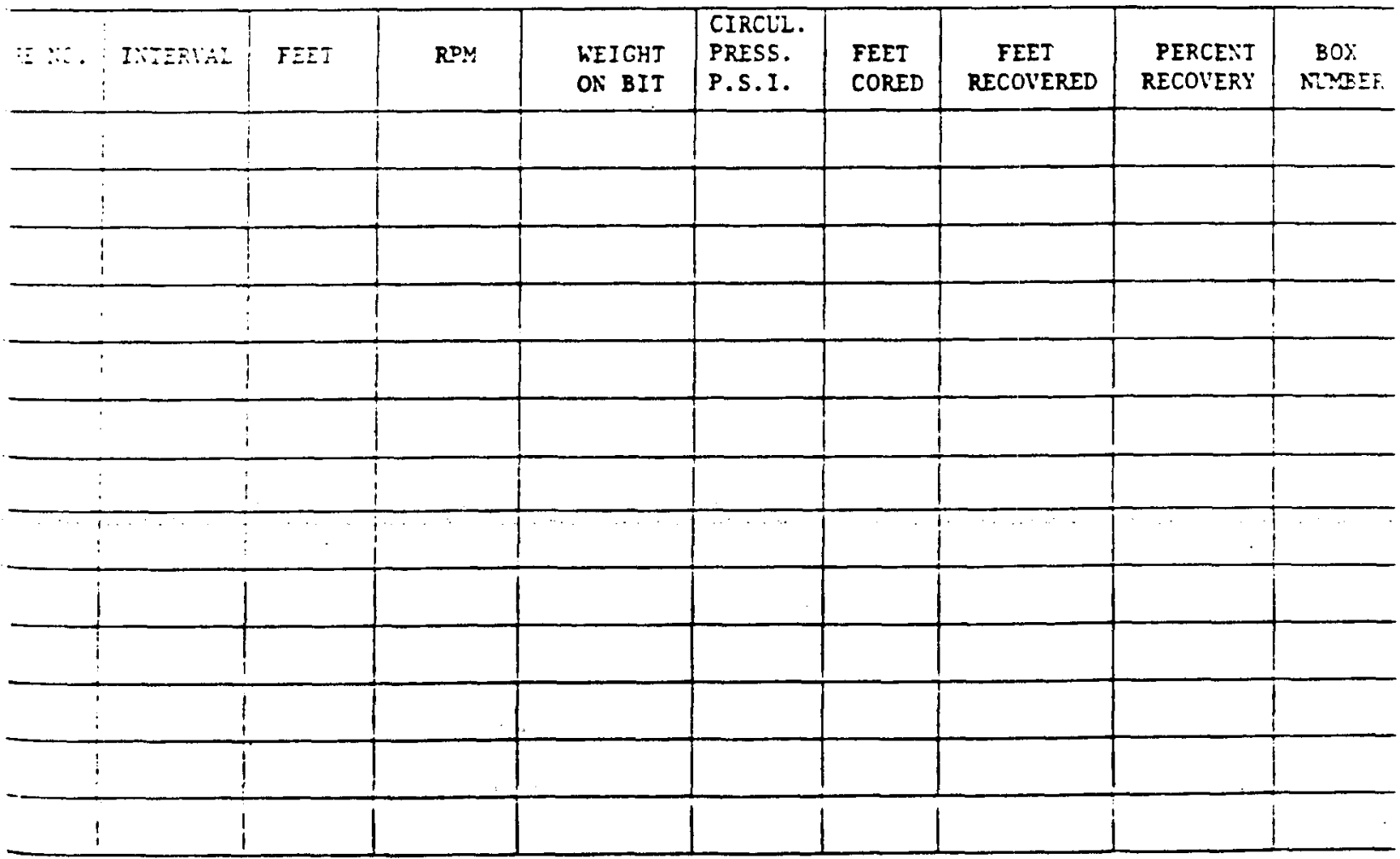


core barrel, but heavy hammering or pounding the barrel on its end is to be avoided. Removal by pumping is permissible upon approval of the Sandia representative supervising the field operations. A hand-operated, positive displacement pump shall be used as required.

As the core is removed, it will be placed in troughs in the order coming out of the barre1. Troughs will be marked with red at top end and black at bottom indicating down direction.

3.2.4.3 Logging (USGS Duty Geologist)

If core is suitable for marking, each major piece should be marked with a visible waterproof ink arrow pointing in the direction the hole is advanaing. Each core piece should be measured, identified and logged indexing each foot with footage expressed to the closest $1 / 10$ of a foot. Depths should be reconciled from measurements of the drill pipe to the nearest foot taken from ground-level unless otherwise specified. Any lost recovery should be logged at the bottom of each core interval unless known to be otherwise and so explained on the core $10 \mathrm{~g}$ 
3.2.4.4 Cleaning (F\&S and contractors)

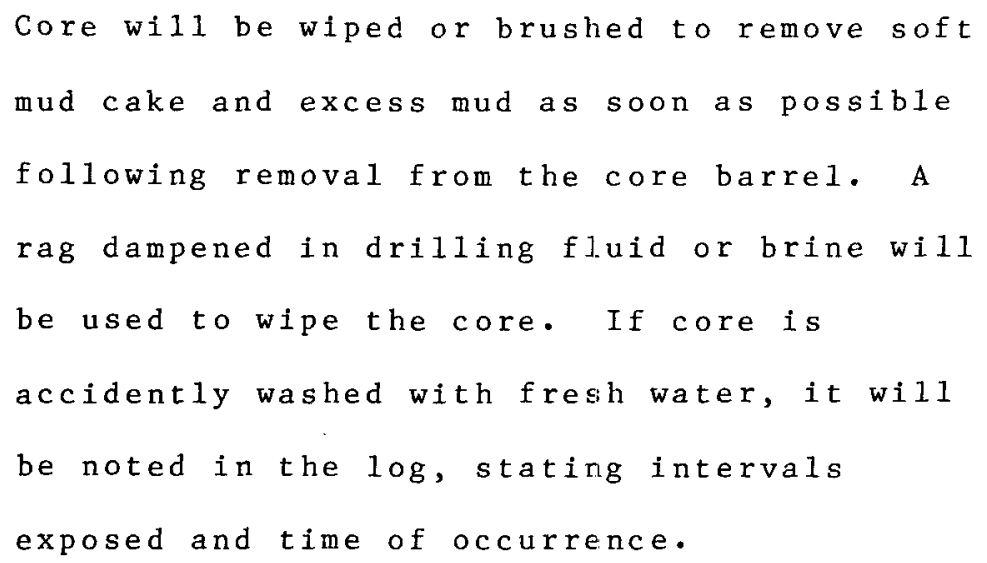




\title{
3.2.4.6 Preservation (Duty Geolog $18 t, F \& S$
} Contractor)

\author{
After core has been photographed, it \\ will be wiped dry and preserved for \\ transportation and storage in the \\ following method:
}

\author{
$3 \cdot 2 \cdot 4 \cdot 6.1$ Core pieces will be separated into \\ lengths appropriate to fit into \\ the core boxes. Pieces will be \\ placed into plastic sleeves of \\ appropriate length or wrapped and \\ taped with plastic sheet if \\ applicable. When using sleeves, \\ use a hot iron sealing tool, seal \\ both ends of plastic sleeve after \\ squeezing all air posstble from \\ sleeve. Place sleeved or wrapped \\ core into box and tape shut. When \\ core intervals are missing, \\ spacers marked with missing \\ footage figures may be inserted in \\ the box as necessary to preserve \\ sequence. Boxes should be labeled \\ in sequence with name of agency, \\ well number, date, core number and \\ depth of core pieces in the box.
}


3.2.4.7 Core Photos (Final Prints)

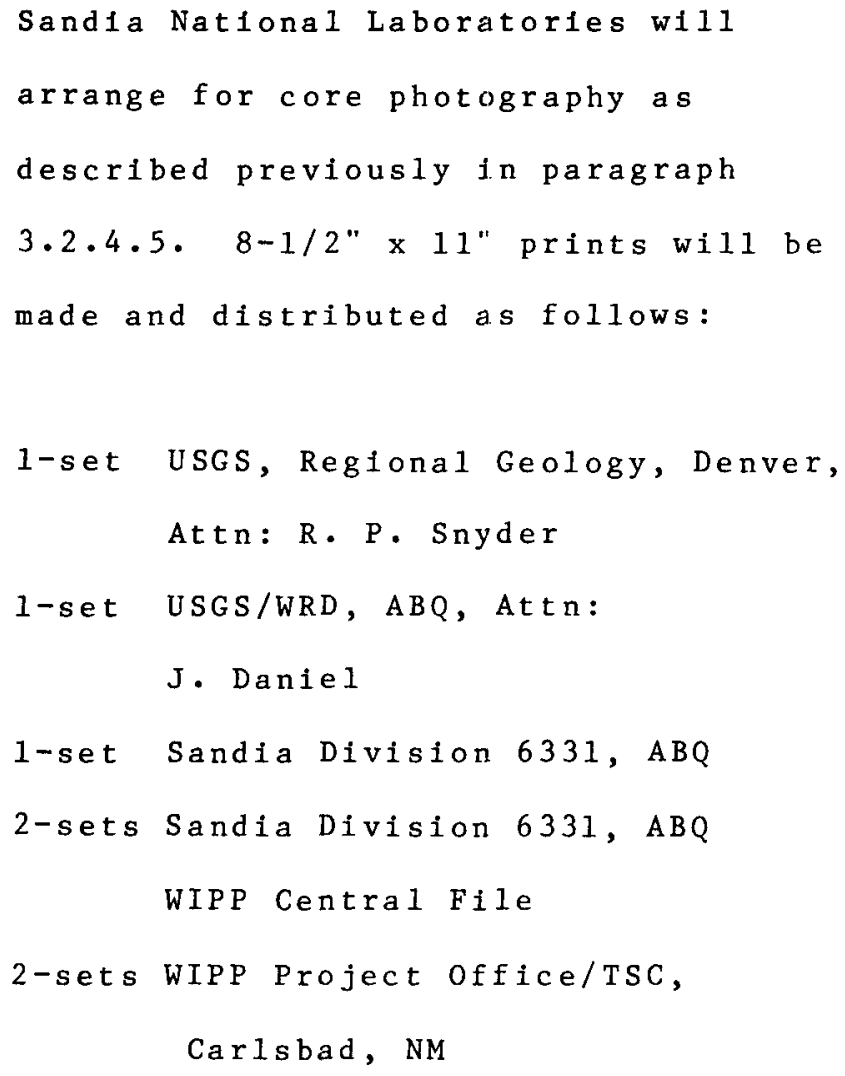

This procedure is prepared by the Field Engineering Division 7133 for use in Sandia National Laboratories WIPP Program, in particular to Phase I testing of DOE-2. The objective is to establish methods and techniques to be 
used in hydrologic testing in order to obtain reliable data ir a uniform manner.

3.3.2 Scope of Work

The hydrologic testing operation is to be conducted to obtain hydraulic properties of the nine selected intervals in the exploratory well. The prime objectives of the testing program are to obtain data necassary to evaluate and measure certain hydraulic parameters. These are:

- hydraulic conductivity

- transmissivity

- storativity

- hydraulic potential or head

It is understood that because of the very low anticipated permeabilities and unknown hole conditions, al1 these parameters may not be obtained from each individual zone. 
The hydrologic tests will all be similar to a conventional drill stem test but may include pressure pulse, slug-withdrawal or slug-injection tests if core or geophysical logs show they may be more appropriate. Volume displacement or submersible pumping tests will be performed in zones where water inflow exceeds $0.5 \mathrm{gpm}$ and hole conditions are acceptable.

Consideration will be given for pumping tests to be performed after the hole is cased. Each test is anticipated to take a minimum of 12 hours to as much as 120 hours. The duration of each test will depend on the quality and amount of data required to achieve test objectives and overcome unknown downole test conditions. 
Sandia Laboratories is conducting the field work under the technical direction of Earth Sciences Division 6331. The Sandia Field Engineering Division 7133 will manage field operations. Fenix \& Scisson will prepare and administer a drilling program from criteria provided by Sandia that includes hydrologic testing, core retrieval, and final hole completion.

$3 \cdot 3 \cdot 4$ Operations

3.3.4.1 The field operations plan prepared for Phase I - DOE-2 wi11 identify the selected intervals to be tested.

3.2.4.2 When the selected test interval has been cored and identified, run gamma $\log$ and caliper to identify potential packer seats. 
3.3.4.3 Run the dril1 stem test hardware using a single inflatable packer sized for 7-7/8" drill hole and attached to $2-3 / 8 "$ tubing. The assembly will include a standing valve in the tubing string above the packer. The packer assembly will include pressure transducer probes capable of measuring pressures above and within the test interva1. The pressure data will be transmitted to a surface data acquisition system where it will be monitored and recorded. The data will be used to adjust flow schedules if necessary.

3.3 .4 .4 set up and operate the test assembly with the capability of running a $12-$ to 72-hour DST test. Prior to opening the test interval to the tubing, the water in the tubing shall be swabbed out. The shortest time schedule for flow and shut-in periods is as follows: 


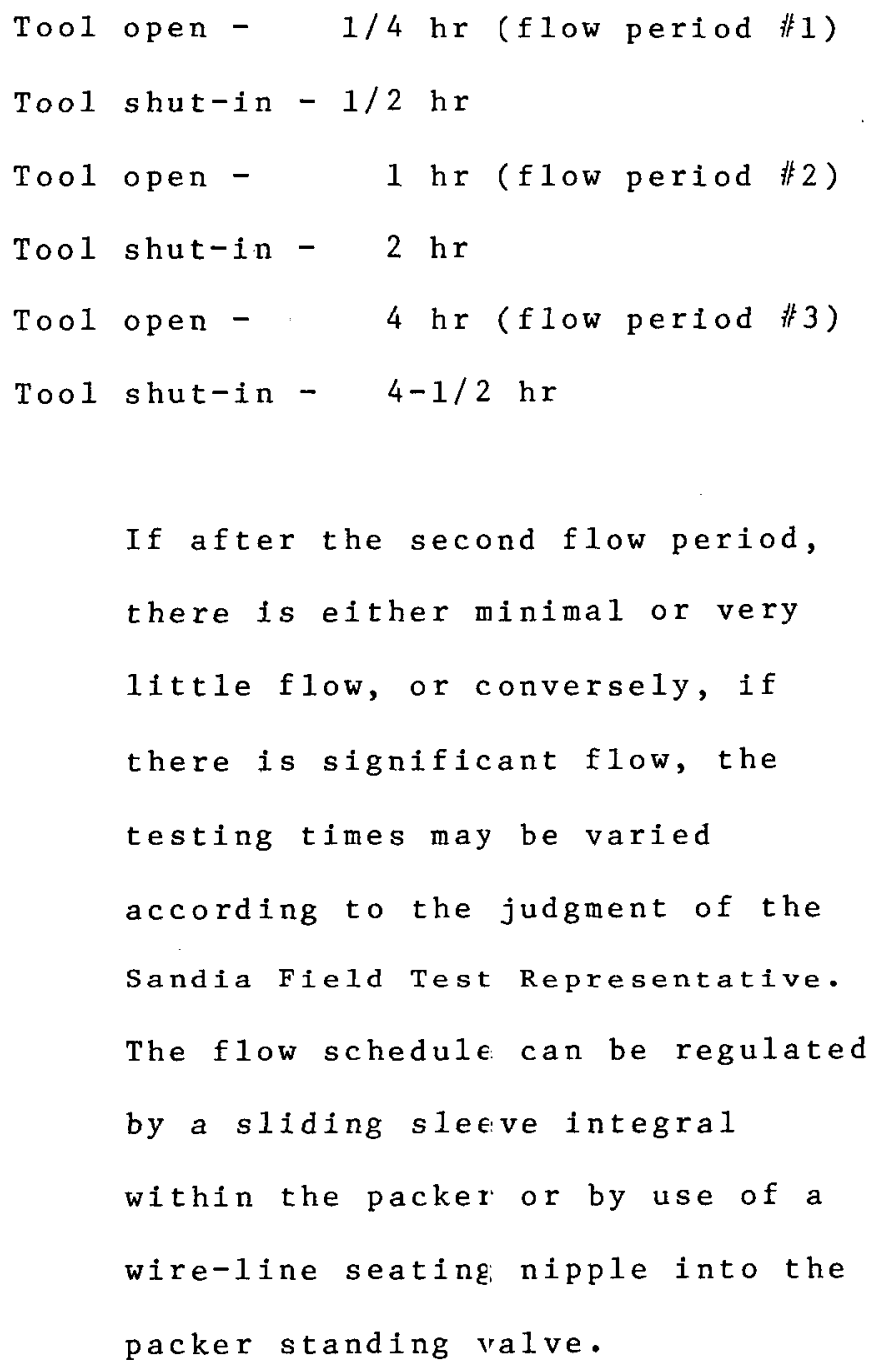




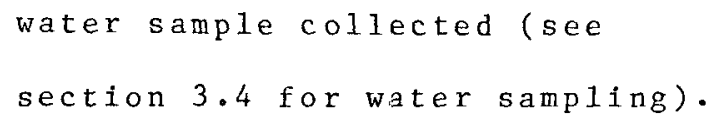

3.3 .4 .6 If the results of the DST are unsatisfactory; i.e., when reasonable estimates of conductivity and head cannot be achieved, then the downhole test assembly will be reconfigured to conduct a pressure pulse test (very low conductivity), slug-tests (moderate to high conductivities), or pump tests (high conductivity).

Pressure Pulse Test - Conductivity is calculated from the pressure time history of an applied pressure-pulse. After the zone is isolated, the tubing shall be filled with formation or density matched fluid and if needed, pressure shall be applied at the surface. After an appropriate pressure is applied on the system, a control valve shall be closed (pulsed) creating an applied pressure-pulse on the test 
interva1. Pressure decay with

time shall be recolded both at the surface and downhole. Duration of these tests will vary depending on test interval permabilities.

Slug-injection - Upon completion of the DST and water sampling, the test interval shall be shut-in and the formation stabilized. The tubing shall be filled with formation or densjty-matched water to a predetermined level above the recorded static pressure. The shut-in tool shall be opened and the resultant pressure decline monitored.

Slug-withdrawal - Upon completion of the DST, the test interval shall be shut-in and the tubing shall be evacuated by swabbing. After pressure ir the test interval has somethat stabilized, the shut-in tool will be opened and the pressure rise with time monitored. 
in particular, to Phase I testing of

DOE-2. The objective is to provide

guidelines to estimate water chemistry

stability before sampling and to provide the method and technique to take a

representative water sample.

3.4.2 Scope of Work

The water sampling program is designed to obtain the best representative water sample from test intervals which contain fluid in the Dewey Lake and Rustler Formations in exploratory wel1 DOE-2. It is anticipated that only the Magenta and Culebra Dolomites and the Rustler-salado contact can produce enough fluid, within a reasonable time period, for sampling. The water samples will be analyzed for major chemical constituents, fluid density, and possibly certain isotopes. It is understood that in field sampling of water under open-hole conditions and under methods described in Section 3, there exists the potential for contamination. It is therefore anticipated that when drilling mud or brine is used, that drilling fluid will need to be "spiked" 
with a tracer to help determine the concentration of contamination in the

formation waters.

\subsubsection{Organization}

Sandia Laboratories is conducting the field work under the technical direction of Field Sciences Division 6331. The Sandia Field Engineering Division 7133 will manage field operations. Fenix \& Scisson will prepare and administer a drilling program from criteria provided by Sandia that includes water sampling.

$3.4 \cdot 4$

Operations

3.4.4.1 The field operations plan prepared for Phase I, DOE-2, will identify the selected intervals to be tested.

3.4.4.2 After the completion of DST and before slug withdrawal and pumping tests and before any slug-injection or pressure pulse tests, water samples will be collected if the test interval 


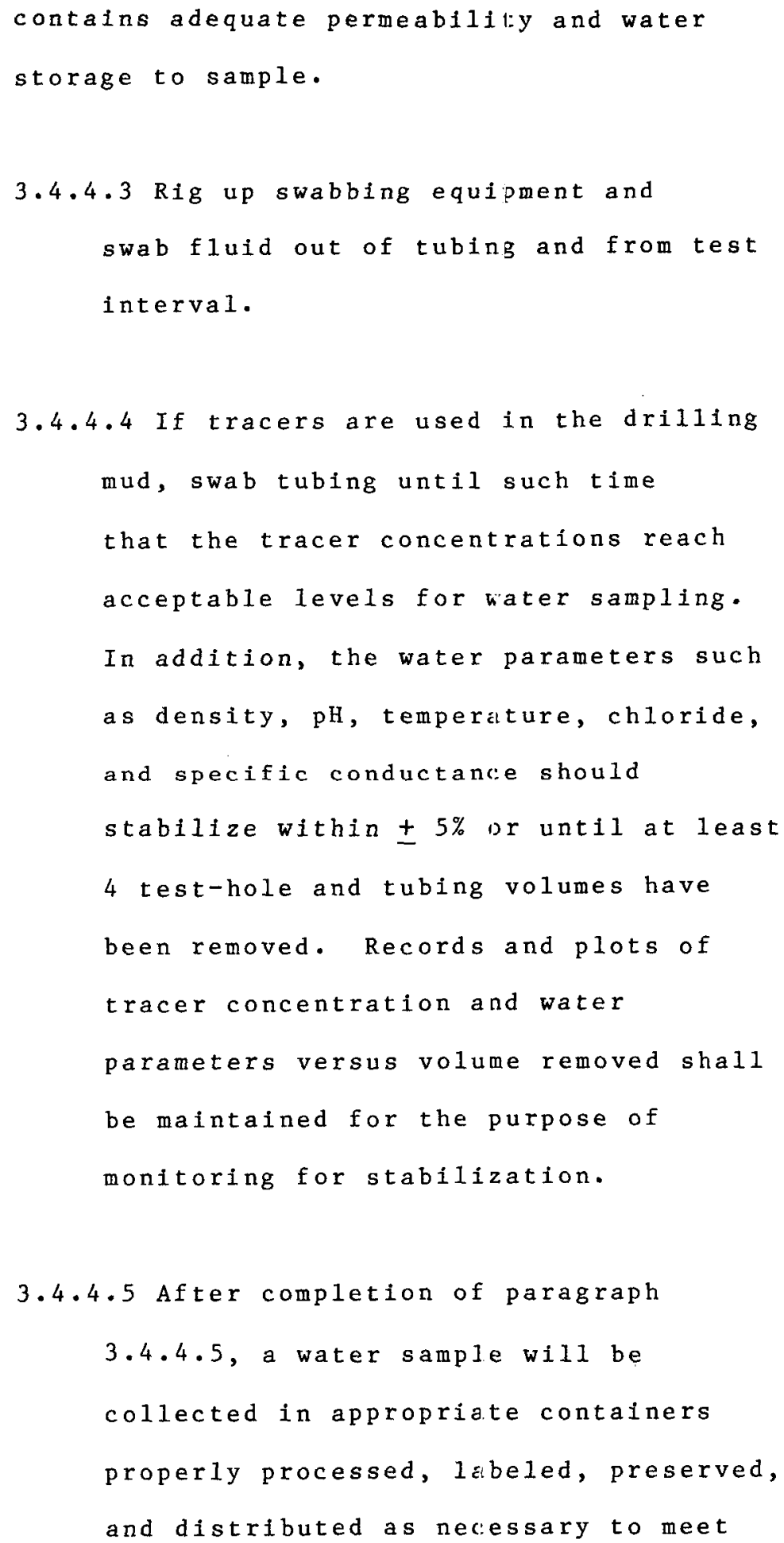




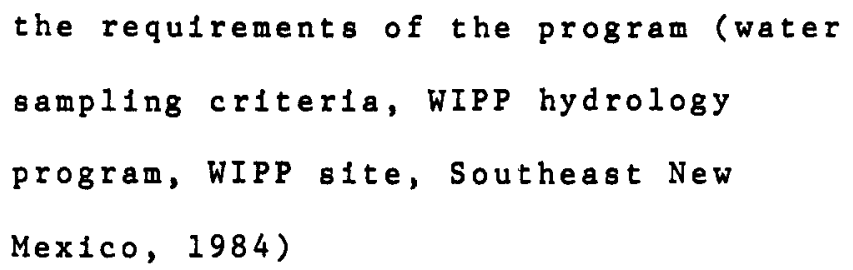




\subsection{Borehole Geophysical Logging Operations Procedure of} Sandia National Laboratories - WIPP Site Investigation

\subsubsection{Introduction}

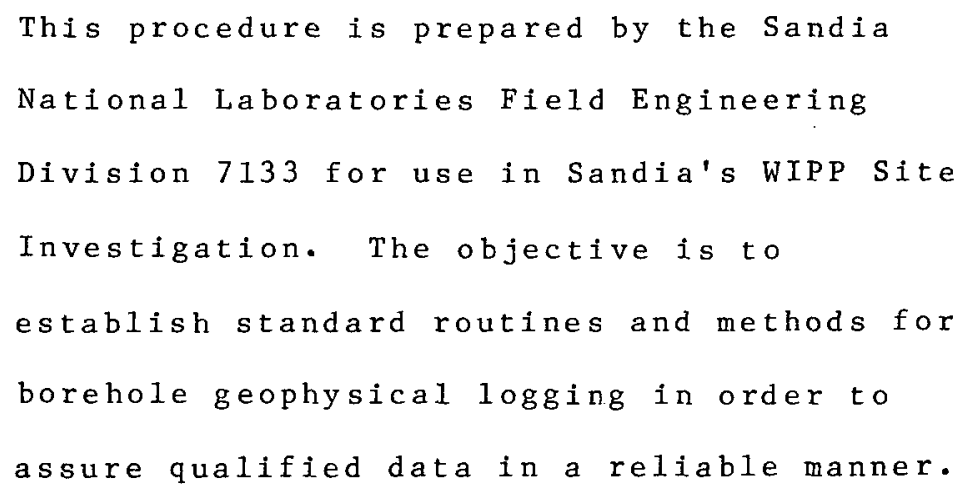

\subsubsection{Scope of Work}

Geophysical logging of bortholes in the WIPP Site Investigations may include a wide variety of individual loggjng services. 


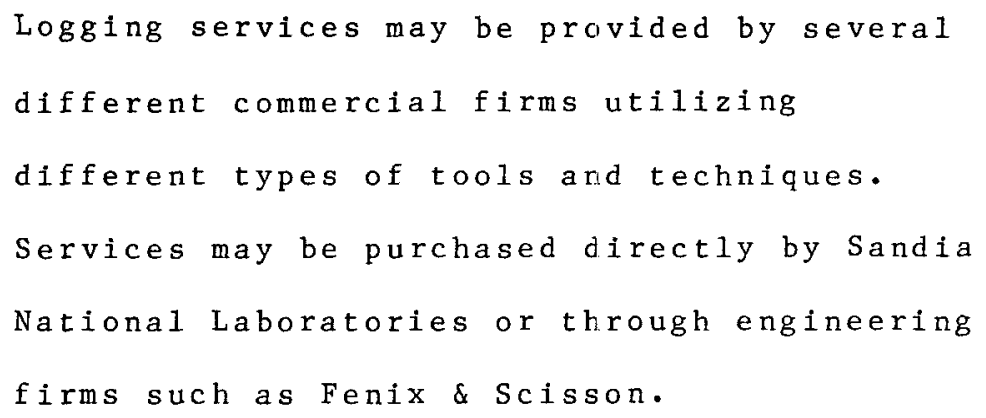

The scope of logging services may change for specific intervals depending on the test horizon conditions. The logging services may be changed at the discretion of the field test director.

\subsubsection{Organization}

The Sandia laboratories is conducting this field work with technical direction from Earth Sciences Division 6331. Field operations are managed by Sandia Field Engineering Division 7133 .

Sandia Labs has arranged with DOE/NVOO for their contractor, F\&S, to prepare and administer a drilling program and associated subcontracts from criteria provided by Sandia which include borehole logging on DOE -2 . 


\section{$3.5 .4 \quad$ Operations}

3.5.4.1 The logging services will consist of all or part of the following:

Natural Gamma Ray Log - Measiures the natural radiation from the wall rock formations, recorded in API Gamma Ray Units versus depth of the hole.

4-Arm Caliper Log - Measures variations in the borehole diameter and is recorded in inches for diameter versus depth; used to select packer seats as well as estimating hole volumes.

Density Log - Measures formation density and is compensated for borehole effects using a gamma source and records bulk density in grams/cc and formation porosity in percent versus depth.

Neutron Log - Measures densjty of hydrogen atoms using a neutron source and is compensated for borehole effects, usually referenced to limestone standard; used for porosity and hydrogen ion concentrations. Recorded as porosity percent versus depth. 
Borehole Compensated Sonic Velocity -

Measures acoustic properties of borehole

wall rock compensated for borehole diameter

changes. Recording is of interval transit

time in microseconds/foot versus depth; used

to measure porosities and detect fractures.

Acoustic Televiewer - Measures acoustic properties of borehole wall and converts attenuation of sonic signal to "picture" of borehole wal1; used to identify and measure fractures and their orientation on borehole wa $11 \mathrm{~s}$.

Dual Laterolog - Measures laterally focused resistivity at two depths of penetration from the borehole wall. Records in ohmmeters versus depth; used to obtain true rock resistivities and can be used as a qualitative measure of permeability

Temperature Log - Measures temperature of borehole fluid and records in degrees fahrenheit versus depth; used to detect possible abnormalities of temperature that may indicate fluid or gas entry into borehole. 
3.5.4.2 Prior to selecting a logging service, a Sandia representative will meet with Fenix \& Scisson and prepare the form "Instructions to Logging Company" for the specific logs to be run (sample instructions form follows).

3.5.4.3 Prior to logging, a qua]ified representative of Sandia Labs will meet with the logging service company's Jogging engineer. He will present the "Instructions..." and discuss :

a) the entire logging program and special requirements,

b) hole conditions that may cause problems, and

c) zones of special interest.

3.5.4.4 During the pre-log conference, the Sandia representative will discuss and request the following to be done:

The equipment will be "warmed up" for the adequate amount of time and tools will be checked to see that they are calibrated as appropriate and functioning properly upon arrival at the location. 
FENIX E SCISSON, INC.

Page of

INSTR!CTIONS TO LOECDNO COPATS

Date

Logging Crofiny

Logglug Enginaer

HLEesed $\mathrm{B}$ ?

Log Aradtings:

Congan Fen!z \& Sclescon Inc.

Well Kumber WIFP No.

Field Cumity

State Nov Mato

Lecation

Section Tumsitip Fane

Peresnes Uxture Elevat1en: R-K.

Log Meanued Frov

D. TE.

Drl11 Iig Viedeured Fxca

C.1.

\begin{tabular}{|c|c|c|c|c|c|c|c|}
\hline Hole Statue: & ST7E & Ffos & IO & & 오조 & FEOM & TO \\
\hline CacIngt & & & & Borehole & & & \\
\hline
\end{tabular}

Type Fuld is Forebule Fluta Lerel

Density 18

$\nabla 1 \sec 10$ Fiñ Lass.

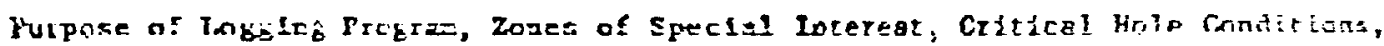
Hcustis. Etr. 
Fealx \& Selsoca, Inc.

$\log$ to.

(a) Vertical Depth seales 2-1nches/100-feet and 5-10ches/10J-feet

(b) Horizontal Logetog Scalea

(c) Logging Speed Desired

(d) Interval to he inged

(e) Zunes of special Iptatest

(1) Specisl Inetruction

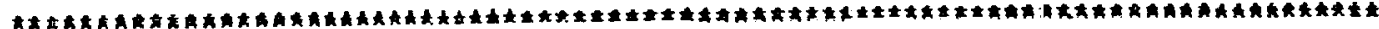

$\log \mathrm{Ki}$.

(a) Vertical Depth Scalce 2-tnches/100-1eel and S-Inches/100-teet

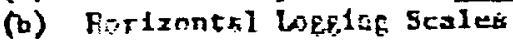

(c) Logeing Spred thesired

(d) Interval to be Logged

(p) Tonee of Sperisil Interese

(f) $\bar{s}_{F=1}=1=1$ In\&eruct lov

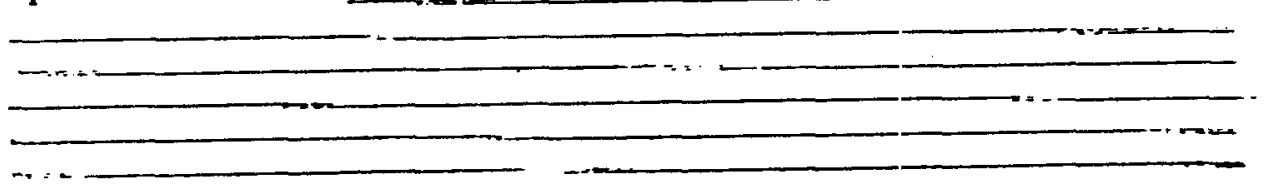

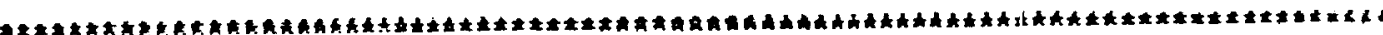

Log to.

(a) Vertical Leptb Scales 2-1nches/100-leer. ad S-inchi:s/105-feet

(b) Borizuatal Logelng Seglea

(c) Lugiteg Epeco Defitea

(d) Intervil co be LogEed

(e) Zones of Speclai Intereat

(f) Sfecial Inatruction 


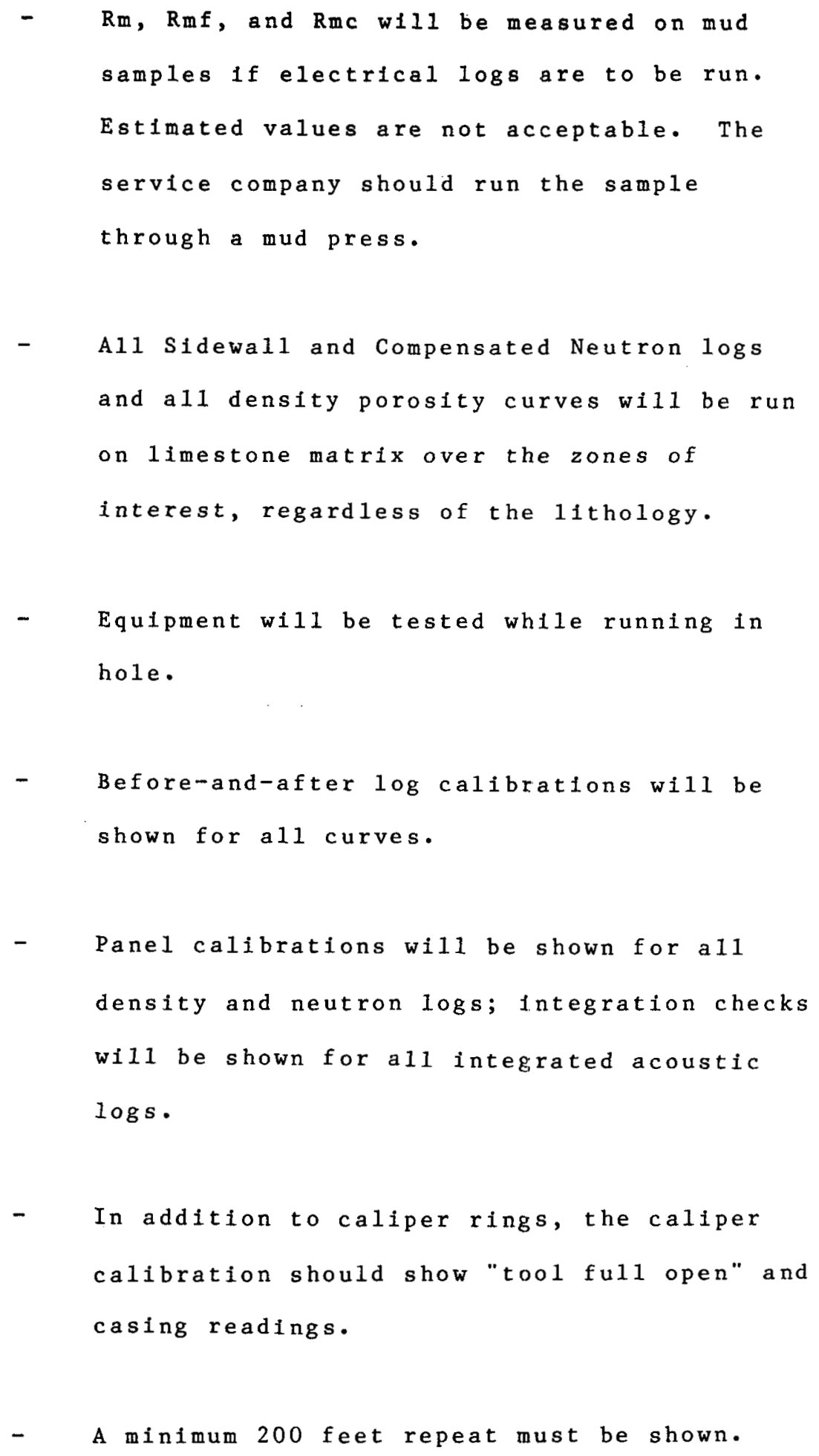


- Overlap previous runs by at least 200 feet.

- All headings information will be completely filled out.

- In addition, all open-hole commercial logs shall be digitized and recorded on magnetic tape.

3.5.4.5 The Sandia logging representative wil1 be present and observe the logging operation to the extent necessary to assure objectives have been met. He should complete a "Log Quality Report" (sample follows) following the operation and, along with a copy of "Instructions to Logging Company", forward to Sandia Field Engineering Division 7133 .

\title{
3.5.5 Records
}

\subsubsection{1 "Instruction to Logging Company"}

\author{
F\&S should prepare irstsructions \\ following a conference with Sandia \\ representative, and provide ten copies \\ to Sandia Field Engineering Division \\ 7133.
}


CHECK ALL BOXES - ACCEPTABLE YES OR UNACCEPTABLE NO

Sections not opplieable to oparticular service. Leove Blonk.

\section{A. HEADINC}

1. Corroet Heading Used

2. Heoding Doto Property Completed

3. Equipment Used Section Completed

4. Equipment Dato Section Completed

5. Scale Changes Noted on Heoding

6. Are oll abnormal conditions explained in the remarks secrion

- calibrations and scales

1. Seoles Correct for Areo

2. Scoles Lobelled

3. Scole Changes Labelled

4. Zeroes Recorded

5. Belore Log Calibrations

6. After Log Colibiotions

7. Repeot Section Recorded

b. Repeat Section Accepiable

c. VALIDITY OF LOC

1. Curves Functioning Correctly

2. Do. Log values fall within reosonable limits

3. Curves on Depth

4. Logeing Speed indecated

3. Loeging Speed Cotrect

D. APPEARANCE

1. Printing or Tyoing Noot

2. Printing er Typing Accutete

2. Grid and Pon Troces

4. Splices sureiphe and Cloan

5. Film Correctly Processed

6. Coneral Prini Quelity
REMARKS: Code Remorks with the proper Section Number For Example: Remarks concerning belore log colibrations would be coded B.5.
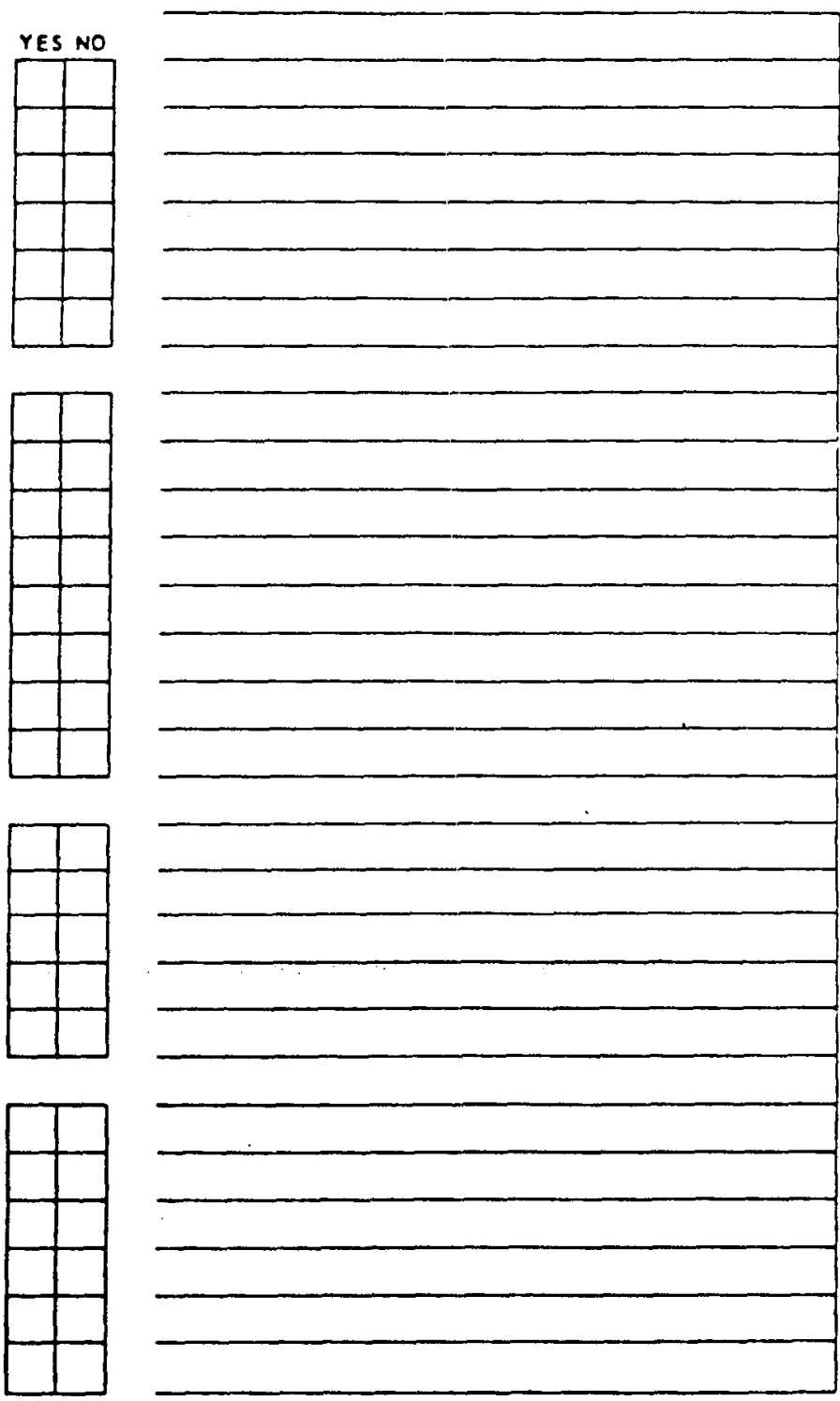


\subsubsection{Distribution should be made as fo110ws :}

1 Logging Company

1 Sandia Representative - observing $10 g$ operations

$1 \quad F \& S$

1 Sandia Carlsbad Hole File

2 Sandia WIPP Central Files (SCWF)

1 Sandia Division 7133, ABQ

1 Sandia Division 6331, $A B Q$

1 USGS, Regional Geology, Denver Attn: R. P. Snyder

1 USGS/WRD, ABQ, Attn: J. Daniel

\subsubsection{Log Quality Report}

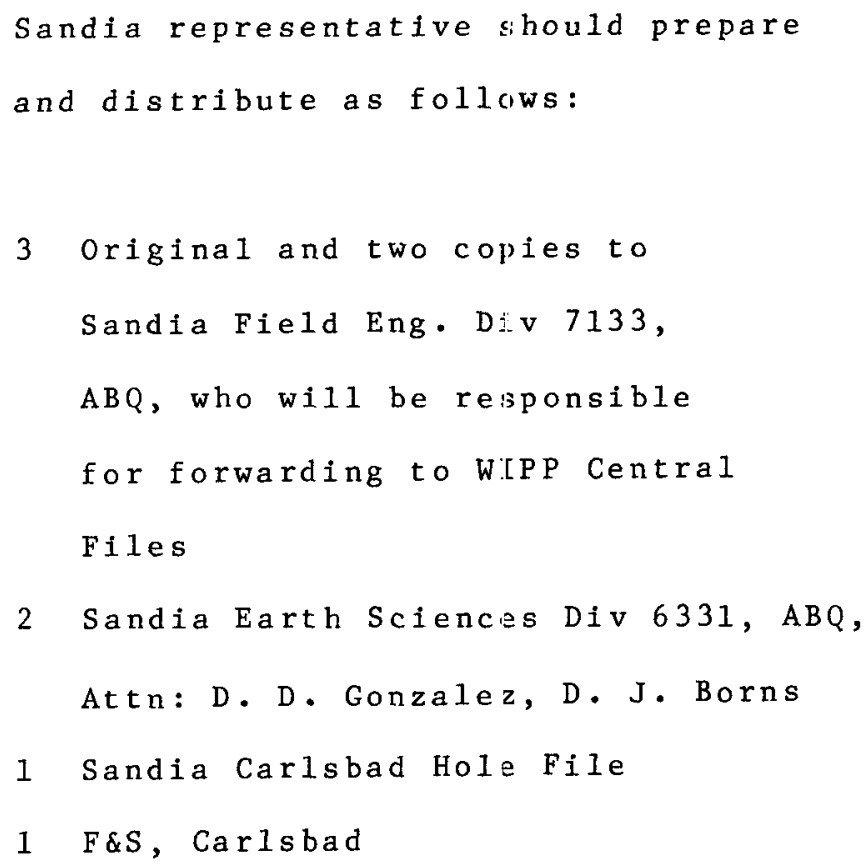


3.5.5.4 Geophysical Logs (Fleld Prints)

F\&S Carlsbad should obtain 10 copies of

$\log$ field prints and distribute as

follows:

1 Sandia Carlsbad Hole File

1 USGS, Regional Geology, Denver,

Attn: R. P. Snyder

1 USGS/WRD, ABQ, Attn: J. Danie1

2 Sandia Div 6331, ABQ, Attn:

D. J. Borns, D. D. Gonzalez

1 Sandia Div 7133, ABQ, Attn:

J. W. Mercer

3 F\&S, Carlsbad ( 3 copies)

3.5.5.5 Geophysical Logs (Final Prints)

F\&S should order 15 final copies of

logs and two copies of library magnetic

tapes of the $\log s$ and distribute as

follows : 


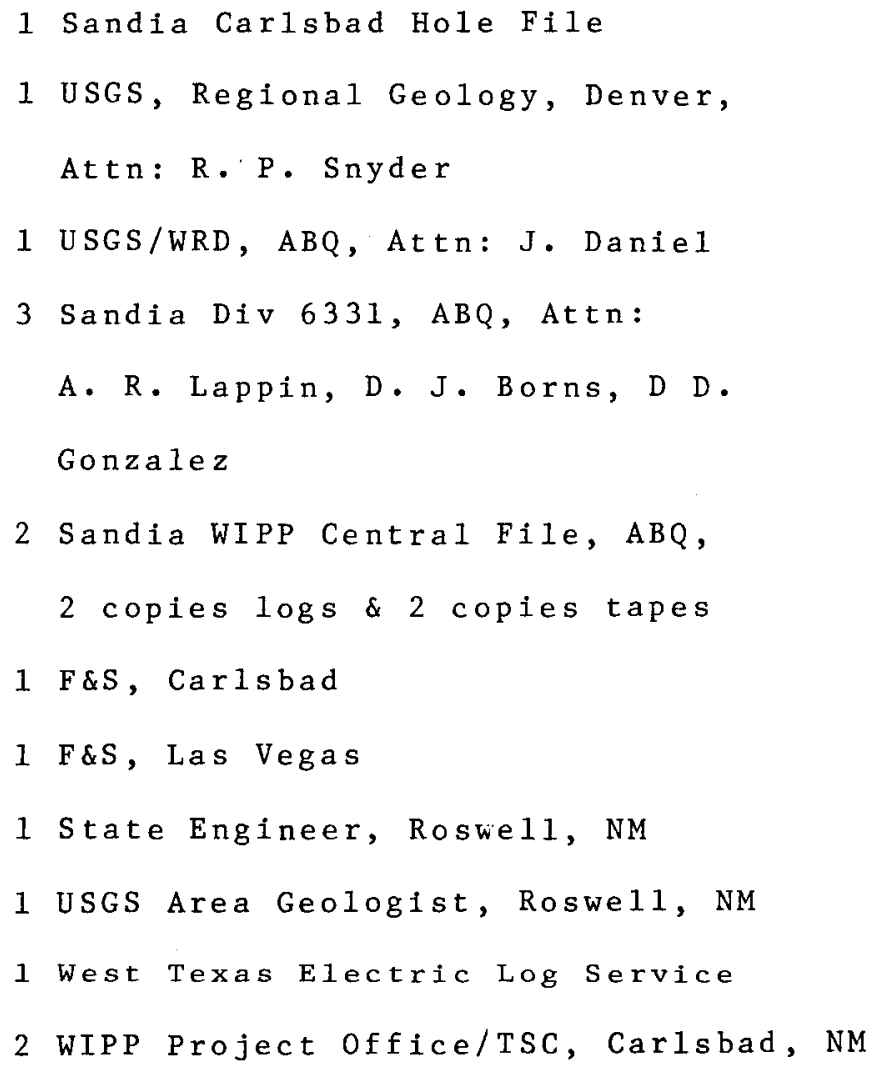




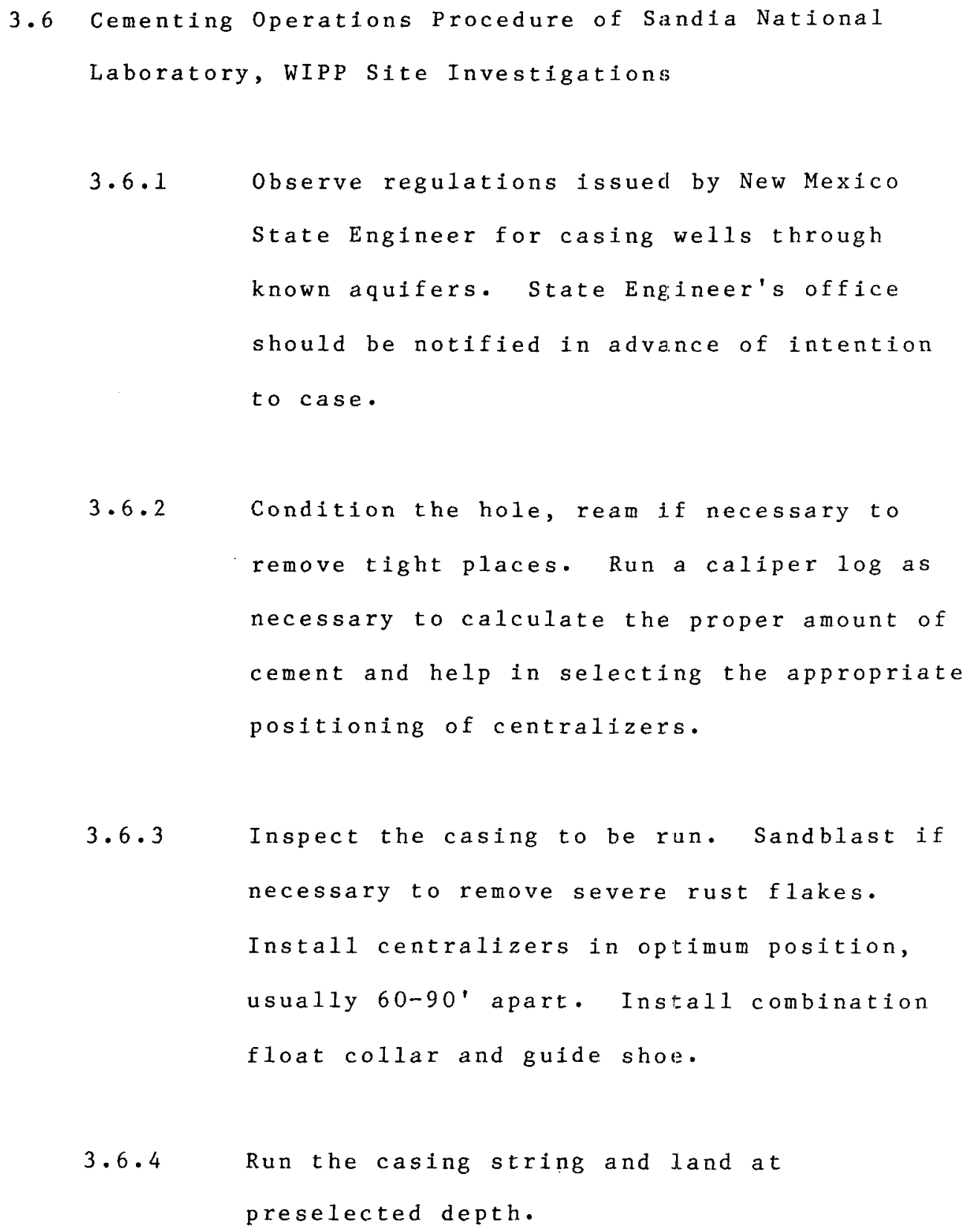


3.6.5 Select a 70-30 poz mix cement slurry mixed with salt to saturation and $2 \%$ bentonite ge1. Weight the slurry as necessary to match density of drilling fluids in the hole.

$3 \cdot 6 \cdot 6$

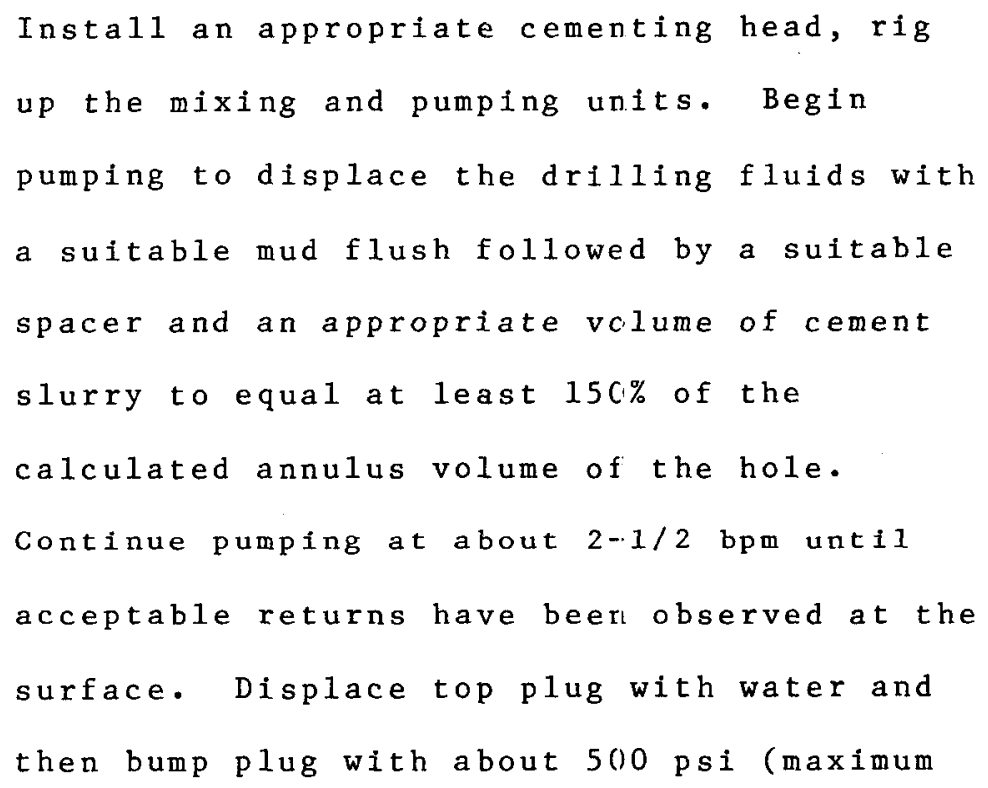


of $1000 \mathrm{ps}$ ) over displacing pressure.

Check float and if it is holding, close in cementing head and W.O.C. for 48 hours.

Maintain tension in the casing string while cement is setting.

3.6.7 Run a casing pressure test before driliing out the plug. Apply a pressure of about 600 psi and hold for 30 minutes and observe. If

a pressure drop of 100 psi or more is observed, take corrective measures and repeat the test. If pressure drop is less, cementing job is considered complete. Pick up the appropiate size bit and proceed to drill out the plug and continue with the program as directed. 


\subsection{REPORTS}

4.1 Daily Report

F\&S, Carlsbad office, will provide to Sandia,

Carlsbad, a copy of the daily report. Sandia,

Carlsbad, will telefax the daily report on weekdays to

Division 6331 and Division 7133 in Albuquerque. A copy of the daily report will be kept on file in the Sandia Carlsbad office.

4.2 Daily Time Log

A Daily Time Log will be maintained by the F\&S drilling specialist. Two copies will be provided to the Sandia, Carlsbad office. Sandia, Carlsbad office will maintain a file of the $10 \mathrm{~g}$.

\subsection{Hole History}

A Hole History of the drilling activities will be prepared by F\&S from their daily time logs and other pertinent records. A reproducible copy of this history is to be sent to R. D. Statler, Division 7133, $A B Q$, following completion of field activities for subsequent distribution. 


\subsection{Miscellaneous Records}

A variety of records are kept by F\&S that will be useful in historical preparation. These are to be kept on file in Carlsbad while the program is active and on completion, a copy forwarded to R. D. Statler, Division 7133, for placement in the WIPP central file. They include:

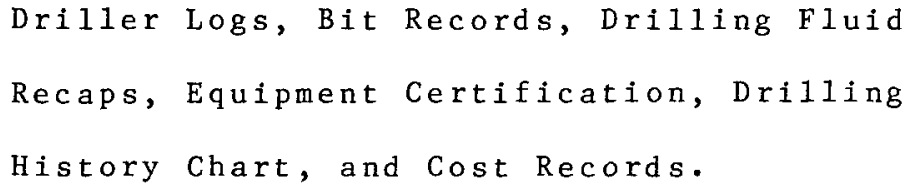




\section{APPENDIX B}

Field Operations Plan of Sandia National Laboratories for WIPP Site Investigations of Drillhole DOE-2, Phases II and III 
Field Operations Plan of Sand ia National Laboratories

WIPP Site Investigations

DOE- 2 Phase II \& III
$2 / 20 / 85$

Exploratory Hole: DOE-2 Phase II \& III

Purpose: To define the work necessary for investigating a

depression in distinct stratigraphic markers, to

gather additional stratigraphic information.

Prepared by:

Reviewed by:

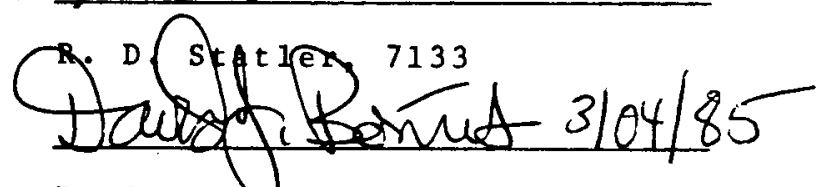

D. J. Boris, 6331

Richard W. Beasheim 2/22/85

R. L. Beauhe1m, 6331

Approved by: 4 2/20/85

A. R. Lapin, 6331

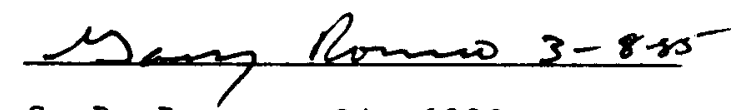

G. R. Romero, QA, 6330

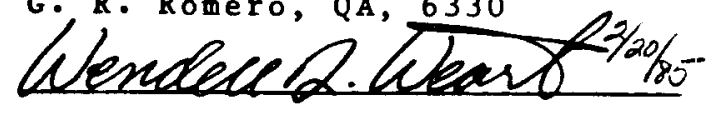

W. D. Heart, 6330

WIPP Project Manager

139 
INTRODUCT ION

1. FIELD OPERATIONS CRITERIA

2. FIELD OPERATIONS PLAN

2.1 Organization and Responsibilities

2.2 Supporting Data

2.3 Drilling Program

3. FIELD OPERATING PROCEDURES FOR QUALITY CONTROL REQUIREMENTS

3.1 Surface Location and Depth Measurements

3.2 Coring

3.3 Testing

3.4 Geophysical Logging

3.5 Cementing

3.6 Water Sampling

4. REPORTS

4.I Daily Report

4.2 Daily Time Log

4.3 Hole History

4.4 Miscellaneous Records

Page 1 


\section{INTRODUCTION}

This document contalns plans, procedures, and specifications for the Phase II drilling and testing of an exploratory drill hole, DOE-2. The recommended location for DOE-2 $1 \mathrm{~s} 130^{\prime} \mathrm{FEL}$, $700^{\circ}$ FSL, Section 8, T22S, R31E. The hole is located $700^{\prime}$ north of the WIPP site northern boundary.

The Phase II program for the exploratory hole will involve taking continuous core and some oriented core from a depth of 981 feet into the Bell Canyon Formation through the Ramsey, Ford, OIds, and into the Hays member to a TD of approximately 4040 feet below surface. Formation tests, water sampling, and geophysical logging will be conducted. The core will be logged, photographed, and packaged at the well site, then retained in the WIPP core library. There is an attached addendum covering hydrologic testing in the Salado Formation prior to penetration by drilling of the Castile formation.

\section{FIELD OPERATIONS CRITERIA}

This operations plan is based on a Scope of Work written by $D$. J. Borns, 6331 , to A. R. Lappin, 6331, on May 8, 1984. It is reproduced in its entirety herein. 


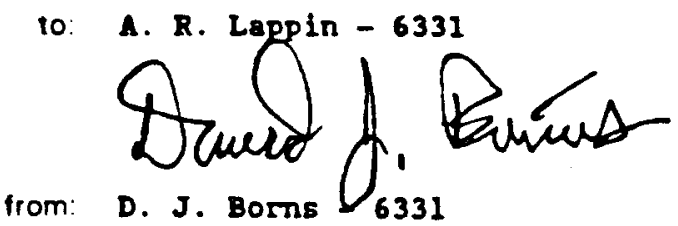

subject: Statement of Work for DOE 2

\section{References}

Borns, J.D., L.J. Barrows, and D.W. Powers, 1983, Deformation of Evaporites Near the Waste Isolation Pilot Plant (WIPP) site. With a section by R.P. Snyder, USGS, SAND82-1069 (Albuquerque, NM: Sandia Uational Laboratories. February 1983).

Davies, P.B., 1983 (June 13), letter to L. Chaturvedi regarding the FC-92 depression.

Gonzalez, D.D., 1983 (June 14), letter to A.R. Lappin regarding Bell Canyon Hydro Test in the WIPP Vicinity.

Powers, D.W., S.J. Lambert, S.-E. Shaffer, L.R. Hill and W.D. Weart, ed., 1978,- Geological Characterization Report. Waste Isolation Pilot Plant (WIPP) Site, Southeastern New Mexico, SAND78-1596, Vol. I and II (Albuquerque, MM: Sandia National Laboratories, 1978).

\section{Introduction}

Herein, we state the objectives, siting requirements, justification and methods of study for a proposed drillhole. This document supplants two earlier draft statements of work, July and Septemier 1983. The purposes of this hole are to:

1. investigate a depression in distinct stratigraphic markers;

2. Gather additional information on the hydrology of the Rustler Formation, Salado Formation, and the Deilaware Mountain Group (DMG).

Hence, drilling will extend through the Castile. Also, since the proposed hole location is within the Disturbed zone (Borns|et al, 1983), there is a possibility that a brine reservoir will be encountered in the upper Castile anhydrites. There may be an opportunity for further testing of another brine reservoir in addition to ERDA 6 and WIPP 12 . 
Objectives

- Determine the origin of the M-139 depression as indicated by the WIPP 34 and FC-92 drillholes. Processes that may have produced this structure are irregular sedimentation, dissolution or gravity-driven tectonics, e.8., halokinesis and gravity sliding.

- Evaluate the M-139 depression and characterize, if present, the deformation and flow structures in the Salado.

- Perform hydro-tests in the Rustler and Bell Canyon aquifers and produce a "whole-hole" test in which the Rustler and Bell Canyon aquifers are interconnected.

\section{Siting Requirements}

The recommended location for DOE 2 is as follows: 130'FEL; 700'FSL; Sec.8, R3IET22S (see Figure 1). Only the $\mathbf{N}-\mathbf{S}$ coordinate may be varied $\pm 100^{\circ}$ to accomodate pad siting and safety considerations. Such a decision may be made in the field. This location is in the SW corrier of the intersection of the new North Access Road and the section boundary. All configurations of the 124 depression, Powers et al (1978), Snyder (in Borns et al, 1983) and Davies (1983), and FC-92 drillcore data are accommodated by this location (see Figure $2 \mathrm{~A}-2 \mathrm{~F}$ ).

Davies (1983) has suggested that the possible presence of faults within the lower Castile and upper DMG in MB 124 depression area should be considered in hole location (see Figure 2A). Such deep structures were originally inferred by Powers et al (1978) within the Bell Canyon sands, and were interpreted as being faults trending NW-SE. However, using higher resolution seismic lines, Barrows (in Borns et al, 1983) does not maintain this interpretation. Another set of faults, which trend NE-SW, in Anhydrite I are inferred from borehole data by Snyder (in Borns et al. 1983). The postulated trace of one crosses the 124 depression.

The trace of this "fault" and the Bell Canyon "fault" apparently intersect within the M-124 depression near FC-92. However, this intersection does not lone justify a specific hole location. The original structures within Bell Canyon sands disappear in the later and more detailed seismic interpretation. The postulated faults in Anhydrite I can only have approximated positions ( \pm 100 's of feet). Therefore, it would be impossible to locate a hole precisely at a projected fault intersection, even if such existed. Conversely, if these faults are not intersected, this cannot be taken as justification for additional drilling in the area. The hole location is still determined basically by the shape of the MB-124 depression and geophysical CSAMT constraints.

\section{Justification of Hole}

- Deformation and Deep Dissolution

Peter Davies (1983) has proposed that the MB 124 depression is evidence of deep dissolution in the WIPP vicinity. Such dissolution is assumed to occur at a rate that induces ductile flow in the halite 
towards the point of dissolution/removal. Drill-core taken through the salado will provide evidence for the presence or absence of such flow structures. The removal of beds by dissolution can also be verified by observation of the core. Important leatures to observe are:

- The presence or absence of dissolution residues (anomalously thick clay zones) and breccias.

b. Departures from normal stratigraphic section.

c. Assoclation of residues with fractured and water-bearing units.

- Hydrology of the Rustler Formation.

The Rustler aquifers and the Magenta and Culebra dolomites are critical units for the hydrogeologic characterization of the WIPP site. In this cruclal area, a hole at the proposed location would allow us to quantify and define the potentiometric surfaces for fluid-bearing zones in the Rustler.

- Additional justifications as the hole is deepened through Castile and completed in the DAC.

a. Additional hydraulic characterization of the Bell Canyon in the area is needed. The hole would be used to obtain static heads, hydrologic parameters and water quality data from the Bell Canyon, namely, Its Hayes, Olds and Ramsey sands and Limar Limestone. -

b. The hole would allow a "whole-hole" test, in which the Bell Canyon and Rustler aquifers are intentionally interconnected and directions of fluid movement monitored (also see statement of work for Cabin Baby recompletion, Conzalez, 1983.)

c. The proposed site is within the disturbed cone (Borns et al, 1983). Oriented core in Castile structures wi.l1 permit determination of flow directions. Such data aid the ongoing study of deformation mechanisms, 1.e.. halokinesis vs. Bravity sliding.

A1so, there is a possibility of encountering a brine reservoir in the Castile. Brine reservolrs have been studlied at WIPP 12 and ERDA 6. Since this data base exists, it may be argued that further tests on a possible reservoir are not a primary purpose of the proposed hole. st111, the level of sainpling/testing of a brine reservolr that could be encountered imust be defined in advance. A brine-producing zone could be cas'ed or packed of $\mathrm{as}$ was done at UIPP 12 as drilling was completied to Anhydrite I. Provisions, however, should be considered to allow mobilization for a reservoir test program, as contained in the WIPP 12 statement of work (Powers, 1981). Since a brine reservoir contingency testing plan is being developed by J. Hercer (SNL, 7133), a detailed test plan for a brine reservoir encounter is not developed in this document. still, during the deepening of DOE 2, provisions should be made for: 
a. Drillers should be prepared for $\mathrm{H}_{2} \mathrm{~S}$ and pressurized flow.

b. Comparison of DOE 2 brine reservoie to WIPP 12 and ERDA 6 occurrences through determination of flow rate, downhole pressure and major element chemistry, .8. TDS.

c. Hole should be maintained in a configuration that permits longer term hydraulic testing during Phase III, but some short-term testing, e.g., may be required in the brine reservoir contingency plan at the time of encounter.

Yethods

The tasks essential to this program are divided Into three phases (in order of completion):

I) Rustler Hydrology and Drilling

II) Drilling and core recovery from base of the Bustler into the Dar.

III) Perform hydrology and other related tests in the whole-hole.

This document 16 primarily a statement of work for Phase II. D.D. Gon$z a l e z$ (6331) and $J$. Mercer (7133) will produce statements for Phase $I$ and Phase III respectively. The proposed drilling for Phase II is $(2-1 / 2$ " or greater core acceptable, 4-1/2" preferred): $=$

1. Drill continuous core across the salado (-945-2515' below ground level) with oriented core at the following intervals:

- one barrel oriented core at MB 124 ( $-2705^{\prime}$ below G.L.)

- one barrel oriented core across Cowden Anhydrite-Infra Cowden contect at $-2355^{\circ}$ below G.L.

2. Drill continuous core across the castile ( $2515^{\circ}-3800^{\circ}$ below G.L.) with oriented core from the following intervals:

- Anhyorite III-Halite II contact at $\sim 2815^{\circ}$ below G.L.

- middle of Anhydrite II at $-2880^{\circ}$ below 6.L.

2a. If a bine reservoir is encountered, some minimal time of testing will be required, and the brine reservoir contingency plan (see Justification section above) will be enacted before drilling is continued.

3. Drill continuous core from the base of the Castile into the DMG, including the Ramsey, Ford, Olds and Hayes members $\left(\sim 3800^{\circ}-4040^{\circ}\right.$ below G.L.) 
4. Perform geophyslcal logging of hole, includinis acoustilog, natural gema, temperature, resistivity, 4-arm caliphier for borehole geometry, neutron (limestone-compensated) and televiewer.

5. Set production packer, on 2-3/8" tubing, above the Bell Canyon to monitor fluid stabilization.

6. Photograph and preserve core according to WIP.P standard practice.

7. Prepare hole as required for Phase III.

\section{Responsibilities}

Statements of Work:

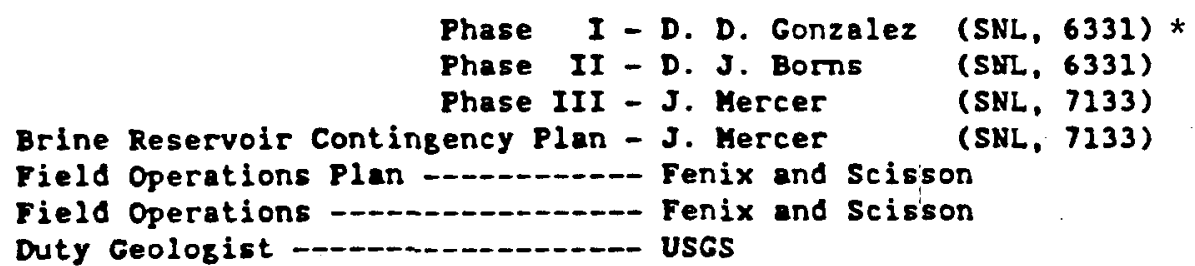

Oual1ty Assurance

Sandia Laboratories will implement this document in accordance with its established $Q A$ pr.cedures. Operational $Q A$ will be performed by Fenix and Scisson and contractors in accordance with their established procedures to meet the objectives of the program. The QA level of this program in $C$ minor; unless a brine reservoir is encountered, then the level for portions of the testing is major.

DJB: $6331: \operatorname{cds}(03711)$

Distribution:

6330 H. D. Weart

6331 Perconnel

6332 L. D. Tyler

7133 R. D. Statler

$7133 \mathrm{~J}$. Nercer

usGS R. P. Bnyder

*Phase I Principal investigator change from D. D. Gonzalez to R. L. Beauheim 


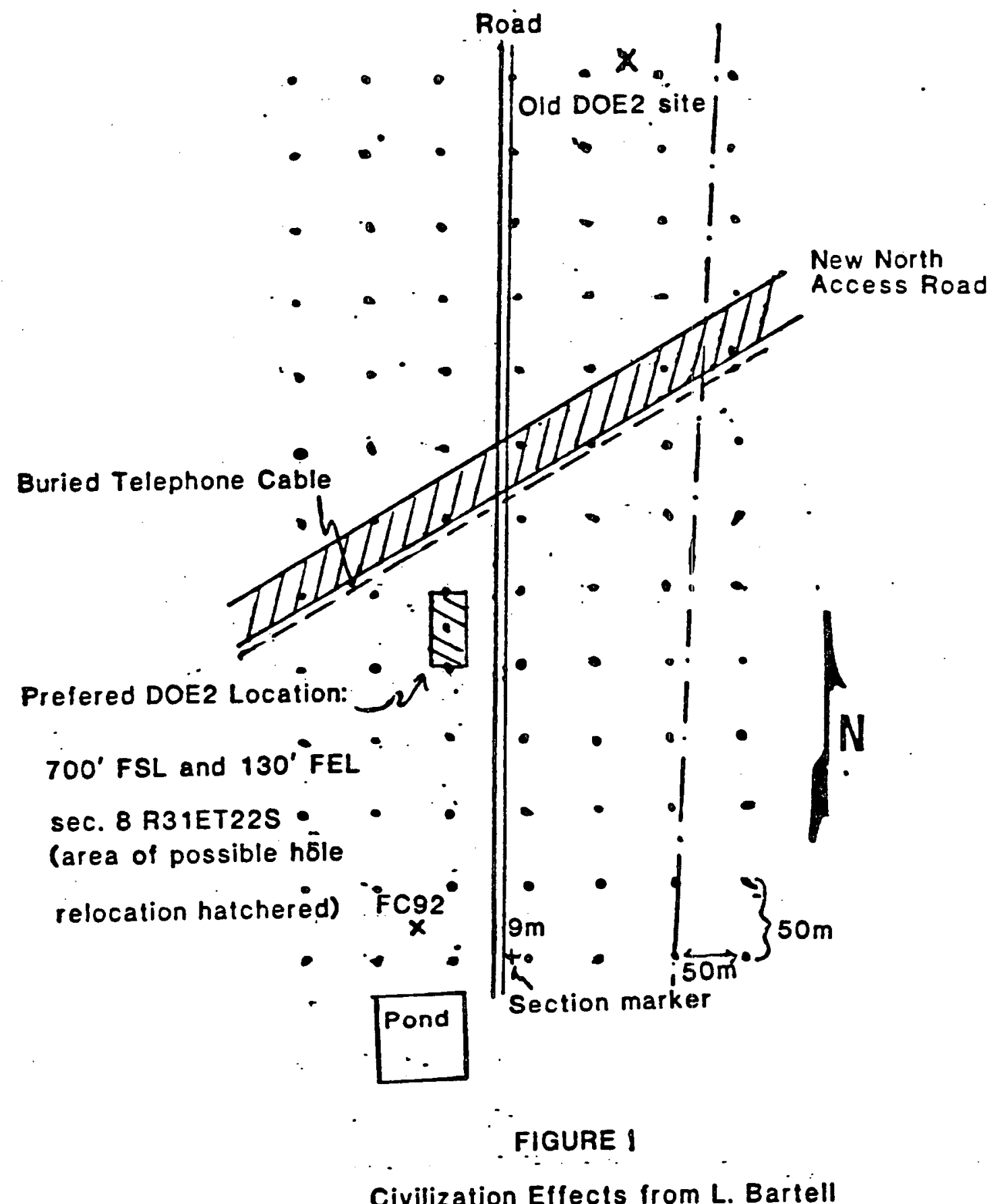




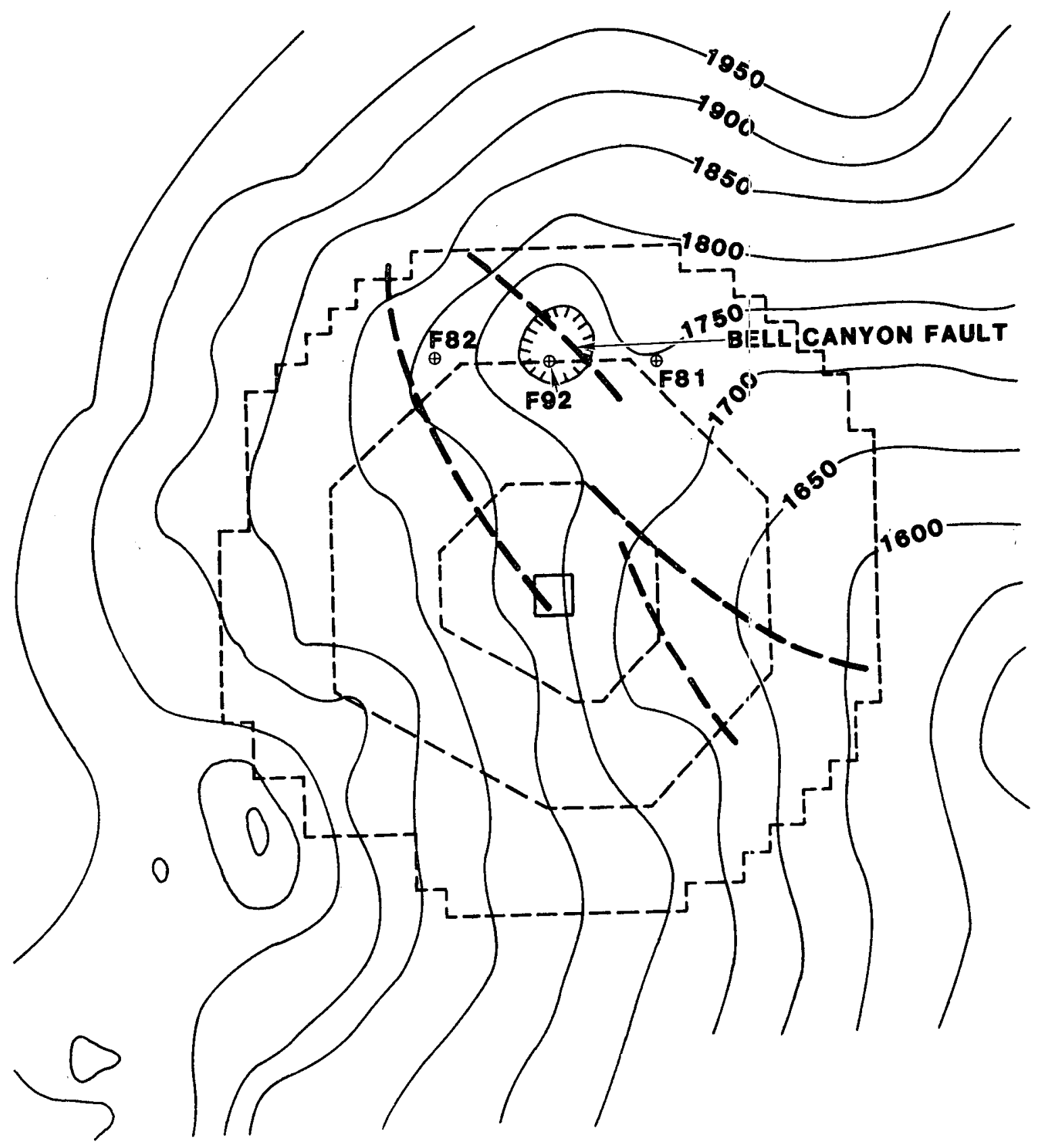

Figure 2A. Marker Bed 124 Depression and Projected Fault Trace From Powers et al.(1978) 


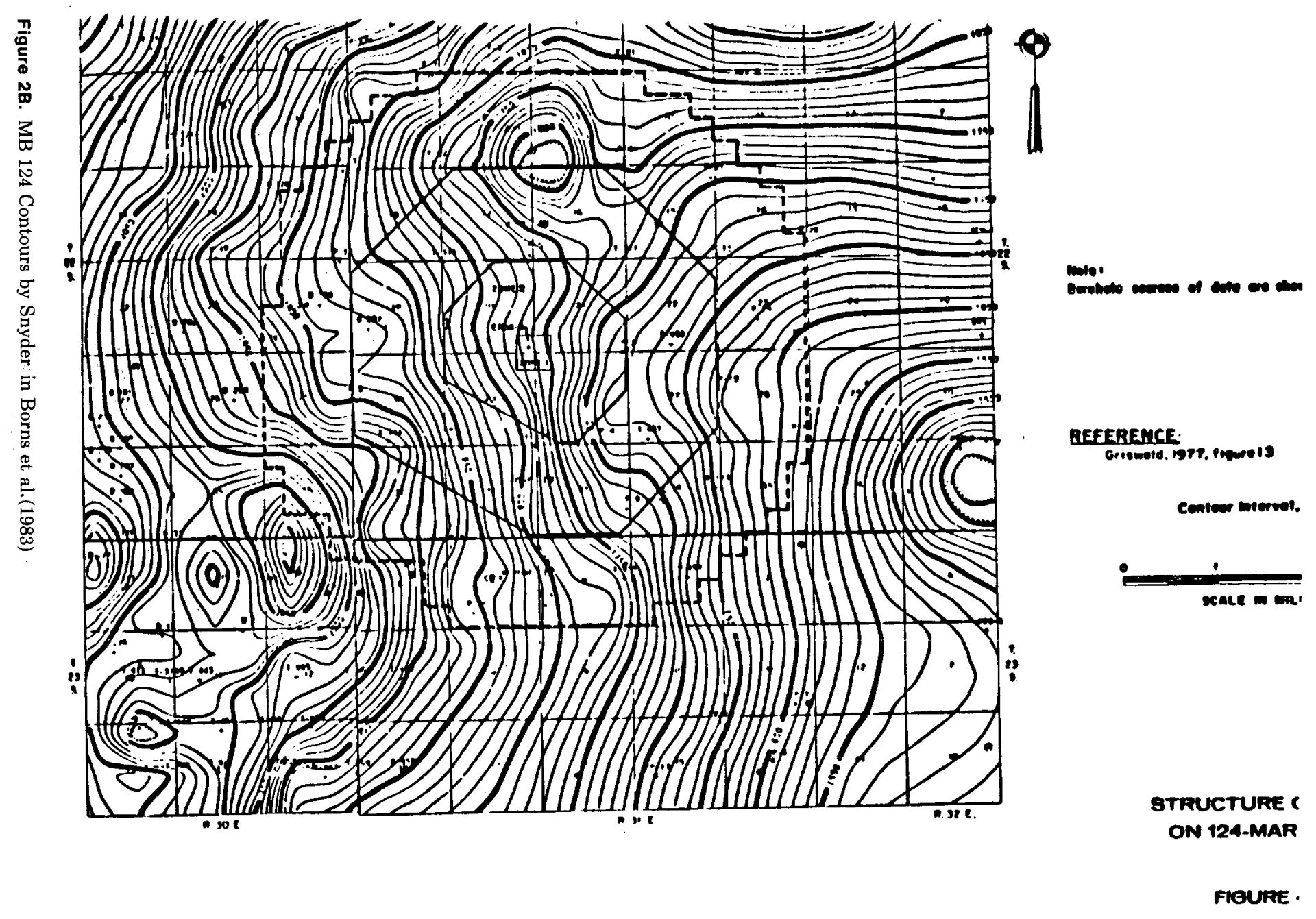


$\frac{\pi}{0}$
$\frac{0}{0}$
0
0
0
0

\section{Structure Contours on 124 Marker Bed}

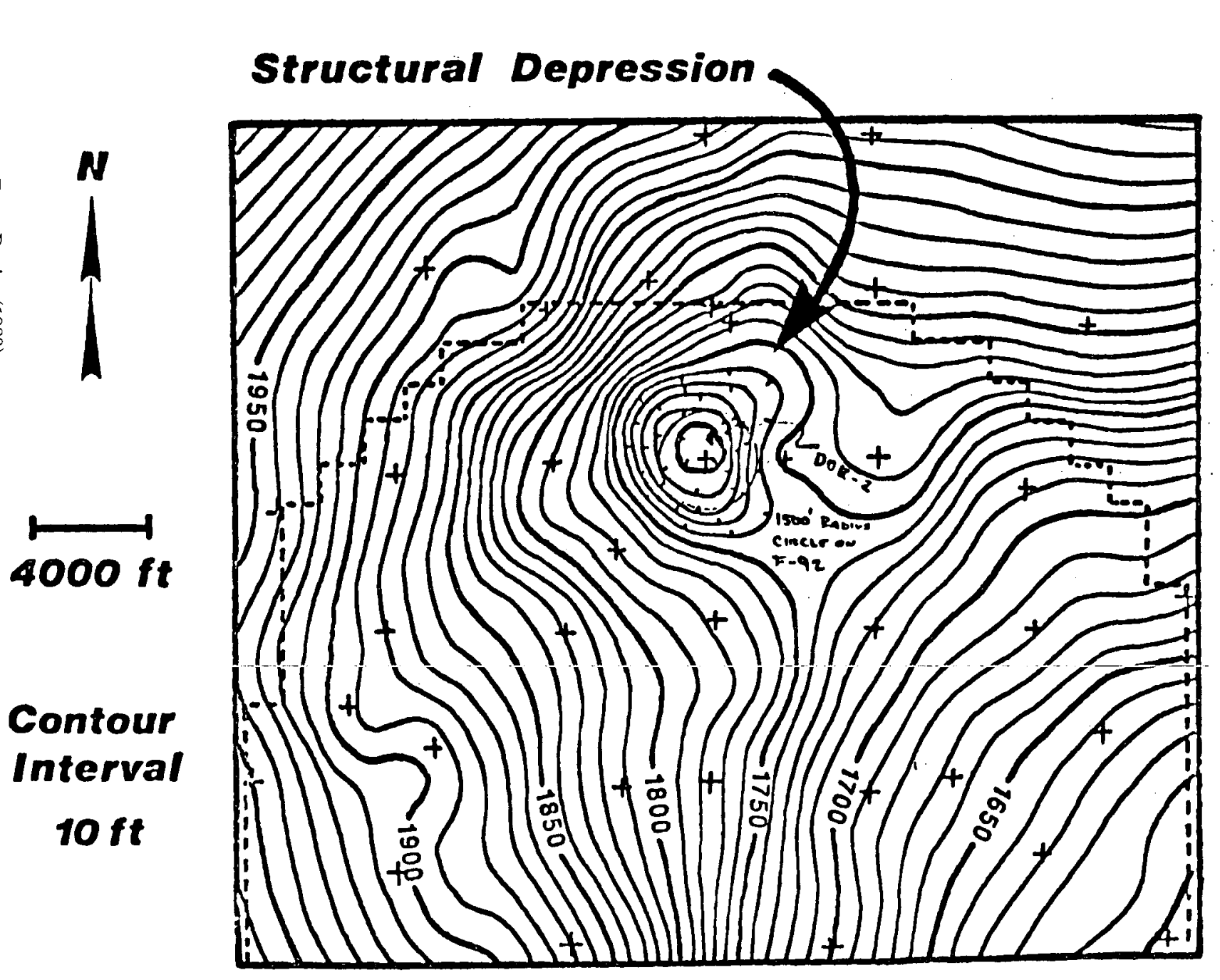

\section{Stratigraphic} Position

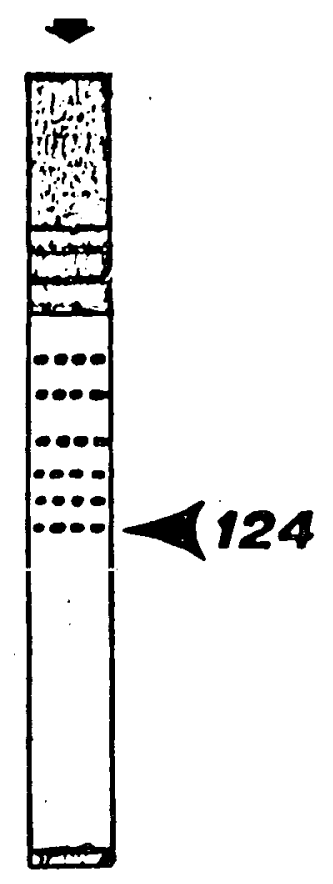




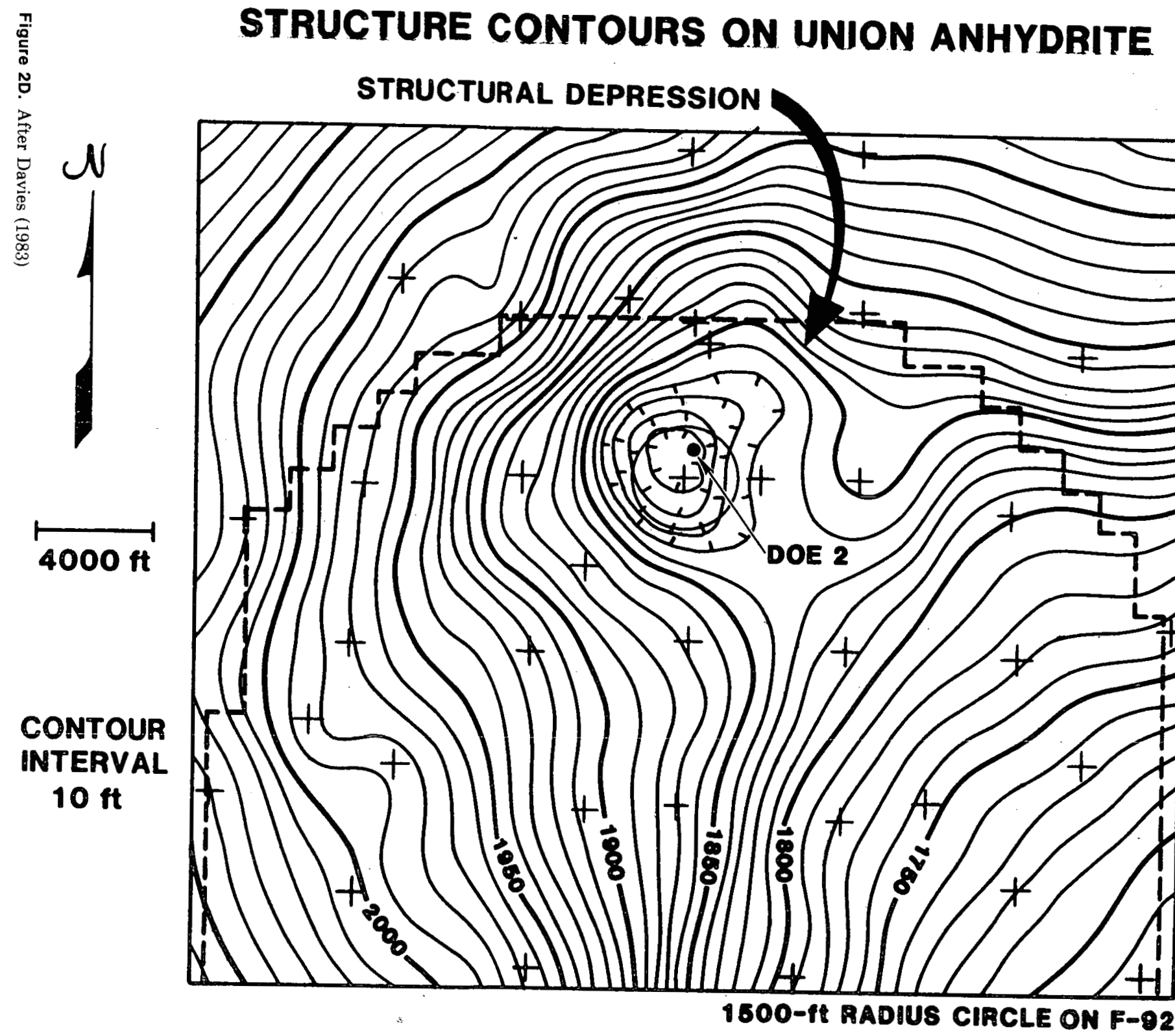

STRATIGRAPHIC POSITION

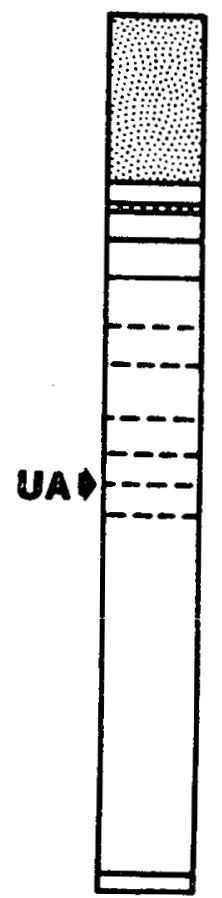



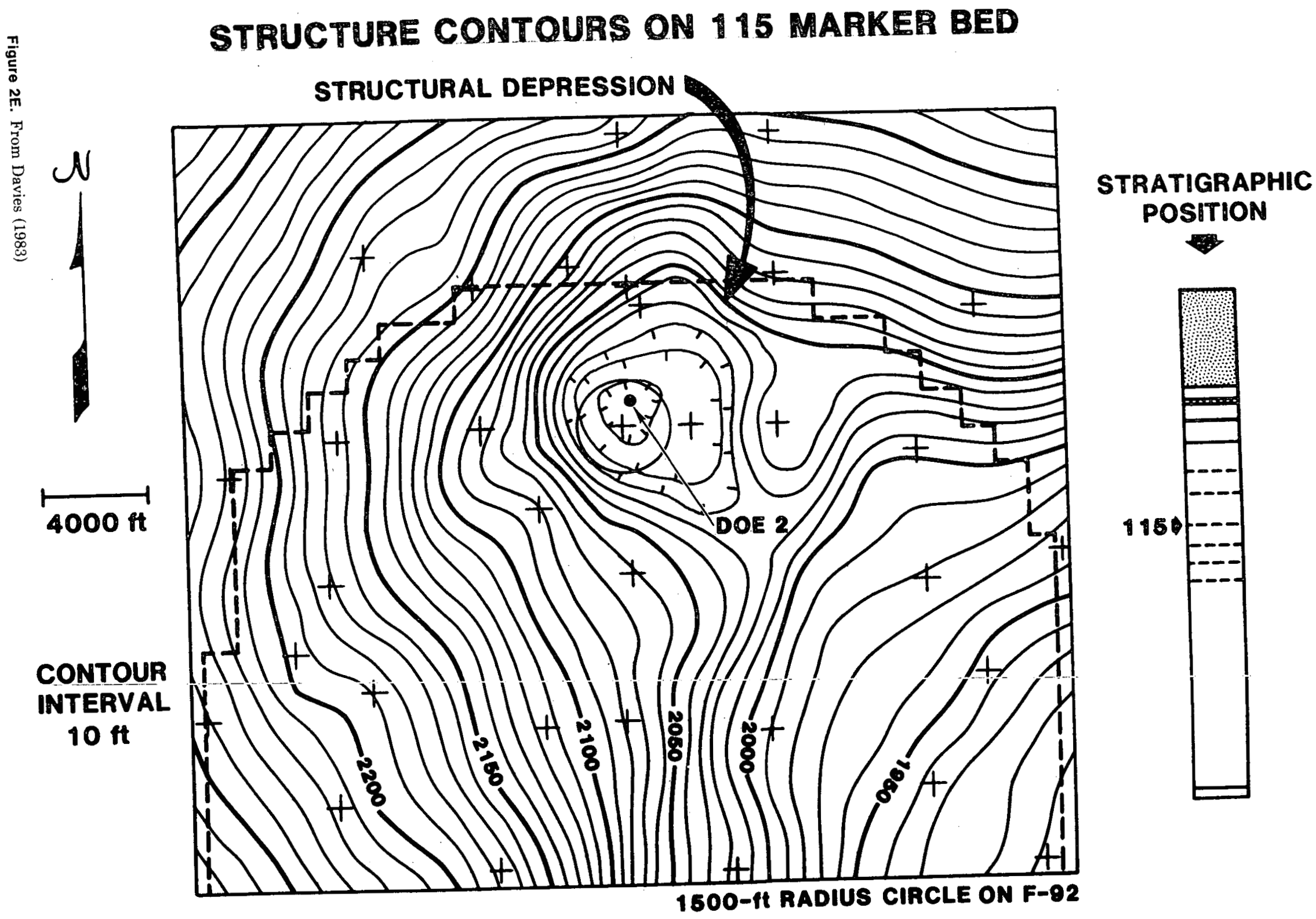


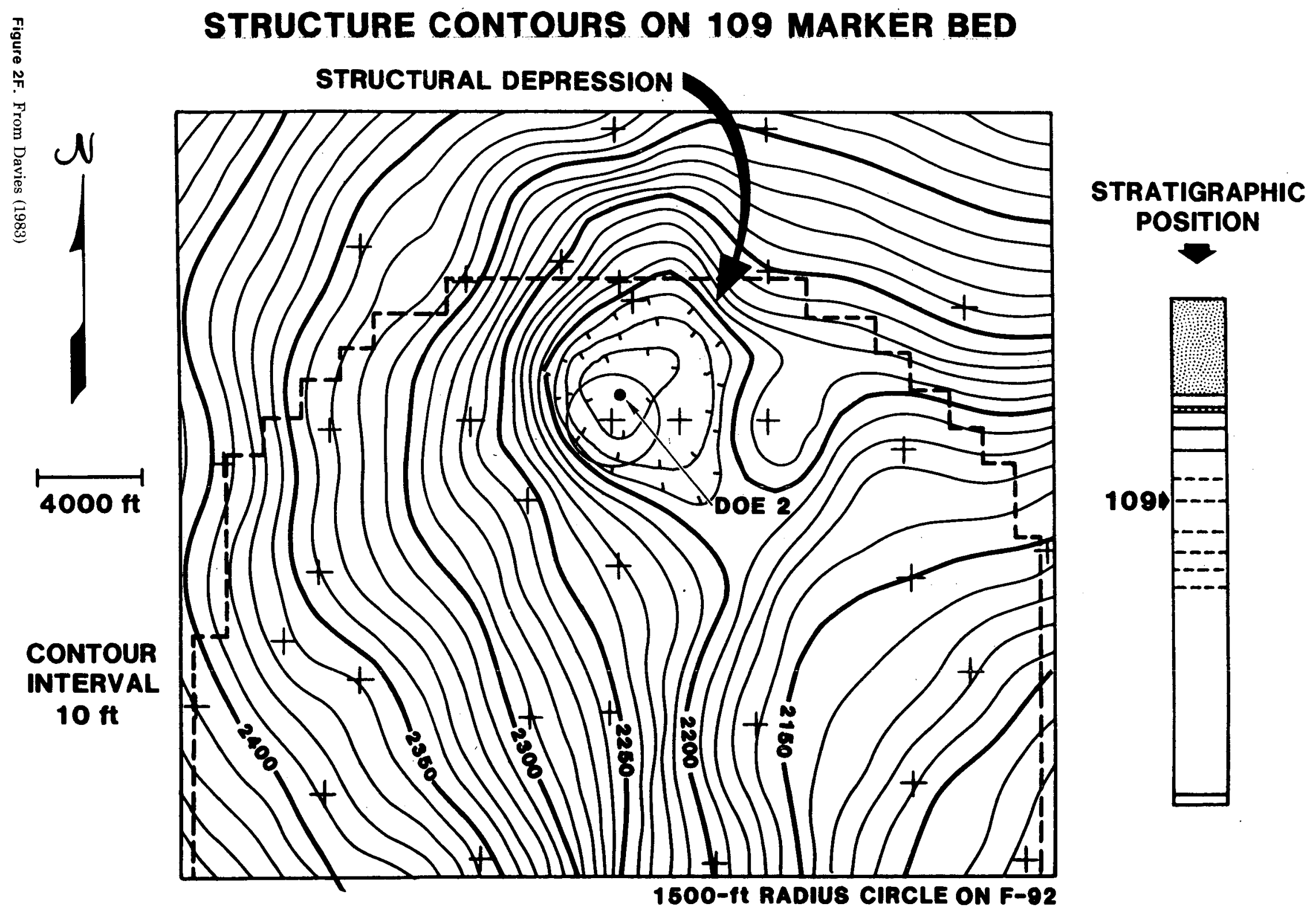




\section{FIELD OPERATIONS PLAN}

\section{I Organization and Responsibilities}

$2 \cdot 1 \cdot 1$

The technical program for Phase II in this

operation is the responsibility of Earth

Sciences Division 6331. D. J. Borns is

responsible for the geological programs.

Field decisions affecting the technical

objectives will be made with full

concurrence of Division 6331 .

2.1.2 The U. S. Geological Survey (Regional

Geology and Water Resources Division) will

be responsible for core description and are

expected to provide their expertise and

recommendations throughout the geophysical

logging program.

2.1.3 The direction of field operations described in this plan is the responsibility of J. W. Mercer, Division 7133 .

Page 3 
2.1.4 Arrangements are being made through the Driling $A / E$ (Fentx\&Scisson) toplan contract for and administer the drilling, coring, logging, testing, and other associated services on a 24-hour basis and according to the technical criteria provided by Sandia. All work and subcontracts will be performed in conformance with sandia org 7133 Quality Manual and the Drilling A/E QA Plan.

$2 \cdot 1 \cdot 5$ The quality level of this program is categorized as "minor". Appropriate Quality Assurance measures on work performed by Division 7133 will conform to the general requirements of the "Field Engineering Directorate Quality Plan", Issue B, dtd December 1983.

\subsection{Supporting Data}

This Field operations Plan covers the tasks essential to the Phase II of DOE-2. While being treated as a separate program, it follows the same format as used for Phase I of DOE-2 which characterized the waterbearing zones in the Dewey Lake and Rustler Formations. Plans call for occupying the same location and reentering the DOE-2 drill hole to rework as necessary to achieve the objectives of Phase II. 


\subsection{Drilling and Testing Program - Phase II}

It should be recognized that the stratigraphy and/or hydrologic conditions may be unusual; therefore, the drilling and testing program may have to be adjusted to provide for abnormalities.

2.3.1 Rehabilitate mud pits and drill site, install BOP (blow-out preventor) and appropriate wellhead safety equipment.

2.3.2 Implement a heavy-duty driling rig on a 24-hour operation to rotary drill and core using the rotary method and brine or brine-polymer mud as a circulating agent. The maximum depth of drilling is estimated to be 4040 feet. The drilling operation should be prepared for the potential of encountering $\mathrm{H}_{2} \mathrm{~S}$ and pressurized brine flows and the use of appropriate safety equipment and detectors $\left(\mathrm{H}_{2} \mathrm{~S}\right)$.

2.3.3 Rig up and run-in-hole with a 12-1/4" bit and ream 7-7/8" hole to TD (about 981 feet).

2.3.4 Run USGS gama log and caliper to calculate proper amount of cement. 


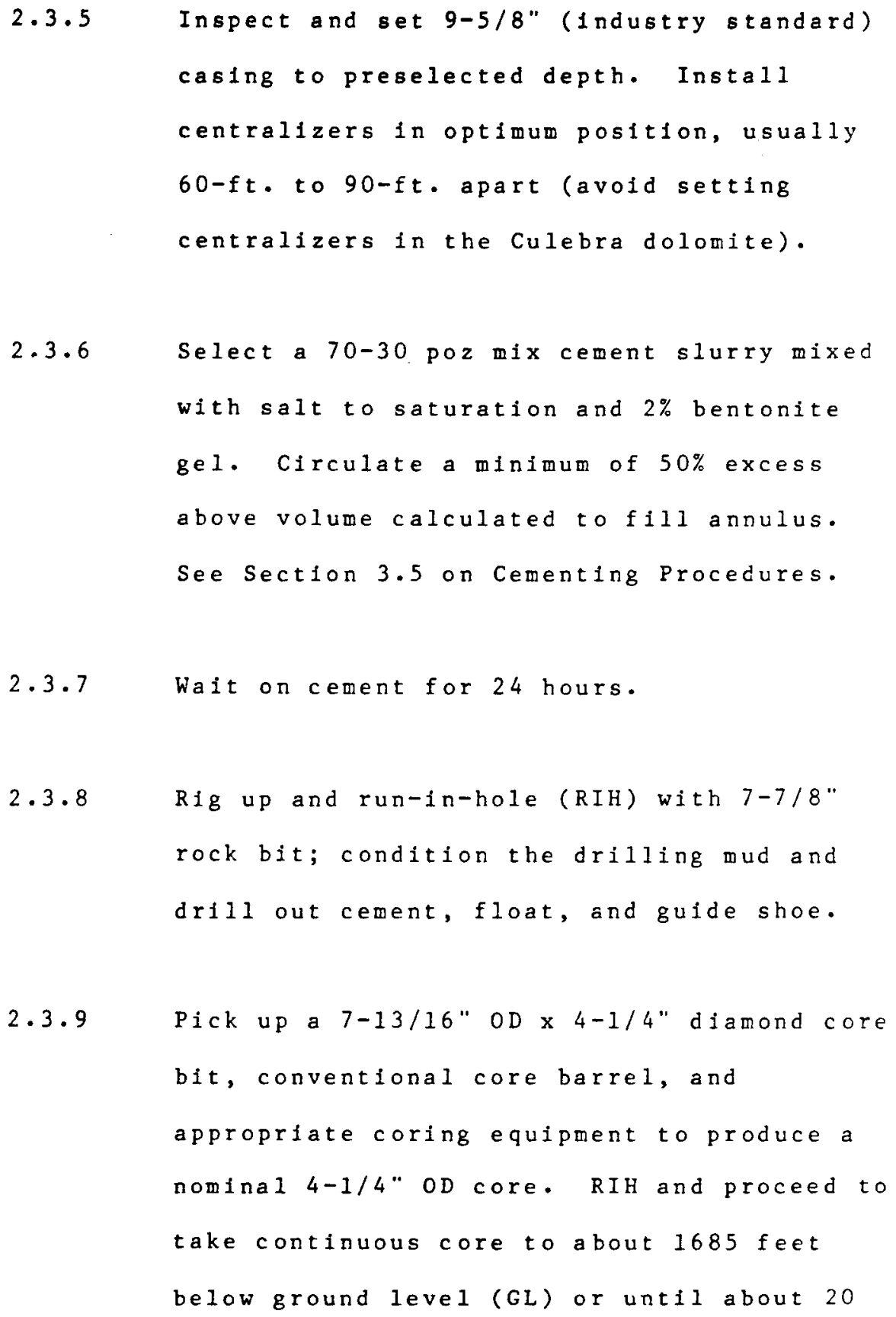


feet above MB-124 (about 1705 feet below GL)

in the Salado Formation. All core to be

logged, marked, and handled according too

procedures outlined in Section 3.2 .

2.3.10 Change over from conventional to oriented

coring equipment to produce a nominal 4-1/4"

$O D$ oriented core for one barrel (about 60

feet) across $M B-124$. One barrel of core

will be acceptable if the $11 B-124$ interval is

cored.

2.3.11 Change over from oriented to conventional

coring equipment and resume continuous

coring to about 2335 feet (GL) or until

about 20 feet above the cowden

Anhydrite-Infra Cowden conzact (about 2355

feet below ground level) in the Salado

Formation.

2.3.12 Change over from conventional to oriented

coring equipment and take one barrel (about

60 feet) of oriented core across the

Cowden-Infra Cowden contact.

Page 7 
Note: See addendum for change in hydrologic testing of the Salado Formation. Coring will be delayed at the salado and Castile Formational contact near 2615 ft. (GL).

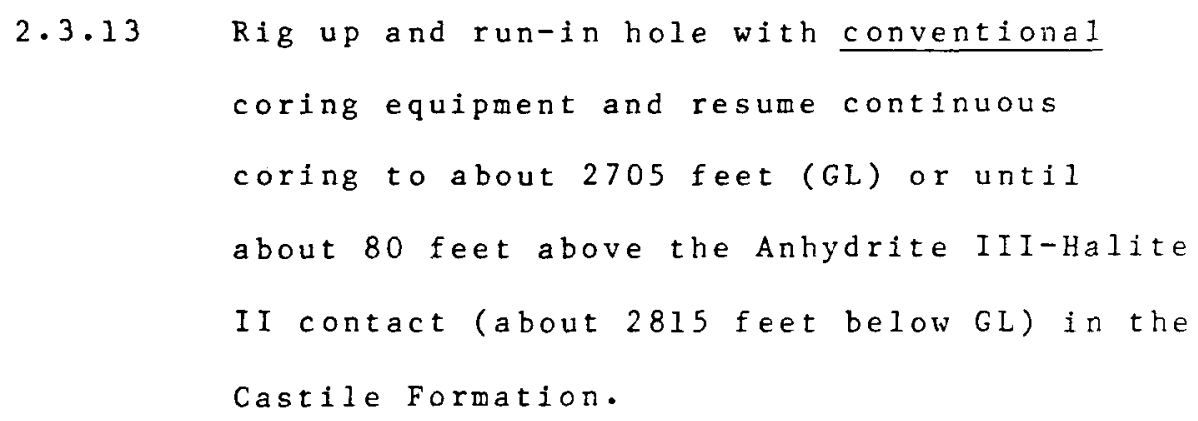

Note: It is in this interval that the pressurized brine with associated $\mathrm{H}_{2} \mathrm{~S}$ was encountered in WIPP-12. The mud circulation should be monitored very closely during the coring of Anhydrite II and at the slightest indication of brine and/or gas, switch to oriented core and immediately enact the brine reservoir contingency plan (Appendix A) .

2.3.14 Change over from conventional to oriented coring equipment and take two barrels (about 120 feet) of oriented core across the Anhydrite II and Halite II contact. 
Change over from oriented to conventional

coring equipment and resume continuous

coring to about 2885 feet (GL) or until

about in the middle of Anhydrite I of the

Castile Formation.

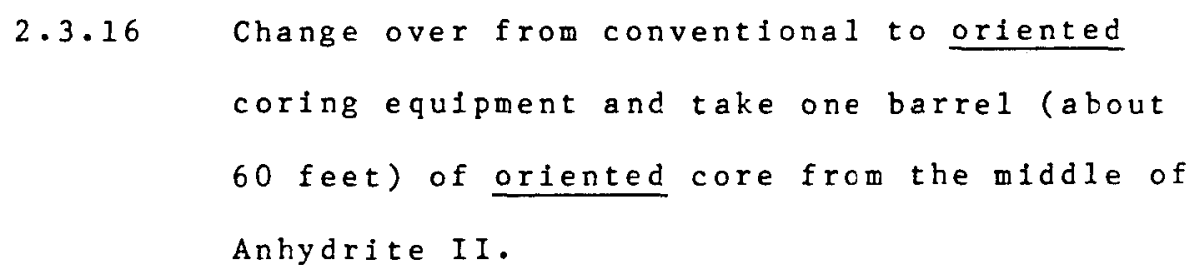


deviation, 4-arm caliper for borehole

geometry, temperature, and fracture

identification (acoustic televiewer). See

Section 3.4 on Geophysical Logging.

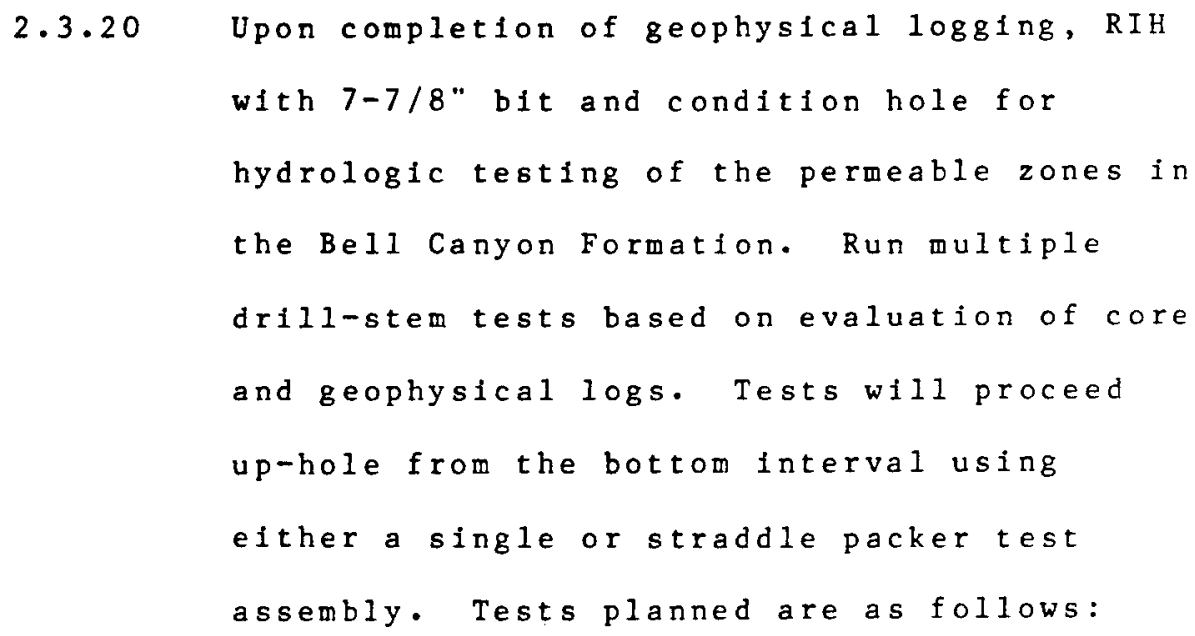

(a) Hays sandstone member (single packer)

(b) olds sandstone (straddle packer)

(c) Ramsey sandstone (straddle packer)

Each DST could run from 24 to 72 hours

depending on data analyses. See Section 3.3

for Hydrologic Testing Procedures.

2.3.21 Swab to produce test interval and collect

water samples. See Section 3.6 on Water

Sampling Procedures.

Page 10 
2.3 .22

Evaluate geophysical logs, drilling history, and coring information from the Castile Formation to see if permeable zones and/or gases and fluids are present. Suspected zones will be investigated by performing DSTs or modifled DSTs by using inflatable packers and test assembly to isolate the test interval. Swab to collect water samples if sufficient permeability exists.

If no permeable zones are identified in the Castile, a "whole interval" test may be requested in which the Castile Formation will be isolated and a DST or pressure buildup test conducted.

2.3.23 Upon completion of hydrolokic testing run a production-injection packer (PIP) on $2-3 / 8$ " tubing to a packer seat near the base of Anhydrite I of the Castile Formation. Swab to produce the Bell Canyon Formation and evacuate driling fluid.

2.3.24 Demobilize rig and monitor the Bell Canyon pressure head until it stabilizes.

Page II 
Appendix A

Brine Reservoir Contingency Plan

If significant flows of brine and/or associated $\mathrm{H}_{2} \mathrm{~S}$ gas are encountered in the Castile Formation during drilling of Phase II, the following plan should be implemented:

1. Once the flows have been identified, proceed to take appropriate safety precautions and assure the well is under control.

2. Shut in the well and allow the pressures and temperatures to equilibrate and then determine bottom hole and surface static pressures through the use of packers and downhole and surface instrumentation.

3. Change over from conventional to orjented coring equipment and take oriented coreto the base of the producing member; keep flow to a minimum using properly weighted mud.

4. Identify the producing zone/zones as necessary through the use of geophysical logs; i.e., high resolution temperature, bulk density, caliper, and acoustic televiewer. 
5. Through the use of inflatable packers, pack off the identified producing interval as necessary and install

downhole instrumentation to observe changes in

downhole pressure and temperature.

6. Following downhole equilibration, run á short-term DST (Drill Stem Test) including period of lilow and buildup. The duration of the test may require as much as 24 hours.

7. Open the well to a short-term flow tes:. The duration of the test will be determined by the initial flow rates. The flow duration could be as long as 12 hours. During the flow period, fluid parameters such as temperature, specific conductance, $p H$, and density should be monitored, and all necessary samples for general bulk chemistry and density should be collected when these parameters have stabilized. Flow depletion as well as reservoir derived gases should be continuously monitored.

8. Shut in the well for pressure buildup test, monitoring constantly the pressure and temperature changes. The duration of the test will depend on previous test analyses and well behavior. 
9. Terminate the brine reservoir testing and prepare hole for further exploration to complete the objectives as outlined for Phase II. Completion of the hole may require the setting of temporary casing and/or terminating driling at Anhydrite I without penetrating the Delaware Mountain Group. 
3. FIELD OPERATING PROCEDURES FOR QUALITY CONTROL REQUIREMENTS

Portions of this field activity are considered to be of sufficient significance that quality control measures have been established. These activities are:

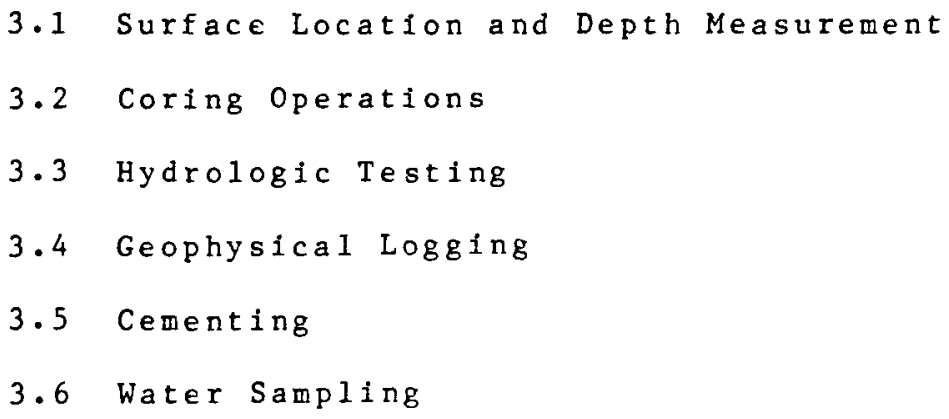

\subsubsection{Introduction}

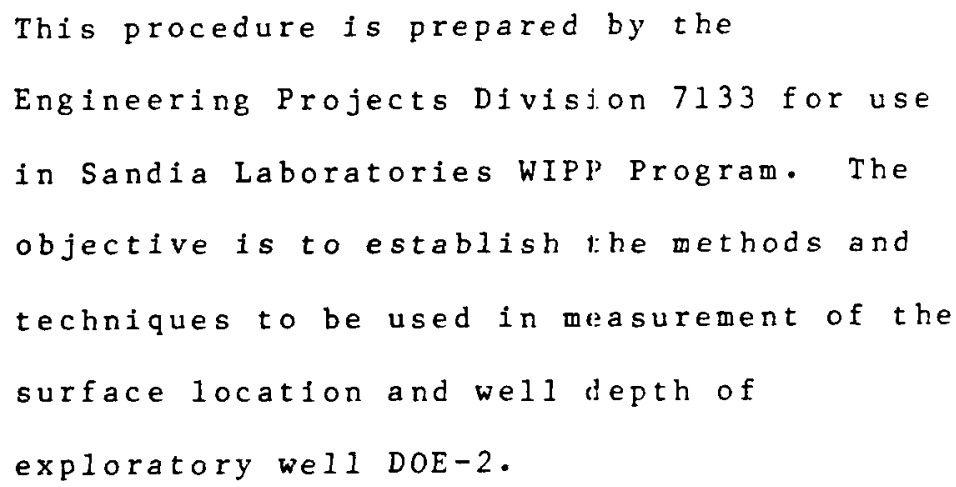

Page 15 


\section{1 .2 Scope of Work}

The surface location and depth measurements are to be done as part of the exploratory program of driling DOE-2. The nature of the location of DOE-2, to accommodate structural considerations and to investigate potential depression in stratigraphic markers, requires unusual accuracy in surface location and depth control.

\subsubsection{Organization}

Sandia National Laboratories is conducting this field work under technical direction

from Earth Sciences Division 6331. The

Sandia Engineering Projects Division 7133

will manage the field operations.

The drilling A/E will be responsible for maintaining depth control on the drilling and testing operations.

Page 16 


\section{$3.1 .4 \quad$ Operations}

3.1.4.1 Surface Location Measurements

(Done under Phase I:)

The general location will be established by Division 6331 following

a review of resistivity surveys, surface features, accessibility and other geo-political considerations. A preliminary land survey shall be conducted by a Registered Land Surveyor to establish access routes and set stakes for drill location and pad boundaries. Dimension of the location will be established with nearest section boundaries and nearest marked section corners to provide data necessary for obtaining land use permits. Drawings or sketches suitable for constructon use shall be submitted. After pad construction is complete, a concrete monument with a brass cap will be set in the immediate vicinity of the borehole at ground level such that it can be used as the datum point for all borehole vertical

Page 17 


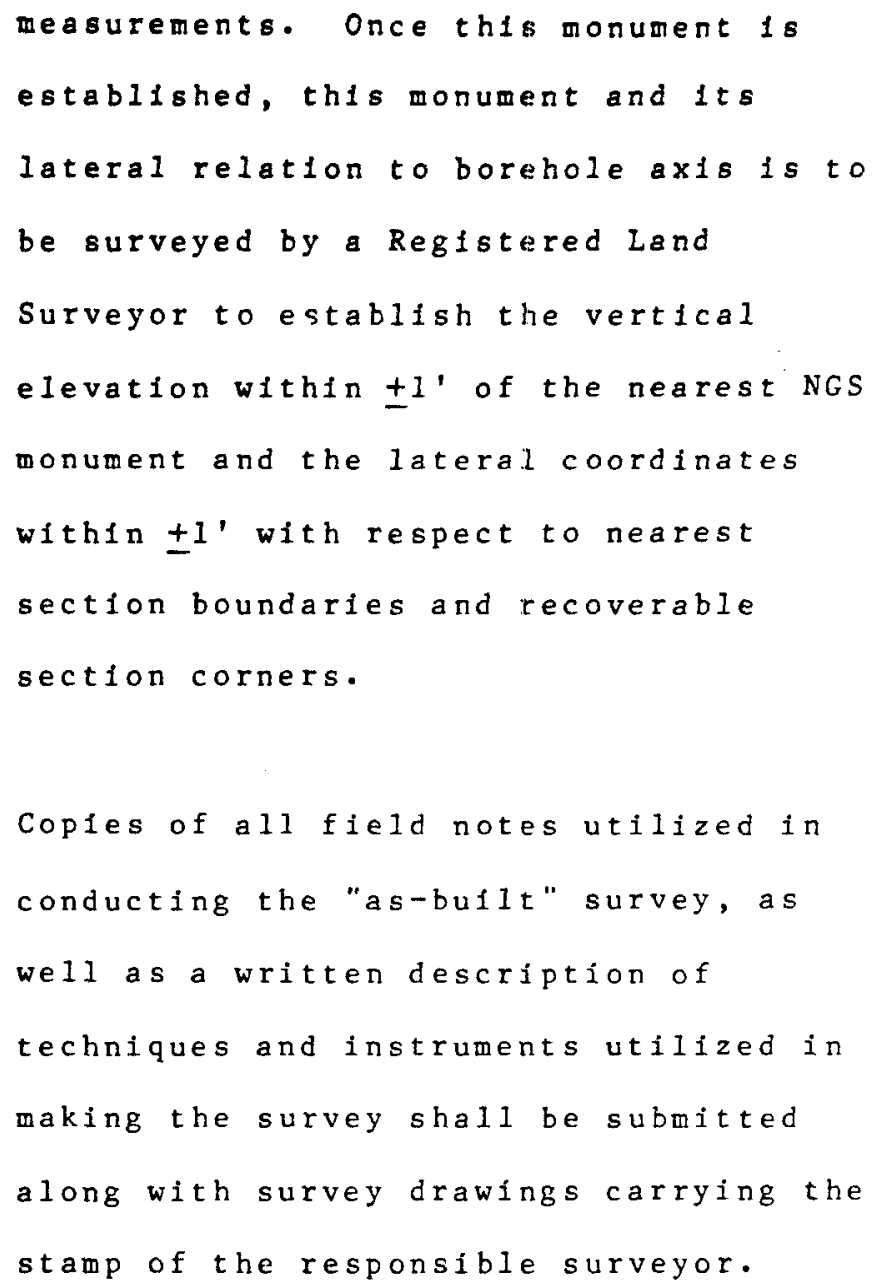

3.1.4.2 Depth Measurements

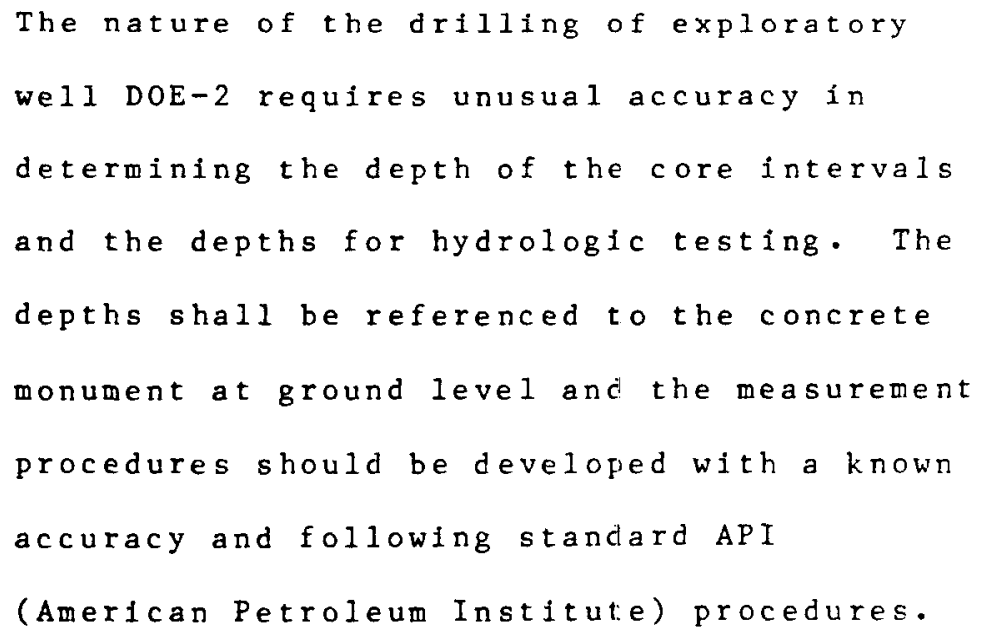




\subsection{Coring Operations Procedure of Sandia National Laboratories - WIPP Site Investigations}

\subsubsection{Introduction}

This procedure is prepared by the Engineering Projects Division 7133 for use in Sandia National Laboratories' WIPP Program. The objective is to establish the methods and techniques to be used in coring operations in order to obtain reliable samples in a uniform manner.

\subsubsection{Scope of Work}

This coring operation is tc be done as a part of exploratory drillirg of Phase II. Coring operation will consist of taking approximately $3060^{\prime}$ of $4.25^{\prime \prime}$ diameter core to a TD of approximately $4040^{\circ}$. Core is to be removed from the core barrel, logged, measured, cleaned, marked, photographed and packaged, transported and stored according to the procedures presented in this document.

Page 19 
Sandia National Laboratories is conducting this field work under technical direction from Earth Science Division 6331. The Sandia Field Engineering Division 7133 will manage the field operations.

The Drilling A/E will prepare and administer a drilling program from criteria provided by Sandia that includes the taking of core. The drilling contractor, the coring contractor and the roustabout contractor are under contract to the A/E. USGS will provide the duty geologist for logging and identifying the core and supervision of core handling in the field. TSC will provide geologists to assist in core identification and logging of core.

Sandia National Laboratories will provide core photography and arrange for core storage.

\section{$3.2 .4 \quad$ Operations}

3.2.4.1 Coring ( $\mathrm{A} / \mathrm{E}$ and their contractors)

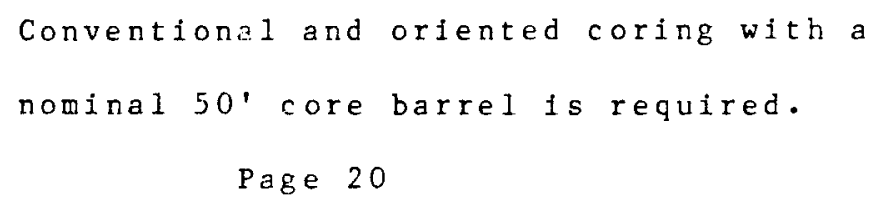




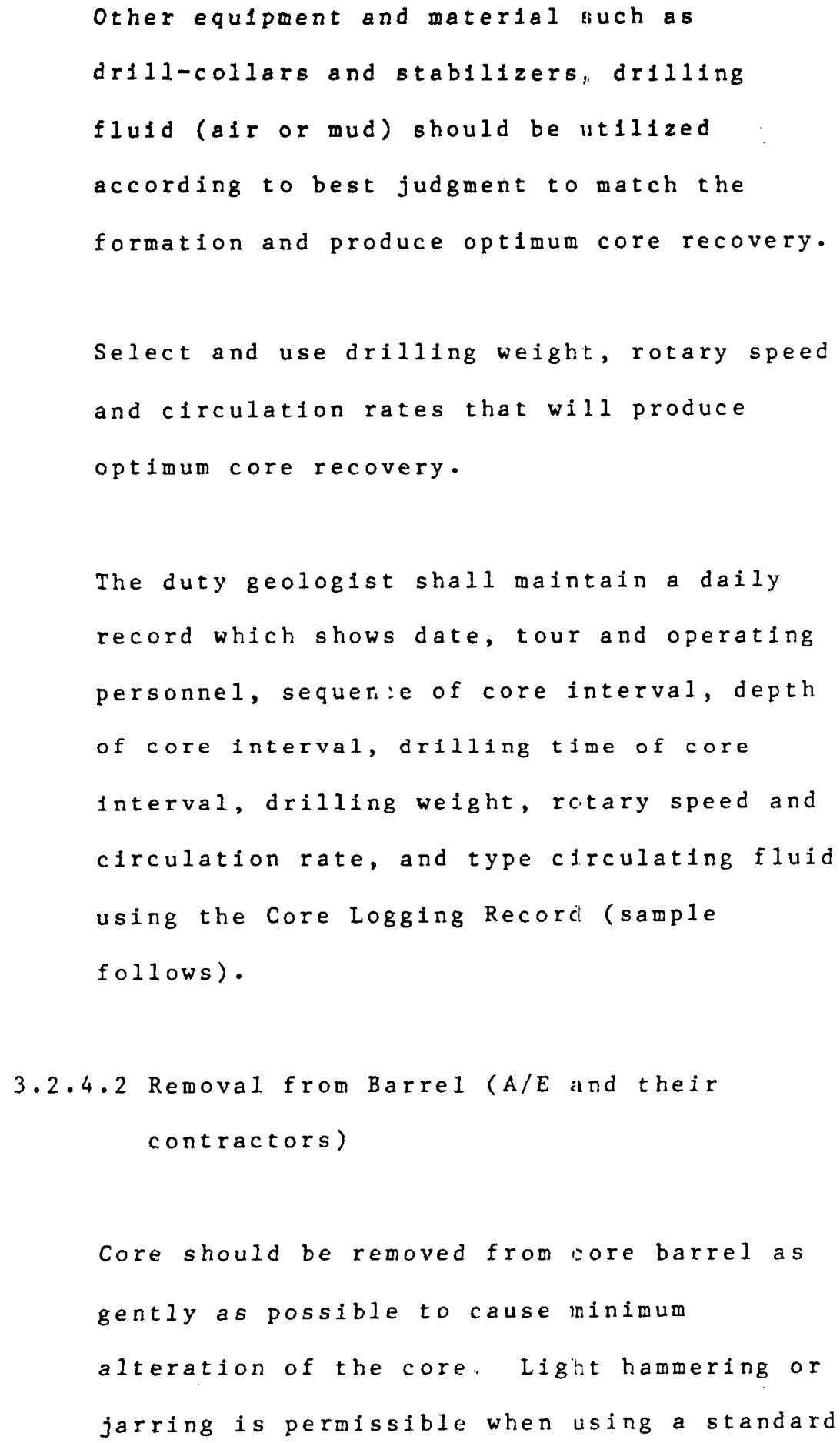

Page 21 
Pase _ of _

\section{DAIIY CORE LOGGING RECORD}

Date DUTY GEOLOGIST

LOG HEADINGS:

Compeny

Well Number WIPP No.

Fiéla

County

State New Mexico

Location

Section

Township

Range

Permanent Datum

Elevations: K.B.

D.F.

G.L.

\begin{tabular}{|c|c|c|c|c|c|c|c|c|c|}
\hline 0. & INTERVAL & $F E E T$ & RPM & $\begin{array}{l}\text { WEIGHT } \\
\text { ON BIT }\end{array}$ & $\begin{array}{l}\text { CIRCUL. } \\
\text { PRESS. } \\
\text { P.S.I. }\end{array}$ & $\begin{array}{l}\text { FEET } \\
\text { CORED }\end{array}$ & $\begin{array}{c}\text { FEET } \\
\text { RECOVERED }\end{array}$ & $\begin{array}{l}\text { ERRCENT } \\
\text { RECOVESY }\end{array}$ & $\begin{array}{c}\text { EOX } \\
20: E=\end{array}$ \\
\hline & & & & & & & & & \\
\hline & & & & & & & & & \\
\hline & & & & & & & & & \\
\hline & & & & & & & & & \\
\hline & & & & & & & & & \\
\hline & & & & & & & & & \\
\hline & & & & & & & & & \\
\hline & & & & & & & & & \\
\hline & & & & & & & & & \\
\hline & & & & & & & & & \\
\hline & & & & & & & & & \\
\hline & & & & & & & & & \\
\hline & & & & & & & & & \\
\hline
\end{tabular}




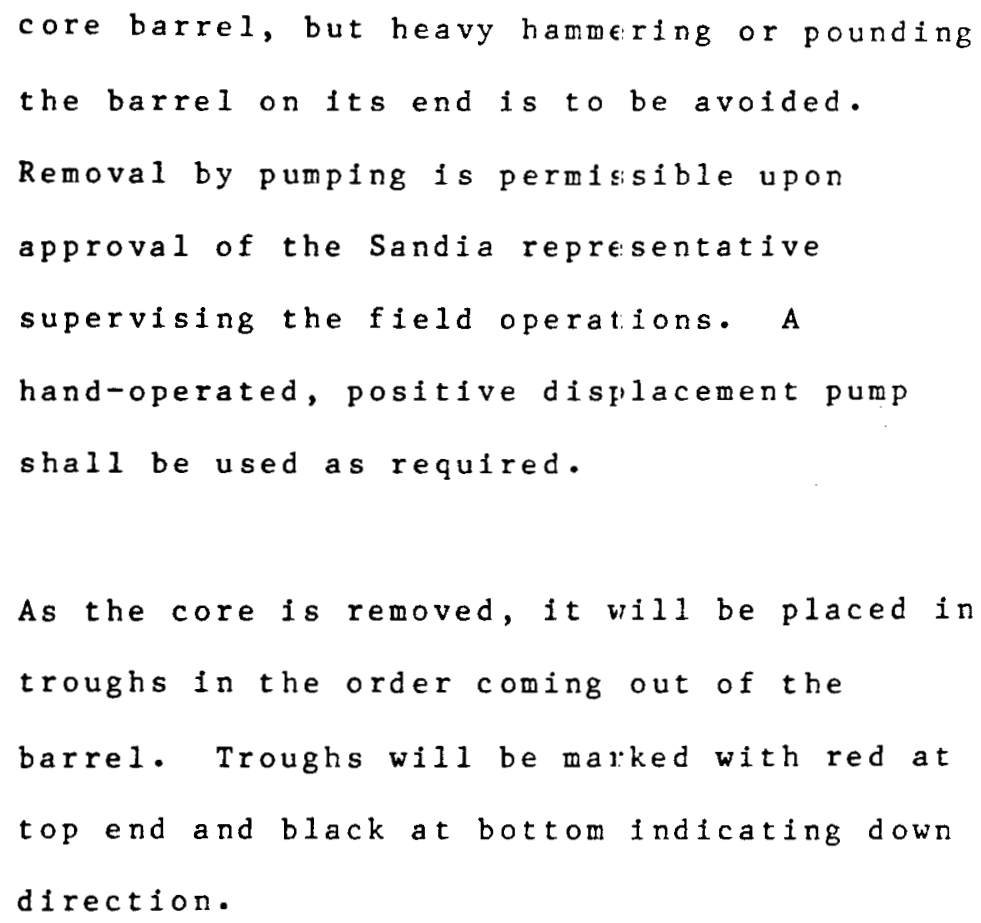


3.2.4.4 Cleaning ( $A / E$ and contractors)

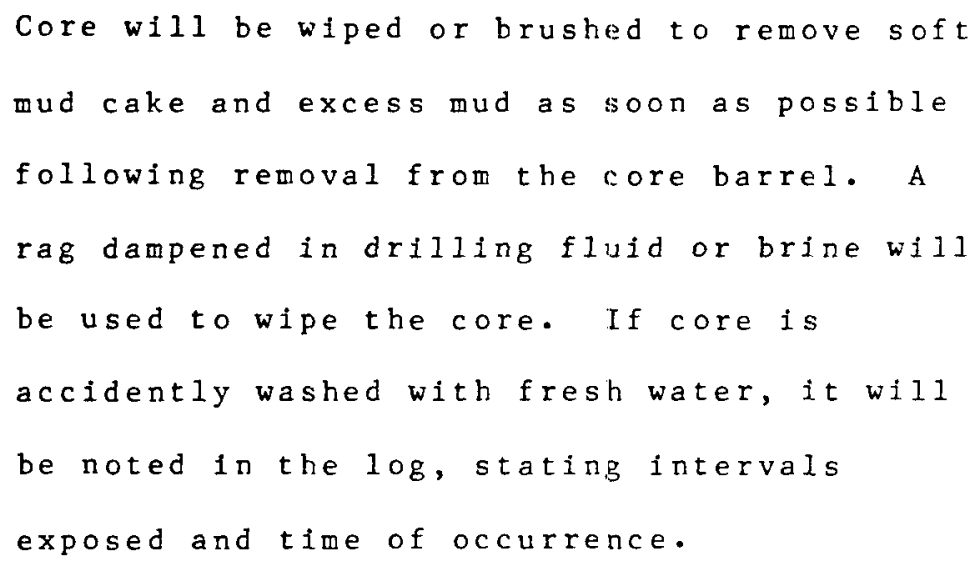

3.2.4.5 Photograph (Sandia and Duty Geologist)

After core has been logged, 1abeled, and cleaned, it will be carefully moved to the core/photo shed and prepared for photography. Core may be wetted with brine to enhance photo coverage. Core should be positioned by the duty geologist to promote coverage of pertinent features such as fractures, bedding plane, color, or any other significant characteristics. Oriented core should be positioned so scribe marks are visible for photos. Each photo should have a title block showing well number, date, core interval and photo number.

Page 23 


\title{
3.2.4.6 Preservation (Duty Geolog1st\& $A / E$
} Contractor)

\author{
After core has been photographed, it \\ w1ll be wiped dry and preserved for \\ transportation and storage in the \\ following method:
}

3.2 .4 .6 .1 Core pieces will be separated into lengths appropriate to fit into the core boxes. Pieces will be placed into plastic sleeves of appropriate length or wrapped and taped with plastic sheet if applicable. When using sleeves, use a hot iron sealing tool, seal both ends of plastic sleeve after squeezing all air possible from sleeve. Place sleeved or wrapped core into box and tape shut. When core intervals are missing, spacers marked with missing footage figures may be inserted in the box as necessary to preserve sequence. Boxes should be labeled in sequence with name of agency, well number, date, core number and depth of core pieces in the box.

Page 24 


\title{
3.2.4.7 Core Photos (Final Prints)
}

\author{
Sandia National Laboratories will \\ arrange for core photography as \\ described previously in paragraph \\ $3.2 .4 .5 .8-1 / 2 " \times 11 "$ prints will be \\ made and distributed as follows: \\ 1-set USGS, Regional Geology, Denver, \\ Attn: R. P. Snyder \\ 1-set Sandia Division $6331, A B Q$ \\ 1-set Sandia Division 6331, ABQ \\ WIPP Central File \\ 2-sets WIPP Project Office/TSC, \\ Carlsbad, NM \\ 1-set Sandia Division 7133, Attn: J. \\ W. Mercer
}

\subsection{Hydrologic Testing Procedures of Sandia National Laboratories - WIPP Site Investigations}

\subsubsection{Introduction}

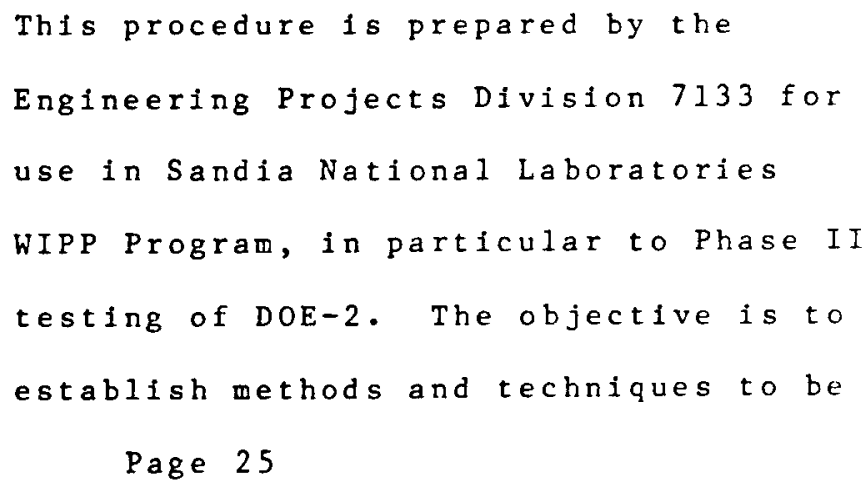


used in hydrologic testing in order to obtain reliable data in a uniform manner.

\section{3 .2 Scope of Work}

The hydrologic testing operation is to be conducted to obtain hydraulic properties of selected intervals, in particular, the permeable zones in the Bell Canyon Formation. The prime objectives of the testing program are to obtain data necessary to evaluate and measure certain hydraulic parameters. These are:

- hydraulic conductivity

- transmissivity

- hydraulic potential or head

It is understood that because of the very low anticipated permeabllities and unknown hole conditiors, all these parameters may not be obtained from each individual zone.

Page 26 


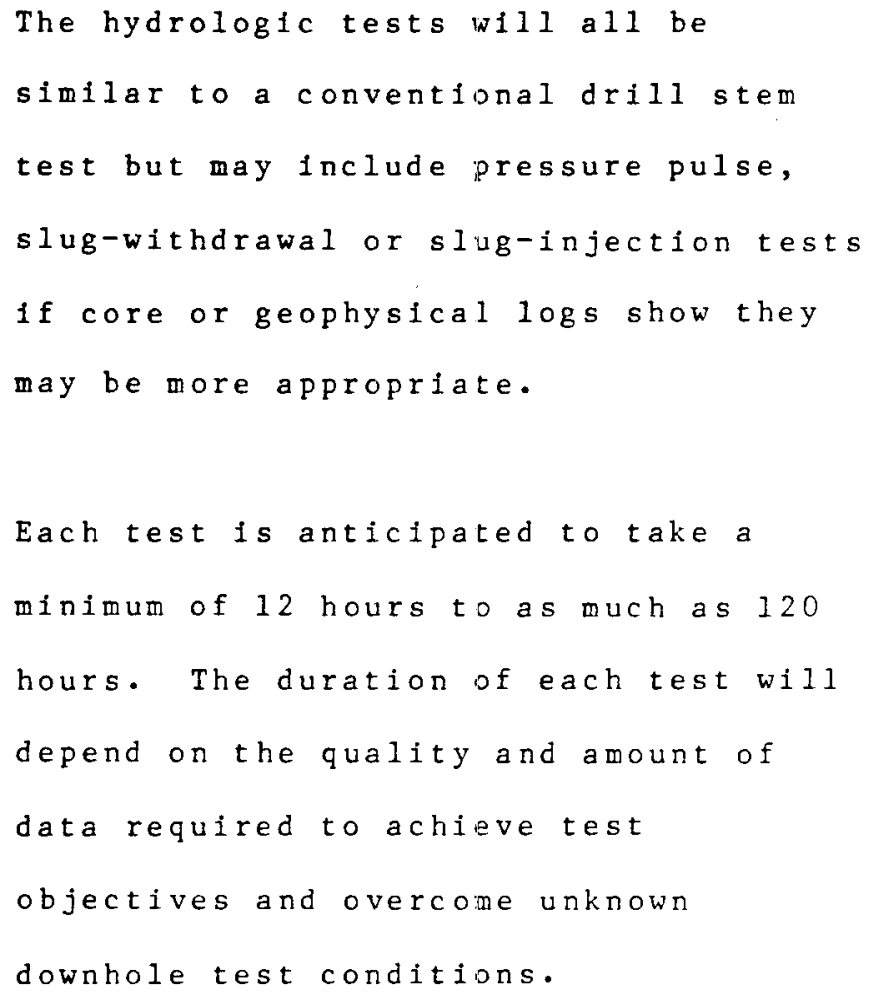




\subsubsection{Organization}

Sand1a Laboratories is conducting the

field work under the technical

direction of Earth Sciences Division

6331. The Sandia Field Engineering

Division 7133 will manage field

operations. The A/E will prepare and

administer a program from criteria

provided by Sandia that includes

hydrologic testing.

\section{$3.3 .4 \quad$ Operations}

3.3 .4 .1 The results of the logging and coring program for Phase II DOE-2 w111 identify the selected intervals to be tested.

3.2.4.2 When the selected test interval has been cored and 1dentified, run gamma $\log$ and caliper to identify potential packer seats.

Page 28 


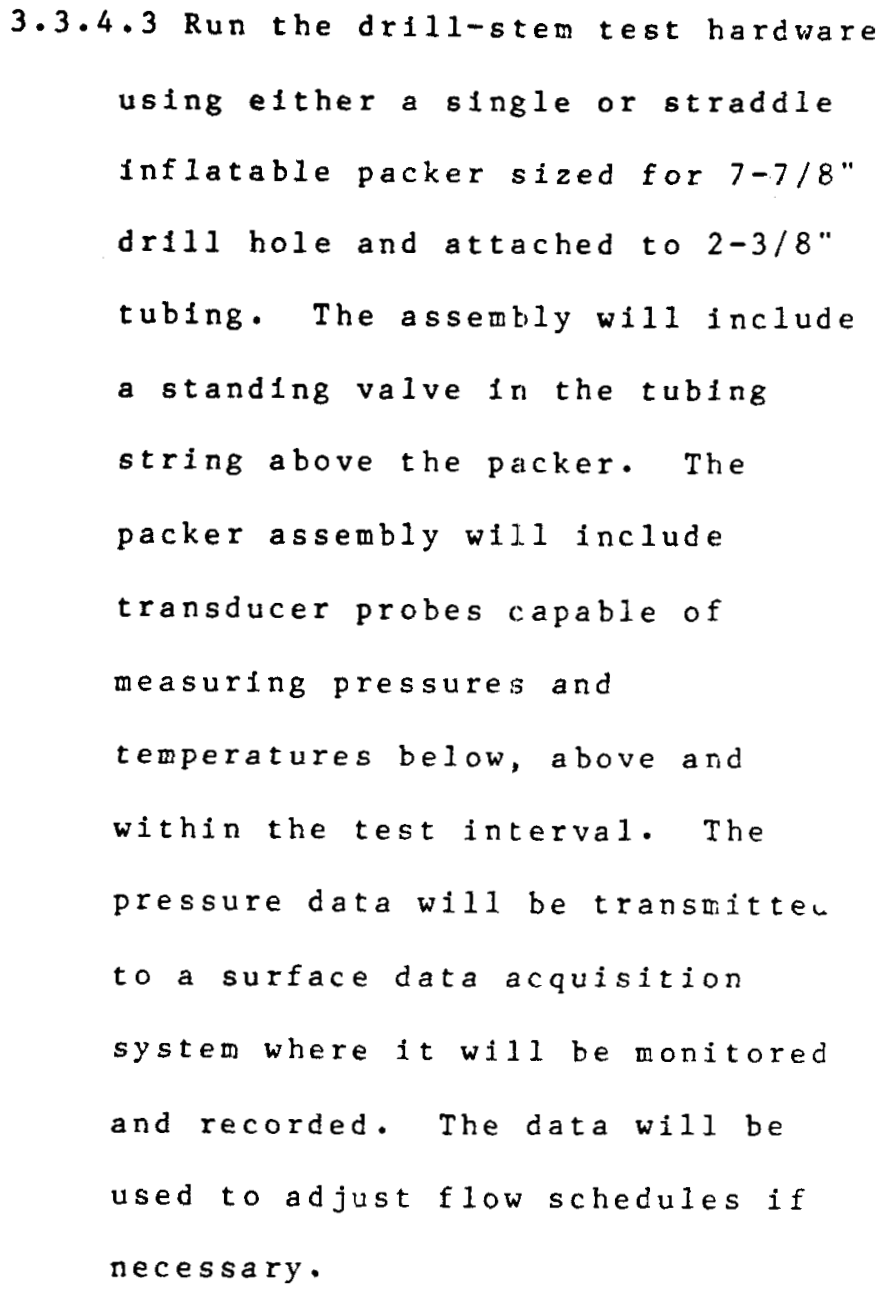

3.3 .4 .4 Set up and operate the test assembly with the capability of runing a 12- to 72-hour DST test. Prior to opening the test interval to the tubing, the water in the tubing shall be swabbed out. The shortest time schedule for flow and shut-in periods 


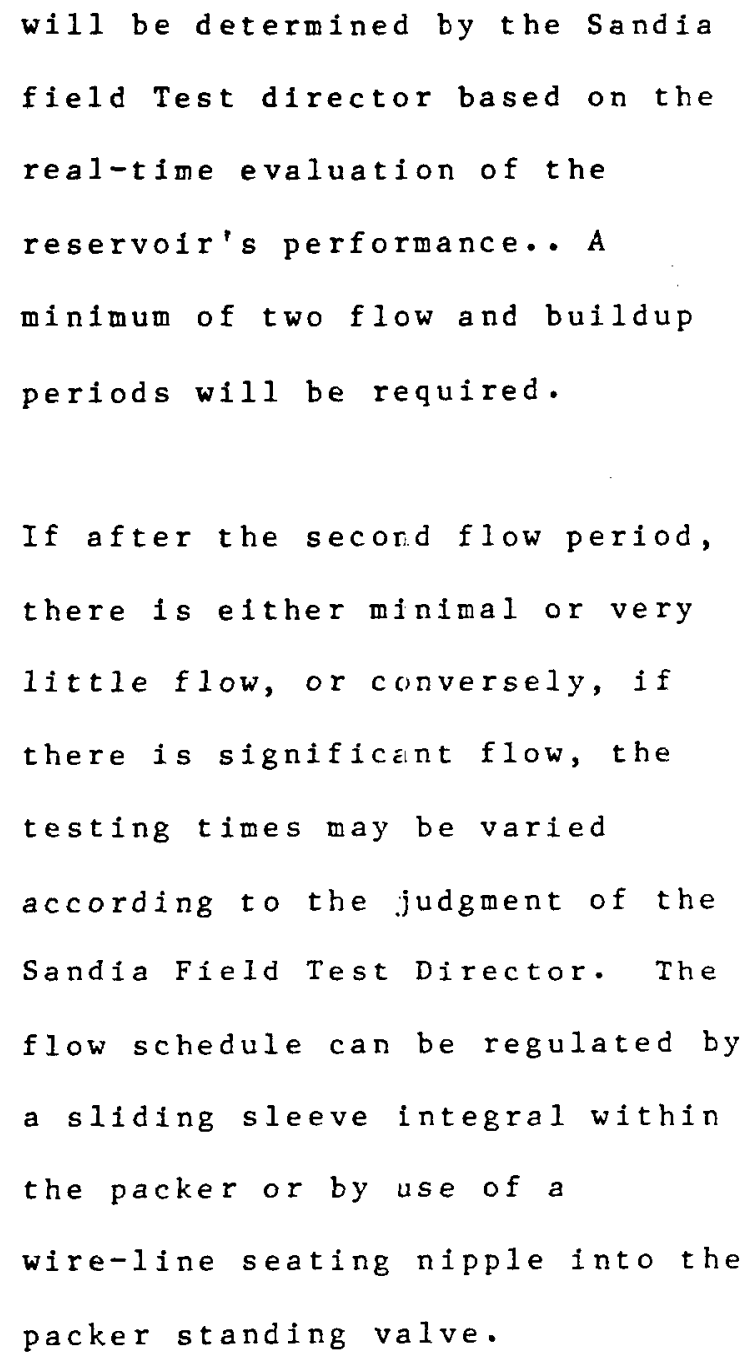

Page 30 


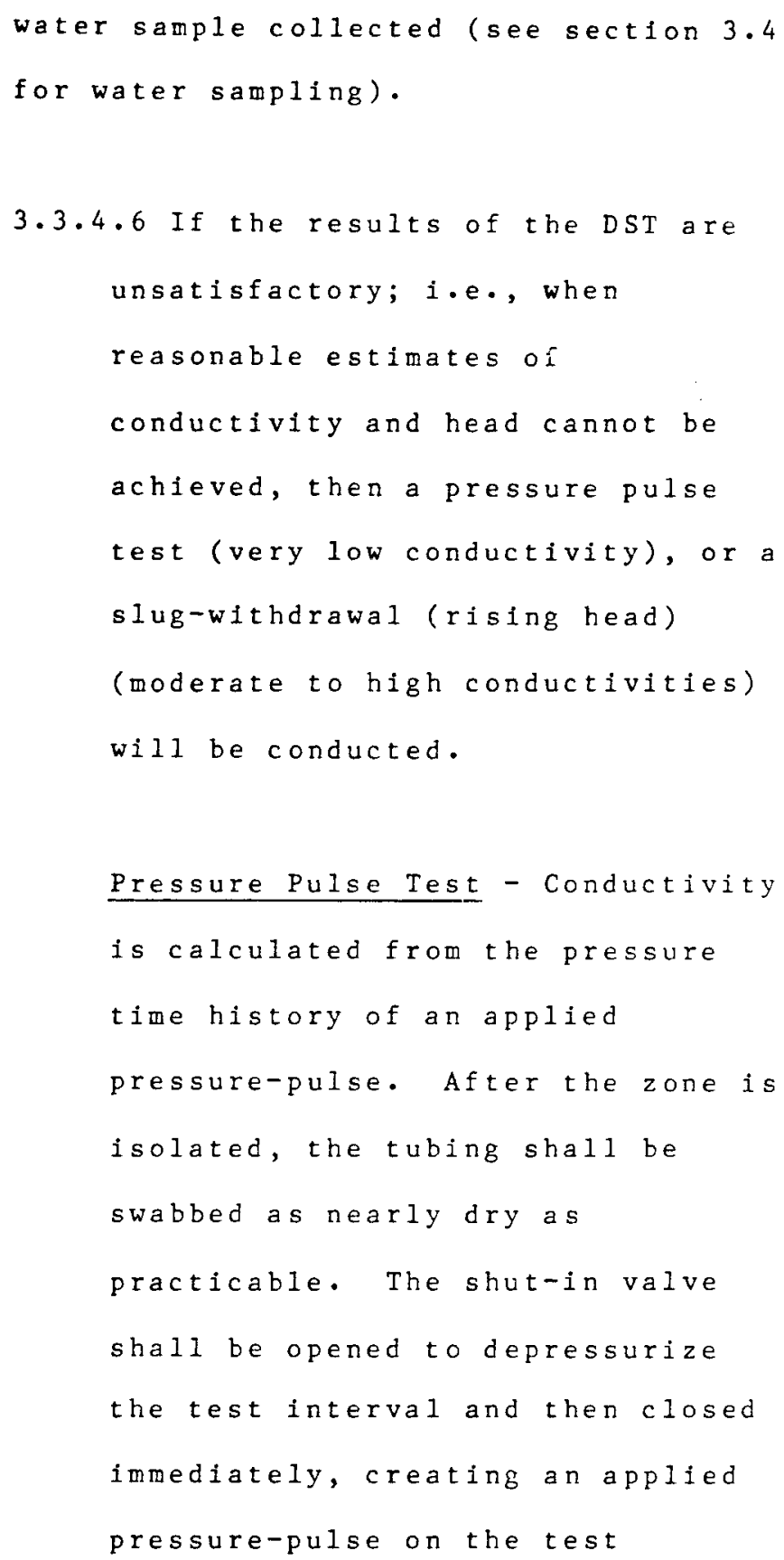

Page 31 


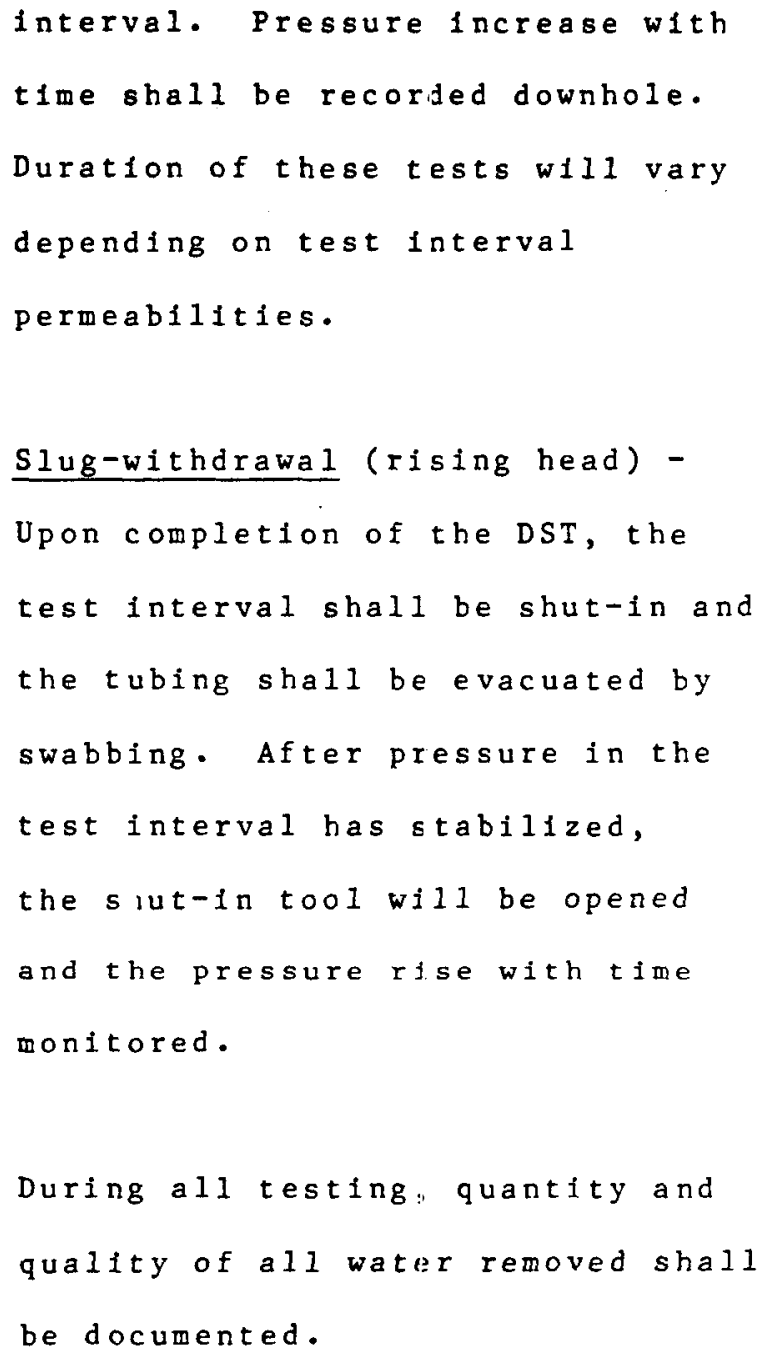




\subsection{Borehole Geophysical Logging Operations Procedure of Sandia National Laboratories - WIPP Site Investigation}

\subsubsection{Introduction}

This procedure is prepared by the Sandia National Laboratories Engineering Projects Division 7133 for use in Sandia's WIPP Site Investigation. The objective is to establish standard routines and methods for borehole geophysical logging in order to assure qualified data in a reliable manner.

To insure accuracy and quality of all work done, the logging company shall provide a description of their calibration and quality standards prior to award of the logging contract. For these tools requiring a calibration standard source, it must be traceable to the API standards or a recognized natural physical constant.

\subsubsection{Scope of Work}

Geophysical logging of boreholes in the WIPP Site Inves: Bations may include a wide variety of individual logging services. 
Logging services may be provided by several

different commercial firms utilizing

different types of tools and techniques.

Services may be purchased directly by Sandia

National Laboratories or through the

Drilling Engineering firms.

The scope of logging services may change for specific intervals depending on the test horizon conditions. The logging services may be changed at the discretion of the field operations director.

\subsubsection{Organization}

The Sandia laboratories is conducting this field work with technical direction from Earth Sciences Division 6331. Field operations are managed by Sandia Engineering Projects Division 7133 . 


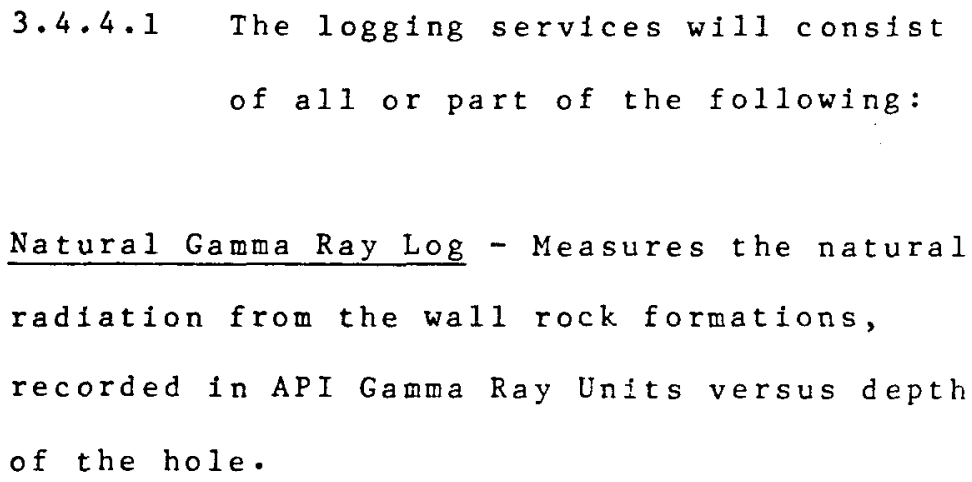




\section{Borehole Compensated Sonic Vejocity -}

Measures acoustic properties of borehole

wall rock compensated for borehole diameter

changes. Recording is of interval transit

time in microseconds/foot versus depth; used

to measure porosities and detect fractures.

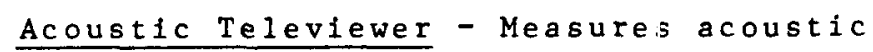

properties of borehole wall and converts

attenuation of sonic signal to "picture" of

borehole wall; used to identify and measure

fractures and their orientation on borehole

wa $11 \mathrm{~s}$.

Dual Laterolog - Measures laterally focused resistivity at two depths of penetration

from the borehole wall. Records in

ohmmeters versus depth; used to obtain true

rock resistivities and can be used as a

qualitative measure of permeability.

Temperature Log - Measures temperature of borehole fluid and records in degrees

fahrenheit versus depth; used to detect possible abnormalities of terperature that

may indicate fluid or gas entry into

borehole.

Page 36 
Directional/Deviation - Uses a compass and

photographic accessories to determine

deviation of the boreholes from vertical and

the direction of the deviation.

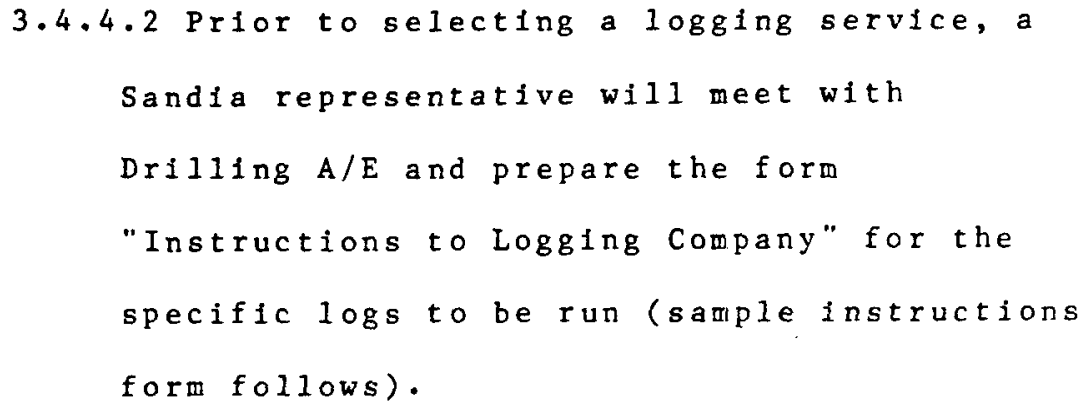

a) the entire logging program and special requirements,

b) hole conditions that may cause problems, and

c) zones of special interest.

3.4.4.4 During the pre-1og conference, the Sandia representative will discuss and request the following to be done: 


\section{INSTRUCTIONS TO LOGCING COMPANY}

Dete

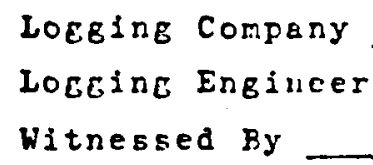

Lor Hendinfs:

Compāny

WeIl Number WJPP No.

Fiela County S_ State New Mexico

Location

Section Township irange

Permanent. Datum Elevations: $\quad K . B$.

LOB Neasured From

D.F.

Drilling Measured From

G. L . -

Hole statusi. SIZE FROM TO

SIZE FROM TO

Casings

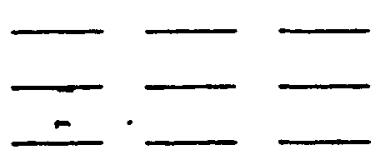

Borehole

Type Fluid in Borehole

Fluid Level

Density

pH

viscosity Fluid Loss -

$---------$

- - - -

Purpose of Loggirg Prograr, Zones or Special Interest, Critical Hole Conditions, Remarks, Etc. 
LOE. No.

(a) Vertical Depth scales 2-inches/100-reet and 5-1nchcs/300-reet

(b) llorizontal LoEgine Scales

(c) Logeing Specd Desircd

(d) Interval to be Loeeed

(e) Zones of Special Interest

(r) Special Instruction

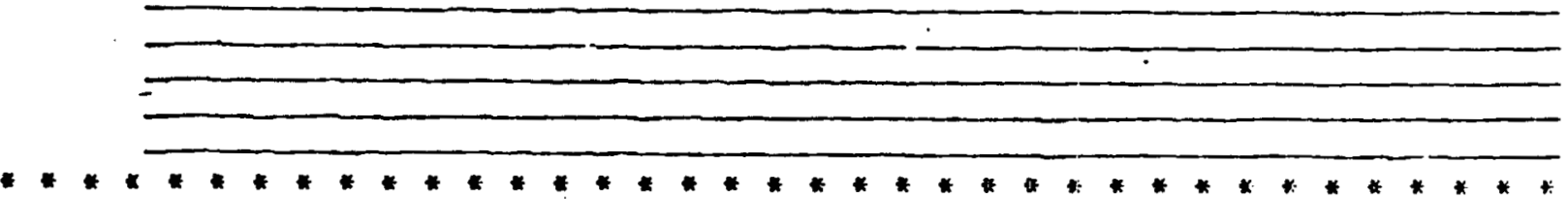

LOE. NO.

(a) Vertical Depth Scales 2-inches/100-reet and 5-inches/200-reet

(b) Horlzontal Loseing Scales

(c) LogBing Speed Desired

(d) Interval to be Logged

(e) Zones of Special Interest

(f) Special Instruction

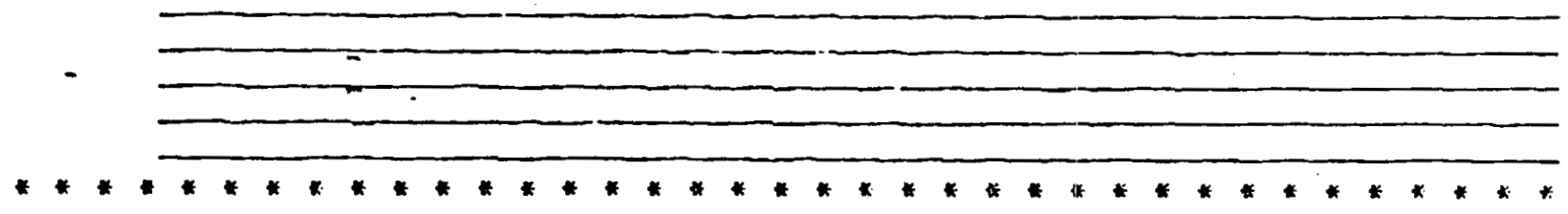

LOE. No.

(a) Vertical Depth Scales 2-inches/100-reet and 5-inches/100-fec:

(b) Horizontal Logeine Scales

(c) LoeEine Speed Dcsired

(d) Interval to be Logecd

(e) zones or special Interest

(r) Special Inctruction 


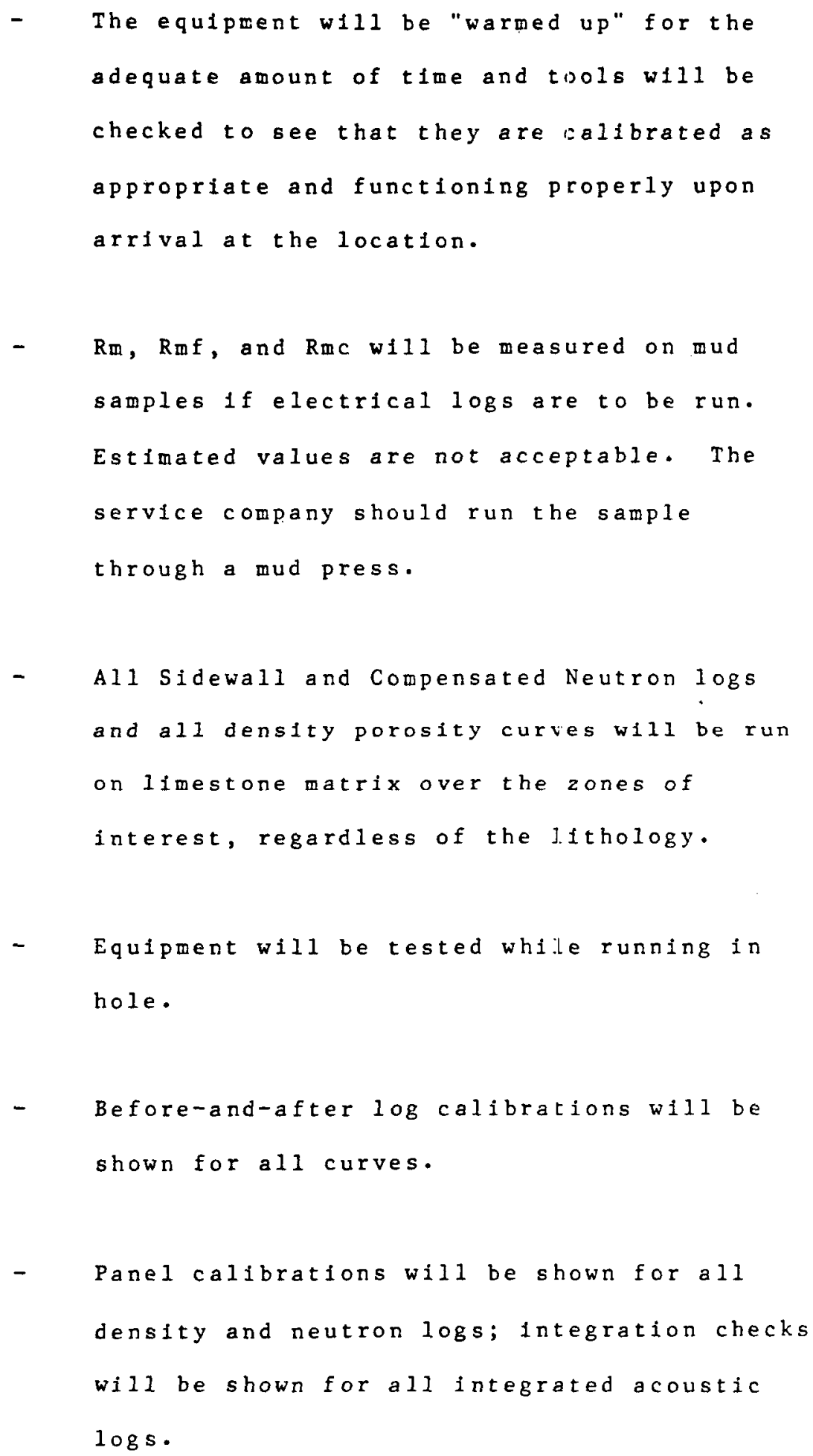

Page 38 
- In addition to caliper rings, the caliper calibration should show "tool full open" and casing readings.

- A minimum 200 feet repeat must be shown.

- Overlap previous runs by at least 200 feet.

- All headings information will be completely filled out.

- In addition, all open-hole commercial logs shall be digitized and recorded on magnetic tape.

3.4.4.5 The Sandia logging representative will be present and observe the logging operation to the extent necessary to assure objectives have been met. He should complete a "Log Quality Report" (sample follows) following the operation and, along with a copy of "Instructions to Logging Company", forward to Sandia Engfneering Projects Division 7133 .

\subsubsection{Records}

\subsubsection{1 "Instruction to Logging Company"}


Hole

Log Dole

Current Dote

$\log$

Run :

fingr.

Ficld Print

Finol Print

$\log$ Anolyst

CHECK ALL BOXES - ACCEPTARLE YES OR UNACCEPTABLE NO

Sestions not opplicoble to o particulor service, Leove Blonk.

A. HEADIRG

1. Correct Heoding Used

2. Heoding Dota Properly Completed

3. Equipment Used Section Compicted

4. Equipment Deto Sestion Completed

5. Scole Charges Noted on Heoding

6. Are oll obnormal conditions exploined in the iemorks section

B. Calibrations and scales

1. Sroles Correst for Areo

2. Seoles Lobelled

3. Seole Chonzes Labellea

4. Zeroes Recorded

5. Before Log Colibrations

6. Aller Log Colibrotions

7. Repeol Section Recorded

8. Repest Section Acceptable

C. VALIDITY OF LOG

1. Curves Functioning Correctly

2. Do Log volues fall within reosonoble limits

3. Curves on Depth

4. Logging Speed Indicoted

3. Lopging Speed Correct

D. APPEARANCE

1. Printing or Typing Neot

2. Prinling or Typing Accurate

3. Grid and ren Traces

4. Splicer siroight and $\mathrm{Cl}_{\text {won }}$

5. Film Correctiy Processod

6. Coneival Punt Quality
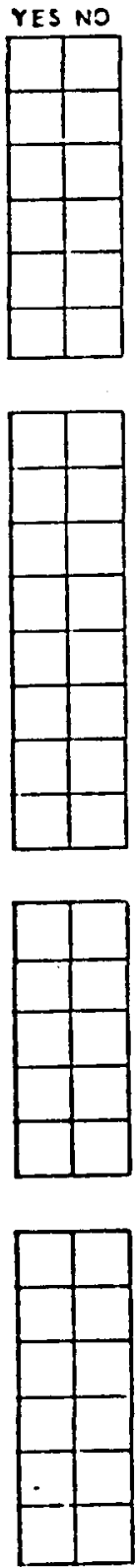

REMARKS: Cose Remarts with the proper Section Numler.

REMARKS: Cose Remorts with live proper Section Number.
For Exomple: Remorks concerning telore log colitirations would be coded B.5.

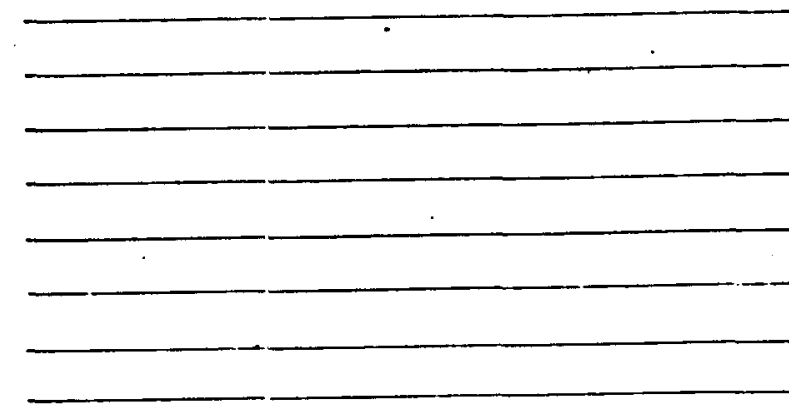


A/E should prepare instsructions

following a conference with Sandia

representative, and provide ten copies

to Sandia Field Engineering Division

7133.

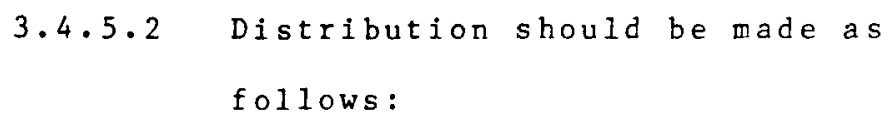

1 Logging Company

1 Sandia Representative - observing $10 g$ operations

I $\mathrm{A} / \mathrm{E}$

2 TSC Records Center, Carlsbad

1 Sandia WIPP Central Files (SCWF)

1 Sandia Division 7133, ABQ

1 Sandia Division 6331, ABQ

1 USGS, Regiona1 Geology, Denver Attn: R. P. Snyder

1 USGS/WRD, ABQ, Attn: J. Hudson

\subsubsection{Log Quality Report}

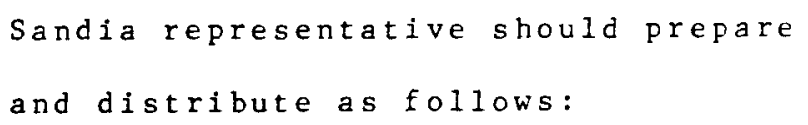

Page 40 
3 Orfginal and two coples to

Sandia Eng. Projectis D1v 7133 ,

$A B Q$, who w1ll be reisponstble

for forwarding to W:LP Central

Files

2 Sandia Earth Sciences Div 6331, ABQ, Attn: D. J. Borns

1 Sandia Carlsbad Hole File

$1 \mathrm{~A} / \mathrm{E}$

3.4.5.4 Geophysical Logs (Field Prints)

A/E should obtain 10 copies of $10 \mathrm{~g}$

field prints and distribute as follows:

1 Sandia Carlsbad Hole File

1 USGS, Regional Geology, Denver, Attn: R. P. Snyder

1 USGS/WRD, ABQ, Attn: J. Daniel

2 Sandia Div 6331 , ABQ, Attn:

D. J. Borns, R. L. Beauheim

I Sandia Div 7133, ABQ, Attn:

J. W. Mercer

$3 \mathrm{~A} / \mathrm{E}$ ( 3 copies)

Page 41 
3.4.5.5 Geophysical Logs (Final Prints)

A/E should order 15 final copies of logs and two coples of library magnetic tapes of the logs and distribute as follows :

2 TSC Records Center, Carlsbad

1 USGS, Regional Geology, Denver, Attn: R. P. Snyder

1 USGS/WRD, ABQ, Attn: J. Hudson

3 Sandia Div 6331, ABQ, Attn:

A. R. Lappin, D. J. Borns, R. L. Beauheim

2 Sandia Div 7133, Abq, Attn: J.W. Mercer

2 Sandia WIPP Central File, $A B Q$, 2 copies $\operatorname{logs} \& 2$ copies tapes

$1 \mathrm{~A} / \mathrm{E}$

1 State Engineer, Roswe11, NM

1 USGS Area Geologist, Roswe11, NM

1 West Texas Electric Log Service

Page 42 


\subsection{Cementing Operations Procedure of Sandia National Laboratory, WIPP Site Investigations}

$3 \cdot 5 \cdot 1$

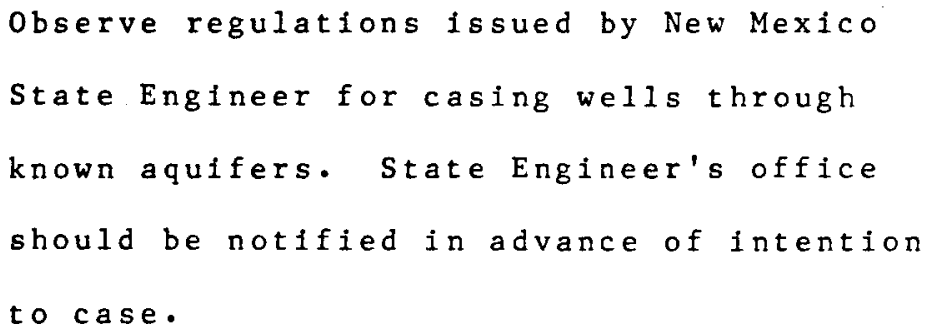

3.5.2 Condition the hole, ream if necessary to remove tight places. Run a caliper log as necessary to calculate the proper amount of cement and help in selecting the appropriate positioning of centralizers.

3.5.3 Inspect the casing to be run. Sandblast if necessary to remove severe rust flakes. Install centralizers in optimum position, usually $60-90^{\circ}$ apart. Install combination float collar and guide shoe.

3.5.4 Run the casing string and land at preselected depth. 


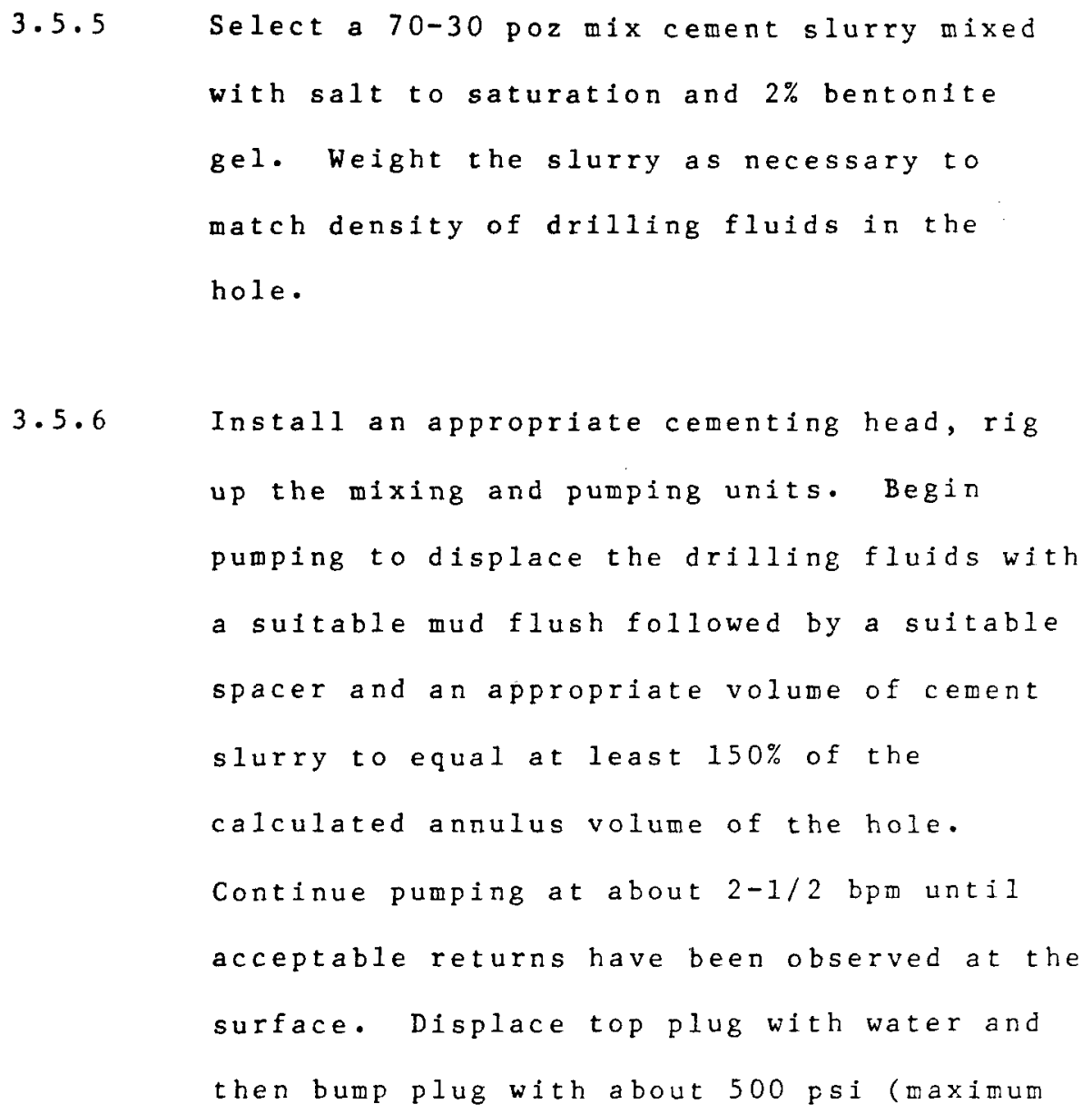


of 1000 psi) over displacinis pressure.

Check float and if it is holding, close in cementing head and W.O.C. for 24 to 48 hours. Maintain tension in the casing string while cement is setting.

$3 \cdot 5 \cdot 7$ Run a casing pressure test before drilling out the plug. Apply a pressure of about 600 psi and hold for 30 minutes and observe. If a pressure drop of 100 psi or more is observed, take corrective measures and repeat the test. If pressure drop is less, cementing job is considered. complete. Pick up the appropriate size bit and proceed to drill out the plug and continue with the program as directed. 


\subsection{Water Sampling Procedures of Sandia National \\ Laboratories - WIPP S1te Invest1gations}

\subsubsection{Introduction}

This procedure is prepared by the Engineering Projects Division 7133 for use In the Sandia National Laboratories WIPP Program; in particular, to Phase II testing of DOE-2. The objective is to provide guidelines to obtain the best representative water sample from fluld-bearing zones in DOE -2 .

\subsubsection{Scope of Work}

The water sampling program of Phase II is designed to obtain the best representative water sample from intervals which contain fluid in exploratory well DOE-2. It is anticipated that only the Bell Canyon Formation can produce enough fluid, within a reasonable time period, for sampling. The water samples will be analyzed for major chemical constituents, fluid density, and 
possibly certain isotopes. It is understood that whenever water samples are taken under open-hole conditions and uncler methods described in Section 3, there exists the potential for contamination.

\subsubsection{Organization}

Sandia Laboratories is conducting the field work under the technical direction of Field

Sciences Division 6331. The Sandia

Engineering Projects Division 7133 will

manage field operations. The A/E will

prepare and administer a drilling progran

from criteria provided by sandia that

Includes water sampling.

\section{$3.6 .4 \quad$ Operations}

3.6.4.I A review of the geophysical logs and DTS of Phase II, DOE-2, will identify the selected intervals to be sampled. 


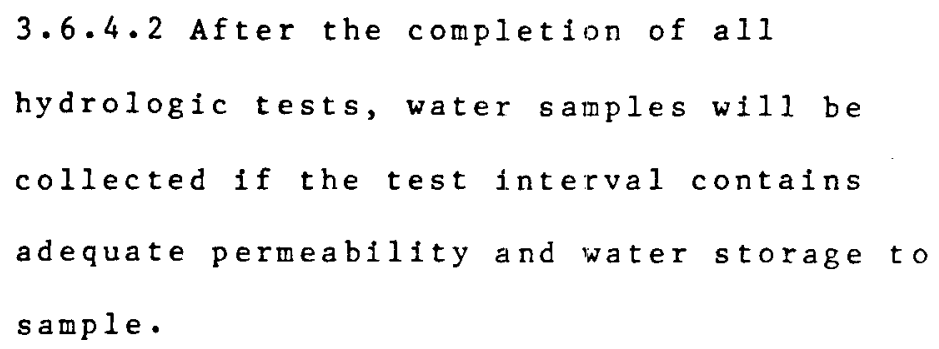

Page 48 


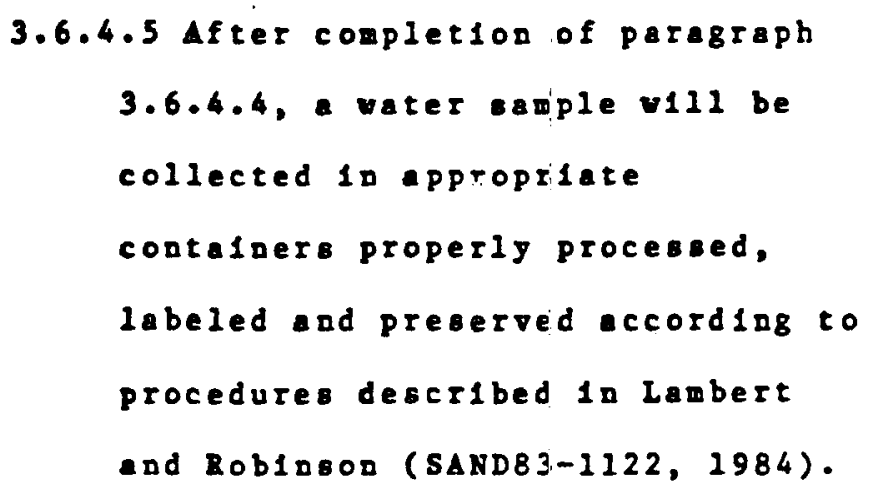

Page 49 


\subsection{Dalis Report}

4/8, Carlobed offlce, v111 provide to sandia, cariabad, a copy of the dally report. Sadia, carlabed, -111 telefax tbe dally report on veekdays to D17101006331 ad D17181087133 1n Albuquerque. A copj of the dally report w111 be kept on file in the sandia Carlobad office.

\subsection{D.11Y TIDe. 208}

$\triangle$ Dalig IIne Log will be wastaloed by the $A / E$ dri1118g epeciallet. Two coples vill be proplded to tbe sadia, carlabad office. Sandia, Carlsbad office will aldata. file of the 108 .

\subsection{Hole Bletory}

$\triangle$ Bole Blatory of the drild108 activities will be prepared by $1 / 2$ fron thelr daly time $10 \mathrm{gB}$ and other pertineat records. A reproducible copg of this b1story to to be cent to J.H. Mercer, D181s10n 7133, ABQ, fol10w108 conpletion of fleld activities for absequat dietribut1od. 


\subsection{Misclianeous Records}

$\triangle$ variety of recorde are kept by $\Delta / E$ that w111 be useful in bletoricel preparation. These are to be kept on flle la Carlabad vblle the progran lo active and on conplet10n, copj forvarded to J. Wercer, D1rla10a 7133, for placenent 1a the ripp central f1le. They 1nclude:

Dr11ler Loge, B1t Records, Dr111108 FIu1d

Recape, Bqu1paent Cert1f1cat100, Dr1111ng

B1story Cbart, ad Cost Records. 


\begin{abstract}
Because of concern orer encountering a bloc-recervolr in the Catile Forietion. the rield Operatione plan is changed to Incorporate bydrologic testing of the salado Poreation inmedlatels after tbe salado-castle contact tas been peretrated ad prior to furtber corlag of the castile Formation.
\end{abstract}

2.3.12.1 Chage over from orlented to confentional corlog equipent ad resume continuous corlog to about 2165 feet (GL) or untll the salado ond Cabtlie Formation contact has been 1deatifled.

\title{
2.3.12.3 Geophyelcal 1086 to be run Include formation denstig, catural radioectivity. porosity, and borehole geometry (calsper).
}

2.3.12.4 OpOD conplet1on of $108 \mathrm{~g} 10 \mathrm{~g}$, wu nulitple drill-stem cecte baed on evaluation of core and geophysical 108*. Tete w111 proceed up-bole from the bottow interval uolog eltber olggle or etraddle test aceabis.

\subsubsection{5 reat Intervals to be lovestgated loclude ang} ouspected cones of permeablilts and/or fluld entry. Becaree of the loterest id the facility horizon, 


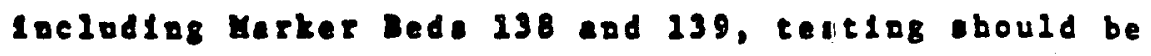
cosducted acrose this laterval.

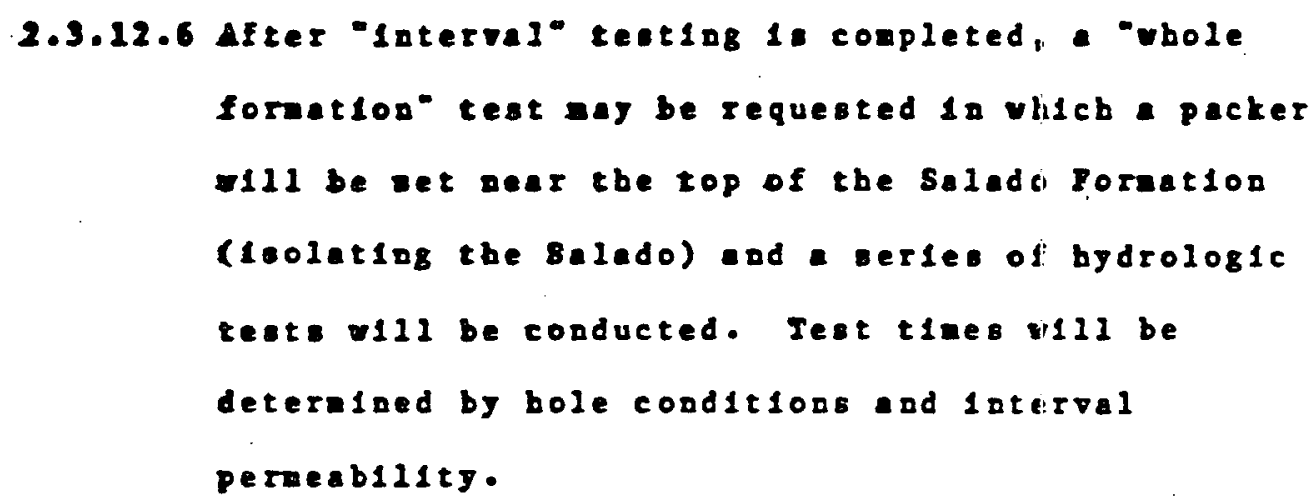




\section{APPENDIX C}

\section{Abridged Hole History of Drillhole DOE-2: Phases I, II, and III}





\section{C.1 Data From Sandia National Laboratories}

Note: Depths reported will be from ground level (GL) unless otherwise noted.

8-13-84 Began constructing a compacted caliche pad at DOE-2 drill site. Removed vegetation and leveled area.

8-14-84 Completed construction of drill site; nominal $100 \times 100-\mathrm{ft}$ pad.

8-15-84 Moved in Abbott Bros. auger rig. Augered nominal 20-in.-dia hole (using air) from 0 to $40.1 \mathrm{ft}$. Set and aligned 13-3/8-in.-OD, 48-1b, H-40 surface casing to $39.9 \mathrm{ft}$. Cemented annulus to surface with $81 \mathrm{ft}^{3}$ of ready-mix.

8-20-84 Moved in SNL B-15 van-trailer, USGS trailer, and generators.

8-24-84 Buried steel mud-pits in preparation for drilling contractor. Moved in Pennsylvania Drilling Co. Failing 2000 drill rig. Completed mobilization of Failing 2000 rig and ancillary equipment.

8-26-84 No activity.

8-27-84 Picked up 4-3/4-in. rock bit and tripped in hole to drill from $40 \mathrm{ft}$ to $45 \mathrm{ft}$ using air as circulating medium. Rigged up casing head for coring.

Note: See attached core record for intervals, times, and recovery.

8-28-84 Repaired injection pump and rigged up flow line. Picked up 10-ft split-core barrel with 3-7/8-in.-OD diamond core head to cut 2-1/4-in.-dia core. Tripped in hole with core barrel to $45 \mathrm{ft}$. Cut cores Nos. 1 through 6 from $45 \mathrm{ft}$ to $98.8 \mathrm{ft}$.

8-29-84 Cut cores Nos. 7 through 13 from $98.8 \mathrm{ft}$ to $161 \mathrm{ft}$.

8-30-84 Cut cores Nos. 14 through 22 from $161 \mathrm{ft}$ to $240 \mathrm{ft}$.

8-31-84 Cut cores Nos. 23 through 32 from $240 \mathrm{ft}$ to $339 \mathrm{ft}$.

9-01-84 Cut cores Nos. 33 through 36 from $339 \mathrm{ft}$ to $371.5 \mathrm{ft}$.

9-02-84 Cut cores Nos. 37 through 38 from $371.5 \mathrm{ft}$ to $382.5 \mathrm{ft}$.
9-03-84 No activity.

9-04-84 Cut cores Nos. 39 through 46 from $382.5 \mathrm{ft}$ to $460.9 \mathrm{ft}$.

9-05-84 Cut cores Nos. 47 through 48 from $460.9 \mathrm{ft}$ to $477 \mathrm{ft}$. Stuck core barrel at $477 \mathrm{ft}$. Backed off pipe one stand down from surface. Star Tool on site; made up fishing tools; working to recover stuck pipe.

9-06-84 Jarring on fish; unable to move core barrel. Decided to shoot off drill pipe and ream hole down to core barrel and wash over same. Rotary Wireline on site to shoot off drill pipe just above core barrel. Pipe shot off; recovered drill pipe. Picked up 4-3/4in. bit, tripped in, and began reaming hole using brine as circulating medium.

9-07-84 Reaming at $190 \mathrm{ft}$; clutch problems. Repaired clutch and reamed down to $444 \mathrm{ft}$.

9-08-84 Tripped drill pipe and picked up washover pipe to top of fish at $445 \mathrm{ft}$. Fish consists of $20 \mathrm{ft}$ of drill pipe and $12 \mathrm{ft}$ of core barrel. Began washover operation. Tripped out with washover pipe to inspect wash-pipe shoe. Tripped back in hole; continued washing over. Made only $5 \mathrm{ft}$; so tripped out of hole and tripped in with 4-3/4-in. bit; tagged fish at $445 \mathrm{ft}$. Tripped out of hole with bit, replaced with new shoe, tripped back in hole to $450 \mathrm{ft}$, and continued washover operation. Not making hole. Tripped washover pipe, breaking joints; found pipe blocked. Cleaned out pipe; tripped back in hole and continued washover. Finally making hole.

9-09-84 Continued washover operation to $477 \mathrm{ft}$. Tripped pipe and ran in 3-1/2-in. overshot; no fish. Tripped in with 3-7/16-in. overshot and recovered core barrel. Broke down fishing equipment. Secured operations at 1000 hr.

9-10-84 Repair work on rotary table and swivel. Picked up core barrel and tripped in to cut cores Nos. 49 through 51 from $478 \mathrm{ft}$ to 501 $\mathrm{ft}$ using $10 \mathrm{lb} / \mathrm{gal}$ brine as circulating medium. Hole taking quite a large volume of brine.

9-11-84 Cut cores Nos. 52 through 58 from $501 \mathrm{ft}$ to $561 \mathrm{ft}$. Constructors Inc. on site to extend drill pad. 
9-12-84 Cut cores Nos. 59 through 64 from $561 \mathrm{ft}$ to $621 \mathrm{ft}$.

9-13-84 Cut cores Nos. 65 through 66 from $621 \mathrm{ft}$ to $641 \mathrm{ft}$. Suspended coring operation to conduct hydrologic tests. Hole evacuated of brine using air. Made up hydrologic test tool, checked out instrumentation, and started tripping in hole.

9-14-84 Set packer at $530 \mathrm{ft}$ with 500 psi. Tried injection test; extremely low permeability; switched to constant head. Formation too tight; terminated test and tripped out with hydrologic test tool. Picked up core barrel and tripped in to cut cores Nos. 67 through 74 from $641 \mathrm{ft}$ to $721 \mathrm{ft}$. Hole continuing to take brine.

9-15-84 Cut cores Nos. 75 through 85 from $721 \mathrm{ft}$ to $831 \mathrm{ft}$.

9-16-84 Cut cores Nos. 86 through 89 from $831 \mathrm{ft}$ to $858.5 \mathrm{ft}$. Hole continuing to take brine. Secured rig for Sunday at $0800 \mathrm{hr}$.

9-17-84 Resumed coring operations at $0800 \mathrm{hr}$ and, while cutting core No. 90 , had to trip core barrel to repair sand line. Core No. 90 ran from $858.5 \mathrm{ft}$ to $861 \mathrm{ft}$. Cut core Nos. 91 through 96 from $861 \mathrm{ft}$ to $921.4 \mathrm{ft}$.

9-18-84 Cut cores Nos. 97 through 102 from $921.4 \mathrm{ft}$ to a total depth of $981 \mathrm{ft}$. Hole completed, tripped out laying down pipe. Secured drill pad until 10-8-84.

10-08-84 Resumed operations. Fluid level in drillhole at $355.24 \mathrm{ft}$ below top of casing. Picked up 4-3/4-in. bit and tripped in to ream drillhole. While reaming hole, hit tight spot at $560 \mathrm{ft}$. Added $12.5 \mathrm{lb}$ of NASCN tracer to $250 \mathrm{bbl}$ of brine. Collected sample for analysis. Added brine with NASCN tracer to drilling fluid while reaming at $650 \mathrm{ft}$. Continued reaming to $690 \mathrm{ft}$. Tripped out pipe with bit. Secured pad at $1600 \mathrm{hr}$.

10-10-84 USGS on site at $0010 \mathrm{hr}$ to run geophysical logs. Geophysical logs run included gamma ray, caliper, gamma-gamma density, neutron porosity, and acoustic televiewer. Completed logging operations at $0900 \mathrm{hr}$. Made up hydrologic test tool, ran calibrations, and checked instrumentation.
10-11-84 Picked up hydrologic test tool and tripped in hole, running test tool on 2-3/8-in. tubing. Straddle packers set isolating the Rustler/Salado contact zone from $945 \mathrm{ft}$ to $967 \mathrm{ft}$. Bailed fluid from tubing and placed well on tést. No flow from test interval; well put on slug test at $2000 \mathrm{hr}$.

10-12-84 Well on test; no flow from interval. Terminated test at $0910 \mathrm{hr}$; deflated packers and moved up hole. Inflated straddle packers at $1015 \mathrm{hr}$ isolating the Culebra dolomite from $823 \mathrm{ft}$ to $846 \mathrm{ft}$. Bailed tubing and collected water sample for density measurement. Conducted series of flow, buildup, and slug tests. Tests indicate rapid response of interval to tests. Terminated hydrolog̣ic tests at $1650 \mathrm{hr}$; deflated packers and $\mid$ moved up hole. Inflated straddle packers, isolating the Tamarisk interval from $79.5 \mathrm{ft}$ to $818 \mathrm{ft}$. Test interval shut in at 1725 hr. Bailed tubing and began hydrologic tests at $2208 \mathrm{hr}$. Well on test.

10-13-84 Continued tests on Tamarisk interval. Terminated test at $1235 \mathrm{hr}$; deflated packers and moved up hole. Inflated straddle packers at $1342 \mathrm{hr}$, isolating Magenta dolomite from $7 \mathrm{CO} 0 \mathrm{ft}$ to $722 \mathrm{ft}$. Bailed tubing and collected sample for density determination. Began flow test on Magenta at $1647 \mathrm{hr}$. Produced very little fluid. Shut in well at $1722 \mathrm{hr}$. Well on test.

10-14-84 Terminated shut-in test and began slug test at $0916 \mathrm{hr}$. Well on test.

10-15-84 Terminated test on Magenta dolomite at $0830 \mathrm{hr}$; deflated packers and moved up hole. Inflated straddle packers at $0917 \mathrm{hr}$, isolating Forty-niner test interval from 664 $\mathrm{ft}$ to $686 \mathrm{ft}$. Test interval shut-in at $0935 \mathrm{hr}$. Bailed tubing. First flow period at $1035 \mathrm{hr}$, with shut-in at $1138 \mathrm{hr}$. Produced very little fluid. Slug test initiated at $2109 \mathrm{hr}$. Well on test.

10-16-84 Terminated test on Forty-niner interval at 0820 h. Deflated packers and tripped out with hydrologic test tool; demobilized tool. Picked up Lynes inflatable-bridge-plug packer to set just below Culebra dolomite. Set bridge plug, but when tried to unlatch from plug, unable to do so. Released bridge plug arid tripped out of hole. 
10-17-84 Called Lynes to bring new bridge plug. Picked up new inflatable-bridge-plug and ran in hole to just below Culebra dolomite; set packer unlatched and tripped out with tubing. Picked up pumping assembly consisting of Red Jacket pump below Baski packer. Set packer and tested pump. Started pump test at $0941 \mathrm{hr}$ at rate of 2.25 $\mathrm{gal} / \mathrm{min}$. Monitored discharge, temperature, and back pressure. Collected sample of fluid at $2300 \mathrm{hr}$. Well on test.

10-18-84 Pumping Culebra dolomite.

10-19-84 Pumping Culebra dolomite. Water quality samples collected at $0300 \mathrm{hr}$ and shut off pump at $0322 \mathrm{hr}$; monitored water level recovery. Deflated packer at $0335 \mathrm{hr}$ and tripped out with packer and pump assembly. Picked up 2-3/8 in. with "J" latch-on tool to retrieve bridge-plug packer. "J"'d onto packer, but unable to completely release packer. Finally dragged bridge packer out of hole. Picked up drill pipe and 7-7/8in. bit to ream hole. Reaming 4-3/4-in. hole to $7-7 / 8$ in. using $10 \mathrm{lb} /$ gal brine spiked with NASCN tracer.

10-20-84 Reaming hole to $7-7 / 8$ in.

10-21-84 Reaming hole to 7-7/8 in.

10-22-84 Reaming hole to 7-7/8 in.

10-23-84 Reaming hole to 7-7/8 in. Tripped pipe to replace bit.

10-24-84 Completed reaming hole to $981 \mathrm{ft}$, but when tripping out, got stuck at $\sim 840 \mathrm{ft}$. Added 5 bbl diesel fuel. Couldn't move up or down or rotate. Called out Star Tool to bring jars to try and get bit free. Rigged up Star equipment and knocked bit loose; tripped out of hole at $2315 \mathrm{hr}$.

10-25-84 Dresser-Atlas on site at $0130 \mathrm{hr}$ to run geophysical logs. Logs run include gamma, caliper, density, acoustic-velocity, neutron porosity, and dual laterolog. Completed logs at $1120 \mathrm{hr}$. Rigged down and demobilized rig. Completed DOE-2 Phase I operations.

\section{C.2 Data From Fenix \& Scisson, Inc., Tulsa, OK}

\section{C.2.1 History Data for Phase II}

Well Name: WIPP DOE-2 (Figure C-1 and C-2)

Location: Sec.8, T.22S, R.31E

County: Eddy, NM Area: Los Medaños

Surface coordinates: Brass Monument; $697.71 \mathrm{ft}$ FSL $121.83 \mathrm{ft}$ FEL

Elevation: Brass Monument; $3418.35 \mathrm{ft}$

Start date: 4/27/85 Completion: 6/14/85

Circulating media: Saturated brine water; no additives

Rig \& Subcontractor: IDECO H-40, Verna Corporation Rig No. 26

\begin{tabular}{rrr}
\multicolumn{3}{c}{ Borehole Record } \\
\hline $\begin{array}{r}\text { Size } \\
\text { (in.) }\end{array}$ & $\begin{array}{c}\text { From } \\
\text { (ft) }\end{array}$ & $\begin{array}{r}\text { To } \\
\text { (ft) }\end{array}$ \\
\hline $17-1 / 2$ & 0 & 39 \\
$12-1 / 4$ & 39 & 1009 \\
$7-7 / 8$ & 1009 & 4325
\end{tabular}

Total depth: $4325 \mathrm{ft}$ below elevation

\section{Remarks:}

This report is for Phase II of the subject hole operations, continuous coring from 1011 to $4325 \mathrm{ft}$.

See attached coring record for intervals, times, and recovery. For geophysical logs, see attached index.

This work conducted under Sandia National Laboratories (SNL) Contract 21-6788. Fenix \& Scisson, Inc. Project \#486.

Prepared for

Sandia National Laboratories

Albuquerque, New Mexico 


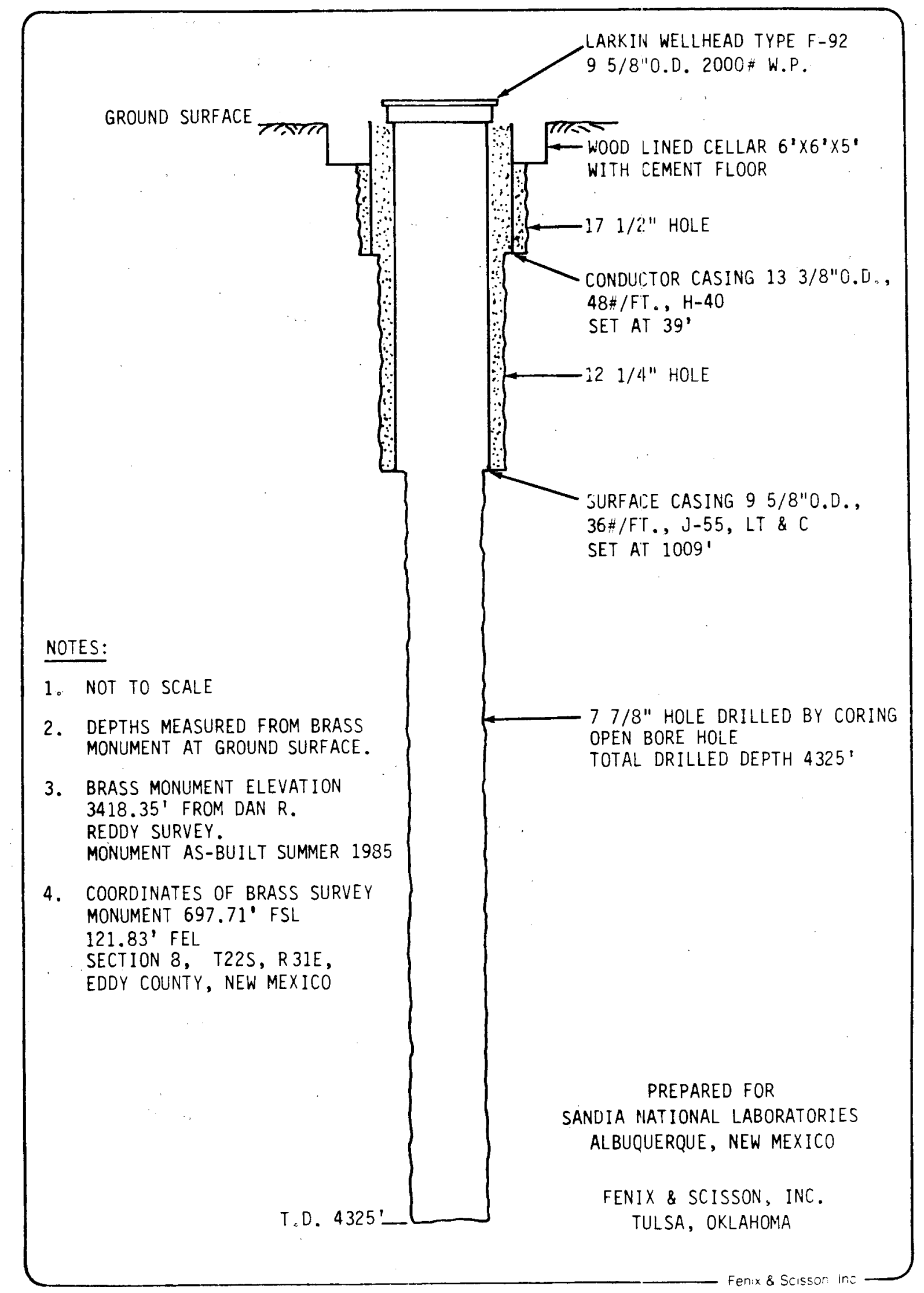

Figure C-1. Drillhole DOE-2 As-Built Conditions After Hydrologic Tests, July 1985 


\section{Survey Monument "As Built" D.O.E. II}

Section_8. Township_22S, Range 3IE NMPM , Eddy County, New Mexico ELEVATION OF BRASS MONUMENT 3418.35 $697.71^{\prime} F S L$ and $121.83^{\prime}$ FEL

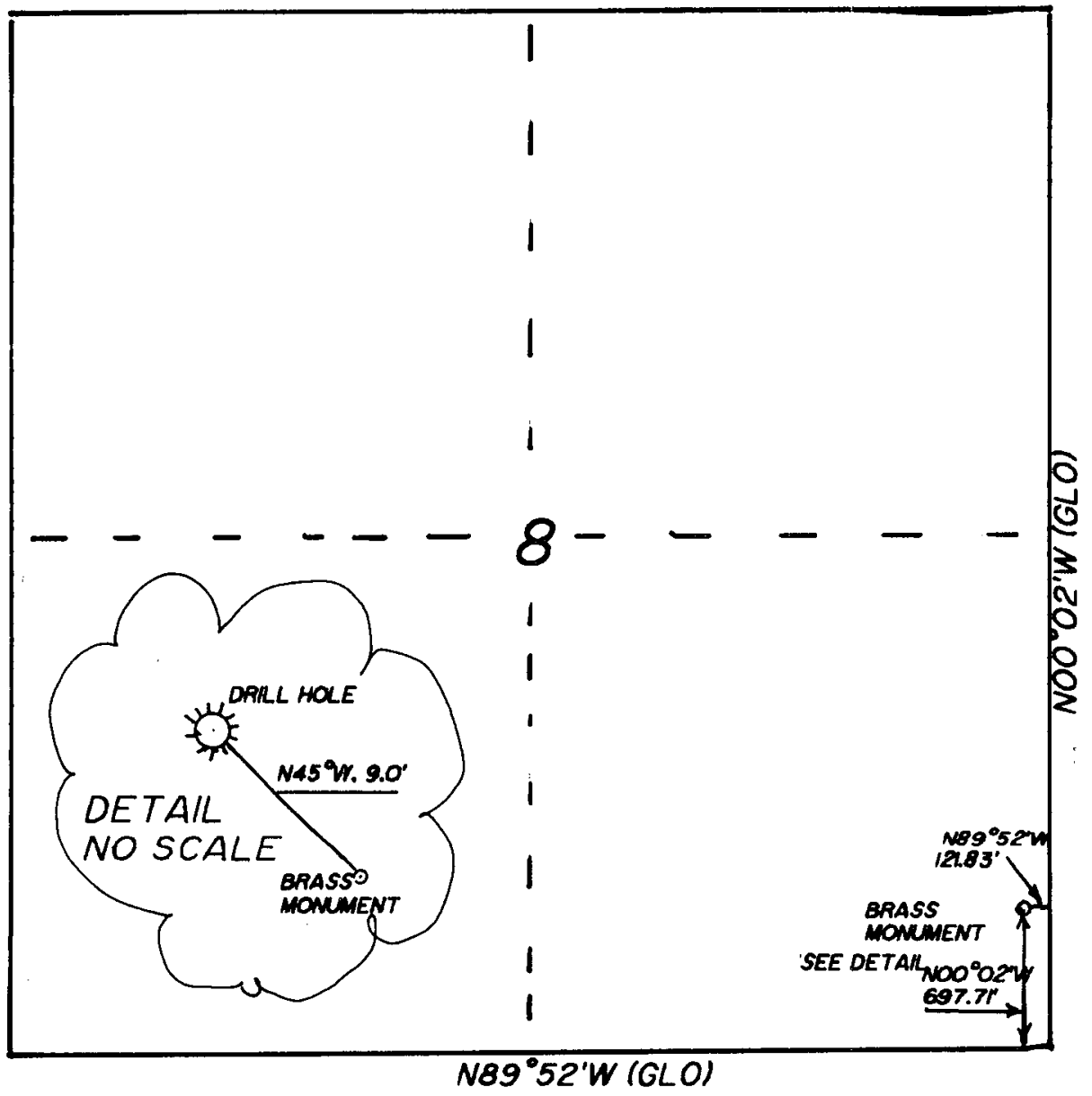

\section{Certification:}

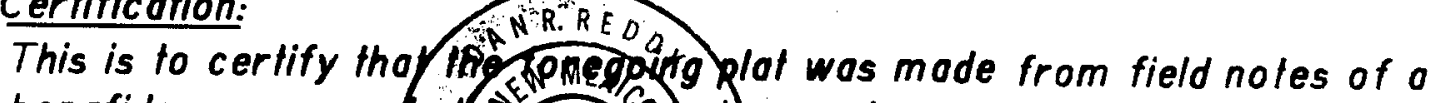
bonofide survey mo e prime anf in the and correct to the best of my knowledge ond belie 50

Figure C-2. As-Built Survey Monument of Drillhole DOE-2

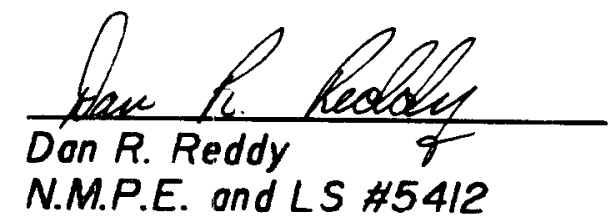




\section{C.2.2 Conditions Existing Before Fenix \& Scisson, Inc. Occupation April 15, 1985, for Phase II}

1. $\pm 100 \times 100-\mathrm{ft}$ compacted caliche pad centered around the borehole.

2. Two $\pm 8 \times 30 \times 5$-ft deep holes. One hole $\pm 20 \mathrm{ft}$ north of the center of the wellbore. One hole on west edge of the pad. A $\pm 8 \times 30$-ft trailer van was located in the west hole.

3. A 13-3/8-in.-OD steel casing was set and cemented to the depth of $39 \mathrm{ft}$ below ground surface.

4. A 7-7/8-in.-dia open borehole was drilled to a depth of $\pm 981 \mathrm{ft}$ below ground surface.

5. A Lynes inflatable test packer was free in the borehole with fill on top of packer at unknown depth below $800 \mathrm{ft}$.

6. The borehole was filled with $\pm 10 \mathrm{lb} / \mathrm{gal}$ brine water.

\section{C.2.3 Abridged Hole History for Phase II}

4-15-85 Commence site preparation to extend existing $\pm 100 \times 100$-ft drill pad to $300 \times 300$ $\mathrm{ft}$ and fill and compact with caliche two existing $\pm 8 \times 30 \times 5$-ft deep holes. Removed vegetation and leveled ground. SNL B-15 trailer van on site in west hole.

4-16-85 Removed trailer van from hole. Continued to construction of drilling pad, a $6 \times 6 \times 5-\mathrm{ft}$ 4-19-85 deep wood-lined cellar and a $\pm 35 \times 75 \times 4$ $\mathrm{ft}$-deep earth reserve pit. Completed building location. Surface ready for drilling contractor.

4-20-85 Drilling contractor, Verna Corporation, drilled rat-and-mouse holes using air. Commenced moving in drilling equipment.

4-21-85 No activity.

4-22-85 Verna on location with Rig No. 26 and started off-loading.

4-23/24 Mobilization and rig-up.

4-25-85 Continued mobilization and rig-up. USGS ran borehole caliper $\log$ to $866 \mathrm{ft}$; ran gamma-ray log from ground level to $859 \mathrm{ft}$; oily fluid on wire line and logging tools. About $3 \mathrm{ft}$ of soft fill at $866 \mathrm{ft}$.
4-26-85 Continued mobilization and rig-up.

4-27-85 Mobilization and rig-up complete at 1100 $\mathrm{hr}$. Ran in hole with 7-7/8-in. bit and one 6-1/4-in. drill collar to top of fill at $855 \mathrm{ft}$. Washecl from $855 \mathrm{ft}$ to $878 \mathrm{ft}$, top of fish Lynes packer. Trip out, with drilling assembly. Trip in with over-shot and latched onto poicker at $878 \mathrm{ft}$. Retrieved and laid down packer at $0030 \mathrm{hr}, 4-28-85$.

4-28-85 Trip in hole with 7-7/8-in. bit. Washed and reamedi from $878 \mathrm{ft}$ to $981 \mathrm{ft}$, original total depth. No junk encountered. Drilled additional new 7-7/8-in. hole from $981 \mathrm{ft}$ to 1000 ft. Trip out drilling assembly. Ran magnetic multishot directional survey on $25-\mathrm{ft}$ stations to total depth. Rigged down survey equipment. Picked-up grant 12-1/4-in.-dia hole opener with 7-7/8-in.-dia pilot bit. Using bririe water, commenced reaming 7-7/8in. hole to $12-1 / 4 \mathrm{in}$. from $39 \mathrm{ft}$ to $115 \mathrm{ft}$. Repairs to swivel. Reamed 7-7/8 in. to 12-1/4 in. from $115 \mathrm{ft}$ to $302 \mathrm{ft}$. Hole taking fluid. Added $450 \mathrm{bbl}$ of brine water to pits: Repairs to rotary table.

4-29-85 Replaced swivel and rotary table. Reamed 7-7/8-in. to 12-1/4-in. diameter from $302 \mathrm{ft}$ to $440 \mathrm{ft}$.

4-30-85 Reamed 7-7/8-in. to 12-1/4-in.-dia from $440 \mathrm{ft}$ to $957 \mathrm{ft}$. Hole taking fluid. Added total of $750 \mathrm{bbl}$ brine water to pits this date.

5-01-85 Reamed 7-7/8-in. to 12-1/4-in. from $957 \mathrm{ft}$ to $1000 \mathrm{ft}$. Drilled additional new $12-1 / 4$-in. diameter from $1000 \mathrm{ft}$ to $1010 \mathrm{ft}$ total depth. Circulated and conditioned hole for caliper log. While tripping out, quickrelease valve did not release; tong handle struck floor man on right shoulder and chest; first aid was applied and injured person was transported to Carlsbad hospital in WIPP ambulance. Rigged up USGS logging unit and ran borehole caliber from $1010 \mathrm{ft}$; to ground level. Rigged up casing crew and ran 26 joints, $1034.28 \mathrm{ft}$, of 9-5/8in. casing, 36\# LT\&C; set at $1009 \mathrm{ft}$ below ground level; float collar $40.27 \mathrm{ft}$ above shoe. Flan centralizers on top of joints 2, 3, 9, 15, and 24. Made up Dowell circulating head and circulated. Commenced cementing with $20 \mathrm{bbl}$ of $\mathrm{CW}-7$ (chemical wash), then $27 \mathrm{bbl}$ of RFC-Class A (Thixotropic), followed by $72 \mathrm{bbl}$ of 70-30 Pozmix. Slurry 
mixed at 14.6 to $14.9 \mathrm{lb} / \mathrm{gal}$; pumped at 2.5 $\mathrm{bbl} / \mathrm{min}$. Released plug and displaced with $76 \mathrm{bbl}$ of brine water; cement back to surface. Total volume cement slurry used 98.7 bbl $-555 \mathrm{ft}^{3}$. Cement in place at $2000 \mathrm{hr}$. Wait on cement to harden.

5-02-85 Cement dropped back to $\pm 160 \mathrm{ft}$ below surface. Pumped $5 \mathrm{yd}^{3}$ of ready-mix 5 sack sand/cement between 13-3/8-in. casing and 9-5/8-in. casing filling $9-5 / 8$-in. annulus to surface.

5-03-85 Cut off 13-3/8-in. casing below ground level and cut off $9-5 / 8$ in. at ground level. Installed 3000-psi rated Larkin casing head. Installed blowout preventor and hydrill. Nippled up.

Note: See attached core record for intervals, times, and recovery.

Note: Core barrel is 6-7/8-in. OD $\times 60 \mathrm{ft}$ long with $7-27 / 32$-in.-OD diamond core head to cut 4-1/4-in.-dia core.

5-04-85 Using Yellow Jacket test unit, tested all BOP equipment to 2000 psi. Installed rotating drilling head and completed nipple up. Pressure-tested 9-5/8-in. casing to 600 psi for $30 \mathrm{~min}$; 50 -psi pressure drop. Using 7-7/8-in. bit, drilled out plug, float collar, cement, and shoe to $1011.6 \mathrm{ft}$ below ground level. Circulated clean and tripped out to pick-up core barrel. Trip in hole with core barrel and commenced coring at $1011.6 \mathrm{ft}$ at $2015 \mathrm{hr}$. Trip out with core No. 1 to $1042.9 \mathrm{ft}$ and laid down $31.7 \mathrm{ft}$ of core at $2400 \mathrm{hr}$. Note: $\pm 10 \mathrm{lb} / \mathrm{gal}$ brine water used as circulating media throughout all drilling and coring operations; no additives were used.

5-05-85 Coring operations; cut cores Nos. 2, 3, 4 from $1042.9 \mathrm{ft}$ to $1222.2 \mathrm{ft}$.

5-06-85 Cut cores Nos. 5, 6, 7, 8 from $1222.2 \mathrm{ft}$ to $1427 \mathrm{ft}$.

5-07-85 Cut cores Nos. 9, 10, 11, 12 from $1427 \mathrm{ft}$ to $1667 \mathrm{ft}$.

5-08-85 Cut core No. 13 from $1667 \mathrm{ft}$ to $1700 \mathrm{ft}$. Changed to oriented barrel. Cut core No. 14 from $1700 \mathrm{ft}$ to $1760.9 \mathrm{ft}$. Orientation surveys on 2 -ft intervals. Change to conventional barrel and cut core No. 15 from 1761 $\mathrm{ft}$ to $1821 \mathrm{ft}$.
5-09-85 Cut cores Nos. 16, 17, 18 from $1821 \mathrm{ft}$ to $2001 \mathrm{ft}$. Made "wiper" trip with 7-7/8-in. bit to $2001 \mathrm{ft}$.

5-10-85 Cut cores Nos. 19, 20, 21 from $2001 \mathrm{ft}$ to $2181 \mathrm{ft}$.

5-11-85 Cut cores Nos. 22, 23, 24, 25 from $2181 \mathrm{ft}$ to $2414.5 \mathrm{ft}$.

5-12-85 Cut cores Nos. 26, 27, 28 from $2414.5 \mathrm{ft}$ to $2595 \mathrm{ft}$.

5-13-85 Cut cores Nos. 29, 30. Core No. 29 was $60 \mathrm{ft}$ of oriented core from $2595 \mathrm{ft}$ to $2656 \mathrm{ft}$. Orientation surveys on 2 - $\mathrm{ft}$ intervals. Core No. 30 was from $2656 \mathrm{ft}$ to $2686 \mathrm{ft}$ oriented and $2686 \mathrm{ft}$ to $2716 \mathrm{ft}$ of conventional core.

5-14-85 Cut cores Nos. 31, 32, 33 from $2716 \mathrm{ft}$ to $2884 \mathrm{ft}$.

5-15-85 Cut cores Nos. 34, 35, 36 from $2884 \mathrm{ft}$ to $3064 \mathrm{ft}$.

5-16-85 Cut core No. 37 from $3064 \mathrm{ft}$ to $3095 \mathrm{ft}$. Tripped in hole with 7-7/8-in. bit and washed to bottom; circulated and conditioned hole to run logs. Commenced running geophysical logs to $3095 \mathrm{ft}$.

5-17-85 Ran gamma-ray, neutron, formation density, and borehole caliper logs from $3095 \mathrm{ft}$ to $\pm 950 \mathrm{ft}$ inside $9-5 / 8$-in.-OD casing. Rigged up tubing equipment to run 23/8-in. tubing for Lynes Hydrological Test Tool Systems. Trip in hole with $7-7 / 8$-in. bit to $3095 \mathrm{ft}$. Circulated and conditioned borehole. Trip out of hole.

5-18-85 Picked up Lynes hydrological test tool with 100-ft straddle and connected PEC conductor line to SNL computer unit. Trip in hole with 2-3/8-in. tubing and set inflatable packers. Bottom packer at $2320 \mathrm{ft}$. Top packer at $2210 \mathrm{ft}$. Operations as directed by SNL Test Director.

5-19-85 Well on test. Operations as directed by SNL Test Director.

5-20-85 Well on test until $1015 \mathrm{hr}$. Trip out with straddle test system. Picked up Lynes single packer test system. Trip in hole with 6 each 4-in.-OD drill collars and 2-3/8-in. tubing. Set inflatable packer at $1036 \mathrm{ft}$. Operations as directed by SNL Test Director. 
5-21-85 Well on test. Operations as directed by SNL Test Director.

5-22-85 Well on test until $1400 \mathrm{hr}$. Released packer and laid down tubing, collars, and Lynes tools. Trip in hole with 7-in.-OD magnet and junk basket.

5-23-85 Completed trip in hole with magnet and junk basket to $3095 \mathrm{ft}$; no fill. Circulated and conditioned hole; tripped out. No junk recovered. Picked up core barrel and tripped in hole for core No. 38 .

5-24-85 Completed cutting core No. 38 from $3095 \mathrm{ft}$ to $3155 \mathrm{ft}$. Started coring No. 39 .

5-25-85 Completed cutting core No. 39 from $3155 \mathrm{ft}$ to $3215 \mathrm{ft}$. Started core No. 40.

5-26-85 Completed cutting core No. 40 from $3215 \mathrm{ft}$ to $3275 \mathrm{ft}$. Cut core No. 41 from $3275 \mathrm{ft}$ to $3335 \mathrm{ft}$.

5-27-85 Changed to 30-ft-long oriented core barrel. Cut core No. 42 from $3335 \mathrm{ft}$ to $3365 \mathrm{ft}$. Orientation surveys on $2 \mathrm{ft}$ intervals. Changed to $60-\mathrm{ft}$ oriented core barrel.

5-28-85 Cut core No. 43 from $3365 \mathrm{ft}$ to $3425 \mathrm{ft}$. Orientation surveys on 2 -ft intervals.

5-29-85 Cut core No. 44 from $3425 \mathrm{ft}$ to $3485 \mathrm{ft}$. Orientation surveys on $2-\mathrm{ft}$ intervals. Changed to conventional core barrel. Started coring No. 45.

5-30-85 Completed cutting No. 45 from $3485 \mathrm{ft}$ to $3545 \mathrm{ft}$ and started No. 46.

5-31-85 Completed cutting core No. 46 from $3545 \mathrm{ft}$ to $3605 \mathrm{ft}$ and cut core No. 47 from $3605 \mathrm{ft}$ to $3665 \mathrm{ft}$.

6-01-85 Cut core No. 48 from $3665 \mathrm{ft}$ to $3725 \mathrm{ft}$ and started coring No. 49.
6-02-85 Completed core No. 49 from $3725 \mathrm{ft}$ to 3785

ft ancl started core No. 50 .

6-03-85 Completed core No. 50 from $3785 \mathrm{ft}$ to $3845 \mathrm{ft}$. Changed to oriented barrel. Started core No. 51. Orientation surveys on 2-ft intervals.

6-04-85 Completed cutting No. 51 from $3845 \mathrm{ft}$ to $3905 \mathrm{ft}$. Changed to conventional barrel. Cut core No. 52 from $3905 \mathrm{ft}$ to $3965 \mathrm{ft}$.

6-05-85 Cut core No. 53 from $3965 \mathrm{ft}$ to $4025 \mathrm{ft}$. Started core No. 54 .

6-06-85 Completed cutting core No. 54 from $4025 \mathrm{ft}$ to $4085 \mathrm{ft}$. Started core No. 55 .

6-07-85 Completed cutting core No. 55 from $4085 \mathrm{ft}$ to $4145 \mathrm{ft}$. Cut core No. 56 from $4145 \mathrm{ft}$ to $4205 \mathrm{ft}$.

6-08-85 Cut core No. 57 from $4205 \mathrm{ft}$ to $4265 \mathrm{ft}$. Cut core INo. 58 from $4265 \mathrm{ft}$ to $4325 \mathrm{ft}$. Coring operations complete. Total depth of the well is $4325 \mathrm{ft}$, ground level measurements. Trip in with $7-7 / 8$-in. bit. Circulate and condition borehole.

6-09-85 Trip out laying down drill pipe and assembly. Commence rigging down. Verna Corporation drill rig No. 26 released for demobilization at $1400 \mathrm{hr}$.

6-10-85 Demobilizing and moving out drilling and to related equipment.

6-12-85

6-13-85 Dresser-Atlas ran borehole geophysical and logs as programmed. (See Geophysical Log 6-14-85 Index: Sheet.)

Phase II operations complete. 


\section{C.2.4 Coring Record for Phase II}

\begin{tabular}{|c|c|c|c|c|c|c|c|}
\hline \multirow{2}{*}{$\begin{array}{c}\text { Core } \\
\text { No. } \\
\end{array}$} & \multirow{2}{*}{$\begin{array}{c}\text { From } \\
\text { (ft) }\end{array}$} & \multirow{2}{*}{$\begin{array}{l}\text { To } \\
\text { (ft) }\end{array}$} & \multicolumn{2}{|c|}{ Feet of Core } & \multirow{2}{*}{$\begin{array}{l}\text { Date } \\
1985\end{array}$} & \multirow{2}{*}{$\begin{array}{l}\text { Time } \\
(\mathrm{min})\end{array}$} & \multirow{2}{*}{$\begin{array}{l}\text { Type } \\
\text { Core }\end{array}$} \\
\hline & & & $\overline{\mathrm{Cut}}$ & Recovered & & & \\
\hline 1. & 1011.6 & 1042.9 & 31.3 & 31.7 & $5-04$ & 80 & C \\
\hline 2. & 1042.9 & 1102.9 & 60.0 & 58.1 & -05 & 205 & \\
\hline 3. & 1102.9 & 1162.6 & 59.7 & 61.4 & -05 & 188 & \\
\hline 4. & 1162.6 & 1222.2 & 59.7 & 61.0 & -05 & 160 & \\
\hline 5. & 1222.3 & 1281.3 & 59.0 & 59.0 & -06 & 147 & \\
\hline 6. & 1281.3 & 1342.0 & 60.7 & 60.0 & -06 & 160 & \\
\hline 7. & 1342.0 & 1402.0 & 60.0 & 60.0 & -06 & 161 & \\
\hline 8. & 1402.0 & 1427.0 & 25.0 & 25.9 & -06 & 124 & \\
\hline 9. & 1427.0 & 1487.0 & 60.0 & 60.0 & -07 & 116 & \\
\hline 10. & 1487.0 & 1547.0 & 60.0 & 59.5 & -07 & 149 & \\
\hline 11. & 1547.0 & 1607.0 & 60.0 & 60.0 & -07 & 222 & \\
\hline 12. & 1607.0 & 1667.0 & 60.0 & 60.0 & -07 & 245 & \\
\hline 13. & 1667.0 & 1700.0 & 33.0 & 32.6 & -08 & 94 & 7 \\
\hline 14. & 1700.0 & 1760.9 & 60.9 & 60.9 & -08 & 402 & $\mathrm{O}$ \\
\hline 15. & 1761.0 & 1821.0 & 60.0 & 60.0 & -08 & 155 & $\mathrm{C}$ \\
\hline 16. & 1821.0 & 1881.0 & 60.0 & 60.0 & -09 & 159 & \\
\hline 17. & 1881.0 & 1941.0 & 60.0 & 60.0 & -09 & 167 & \\
\hline 18. & 1941.0 & 2001.0 & 60.0 & 60.0 & -09 & 216 & \\
\hline 19. & 2001.0 & 2061.0 & 60.0 & 59.0 & -10 & 178 & \\
\hline 20. & 2061.0 & 2121.0 & 60.0 & 60.0 & -10 & 208 & \\
\hline 21. & 2121.0 & 2181.0 & 60.0 & 60.0 & -10 & 298 & \\
\hline 22. & 2181.0 & 2241.0 & 60.0 & 60.0 & -11 & 187 & \\
\hline 23. & 2241.0 & 2301.0 & 60.0 & 52.9 & -11 & 155 & \\
\hline 24. & 2301.0 & 2354.5 & 53.5 & 59.8 & -11 & 167 & \\
\hline 25. & 2354.5 & 2414.5 & 60.0 & 60.8 & -11 & 242 & \\
\hline 26. & 2414.5 & 2475.0 & 60.5 & 60.5 & -12 & 168 & \\
\hline 27. & 2475.0 & 2535.0 & 60.0 & 60.0 & -12 & 274 & \\
\hline 28. & 2535.0 & 2595.0 & 60.0 & 60.9 & -12 & 276 & 1 \\
\hline 29. & 2595.9 & 2656.0 & 60.1 & 59.5 & -13 & 356 & 0 \\
\hline 30. & 2656.0 & 2716.0 & 60.0 & 59.8 & -13 & 367 & $\mathrm{O}$ \\
\hline 31. & 2716.0 & 2776.0 & 60.0 & 47.4 & -14 & 176 & C \\
\hline 32. & 2776.0 & 2824.0 & 48.0 & 60.0 & -14 & 244 & \\
\hline 33. & 2824.0 & 2884.0 & 60.0 & 60.2 & -14 & 469 & \\
\hline 34. & 2884.0 & 2944.0 & 60.0 & 60.2 & -15 & 166 & \\
\hline 35. & 2944.0 & 3004.0 & 60.0 & 60.2 & -15 & 310 & \\
\hline 36. & 3004.0 & 3064.0 & 60.0 & 60.3 & -15 & 250 & \\
\hline 37. & 3064.0 & 3095.0 & 31.0 & 31.7 & -16 & 442 & \\
\hline 38. & 2095.0 & 3155.0 & 60.0 & 60.3 & -23 & 1306 & \\
\hline 39. & 3155.0 & 3215.0 & 60.0 & 60.0 & -24 & 1273 & \\
\hline 40. & 3215.0 & 3275.0 & 60.0 & 59.5 & -25 & 810 & \\
\hline 41. & 3275.0 & 3335.0 & 60.0 & 60.2 & -26 & 635 & 1 \\
\hline 42. & 3335.0 & 3365.0 & 30.0 & 30.0 & -27 & 520 & O \\
\hline 43. & 3365.0 & 3425.0 & 60.0 & 60.0 & -28 & 1125 & $\mathrm{O}$ \\
\hline 44. & 3425.0 & 3485.0 & 60.0 & 60.0 & -29 & 924 & $\mathrm{O}$ \\
\hline 45. & 3485.0 & 3545.0 & 60.0 & 59.6 & -30 & 752 & $\mathrm{C}$ \\
\hline 46. & 3545.0 & 3605.0 & 60.0 & 60.0 & -30 & 796 & \\
\hline 47. & 3605.0 & 3665.0 & 60.0 & 60.0 & -31 & 676 & \\
\hline 48. & 3665.0 & 3725.0 & 60.0 & 60.0 & $6-01$ & 755 & \\
\hline 49. & 3725.0 & 3785.0 & 60.0 & 59.6 & -02 & 836 & 1 \\
\hline
\end{tabular}




\begin{tabular}{|c|c|c|c|c|c|c|c|}
\hline \multirow{2}{*}{$\begin{array}{c}\text { Core } \\
\text { No. }\end{array}$} & \multirow{2}{*}{$\begin{array}{c}\text { From } \\
\text { (ft) }\end{array}$} & \multirow{2}{*}{$\begin{array}{l}\text { To } \\
\text { (ft) }\end{array}$} & \multicolumn{2}{|c|}{ Feet of Core } & \multirow{2}{*}{$\begin{array}{l}\text { Date } \\
1985\end{array}$} & \multirow{2}{*}{$\begin{array}{l}\text { Time } \\
\text { (min) }\end{array}$} & \multirow{2}{*}{$\begin{array}{l}\text { Type } \\
\text { Core }\end{array}$} \\
\hline & & & $\overline{\mathrm{Cut}}$ & Recovered & & & \\
\hline 50. & 3785.0 & 3845.0 & 60.0 & 59.8 & $6-02$ & 843 & $\mathrm{C}$ \\
\hline 51. & 3845.0 & 3905.0 & 60.0 & 60.0 & -03 & 866 & 0 \\
\hline 52. & 3905.0 & 3965.0 & 60.0 & 59.5 & -04 & 834 & $\mathrm{C}$ \\
\hline 53. & 3965.0 & 4025.0 & 60.0 & 59.7 & -05 & 907 & \\
\hline 54. & 4025.0 & 4085.0 & 60.0 & 59.6 & -06 & 833 & \\
\hline 55. & 4085.0 & 4145.0 & 60.0 & 61.1 & -07 & 918 & \\
\hline 56. & 4145.0 & 4205.0 & 60.0 & 59.4 & -07 & 403 & \\
\hline 57. & 4205.0 & 4265.0 & 60.0 & 60.6 & -08 & 181 & \\
\hline 58. & 4265.0 & 4325.0 & 60.0 & 60.0 & -08 & 197 & 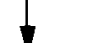 \\
\hline
\end{tabular}

Total core cut: $\quad 3313.4 \mathrm{ft}$

Total core recovered: $\quad 3310.3 \mathrm{ft}$

Percent recovery: $\quad 99.9 \%$

Total coring time: $\quad 407 \mathrm{hr} .53 \mathrm{~min}$

Average coring rate: $\quad 7.39 \mathrm{~min} / \mathrm{ft}$

Type

$\overline{\mathrm{C}}=$ Conventional

$\mathrm{O}=$ Oriented

\section{C.2.5 Geophysical Log Index Sheet for Phase II}

\begin{tabular}{|c|c|c|c|c|c|c|}
\hline \multirow[b]{2}{*}{ Type of Log } & \multirow[b]{2}{*}{ Date } & \multirow[b]{2}{*}{$\begin{array}{l}\text { Run } \\
\text { No. }\end{array}$} & \multirow{2}{*}{$\begin{array}{l}\text { Depth } \\
\text { Driller } \\
\text { (ft) }\end{array}$} & \multirow{2}{*}{$\begin{array}{l}\text { Depth } \\
\text { Logger } \\
\text { (ft) }\end{array}$} & \multicolumn{2}{|c|}{ Logged } \\
\hline & & & & & $\begin{array}{c}\text { From } \\
\text { (ft) }\end{array}$ & $\begin{array}{l}\text { Too } \\
\text { (fit) }\end{array}$ \\
\hline \multicolumn{7}{|l|}{ Dresser-Atlas Logs } \\
\hline Temperature & $6-13-85$ & 1 & 4325 & 4248 & 0 & 4247 \\
\hline Neutron - gamma ray & $6-13-85$ & 1 & 4325 & 4246 & 4245 & 0 \\
\hline Gamma ray - simul. & $6-13-85$ & 1 & 4325 & 4245 & 4245 & 900 \\
\hline $\begin{array}{l}\text { BHC Acoustilog - } \\
\text { gamma ray }\end{array}$ & $6-13-85$ & 1 & 4325 & 4245 & 4245 & 1010 \\
\hline $\begin{array}{l}\text { Dual laterolog - } \\
\text { gamma ray }\end{array}$ & $6-13-85$ & 1 & 4325 & 4245 & 4245 & 1010 \\
\hline $\begin{array}{l}\text { Compensated densilog - } \\
\text { gamma ray }\end{array}$ & $6-13-85$ & 1 & 4325 & 4245 & 4243 & 1008 \\
\hline Directional survey & $6-14-85$ & 1 & 4325 & 4246 & 4243 & 1000 \\
\hline
\end{tabular}




\section{C.2.6 History Data for Phase III}

Well Name: WIPP DOE-2

Location: Sec.8, T.22S, R.31E

County: Eddy, NM Area: Los Medaños

Surface coordinates: Brass Monument;

$697.71 \mathrm{ft}$ FSL $121.83 \mathrm{ft}$ FEL

Elevation: Brass Monument; $3418.35 \mathrm{ft}$

Start date: $7 / 9 / 85 \quad$ Completion: $7 / 31 / 85$

Circulating media: Saturated brine water

Rig \& Subcontractor: Well Service Unit,

Pool Well Service

\begin{tabular}{rrr}
\multicolumn{3}{c}{ Borehole Record } \\
\hline $\begin{array}{r}\text { Size } \\
\text { (in.) }\end{array}$ & $\begin{array}{c}\text { From } \\
\text { (ft) }\end{array}$ & $\begin{array}{r}\text { To } \\
\text { (ft) }\end{array}$ \\
\hline $17-1 / 2$ & 0 & 39 \\
$12-1 / 4$ & 39 & 1009 \\
$7-7 / 8$ & 1009 & 4325
\end{tabular}

Casing Record

\begin{tabular}{cccccr}
\hline $\begin{array}{c}\text { Size OD } \\
\text { (in.) }\end{array}$ & $\begin{array}{c}\text { Wt/Ft } \\
\text { (lb) }\end{array}$ & Grade & CPL'G & $\begin{array}{c}\text { From } \\
\text { (ft) }\end{array}$ & $\begin{array}{r}\text { To } \\
\text { (ft) }\end{array}$ \\
\hline $13-3 / 8$ & 48 & H-40 & 0 & 0 & 39 \\
$9-5 / 8$ & 36 & J-55 & LT\&C & 0 & 1009
\end{tabular}

Total depth: $4325 \mathrm{ft}$ below elevation

\section{Remarks:}

This report is for Phase III of the subject hole operations, a series of hydrologic tests as directed and reported by the Sandia Test Director. This report does not include the results of those tests.

This work conducted under Sandia National Laboratories (SNL) Contract 21-6788. Fenix \& Scisson, Inc. Project \#486.

Prepared for

Sandia National Laboratories

Albuquerque, New Mexico

\section{C.2.7 Abridged Hole History for Phase III}

Note: All test operations as directed by SNL Test Director

7-09-85 Moved in Pool Well Service Co. double drum/double derrick well service unit. Set unit over borehole and rigged up equipment.

7-10-85 Made up 6-1/8-in.-dia rock bit on 2-3/8-in.$0600 \mathrm{hr}$ OD tubing. Trip in hole to check for bridges and/or fill. Encountered bridge at \pm 4228 ft. Worked through bridge down to \pm 4235 ft. Encountered fill. Trip out with bit assembly. Picked up Lynes hydrological test tool with 50 -ft straddle between $6-5 / 8$-in.OD inflatable packers. Connected 1/4-in.OD steel PEC (Polyethylene Encased Conductor) wire to SNL computer unit. Trip in hole with test assembly on 2-3/8-in.-OD tubing; strapping PEC wire to tubing as progressing downhole. Test equipment dragging at $1370 \mathrm{ft}$. Worked through to $1700 \mathrm{ft}$. Checked instrumentation; not working. Pulled up hole three tubing stands; equipment dragging. Ran five tubing stands back in hole; checked instrumentation. Check OK. Secured operations at $2030 \mathrm{hr}$.

7-11-85 Resume trip in hole to $2350 \mathrm{ft}$. Checked $0700 \mathrm{hr}$ instrumentation; not working. Pulled up hole four tubing stands; checked instrumentation. Check OK. Resume trip in to $2413 \mathrm{ft}$. Check instrumentation; OK. Trip in to $2602 \mathrm{ft}$. Checked instrumentation; OK. Trip in to $2792 \mathrm{ft}$. Checked instrumentation; not working. Pulled up hole to 2509 ft. Filled tubing with $10 \mathrm{lb} / \mathrm{gal}$ brine water and set packers. Swabbed fluid from tubing down to $2000 \mathrm{ft}$. System check from $1200 \mathrm{hr}$ to $1600 \mathrm{hr}$.

Deflated packers. Resumed trip in hole to $4222 \mathrm{ft}$; tagged fill in borehole. Pulled up hole $32 \mathrm{ft}$. Filled tubing with brine water. Attempted to set packers; no set. Swabbed fluid from tubing to $2000 \mathrm{ft}$; attempted to set tool; no set. Filled tubing with brine 
water. Swabbed fluid from tubing. Hit bridge inside tubing at $2250 \mathrm{ft}$. Ran sinker bar and knocked out bridge. Swabbed fluid from tubing to $3500 \mathrm{ft}$. Moved test tool downhole to $4221 \mathrm{ft}$. Worked "J" latch mechanism in test tool. Moved test tool up hole; bottom packer at $4177.51 \mathrm{ft}$, top packer at $4130.73 \mathrm{ft}$. Filled tubing with brine water; set packers and closed tool to test zone. Swabbed fluid from tubing to $4060 \mathrm{ft}$. Secured operations at $1930 \mathrm{hr}$. Allowed system to stabilize.

7-12-85 SNL instrumentation recordings indicated $0700 \mathrm{hr}$ destabilization at $0630 \mathrm{hr}$. Conducted series of open, close, shut-in, swabbing, and "slug" tests as directed by SNL Test Director. Secured operations at $1915 \mathrm{hr}$. SNL computer unit monitoring downhole instrumentation.

7-13-85 SNL computer unit monitoring downhole and instrumentation. Packers set straddling 7-14-85 the zone from 4177.51 to $4130.73 \mathrm{ft}$. No rig crew on site.

7-15-85 Deflated packers and tripped out of hole $0700 \mathrm{hr}$ with test assembly. Observations on trip out; some questionable connections at splices and three crushed areas in 1/4-in.OD steel PEC wire; bottom packer element partially inflated.

Rigged-up circulating unit and associated equipment to clean out fill from borehole. Tripped in hole with 7-7/8-in. bit, two 4-3/4-in.-OD drill collars on 2-3/8-in.-OD tubing to $3918 \mathrm{ft}$. Secured operations at $1730 \mathrm{hr}$.

7-16-85 Resumed trip in hole and cleaned out fill $0700 \mathrm{hr}$ from $4227 \mathrm{ft}$ to $4325 \mathrm{ft}$ total depth. Circulated and conditioned hole. Pulled up hole 10 stands. Wait $3 \mathrm{hr}$. Tripped back to bottom, tagged fill at $4323.5 \mathrm{ft}$. Pulled up hole 10 stands. Secured operations at $1645 \mathrm{hr}$.

7-17-85 Tripped back to bottom, tagged fill at 4321 $0700 \mathrm{hr}$ ft. Tripped out of hole and laid down drilling assembly. Picked up Lynes hydrological test tool with single 6-5/8-in.-OD inflatable packer. Connected 1/4-in.-OD steel PEC wire. Trip in hole strapping PEC to 2-3/8-in.-OD tubing. Stopped and checked instrumentation every 10 stands. Made repair splices in PEC wire at $882 \mathrm{ft}$ and 2583 ft. Instrumentation check at $2583 \mathrm{ft}$; PEC wire shorted out. Started trip out of hole checking 1/4-in.-OD steel PEC wire for leaks. Secured operations at $1800 \mathrm{hr}$.

7-18-85 Resume trip out hole. Splice kit just above $0700 \mathrm{hr}$ test asssembly shorted out. Replaced splice kit. Trip back in hole with same system. Instrumentation checks every 10 stands. Filled tubing with brine water, inflated and set bottom of packer element at $4220 \mathrm{ft}$. Condiucted series of shut-in, flow, and swabbing 2-3/8-in. tubing as directed by SNL 'Test Director. Secured operations at $1830 \mathrm{hr}$. SNL computer unit monitored inflow from $4220 \mathrm{ft}$ to total depth of hole.

7-19-85 Testing the zone from $4220 \mathrm{ft}$ to total depth $0700 \mathrm{hr}$ of hole. Conducted series of shut-in, flow, and swabbing operations as directed by SNL Test Director. Secured operations at $1800 \mathrm{hr}$.

7-20-85 Conducted series of swabbing runs in $0700 \mathrm{hr}$ 2-3/8:in.-OD tubing. SNL Test Director collected fluid samples and monitored inflow pressures. Secured operations at 1900 hr.

7-21-85 SNL computer unit monitoring downhole instrumentation. Testing zone from $4220 \mathrm{ft}$ to total depth of hole. No rig crew on site.

$7-22-85$ $0700 \mathrm{hr}$

Conducted series of swabbing runs in 2-3/8-in.-OD tubing. SNL Test Director collected fluid samples and monitored inflow pressures. Secured operations at 1830 hr.

7-23-85 Conducted series of swabbing runs in $0700 \mathrm{hr}$ 2-3/8-in.-OD tubing. SNL Test Director collected fluid samples and monitored inflow pressures. Sampling complete at 1140 $\mathrm{hr}$. Rigged down swabbing equipment and prepared to trip out test equipment. Difficulty releasing packer; pulled to $30000 \mathrm{lb}$ to uriseat. Tripped out of hole, wet tubing string, packer dragging and swabbing borehole and 9-5/8-in.-OD casing. When retrieved, packer element still inflated. Laid down test assembly. Secured operations at $1800 \mathrm{hr}$.

7-24-85 Rigged up circulating unit and associated $0700 \mathrm{hr}$ equipment. Tripped in hole with 7-7/8-in. bit, two 4-3/4-in.-OD drill collars on 2-3/8in.-CD tubing. Tagged fill in borehole at $4247 \mathrm{ft}$. Cleaned out fill from $4247 \mathrm{ft}$ to 
$4309 \mathrm{ft}$. Circulated and conditioned borehole. Pulled up hole seven stands. Wait 1-1/2 hr. Tripped back to $4309 \mathrm{ft}$; no fill. Tripped out and laid down drilling assembly. Secured operations at $1700 \mathrm{hr}$.

7-25-85 Picked up Lynes hydrological test tool with $0700 \mathrm{hr} \quad 50$-ft straddle between 6-5/8-in.-OD inflatable packers. Connected 1/4-in.-OD steel PEC wire. Trip in hole strapping PEC to 2-3/8-in.-OD tubing. Stopped and checked instrumentation every 10 stands. Filled tubing with brine water; inflated and set packers. Bottom element at $4220 \mathrm{ft}$, top element at $4175 \mathrm{ft}$. Swabbed fluid from 2-3/8-in.-OD tubing down to $2470 \mathrm{ft}$. Conduct series of flow and shut-in operations as directed by SNL Test Director. Swabbed fluid from 2-3/8-in.-OD tubing down to seating nipple at $4146 \mathrm{ft}$. Shut-in and secured operations at $1700 \mathrm{hr}$.

7-26-85 Conducted series of flow and shut-in opera$0700 \mathrm{hr}$ tions as directed by SNL Test Director. At $1300 \mathrm{hr}$ shut-in the test tool and secured rig operations. SNL computer unit monitored downhole instrumentation. Testing zone from $4175 \mathrm{ft}$ to $4220 \mathrm{ft}$.

7-27-85 SNL computer unit monitored downhole instrumentation. Shut-in test continued until $0848 \mathrm{hr}$. Opened to test zone at 0848 hr. No rig crew this date.

7-28-85 Flow test continued. SNL computer unit monitored. No rig crew this date.
7-29-85 Discontinued test. Deflated and released $0700 \mathrm{hr}$ packers. Tripped out of hole with test assembly. Pulling wet string after 27 stands $( \pm 1620 \mathrm{ft})$ out. Upon entering 9-5/8-in.OD casing at $1009 \mathrm{ft}$, test assembly dragged and swabbed casing. Upon retrieval, top packer damaged at bottom; bottom element partially inflated. Laid down test assembly. Picked up Lynes Production Injection Packer (PIP) with 6-5/8-in.-OD element. Tripped in hole packer in hole on 2-3/8-in.-OD tubing. Filled tubing with brine water, inflated and set packer with top of element at $4051.60 \mathrm{ft}$. Packer set with $4000 \mathrm{lb}$ tension over string weight. Swabbed fluid from 2-3/8-in.-OD tubing down to seating nipple. Secured operations at $1800 \mathrm{hr}$.

7-30-85 Conducted series of swabbing runs through $0700 \mathrm{hr} \quad 2-3 / 8$-in.-OD tubing. SNL Testing Director metered fluid recovered and collected samples from Bell Canyon Formation. Secured operations at $1700 \mathrm{hr}$.

7-31-85 Resumed swabbing and sampling opera$0700 \mathrm{hr}$ tions until $0815 \mathrm{hr}$. Test complete as directed by SNL. Set in Larkin Wellhead Pack-Off Assembly and set slips with 3000 lb tension on tubing string. Released Pool Service Unit and demobilized at $1000 \mathrm{hr}$.

Phase III complete. 
APPENDIX D

Permits and Miscellaneous Documents 


\section{United States Department of the Interior \\ GEOLOGICAL SIIRIFI \\ BOX 25046 M.S. 913 \\ DENVER FEDERAL CFNIER \\ DENVER, COL.ORADO 8029:}

May 23, 1984

Jerry Mercer

Division 7133, Box 5800

Sandia National Laboratories

Albuquerque, New Mexico 87115

Dear Jerry:

The following list is the latest I have for depth estimates for DOE-2. The numbers are based on siting the drill hole in section 8, 710 feet FSL, 130 feet FEL at an estimated surface elevation of 3,415 feet. Tens of feet one way or another for the horizontal numbers will make no difference.

$\begin{array}{lr}\text { Santa Rosa } & 10 \pm \text { feet } \\ \text { Dewey Lake } & 115 \text { feet } \\ \text { Rustler } & 635 \text { feet } \\ \text { Magneta } & 700 \mathrm{feet} \\ \text { Culebra } & 820 \mathrm{feet} \\ \text { Salado } & 960 \mathrm{feet} \\ \text { Vaca Triste } & 1,440 \mathrm{feet} \\ \text { Base 124 MB } & 1,732 \text { feet }\end{array}$

Any depths to units below the $124 \mathrm{MB}$ are really estimates at this time. If there are no signs of dissolution in the lower Salado, we may be able to predict depths to Castile and Delaware Mountain units.

Sincerely yours,<smiles>CCCC</smiles>

Richard P. Snyder, Geologist

Branch of Central Regional Geology

Figure D-1. DOE-2 Depth Estimates 


\section{Sandia Laboratories}

Albuquerque, New Mexico 87115

June 12,1984

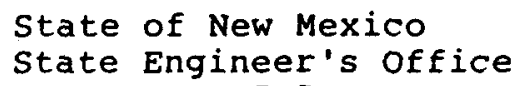

As you are aware, this hole is part of the investigations that Sandia National Laboratories is conducting for the U. $S$. Department of Energy in conjunction with the WIPP Program.

If you have any questions, please feel free to contact me at 505-844-5042.

Yours truly,

$$
\text { R. Ci. STAThes }
$$

R. [1. Statler, Supervisor Engineering Projects Div., 713 Sandia National Laboratories

PDS : 7135 : jrh

Copy to: (Blind)

7133 J. W. Mercer

7135 P. D. Seward

7133 R. D. Statler 


\section{STATE OF NEW MEXICO STATE ENGINEER OFFICE \\ ROSWEL}

June 15, 1984

DISTRICT 2

SO9 EAST 2ND ST

P.O. BOX 1717

Juin 201984

Sandia iational Laboratories

PO 50x 5200

Albucuerque, ivew Hexico 87185

Genclemen:

Inciosed is your copy of the above numbered lotice of Intention

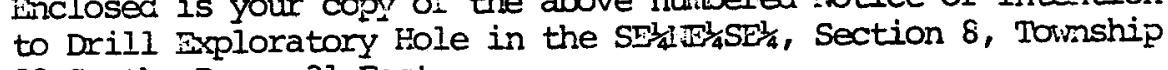
22 South, Range 31 East.

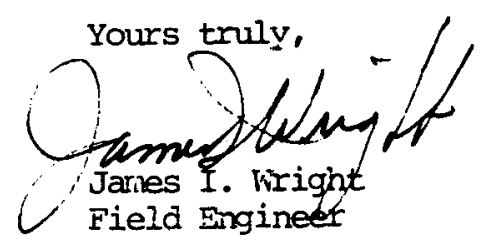

$\mathrm{JIW} / \mathrm{ting}$

Enclosure

$\mathrm{CC}$ Santa $\mathrm{Fe}$

Figure D-2. Notice of Intention to Drill from the State Engineer's Office, State of New Mexico 
1. Drilling of hole shall be subject to compliance with the New Mexico Statutes and all rules and regulations of the State Engineer.

2. Casing shall not be installed or cemented without prior notification of the State Engineer office.

3. Hole shall not be plugged without prior notification of the State Engineer office.

4. Log of hole and plugging record shall be filed with the State Engineer office as soon as hole is completed.

LOCATE hOLE AS ACCURATELY AS POSSIBLE ON FOLLOWING PLAT:

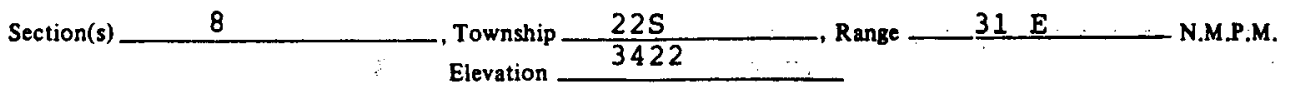

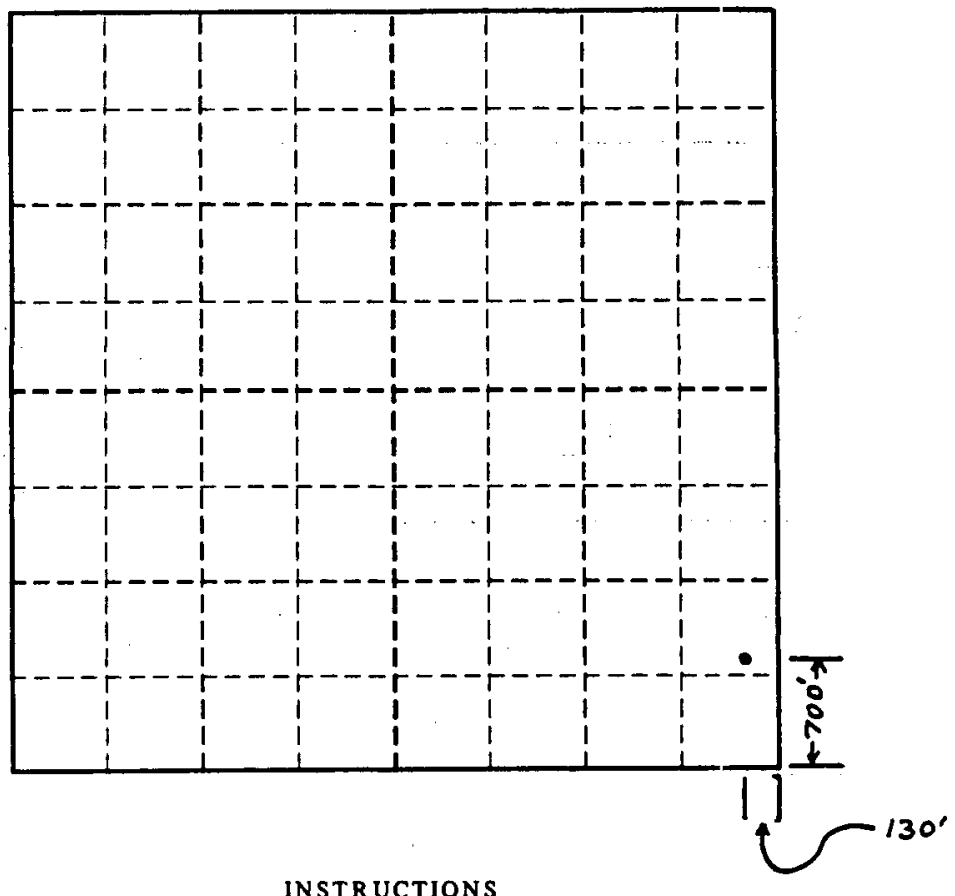

This form shall be executed, preferably typewritten, in triplicate.

Each of the triplicate copies must be properly signed.

A separate notice must be filed for each hole drilled

Sections 1-4 - Fill out all blanks fully and accurately.

Section 7 - Estimate time reasonably required to commence drilling. Drilling shall not commence until the Engineer is notified.

Forms should be filed with the Field Engineer, Box 1717, Roswell, New Mexico 88201 


\section{NOTICE OF INTENTION TO DRILL EXPLORATORY HOLE}

$\frac{\text { Eddy }}{\text { County }}$

Date Received J.. June 14, 1984 File No. 0-08-1467

1. Name Sandia National Laboratories

Mailing Address P. O. Box 5800

City and State Albuquerque, N.M. 87185 - Attn: Org. 7133

2. Hole is to be drilled under contract for U, S, DOE

and is to be known as the DOE \#2

(self or company)

3. The hole is to located 700 feet from the $\_$_ L Line and 130 feet from the $E$ Line of Section 8 Township _ 22S_- Range 31 E_- N.M.P.M., on land owned by U.S. Government of

4. Drilling will commence on or about _ July 15,1984

5. Description of Hole: Depth to be drilled 4,040 It is our intention to

a. $\square$ complete this hole as follows without cementing casing and to plug this hole immediately af ter completion of drilling in accordance with the rules and regulations of all appropriate regulatory agencies.

b. cement casing and retain hole completed as follows:

\begin{tabular}{|c|c|c|c|c|c|c|c|c|}
\hline \multirow{3}{*}{$\begin{array}{l}\text { Diameter } \\
\text { of hole }\end{array}$} & \multicolumn{6}{|c|}{ Casing } & \multicolumn{2}{|c|}{ Mud or Cement } \\
\hline & \multirow{2}{*}{ Size } & \multirow{2}{*}{ New/Used } & \multirow{2}{*}{ API Grade } & \multirow{2}{*}{ Wt/Foot } & \multicolumn{2}{|c|}{ Interval } & \multirow{2}{*}{ Type } & \multirow{2}{*}{ Sacks } \\
\hline & & & & & From & To & & \\
\hline 18 & $\mid 3-1$ & New & $\mathrm{H}-40$ & $48 \#$ & 0 & 40 & Batch & To $\begin{array}{c}\text { To } \\
\text { S }\end{array}$ \\
\hline $12 \frac{1}{4}$ & $9-5 / 8$ & New & $J-55$ & $36 \#$ & 0 & 985 & $\begin{array}{c}\text { Salt } \\
\text { Resistant }\end{array}$ & $\begin{array}{c}\text { to } \\
\text { surf }\end{array}$ \\
\hline $7-7 / 8$ & Open & Hole & & & 985 & 4040 & & \\
\hline & & & & & & & & \\
\hline
\end{tabular}

6. Location of hole is confidential _.___ ; not confidential $\ldots$

7. Logs of hole are confidential __ not confidential _

8. Additional statements or explanations: This drilling program will consist of three phases, $i . e .$, phase I Rustler drilling and hydro studies; Phase II deepening from base of Rustler to Bell Canyon; Phase III hydro and other related tests in whole-hole. Reference attached Field operations plan for details.

I, R. D. Statler , depose and say that I have carefully read the foregoing statement and each and all of the jtems contained therein, and that the same are true to the best of my knowledge and belief.

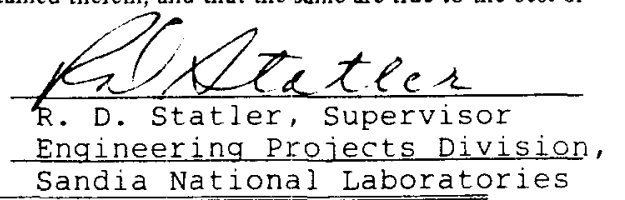

Sandia National Laboratories

The above proposed casing, cementing, and plugging program has been reviewed by me, in my capacity as a duly appointed representative of the New Mexico State Engineer, and to the best of my knowledge and belief will be adequate to insure that waters and other minerals will be permanently confined to the zones in which they are encountered. (See reverse side of form for specific State Engineer regulations regarding the drilling of this hole).

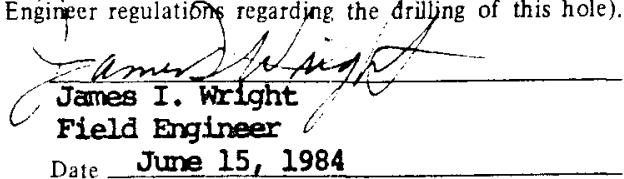


BHIDIA IHTONAL LABIRATURIES

Altuaverqu: NEL Miexico 87185

date: June 10, 1984

to: Arlen Hunt - [IÜLiWFa

from: Al Lapnin- 6331

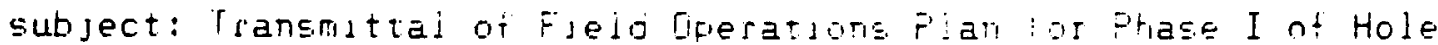
DOE-2.

Attached please firid a cofy rit:

1. Field Operations Flar of Saridia Natronal Laooretories. WIPF

Site Investigations. DOIE-2 Fitiase I - J. W. Mercer.

This document describes the detailed fleld operations to be used in completing and testing the first portion ot bue-2: i.e., to the base of the Rustier Formation. It also refrocices the firal form of two other documents:

a. Statement of Work for DCIE-2: Phase II (Stratigraphy and Structure) - D. J. Eorns.

D. Statement of Work for DOJE-2: WiPf hyjroiogy (fiustler) - D. [). Gonzalez.

Fiease advise concerming the oletrloutdor you wrild bike us to use for this docurient.

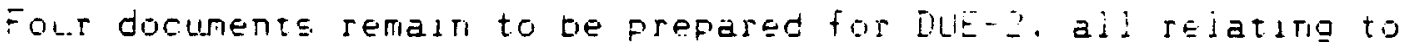
wort: to be carried out in the second, deeper portion of the nole. These documents include:

1. Scope of work for the oriling and gerieral testing of the deeper portion of the whole, incluoing contingency planring in: the event of a brine encounter in the castals.

2. Detalled field operations plan for drilling and gerieral hydrologic testing of the deeper portion of the hole.

3. Scope of work for "whole-hole" tests and related studies in DOE-2.

4. Detalled fleld oferations plan for the "uriole-hole" tests and related studies in DUE-2.

These documents w1l be prepared in a timeiy mantier, consistent with the beginning of operatioris for Phase I of DOE-2 getting highest firiority.

AFL : 6331:arl

0,330 - W. D. Weart (w/o encl.)

7133 - J.W. Mercer (w/o encl.)

Figure D-3. Transmittal of Field Operations Plan for Phase I of Drillhole DOE-2 


\section{Sandia National Laboratories}

date: JUN 131984

Albuquerque. New Mexico 87185

to: W. R. Cooper, DOE/ALO/WPO

Origina! Signed By WENOELI D. WEAT

from: W. D. Weart, 6330

subject: Request for Access Approval for Drilling and Testing Exploratory Borehole DOE-2

The above borehole will be located in the Southeast corner of Section 8, Township 225, Range 31E, which is Federal land administered by the BLM.

The drill pad itself will be $300^{\prime} \times 300^{\prime}$ stabilized with a 6 " caliche base. The attached Survey Plat (Encl. \#1) depicts the orientation and dimensioning. Access to this location is possible by using existing roads that will require only minimal rehabilitation, thus precluding further surface disturbance. Enclosure \#2 details this access route.

An archaeological survey has been performed to assure that the area is clear of any cultural artifacts. A copy of this survey is enclosed (Encl. \#3).

The details of the drilling and testing program for DOE-2 are contained in the Field Operations plan dated June 10, 1984, and should be sufficient with the above information to obtain BLM approval for this investigation.

Your assistance will be appreciated.

PDS : $7135:$ jrh

Copy to:

All w/Encls. $1,2 \& 3$

6331 - A. R. Lappin

7133 - R : D. Stàtler

7133 - J. W. Mercer

7135 - P. D. Seward

6330 - W. D. Weart

Figure D-4. Request to DOE for Access Approval 
Enc. $=1$

\section{PLAT OF SURVEY}

Proposed drill hole site: DOE 2

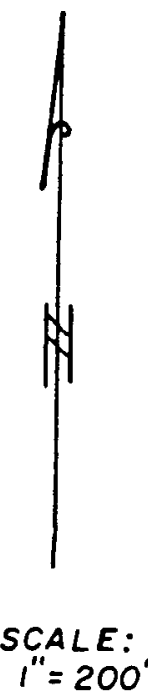

$700^{\prime}$ From South line
130

Section 8

Township 22 South

Range $3 /$ East

Unit $P$

Eddy Courity, New Mexico

$I^{\prime \prime}=200^{\prime}$

South line Sec.8 -

$$
\text { N89. } \overline{5} \overline{2^{\prime} W(G L O)} \frac{8}{17} 16
$$

CERT IF ICATION :

This is to certify that the foregoing plat was made from fleld notes of a bonafide survey made by me and is true and correct to the best of my knowledge and belief.
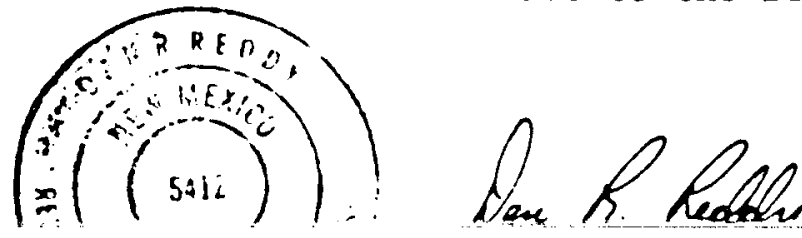


$$
\begin{gathered}
\text { PROPOSED ACCESS } \\
\text { DOE-2 }
\end{gathered}
$$

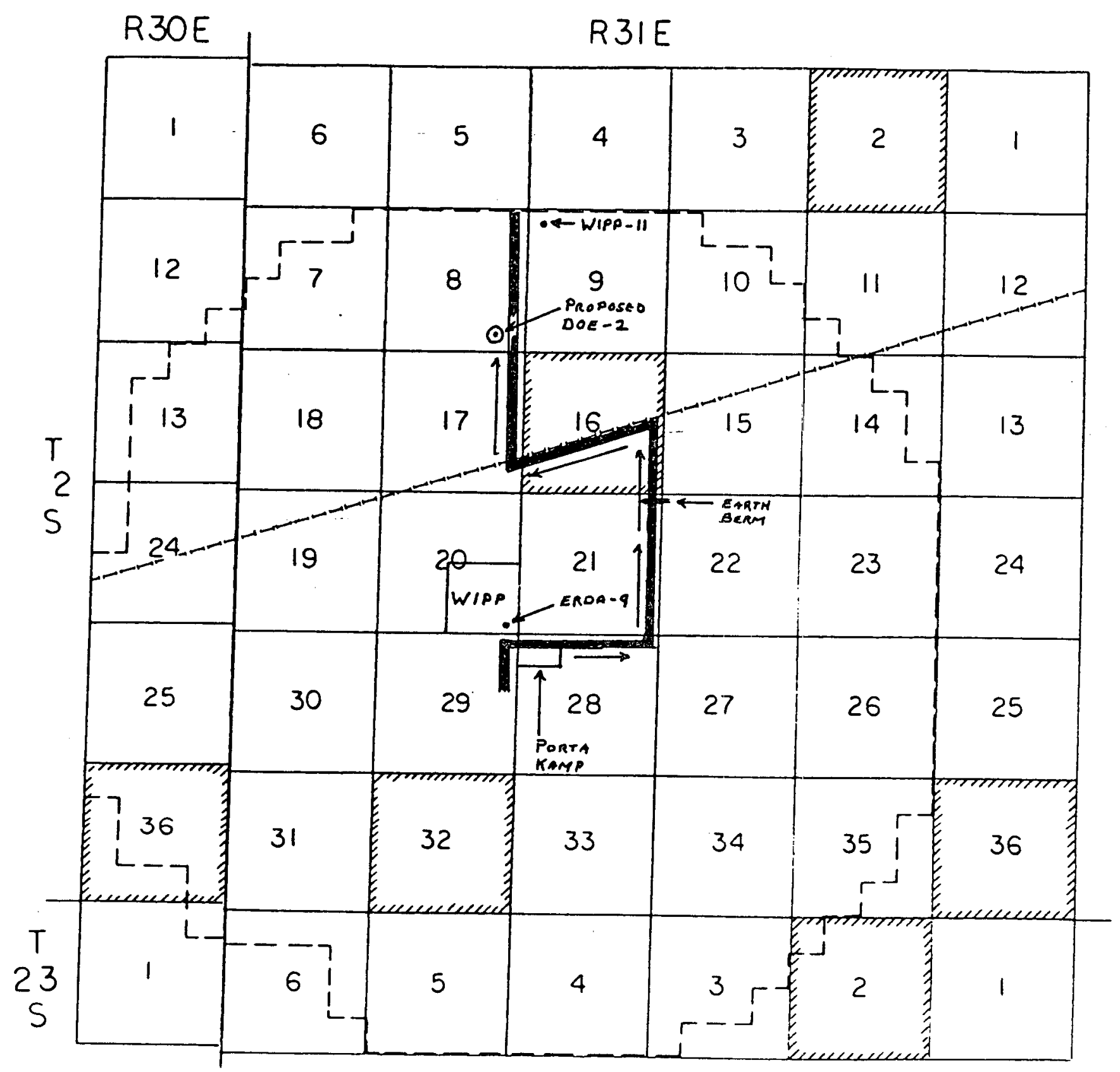

ஐルッゅ NATURAL GAS LINE 


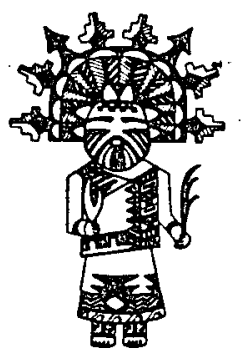

Reconnaissance

Excauation

Analysis

Explanation

Curation
NMAS

New Mexico Archaeological Services, Inc. P. O. Box 1341

Carlsbad, New Mexico 88220

(505) 887-7646

7 June 1984

Mr. P.D. Seward

Division 7135

SANDIA NATIONAL LABORATORIES

P.O. Box 5800

Albuquerque, New Mexico 87185

Dear Mr. Seward:

Enclosed please find NMAS' Archaeological. Clearance Report for SANDIA NATIONAL LABORATORIES' proposed drill hole site: DOE 2 in Sections 8 and 9, T22S, R3IE, NMPM, Eddy County, New Mexico. No cultural resources were recorded during this reconnaissance; therefore, NMAS is suggesting clearance for this project.

If you have any questions pertaining to this report, please call my office. Thank you for asking NMAS to do this reconnaissance.

Yours sincerely,

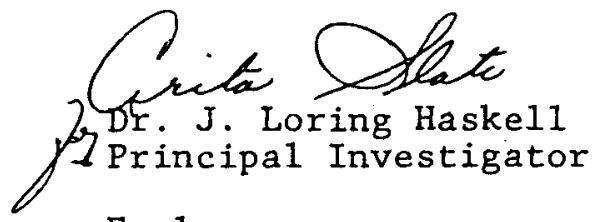

Enclosure

cc: Ms. Linda Brett, BLM, Carlsbad

Mr. Curtis Schaafsma, Laboratory of Anthropology, Santa $\mathrm{Fe}$

Mr. Thomas W. Merlan, SHPO, Santa Fe

as

Figure D-5. Archaeological Clearance Report 


\title{
Archaeological Clearance Report \\ for \\ SANDIA NATIONAL LABORATORIES
}

\section{Proposed Drill Hole Site: DOE 2 \\ Sections 8 and $9, \mathrm{~T} 22 \mathrm{~S}, \mathrm{R} 31 \mathrm{E}$, NMPM, Eddy County, NM}

\author{
Prepared \\ By
}

Dr. J. Loring Haske11

\author{
Submitted \\ By \\ Dr. J. Loring Haskell \\ Principal Investigator \\ New Mexico Archaeological Services, Inc. \\ Carlsbad, New Mexico \\ 7 June 1984 \\ Permit No. 82-NM-376
}

Figure D-5. 


\section{ABSTRACT}

New Mexico Archaeological Services, Inc., representing SANDIA NATIONAL LABORATORIES, Albuquerque, undertook an archaeological reconnaissance of Bureau of Land Management lands scheduled to be impacted by the construction of a drill hole site. The proposed work will be situated in Sections 8 and 9, T22S, R31E, NMPM, Eddy County, New Mexico. No cultural resources were recorded during this reconnaissance; therefore, NMAS is suggesting clearance for SANDIA NATIONAL LABORATORIES' proposed work.

Figure D-5. 


\section{Introduction}

On 6 June 1984, New Mexico Archaeological. Services, Inc., (NMAS), Carlsbad, undertook for SANDIA NATIONAL LABORATORIES, Albuquerque, an archaeological reconnaissance of federal lands administered by the Bureau of Land Management in Eddy County, New Mexico. The reconnoitered area will be impacted by a drill hole site. This project was advanced by Mr. P.D. Seward, SANDIA NATIONAL JABORATORIES and administered by $\mathrm{Dr}$. J. Loring Haske11, Principal Investigator, NMAS, Inc. This reconnaissance was undertaken by Dr. Haskell.

Survey Technique

For this investigation, SANDIA NATIONAI, LABORATORIES' proposed drill hole site was reconnoitered for evidence of man's past activities by walking it in a series of $25 \mathrm{ft}$ wide, close interval ( $15^{\circ}$ or less), zigzag transects. In addition, an added zone extending $20 \mathrm{ft}$ on each side of the staked $300 \times 300 \mathrm{ft}$ pad, and lying outside the bounds of the proposed work area, was reconnoitered by a similar means. Methodologically, this procedure served to promote opitmal conditions for the visual examination of areas to be impacted by constructionrelated activities.

Proposed Drill Hole Site: DOE 2

Location

The proposed drill hole site will measure $300 \mathrm{X} 300$ ft (Actual Area Surveyed 2.35 Acres) on federal lands and will be situated $700 \mathrm{ft}$ from the south 1 ine and $130 \mathrm{ft}$ from the east line:

Section 8, T22S, R31E, NMPM, Eddy County, NM

Thus it will be situated in the:

SE $\frac{1}{4} S E \frac{1}{4}$, Section $8, T 22 S, R 3 I E$, NMPM, Eddy County, NM

SW $\frac{3}{4} S_{1}^{\frac{1}{4}}$, Section 9, T22S, R31E, NMPM, Eddy County, NM 
This drill hole site is situated next to an existing road. Map Reference: USGS NASH DRAW QUADRANGLE, 15 Minute Series, 1939. Terrain

SANDIA NATIONAL IABORATORIES' proposed drill hole site will be situated on a rolling landform located due east of Nash Draw. Overlain by material, the coeval surface is distinguished by minor, coppice-type duens and related, closed deflation basins. Overall, dune development is minor in the general vicinity. Soils uniformly are dominated by the sand separate and commonly harbor gravel-sized, cherty inclusions. Soil individuals are assignable to the Typic Torripsament taxon. Drainage is to the southwest.

\section{Floristics}

Plants composing the floral community's overstory are Quercus havardii, Artemisia juliflora, Yucca glauca and occasionally Prosopis juliflora and very diminutive Sapindus drummondii. Associated forbs include: Gutierrezia sarothrae, Monarda punctata, Euphorbia sp., Hedyotis humifusa, Asclepias sp., Phylanthus sp., Hoffmanseggia sp., Phacelia integrifolia and Croton sp. The Gramineae is represented by Aristida sp. and Andropogon spp.

\section{Cultural Resources}

No cultural properties were recorded during the course of this reconnaissance. Locally, land usage was brief and transitory and focused on hunting and gathering concerns. Actual utilization by man probably dates back to Paleoindian times; however most usage probably occurred during Late Archaic (A.D. 750-950) and Eastern Jornada Mogolloon (A.D. 950-1350) times. Contributary to the dearth of cultural properties are the bona fide lack of siliceous lithic 
material, shelter and potable water.

Recommendations

NMAS recommends clearance for SANDIA NATIONAL LABORATORIES'

proposed drill hole site, DOE 2, and suggests that work-related activities proceed in accordance with company plans. Clearance, of course, is granted by the Bureau of Land Management. If cultural resources are encountered during construction, the BLM and NMAS should be notified immediately. Duned settings are notorious for covering and uncovering cultural properties. 


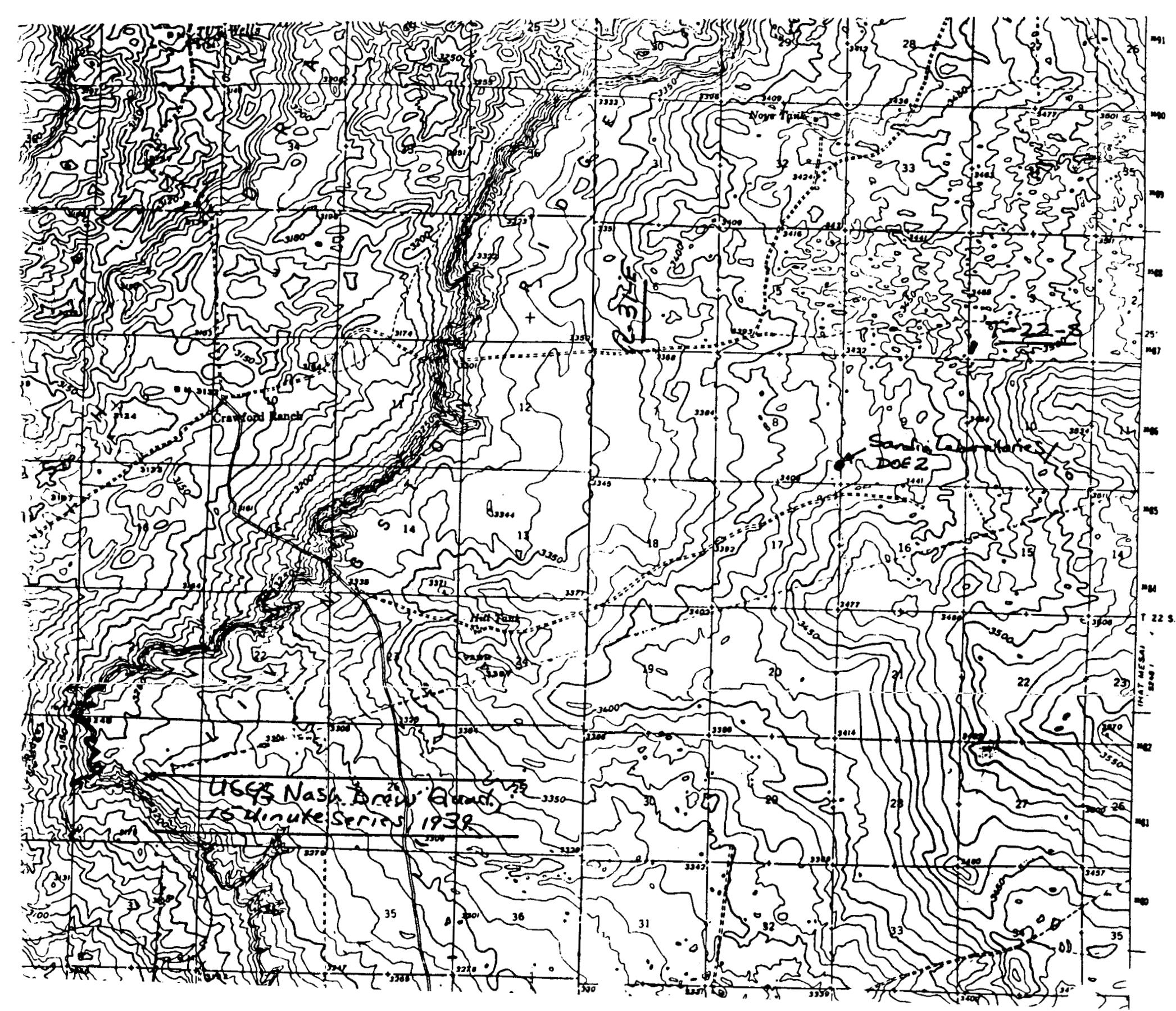




\section{U.S. DEPARTMENT OF ENERGY ALBUQUERQUE OPERATIONS OFFICE}

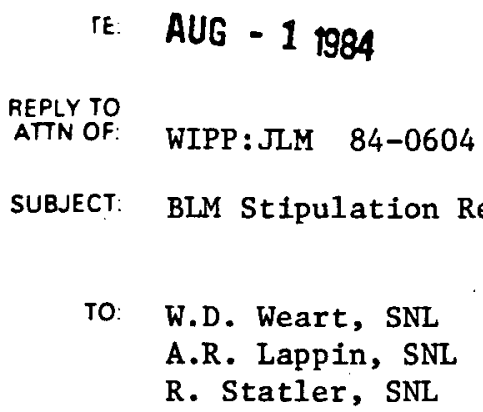

TO: W.D. Weart, SNL

A.R. Lappin, SNL

R. Statler, SNL

We have received concurrence from the BLM for the siting of DOE-2 as requested in our letter dated July 5, 1984. However, they have made several stipulations regarding development and abandonment of the drill pad and borehole which should be observed. A copy of these stipulations is attached. Please advise me if you foresee any difficulty in meeting these stipulations. If we can be of any assistance with respect to coordinating fulfillment of the stipulated activities with the BLM, please let me know.

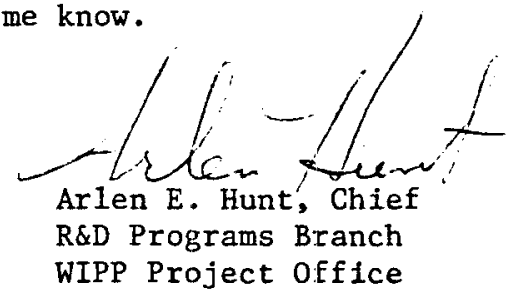

Attachment

cc w/at tachment

P.A. Miskimin, TSC

Figure D-6. BLM Stipulations Regarding Drilling of DOE-2 


\section{STIPULATIONS FOR DEPARTMENT OF ENERGY' \\ EXPLORATORY DRILL HOLE D.O.E.-2 \\ located in $700 \mathrm{FSL} 130 \mathrm{FEL}$ \\ Section 8, T22S, R31E}

1. If, during operations, any archeological or historical sites, or any object of antiquity subject to the applicable Antiquities Acts are discovered, all operations which would affect such sites are to be suspended and the discovery reported promptly to the appropriate offices of the Minerals Management Service. When it is impossible to avoid identified cultural resource sites, the excavation, bollection, analysis and interpretation by an approved cultural resources contractor may be required before resumption of operations.

2. Prior approval of the District Supervisor is required for variance from the approved Surface Use plan or drilling program. Similar approval is also required for addition to or alteration of facilities and before commencing plugging operations, plugback work, casing repair work, corrective cementing operations, or suspending drilling operations indefinitely. Emergency approval may be obtained orally, but such approval does not waive the written report requirements.

3. Well areas will be maintained in a workmanlike manner with due regard to safety, conservation, and appearance. All waste assicciated with the drilling operations will be contained and will be buried in place (in a separate trash pit) or removed and deposited in an approved sanitary landfill. All garbage (metal containers will be crushed) and debris left on site will be buried at least two feet deep. All trash and d?bris will be buried or removed from the site after removal of the drilling rig and/or completion rig, and the wellsite will be kept clean and in an aesthetically satisfactory condition for the life of the well.

4. Roads will be constructed to adequately accomodate servicing all vehicular traffic associated with drilling and production of oil and gas wells, and will be maintained to control runoff and soil erosion.

5. No payment or other consideration will be made to other users, licenses, permittees, or lessees for any damage to or loss of natural vegetation, wildlife, mineral material, or for soil or livestock disturbances occurring on public lands, which result from operation, development, or construction activities carried out under the authority of an approved permit to drill.

6. Caliche, gravel, or other related minerals from new or existing pits on Federal mineral estate will not be taken without prior approval from the appropriate surface managing agency.

7. Unless otherwise approved, and/or maintained, all access roads constructed in conjunction with the drilling permit (APD) will be limited to a 15 foot wide surface, excluding turn-arounds. Surface disturbance associated with construction and/or use of the road will be limited to 20 feet in width. All roads will be adequately drained to control runoff and soil erosion. Drainage facilities may include ditches, water bars, culverts and/or any other measures deemed necessary by the authorized 
officer of the surface managmeent agency. The following is a general guide for the spacing of water bars:

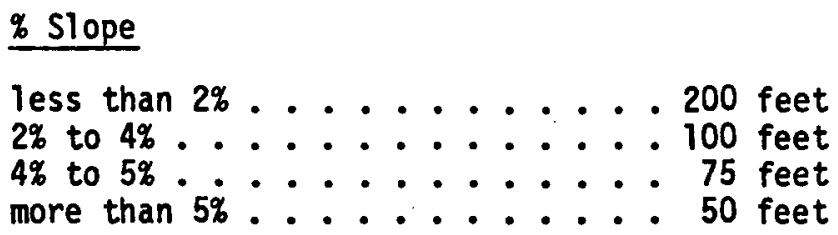

8. Vegetative materials removed during construction must be disposed of in such manner that it does not detract from the aesthetics of the area and does not accelerate erosion. Vegetation removed during clearing operations should be placed in drainages, washes, gullies, etc., and "walked down" by crawler type tractor. If there are no drainages in the immediate area, the vegetation should be "walked down" in place. All trash resulting from construction activities will be disposed of. Any large rocks resulting from construction activities will not be piled or left in rows but will be left so they do not detract from the natural appearance of the area. Any available topsoil encountered during construction should be stockpiled for use in restoring the pit area after the pits are covered.

9. Drilling Pits:

a. Mud pits will be constructed so as not to leak, break, or allow discharge of liquids. Pits are not to be located in natural drainage. If plastic material is used to line pits, it must be removed to below ground level before pits are covered.

b. All unguarded pits containing liquids will be fenced and any unguarded pit containing oil and/or toxic liquids will be covered with a fine mesh netting if necessary to protect wildlife.

c. Liquids in pits will be allowed to evaporate, or be properly disposed of otherwise, before pits are broken. Under no circumstances will pits be allowed to be cut to be drained.

10. Any additional construction, re-construction, or al terations of facilities, including roads, which will result in the disturbance of new ground, will require the filing of a suitable plan and prior approval by the BLM.

11. If the well is dry and is to be plugged, approval of the proposed plugging program may be octained orally. However, oral approval must be confirmed in writing by imnediately filing seven (7) copies of the Notice of Intention to Abandon on Form 9-331 with the District Supervisor. The report should show the total depth reached, the reason for plugging, and the proposed intervals, by depths, where cement plugs are to be placed, type of plugging mud, etc.

12. Plugging Procedures:

a. Plugging equipment used shall have separate mixing and displacement pumps and a calibrated tank to assure proper displacement of plugs. 
b. A proper tank or pit will be used to contain all fluids pumped from the well during plugging operations.

c. All cement plugs are to be placed through tubing (or drillpipe) and shall be a minimum of 25 sacks or 100 feet in lengths, whichever is greater. The minimum length of plugs for deeper we1ls is 150 feet in length for depths $\left(4,000^{\prime}-10,000^{\prime}\right)$ and 200 feet in length for depths below $10,000^{\prime}$.

d. Any cement plug placed when well is not full of fluid, or when well may be taking fluid, will be touched after cement has set to verify proper location.

e. Mud must be placed between plugs. Minimum consistency of plugging mud must be that obtained by mixing at the rate of 25 sacks of gel per 100 barrels of water.

13. Upon abandonment of well on Federal surface rehabilitation will be required. Rehabilitation may include ripping, leveling, contouring, water-barring, barricading and reseeding. Specific measures will be provided under special stipulations.

14. Within 15 days after plugging the we11, six copies of a Subsequent Report of Abandonment is to be filed on form 9-331 showing the imanner in which the well was plugged, including depths where casing was cut and pulled from, intervals (by depths) where cement plugs were placed, and the date plugging was completed.

15. Seeding Procedures:

a. Time:

Normally, the best time for seeding is between June 15 and September 15. However, the grantee may seed immediately after construction. In any event, if seed does not germinate after one growing season, reseeding may be required.

Seeding Operation:

Seeding will be done with a disc-type drill with two boxes for various seed sizes. The drill rows will be eight to ten inches apart. The seed will be planted not less than one-half inch deep or more than one inch deep. The seeder will be followed with a drag, packer, or roller tc ansure uniform coverage of the seed, and adequate compaction. Drilling will be done on the contour where possible, not up and down the slope. Where slopes are too steep for contour drilling, a "cyclone" hand seeder or similar broadcast seeder will be used. Seed will then be covered to the depth described above by whatever means is practical.

c. Species To Be Planted In Pounds of Pure-Live-Seed Per Acre:

If seed is broadcast, double the seeding rate. Percent purity $x$ percent germination $=$ Percent pure-live-seed . 
The Seed mixture(s) listed below, to be employed in rehabilitation, will be specified in the special stipulations.

(1) SEED MIXTURE 1 (Loamy sites)

LEHMANNS LOVEGRASS (Eragrostis Tehmanniana) $\quad .25$

SIDE OATS GRAMA (Bouteloua curtipendula)

SAND DROPSEED (Sporobolus cryptandrus)

(2) SEED MIXTURE 2 (Sandy Sites)

SAND DROPSEED (Sporobolus cryptandrus)

SAND LOVEGRASS (Eragrostis trichodes) $\quad .50$

Little Bluestem (Andropogon scoparius)

(3) SEED MIXTURE 3 (Shallow Sites)

SIDEOATS GRAMA (Bouteloua Curtipendual) $\quad 7.00$

LEHMANN'S LOVEGRASS (Eragrostis lehmanniana) $\quad .50$

or BOER LOVEGRASS (E. chioromelas)

(4) SEED MIXTURE 4 ("Gyp" Sites)

ALKALI SACATION (Sporobolus airoides)

FOUR-WING SALTBUSH (atriplex canescens) $\quad 9.00$

It may be necessary to mix small seeds with rice hulls or sand to obtain uniform coverage. Rice hulls are generally available from seed dealers for this purpose. 


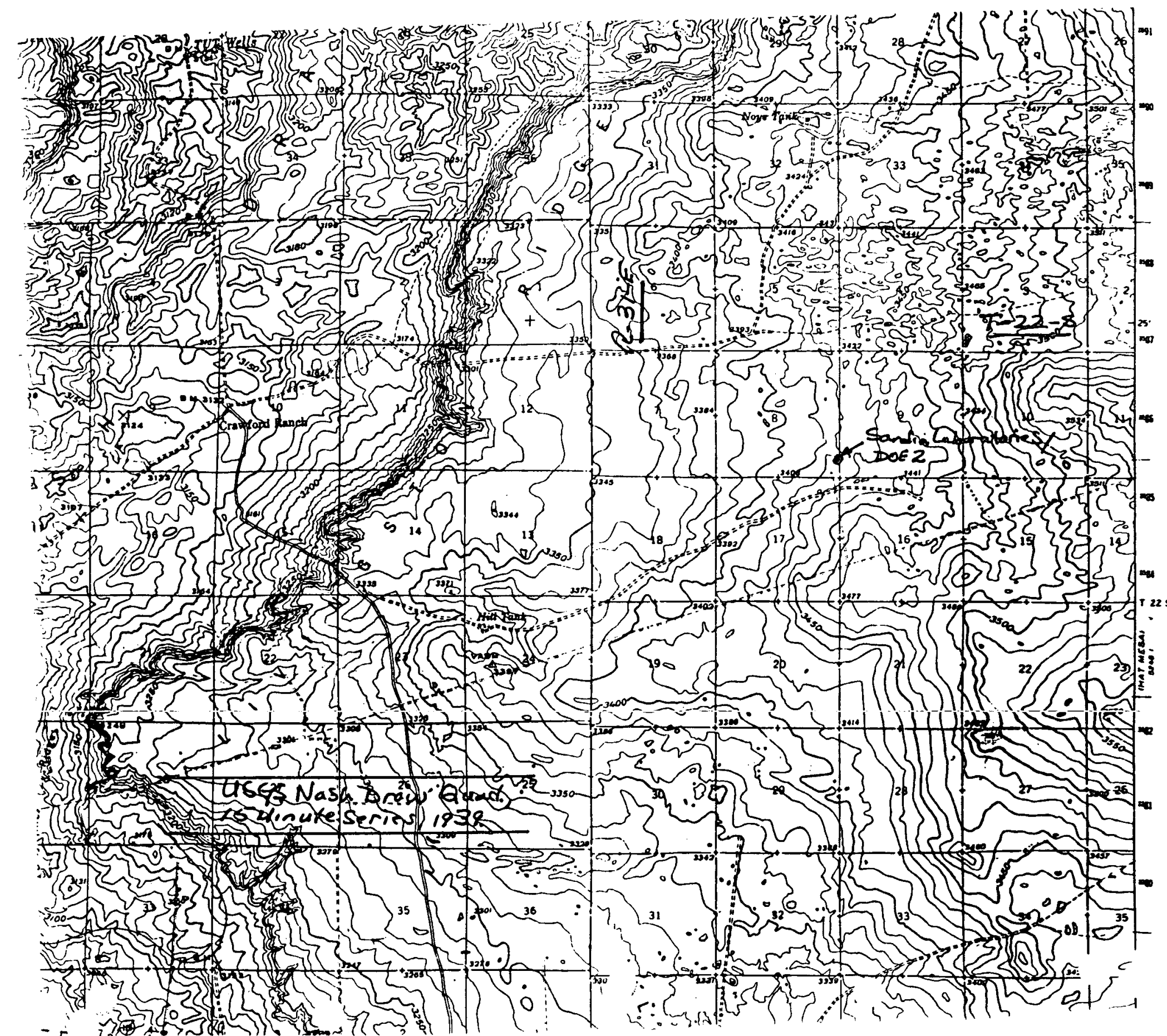




\section{United States Department of the Interior \\ BUREAU OF LAND MANAGEMENT \\ Roswell District OHice \\ SPECIAL APPROVAL STIPULATIONS}

THE FOLLOWING DATA IS REQUIRED ON THE WELL SIGN

The special stipulations check marked below are applicable to the above described well and approval of this application to drill is conditioned upon compliance with such stipulations in addition to the

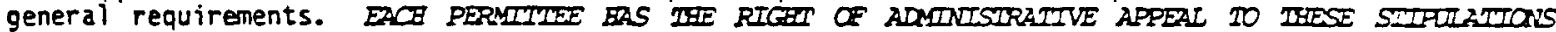
PLRSTETT TO LIIE 43 CFR 3165.3 AND 3165.4.

[ ] A. The Bureau of Land Management office is to be notified at:

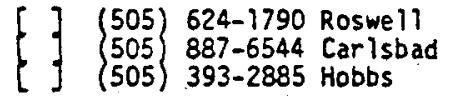

in sufficient time for a representative to witness:

[] 3.
[ ] 3.

J B. At least one working day prior to constructing the well pad, access roads and/or reiated facilities, the operator or dirt contractor shall notify the euthorized officer of the surface management agency. The surface management agency may be contactec at:

$$
\left\{\begin{array}{l}
\text { BLM phone (505) } 887-6544 \text { Carisbad, New Mexico colled ou } 8 / 7 / 84 \text { BLM optoK) } \\
\text { BLM phone (505) } 624-1790 \text { Roswe11. New Mexico }
\end{array}\right.
$$

He shall also notify the surface management agency within two working days after completion of earth-moving activities.

DC. Roads in the area of operation of this authorization will require surfacing.

[ ] $D$.

surface casing should be set in the Rustler Anhydrite formation and cement circulated to the surface. If surface casing is set at a lesser depth, the

casing must be cemented from the casing shoe to the surface or cemented to the surface through a staoe tool set at least 50 feet below the top of the Rustler after cementing around the shoe with sufficient cement to fill to the base of the salt section.

[ ] E. Before drilling below the of a minimum of one annular type and two ram type preventers.

[ ] F. Minimum required fill of cement behind the casing is to

[ ] G. After setting the casing string and before drilling into the formation, the blowout preventers and related control equipment shall be pressure tested to rated working pressures by an Independent service company. Any equipment failing to test satisfactorily shall be repaired or replaced. This office should be notified in sufficient time for a representative to witness the tests and shall be furnished a copy of the pressure test report. 
[ ] H. Mud system monitoring equipment, with derrick floor indicators and visual and audio alarms, shall be installed and operating before drilling into the formation and used unt 11 production casing is run and cementec. Finizoring equipment shall consist of the following:

[ ]. A recording pit level indicator to determine pit volume gains and losses.

[].2. A mud volume measuring device for accurately determining mud volume necessary to fill the hole on trips.

[ ] 3. A flow sensor on the flow-line to warn of any abnomial mud returns from the well.

[ ] 1. A kelly cock will be installed and maintained in operable condition.

[ ] J. A Communitization Agreement covering the acreage dedicated to the well must be filed for approval with the Bureau of Land Management, P.0. Box 1379, Hoswell, New Mexico 88201. The effective date of the agreenent must be prior to any saies.

[ ] K. Above ground structures, not subject to applicable safety requirements shall be painted. The paint color is to simulate:

$\left\{\begin{array}{l}\text { Sandstone Brown, Fed. Std. 595-20318 or } 30318 \\ \text { Sagebrush Gray. Fed. Std. 595-26357 or } 36357\end{array}\right.$

[. ] 1. A Gana Ray-Compensated Neutron log is required from the liase of the salt section to the surface with cable speed not to exceed 30 feet per minute.

1. Rehabilitation

2 At least 3 working days prior to comencing any of the following rehabilitation activities, the operator shall notify the appropriate surface managing agency, show in part B.

DJ 1. Upon the conclusion of drflling and completion operations when mud pits are dry they will be leveled, plastic will be removed and area reseeded with mixture No. shown on last page of General Requirements.

12. Following the down-hole plugging and abandonment of all operation:

If a. The drill pad and miles of aecess road shall be ripped to a minimum of $12^{\circ}$ in depth. Ripping shall be on the contour with rips being approximately 3 feet or less apart.

D. The drill site and mixture No.

mitues of access road will be reseeded with

4x

c. All ripped surfaces are to be protected from "ehicular travel by constructing a dead-end oitch and earthen barricade at the entrince to these ripped areas. The barricade is to be constructed using spofl materials from the ditch and should be of sufficient magnitude to discourage vehicle entry.

[ ]. D. Private Surface: Abandonment stipulations tc coincide with operator-landowner agreement. (where no agreement exists, BLM will be requested to provide abandonment stipulations.

Xe. The surface location is to be cleaned and leveled.

1 2 3. Modifications in the rehabilitation stipulations made necessary by unforeseen circumstances or improvements in rehabilitation methods may be made when the Notice of Intention to Abandon is filed.

[ ]N. Other: 


\section{APPENDIX E \\ Geophysical Logs of Drillhole DOE-2}


The following logs are incorporated into this appendix by reference:

\begin{tabular}{|c|c|c|c|c|c|c|}
\hline \multirow{2}{*}{ Type of Log } & \multirow[b]{2}{*}{ Date } & \multirow{2}{*}{$\begin{array}{l}\text { Run } \\
\text { No. }\end{array}$} & \multirow{2}{*}{$\begin{array}{l}\text { Depth } \\
\text { Driller }\end{array}$} & \multirow{2}{*}{$\begin{array}{l}\text { Depth } \\
\text { Logger }\end{array}$} & \multicolumn{2}{|c|}{ Logged Interval } \\
\hline & & & & & Top & Bottom \\
\hline \multicolumn{7}{|l|}{ Phase I (Dresser-Atlas Logs) } \\
\hline $\begin{array}{l}\text { Neutron-gamma ray } \\
\text { Compensated densilog-gamma }\end{array}$ & $10-25-84$ & 1 & 986 & 960 & 0 & 958 \\
\hline ray & $10-25-84$ & 1 & 986 & 959 & 0 & 956 \\
\hline BHC acoustilog-gamma ray & $10-25-84$ & 1 & 986 & 957 & 0 & 950 \\
\hline Dual laterolog-gamma ray & $10-25-84$ & 1 & 986 & 955 & 0 & 954 \\
\hline \multicolumn{7}{|l|}{ Phase II (Dresser-Atlas Log) } \\
\hline 4-arm caliper-gamma ray & $6-13-85$ & 1 & 4325 & 4242 & 900 & 4242 \\
\hline Temperature & $6-13-85$ & 1 & 4325 & 4248 & 0 & 4247 \\
\hline Neutron-gamma ray & $6-13-85$ & 1 & 4325 & 4246 & 0 & 4245 \\
\hline Gamma ray-simul & $6-13-85$ & 1 & 4325 & 4245 & 900 & 4245 \\
\hline $\mathrm{BHC}$ acoustilog-gamma ray & $6-13-85$ & 1 & 4325 & 4245 & 1010 & 4245 \\
\hline Dual laterolog-gamma ray & $6-13-85$ & 1 & 4325 & 4245 & 1010 & 4245 \\
\hline \multicolumn{7}{|l|}{ Compensated densilog-gamma } \\
\hline ray & $6-13-85$ & 1 & 4325 & 4245 & 1008 & 4243 \\
\hline Directional survey & $6-14-85$ & 1 & 4325 & 4246 & 1000 & 4243 \\
\hline
\end{tabular}

NOTE: Original data are retained in Sandia WIPP Central File, Dept. 6330, Sandia National Laboratories, Albuquerque, NM, 87185. 
<smiles>[Tl]</smiles> 


\section{APPENDIX F \\ USGS Lithologic Log for Drillhole DOE-2}




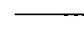




\section{USGS Lithologic Log for Drillhole DOE-2}

[Color designations are from the Rock Color Chart (Goddard and others, 1948);

"no recovery" designates where core was lost during coring operations]

Lithologic description

Depth interval

Feet

Pad fill, caliche, and sand, moderate-reddish-orange (10R-5/6), fine grained, rounded quartz, unconsolidated

Caliche, very light gray (N8)

$0-8$
$8-13$
$13-48.1$

Sandstone, moderate-reddish-brown (10R-3/4), very fine to fine grained quartz, subrounded, moderately to well indurated, calcium sulfate cememt; rock bit 40 to $48.1 \mathrm{ft}$

Siltstone and claystone, dark-reddish-brown (10R-3/4); siltstone very thin cross-bedding, horizontal, well indurated, calcium sulfate cement; claystone laminated; disseminated grayish-green (5G-5/2) alteration streaks and blebs disseminated throughout core; pale-yellowish-brown (10YR-6/2) fine-grained sandstone from 52.6 to $52.7 \mathrm{ft}$

$\begin{array}{lll}48.1 & - & 58.1 \\ 58.1 & - & 59.0 \\ 59.0 & - & 51.0 \\ & & \\ 61.0 & - & 53 . ? \\ 63.2 & - & 63.6 \\ & & \\ & & \\ 63.6 & - & 70.4\end{array}$

No recovery

Siltstone and claystone, similar to unit at 48.1 to $58.1 \mathrm{ft}$

Sandstone, light-olive-gray (5Y-5/2), fine- to medium-grained; bands and blebs of grayisn-green (10GY-5/2) reduction zones; dark-reddish-brown (10R-3/4) claystone flakes along bedding planes, especially in upper $0.1 \mathrm{ft}$ and at 70.6 to $70.7 \mathrm{ft}$ where bedding dips $5^{\circ}$

Siltstone, dark-reddish-brown (10R-3/4), sandy

Sandstone, similar to unit at 63.2 to $63.6 \mathrm{ft}$; contains thin stringers of grayishyreen (1UGY-5/2) claystone along bedding planes and as isolated blebs

\begin{tabular}{|c|c|}
\hline 70.4 & - \\
\hline 71.6 & - \\
\hline 72.7 & - \\
\hline 73.2 & - \\
\hline 78.7 & - \\
\hline
\end{tabular}

of grayish-green (10GY-5/2) alteration zones disseminated throughout core

Sandstone, pale-0live $(10 Y-6 / 2)$, fine- to medium-grained; grayish-green (5G-5/2) clay streaks throughout core, 0.2-ft-thick beds near top and bottom of unit, thin clay seam at top of unit

$88.8-9 n .1$ 
USGS Lithologic Log (continued)

[Color designations are from the Rock Color Chart (Goddard and others, 1948);

"no recovery" designates where core was lost during coring operations]

Lithologic description

Depth interval

Feet

Sandy siltstone, dark-reddish-brown (10R-3/4), minor streaks and blebs of pale-olive

$(10 Y-6 / 2)$ reduction zones

$90.1-91.1$
$91.1-91.6$

Sandstone, pale-olive $(10 \mathrm{Y}-6 / 2)$, similar to unit at 88.8 to $90.1 \mathrm{ft}$

(2)

Sandstone, dark-reddish-brown (10R-3/4), fine- to medium-grained, well induratied, minor disseminated beds of claystone and siltstone; light-olive-gray (5Y-5/2)

layers at 93.9 to 94.1 and 95.6 to $95.7 \mathrm{ft}$, lower layer has thin clay seam al: top; bedding dips 5 to $10^{\circ}$

$91.6-103.8$

Sandstone, greenish-gray $(5 G Y-6 / 1)$, medium-grained, well indurated

$103.8-104.0$

Claystone, dark-reddish-brown (10R-3/4); minor grayish-green (5G-5/2) alteration streaks

$104.0-104.9$

Sandstone, similar to unit at 103.8 to $104.0 \mathrm{ft}$

$104.9-105.2$

Claystone, similar to unit at 104.0 to $104.9 \mathrm{ft}$

$105.2-105.4$

Sandstone, grayish-red (10R-4/2), medium to coarse grained, well indurated; dark-reddish-brown (10R-3/4) siltstone at 107.2, 107.3 to 107.6 and

109.7 to $109.9 \mathrm{ft}$; very thin clay partings at top and bottom of siltstone

$105.4-110.0$

Sandstone, dark-reddish-brown (10R-3/4), fine- to medium-grained, well indurated; zones containing clay galls at $111.3,111.9$ to 112.4 and $115.2 \mathrm{ft}$

$110.0-116.0$

Sandstone, grayish-red (10R-4/2) and dark-reddish-brown (10R-3/4); zones containing clay galls throughout core; bedding dips $5^{\circ}$

$116.0-118.5$

Sandstone, pale-yellowish-brown (10YR-6/2) and pale-olive (10Y-6/2), fine- to medium-grained; minor clay galls and alteration streaks

$118.5-119.3$

Claystone, dark-reddish-brown (10R-3/4)

$119.3-120.7$

Sandstone, dark-yellowish-brown (10YR-4/2) grading to dark-reddish-brown $(10 R-3 / 4)$ at $121.3 \mathrm{ft}$ and to light-olive-gray $(5 Y-6 / 1)$ and dark-yellowishbrown $(10 \mathrm{Yr}-4 / 2)$ at $124.9 \mathrm{ft}$, fine- to medium-grained, laminated to thin bedded; vein dipping $60^{\circ}$ between 122 and $123 \mathrm{ft}$ healed with calcium sulfate

Siltstone, pale-yellowish-brown (1OYR-6/2), appears to be silicified

$120.7-126.8$

$126.8-127.0$

Siltstone and claystone, alternating beds; pale-brown (5YR-5/2) and darkreddish-brown (1OR-3/4); siltistone slightly sandy, contains clay galls; claystone slightly deformed laminae; white (N9) sandstone from 128.0 to $128.2 \mathrm{ft}$ contains fragments of overlying claystone

$127.0-128.4$

Sandstone, dark-reddish-brown (10R-3/4) and grayish-red (10R-4/2), fine- to medium-grained, laminated to very thin bedded; some beds crossbedded; disseminated clay galls; most bedding horizontal

$128.4 \quad 130.8$

No recovery

$130.8-131.0$ 


\section{USGS Lithologic Log (continued)}

[Color designations are from the Rock Color Chart (Goddard and others, 1948); "no recovery" designates where core was lost during coring operations]

Sandstone, similar to unit at 128.4 to $130.8 \mathrm{ft}$; dark-reddish-brown (10YR-3/4), clay seam, $4 \mathrm{~mm}$ thick, at base

$131.0 \quad-131 . ?$
$131.2-131.6$
$131.6-132.0$
$132.0 \quad-132 . ?$
$132.2 \quad-133.3$

$(10 G-7 / 2)$ clay

Siltstone and claystone, dark-reddish-brown (10R-3/4), alternating laminae and very thin beds, many laminae wavy and slightly contorted, some very thin beds of lenticular flattened claystone in siltstone matrix; grayish-green (10GY-5/2) and pale-yellowish-brown (10YR-6/2) alteration bands at 137.6, 137.7 to 137.9, and $139.6 \mathrm{ft}$; numerous 1 to $3 \mathrm{~mm}$ diameter grayish-green (10GY-5/2) alteration spots

\begin{tabular}{|c|c|c|}
\hline 133.3 & - & 140.5 \\
\hline 140.5 & - & 141.7 \\
\hline 141.0 & - & 144.1 \\
\hline 144.1 & - & 144.4 \\
\hline 144.4 & - & 147.9 \\
\hline 147.9 & - & 148.3 \\
\hline 148.3 & - & $149 . n$ \\
\hline 149.0 & - & $15 n .1$ \\
\hline 150.1 & - & $15 n .5$ \\
\hline 150.5 & - & 151.4 \\
\hline 151.4 & - & 151.6 \\
\hline 151.6 & & 153.1 \\
\hline
\end{tabular}

No recovery

Siltstone and sandstone, dark-reddish-brown (10R-3/4) laminated to thin bedded; claystone chips in fine-grained sandstone; grayish-green (10GY-5/2) alteration spots and large vuggy blebs of white (N9) mineral at 142.2 to $142.3 \mathrm{ft}$

Sandstone, grayish-red (1OR-4/2), grading to light-olive-gray $(5 Y-6 / 1)$, fineyrained; very thin parting of gray (N6) claystone at base

Siltstone and fine-grained sandstone with laminae of claystone, dark-reddishbrown (10R-3/4); small grayish-green (10GY-5/2) reduction blebs; irregular band band of white ( $N 9$ ) gypsum at $147.0 \mathrm{ft}$

Siltstone, dark-reddish-brown (10R-3/4), thin bedded

No recovery (no recovery zone put inside core run, not at base; core badly broken starting at $148.3 \mathrm{ft}$ )

Siltstone, similar to unit at 147.9 to $148.3 \mathrm{ft}$

Sandstone, pale-olive (10Y-6/2), fine-grained; greenish-gray (5G-6/1)

claystone, $0.1 \mathrm{ft}$ thick at base

Siltstone, dark-reddish-brown (1OR-3/4), thin bedded

$151.6-153.1$ 


\section{USGS Lithologic Log (continued)}

[Color designations are from the Rock Color Chart (Goddard and others, 1948);

"no recovery" designates where core was lost during coring operations]

Litnologic description

Depth interval

Feet

Sandstone, pale-0live $(10 Y-6 / 2)$, fine-grained

Siltstone, dark-reddish-brown (1OR-3/4), disrupted or slumped thin beds; large blebs of vuggy gypsum

Siltstone, dark-reddish-brown (10R-3/4), massive; basal $0.1 \mathrm{ft}$ is dark-reddishbrown (10R-3/4) claystone chips and gypsum in fine-grained sandstone

Sandstone, grayish-red (10R-4/2), fine-grained, cross bedded

Siltstone, dark-reddish-brown $(10 R-3 / 4)$, thin bedded

Sandstone, dark-reddish-brown (10R-3/4), fine-grained, massive to thinly crossbedded

Sandstone, dark-reddisn-brown (10R-3/4), fine-grained, massive

Siltstone and very fine grained sandstone $(10 R-3 / 4)$, thin bedded

Sandstone, siltstone, and claystone, light-olive-gray (5Y-6/1), dark-reddishbrown $(10 R-3 / 4)$ and greenish-gray $(5 G Y-6 / 1)$; clay seam at base has wavy contact with unit below

Sandstone, dark-reddish-brown (10R-3/4), very fine grained, massive

Sandstone and siltstone, dark-reddish-brown (10R-3/4); very fine grained sandstone; thin bedded

Siltstone and mudstone, dark-reddish-brown $(10 R-3 / 4)$, thin bedded

Sandstone, light-olive-gray $(S Y-6 / 1)$, very fine grained; thin gray (N6) parting at base

Siltstone, mudstone, and very fine grained sandstone, dark-reddish-brown $(10 R-3 / 4)$, thin bedded

No recovery (actual measure $7.1 \mathrm{ft}$, but $0.8 \mathrm{ft}$ recovered in next core

Sandstone, light-0 live-gray $(5 Y-6 / 1)$, very fine grained; disseminated chips of dark-reddish-brown $(10 R-3 / 4)$ mudstone

Claystone and siltstone, dark-reddish-brown (1OR-3/4) and grayish-red (10R-4/2), laminated to thin bedded, some wavy beds, most beds and laminae horizontal, occasional clay galls in silty matrix; yellowish-gray $(5 Y-8 / 1)$, fine-grained sandstone at 177.4 to $177.5 \mathrm{ft}$ contains rounded, oblong claystone fragments; selenite veins along bedding planes as thick as $2 \mathrm{~cm}$ show antitaxial crystal growth, most crystals normal to bedding, but few show slight curvature at contact with wall rock; occasional reduction zones parallel to bedding; 1 to $4 \mathrm{~mm}$ diameter reduction spots disseminated through core. First major selenite occurrence at $177.7 \mathrm{ft}$
$153.1-153.2$

$153.2-153.7$

$153.7-154.5$

$154.6-154.8$

$154.8-156.4$

$156.4-161.9$

161.9 - 166.9

$166.9-167 . ?$

$167.2-167.5$

$167.5-167.9$

$267.9-169.1$

$169.1-169.4$

$169.4-169.5$

$169.5-170.3$

$170.3-176.6$

$176.6-176.7$

$176.7-190.5$ 


\section{USGS LIthologic Log (continued)}

[Color designations are from the Rock color Chart (Goddard and others, 1948); "no recovery" designates where core was lost during coring operations]

Sandstone, dark-reddish-brown (1OR-3/4), very fine to fine grained, laminated, soft sediment deposition laminae; numerous 1 to $2 \mathrm{~mm}$ diameter reduction spots; some crossbedding at base of unit

$190.5-191.1$

$191.1-191.9$

$191.9-192.1$

$192.1-193 . ?$ deformation in bed at $192.8 \mathrm{ft}$

Sandstone, grading from 1 ight-olive-gray $(5 Y-6 / 1)$ and greenish-gray (5GY-6/1) to grayish-red (1OR-4/2) to dark-reddish-brown (IOR-3/4), thin bedded; selenite vein at $194.4 \mathrm{ft} 5 \mathrm{~mm}$ thick; soft sediment deformation in bedding at 194.3 and $194.7 \mathrm{ft}$

Siltstone and claystone, similar to unit at 191.1 to $191.9 \mathrm{ft}$

Sandstone, grayish-red (10R-4/2) and dark-reddish-brown (10R-3/4), grades downward from laminated to thin bedded, crossbedded in thicker beds; $15-\mathrm{mm}-\mathrm{thick}$ selenite vein at $197.6 \mathrm{ft}$, cross bedding from 197.6 to $198.7 \mathrm{ft}$ outlined with dark streaks (dark minerals?); clay and selenite seam at 199.1 to $199.2 \mathrm{ft}$; contains grayish-green (5GY-6/1) sandstone from 199.6 to $199.8 \mathrm{ft}$ Siltstone and claystone, similar to unit at 191.1 to $191.9 \mathrm{ft}$

Siltstone, grayish-0)ive (10Y-4/2), 3-mm-thick selenite vein at base

Siltstone and very fine grained sandstone, dark-reddish-brown (10R-3/4), laminated to very thin bedded, $1-$ mm-thick selenite vein cutting bedding at $5^{\circ}$ at $200.5 \mathrm{ft}$ paper-thin median suture

Siltstone and sandstone, similar to unit at 200.3 to $201.5 \mathrm{ft}$, siltstone laminated, sandstone massive; 4-mm-thick selenite at $204.4 \mathrm{ft}$ and $3-\mathrm{mm}$ selenite at $204.5 \mathrm{ft}$ parallel to bedding, 2-mm-thick selenite vein at $204.7 \mathrm{ft}$ cuts bedding at $10^{\circ}$; grayish-green $(5 \mathrm{G}-5 / 2)$ clay seam at $202.6 \mathrm{ft}$ directly over $0.1-f t-t h i c k$ light-olive-gray $(5 Y-6 / 1)$ sandstone; greenish-gray (5GY-6/1), very fine grained sandstone at 204.9 to $205.0 \mathrm{ft}$

Siltstone and claystone, dark-reddish-brown (10R-3/4), siltstone very thin bedded, claystone laminated and shows evidence of dessication cracking and rehealing with siltstone matrix No recovery
$200.3-201.5$
$201.5-201.7$

$201.7-205.5$

$205.5-208.0$

$193.2-194 . R$

$194.8-195.4$

$195.4-199.9$
$199.9-200.2$
$200.2-200.3$

$208.0-210.0$ 


\section{USGS Lithologic Log (continued)}

[Color designations are from the Rock Color Chart (Goddard arld others, 1948);

"no recovery" designates where core was lost during coring operations]

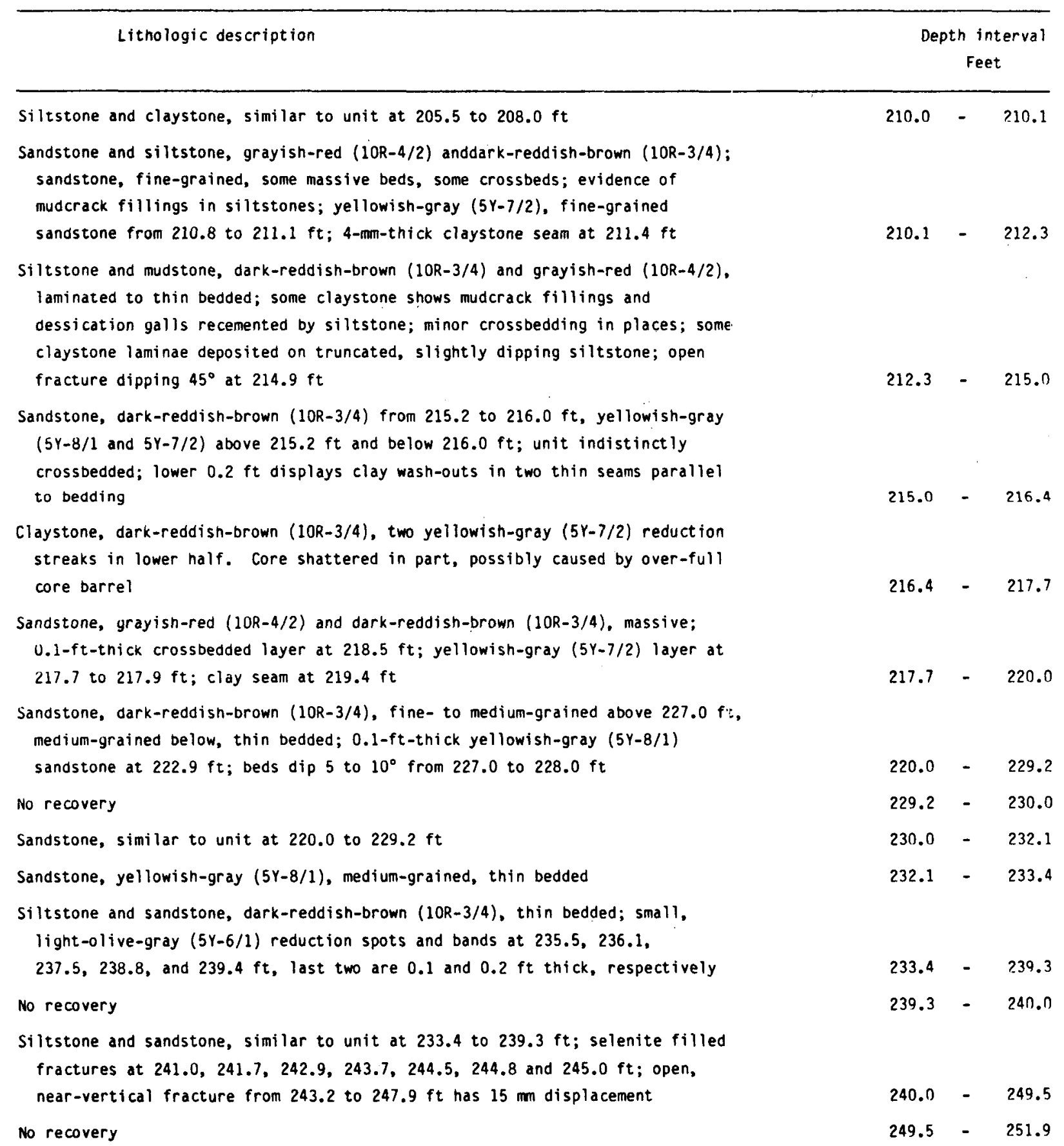


USGS Lithologic Log (continued)

[Color designations are from the Rock Color Chart (Goddard and others, 1948);

"no recovery" designates where core was lost during coring operations]

Siltstone and fine-grained sandstone, dark-reddish-brown (1OR-3/4), laminated to thinly bedded; numerous selenite veins parallel to bedding; small reduction blebs, light-olive-gray $(5 Y-6 / 1)$ throughout core and concentrated from

254.7 to $257.0 \mathrm{ft}$

$251.9-270.0$

Selenite, translucent vein filling

Siltstone and very fine grained sandstone, dark-reddish-brown (10R-3/4), thin bedded; selenite bands at $270.4,270.6$ to $270.67,271.2,271.65,272.25$, 272.35 , and 272.95 to $273.05 \mathrm{ft}$; light-0live-gray $(5 \mathrm{Y}-6 / 1)$ reduction bands at 271.85 and 272.4 to $272.45 \mathrm{ft}$

$270.2-273.3$

Sandstone, grayisn-red (10R-4/2), grading downward from fine grained to medium grained; salt-and-pepper appearance from 278.0 to $279.9 \mathrm{ft}$; selenite seams at $275.8,276.1,276.8,277.5,277.7$ and $278.0 \mathrm{ft}$; below $278.0 \mathrm{ft}$ numerous thin crosscutting selenite veins; large clay clasts incorporated from 275.5 to 276.0 and in lower foot

Sandy siltstone, dark-reddish-brown (10R-3/4), becomes more sandy in lower half; laminated to massive, some thin crossbedded units; selenite vein at $280.7 \mathrm{ft}$ and 4 veins between 281.3 to $281.8 \mathrm{ft}$; vein at $280.7 \mathrm{ft}$ has clast elevated above host rock; pale-olive $(10 \mathrm{Y}-6 / 2)$ alteration spots 1 to $5 \mathrm{~mm}$ in diameter

Sandstone, mottled dark-reddish-brown (10R-3/4) and light-olive-gray (5Y-5/2), medium-grained; very thin selenite veins throughout

Sandy siltstone, similar to unit at 279.9 to $282.0 \mathrm{ft}$; horizontal selenite vein at 282.6 and one at $282.9 \mathrm{ft}$ dips $15^{\circ}$ to bedding

Sandstone, light-olive-gray $(5 Y-6 / 1)$, medium-grained, very thin bedded, beds dip as much as $15^{\circ}$; base of unit cut into unit below (channel?)

Sandy siltstone, similar to unit at 279.9 to $282.0 \mathrm{ft}$; 1 aminated to very thin bedded, few minor cross-beds; selenite veins at 284.5 and $285.0 \mathrm{ft}$

Siltstone, dark-reddish-brown $(10 R-3 / 4)$ and grayish-red $(10 R-4 / 2)$, laminated to very thin bedded, minor crossbeds; sandy layer from 286.6 to $286.9 \mathrm{ft}$; claystone clasts in some beds; thin claystone at $288.8 \mathrm{ft}$; thin selenite veins at 286.1 to 286.8 and $288.8 \mathrm{ft}$; disseminated pale-0live $(10 \mathrm{Y}-6 / 2)$ reduction spots 1 to $5 \mathrm{~mm}$ in diameter in upper foot

Siltstone, pale-yellowish-brown (10YR-6/2), grayish-green massive; (5G-5/2), thin bed at base

Claystone, dark-reddish-brown (10R-3/4), laminated to very thin bedded; minor crossbedded silty layers; four thin selenite veins in upper half, $1-\mathrm{cm}-\mathrm{thick}$ vein at base
$273.3-279.9$

$270.0-270 . ?$

$279.9-282.0$

$282.0-282 . ?$

$282.2-283.0$

$283.0-284.1$

$284.1-285.0$

$285.0-289.3$

$289.3-289.9$

$289.9-290.7$ 
USGS Lithologic Log (continued)

LColor designations are from the Rock Color Chart (Goddard anc others, 1948); "no recovery" designates where core was lost during coring operations]

Lithologic description

Depth interval

Feet

Siltstone, dark-reddish-brown (10R-3/4) and grayish-red (10R-4/2), interbedded with thin claystones, laminated to thin bedded, some wavy and contorted bedding; numerous very thin selenite veins, most parallel to bedding, some crosscutting bedding by as much as $20^{\circ}$, one selenite vein from 296.8 to $297.6 \mathrm{ft}$ dips $76^{\circ}$; evidence of channel cut-and-fill; mud-crack filling at 298.0ft; several thick selenite veins ranging from 1 to $4 \mathrm{~cm}$ thick, mostly with claystone on either side, some median sutures in selenite attest to antitaxial nature of vein fillings, all veins show no curvature of selenite crystals; crossbedding becomes major below $299.3 \mathrm{ft}$; pale-yellowish-brown (10YR-4/2) fine-grained sandstone $1.5-\mathrm{cm}-\mathrm{thick}$ at $300.4 \mathrm{ft}$ overlies $2.5-\mathrm{cm}-\mathrm{thick}$ grayish-green (106-5/2) claystone; thin selenite veins at $303.7,303.9,309.0$ and $309.5 \mathrm{ft} ; 1.5-\mathrm{cm}-\mathrm{thick}$ selenite veins at 308.4, 308.5, and $309.4 \mathrm{ft}$, thin selenite vein at $306.5 \mathrm{ft}$ fills en echelon bedding plane fractures; grayish-green (10GY-5/2) reduction spots througnout core and very concentrated at 300.1 to $300.4 \mathrm{ft}$; mud-crack filling at 309.0 to $309.3 \mathrm{ft}$; selenite-filled fracture dipping $45^{\circ}$ below $310.2 \mathrm{ft}$; 5 -mm-tnick selenite vein at base partially cuts bedding

$290.7-311.2$

Claystone, dark-reddish-brown (IOR-3/4), and siltstone, pale-yellowish-brown (10YR-6/2) and grayish-green (5G-5/2); healed selenite-filled fracture $3 \mathrm{~mm}$ i:hick dips $30^{\circ}$ at $311.5 \mathrm{ft}$; very thin selenite vein at base

$311.2-311.7$

Sandy siltstone, dark-reddish-brown (10R-3/4) and very thin laminae of very dusky red (IOR-2/2), laminated to thin bedded, some crossbedding and severely conturted Dedding and laminae; disseminated minor blebs and streaks of grayish-green (5G-b/2) reduction zones; selenite vein $2 \mathrm{~cm}$ thick at $314.9 \mathrm{ft}$ shows 2 media) sutures and a fragment of host rock rafted upward into vein, selenite vein $5 \mathrm{~cm}$ thick at $317.2 \mathrm{ft}$ has 3 medial sutures and small rafted fragments of host rock in vein; at 319.2 to $319.6 \mathrm{ft}$ are 2 selenite-filled fractures dipping $60^{\circ}$; rock very well indurated, breaks sometimes occur at places other than vein-rock contact

$311.7-32 n .0$

Sandstone, dark-reddish-brown $(10 R-3 / 4)$ to grayish-red $(10 R-4 / 2)$, fine-grainec; scattered light-olive-gray $(5 Y-6 / 1)$ reduction spots especially common at $32: .0$, 321.5 and $326.0 \mathrm{ft}$; selenite vein fillings parallel to bedding at $321.25,3 \% 1.3$, $321.4,321.85,322.15,322.55,322.65,322.7,324.83$ to 324.9 and 326.9 to $327.0 \mathrm{ft}$

Siltstone and claystone, dark-reddish-brown (10R-3/4) to grayish-red (10R-4/2), laminated to thin bedded; grayish-green (5G-5/2) reduction zone at $328.9 \mathrm{ft}$, numerous 1 to $5 \mathrm{~mm}$ diameter reduction spots, wavy bedding below $330.0 \mathrm{ft}$; claystone content increases below $332.0 \mathrm{ft}$ and forms most of unit from 335.2 to $336.7 \mathrm{ft}$; thin selenite-filled fracture at $330.2 \mathrm{ft}$ dips $45^{\circ}$, and one at $336.6 \mathrm{ft}$ dips $60^{\circ}$ thin selenite vein at $336.6 \mathrm{ft}$ parallel to bedding and $1-\mathrm{cm}$-thick vein cuts bedding $20^{\circ}$ at $338.1 \mathrm{ft}$

$327.3-338.4$

No recovery (recovered in next core run)

$338.4-339.0$ 
USGS Lithologic Log (continued)

[Color designations are from the Rock Color Chart (Goddard and others, 1948);

"no recovery" designates where core was lost during coring operations]

Litnologic description

Depth interval

Feet

Siltstone and claystone, similar to unit from 330.0 to $338.4 \mathrm{ft}$

$339.0-339.5$

Sandy siltstone, dark-reddish-brown (10R-3/4), very thin to massive bedded; thin selenite-filled fracture dipping $70^{\circ}$ at $342.7 \mathrm{ft}$; pale-yellowish-brown (10rR-6/2) sandstone and grayish-green (5G-5/2) claystone $1 \mathrm{~cm}$ thick at base

$339.5-343.7$

Siltstone and claystone, dark-reddish-brown (10R-3/4) and graytsh-red (1OR-4/2), laminated to very thin bedded; disseminated concentrations of grayish-green (5G-5/2) reduction spots; selenite $2.5 \mathrm{~cm}$ thick with 3 median sutures at $346.7 \mathrm{ft}$, $1 \mathrm{~cm}$ thick at $347.5 \mathrm{ft}, 2 \mathrm{~cm}$ thick at $349.2 \mathrm{ft}, 0.5 \mathrm{~cm}$ thick at $350.2 \mathrm{ft}$, lawer two have angled healed fracture joining them; splintered fractures parallel to bedding nealed by selenite at 352.3 to $352.4 \mathrm{ft}$, two very thin fractures dipping $70^{\circ}$, top of one at $352.7 \mathrm{ft}$, top of other at $353.2 \mathrm{ft}$; pale-yel lowish-brown (10YR-6/2) band overlying grayish-green (5G-5/2) band between 355.5 and $355.6 \mathrm{ft}$; 8-mm selenite vein filling at $355.9 \mathrm{ft}$ contains fragments of underlying claystone as does 1 -cm-thick selenite at $357.4 \mathrm{ft}$; mud-crack fillings and soft sediment. deformed bedding in portions of core

$343.7-357.5$

Sandstone and siltstone, dark-reddish-brown (10R-3/4); sandstone, fine-grained; tninly laminated to $360.2 \mathrm{ft}$, crossbedded and soft sediment slump features; below $360.2 \mathrm{ft}$ grain size increases to medium and rock is massive; selenitefilled veins at $358.7,359.7$, and $359.8 \mathrm{ft}$; reduction spots comon; basal $0.1 \mathrm{ft}$, fine-grained, grayish-green (5G-5/2) sand-stone; basal contact irregular

Siltstone and fine-grained to very fine grained sandstone, dark-reddish-brown (1UR-3/4), laminated to thin bedded, small scale crossbedding and soft sediment deformation structures common; selenite-filled 0.1 -ft-thick fracture dipping $80^{\circ}$ at $366.9 \mathrm{ft}$, selenite-filled veins at $363.2,369.4,369.6,376.2$ and $380.5 \mathrm{ft}$ show median suture; reduction bands at $363.7,367.5,372.5,374.6$, and $376.2 \mathrm{ft}$, common reduction spots, grayish-green ( $5 \mathrm{G}-5 / 2)$ medium-grained sandstone from 377.0 to $377.3 \mathrm{ft}$

Sandstone, dark-reddish-brown $(10 R-3 / 4)$ very fine grained to fine-grained, small scale crossbedding and soft sediment deformation structures common; seienite veins at $384.1,385.9$ and $389.6 \mathrm{ft}$ range in thickness from 1.2 to $2.4 \mathrm{~cm}$; selenite-filled fractures dipping $82^{\circ}$ at $384.8 \mathrm{ft}$, and $60^{\circ}$ at $388.0 \mathrm{ft}$, both $1 \mathrm{~cm}$ thick; reduction bands at 378.9 and $379.8 \mathrm{ft}$; base of unit is clay fragments both rounded and flat

$377.3-393.9$

Sandy siltstone and claystone, dark-reddish-brown (10R-3/4), siltstone in upper $0.4 \mathrm{ft}$, thin bedded and contains clay galls at base; lower $0.2 \mathrm{ft}$ is seams of claystone and selenite; claystone fragments "rafted" up into selenite; no evidence of crystal bending in selenite

$393.9-394.5$ 
USGS Lithologic Log (continued)

[Color designations are from the Rock Color Chart (Goddard and others, 1948);

"no recovery" designates where core was lost during corifig operations]

Lithologic description

Depth interval

Feet

Sandstone, dark-reddish-brown (10R-3/4), similar to unit at 382.5 to $393.9 \mathrm{ft}$, laminated to thin bedded, very fine grained in upper $0.8 \mathrm{ft}$, fine-grained in lower $0.2 \mathrm{ft}$

$394.5-395.5$

Siltstone and very fine grained sandstone, dark-reddish-brown (10R-3/4), laminated to thin bedded; 5-mm-thick selenite vein at top of unit; 3-cm-thick selenite at $396.0 \mathrm{ft}$; claystone layers near top of unit have laminae incorporated in selenite, claystone layers above selenite at $396.0 \mathrm{ft}$; minor crossbedding in sandstone layers

$395.5-396.4$

Sandstone, similar to unit at 382.5 to $393.9 \mathrm{ft}$, massive

$396.4 \quad-397.4$

Siltstone and very fine grained sandstone, dark-reddish-brown (10R-3/4), very thin to massive bedded, some crossbedded sandstones; selenite vein $13 \mathrm{~mm}$ thick dippirig $10^{\circ}$ at $398.3 \mathrm{ft}, 1-\mathrm{cm}-\mathrm{thick}$ selenite at $400.8 \mathrm{ft}$; minor $\mathrm{clay}$ galls and soft sedinent deformation in lower half of unit; pale-yellowish-brown (10YR-6/2), fine-grained sandstone in lower $0.1 \mathrm{ft}$ of unit

Claystone, grayish-green (5G-5/2) in upper $1.5 \mathrm{~cm}$, dark-reddish-brown (10R-3/4) in lower part, laminated

Sandstone, dark-reddish-brown $(10 R-3 / 4)$, fine-grained, crossbedded; 3-mm-thick selenite at base

Siltstone, dark-reddish-brown (10R-3/4), laminated to very thin bedded

Sandstone, dark-reddish-brown (10R-3/4), laminated to thick bedded, very fine grained to fine-grained, evidence of soft sediment deformation features; claystone clasts at 407.2 and $408.2 \mathrm{ft}$, slightly coarser grained from 407.9 to $408.5 \mathrm{ft} ; 0.1 \mathrm{ft}$ thick grayish-green $(5 \mathrm{G}-5 / 2)$ sandstone 408.5 to $408.6 \mathrm{ft}$; 2-mm-thick selenite at $402.6 \mathrm{ft}, 8-\mathrm{mm}-\mathrm{thick}$ at $404.4 \mathrm{ft}, 3-\mathrm{mm}-\mathrm{thick}$ at $405.9 \mathrm{ft}$, $1.5 \mathrm{~cm}$-thick at 408.6 and $408.8 \mathrm{ft}$; healed hairline fractures dipping $40^{\circ}$ at 404.1 and $404.3 \mathrm{ft}$; grayish-green $(5 \mathrm{G}-5 / 2)$ reduction spots 1 to $10 \mathrm{~mm}$ in diameter disseminated throughout core, concentrated from 404.5 to $405.0 \mathrm{ft}$

$402.5-409.8$

Sandstone, grayish-red $(10 R-4 / 2)$ and light-gray (N7), fine-grained to mediumyrained, very thin to thin bedded; selenite vein $2 \mathrm{~mm}$ thick at $410.3 \mathrm{ft}$

$409.8-411.3$

Sandstone, siltstone, and minor claystone, dark-reddish-brown (10R-3/4) and grayisn-red (10R-4/2); sandstone very thin bedded to thin bedded, some layers: of soft sediment deformation; some siltstones fractured and rehealed with sandstone, siltstones very thin bedded; claystones laminated; selenite veins very numerous, most parallel to bedding, others dip 15 to $60^{\circ}$; all but one vein show median sutures and no curved crystals, one vein dipping $50^{\circ}$ at $420.0 \mathrm{ft}$ shows crystals curving toward each other at the median suture; numerous 1 to $10 \mathrm{~mm}$ diameter grayish-green (5G-5/2) reduction spots throughout core

$411.3-420.8$

No recovery

$420.8-421.0$ 


\section{USGS Lithologic Log (continued)}

[Color designations are from the Rock Color Chart (Goddard and others, 1948);

"no recovery" designates where core was lost during coring operations]

Lithologic description

Depth interval

Feet

Sandstone, siltstone, and claystone, similar to unit from 411.3 to $420.8 \mathrm{ft}$

$421.0-421.2$

Siltstone and sandy siltstone, minor claystone, dark-reddish-brown (10R-3/4), laminated to thin bedded, crinkly laminae 425.6 to 426.1 and 422.7 to $422.8 \mathrm{ft}$, some crossbedded sandy siltstones; grayish-green (56-5/2) siltstone 426.3 to $426.6 \mathrm{ft}$, pale-yel lowish-brown (10YR-6/2), fine-grained sandstone 426.6 to $426.7 \mathrm{ft}$; numerous selenite veins dipping 30 to $40^{\circ}, 421.4$ to $424.3 \mathrm{ft}$; numerous veins parallel to bedding 423.2 to $430.6 \mathrm{ft}$; grayish-green (5G-5/2) reduction spots in lower $3 \mathrm{ft}$

$421.2-430.6$

No recovery

$430.6-431.0$

Siltstone, dark-reddish-brown (1OR-3/4) slightly sandy, thin bedded to massive; unit contains 54 selenite veins parallel to bedding ranging from $5 \mathrm{~mm}$ to $6 \mathrm{~cm}$ thick and numerous 0.5 to $1 \mathrm{~mm}$ thick veins also parallel to bedding, nearly all tnicker veins show antitaxial crystal growth and median sutures; selenitefilled fractures dip $25^{\circ}$ at $443.35 \mathrm{ft}, 80^{\circ}$ at $445.7 \mathrm{ft}, 75^{\circ}$ at $447.35 \mathrm{ft}, 50^{\circ}$ at $449.35 \mathrm{ft}, 70^{\circ}$ at $461.5 \mathrm{ft}, 20^{\circ}$ at 468.1 and $468.2 \mathrm{ft}, 70^{\circ}$ at $470.6 \mathrm{ft}$, $20^{\circ}$ at $472.5 \mathrm{ft}, 45^{\circ}$ at 473.7 and $474.0 \mathrm{ft}$, and $80^{\circ}$ at $475.0 \mathrm{ft}$; reduction Dands grayish-green $(5 \mathrm{G}-5 / 2)$ at 442.75 to $442.85 \mathrm{ft}, 438.3$ to $438.4 \mathrm{ft}, 451.3$ to $451.35 \mathrm{ft}$, and $463.75 \mathrm{ft}$; reduction spots common throughout unit

Clay and claystone, dark-reddish-brown (10R-3/4), poorly consolidated

No recovery

(Note: Bit stuck at $478 \mathrm{ft}$, fished core barrel out and continued coring, using brine)

Clayey siltstone, dark-reddish-brown (10R-3/4), numerous $0.5-$ to 1 -mml-thick selenite veins paralleito bedding; $8-\mathrm{mm}-\mathrm{thick}$ vein at $480.6 \mathrm{ft}$; unit very thin to thin bedded, competent

$478.0-481.1$

Sandy siltstone, dark-reddish-brown (1OR-3/4) grading downward to siltstone, laminated to thin bedded, very competent; numerous 0.5 - to 1-mm-thick selenite veins parallel and sub-parallel to bedding; slightly "spongy" textured $1.5-\mathrm{cm}$ selenite vein at $482.2 \mathrm{ft}$, clayey "spongy" textured 5 -mm-thick vein at $482.3 \mathrm{ft}$; selenite vein dipping $50^{\circ}$ at $486.2 \mathrm{ft}$ displaces two subhorizontal veins, but not two others; sandy siltstone near base; 1 to $2 \mathrm{~cm}$ diameter reduction spots in lower $3 \mathrm{ft}$

$431.0-475.8$
$475.8-476.8$
$476.8-478.0$

Siltstone, dark-reddish-brown (1OR-3/4), laminated to thin bedded, very competent;

$481.1-491 . n$ numerous very thin selenite veins parallel to bedding; 1 -cm-thick vein at $500.4 \mathrm{ft}$ contains indistinct crystals, at leastone median suture, and flakes of wall rock: grayish-green (5G-5/2) layers at $492.5,496.4,497.0$ and 499.0 to $499.2 \mathrm{ft}$; claystone seams throughout unit

$491.0-50 n .9$ 
USGS LIthologlc Log (continued)

[Color designations are from the Rock Color Chart (Goddard and others, 1948);

"no recovery" designates where core was lost during coring ijperations]

No recovery

Siltstone, similar to unit at 491.0 to $500.9 \mathrm{ft}$

Sandy siltstone, dark-reddish-brown (10R-3/4), very thin to thin bedded; numerous very thin to 2 -mim-thick selenite veins parallel to bedding; very thin claystone beds at 503.9 and 505.4 to $505.6 \mathrm{ft}$

Sandstone, dark-reddish-brown (1OR-3/4) and grayish-red (10R-4/2), fine-grained, thin bedded, four 3-to 8-mm-thick selenite veins; numerous $1 \mathrm{~cm}$ diameter grayish-green (5G-5/2) reduction spots from 506.0 to $507.1 \mathrm{ft}$

Siltstone and claystone, dark-reddish-brown (10R-3/4) very thin to thick bedded; selenite veins, $2 \mathrm{~mm}$ to $1 \mathrm{~cm}$ thick, parallel and sub-parallel to bedding; numerous very thin veins

No recovery (recovered $0.4 \mathrm{ft}$ in next core run)

Siltstone and claystone, similar to unit at 507.4 to $510.5 \mathrm{ft}$; sandy siltstone 513.4 to $513.6 \mathrm{ft}$; $1-\mathrm{cm}-\mathrm{thick}$ selenite at $513.1 \mathrm{ft}$; selenite vein $1.5 \mathrm{~cm}$ thick dipping $20^{\circ}$ at $513.6 \mathrm{ft}$ contains good median suture

Siltstone, dark-reddish-brown (1OR-3/4), laminated to thin bedded, very competent; few disseminated small reduction spots, large blobs and streaks 518.0 to 518.5 and 519.8 to $520.3 \mathrm{ft}$; 4 -mm-thick, horizontal selenite vein displaced $2 \mathrm{~mm}$ by $30^{\circ}$ dipping vein at $527.1 \mathrm{ft}$; few selenite veins 2 to $4 \mathrm{~mm}$ thick

Siltstone, dark-reddish-brown (10R-3/4), grading downward to slightly clayey siltstone; clay seam at $524.2 \mathrm{ft}$; numerous very thin selenite veins parallel to bedding and crisscrossing beds; 7-mm-thick vein at $530.8 \mathrm{ft}$; disseminated 1 to $2 \mathrm{~cm}$ diameter reduction spots

No recovery

Clayey siltstone, dark-reddish-brown (10R-3/4) grading downward to silty claystone, laminated to very thin bedded; from $532 \mathrm{ft}$ to base of unit 14 selenite veins 2 to $7 \mathrm{~mm}$ thick parallel to bedding; at $540.5 \mathrm{ft}, 3-\mathrm{mm}-\mathrm{thick}$ vein dipping $70^{\circ}$ with what appear to be slickensides (vertical) but may be elongated selenite crystals; disseminated $3-$ to $10-\mathrm{mm}$ diameter reduction spots

No recovery

Silty claystone, similar to unit at 531.0 to $540.8 \mathrm{ft}$; half of unit is selenite vein

Siltstone, dark-reddish-brown (10R-3/4), laminated to thin bedded; grayish-green $(5 G-5 / 2)$ streaks from 549.2 to $549.7 \mathrm{ft}$; disseminated 1 - to $5-\mathrm{mm}$ diameter reduction spots; 3 - to 8 -mm-thick selenite veins parallel to bedding spaced about $0.5 \mathrm{ft}$ apart from 542.0 to $546.5 \mathrm{ft}$; vein at $546.1 \mathrm{ft}$ dipping $80^{\circ}$; nearly vertical vein 4 to $15 \mathrm{~mm}$ thick from 549.0 to $550.8 \mathrm{ft}$ (base of core); median sutures and elongated crystals more noticeable than in overlying $30 \mathrm{ft}$
$500.9-501.0$

$501.0-503.2$

$503.2-505.9$

$505.9-507.4$

507.4 - 510.5

$510.5-511.0$

$511.0 \quad-516.5$

$516.5-521.0$

$521.0-530.9$

530.9 - 531.0

$\begin{array}{lll}531.0 & - & 540.8 \\ 540.8 & - & 541.0 \\ 541.0 & - & 541.1\end{array}$

$541.1-550,8$ 
USGS Lithologic Log (continued)

[Color designations are from the Rock Color Chart (Goddard and others, 1948);

"no recovery" designates where core was lost during coring operations]

Lithologic description

Depth interval

Feet

No recovery

$550.8-551.0$

Siltstone, similar to unit at 541.1 to $550.8 \mathrm{ft}$; near vertical vein continues to $335.2 \mathrm{ft}$, displacement across vein is $3-4 \mathrm{~mm}$; vein dipping $50^{\circ}$ at $557.3 \mathrm{ft}$; scattered, very thin veins parallel to and at various angles to bedding

$551.0-557.5$

Sandstone, dark-reddish-brown (10R-3/4), very fine grained to fine-grafned, very

tnin to thin bedded; disseminated selenite veins mostly parallel to bedding;

unit grades to silty sandstone in lower $0.6 \mathrm{ft}$

$557.5-561.6$

Siltstone, dark-reddish-brown (10R-3/4), laminated to thin-bedded; numerous thin selenite veins parallel to bedding; disseminated 1 to $3 \mathrm{~mm}$ diameter reduction spots

$561.6-565.0$
$565.0-570.5$
$570.5-571.0$

Claystone, dark-reddish-brown (10R-3/4), laminated, parts easily along laminae;

very thin selenite veins in boxy network; disseminated reduction spots

No recovery

$571.0-585.4$
$585.4-590.5$
$590.5-591.0$

Claystone, similar to unit at 565.0 to $570.5 \mathrm{ft}$; numerous very thin to 2 -mm-thick selenite veins at various angles to bedding; silty in part

Siltstone, dark-reddish-brown $(10 R-3 / 4)$, well indurated

No recovery

Siltstone, dark-reddish-brown $(10 R-3 / 4)$, slightly clayey, laminated to thin bedded, competent; numerous very thin to 3 -mm-thick selenite veins parallel to bedding, several high angle veins; cavities less than $1 \mathrm{~mm}$ disseminated throuyhout core

$591.0-600.9$

No recovery

$600.9-601.0$

Siltstone, similar to unit at 591.0 to $600.9 \mathrm{ft}$; tiny cavitles have square, rnomboidal, or oblong shape, concentrated in upper foot but disseminated throughout core and may have held gypsum crystals; numerous very thin to 2-mm-thick selenite veins parallel to bedding; numerous $1 \mathrm{~mm}$ to $1 \mathrm{~cm}$ diameter reduction spots

$601.0-607.4$

Claystone, dark-reddish-brown (10R-3/4), laminated to very thin bedded, competent; selenite veins 2 to $4 \mathrm{~mm}$ thick, about 3 per $\mathrm{ft}$; few very thin veins, both types parallel to bedding; disseminated cavities as in unit above; 3 to $10 \mathrm{~mm}$ diameter reduction spots concentrated from 609.0 to $610.0 \mathrm{ft}$

No recovery

Claystone, similar to unit from 607.4 to $610.6 \mathrm{ft}$

$610.6-611.0$

No recovery

$611.0-620.9$

$620.9-621.0$ 


\section{USGS Lithologic Log (continued)}

[Color designations are from the Rock Color Chart (Goddard and others, 1948); "no recovery" designates where core was lost during coring operations]

Claystone, similar to unit from 607.4 to $610.6 \mathrm{ft}$; selenite veins very numerous: and no thicker than $2 \mathrm{~mm}$; brick-like network of veins in portions of core; numerous 1 to $5 \mathrm{~mm}$ diameter reduction spots; numerous 0.5 to $1 \mathrm{~mm}$ cavities increasing in size to 1 to $2 \mathrm{~mm}$ in lower $8.1 \mathrm{ft}$; grayish-green (5G-5/2)

claystone $0.1 \mathrm{ft}$ thick at base of unit cuts into underlying unit

$621.0-639.1$

Anhydrite; medium-gray (N5) and light-gray (N7), massive, dense; upper foot contains clots and vein fillings of gypsum crystals 2 to $3 \mathrm{~mm}$ long; lower half foot contains vertical fractures filled with gypsum

$639.1-640.6$

No recovery

Annydrite, medium-dark-gray (N4), microcrystalline, laminated, some wavy; upper foot fractured and rehealed with gypsum; irregular high angle fractures; $b$ to 10 -mm-tnick gypsum-healed fractures dipping $65^{\circ}$ at 643.0 and $643.5 \mathrm{ft}$ (opposing dips), gypsum-healed fracture dipping $70^{\circ}$ at $655.3 \mathrm{ft}$, and gypsumnealed fracture dipping $60^{\circ}$ at $657.4 \mathrm{ft}$; pale-yellowish-brown (10YR-6/2) laminae every 4 to $10 \mathrm{~mm}$; gypsiferous from 644 to 646 and 650 to $652 \mathrm{ft}$

bypsum, medium-dark-gray (N4), laminated and spotted with pale-yellowish-brown (10Yk-6/2); numerous clear gypsum crystals; pale-yellowish-brown (10YR-6/2) clay laminae

Gypsum, medium-dark-gray (N4) laminated with pale-red (10R-6/2) and grayish-red $(10 R-4 / 2)$; unit has blotchy appearance caused by gypsum crystals and silt; clear transparent gypsum from 666.0 to $666.1 \mathrm{ft}$ directly underlying $1 \mathrm{~cm}$ thick siltstone; 1- to 5-mm-thick veins of clear gypsum parallel to bedding disseminated throughout core

$665.2-670.0$
$670.0-670.5$
$670.5-671.0$

No recovery

Claystone, grayish-red $(10 R-4 / 2)$, poorly indurated, very thinly bedded; very thin siltstone wedges and pods in upper foot; thin grayish-green (5G-5/2) siltstone layers between 673 and $674 \mathrm{ft}$; disseminated reduction spots from 673 to $677.3 \mathrm{ft}$; core nighly shattered from 675 to $676.2 \mathrm{ft}$; core partially washed away from 673 to $676.2 \mathrm{ft}$; gypsum bands (secondary) throughout core

Claystone, alternating grayish-red (10R-4/2) and grayish-green (5G-5/2), wavy laminae and very thinly bedded; rounded siltstone fragments recemented by silt and $\mathrm{clay}$

$677.3-678.0$

Claystone and siltstone, grayish-green (5G-5/2); alternating very thin beds, wavy bedding and scour and fill structures; competent

$678.0-679.0$

No recovery

$679.0-680.9$ 


\section{USGS Lithologic Log (continued)}

[Color designations are from the Rock Color Chart (Goddard and others, 1948);

"no recovery" designates where core was lost during coring operations]

Gypsum, medium-dark-gray (N7) laminated with light-gray (N7), wavy bedding surfaces;

"chicken-wire" structure

Annydrite, medium-dark-gray (N7), very thinly bedded; healed fracture dipping $80^{\circ}$ at $685.8 \mathrm{ft}$ extends into unit below

Gypsiferous anhydrite, medium-dark-gray (N7) laminated with pale-yellowish-brown (10YR-6/2) clay; "chicken-wire" structure; large $(1.5 \mathrm{~cm})$ gypsum crystal aggregates disseminated throughout core

Gypsum, medium-dark-gray (N7), and pale-yellowish-brown (10YR-6/2), laminated to very thinly bedded

Gypsum and dolomite, gypsum medium-dark-gray ( $N 7)$, microcrystalline; dolomite dark-yellowish-brown (10YR-4/2); thin vein of gypsum crystals at base of unit

Nolomite, pale-yellowish-brown (10YR-6/2) and dark-yellowish-brown (10YR-4/2), laminated to thinly bedded, competent; zone of dark-gray (N3) wavy laminae and gypsum crystals $0.1 \mathrm{ft}$ thick at $700.8 \mathrm{ft}$

Dolomite; light-0 1 ive-gray $(5 \gamma-6 / 1$ and $5 \gamma-5 / 2)$, laminated to thickly bedded; unit is mostly gypsum crystals from 701.7 to $702.0 \mathrm{ft}$; unit contains minor 01 ive-gray $(5 Y-3 / 2)$ and yellowish-gray $(5 Y-7 / 2)$ clayey laminae and very thin Deds; laminae are slightly wavy, some crossbedded

$701.0-710.1$
$710.1-710.9$

No recovery

Nolomite, light-0live-gray $(5 Y-6 / 1$ and $5 Y-5 / 2)$, laminated to very thinly bedded; selenite-healed fracture dipping $60^{\circ}, 7 \mathrm{~mm}$ thick at $712.9 \mathrm{ft}$; from 718.5 to $720.2 \mathrm{ft}$ are about 20 selenite veins 2 to $6 \mathrm{~mm}$ thick parallel to bedding planes; minor crossbedded and lensing beds; lower foot contains wavy bedding; very thin clay seam at $714.9 \mathrm{ft}$

$710.9-7 ? 1.0$

Dolomite, olive-gray $(5 Y-3 / 2)$ and light-olive-gray $(5 Y-5 / 2)$, laminated to very thinly bedded, lenses and wavy laminae

$721.0-722.4$

Gypsum, dark-gray (N3) and brownish-gray (5YR-4/1), contorted, microcrystalline laminae and thin beds some nodular structure; gypsum vein fillings parallel laminae and beds

$722.4-727.0$

Anhydrite, dark-gray (N3) and brownish-gray (5YR-4/1), very thinly bedded, slightly contorted bedding; some nodular structure

$727.0-731.0$ 
USGS Lithologic Log (continued)

[Color designations are from the Rock Color Chart (Goddard and others, 1948); "no recovery" designates where core was lost during coring operations]

bypsiferous anhydrite, dark-gray (N3) and brownish-gray (5YR-4/1) grading downward to medium-dark-gray (N4) and light-gray (N7), laminated to very thinly bedded; gypsum crystals laminated with grayish-black (N2) clay from 741.2 to 742.2 and 744.2 to $745.0 \mathrm{ft}$; "chicken wire" structure especially prominent from 739.7 to $740.6,745.0$ to 746.6 and 747.1 to $750.3 \mathrm{ft}$; swallow-tail gypsum crystals from 736.2 to 739.2 and 751.0 to $760.0 \mathrm{ft}$; gypsum-healed fractures dipping $70^{\circ}$ cross each other between 745.6 and $746.7 \mathrm{ft}$; three gypsum-healed fractures dipping $70^{\circ}$ between 747.4 and $750.3 \mathrm{ft}$ and one at $756.4 \mathrm{ft}$; unit medium-dark-gray (N4) in lower foot

Gypsum, medium-dark-gray (N4) and light-gray (N7), laminated, crinkly laminae, microcrystalline to very finely crystalline

$$
761.0
$$$$
765.1-771.0
$$
(bY-6/1), laminated to thinly bedded, very finely crystalline to crystals is large as $1 \mathrm{~cm}$; some wavy laminae; secondary fracture fillings of gypsum at $765.8,766.2$ and $769.4 \mathrm{ft}$; some nodular gypsum laminae

Gypsum, similar to unit above; laminae of yellowish-gray $(5 Y-8 / 1)$ at 773.7 and $778.4 \mathrm{ft}$; most laminae nearly horizontal but at 773.7 to $773.8 \mathrm{ft}$ dips of $35^{\circ}$ may be caused by deformation in conversion of anhydrite to gypsum; clear gypsum vein $3 \mathrm{~mm}$ thick at $773.7 \mathrm{ft}$; unit mostly microcrystalline, some very finely, crystalline, some nodular gypsum; 0.1-ft clayey zone at base

$771.0-782.4$

Gypsum, light-olive-gray $(5 Y-6 / 1)$ and light-gray (N7), alternating zones of microcrystalline gypsum and gypsum crystals; some "chicken-wire" structure; crystals range from very fine to coarse $(<1 \mathrm{~cm})$; crystal zones have glassy luster; lower $0.4 \mathrm{ft}$ shows evidence of soft sediment deformation

Gypsum and claystone; gypsum, medium-light-gray (N6) and transparent crystals; claystone, light-brownish-gray $(5 Y R-6 / 1)$ and brownish-gray (5YR-4/1), laminated to very thinly bedded; soft sediment deformation has contorted bedding; gypsum in vein fillings

$796.0-797.1$
$797.1-798.3$
$798.3-798.7$

Clay, light-bluish-gray $(5 B-6 / 1)$, poorly consolidated

Clay, dark-reddish-brown $(10 R-3 / 4)$, poorly consolidated, contains platey crystals (probably selenite/gypsum); contact with underlying siltstone irregular and steeply dipping

Siltstone, pale-yellowish-brown (10YR-6/2) and olive-gray (5Y-4/1), interbedded with dark-reddish-brown (10YR-3/4) clay; unit appears to be brecciated and is poorly cemented with clay
$800.3-801.2$
$798.7 \quad-\quad 800.3$ 
USGS Lithologic Log (continued)

[Color designations are from the Rock Color Chart (Goddard and others, 1948);

"no recovery" designates where core was lost during coring operations]

Lithologic description

Depth interval

Feet

Clay and gypsum crystals, dark-reddish-brown (10YR-3/4), clay poorly consolidated, yypsum in blades, rosettes, and pods; gypsum fragments 3 and $<6 \mathrm{~cm}$ at 803.4 and $804.3 \mathrm{ft}$; grayish-green $(56-5 / 2) \mathrm{clay}$ and gypsum seam at base

$801.2-804.9$

Gypsum, grayish-red (10R-4/2) in upper $0.4 \mathrm{ft}$ mostly crystals and clay; dark-gray

(N3) to medium-lignt-gray (N6) gypsum crystals in lower $0.9 \mathrm{ft}$; dark-gray (N4)

clay seam at $805.3 \mathrm{ft}$

$804.9-806.2$

Gypsiferous anhydrite, light-brownish-gray (5YR-6/1) and light-gray (N7); gypsum crystals as large as $1 \mathrm{~cm}$ in zones and singly; minor amount of "chicken wire" structure, some swallow-tail gypsum crystals

$806.2-811.3$

Clayey gypsum and clay, medium-dark-gray (N4), clay laminated and shows signs of soft sediment deformation; gypsum crystals in clay-filled horizontal fracture

$811.3-811.9$

Anhydrite, pale-yellowish-brown (10YR-6/2) and very light-gray (N8), laminated to thin bedded, gypsiferous in upper $2 \mathrm{ft}$; numerous clayey seams in upper $2 \mathrm{ft}$; $0.1-\mathrm{ft}$-thick seam of gypsum crystals at $814.8 \mathrm{ft}$

$811.9-815.0$

Annydrite, grayisn-black (N3) and light-gray (N8), microcrystalline, laminated clay seams between thinly bedded anhydrite, slightly coarser crystals from 819.0 to $819.3 \mathrm{ft}$

$815.0-821.0$

Gypsiferous annydrite, light-gray (N6) and dark-yellowish brown (10YR-4/2), laminated to very thinly bedded; nodular gypsum in lower $0.6 \mathrm{ft}$, clayey streaks in lower $2 \mathrm{ft}$

$821.0-823.7$

Silty dolomite, moderate-yellowish-brown (10YR-5/4), very thinly bedded, partly well indurated

$823.7-824.2$

Volomite, light-olive-gray $(5 Y-6 / 1)$, very thin to thinly bedded, slightly fractured; moderate-yellowish-brown (10YR-5/4) silty dolomite 825.4 to 825.8 and 825.9 to $826.0 \mathrm{ft}$; partially open fracture dipping $70^{\circ}$ at $824.8 \mathrm{ft}$; vertical gypsum-healed fracture 826.0 to $827.2 \mathrm{ft}$; anhydrite and siltstone norizontal band $0.1 \mathrm{ft}$ thick at $828.6 \mathrm{ft}$, vertical gypsum-healed fracture from 828.7 to $829.2 \mathrm{ft}$; vugs as large as $5 \mathrm{~mm}$ disseminated throughout core; zones of numerous vugs 0.5 to $1 \mathrm{~mm}$ in diameter at $1-\mathrm{ft}$ intervals; core breaks in lengths 0.3 to $1.2 \mathrm{ft}$ long

$824.2-829.6$

No recovery

$829.6-831.0$

volomite, similar to unit at 824.2 to $829.6 \mathrm{ft}$; gypsum-filled fracture $5 \mathrm{~mm}$ thick dips $80^{\circ}$ at $831.7 \mathrm{ft}$; silty dolomite from 834.2 to $835.0 \mathrm{ft}$; core from 833.0 to $841.4 \mathrm{ft}$ shattered (open fractures and numerous large vugs), few core lengtns to $0.6 \mathrm{ft}$, most $<0.1 \mathrm{ft}$; rare gypsum-filled vugs; moderate-yellowishbrown $(10 Y K-5 / 4)$ dolomite 842.3 to $843.6 \mathrm{ft}$; unit very clayey in lower foot

$831.0-846.0$ 
USGS Lithologic Log (continued)

[Color designations are from the Rock Color Chart (Goddard and others, 1948);

"no recovery" designates where core was lost during coring operations]

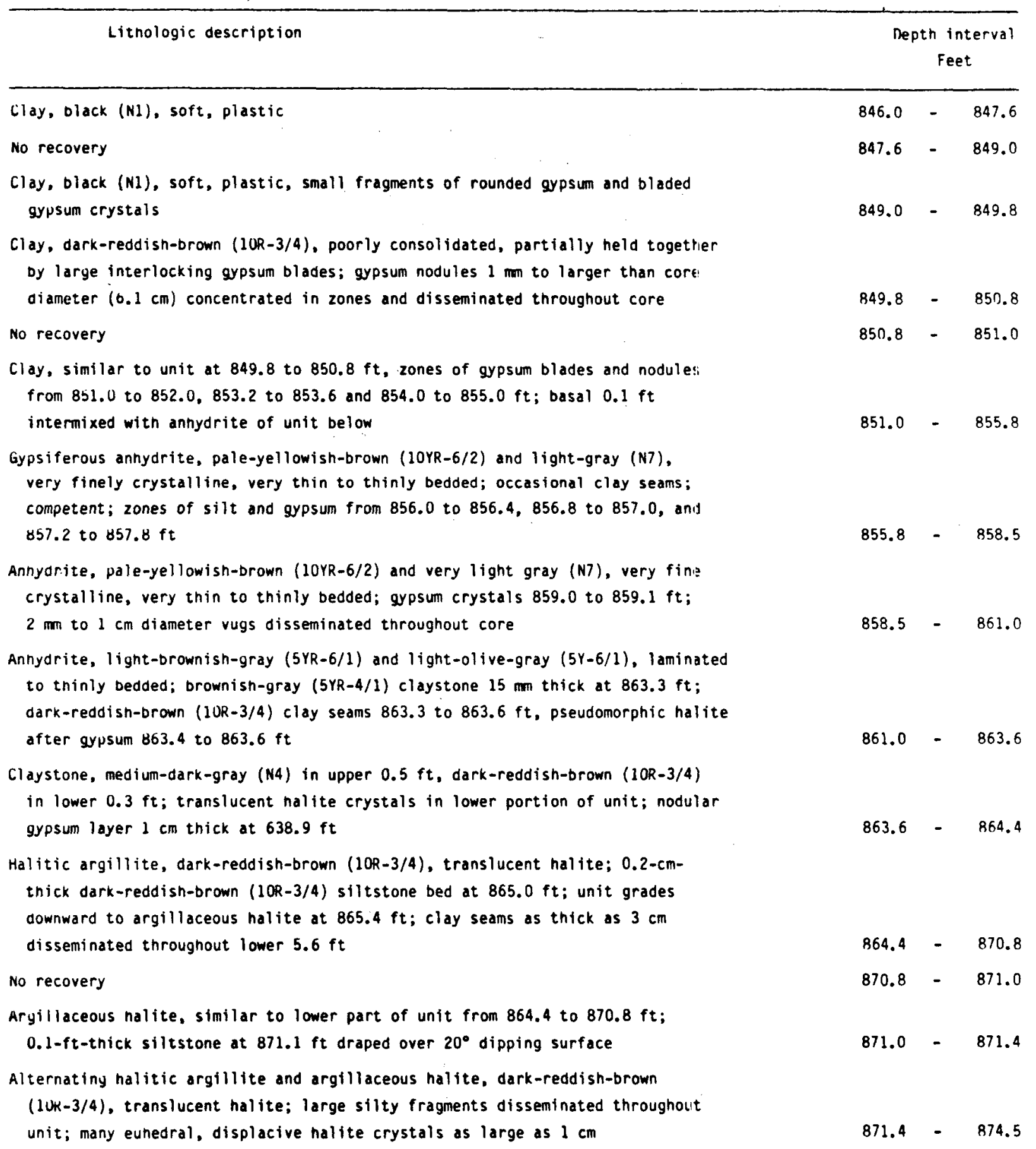


USGS Lithologic Log (continued)

[Color designations are from the Rock Color Chart (Goddard and others, 1948);

"no recovery" designates where core was lost during coring operations]

Halite, moderate-reddish-orange $(10 R-6 / 6)$. translucent halite crystals as large as $5 \mathrm{~mm}$; polyhalitic; grayish-green (5G-5/2) clay seam at $874.9 \mathrm{ft}$; dark-reddishDrown (1UR-3/4) clay seam at $875.2 \mathrm{ft}$; siltstone fragment, $15 \mathrm{~mm}$ long, at $87 \mathrm{~b} .1 \mathrm{ft}$; basal $0.2 \mathrm{ft}$ contains dark-reddish-brown (1OR-3/4) rounded siltstone fragments

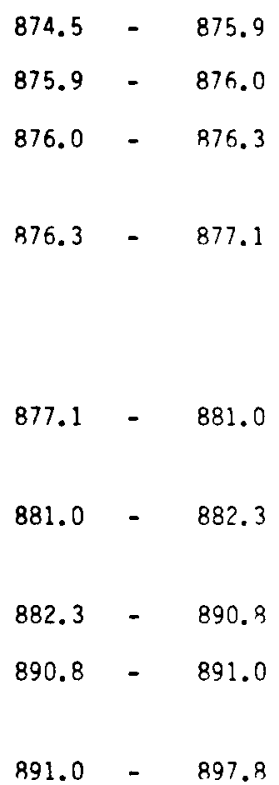
downwara to nearly zero; displacive halite crystals 3 to $4 \mathrm{~mm}$ in size

Siltstone, dark-reddish-brown (1OR-3/4), laminated to very thin bedded; very minor amount of halite in upper foot; competent; some dusky-yellow-green (56Y-5/2) and thinly laminated black (N1) siltstone from 899.0 to $903.3 \mathrm{ft}$; fault at $901.3 \mathrm{ft}$ dips $70^{\circ}$, fault at $901.6 \mathrm{ft}$ dips $20^{\circ}$, beds above, between, and below contorted; 1 - to $3-\mathrm{mm}$ gypsum blebs between 905.0 and $907.3 \mathrm{ft}$; $2-\mathrm{Cm}$ Dled at $903.7 \mathrm{ft}$; $2-\mathrm{cm}$ long halite sliver parallel to bedding at $905.3 \mathrm{ft}$

$897.8-911 . ?$

Siltstone, dark-reddish-brown (2OR-3/4) and greenish-gray $(5 \gamma-6 / 1)$, laminated to thinly bedded; b-mm-thick halite-filled near-vertical fracture 911.3 to $913.2 \mathrm{ft} ; 1$ to $2 \mathrm{~mm}$ thick near-vertical halite-filled fracture 914.3 to $915.4 \mathrm{ft}$

$911.2-915.6$

Siltstone and claystone, greenish-gray (5GY-6/1), laminated to very thinly bedded; $1 \mathrm{~mm}$ thick nalite-filled fracture dipping $80^{\circ} 916.0$ to $917.2 \mathrm{ft}$; 2-mm-thick curving, near-vertical halite-filled fracture 910.3 to $918.8 \mathrm{ft}$
$915.6-923.7$ 
USGS Lithologic Log (continued)

[Color designations are from the Rock Color Chart (Goddard and others, 1948);

"no recovery" designates where core was lost during corinig operations]

Lithologic description

Depth interval

Feet

Claystone, grayfsh-olfve-green (5GY-3/2), laminated, rock parts eastly along some laminae; minor fractures healed with halite; small blebs of 11ght-gray (N7) gypsum disseminated throughout core from 926.5 to $927.6 \mathrm{ft}$; below $931.0 \mathrm{ft}$ are patches and streaks of sllty halite, often in fractures; clay-healed fracture dipping $60^{\circ}$ at $933.0 \mathrm{ft}$; partially halfte-filled fracture ofpping $75^{\circ}$ at $939.7 \mathrm{ft}$; halite transparent and bladed, contains minor clay; slightly slity from 941.0 to $949.9 \mathrm{ft}$; 1 - to 2 -mm-thick halite veins 945.4 to 947.8 and 947.7 to $948.5 \mathrm{ft}$; 2-mm-thick halite-filled fracture dipping $60^{\circ}$ at $955.1 \mathrm{ft}$, and another dippirig $30^{\circ}$ at $958.4 \mathrm{ft} ; \mathrm{clay}-\mathrm{f} f 1$ led fracture dipping $45^{\circ}$ at $957.1 \mathrm{ft}$

$923.7-958.7$
$958.7-960.1$
$960.1-960.9$
$960.9-961.9$
$961.9-963.5$

Claystone, dark-reddish-brown (1OR-3/4), laminated to thinly bedded; highly fractured (possibly caused by coring operation

Halite, grayish-red (1OR-4/2), slightly argillaceous, medi um crystalline, splatches of moderate-red $(5 R-4 / 6)$ polyhalite; dark-reddish-brown (10R-3/4) and grayish-green (56-5/2) clay seam ot $964.9 \mathrm{ft}$

$963.5-965.6$

Halite, moderate-reddish-brown (1OR-3/4) and moderate-red (5R-4/6); medium to coarsely crystalline; polyhalitic with polyhalite bands at 967.3 to $967.4 \mathrm{ft}$

Siltstone, dark-reddish-brown (10R-3/4); cut by vertical halite-filled fractures Argillaceous halite, dark-reddish-brown (10R-3/4), fine to mediun crystalline

Polyhalitic haltte, grayish-red $(5 R-4 / 6)$ and moderate-reddish-brown $(10 R-3 / 4)$. medium to coarsely crystalline; argillaceous from 960.0 to 960.1 and 969.8 tio $970.0 \mathrm{ft}$

$967.8-970.0$

Anhydritic halite, pale-brown (5YR-5/2) and transparent, finely to medium crystalline

$970.0-970.1$

Halite, dark-reddish-brown (1OR-3/4), grayish-red (5R-4/6) and transparent; argillaceous and polyhalitic; finely crystalline grading downward to coarsely crystalline

$970.1-973.0$
$973.0-976.8$
$976.8-977.0$

Halite, translucent, medium crystalline; anhydrite stringers in lower half of unit; sucrosic texture in lower $0.1 \mathrm{ft}$

$965.6-967.5$

$967.5-967.6$

$967.6-967.8$

Polyhalite, moderate-reddish-orange $(10 R-3 / 4)$ and moderate-red $(5 R-5 / 4)$, halfitic, granular 


\section{USGS Lithologic Log (continued)}

[Color designations are from the Rock Color Chart (Goddard and others, 1948); "no recovery" designates where core was lost during coring operations]

$$
\begin{array}{r}
977.0-977.1 \\
977.1-981.0 \\
981.0-1011.2 \\
1011.2-1011.6 \\
1011.6-1014.7
\end{array}
$$

Halite, similar to unit at 973.0 to $976.8 \mathrm{ft}$; polyhalitic in moderate-reddishorange (10R-6/6) bands, medium crystalline

Halite, transparent, medium crystalline, flecks of light-gray (N7) anhydrite; dark-greentsh-gray (5GY-4/1) clay 9-mm-ft thick at base

Halite, dark-reddish-brown (1OR-3/4), very argillaceous, medium to coarsely crystalline; lower $0.6 \mathrm{ft}$ grades downward to underlying untt

Halite, translucent, medium to coarsely crystalline; stringers of dark-reddishbrown (10R-3/4) clay and light-gray (N7) anhydrite blebs spaced from 0.1 to $0.5 \mathrm{ft}$ apart throughout unit; intercrystalline clay gives dark-reddish-brown $(10 R-3 / 4)$ tint to unit

$1014.7-1021.8$

Halite, transparent, medium crystalline; lower contact sharp, slightly undulatory and horizontal

$1021.8-1025.5$

Halite, dark-reddish-brown (1OR-3/4), very argillaceous in upper $6.5 \mathrm{ft}$ grading downward to argillaceous in lower $2.8 \mathrm{ft}$, medium to very coarsely crystalline; clay in blebs and intercrystalline; minor light-gray (N7) blebs and stringers of anhydrite; basal contact fairly sharp

$1025.5-1034.8$

Halite, transparent, medium to very coarsely crystalline; streaks and blebs of dark-reddish-brown (1OR-3/4) and greenish-gray (5G-6/1) clay; minor blebs of moderate-reddish-brown $(10 R-4 / 6)$ polyhalite

$1034.8-1040.1$

Halite, transparent, very coarsely crystalline; stringers and blebs of moderatereddish-brown (10R-4/6) polyhalite and light-gray (N7) anhydrite

$1040.1-1041.0$

Halite, transparent to translucent, medium to coarsely cyrstalline; stringers of light-gray (N7) anhydrite in lower half of unit; lower $0.2 \mathrm{ft}$ polyhalitic and argillaceous; basal contact sharp and slightly undulatory, horizontal

$1041.0-1042.5$

Halite, same as unit from 1011.6 to $1014.7 \mathrm{ft}$; clay bed from 1047.3 to $1047.5 \mathrm{ft}$; basal contact gradational

$1042.5-1051.0$

Halite, dark-reddish-brown (10R-3/4) and transparent medium to coarsely crystalline; light-gray (N7) anhydrite stringers in lower two feet; basal contact fairly sharp

$1051.0-1055.3$

Halite, transparent, coarsely crystalline; diffuse polyhalite tints most of unft moderate-reddish-orange $(10 R-6 / 6)$; basal contact sharp

$1055.3-1056.9$ 
USGS Lithologic Log (continued)

[Color designations are from the Rock Color Chart (Goddard and others, 1948);

"no recovery" designates where core was lost during coring operations]

Halite, dark-reddish-brown (1OR-3/4), very argillaceous in part; nearly clayfree zone from 1068.0 to $1069.6 \mathrm{ft}$; 1ight-gray (N7) anhydrite stringers and dark-reddish-brown (10R-3/4) clay blebs throughout core; basal contact sharp and slightly undulatory

$1056.9-1071.0$

Sandstone, dark- to moderate-reddish-brown (10R-3/4-10R-4/6), fine to very fine grained; basal contact slightly diffuse

$1071.0-1075.0$

Halitic sandstone, dark-reddish-brown (1OR-3/4), very fine grained sandstone, medium crystalline halite; minor blebs of very light gray (N8) anhydrite; basal contact fairly sharp

$1075.0-1077.7$

Halite, transparent to moderate-reddish-brown (1OR-4/6), medium to coarsely crystalline; blebs of light-gray (N7) anhydrite in lower $0.6 \mathrm{ft}$; basal contact slightly diffuse

$1077.7-1080.3$

Polyhalite, pale-reddish-brown (10R-5/4), microcrystalline; basal contact nearly horizontal and sharp

$1080.3-1082.2$

Halite, moderate-reddish-brown $(10 R-4 / 6)$ and transparent, medium to coarsely crystalline; polyhalite stringers and bands throughout unit

Polyhalite, same as unit from 1080.3 to $1082.2 \mathrm{ft}$; basal contact sharp

$1082.2-1083.0$

Halite, dark-reddish-brown (1OR-3/4) and transparent, coarsely crystalline; unit contains 5 polyhalite bands; basal $0.2 \mathrm{ft}$ is polyhalite; basal contact sharp

Halite, grayish-red $(10 R-4 / 2)$ alternating with moderate-reddish-brown $(10 R-4 / 6)$ and transparent, medium to very coarsely crystalline; blebs of pale-yellowishbrown $(10 Y R-6 / 2)$ clay as large as $0.4 \mathrm{ft}$; stringers and blebs of light-gray (N7) anhydrite from 1092.3 to $1099.1 \mathrm{ft}$; clay content decreases downward; trace of polyhalite blebs; from 1106.3 to $1107.3 \mathrm{ft}$, blebs as large as 1.0 to $0.3 \mathrm{ft}$; basal contact diffuse, marked by abrupt decrease in clay content

$1085.7-1109.3$

Halite, transparent to moderate-reddish-orange (1OR-6/6), medium to coarsely crystalline; locally polyhalitic as blebs; polyhalite absent from 1110.4 to $1112.3 \mathrm{ft}$; randomly oriented and sub-horizontal stringers of medium-light-graly (N6) anhydrite; $0.2-$ to 0.8 -ft-thick microcrystalline anhydrite bands at 1114.8 , $1115.1,1115.5,1116.0$ and $1116.4 \mathrm{ft}$; basal contact sharp

$1109.3-1116.6$

Polyhalite, moderate-reddish-brown (10R-4/6) grading to moderate-red (5R-4/6); light-gray (N7) anhydrite at base, microcrystalline; locally contains interbeds and blebs of transparent halite; basal contact sharp

$1116.6-1117.7$ 


\section{USGS Lithologic Log (continued)}

[Color designations are from the Rock Color Chart (Goddard and others, 1948);

"no recovery" designates where core was lost during coring operations]

Halite, transparent to moderate-reddish-orange $(10 R-6 / 6)$, coarsely crystalline, trace of thin annydrite stringers decreasing downward; trace of disseminated polyhalite blebs; minor intercrystalline clay from 1118.0 to $1118.8 \mathrm{ft}$; basal contact gradational marked by increase in anhydrite and decrease in polyhalite

Halite, transparent to medium-gray (N5), coarsely crystalline; abundant stringers and blebs of annydrite decrease with depth to $1130.0 \mathrm{ft}$ where anhydrite increases abrupt 1. trace of polynalite and intercrystalline clay; basal contact sharp and slightly undulatory

Annydrite, medium-gray (N5) to medium-dark-gray (N4), microcrystalline, locally micro- to thinly laminated; locally horizontal bands of halite pseudomorphs after gypsum (swallow-tail twinning) as long as $0.1 \mathrm{ft}$, mostly subvertical, a few are crushed; disseminated zones of individual fine halite crystals; locally interbedded with pale-yellowish-brown (10YR-6/2) laminated anhydrite increasing abruptly from $1140.2 \mathrm{ft}$; from 1140.2 to $1142.0 \mathrm{ft}$ unit is pale-yellowish-brown (1UYR-6/2), contains no nalite, laminated, laminae occasionally pinch-out; laminated $1142.0 \mathrm{ft}$ and locally nodular; basal contact sharp

$1130.4-1143.5$

Claystone, medium-dark-gray (N4) grading to moderate-reddish-brown $(10 R-3 / 4)$ at base; slightly silty; structureless; basal contact irregular and undulatory'

$1143.5-1144.3$

Halite, transparent to brownish-gray (5YR-4/1), medium to coarsely crystalline, slightly argillaceous; clay content decreases downward, occurs as moderate-brown (bYR-4/4) stringers, and intercrystalline material; locally traces of polyhalite blebs and anhydrite stringers; basal contact diffuse over $0.2 \mathrm{ft}$

Halite, transparent to moderate-reddish-orange (10R-6/6), coarsely crystalline; trace disseminated polyhalite blebs; intercrystalline clay near top of unit; rare stringers and blebs of light-gray (N7) anhydrite, 6- to 18-mm-thick anhydrite band at $1154.6 \mathrm{ft}$ dips $20^{\circ}$; basal contact sharp and dips $20^{\circ}$ on dissolution surface of underlying unit

$1151.5-1154.7$

Anhydrite, pale-yellowish-brown (104R-6/2) and medium-light-gray (N6), microcrystalline; trace of halite near base; basal contact sharp

$1154.7-1155.1$

Halite, transparent to moderate-reddish-orange $(10 R-6 / 6)$ to grayish-red $(10 R-4 / 2)$, coarsely crystalline; trace disseminated polyhalite blebs decrease downward; trace randomily oriented stringers and blebs $(0.1$ to $0.2 \mathrm{ft})$ of annydrite decreasing downward; locally traces of intercrystalline clay; basal contact sharp

$1155.1-1164.0$

Halite, transparent to tinted moderate-reddish-orange $(10 R-6 / 6)$, medium to coarsely crystalline; disseminated blebs of light-gray (N7) anhydrite from 1164.0 to 1165.0; trace of disseminated polyhalite blebs; slightly argillaceous decreasing downward; clay content increases abruptly at $1169.3 \mathrm{ft}$ then decreases; basal contact sharp

$1164.0-1170.8$ 
USGS Lithologic Log (continued)

LCoior aesignazions are from the kock color linart (Goddard ind otners, 1940); "no recovery" designates where core was lost during coring operations]

Lithologic description

Depth interval Feet

Polyhalite, moderate-reddish-brown (1OR-4/6), microcrystalline; halitic, large irregularly shaped zones of clear halite; basal contact sharp

$1170.8-1171.8$

Halite, transparent and moderate-reddish-brown $(10 R-4 / 6)$ to $1173.5 \mathrm{ft}$, mostly transparent below $1173.5 \mathrm{ft}$, medium to coarsely crystalline; disseminated discontinuous randomly oriented stringers of light-gray (N7) anhydrite; raro: blebs of polyhalite; undulating bed of polyhalitic anhydrite 1ight-gray (N7) and moderate-reddish-brown $(10 \mathrm{R}-4 / 6), 15$ to $30 \mathrm{~mm}$ thick, at $1170.8 \mathrm{ft}$; polyhalite content increases near base; basal contact sharp and marked by two $0.1 \mathrm{ft}$ thick irregular polyhalite beds separated by 0.1 -ft-thick clear polyhalitic halite

$1171.8-1189.5$

Haifte, transparent to tinted moderate-reddish-brown (1OR-4/6), medium crystalline grading downward to coarsely crystalline; moderately argillaceous at top of unit, clay content decreases downward and abruptly at $1191.1 \mathrm{ft}$; trace of disseminated polyhalite blebs and stringers of itght-gray (N7) anhydrite; 3- to 18-mm-thick discont inuous anhydritic polyhalite bed at $1194.2 \mathrm{ft}$; basal contact sharp

Polyhalite, moderate-reddish-brown $\{10 R-4 / 6\}$, microcrystalline; basal contact sharp $1189.5-1194.3$

Halite, transparent to moderate-reddish-orange (1OR-6/6), medium to coarsely crystalline; moderately argillaceous content decreases downward to randomly' oriented stringers and blebs; trace of disseminated moderate-reddish-brown (10R-4/6) polyhalfte blebs; and light-gray (N7) anhydrite stringers and blebs; basal contact gradational over $0.1 \mathrm{ft}$

$1194.6-1206.5$

Argillaceous halite grading downward to halitic claystone, moderate-reddish-brown (10R-4/6); halite occurs as clear isolated crystals and aggregates of finely crystalline halite; basal contact gradational over $0.1 \mathrm{ft}$

$1206.5-1207.3$

Halite, transparent to moderate-reddish-brown (10R-3/4), medium to coarsely crystalline; trace of moderate-reddish-brown (10R-3/4) clay in disseminated stringers, blebs, and intercrystalline material; trace of blebs and stringers of polyhalite light-gray (N7) anhydrite; disseminated moderate-reddish-brown (10R-4/6) blebs; basal contact sharp

$1207.3-1212.5$

Halite, transparent to tinted moderate-reddish-orange (1OR-6/6); trace of moderate-reddish-brown (10R-4/6) polyhalite blebs; trace 11ght-gray (N7) anhydrite stringers; basal contact sharp

Halite, same as unit from 1207.3 to $1212.5 \mathrm{ft}$, basal contact sharp

$1212.5-1216.3$

Halite, moderate-reddish-brown (10R-4/6) and transparent, medium to

$1216.3-1225.9$ coarsely crystalline, polyhalitic; polyhalite disseminated throughout core increasing downward; basal contact very sharp and horizontal

$1225.9-1228.0$ 


\section{USGS Lithologic Log (continued)}

[Color designations are from the Rock Color Chart (Goddard and others, 1948); "no recovery" designates where core was lost during coring operations]

Polyhalite, moderate-reddish-brown (10R-4/6), very finely crystalline;

lower $0.1 \mathrm{ft}$ is light-0live-gray $(5 Y-6 / 1)$; basal contact sharp

Halite, same as unit from 1225.9 to $1228.0 \mathrm{ft}$; greenish-gray $(56 \mathrm{Y}-6 / 1)$ clay seam at $1230.2 \mathrm{ft}$ sharp and wavy, disseminated $\mathrm{clay}$ as blebs and stringers from 1230.2 to $1231.3 \mathrm{ft}$; very little polyhalite from 1232.5 to $1236.1 \mathrm{ft}$; very polyhalitic in lower foot; basal contact sharp and wavy

Polynalite, moderate-reddish-brown (10R-4/6), microcrystalline; greenish-gray $(56-6 / 1)$ clay seam in lower $0.1 \mathrm{ft}$; basal contact gradational over $15 \mathrm{~mm}$ with underlying unit

$1237.5-1238.1$

Halite, dark-reddish-brown (10R-3/4) and transparent, medium to very coarsely crystalline; argillaceous and polyhalitic; disseminated blebs and stringers of moderate-reddish-orange $(10 R-6 / 6)$ polyhalite; occasional dark-reddish-brown $(10 R-3 / 4)$ clay seams; probable clay seam at base of unit $1258.4 \mathrm{ft}$; lower $0.6 \mathrm{ft}$ contains alternating very thin beds of anhydrite and nalite; basal contact gradational

Anhydrite, medium-light-gray (N6), laminated with transparent halite pseudomorphs after gypsum; laminae wavy, amplitudes as much as $0.1 \mathrm{ft}$; some halite is polyhalitic; massive from 1264.3 to $1264.4 \mathrm{ft}$; moderatereddisn-brown $(10 R-4 / 6)$ clay seam at $1263.4 \mathrm{ft}$; polyhalitic from 1264.4 to $1264.7 \mathrm{ft}$; clay and polyhalite from 1264.7 to $1265.0 \mathrm{ft}$; basal contact sharp

Halite, transparent, dark-reddish-brown $(10 R-3 / 4)$, and moderate-reddish-brown $(10 R-4 / 6)$, medium to coarsely crystaliine; argillaceous in upper $2 \mathrm{ft}$, polyhalitic in lower $5 \mathrm{ft}$; stringers of polyhalite in lower $1.5 \mathrm{ft}$; basal contact sharp and wavy

Anhydrite, light-gray (N7), massive, lens of halite at $1273.0 \mathrm{ft}$; very light gray (NB) stringers disseminated throughout core; basal contact fairly sharp

Halite, transparent, medium crystalline, very slightly polyhalitic; basal contact gradational

$1273.4-1275.7$ 
USGS Lithologic Log (continued)

[Color designations are from the Rock Color Chart (Goddard and others, 1948);

"no recovery" designates where core was lost during coring operations]

Lithologic description

Depth interval

Feet

Anhydrite, same as unit from 1272.2 to $1273.4 \mathrm{ft}$; basal contact sharp

$1275.7-1275.9$

Halite, same as unit from 1273.4 to $1275.7 \mathrm{ft}$; basal contact sharp

$1275.9-1277.9$

Anhydrite, 1ight-gray (N7) and light-brownish-gray (5YR-6/1), massive to

laminated; pseudomorphs of halite after gypsum interlaminated with

anhydrite; nodular anhydrite interspersed with halite from 1278.0 to

$1278.2 \mathrm{ft}$; basal contact very sharp

$1277.9-1279.3$

Halite, transparent and dark-reddish-brown (10R-3/4), grading downward to moderate-reddish-brown ( $1 O R-4 / 6)$, finely to medium crystalline;

argillaceous near top grading to polyhalitic and anhydritic at base; basal

contact sharp

$1279.3-1281.0$

Anhydrite, light-brownish-gray (5YR-5/1), massive, microcrystalline; halite pseudomorphs after gypsum at 1283.1, 1283.2, and $1283.4 \mathrm{ft}$; halite lens at $1283.4 \mathrm{ft}$; basal contact sharp

$1281.0-1283.5$

Halite, translucent and pale-red (5R-6/2), medium to coarsely crystalline; argillaceous; flakes of 11 ght-gray (N7) anhydrite as large as $15 \mathrm{~mm}$ from 1283.5 to $1285.1 \mathrm{ft}$; blebs of polyhalite from 1285.2 to $1286.2 \mathrm{ft}$; basal contact gradational

$1283.5-1286.2$

Halite, transiucent and pale-reddish-brown (10R-5/4), medium crystalline; polyhalitic and slightly argillaceous; blebs and stringers of moderatereddish-orange (10R-6/6) polyhalite disseminated throughout unit; 0.5 -ft-thick polyhalite band at $1289.2 \mathrm{ft}$; basal contact at very thin darkgreenish-gray $(5 G Y-4 / 1)$ clay seam; contact sharp

$1286.2-1290.7$

Argillaceous halite, translucent, moderate-reddish-brown (10R-4/6) and grayisinred $(10 R-4 / 2)$, medium crystalline; basal contact gradational

$1290.7-1291.6$

Halite, alternating bands of translucent, grayish-red (1OR-4/2), and moderatereddish-orange (10R-6/6), medium and coarsely crystalline; grayish-red bands are argillaceous, reddish-orange bands are polyhalftic, bands range in thickness from 1.0 to $3.5 \mathrm{ft}$; very argillaceous from 1293.6 to $1294.7 \mathrm{ft}$; clay seams at 1294.7, 1296.4, and $1314.7 \mathrm{ft}$; basal contact at clay seam is sharp

$1291.6-1315.4$

Argillaceous halite, grayish-red (10R-4/2), pale-reddish-brown (10R-5/4), and translucent, medium to coarsely crystalline; stringers and blebs of very light gray (NB) and moderate-reddish-brown (10R-4/6) polyhalite; basal contact gradational

$1315.4-1321.2$ 
USGS Lithologic Log (continued)

[Color designations are from the Rock Color Chart (Goddard and others, 1948);

"no recovery" designates where core was lost during coring operations]

Lithologic description

Depth interval

Halite and polyhalite; hallte dark-reddish-brown (10R-5/4), very coarsely crystalline; polyhalite moderate-reddish-brown (10R-4/6); light gray (N7) very thin clay seam at base

$1321.2-1322.3$

Halite, translucent and pale-red (10R-5/4) at top of unit grading downward to translucent and moderate-reddish-orange (10R-6/6), coarsely crystalline; moderate-reddish-orange (1OR-6/6) polyhalite band $0.2 \mathrm{ft}$ thick at $1330.8 \mathrm{ft}$, base horizontal, top dips $15^{\circ}$; dark-reddish-brown $(10 R-3 / 4)$ clay containing halite crystals from 1334.1 to $1334.4 \mathrm{ft}$; basal contact sharp and irregular

Argillaceous halite, moderate-reddish-brown $(10 R-4 / 6)$ and translucent, finely to coarsely crystalline; moderate-reddish-brown (10R-4/6) clay zones from 1335.6 to $1336.9 \mathrm{ft}$; very light gray (N8) clay seams at 1339.1 and $1339.5 \mathrm{ft}$, basal contact gradational over $0.2 \mathrm{ft}$

$1335.3-1342.8$

Halite, transparent to moderate-reddish-brown (10R-4/6) and medium-gray (N5), argillaceous and polyhalitic; thin randomly oriented polyhalite stringers and blebs; trace of light-gray (N7) anhydrite; medium- to light-gray (N5 to N7) intercrystalline clay; polyhalite content increases downward; basal contact gradational over $0.1 \mathrm{ft}$ and highly irregular

$1342.8-1347.0$

Polyhalite and halite; polyhalite is microcrystalline and moderate-reddish-brown $(10 R-6 / 6)$; halite is clear and medium to coarsely crystalline; halite occurs as irregularly shaped clots surrounded by polyhalite; two greenish-gray (56-6/1) claystone beds separated by thin polyhalitic halite bed mark base of unit; basal contact sharp

$1347.0-1349.2$

Halite, transparent to moderate-reddish-brown (10R-4/6) to light-gray (N7), medium to coarsely crystalline; polyhalitic, polyhalite as blebs and stringers; intercrystalline clay-rich zones from 1350.1 to $1350.5,1351.9$ to $1353.6,1354.5$ to 1355.4 and 1355.8 to $1357.6 \mathrm{ft}$; from 1360.6 to $1362.7 \mathrm{ft}$ moderate-reddishbrown $(10 R-4 / 6)$ and light-gray (N7) clay occurs as matrix supporting halite crystals and aggregates; basal contact undulatory and sharp

$1349.2-1365.5$
$1365.5-1365.8$
$1365.8-1372.4$
$1372.4-1372.9$ marked by clay seam, sharp 
USGS Lithologic Log (continued)

[Color destgnations are from the Rock Color Chart (Goddard and others, 1948);

"no recovery" designates where core was lost during coring operations]

Lithologic description

Depth interval

Feet

Halfte, transparent to locally light-gray (N7), occasionally tinted moderatereddish-orange (1OR-6/6), medium to coarsely crystalline; slightly polyhalitic as disseminated blebs and randomly oriented stringers; rare blebs and stringers of anhydrite; locally argillaceous from 1374.2 to 1374.9 and 1385.3 to $1385.8 \mathrm{ft}$; very argillaceous from 1386.9 to $1389.1 \mathrm{ft}$; $\mathrm{clay}$ occurs as matrix and as intercrystalline material; discontinuous moderate-reddish-orange $(10 R-6 / 6)$ polyhalite at $1386.9 \mathrm{ft}$; basal contact sharp

$1372.9-1386.9$

Polyhalite, moderate-reddish-orange (1OR-6/6) to moderate-reddish-brown $(10 R-4 / 6)$, microcrystalline; thin clay seam at base, basal contact sharp

Halite, same as unit from 1372.9 to $1394.3 \mathrm{ft}$; basal contact sharp and irregular

Polyhalite, moderate-reddish-brown (1OR-4/6), microcrystalline; irregularly shaped halite crystals, basal contact sharp and irregular

$1394.3-1394.8$
$1394.8-1395.5$
$1395.5-1395.7$

Halite, same as unit from 1372.9 to $1394.3 \mathrm{ft}$; moderately argillaceous from 1398.1 to $1399.0 \mathrm{ft}$; polyhalite decreases, clay and anhydrite not present below $1402.0 \mathrm{ft}$

$1395.7-1402.8$

Polyhalitic halite, moderate-reddish-brown (10R-4/6) to transparent, medium to coarsely crystalline; polyhalite occurs as blebs and stringers; basal contact irregular, undulatory, and sharp

Polyhalite, moderate-reddish-brown (10R-4/6), microcrystalline; frregular shaped zones filled with medium crystalline halite; basal contact irregular and sharp

Polyhalfic halite, same as unit from 1402.8 to $1404.3 \mathrm{ft}$

Argillaceous halite, transparent to medium-light-gray (N6), finely to coarsely crystalline; clay occurs intercrystalline and in randomly oriented stringers; basal contact gradational over 6-mm interval

$1405.7-1406.3$

Polyhalitic halite, same as unit at 1402.8 to $1404.3 \mathrm{ft}$, polyhalite content decreases downward; zone of abundant polyhalite from 1409.0 to $1409.2 \mathrm{ft}$; medium-gray (N5) argillaceous zone from 1411.3 to $1411.5 \mathrm{ft}$; basal contact gradational over $0.1 \mathrm{ft}$

$1406.3-1412.3$

Argillaceous halite, transparent to dark-reddish-brown (10R-3/4) to light-gray (N7), finely to coarsely crystalline; clay occurs as intercrystalifine in less argillaceous zones and as matrix in more argillaceous zones and as randomly orfented stringers; locally moderately abundant stringers and blebs of polyhalite; irregular zone of polyhalite at $1418.0 \mathrm{ft}$; $\mathrm{clay}$ content decreasies abruptiy below $1419.9 \mathrm{ft}$; basal contact gradational over $0.1 \mathrm{ft}$

$1412.3-1424.6$

Polyhalitic halite, same as unit from 1402.8 to $1404.3 \mathrm{ft}$

$1424.6-1427.7$ 
USGS Lithologic Log (continued)

[Color designations are from the Rock Color Chart (Goddard and others, 1948);

"no recovery" designates where core was lost during coring operations]

Polyhalite, moderate-reddish-orange (10R-6/6), microcrystalline, from 1427.7 to

$1428.9 \mathrm{ft}$ rock is mixture of polyhalfte, light-gray (N7) anhydrite, and

transparent halite; irregularly shaped zones of halfte throughout untt; basal

contact marked by light-gray (N7) claystone bed, contact sharp, undulates

vertically as much as $0.1 \mathrm{ft}$

$1427.7-1430.6$

Halite, transparent to tinted moderate-reddish-orange (10R-6/6), medi um to coarsely crystalline; trace of polyhalite below $1431.8 \mathrm{ft}$; basal contact sharp and undulatory

$1430.6-1432.1$

Polyhalite, moderate-reddish-brown (10R-4/6), microcrystalline; basal contact sharp

$1432.1-1432.2$

Halite, transparent to moderate-reddish-brown (10R-4/6), dusky-red (5R-3/4) in upper part; moderately polyhalitic, polyhalite as disseminated blebs and stringers decreases downward; slightly argillaceous to $1433.7 \mathrm{ft}$, no clay below this; basal contact marked by undulatory irregular 6 to $12-m$ m-thick bed of light-gray (N7) anhydrite

$1432.2-1437.0$

Halite, transparent to moderate-reddish-brown (10R-4/6), medium to coarsely crystalline; trace of polyhalite as disseminated blebs and randomly oriented stringers; $6 \mathrm{~mm}$ thick polyhalite at $1438.5 \mathrm{ft}$

$1437.0-1439.3$

Polyhalite, moderate-reddish-brown (1OR-4/6) and light-gray (N7), microcrystalline; anhydritic in upper part decreasing downward; locally contains halite in irregularly shaped zones and as 3 to $6 \mathrm{~mm}$ long pseudomorphs after gypsum swallow-tail crystals, some slightly crushed; thin 1ight-gray (N7) claystone bed at base; basal contact sharp

Halite, transparent and brownish-gray $(5 Y R-4 / 1)$ at top grading to moderatereddish-brown $(10 R-4 / 6)$ at base, medium to coarsely crystalline; moderately argillaceous to $1442.9 \mathrm{ft}$; polyhalite as disseminated blebs and randomly oriented stringers; basal contact gradational over $12 \mathrm{~mm}$

$1441.4-1447.5$

Argillaceous halite, transparent and moderately-reddish-brown $(10 R-4 / 6)$ and minor light-gray (N7), medium crystalline; clay occurs as intercrystalline material; basal contact gradational over $5 \mathrm{~mm}$

$1447.5-1448.7$

Argillaceous siltstone, dark-reddish-brown (10R-3/4), slightly sandy; faint thin laminations locally; halitic in zones of aggregates and finely crystalline individual crystals, more halitic near top and bottom; increased clay content $0.1 \mathrm{ft}$ thick at $1454.8 \mathrm{ft}$; dark-reddish-brown (10R-3/4) polyhalftic halite containing polyhalite stringers from 1454.9 to $1456.1 \mathrm{ft}$; grades into underlying unit

$1448.7-1456.1$ 
USGS Lithologic Log (continued)

[Color designations are from the Rock Color Chart (Goddard and others, 1948);

"no recovery" designates where core was lost during coring operations]

Halite, moderate-reddish-orange (10R-6/6), moderate-reddish-brown (10R-4/6), and grayish-red (10R-4/2); polyhalitic and argillaceous bands range from 0.2 to $2.0 \mathrm{ft}$ thick; polyhalite stringers in $0.3-\mathrm{ft}$-thick band at $1458.6 \mathrm{ft}$

$1456.1-1477.9$

Halite, moderate-reddish-orange (10R-6/6), translucent, and dark-reddish-browin (10R-3/4), finely to medium crystalline; alternating bands of polyhalitic and argillaceous halite vary in thickness, generally less than $1 \mathrm{ft}$, contacts gradational; polyhalite bands from 1480.2 to $1480.4,1484.3$ to 1484.5 , and 1485.0 to $1485.1 \mathrm{ft}$ contain halite blebs; basal contact undulatory and sharp

Argillaceous halite and interbedded siltstone, moderate-reddish-brown (10R-4/5) and grayish-red (1OR-4/2), fine to medium crystalline halite; upper 15 to $310 \mathrm{~mm}$ is medium-light-gray (N6) clay; clay matrix soft and not well cemented; basal $0.4 \mathrm{ft}$ very argillaceous halite containing moderate-reddish-brown $(10 R-4 / 6)$ polyhalite stringers

Halite, dark-reddish-brown (10R-3/4) medium to coarsely crystalline; moderatereddish-brown (10R-4/6) polyhalite stringers and blebs; light-gray (N7) very soft clay seam 0.2 to $0.4 \mathrm{ft}$ thick at $1490.5 \mathrm{ft}$

$1489.7-1491.0$

Halite, alternating translucent halite, dark-reddish-brown (10R-3/4) argillaceous halite, and moderate-reddish-brown (1OR-4/6) polyhalitic halitie, coarsely crystalline; bands range from 0.1 to $0.3 \mathrm{ft}$ thick; moderate-reddishorange $(10 R-6 / 6)$ polyhalite stringers occur mostly in argillaceous halite; basal $1.0 \mathrm{ft}$ contains cavities that probably contained potash minerals (dissolved out during coring)

$1491.0-1499.8$

Halite, pale-reddish-brown (10R-5/4), medium crystalline, at top of unit, crystal size decreases downward; upper $f t$ contains cavities as in unit above; upper and lower portions contain light-gray (N7) clay zones; remnant boxwork structures in upper part are dark-reddish-brown (1OR-3/4)

$1499.8-1503.4$

Halite, translucent, moderate-reddish-orange (10R-6/6), and dark-reddish-browin (10R-3/4); polyhalitic and argillaceous; stringers of polyhalite increase in thickness downward, blebs of polyhalite $6 \mathrm{~mm}$ to $6 \mathrm{~cm}$ in size near base; basal contact gradational halite and polyhalite alternating bands; basal contact dips $20^{\circ}$

$1503.4-1510.0$

Polyhalite and anhydrite, moderate-reddish-brown (1OR-4/6) and light-gray

Halite, translucent, pale-reddish-brown (10R-5/4), and dark-reddish-brown (10R-3/4), finely to coarsely crystalline; polyhalitic and argillaceous; argillaceous halfte dominates in lower $12 \mathrm{ft}$; basal $7 \mathrm{ft}$ contains increasing quantities of light-gray (N7) clay 


\section{USGS Lithologic Log (continued)}

[Color designations are from the Rock Color Chart (Goddard and others, 1948);

"no recovery" designates where core was lost during coring operations]

Polyhalite, moderate-reddish-brown (10R-4/6); sharp upper contact, basal contact below 6-mm-thick light-gray (N7) clay seam

Halite, pale-reddish-brown (10R-5/4), coarsely crystalline; polyhalfic; few bands of grayish-red (10R-4/2) argillaceous halite; pale-red (10R-6/2) polyhalite $0.1 \mathrm{ft}$ thick at $1538.6 \mathrm{ft}$ and $0.7 \mathrm{ft}$ thick at 1540.1 to $1540.8 \mathrm{ft}$ containing stringers of halite

$1534.7-1543.9$

Halite, grayish-red (10R-4/2), finely crystalline; pale-reddish-brown (10R-5/4) clay at 1544.4 and $1545.7 \mathrm{ft}$; dark-reddish-brown $(10 R-3 / 4)$ clay at $1545.2 \mathrm{ft}$; clay content increases downward; basal contact nearly horizontal, wayy and sharp

$1543.9-1549.5$

Halite, translucent and moderate-red $(5 R-4 / 6)$, coarsely crystalline; disseminated cavities ranging from less than $3 \mathrm{~mm}$ to $3 \mathrm{~mm}$ in size, probably areas of sylvite; basal contact fairly sharp and horizontal

$1549.5-1551.8$

Halite, transparent, grayish-red (10R-4/2), and maderate-reddish-brown (10R-4/6), medium to coarsely crystalline; disseminated stringers and blebs of clay and polyhalite and cavities (probable sylvite sites); basal contact sharp, horizontal and slightly wavy

$1551.8-1556.8$

Polyhalite, moderate-red $(5 R-4 / 6)$ and moderate-reddish-brown (10R-4/6), granular texture; leached-out vertical cavities appear to have contained sylvite pseudomorphs after gypsum; basal contact not seen (rock shattered in lower half of unit)

$1556.8-1557.9$

Halite, alternating bands 0.2 to $0.8 \mathrm{ft}$ thick of translucent, grayish-red $10 R-4 / 2)$ and moderate-reddish-orange (10R-6/6), translucent and reddishorange bands coarsely crystalline, grayish-red bands finely to medium crystalline; disseminated blebs and stringers of light-gray (N7) anhydrite in lower $0.5 \mathrm{ft}$; basal contact slightly diffuse

Halite, moderate-reddish-orange (1OR-6/6), medium crystalline; stringers of anhydrite at 1564.6 and $1564.9 \mathrm{ft}$; basal contact diffuse

$1563.4-1565.8$

Halite, grayish-red (10R-4/2), finely to coarsely crystalline; cavities (probable sylvite sites) as large as $0.1 \mathrm{ft}$; basal contact diffuse

$1565.8-1567.0$

Halite, pale-red (10R-6/2) and moderate-reddish-orange (10R-6/6), medium to coarsely crystalline; cavities (probable sylvite sites); basal contact sharp and horizontal

$1567.0-1568.7$

Argillaceous halite, greenish-gray (5G-6/1) and pale-reddish-brown (10R-5/4), finely to medium crystalline; very dark red (5R-2/6) sylvite crystals; much of unit originally contained sylvite now dissolved and core recovered in fragments; $2 \mathrm{ft}$ of core loss assigned to this interval; basal contact diffuse

$1568.7-1573.8$ 
USGS Lithologic Log (continued)

[Color designations are from the Rock Color Chart (Goddard and others, 1948);

"no recovery" designates where core was lost during coring operations]

Halite, translucent, grayish-red (10R-4/2), and moderate-reddish-orange (10R-6/6); numerous cavities $3 \mathrm{~mm}$ to $24 \mathrm{~cm}$ in size (probable syivite sites); light-gray (N7) anhydrite stringers in iower $4 \mathrm{ft}$; possible 1ight-gray (N7) and pale-red (1OR-6/2) 0.3-ft-thick langbeinite bed at $1580.0 \mathrm{ft}$; basal contact sharp, jagged and probably contained sylvite

Polyhalite, dark-reddish-brown (1OR-3/4), microcrystalline; dark-greenish-gray (5G-4/1) clay seam at base; basal contact sharp and wavy (depth interval taken from density and gamma logs because of core loss caused by dissolution of sylvite during coring)

$1581.4-1581.8$

Halite, transparent and moderate-reddish-orange (10R-6/6), medium to coarsely crystalline; slightly polyhalitic; cavities as large as $0.1 \mathrm{ft}$ (probable sylvite sites); basal contact diffuse

$1581.8-1585.2$

Argillaceous halite, grayish-red (10R-4/2), medium to coarsely crystalline; numerous cavities (probable sylvite sites); basal contact sharp; $1 \mathrm{ft}$ of core loss assigned to this interval caused by sylvite dissolution

$1585.2-1588.7$

Halite, grayish-red (10R-4/2) grading downward to moderate-reddish-brown $(10 R-4 / 6)$ and translucent; few disseminated cavities $3 \mathrm{~mm}$ in size

$1588.7-1594.0$

Halite, transparent and moderate-reddish-orange $(10 R-6 / 6)$, medium to coarsely crystalline; polyhalftic content increases downward; basal $0.1 \mathrm{ft}$ contains polyhalite stringers; basal contact sharp and jagged

$1594.0-1598.5$

Polyhalite, moderate-reddish-brown (10R-3/6) microcrystalline; minor halite and sylvite; light-bluish-gray $(5 B-7 / 1)$ clay seam at base; basal contact sharp and horizontal

$1598.5-1599.8$

Halite, transparent and moderate-reddish-orange (1OR-6/6), finely to coarsely crystalline; slightly argillaceous in upper $2 \mathrm{ft}$; disseminated cavities as large as $0.1-\mathrm{ft}$; basal contact in broken core

$1599.8-1606.6$

Polyhalite, moderate-red $(5 R-4 / 6)$ to moderate-reddish-brown $(10 R-4 / 6)$, microcrystalline, dense; stringers of cavities near top of untt

$1606.6-1607.5$

Halite, transparent to moderate-reddish-brown $(10 R-4 / 6)$ and very light gray (N(3), finely to medium crystalline; moderately polyhalitic and argillaceous, contents vary locally; $0.1-\mathrm{ft}$-thick transparent bands of halite spaced 0.3 to $0.4 \mathrm{ft}$ apart below $1609.8 \mathrm{ft}$

$1607.5-1611.1$

No recovery

$1611.1-1613.1$

Halite, transparent to locally tinted moderate-reddish-orange (1OR-6/6). finely to coarsely crystalline; evidence of removal of sylvite by dissolution during coring; basal contact gradational over $0.1 \mathrm{ft}$

$1613.1-1613.9$ 
USGS LIthologic Log (continued)

[Color designations are from the Rock Color Chart (Goddard and others, 1948);

"no recovery" designates where core was lost during coring operations]

Lithologic description

Depth interval

Feet

Argillaceous halfte, transparent to medium-gray (N5) to locally moderate-red (5R-4/6); slightly polyhalitic; clay occurs locally as matrix; evidence of removal of sylvite by dissolution during coring; basal contact diffuse

$1613.9-1614.8$

Halite, transparent and moderate-reddish-orange (10R-6/6), medium to coarsely crystalline; trace amounts of sylvite, removed at core surface during coring; basal contact gradational over $3 \mathrm{~mm}$

$1614.8-1619.3$

Argillaceous halite, transparent, dusky-red (5R-3/4), and medium-light-gray (N6), finely to coarsely crystalline; clay occurs intercrystalline, as matrix and as blebs, clay varies from dark-reddish-brown (10R-3/4) to medium-light-gray (N6); trace of moderate-reddish-orange $(10 R-6 / 6)$ polyhalite blebs; clay content decreases downward below $1622.6 \mathrm{ft}$; undulatory slightly silty halitic claystone at $1621.3 \mathrm{ft}$ may contain sylvite; trace amount of sylvite leached from rock; basal contact not observed

Polyhalfte, moderate-reddish-brown (10R-4/6), microcrystalline; halitic, concentrated in upper part; anhydritic from 1632.1 to $1633.1 \mathrm{ft}$; 1 arge volumes of halite or sylvite leached from rock during coring; basal contact sharp

$1630.1-1633.1$

Anhydrite, medium-gray (N5), microcrystalline; locally halitic as irregularly shaped zones; locally sylvite leached from surface of rock; upper 15 mn faintly microlaminated alternating medium-gray (N5) and medium-dark-gray (N4); thin claystone bed at base; basal contact sharp

$1633.1-1637.9$

Halite, transparent and moderate-reddish-orange (1OR-6/6), medium to coarsely crystalline; trace polyhalite blebs; trace light-gray (N7) clay as stringers, blebs, and locally intercrystalline; trace amounts of syivite leached from rock; slightly argillaceous zones from 1648.9 to $1650.0,1650.8$ to 1551.2, 1651.5 to 1651.8 , and 1653.4 to $1654.0 \mathrm{ft}$; basal contact sharp

$1637.9-1654.9$

Argillaceous halite, transparent, moderate-reddish-orange (10R-6/6), and moderately reddish-brown (10R-4/6), finely to medium crystalline, locally coarsely crystalline; irregular patches of polyhalitic halite and disseminated polyhalite blebs; irregular patches of dark-reddish-brown (20R-3/4) halitic argillaceous siltstone; light-gray (N7) and dark-reddish-brown (1OR-3/4) occur together locally; clay occurs as intercrystalline and disseminated blebs; thin dark-reddish-brown (1OR-3/4) halitic claystone bed at $1656.5 \mathrm{ft}$

$1654.9-1663.4$

Halite, transparent and moderate-reddish-orange (10R-6/6), medium to coarsely crystalline; disseminated polyhalite blebs; trace light-gray (N7) clay stringers and blebs at top of unit, trace of clay as intercrystalline from 1666.8 to $1667.0 \mathrm{ft}$; minor disseminated sylvite from 1670 to $1673 \mathrm{ft}$

$1663.4-1676.0$ 
USGS Lithologic Log (continued)

[Color designations are from the Rock Color Chart (Goddard and others, 1948);

"no recovery" designates where core was lost during coring operations]

Lithologic description

Depth interval

Feet

Argillaceous halite, dark-reddish-brown (10R-3/4), finely crystalline increasing to medium downward, abundant moderate-reddish-brown (10R-4/6) polyhalite stringers; undulating dark-gray (N3) clay layer $3 \mathrm{~mm}$ thick at $1676.0 \mathrm{ft}$; traces of colorless crystalline blebs of potash mineral (langbeinite?)

$1676.0-1679.0$

Halite, moderate-reddish-orange (10R-6/6) and maderate-reddish-brown (10R-4/6) from 1685.0 to $1697.4 \mathrm{ft}$, medium to coarsely crystalline; abundant blebs and stringers of moderate-reddish-brown (10R-4/6) polyhalite; finely to medium crystalline, clear to pinkish-gray (5YR-8/1) langbeinite(?), most abundant from 1679.0 to $1685.0 \mathrm{ft}$; liberally disseminated sylvite

$1679.0-1702.1$

Halite, dark-reddish-brown (10R-3/4) and translucent, finely to coarsely crystalline; very argillaceous at top grading downward to slightly argillaceous; basal contact very gradational; disseminated zones contain cavities (sylvite sites)

$1702.1-1704.1$

Halite, translucent, medium to coarsely crystalline; disseminated blebs and stringers of very light gray (N8) anhydrite increasing downward; basal foot is half anhydrite; basal contact sharp and jagged

$1704.1-1716.5$

Anhydrite, light-brownish-gray (5YR-6/1), microcrystalline; disseminated blets of white (N9) anhydrite; disseminated zones of halite, some pseudomorphic after gypsum; fairly sharp basal contact

$1716.5-1721.9$

Halite, translucent, medium crystalline; anhydrite zone from 1723.5 to $1723 . \mathrm{ft}$; thin anhydrite stringers in lower half of unit; basal foot slightly polyhalitic; basal contact diffuse

$1721.9-1727.3$

Halite, moderate-reddish-orange $(10 R-6 / 6)$, finely to coarsely crystalline; very polyhalitic; $0.1 \mathrm{ft}$ very light gray (N8) anhydrite seams contain halite; basal contact sharp, wavy, and nearly horizontal

$1727.3-1728.8$

Anhydrite, medium-gray (N5) to medium-light-gray (N7), microcrystalline; upper $1.5 \mathrm{ft}$ contain numerous halite pseudomorphs after gypsum; clay seam at $1733.0 \mathrm{ft}$; massive in upper part of unit, laminated in lower $3 \mathrm{ft}$; basal contact sharp and horizontal

$1728.8-1736.1$

$\mathrm{Clay}$, medium-dark-gray (N4)

$1736.1-1737.3$

Polyhalfte, moderate-reddish-orange (10R-6/6), microcrystalline; greenish-graly $(5 G Y-5 / 1)$ clay abundant in upper $0.2 \mathrm{ft}$ and lower $0.1 \mathrm{ft}$ and disseminated throughout core; basal contact at clay seam, contact sharp

$1737.3-1738.4$

Halite, transparent and moderate-reddish-orange (10R-6/6), finely to medium crystalline; argillaceous zone from 1744.8 to $1745.3 \mathrm{ft}$; dark-greenish-gray (5GY-4/1) clay seam at top of argillaceous zone; possible langbeinite from 1746.0 to $1748.5 \mathrm{ft}$; basal contact diffuse

$1738.4-1748.5$ 
USGS Lithologic Log (continued)

[Color designations are from the Rock Color Chart (Goddard and others, 1948);

"no recovery" designates where core was lost during coring operations]

Litholagic description

Depth interval

Feet

Halite, dark-reddish-brown (10R-3/4) and transparent; medium and coarsely crystalline; two 0.3-ft-thick polyhalitic halite beds at 1750.3 and $1751.2 \mathrm{ft}$; few disseminated cavities (probable syivite sites); basal contact fairly sharp

$1748.5-1752.5$

Halite, transparent and moderate-reddish-orange (10R-6/6), medium to coarsely crystalline; basal $0.1 \mathrm{ft}$ very polyhalitic; basal contact slightly diffuse

$1752.5-1756.2$

Halite, dark-reddish-brown (1OR-3/4) alternating with transparent and moderatereddish-orange (10R-6/6), bands range from 0.1 to $1.6 \mathrm{ft}$ thick, medium to coarsely crystalline, very argillaceous in upper $0.4 \mathrm{ft}$; minor amount of small cubic cavities in dark-reddish-brown portion; trace of disseminated polyhalite blebs increasing downward; olive-gray $(5 y-4 / 1)$ bands replace dark-reddish-brown ones below $1764.2 \mathrm{ft}$; thin dark-reddish-brown (10R-3/4) claystone beds at 1761.5 and $1761.7 \mathrm{ft}$; basal contact sharp

$1756.2-1778.6$

Argillaceous halite, transparent and olive-gray $(5 \mathrm{Y}-4 / 1)$ to $1780.5 \mathrm{ft}$, transparent and dark-reddish-brown $(10 \mathrm{R}-3 / 4)$ below $1780.5 \mathrm{ft}$, medium to coarsely crystalline; thin dark-reddish-brown (10R-3/4) claystone bed at $1780.5 \mathrm{ft}$; trace of polyhalite blebs; irregular cavities in core caused by solution of sylvite; basal contact sharp

$1778.6-1782.1$

Halite, transparent and moderate-reddish-orange (10R-6/6), medium to coarsely crystalline; trace of disseminated polyhalite blebs and stringers; lacally trace of medium-light-gray (N6) clay; local zones free of polyhalite; basal contact sharp

$1781.2-1793.1$

Halite, transparent, moderate-reddish-brown (10R-4/6), and medi um-light-gray (N6), finely to coarsely crystalline; moderately argillaceous; upper $0.4 \mathrm{ft}$ moderately-reddish-brown $(10 R-4 / 6)$, slightly silty, halitic claystone, trace disseminated moderate-reddish-orange (10R-6/6) polyhalite blebs and stringers; clay as intercrystalline material; clay content decreases locally in $0.1-$ to 1.5-ft-thick bands; locally irregular cavities from solution of sylvite

No recovery

Polyhalite, moderate-reddish-brown $(10 R-4 / 6)$; interbedded with finely to very coarsely crystalline halite, and dark-reddish-brown (10R-3/4) clay; basal contact at medium-light-gray (N6) clay, basal contact sharp

$1821.0-1821.3$

Halite, transparent and pale-reddish-brown (10R-5/4), coarsely to very coarsely crystalline; discontinuous stringers and blebs of moderate-reddish-brown $(10 R-4 / 6)$ polyhalite; basal contact sharp and irregular

$1821.3-1827.4$

Halite, translucent, medium to coarsely crystalline; discontinuous moderatereddish-brown (10R-4/6) polyhalite blebs, argillaceous from 1827.9 to $1828.8 \mathrm{ft}$ grading downward to slightly argillaceous; basal contact sharp and irregular

$1827.4-1833.3$ 
USGS Lithologic Log (continued)

[Color designations are from the Rock Color Chart (Goddard anid others, 1948);

"no recovery" designates where core was lost during coring operations]

Lithologic description

Depth interval

Feet

Halite, translucent alternating with moderate-reddish-brown (10R-4/6), finely

to coarsely crystalline; discontinuous polyhalite stringers and blebs; moderate-

brown (5YR-4/4) clay seams; basal contact diffuse

$1833.3-1847.9$

Halite, translucent, medium to coarsely crystalline; discontinuous moderate-redclishorange $(10 R-6 / 6)$ polyhalite stringers and blebs; basal contact gradational

$1847.9-1852.3$

Halite, translucent to transparent, medium to coarsely crystalline; moderate-recldishorange $(10 R-6 / 6)$ polyhalite stringers and blebs; intercrystalline light-brown

$(5 Y R-5 / 6)$ clay; basal contact slightly gradational, dips about $45^{\circ}$

$1852.3-1852.7$

Polyhalite, moderate-reddish-orange $(10 R-6 / 6)$ and medium-light-gray (N5)

anhydrite stringers, polyhalite fine to medium crystalline, anhydrite

microcrystalline; thin $(6 \mathrm{~mm})$ transparent halite band at $1853.2 \mathrm{ft}$; basal

contact sharp

$1852.7-1853.8$

Halite, translucent, medium to coarsely crystalline; discontinuous stringers of moderate-reddish-orange $(1 \mathrm{OR}-6 / 6)$ polyhalite; basal contact diffuse

$1853.8-1854.7$

Argillaceous halite, transparent, medium crystalline; discontinuous moderate-rejdishorange (1OR-6/6) microcrystalline to finely crystalline polyhalite; medium-darkgray (N4) clay $15 \mathrm{~mm}$ thick, at $1855.3 \mathrm{ft}$; basai contact diffuse

$1854.7-1856.8$

Halite, translucent, medium to very coarsely crystalline; discontinuous moderatereddish-brown (10R-4/6) polyhalite stringers and blebs; 1 ower $1.2 \mathrm{ft}$ increasingly anhydritic, very light gray (N8) and polyhalitic, moderate-reddish-orange (10R-4/6) microcrystalline; basal contact diffuse and irregular

$1856.8-1864.5$

Polyhalite and anhydrite, alternating beds of fine to medium crystalline, moderatereddish-orange (10R-6/6), and microcrystalline, medium-gray (N5) anhydrite; basal contact at dark-gray (N4) clay seam, sharp and irregular

$1864.5-1865.5$

Halite, translucent to transparent, medium crystalline; moderate-reddish-orange (10R-6/6) polyhalite stringers; moderate-brown (5YR-3/4) clay stringer at $1866.4 \mathrm{ft}$; alternating banding of argillaceous halite and polyhalitic halite in lower $4 \mathrm{ft}$; basal contact diffuse

$1865.5-1873.1$

Argillaceous halite, medium-dark-gray (N4) and moderate-reddish-brown (10R-4/6), medium to coarsely crystalline; moderate-reddish-brown (10R-4/6) clay seams at $1874.5,1877.9,1879.1,1880.3,1881.2,1883.3$, and $1883.8 \mathrm{ft}$, varying in thickness from $24 \mathrm{~mm}$ to $12 \mathrm{~cm}$; clay content decreases downward; finely crystalline interval from 1882.4 to $1883.4 \mathrm{ft}$

$1873.1-1885.0$

Halfte, translucent and moderate-reddish-orange $(10 R-6 / 6)$ as alternating bands 0.4 to $1.4 \mathrm{ft}$ thick; finely to medium crystalline; blebs and stringers of polyhalite band at $1889.5 \mathrm{ft}$; basal contact diffuse

$1885.0-1889.9$ 
USGS Lithologic Log (continued)

[Color designations are from the Rock Color Chart (Goddard and others, 1948);

"no recovery" designates where core was lost during coring operations]

Polyhalite, moderate-reddish-orange (1OR-6/6) and dusky-red (5R-3/4), microcrystalline to very finely crystalline; dark-greenish-gray (5GY-4/1)

clay seam at base of unit; basal contact sharp and nearly horizontal

$1889.9-1891.8$

Argillaceous halite, grayish-red (10R-4/2), translucent, and moderate-reddishorange (10R-6/6), finely to medium crystalline in colored portions, medium to coarsely crystalline in translucent portions; dark-reddish-brown (10R-3/4) clay seams at 1894.3, 1894.7, 1894.8, 1895.3, and $1895.9 \mathrm{ft}$; basal contact slightly diffuse

$1891.8-1896.6$

Halite, translucent and moderate-reddish-orange (10R-6/6), medium to coarsely crystalline; alternating bands range in thickness from 0.1 to $1.4 \mathrm{ft}$; slightly argillaceous from 1901.0 to $1901.4 \mathrm{ft}$; basal contact slightly diffuse

$1896.6-1901.8$

Polyhalite, dark-reddish-brown (10R-3/4), microcrystalline; basal contact includes seam of dark-greenish-gray $(5 G-4 / 1)$ elay, contact is sharp and jagged

$1901.8-1902.0$

Argillaceous halite, moderate-reddish-brown (10R-4/6), alternating with translucent, finely to medium crystalline; dark-reddish-brown $(10 ;-3 / 4)$ clay seams at 1903.7 and $1905.2 \mathrm{ft}$; polyhalite stringer at $1906.4 \mathrm{ft}$; basal contact diffuse

$1902.0-1906.7$

Halite, translucent and moderate-reddish-orange (10R-6/6), medium to coarsely crystalline, polyhalitic throughout most of unit; basal contact slightly diffuse

$1906.7-1908.8$

Halite, alternating bands 0.2 to $0.4 \mathrm{ft}$ thick of translucent, grayish-red $(10 R-4 / 2)$ and moderate-reddish-orange (10R-6/6), translucent portion coarsely crystalline, rest is finely to medium crystalline

$1908.8-1910.9$

Halite, translucent bands alternating with moderate-reddish-orange (10R-6/6), coarsely to very coarsely crystalline; basal $0.1 \mathrm{ft}$ very polyhalitic; basal contact sharp and jagged

$1910.9-1913.5$

Argillaceous halite, grayish-red (10R-4/2), finely to coarsely crystalline; argillaceous material decreases downward; dark-reddish-brown (1OR-3/4) clay seam at $1914.4 \mathrm{ft}$; numerous blebs and stringers of polyhalite in lower $2 \mathrm{ft}$; basal contact very diffuse

$1913.5-1917.6$

Halite, translucent, very coarsely crystalline; basal contact sharp to diffuse and angular

$1917.6-1923.4$

Halite, grayish-red (10R-4/2) grading downward to translucent, medium to coarsely crystalline; very argillaceous from 1924.0 to $1926.4 \mathrm{ft}$; basal contact very diffuse

$1923.4-1928.0$ 
USGS Lithologic Log (continued)

[Color designations are from the Rock Color Chart (Goddard and others, 1948);

"no recovery" designates where core was lost during coring operations]

Halite, transiucent grading downward to moderate-reddish-orange $(10 R-6 / 6)$ and

then to translucent, medium to coarsely crystalline; polyhalitic from 1928.9 to

base of unit; basal contact diffuse

$1928.0-1933.6$

Halite, grayish-red (1OR-4/2) and translucent, finely to coarsely crystalline; very argillaceous from 1933.6 to 1934.3 and 1934.6 to $1935.0 \mathrm{ft}$; moderatereddish-orange (10R-6/6) polyhalitic argillite stringers and blebs in basal $3.7 \mathrm{ft}$; dark-reddish-brown $(10 R-3 / 4)$ clay seam at top of unit; basal contact diffuse

$1933.6-1938.3$
$1938.3-1940.8$

Halite, translucent, medium to coarsely crystalline; few disseminated polyhalite blebs

$1938.3-1940.8$

Halite, dark-reddish-brown (10R-3/4), medium to coarsely crystalline; very argillaceous in upper $1.7 \mathrm{ft}$ grading downward to slightly argillaceous; basal contact diffuse

$1940.8-1943.6$

Halite, translucent and moderate-reddish-orange (10R-6/6), medium to very coarsely crystalline; slightly argillaceous in middle of unit; dark-greenishgray (5GY-4/1) clay seams and blebs 1944.8 to $1945.3 \mathrm{ft}$; polyhalite blebs ard stringers 1944.5 to $1947.0 \mathrm{ft}$; basal contact diffuse

$1943.6-1947.0$
$1947.0-1951.9$
$1951.9-1952.5$
$1952.5-1952.9$

Halite, same as unit from 1947.0 to $1951.9 \mathrm{ft}$

Halite, dark-reddish-brown $(10 R-3 / 4)$ and grayish-red $(10 R-4 / 2)$, finely to coarsely crystalline; very argillaceous from 1952.9 to $1954.7 \mathrm{ft}$; polyhalitic and slightly argillaceous from 1954.7 to $1957.2 \mathrm{ft}$; numerous dark-reddish-brown $(10 R-3 / 4)$ clay seams in upper $2 \mathrm{ft}$; lower contact very diffuse

$1952.9-1957.2$
$1957.2-1958.1$
$1958.1-1959.9$

Halite, same as unft from 1952.9 to $1957.2 \mathrm{ft}$; very arglllaceous in upper $0.3 \mathrm{ft}$ and from 1958.9 to $1959.2 \mathrm{ft}$; clay seam at $1958.9 \mathrm{ft}$

Halite, translucent and moderate-reddish-orange (10R-6/6), medium to coarsely crystalline; finely crystalline from 1961.8 to $1962.1 \mathrm{ft}$; alternating bands of clear and polyhalitic halite range from 0.2 to $0.8 \mathrm{ft}$ thick; anhydrite bands $<0.1 \mathrm{ft}$ thick at $1965.6,1966.3,1966.9$, and $1969.7 \mathrm{ft}$; basal $0.4 \mathrm{ft}$ very polyhalftic and contains a $12 \mathrm{~mm}$ thick polyhalite band; basal contact sharp and jagged

$1959.9-1971.2$ 
USGS Lithologic Log (continued)

[Color designations are from the Rock Color Chart (Goddard and others, 1948);

"no recovery" designates where core was lost during coring operations?

Lithologic description

Depth interval

Feet

Polyhalite, moderate-reddish-brown (10R-4/6), microcrystalline; basal $0.1 \mathrm{ft}$ is brownish-gray (5YR-4/1) silty claystone; contact between is sharp as is basal contact

$1971.2-1971.7$

Argillaceous halite, brownish-gray (5YR-4/1), finely to medium crystalline, locally clay occurs as matrix; basal contact gradational over $15 \mathrm{~mm}$

$1971.7-1971.9$

Argillaceous halite, transparent, medium-dark-gray (N4), and moderate-reddishbrown (1OR-416), finely to coarsely crystalline; clay occurs intercrystalline and as stringers; trace moderate-reddish-orange (10R-6/6) polyhalite blebs;

locally halite very clear; basal contact gradational over $0.1 \mathrm{ft}$

$1971.9-1975.6$

Halite, transparent, minor moderate-reddish-orange (10R-6/6), medium to coarsely crystalline; bands of alternating colors 0.1 to $0.3 \mathrm{ft}$ thick; trace amounts of polyhalite blebs; halitic polyhalite bed from 1978.7 to $1978.8 \mathrm{ft}$; basal contact sharp

$1975.6-1980.7$

Halite, same as unit from 1971.9 to $1975.6 \mathrm{ft}$

$1980.7-1982.9$

Halite, same as unit from 1975.6 to $1980.7 \mathrm{ft}$

$1982.9-1986.1$

Halite, same as unit from 1971.9 to $1975.6 \mathrm{ft}$; thin claystone beds at 1988.6 and $1989.8 \mathrm{ft}$; clay content decreases rapidly from 1991.2 to $1993.7 \mathrm{ft}$; basal contact gradational over $0.1 \mathrm{ft}$

$1986.1-1993.7$

Halite, same as unit from 1975.6 to $1980.7 \mathrm{ft}$; trace clay from 1995.5 to $1996.4 \mathrm{ft}$; lower $0.4 \mathrm{ft}$ very polyhalitic; basal contact very irregular, undulatory, and sharp

$1993.7-2000.0$

Polyhalite, moderate-reddish-orange $(10 R-6 / 6)$, microcrystalline; trace medi umlight-gray (N6) clay at $2001.0 \mathrm{ft}$

$2000.0-2001.2$

Halite, moderate-reddish-orange (10R-6/6) and transparent; medium crystalline; upper 0.3 and lower $0.4 \mathrm{ft}$ polyhalitic, rest of unit clear; polyhalite stringers in lower $0.4 \mathrm{ft}$; basal contact gradational

$2001.2-2002.3$

Argillaceous halite, dark-reddish-brown (10R-3/4), moderate-reddish-orange (10R-6/6) and medium-dark-gray (N4), finely crystalline; banded; abundant medium-dark-gray (N4) clay stringers, moderate amount of dark-reddish-brown $(10 R-3 / 4)$ clay stringers and disseminated polyhalite throughout unit; basal contact diffuse

$2002.3-2005.0$

Halite, transparent, fine to medium crystalline; upper $1.0 \mathrm{ft}$ slightly argillaceous and polyhalftic; slight bands of moderate-reddish-orange (10R-6/6); anhydrite beds, 6 to $24 \mathrm{~mm}$ thick ranging from 0.3 to $2.0 \mathrm{ft}$ apart with depth; basal contact diffuse

$2005.0-2016.0$ 


\section{USGS Lithologic Log (continued)}

[Color designations are from the Rock Color Chart (Goddard and others, 1948);

"no recovery" designates where core was lost during coring operations]

Halite, transparent and moderate-reddish-orange (10R-6/6), fine to medium crystalline; thin (6 $\mathrm{mm}$ to $3.6 \mathrm{~mm}$ thick) bands of finely crystalline polyhalite and anhydrite 0.4 to $0.5 \mathrm{ft}$ apart; basal contact sharp and wavy

Anhydrite, medium-light-gray (N5); moderate-reddish-brown (10R-4/6) polyhalite bands $6 \mathrm{~mm}$ to $6 \mathrm{~cm}$ thick; bed of finely to medium crystalline moderate-reddishorange (1OR-6/6) halite from 2019.8 to $2020.4 \mathrm{ft}$; medium-dark-gray (N4) clay content increases in lower $0.4 \mathrm{ft}$; basal contact gradational

$2018.8-2021.7$

Polyhalitic and argillaceous halite, finely crystalline; polyhalfic halite is transiucent, moderate-reddish-orange (10R-6/6), and moderate-reddish-brown $(10 R-4 / 6)$, argillaceous halite is translucent and medium-light-gray (N6) to medium-gray (N5); stringers of very light gray (N8) anhydrite and moderatereddish-orange $(10 R-6 / 6)$ polyhalite sparsely disseminated throughout unit; basal contact diffuse

$2021.7-2025.7$

Argillaceous halite, translucent and medium-gray (N5), finely to medium crystalline; basal contact fairly sharp

$2025.7-2030.0$

Polyhalitic halite, translucent to moderate-reddish-orange (10R-6/6), medium to coarsely crystalline; basal contact fairly sharp

Argillaceous halite, same as unit at 2025.7 to $2030.0 \mathrm{ft}$; basal contact diffuse

Polyhalitic and argillaceous halite, same as unit from 2021.7 to $2025.7 \mathrm{ft}$; less anhydrite

Polyhalitic halite; moderate-reddish-orange $(10 R-6 / 6)$ and translucent; stringers of pinkish-gray (5YR-8/1) disseminated throughout unit increasing downward; minor amount of translucent and medium-gray (N5) argillaceous halite; polyhalite bands as thick as $0.4 \mathrm{ft}$ at 2050.0 and at base of unit; basal contact sharf and irregular

$2045.0-2050.9$

Anhydritic halite, transparent and medium-light-gray (N5); halite pseudomorphis after gypsum; basal $5 \mathrm{~mm}$ medium-gray (N5) anhydrite; basal contact diffuse

$2050.9-2051.8$

Argillaceous halite, pale-reddish-brown (10R-5/4) and translucent, finely crystalline; medium-light-gray (N7) clay as blebs and stringers; basal contact at clay seam, sharp and irregular

$2051.8-2052.6$

Halite, translucent and moderate-reddish-brown (10R-4/6), finely crystalline at top of unit becoming medium to coarsely crystalline downward; numerous paliereddish-brown (10R-5/4) polyhalite stringers; medium-1ight-gray (N6) clay stringers decrease downward; clay seam at base of unit 
USGS Lithologic Log (continued)

[Color designations are from the Rock Color Chart (Goddard and others, 1948);

"no recovery" designates where core was lost during coring operations]

Lithologic description

Depth interval

Feet

Argillaceous halfte, light-gray (N7) to medium-gray (N6) and translucent; minor moderate-reddish-orange (10R-6/6) polyhalite blebs; blebs of $\mathrm{clay} 15 \mathrm{~mm}$ to $4 \mathrm{~cm}$ throughout unit; $c$ lay seam at $2060.0 \mathrm{ft}$; translucent halite at 2062.4 to $2062.6 \mathrm{ft}$; basal contact diffuse

$2059.0-2063.6$

Halite, moderate-reddish-orange (10R-6/6) and translucent, medium to coarsely crystalline;polyhalite as blebs and stringers and finely disseminated throughout unit; medium-gray (N6) clay seam at $2067.7 \mathrm{ft}$, argillaceous from 2067.7 to $2068.1 \mathrm{ft}$; anhydrite and halite from 2068.1 to $2068.4 \mathrm{ft}$; basal contact sharp and nearly horizontal

$2063.6-2068.4$

Halite, moderate-reddish-orange (1OR-6/6), medium crystalline, very polyhalitic;

3- to 9-mm-thick anhydrite bands; basal contact fairly sharp

$2068.4-2069.3$

Anhydrite, light- to medium-gray (N7-N6), microcrystalline, massive; pseudomorphs of halite after gypsum show swallow-tail twinning; pseudomorphs as long as $0.1 \mathrm{ft}$, very abundant; medium-dark-gray (N4) clay at base, basal contact sharp

$2069.3-2081.0$

Halite, medium-gray (N5) and translucent, medium crystalline, moderately argillaceous; light-gray (N7) anhydrite stringers in lower ft; $0.1-\mathrm{ft}$ thick dark-gray (N4) Clay bleb at $2082.4 \mathrm{ft}$; basal contact 51 ightly diffuse

$2081.0-2086.0$

Halite, similar to unit above, but less argillaceous; clay bleb $0.2 \mathrm{ft}$ thick at $2097.1 \mathrm{ft}$; lower $\mathrm{ft}$ contains abundant anhydrite stringers; basal contact sharp and may dip $20^{\circ}$

$2086.0-2099.8$

Anhydrite, medium-dark-gray (N4), microcrystalline, massive; basal contact sharp, dips $20^{\circ}$

$2099.8-2100.5$

Halite, pale-red $(10 R-6 / 2)$, grayish-red (1OR-4/2), and translucent, medium to coarsely crystalline, moderately argillaceous; grayish-green (5G-5/2) clay seam at $2104.9 \mathrm{ft}$; dark-reddish-brown (10R-3/4) clay seam at $2106.1 \mathrm{ft}$; basal contact sharp, horizontal

$2100.5-2110.9$

Halite, similar to unit above, contains blebs and stringers of moderatereddish-orange $(10 R-6 / 6)$ polyhalite; basal contact dark-reddish-brown $(10 R-3 / 4)$ clay seam dipping about $10^{\circ}$

$2110.9-2118.7$

Halite, translucent and moderate-reddish-orange (1OR-6/6), medium to coarsely crystalline; slightly argillaceous from 2120.4 to 2120.6 ; basal contact gradational over $0.1 \mathrm{ft}$

$2118.7-2120.9$ 
USGS Lithologic Log (continued)

[Color designations are from the Rock Color Chart (Goddard and others, 1948);

"no recovery" designates where core was lost during coring operations]

Halite, brownish-gray (5YR-4/1), grayish-red (1OR-4/2), and transparent, finely to coarsely crystalline, moderateiy argillaceous grading downward to slightiy argillaceous at base; trace disseminated polyhalite blebs; clay as intercrystalline material and as stringers and blebs; locally contains clay.free zones; basal contact gradational over $0.1 \mathrm{ft}$

$2120.9-2127.5$

Halite, same as unit from 2118.7 to $2120.9 \mathrm{ft}$

$2127.5-2129.6$

Argillaceous halite, grayish-red (10R-4/2), brownish-gray (5YR-4/1) and transparent, finely to coarsely crystalline; clay occurs as matrix, blebs and stringers, and intercrystalline decreasing downward; below $2139.9 \mathrm{ft}$ unit becomes increasingly polyhalitic; local zones of clear halite; irregular polyhalitic beds at 2143.9 and $2144.1 \mathrm{ft}$; basal contact sharp

$2129.6-2144.9$

Polyhalite and anhydrite; moderate-reddish-brown (10R-4/6) polyhalite from 2144.9 to 2145.4 and 2150.5 to $2156.7 \mathrm{ft}$; medium-gray (N5) anhydrite from 2145.4 to $2150.5 \mathrm{ft}$; halite in irregular zones and as pseudomorphs after gypsum, crystals $0.1 \mathrm{ft}$ in length to $2152.0 \mathrm{ft}$; basal contact sharp

$2144.9-2156.7$

$\mathrm{Cl}$ aystone grading to argillaceous halite, medium-dark-gray (N4); basal contact gradational over $9 \mathrm{~mm}$

$2156.7-2157.3$

Halite, transparent and light-brownish-gray (5YR-6/1), medium to coarsely crystalline; trace moderate-reddish-orange $(10 R-6 / 6)$ polyhalite and clay; $.12-m m-t h i c k$ anhydrite bed at $2157.7 \mathrm{ft}$; medium-gray (N5) argillaceous anhydrite bed $0.16 \mathrm{ft}$ thick at $2159.9 \mathrm{ft}$; locally banded argillaceous zones 0.1 to $1.0 \mathrm{ft}$ thick; basal contact gradational over $0.1 \mathrm{ft}$

Polyhalitic halite, moderate-reddish-orange (10R-6/6) and transparent, medium to coarsely crystalline; polyhalite disseminated as stringers and blebs; basal contact gradational over $0.1 \mathrm{ft}$

$2164.1-2167.2$

Halite, transparent, medium-dark-gray (N4), and moderate-reddish-orange $(10 R-6 / 6)$, medium to coarsely crystalline; moderately argillaceous grading downward to slightly argillaceous and at $2170.4 \mathrm{ft}$ not argillaceous; slightly polyhalitic from 2170.4 to $2175.0 \mathrm{ft}$; clean halite below $2175.0 \mathrm{ft}$ except for few 0.1-ft-thick polyhalitic halite bands; $12-m m-t h i c k$ anhydrite at $2177.7 \mathrm{ft}$; large blebs of polyhalite at $2177.4 \mathrm{ft}$; basal contact gradational over $0.01 \mathrm{ft}$

Halfte, transparent, grayish-red (1OR-4/4), and locally moderate-reddish-brown $(10 R-4 / 6)$; medium to coarsely crystalline; slightly argillaceous; trace disseminated polyhalite blebs increasing downward from 2186.3 to $2187.8 \mathrm{ft}$ : moderate-brown (5YR-4/4) 6-mm-thick clay seams dipping $30^{\circ}$ at 2193.6 and $2194.1 \mathrm{ft}$; basal contact gradational over $0.16 \mathrm{ft}$

$2179.6-2199.8$ 
USGS Lithologic Log (continued)

[Color designations are from the Rock Color Chart (Goddard and others, 1948);

"no recovery" designates where core was lost during coring operations]

Lithologic description

Depth interval

Feet

Halite, translucent and moderate-reddish-orange (10R-6/6), medium to coarsely crystalline; moderate-reddish-orange $(10 R-6 / 6)$ polyhalite blebs and stringers; microcrystalline polyhalite bed $0.15 \mathrm{ft}$ thick at $2203.1 \mathrm{ft}$; basal contact diffuse over $24 \mathrm{~mm}$, dips $30^{\circ}$

$2199.8-2203.7$

Argillaceous halite, medium-dark-gray (N4) and transparent, medium to coarsely crystalline; stringers and intercrystalline material of moderate-brown (5YR-4/4) and Ifght-bluish-gray (5B-7/1) clay; moderate-reddish-orange (10R-6/6) polyhalite blebs and stringers increasing downward; 18-mm-thick irregular anhydrite stringers at 2205.4 and from 2208.8 to $2209.2 \mathrm{ft}$; basal contact sharp, irregular and mostly horizontal

$2203.7-2215.2$

Argillaceous halite, light-brown (5YR-6/4) and translucent; finely to medium crystalline; argillaceous content decreases downward; basal contact sharp and irregular

$2215.2-2216.1$

Argillaceous halite, medium-gray (N6) and translucent, medium to coarsely crystalline, clay occurs as stringers and intercrystalline; moderate-reddishbrown (1OR-4/6) clay seam from 2218.8 to $2218.9 \mathrm{ft}$; unit grades downward into unit below

Polyhalitic halite, moderate-reddish-orange (10R-6/6), medium to coarsely crystalline; slightly argillaceous in upper $0.16 \mathrm{ft}$; basal contact sharp and irregular

Halite, moderate-reddish-orange (10R-6/6), medium-light-gray (N6), and translucent, medium to very coarsely crystalline; upper $1.0 \mathrm{ft}$ is transparent, contains few polyhalite blebs; argillaceous content increases downward and grades into polyhalitic halite at $2276.2 \mathrm{ft}$; lower $1.0 \mathrm{ft}$ contains moderatereddish-orange $(10 R-6 / 6)$ polyhalite stringers; basal contact sharp, dips $30^{\circ}$

Anhydrite, medium-light-gray (N5); translucent halite as blebs and pseudomorphic after gypsum (swallow-tail twins); basal contact sharp, dips $20^{\circ}$

Argillaceous halite, medium-light-gray (N6) and translucent, finely to coarsely crystalline; 0.1-ft-thick light-bluish-gray (5B-7/1) clay seam at $2234.6 \mathrm{ft}$; upper foot contains discontinuous stringers and blebs of clay; moderate-reddishbrown $(10 R-4 / 6)$ clay seam at $2236.6 \mathrm{ft}$; crystal size increases downward; basal contact diffuse

$2234.6-2241.2$

Halite, translucent, medium to coarsely crystalline; very minor amount of moderate-reddish-orange (1OR-6/6) polyhalite blebs in lower foot; basal contact slightly diffuse

$2241.2-2242.9$ 
USGS Lithologic Log (continued)

[Color designations are from the Rock Color Chart (Goddard and others, 1948);

"no recovery" designates where core was lost during corting operations]

Lithologic description

Depth interval

Feet

Halite, transparent grading downward to medium-dark-gray (N4), argillaceous content increases downward, zones of finely crystalline halfte 0.1 to $0.2 \mathrm{ft}$ thick in upper $2 \mathrm{ft}$; majority of unit medium to coarsely crystalline; polyhalitic in upper 1.2 and lower $1.3 \mathrm{ft}$; medium-gray (N5) clay seams at 2244.8 and $2245.4 \mathrm{ft}$; blebs and stringers of clay disseminated throughout unit; basal contact fairly sharp

$2242.9-2247.0$

Halite, translucent and moderate-reddish-orange (1OR-6/6), medium crystalline; alternating bands of clear and polyhalitic halite 0.1 to $0.4 \mathrm{ft}$ thick; few stringers and blebs of light-gray (N7) anhydrite; medium-gray (N5) clay seani $.05 \mathrm{ft}$ thick at base dips $15^{\circ}$, basal contact sharp

$2247.0-2251.3$

Halite, translucent, medium-gray (N5) to dark-reddfsh-brown (1OR-3/4), and moderate-reddish-orange $(10 R-6 / 6)$, finely to coarsely crystalline; argillaceous content increases and polyhalitic content decreases downward; basal contact diffuse

$2251.3-2258.3$

Halite, moderate-reddish-orange (1OR-6/6) and transparent, medium crystalline; very polyhalitic; disseminated blebs and stringers of 1ight-gray (N7) anhydrite; basal contact sharp, jagged, and irregular

$2258.3-2262.2$

Anhydrite, light-gray (N7) and transparent, coarsely crystalline halite, basal contact diffuse and irregular

$2262.2-2262.3$

Halite, moderate-reddish-orange $(10 R-6 / 6)$ and translucent, finely to medium crystalline; basal contact sharp and jagged

$2262.3-2263.9$

Anhydrite, very light gray (N8), microcrystalline; inclusions of coarsely crystalline transparent halite; basal contact medium-gray (N5) Clay seam, sharp and nearly horizontal

$2263.9-2264.2$

Halite, medtum-gray (N5) to medium-light-gray (N4), medium crystalline, argillaceous; basal contact diffuse

$2264.2-2266.0$

Halite, translucent, foot grading to moderate-reddish-orange (10R-6/6), finely to medium crystalline; light-gray (N7) anhydrite stringers dissemineited throughout unit; polyhalitic in basal foot; basal contact sharp and slightly irregular

$2266.0-2271.7$

Anhydrite, pale-yellowish-brown (10YR-6/2), microcrystalline, basal contact sharp and extremely irregular; unit varies from 0.1 to $0.2 \mathrm{ft}$ thick

$2271.7-2271.9$

Halite, same as unit from 2258.3 to $2262.2 \mathrm{ft}$; basal contact fairly sharp and irregular, matches contact at top of unit

$2271.9-2272.7$

Halite, same as unit from 2242.9 to $2247.0 \mathrm{ft}$; very argillaceous in upper folst, decreasing downward; basal contact diffuse

$2272.7-2277.2$ 
USGS Lithologic Log (continued)

[Color designations are from the Rock Color Chart (Goddard and others, 1948);

"no recovery" designates where core was lost during coring operations]

Lithologic description

Depth interval

Feet

Halite, same as unit from 2266.0 to $2271.7 \mathrm{ft}$; basal contact diffuse

$2277.2-2282.2$

Halite, same as unit from 2264.2 to $2266.0 \mathrm{ft}$; very argillaceous from 2283.4 to $2284.0 \mathrm{ft}$; clay seam at $2284.9 \mathrm{ft}$; lower $2.5 \mathrm{ft}$ slightly polyhalitic; basal contact diffuse

$2282.2-2287.6$
$2287.6-2289.7$
$2289.7-2296.4$

Halite, same as unit from 2247.0 to $2251.3 \mathrm{ft}$; basal contact fairly sharp to diffuse

Halite, same as unit from 2264.2 to $2266.0 \mathrm{ft}$; very coarsely crystalline from 2293.2 to $2293.7 \mathrm{ft}$; diffuse polyhalite zones, basal contact diffuse

$2296.4-2303.3^{\circ}$ as blebs and stringers; basal contact sharp, jagged and dips about $5^{\circ}$

Anhydrite, light-gray (N7) and polyhalite, moderate-reddish-brown (10R-4/6); upper $15 \mathrm{~mm}$ is dense polyhalite; below this to $2304.7 \mathrm{ft}$ is dense anhydrite containing abundant pseudomorphs of halite after gypsum; from 2304.6 to $2304.8 \mathrm{ft}$ polyhalite; 2304.8 to $2305.5 \mathrm{ft}$ anhydrite and polyhalite pseudomorphs after gypsum; 2305.5 to $2305.9 \mathrm{ft}$ dense polyhalite; 2305.9 to $2306.3 \mathrm{ft}$ anhydrite; medium-gray (N5) clay seam at base of unit dips $5^{\circ}$

$2303.3-2306.3$
$2306.3-2306.6$
$2306.6-2307.8$

Halite, moderate-reddish-orange (1OR-6/6), medium to coarsely crystalline; becomes less polyhalitic downward; basal contact diffuse

Halite, alternating diffuse bands 0.1 to $0.6 \mathrm{ft}$ thick, translucent, moderatereddish-brown $(10 R-3 / 4)$, and grayish-red $(10 R-4 / 2)$, finely to coarsely crystalline, finely crystalline portions more argillaceous than rest; basal contact sharp and irregular, medium-gray (N5) clay seam $0.3 \mathrm{~mm}$ thick

Halite, moderate-reddish-orange (10R-6/6), medium to coarsely crystalline; numerous blebs and stringers of polyhalite; basal $0.2 \mathrm{ft}$ contains large polyhalite bleb in which are numerous finely crystalline halite stringers; basal contact dips $20^{\circ}$, is fairly sharp and is marked by 0.6 -mm-thick lightgray (NT) clay seam

$2313.8-2317.0$

Halite, translucent and medium-gray (N5), very coarsely crystalline in upper $0.4 \mathrm{ft}$, medium to coarsely crystalline in lower $0.9 \mathrm{ft}$; slightly argillaceous and polyhalitic; basal contact slightiy diffuse

$2317.0-2318.3$

Halite, moderate-reddish-orange $(10 R-6 / 6)$ and pale-red $(5 R-6 / 2)$, mediun to very coarsely crystalline; silightly argillaceous; very argillaceous from 2319.3 to $2320.0 \mathrm{ft}$; increasingly polyhalitic downward; basal contact sharp, dips about $20^{\circ}$

$2318.3-2326.6$ 
USGS Lithologic Log (continued)

[Color designations are from the Rock Color Chart (Goddard and others, 1948);

"no recovery" designates where core was lost during coring operations]

Halite, translucent and medium-gray (N5), finely to coarsely crystalline; darkreddish-brown (1OR-3/4) clay stringers at $2327.2 \mathrm{ft}$ and indistinct clay zories from 2327.2 to $2328.7 \mathrm{ft}$; base of unit grades into underlying unit

$2326.6-2331.5$

Halite, moderate-reddish-orange $(10 R-6 / 6)$ and translucent, medium to coarsely' crystalline; finely disseminated polyhalte and blebs and stringers throughout unit; basal contact sharp, dips about $5^{\circ}$

Anhydrite, medium-gray (N5), dense; basal contact sharp, dip5 $5^{\circ}$

$2331.5-2336.6$

$2336.6-2336.8$

Halite, translucent and medium-gray (N5), medi um crystalline; slightly argillaceous from $2336^{\circ} .8$ to $2339.1,2339.4$ to $2342.5,2343.4$ to 2344.5 , 2346.0 to 2352.0 , and 2352.8 to $2353.7 \mathrm{ft}$; basal contact gradational over 1$) .1 \mathrm{ft}$

$2336.8-2354.6$

Halite, transparent to medium-gray (N5), medium to coarsely crystalline; traise of intercrystalline clay, also as stringers; trace anhydrite stringers and blebs in lower portion of unit; 0.1 - to $0.25 \mathrm{ft}$-thick beds of microcrystalline anhydrite at $2370.4 \mathrm{ft}$, continuous stringers at $2370.7,2371.2$, and $2371.7 \mathrm{ft}$; basal contact sharp

$2354.6-2372.1$

Anhydrite, medium-dark-gray (N4), microcrystalline; upper $0.9 \mathrm{ft}$ contains abundant horizontal to subhorizontal bands of halite pseudomorphs after gypsum swallow-tail crystals as long as $0.32 \mathrm{ft}$; upper contact marked by pseudomorphs; halite-rich zone at $2381.0 \mathrm{ft}$; lower portion laminated to nodular to enterolithic; thin claystone bed at $2384.9 \mathrm{ft}$; argillaceous anhydrite from 2385.0 to $2386.0 \mathrm{ft}$ emits petrolfferous $\left(\mathrm{H}_{2} \mathrm{~S}\right)$ odor; unit grades to claystone at $2386.0 \mathrm{ft}$; basal contact sharp

Silty claystone, medium-light-gray (N6); $\mathrm{H}_{2} \mathrm{~S}$ odor; basal contact sharp, undulatory $2372.1-2387.8$

Halite, transparent to medium-gray (N5), medium to coarsely crystalline; trace clay as intercrystalline and blebs and rare stringers; clay-free bands 0.1 to $1.2 \mathrm{ft}$ thick; medium-gray (N5) silty claystone from 2392.1 to $2392.2 \mathrm{ft}$; rare stringers of anhydrite; anhydrite bed 0.16 to $0.25 \mathrm{ft}$ thick containing halite at $2410.8 \mathrm{ft}$; broken rock from 2399.4 to $2401.6 \mathrm{ft}$ and 2413.5 to $2414.5 \mathrm{ft}$; 6 - to $12 \mathrm{~mm}$-thick medium-light-gray (N6) clay at $2435.9 \mathrm{ft}$; basal contact gradational over $0.2 \mathrm{ft}$

$2388.0-2436.7$

Halite, transparent to medium-light-gray (N6), medium to coarsely crystalline; moderate-reddish-orange (10R-6/6) polyhalite as blebs and stringers from 2436.7 to $2438.8 \mathrm{ft}$; polyhalite decreases downward to $2442.6 \mathrm{ft}$, clay content increases downward; alternating bands of translucent, argillaceous, and polyhalitic halfte from 2442.6 to $2450.1 \mathrm{ft}$; basal contact gradational over $0.1 \mathrm{ft}$

$2436.7-2450.1$ 


\section{USGS Lithologic Log (continued)}

[Color designations are from the Rock Color Chart (Goddard and others, 1948); "no recovery" designates where core was lost during coring operations]

Polyhalite, moderate reddish-orange (10R-5/5), finely crystalline; stringers and blebs of medium-light-gray (N6) anhydrite as thick as $0.25 \mathrm{ft}$; transparent halite pseudomorphs after gypsum swallow-tail crystals; halite-rich zone at: $2451.7 \mathrm{ft}$ contains coarsely crystalline moderate-blue (5B-5/6) halite; 0.35-ft-thick medium gray (N5) claystone bed at base of unit underlying 15 -mm-thick very light gray (N8) anhydrite seam; claystone cut by vertical fracture filled by acicular halite crystals, crystals nearly horizontal and normal to fracture walls, filling about 15 mm thick; basal contact sharp, dips about $5^{\circ}$

$2450.1-2454.5$

Halite, moderate-reddish-orange (1OR-6/6) and translucent, medium to coarsely crystalline; polyhalitic as blebs and discontinuous stringers; basal contact diffuse over $0.1 \mathrm{ft}$

$2454.5-2455.4$

Argillaceous halite, 1ight-olive-gray $(5 \gamma-6 / 1)$, translucent to transparent, medium to coarsely crystalline; stringers of clay as thick as $6 \mathrm{~mm}$ and intercrystalline clay; zones of moderate-reddish-orange (10R-6/6) polyhalitic halite; clear halite, and argillaceous halite range from 0.1 to $1.4 \mathrm{ft}$ thick; basal contact slightly diffuse, dips $30^{\circ}$

$2455.4-2487.6$

Halite, medium-gray (N5) and translucent; finely to medium crystalline; alternating zones of halfte and slightly argillaceous halite range from 0.1 to $1.7 \mathrm{ft}$ thick; 0.1-ft-thick anhydrite stringer at $2503.2 \mathrm{ft}$, jagged upper and lower contacts, transparent coarsely crystalline halite above anhydrite; basal contact sharp, jagged, and irregular

$2487.6-2503.6$

Anhydrite, light-brownish-gray (5YR-6/1), microcrystalline; abundant zones of halite pseudomorphs after gypsum swallow-tail crystals;basal contact jagged and irregular

Halite, translucent, medium crystalline; anhydrite stringers in upper $0.1 \mathrm{ft}$; basal contact at $.6 \mathrm{~mm}$-thick light-gray (N7) clay seam sharp and dips $5^{\circ}$

Anhydrite, medium-light-gray (N6), microcrystalline; thinly bedded to laminated, dips range from 0 to $45^{\circ}$; abundant halite pseudomorphs after gypsum swallow-tail crystais throughout unit; light-brown (5YR-6/1) laminae from 2510.4 to $2511.5 \mathrm{ft}$; translucent, medium crystalline halite seams at $2514.0,2514.5$, and $2515.3 \mathrm{ft}$; clayey anhydrite laminae from 2516.8 to $2517.0 \mathrm{ft}$ dip $20^{\circ}$; dense, well-cemented brownish-gray $(5 Y R-4 / 1)$ clay bed in basal $0.6 \mathrm{ft}$ dips $20^{\circ}$; basal contact sharp

Halite, medium-gray (N5) and translucent, finely to very coarsely crystalline; slightly argillaceous; very light gray (N8) anhydrite stringers and blebs disseminated throughout unit from 2517.9 to 2527.0 and 2532.0 to $2556.3 \mathrm{ft}$; irregular thick anhydrite stringer at $2555.5 \mathrm{ft}$; basal contact sharp
$2506.8-2517.9$

$2503.6-2506.0$
$2506.0-2506.8$

$2517.9-2556.3$ 
USGS Lithologic Log (continued)

[Color designations are from the Rock Color Chart (Goddard and others, 1948);

"no recovery" designates where core was lost during coring operations]

Lithologic description

Depth interval

Feet

Anhydrite, medium-gray (N5), microcrystalline; irregular halite zones near top and base; basal contact sharp and undulatory; 0.1-ft-thick dark-medium-gray

(N4) silty claystone at base; basal contact sharp to gradational

$2556.3-2557.4$

Halite, same as unit at 2517.9 to $2556.2 \mathrm{ft}$; no anhydrite; basal contact

gradational over $0.1 \mathrm{ft}$

$2557.4-2561.0$

Halite, transparent, medium to coarsely crystalline; stringers and blebs of medium-light-gray (N6) anhydrite below $2564.3 \mathrm{ft}$; basal contact gradational over 12 to $36 \mathrm{~mm}$

$2561.0-2566.4$

Anhydrite, pale-yellowish-brown (10YR-6/2) and light-gray (N7), microcrystalline; laminated to massive; upper $0.3 \mathrm{ft}$ very halitic, locally irregularly shaped zones; argillaceous in lower $0.2 \mathrm{ft}$; basal contact sharp

$2566.4-2571.6$

Halite, transparent to medium-gray (N7), medium to coarsely crystalline; slightly argillaceous, blebs, stringers and intercrystalline clay decrease below $2585.8 \mathrm{ft}$; trace of disseminated anhydrite stringers and blebs below $2588.2 \mathrm{ft}$; 6 - to $12 \mathrm{~mm}$-thick anhydrite at $2588.4 \mathrm{ft}, 6 \mathrm{~mm}$ thick anhydrite at $2589.6 \mathrm{ft}$; basal contact sharp

$2571.6-2589.8$

Anhydrite, medium-light-gray (N6), microcrystalline; bands of halite pseudomorphs after gypsum swallow-tail crystals as large as $6 \mathrm{~mm}$ basal contact marked by thin claystone bed, sharp

$2589.8-2590.3$

Halite, same as interval from 2571.6 to $2589.8 \mathrm{ft}$; contains no anhydrite above: $2602.0 \mathrm{ft}$; clay-free zones as thick as $2 \mathrm{ft}$; anhydrite stringers disseminated throughout unit from $2602.0 \mathrm{ft}$ to base of unit; basal contact sharp and jagyed

$2590.3-2603.6$

Anhydrite, light-gray (N7), dense, microcrystalline; halite stringer at $2604.2 \mathrm{ft}$; basal $0.1 \mathrm{ft}$ clayey; basal contact sharp dipping about $5^{\circ}$

Halite, same as unit from 2571.6 to $2589.8 \mathrm{ft}$; basal contact fairly sharp

Halitic anhydrite, light-gray (N7); basal contact sharp, dips less than $5^{\circ}$

Halite, same as unit from 2571.6 to $2589.8 \mathrm{ft}$; basal contact fairly sharp and jagged
2603.6 - 2604.5
$2604.5-2607.0$
$2607.0-2607.2$
$2607.2-2610.1$
2610.1 - 2611.1
$2611.1-2615.3$
$2615.3-2615.7$
$2615.7-2644.5$
$2644.5-2655.4$

Anhydrite, light-gray (N7); upper $0.2 \mathrm{ft}$ halitic; basal $0.5 \mathrm{ft}$ clayey;

basal contact sharp, dips less than $5^{\circ}$

Halite, same as unit from 2571.6 to $2589.8 \mathrm{ft}$; basal contact sharp and irregular

Halitic anhydrite, light-gray (N7), dense; basal contact sharp, slightly wavy

Kalite, same as unit from 2571.6 to $2589.8 \mathrm{ft}$; basal $0.6 \mathrm{ft}$ very coarsely crystallirie and transparent; basal contact sharp and jagged

Anhydrite, yellowish-olive-gray $(5 Y-6 / 2)$, dense; disseminated halite crystals from 2648.2 to $2651.6 \mathrm{ft}$ 
USGS Lithologic Log (contInued)

[Color designations are from the Rock Color Chart (Goddard and others, 1948); "no recovery" designates where core was lost during coring operations]

\begin{tabular}{lc} 
Lithologic description & $\begin{array}{c}\text { Depth interval } \\
\text { Feet }\end{array}$ \\
\hline
\end{tabular}

No recovery

$2655.4-2656.0$

Anhydrite, same as unit from 2644.5 to $2655.4 \mathrm{ft}$; disseminated halite crystals from 2656.0 to $2661.4 \mathrm{ft}$; faint $\mathrm{H}_{2} \mathrm{~S}$ odor from 2662.0 to $2668.4 \mathrm{ft} ; 18 \mathrm{~mm}$ thick olive-gray $(5 \mathrm{Y}-4 / 1)$ anhydrite at $2668.4 \mathrm{ft}$; basal contact sharp and undulatory, dipping about $10^{\circ}$

$2656.0-2669.5$

Halite, translucent to medium-light-gray. (N6), finely to medium crystalline; transparent coarsely crystalline halfte 0.1 to $0.8 \mathrm{ft}$ thick; stringers of olivegray (5YR-3/2) anhydrite at $2700.9 \mathrm{ft}$; basal contact sharp, wavy, dipping $30^{\circ}$

$2669.5-2701.2$

Anhydrite, light-brownish-gray (5YR-6/1), dense; disseminated halite crystals mostly in upper half of unit; halite bands as thick as $0.1 \mathrm{ft}$; basal contact sharp and jagged

$2701.2-2703.5$

Halite, transparent, translucent, light-gray (N7) to medium-gray (N5), finely to medium crystalline; slight to moderate amounts of medium-light-gray (N6) intercrystalline clay; bottom foot of unit badly broken

$2703.5-2715.8$

No recovery

$2715.8-2716.0$

Halite, medium-light-gray (N6) to medium-gray (N5) and translucent, mostly finely to coarsely crystalline, coarsely crystalline in disseminated zones; minor amount of intererystalline clay; alternating indistinct bands 0.1 to $2 \mathrm{ft}$ thick of clear and slightly arglllaceous halite; basal contact sharp, slightly jagged, and nearly horizontal

$2716.0-2719.6$

Anhydrite, 1ight-brownish-gray (5YR-6/1), dense microcrystalline; 15-mm-thick band of halite crystals at $2720.0 \mathrm{ft}$; discontinuous halite seam at $2720.9 \mathrm{ft}$; basal contact contains minor amount of medium-gray (N5) clay; basal contact sharp and horizontal

$2719.6-2721.0$

Halite, same as unit at 2716.0 to $2719.6 \mathrm{ft}$; most of halite is coarsely crystalline; slightly argillaceous zones are often very irregularly outlined (not bedding planes); anhydrite stringers abundant in lower foot; light-gray (N7) anhydrite bed from 2806.3 to $2806.7 \mathrm{ft}$ has 1rregular upper contact, sharp lower contact dipping $5^{\circ}$; basal contact sharp, undulatory, dipping $30^{\circ}$

$2721.0-2809.6$

Anhydrite, light-gray (N7), dense, microcrystalline; abundant halite in lower half; clayey zone $15 \mathrm{~mm}$ thick at base has $\mathrm{H}_{2} \mathrm{~S}$ odor; basal contact sharp, dipping $15^{\circ}$

$2809.6-2810.2$

Halite, same as unit from 2716.0 to $2719.6 \mathrm{ft}$; few anhydrite stringers in lower $2 \mathrm{ft}$; basal contact diffuse over $0.3 \mathrm{ft}$

$2810.2-2826.1$

Halite, transparent to white (N9), coarsely crystalline; basal contact sharp and jagged, dipping $45^{\circ}$

$2826.1-2828.1$ 
USGS Lithologic Log (continued)

[Color designations are from the Rock Color Chart (Goddard and others, 1948);

"no recovery" designates where core was lost during coring operations]

Lithologic description

Depth interval

Feet

Anhydrite, medium-light-gray (N6) to medium-gray (N5), microcrystalline; aburidant

translucent, coarsely crystalline seams and blebs of halite; basal contact sharp,

wavy, dipping at $40^{\circ}$

$2828.1-2829.7$

Halite, translucent to light-brownish-gray (5YR-6/1), medium crystalline; basal contact sharp, wavy, dipping $30^{\circ}$

$2829.7-2831.1$

Anhydrite, medium-light-gray (N6) to medium-gray (N5), dense, microcrystallille; disseminated halite crystals from 2831.3 to $2831.8 \mathrm{ft}$; discontinuous halite seam at $2832.5 \mathrm{ft}$; basal contact sharp, dipping $15^{\circ}$

$2831.1-2832.7$

Halite, medium-light-gray (N6) to medium-gray (N5) and translucent, medium to coarsely crystalline; medium-dark-gray (N4) clay stringers; basal contact gradational over $0.2 \mathrm{ft}$

$2832.7-2850.5$

Halite, transparent to white (N9) and transiucent, medium to coarsely crystalline; light-gray (N6) stringers of anhydrite as thick as $12 \mathrm{~mm}$ at 2853.3 and 28.56.6 ft; stringers more numerous in lower $0.5 \mathrm{ft}$; basal contact sharp and horizontal

$2850.5-2858.4$

Anhydrite, medium-light-gray (N6), microcrystalline, interbedded with 6 to 18-mmthick discontinuous translucent bands of halite pseudomorphs after gypsum swallow-tail crystals; basal contact sharp and wavy

Halite, same as unit from 2850.5 to $2858.4 \mathrm{ft}$; basal contact sharp and horizontal

Anhydrite, same as unit from 2858.4 to $2859.5 \mathrm{ft}$

$2859.5-2862.6$

Halite, same as unit from 2850.5 to $2858.4 \mathrm{ft}$; medium-light-gray (N6) anhydrite stringers at 2867.0 and $2867.3 \mathrm{ft}$; basal contact sharp and nearly horizontal

Anhydrite, same as unit from 2858.4 to $2859.5 \mathrm{ft}$

Halite, same as unit from 2850.5 to $2858.4 \mathrm{ft}$

Anhydrite, same as unit from 2858.4 to $2859.5 \mathrm{ft}$; basal contact sharp, wavy, nearly horizontal

$2862.6-2863.0$

$2863.0-2867.8$

$2867.8-2869.9$

$2869.9-2873.8$

$2873.8-2874.1$

Halite, translucent and light-gray (N7) to medium-gray (N5), finely to medium crystalline; medium-dark-gray (N4) clay as stringers and intercrystalline; zones of very coarsely crystalline halite; dips between translucent and gray zones range from 0 to $30^{\circ}$; convoluted and pull-apart structures in anhydrite stringers in lower $2.5 \mathrm{ft}$; basal contact sharp and irregular

$2874.1-2940.7$

Anhydrite, light-gray (N7) to medium-light-gray (N6), dense, microcrystalline; halite crystal masses in upper and lower $0.2 \mathrm{ft}$, lower halite masses exhibit boudinage structure, anhydrites between halite masses "neck-down" as if drawnout; basal $0.3 \mathrm{ft}$ clayey and has $\mathrm{H}_{2} \mathrm{~S}$ odor; basal contact sharp, slight ly undulatory, dipping $65^{\circ}$

$2940.7-2941.3$ 
USGS Lithologic Log (continued)

[Color designations are from the Rock Color Chart (Goddard and others, 1948);

"no recovery" designates where core was lost during coring operations]

Halite, similar to unit at 2874.1 to $2884.2 \mathrm{ft}$; from 2944.2 to $2945.4 \mathrm{ft}$ unit is about 20 percent irregularly shaped anhydrite; few disseminated stringers of anhydrite throughout unit, concentrated from 2972.7 to 2973.1, 2979.7 to 2981.8, and 2995.5 to $2996.0 \mathrm{ft}$; zones of halite crystals surrounded by anhydrite, crystal boundaries exhibiting evidence of apparent solution; numerous 0.1 to 1.0-ft intervals from 2965.4 to base of unit, especially abundant zones from 2999.0 to $3003.5 \mathrm{ft}$; anhydrite stringer from 3042.7 to $3043.5 \mathrm{ft}$ is recumbent fold; alternating thin bands of anhydritic halite and halite from 3044.9 to $3050.3 \mathrm{ft}$; basal contact sharp. slightly undulatory, dipping $10^{\circ}$

$2941.3-3050.3$

Anhydrite, medium-light-gray (N4), laminated, halite crystals in wavy bed exhibits "pull-apart" structure; basal contact sharp, undulatory, dipping $10^{\circ}$

Halite, similar to unit at 2874.1 to $2884.2 \mathrm{ft}$; upper $6.3 \mathrm{ft}$ has alternating clear and anhydritic halite beds dipping $30^{\circ}$, contacts between beds sharp to diffuse; lower $8 \mathrm{ft}$ numerous stringers and beds of halitic anhydrite dipping $60^{\circ}$; lower $0.5 \mathrm{ft}$ contains discontinuous argillite bands dipping $4.5^{\circ}$

Anhydrite, light-gray (N7); interlayered with halite bands dipping $45^{\circ}$

Halite, medium-light-gray (N6); discontinuous argillite bands dipping $45^{\circ}$

Anhydrite, light-gray (N7); interlayered with halite,dipping $45^{\circ}$

Halite, same as unit from 3066.1 to $3067.0 \mathrm{ft}$; 0.3-ft-thick anhydrite bands dipping $45^{\circ}$

Anhydrite, medium-dark-gray (N6), laminated; basal contact dipping $30^{\circ}$

Halite, light-gray (N7), interlayered with anhydrite dipping opposite sense of unit from 3070.9 to $3072.0 \mathrm{ft}$

Anhydrite, same as unit from 3070.9 to $3072.0 \mathrm{ft}$

Halite, very light gray (N8), convolute anhydrite stringers penetrated by fold of underlying anhydrite

Anhydrite, similar to unit at 3070.9 to $3072.0 \mathrm{ft}$; laminations near vertical; halite interiaminations dipping from 0 to $45^{\circ}$

Ha)ite and laminated anhydrite mixed in marbled zone; laminations at various angles

Anhydrite, medium-gray (N5) to medium-ifght-gray (N6), very finely crystalline; laminations nearly horizontal in upper part of unit, horizontal to about $15^{\circ}$ in lower part of unit; organic material in some laminae; basal contact diffuse

Anhydrite, medium-light-gray (N6) to medium-dark-gray (N4); laminated with hydrocarbon-containing bands; petroleum odor very pronounced; basal contact diffuse and gradational
$3050.3-3050.6$

$3050.6-3065.5$

$3065.5-3066.1$

$3066.1-3067.0$

$3067.0-3067.9$

$3067.9-3070.9$

$3070.9-3072.0$

$3072.0-3072.7$

$3072.7-3073.7$

$3073.7-3075.7$

$3075.7-3081.5$

$3081.5-3082.8$

$3082.8-3111.4$

$3111.4-3112.3$ 
USGS LIthologic Log (continued)

[Color designations are from the Rock Color Chart (Goddard and others, 1948);

"no recovery" designates where core was lost during corinị operations]

Anhydrite; medium-gray (N5), laminated with organic material similar to two units above; laminae become less numerous downward, except for concentration from $3 i 25.4$ to $3129.0 \mathrm{ft}$; basal contact arbitrary as laminae become less abundant and indistinct

$3112.3-3148.0$

Anhydrite, medium-gray (N5) to medium-light-gray (N6), very finely crystalline to microcrystalline; faint horizontal laminations in lower $4.4 \mathrm{ft}$; glauberite sparsely dispersed in lower $4.4 \mathrm{ft}$

$3148.0-3160.3$

Anhydrite, similar to unit above; contains spots and marly laminations of olive-: gray (5Y-4/1) to olive-black (5Y-2/1) organics; locally nodular, especially from 3168.0 to $3170.2 \mathrm{ft}$; 1 ower $1.8 \mathrm{ft}$ contains nodules outlined with olive-black $(5 Y-2 / 1)$ material

$3160.3-3170.2$

Anhydrite, medium-gray (N6) to olive-gray $(5 \mathrm{Y}-4 / 1)$, horizontal laminae wavy and spotty; bands of halite pseudomorphs after gypsum swallow-tail crystals; glauberite crystals and clots increasing in size downward to $0.18 \mathrm{ft}$ across; possible white (N9) magnesite(?) sparsely disseminated throughout unit

$3170.2-3183.0$

Anhydrite, medium-gray (N5), few to no laminations; 0.12 - to 0.18 -ft-thick glauberite crystals concentrated from 3202.0 to $3205.0 \mathrm{ft}$; possible sparse magnesite(?)

$3183.0-3217.0$

Anhydrite, medium-light-gray (N6) and opaque; numerous flakes and swirly discontinuous laminae of olive-gray $(5 \gamma-4 / 1)$ mineral slightly soluble in concentrated brine drilling fluid give rock a turbid texture; medium-gray (N5) band at 3225.5 to $3225.8 \mathrm{ft}$; glauberite band $0.18 \mathrm{ft}$ thick at $3227.9 \mathrm{ft}$, sparsie glauberite disseminated throughout unit; irregular laminae dipping about $20^{\circ}$; very nodular structure in 1 ower $1.7 \mathrm{ft}$

$3217.0-3233.2$

Anhydrite, medium-dark-gray ( $N 4)$, wavy olive-gray (5Y-4/1) laminations dip aboul: $60^{\circ}$; glauberite(?) zones irregularly shaped, 0.2 to $0.5 \mathrm{ft}$ across; basal contact contains faint drusy crystals

Anhydrite, same as unit from 3217.0 to $3233.2 \mathrm{ft}$, very finely crystalline, laminations very indistinct downward; 1 arge glauberite crystal at $3267.4 \mathrm{ft}$

$3234.0-3275.4$

Anhydrite, dark-gray (N3) grading downward to light-brownish-gray (5YR-6/1), dark-yellowish-brown (10YR-4/2), and medium-gray (N5), mi crocrystalline, densla, masstve; clots of brownish-gray (5YR-4/1) glauberite slightly soluble in saturated brine drilling fluid disseminated throughout unit, zones containing laths, needies, and cubes of glauberite from 3285.0 to 3285.1 and 3302.5 to $3305.0 \mathrm{ft}$; horizontal stylolite at $3302.5 \mathrm{ft}$; pale-yellowish-brown (10YR-6/2) faint laminae and blebs from 3303.6 to $3305.0 \mathrm{ft}$; basal contact sharp 
USGS Lithologic Log (continued)

[Color designations are from the Rock Color Chart ('Goddard and others, 1948);

"no recovery" designates where core was lost during coring operations]

Anhydrite, brownish-gray (5YR-4/1), microcrystalline, massive to laminated, laminae pale-brown (5YR-5/2), $3 \mathrm{~mm}$ to $30 \mathrm{~cm}$ apart; strike of laminae not consistent; dips range from 25 to $35^{\circ}$; at $3386.6 \mathrm{ft}$ laminae roll over as if at axis of overturned beds, laminae above roll-over dip in opposite sense of laminae below; indistinct widely spaced laminae from 3417.0 to $3419.1 \mathrm{ft}$; basal contact at lowest lamination

$3374.4-3419.1$

$3419.1-3429.6$

nearly horizontal laminae from 3426.7 to $3427.4 \mathrm{ft}$

Anhydrite, medium-dark-gray (N4) to dark-gray (N3), dense, microcrystall ine; pale-brown (5YR-5/2) laminae generally $12 \mathrm{~mm}$ apart dipping $15^{\circ}$; few disseminated clots of glauberite as large as $9 \mathrm{~mm}$

$3429.6-3431.6$

Anhydrite, medium-dark-gray (N4), dense, massive, microcrystalline; few disseminated clots of glauberite as large as $12 \mathrm{~mm}$; basal contact slightly diffuse

$3431.6-3451.2$

Anhydrite, pale-yellowish-brown (10YR-6/2) and medium-gray (N5), finely to coarsely crystalline, massive, dense; clots of cubic mineral as large as $0.1 \mathrm{ft}$, mostly 3 to $12 \mathrm{~mm}$; basal contact fairly sharp

$3451.2-3467.8$

Anhydrite, medium-gray (N5) to dark-gray (N3), microcrystalline; two vertical fractures healed by recrystallized anhydrite at $3475.9 \mathrm{ft}$ (not visible on outside of core); few 1 aminae pale-brown (5YR-5/2) dipping $25^{\circ}$ disseminated from 3468.5 to $3475.4 \mathrm{ft}$; faint discontinuous mottled appearance from 3476.5 to $3485.5 \mathrm{ft}$; clots of glauberite increase in 1 ower $9.1 \mathrm{ft}$; unit becomes finely crystalline, pale-brown (10YR-6/2) along with grays in lower $8.6 \mathrm{ft}$; basal contact diffuse

Anhydrite, pale-brown (10YR-6/2), microcrystalline, basal contact diffuse

Anhydrite, medium-gray (N5) to dark-gray (N3), finely crystalline; numerous palebrown laminae mostly wavy, horizontal, $15 \mathrm{~mm}$ to $30 \mathrm{~cm}$ apart; 6-mm-thick dolomitic and anhydrite band dipping 15\%, anhydrite nodules $6 \mathrm{~mm}$ in length along band; basal contact diffuse

Anhydrite, medium-gray (N5) to dark-gray (N3) and pale-brown (10YR-6/2), microcrystalitine; few pale-brown (10YR-6/2) laminations; clots of glauberite disseminated throughout unit; 8 laminae from 3550.0 to $3552.0 \mathrm{ft}$ range in dip from 0 to $35^{\circ}$; lamination at 3576.7 dipping $35^{\circ}$; streaky, horizontal laminae from 3577.2 to $3577.4 \mathrm{ft}$; 2 lamt nae from 3580.1 to 3580.3 dipping $20^{\circ}$; nearly horizontal laminae at 3583.7; from 3601.2 to $3604.0 \mathrm{ft}$ core broken during removal from barrel, not known if pieces right-side-up
$3514.5-3525.9$

$3504.1-3514.5$

$3525.9 \quad-\quad 3605.0$
$3467.8-3504.1$ 
USGS Lithologic Log (continued)

[Color designations are from the Rock Color Chart (Goddard and others, 1948);

"no recovery" designates where core was lost during coring operations]

Lithologic description

Depth interval

Feet

Anhydrite, medium-gray (N5) to dark-gray (N3), olfve-gray (5Y-4/1) and minor amount of brownish-gray (5YR-4/1), massive to possibly nodular, dense; trace amounts of clear tabular mineral 1.5 to $12 \mathrm{~mm}$ disseminated throughout unit, locally rhombic habit; below $3665.0 \mathrm{ft}$ few pale-brown (10YR-6/2) wavy laminae dipping from 5 to $60^{\circ}$; contorted laminae from 3690.4 to $3691.0 \mathrm{ft}$; horizontal to $60^{\circ}$ dipping laminae from 3695.0 to $3696.0 \mathrm{ft}$; 0.1 -ft-thick bandof grayish-brown (10rR-3/2) dolomitic material at $3693.7 \mathrm{ft} ; 3$ to $9 \mathrm{~mm}$ thick wavy, nearly horizontal laminae from 3721.2 to $3724.0 \mathrm{ft}$

Anhydrite, medium-gray (N5) to medium-dark-gray (N4), olive-gray (5Y-4/1), locally medium-light-gray (N6), microcrystalline, massive to laminated to thinly laminated; nodular and enterolithic structures commonly associated with laminated portions; locally interbedded dusky-yellowish-brown (10YR-2/2) and light-olive-gray (5Y-5/2) often contorted carbonate laminae; from 3725.7 to $3725.9 \mathrm{ft}$ laminae dipping 20 to $30^{\circ}$, contain $6 \mathrm{~mm}$ thick anhydrite nodules; carbonate 1 aminae from 3726.5 to $3726.8 \mathrm{ft}$ associated with incipient nodularanhydrite; from 3729.1 to $3733.5 \mathrm{ft}$ anhydrite interbedded with abundant carbonate laminae commonly dip from 5 to $40^{\circ}$, dip direction rotates downward, laminae in microlaminar groups occasionally exhibit clastic appearance; froin 3738.1 to $3765.3 \mathrm{ft}$, often contorted carbonate laminae dipping 5 to $40^{\circ}$ occur as isolated thin laminae and groups of microlaminae spaced at $0.1-$ to $0.32-\mathrm{ft}$ intervals, laminae locally teminated; below $3765.3 \mathrm{ft}$, laminae locally abundant, often occur in groups $12 \mathrm{~mm}$ to $12 \mathrm{~cm}$ thick interbedded with anhydrite, of ten crenulated and contorted, locally associated with enterolithic anhydrite, internal structure resembles soft sediment dewatering structures at 3776.9 to $3777.1,3781.5$ to 3781.7 , and 3782.1 to $3782.3 \mathrm{ft}$; dips range from 10 to $75^{\circ}$; horizontal to sub-horizontal healed fractures at $3746.9,3750.2,3758.6,3759.4$, 3768.5 , and $3780.4 \mathrm{ft}$; high-angle healed fractures at 3747.9 to $3748.5 \mathrm{dipping}$ $80^{\circ}, 3750.0$ to 3750.5 dipping $85^{\circ}, 3758.5$ to 3758.6 dipping $50^{\circ}, 3758.6$ to 3759.4 dipping $65^{\circ}$ to $90^{\circ}, 3761.8$ to 3762.3 dipping $70^{\circ}, 3764.0$ to 3764.5 dipping $85^{\circ}, 3768.4$ to 3768.9 dipping $70^{\circ}$, and 3776.3 to 3776.6 dipping $65^{\circ}$; trace thin bladed clear mineral disseminated throughout unit; unit grades downward at base to pale-yellowish-brown (10YR-6/2) microcrystalline massive anhydrite, basal contact at very wavy lamination 


\section{USGS Lithologic Log (continued)}

[Color designations are from the Rock Color Chart (Goddard and others, 1948);

"no recovery" designates where core was lost during coring operations]

Anhydrite, medium-gray (N5) to medium-dark-gray (N4) and dark-yellowish-brown (10YR-4/2), and pale-yellowish-brown (10YR-6/2) carbonaceous laminae; very contorted, thrust-broken laminations from 3785.2 to $3786.3 \mathrm{ft}$; walvy, contorted, very numerous laminations from 3786.3 to $3790.5 \mathrm{ft}$, dipping $60^{\circ}$; gassy odor and probable oil stain at $3790.7 \mathrm{ft}$; laminations from 3790.5 to $3797.8 \mathrm{ft}$ less: numerous and nearly horizonta 1 ; very numerous laminations from 3797.8 to $3799.2 \mathrm{ft}$ dipping $15^{\circ}$; laminations from 3799.2 to $3800.0 \mathrm{ft}$ highly contorted and broken; laminations from 3800.0 to 3801.1 fairly numerous, regular, and dipping $45^{\circ}$; basal contact sharp, contains recrystallized halite on slightly irregular surface, dipping $45^{\circ}$

Halite, translucent, very coarsely crystalline; faint banding caused by less translucent zones dipping $15^{\circ}$; basal contact dipping $20^{\circ}$, very sharp; bottom of basal halite contains minor amount of anhydrite

Anhydrite, dark-yellowish-brown (10YR-4/2) grading downward to include medium-gray (N5), microcrystalline; dark-yellowish-brown (10YR-4/2) carbonate laminae, dipping 0 to $15^{\circ}$, disseminated throughout unit; some laminae 3 to $6 \mathrm{~mm}$ thick and wavy; basal contact where laminations constitute more than half of rock, dipping $15^{\circ}$

Anhydrite, interlaminated medium-dark-gray (N4) and dusky-yel lowish-brown (10YR-2/2); laminations very thin and numerous; very regular, dipping 10 to $15^{\circ}$ to $3830.8 \mathrm{ft}$; 1 aminations from 3830.8 to $3840.2 \mathrm{ft}$ occasionally wavy carbonate enclosed by nodular anhydrite; laminations from 3830.8 to 3844.3 very regular, strafght, and dip 5 to $10^{\circ}$

$3824.6-3844.3$

No recovery

$3844.3-3845.0$ 
USGS Lithologic Log (continued)

[Color designations are from the Rock Color Chart (Goddard anid others, 1948); "no recovery" designates where core was lost during coring operations]

Anhydrite, dusky-yellowish-brown $(10 Y R-2 / 2)$ bedded and laminated with dark-gray

(N3), microcrystalline; dusky-yellowish-brown beds generally about $1 / 6$ to $1 / 10$ as thick as dark-gray beds; cyclic deposition, numerous very thin laminations followed by bed of dusky-yellowish-brown dolomitic anhydrite and then by dark. gray anhydrite, pattern holds throughout unit; most laminations straight, dipping 5 to $10^{\circ}$; occasional wavy laminae in thicker dark-gray anhydrite beds; cycles range in thickness from less than $0.5 \mathrm{ft}$ to more than $2 \mathrm{ft}$; zones of dark-gray anhydrite from 3879.3 to 3883.3 and 3895.3 to $3897.3 \mathrm{ft}$ contain contorted and wavy laminae of dolomitic anhydrite, lower zone contains bifurcating laminae; dips steepen to as much as $11^{\circ}$ from 3958.4 to $3964.6 \mathrm{ft}$; disrupted wavy laminae from 3924.0 to $3924.7,3936.4$ to $3938.0,3955.5$ to 3958.3, and 3962.3 to $3964.6 \mathrm{ft}$; small monoclinal fold at $3918.6 \mathrm{ft}$; carbonaceous band $0.1 \mathrm{ft}$ thick at $3945.7 \mathrm{ft}$; below $3964.6 \mathrm{ft}$ dip decreases to nearly constant $5^{\circ}$, not always same direction; zones of anhydrite nodules that: compress adjacent carbonate laminations from 3976.7, 3977.2, 3977.9, 3981.4 to $3981.7,3982.2,3992.8,3997.5$ to $3998.5,3999.7,4005.1$ to $4005.8,4009.8$ to $4010.0,4010.3$, and 4012.7 to $4012.9 \mathrm{ft}$, at $4009.4 \mathrm{ft}$ two $0.2-\mathrm{ft}$ diameter (ovill) nodules squeezed laminations together; from 4013.4 to $4022.3 \mathrm{ft}$ rock is most ly dolomitic laminae; oil-stained 1 aminae $0.2 \mathrm{ft}$ thick at $3965.8 \mathrm{ft}$; below $4024.3 \mathrm{ft}$ dip of laminations ranges from 3 to $6^{\circ}$; anhydrite nodules compress carbonate laminae from 4039.8 to $4043.5 \mathrm{ft}$; from 4044.4 to $4045.2 \mathrm{ft}$ rock mos: $1 \mathrm{y}$ carbonaceous and carbonate laminations; from 4045.2 to $4045.3 \mathrm{ft}$ rock is most ly carbonaceous; laminations near base kinked and folded; basal contact very wavy and sharp

Anhydrite, medium-dark-gray (N4), microcrystalline; nodular structure breaks anid disrupts most dusky-yellow-brown (10YR-2/2) laminations; few 3-mm-thick laminile, wavy; basal contact sharp, sifghtly irregular, and horizontal

$4045.3-4069.7$

Dolomite and anhydrite, dusky-yellowish-brown (10YR-2/2) and dark-gray (N3), horizontal laminae; oil bleeding from vertical nearly-healed fracture; basal contact sharp and horizontal

Shale, grayish-black (N2) to dark-gray (N3), calcareous, basal contact sharp $4069.7-4071.4$ $4071.4-4073.8$

Limestone, grayish-black (N2), bedded with dark-gray (N3); pelecypod shells as long as $6 \mathrm{~mm}$ and corals(?); basal $5.5 \mathrm{ft}$ alternating 0.1 - to 1.0-ft-thick bed 5 of brownish-gray (5YR-4/1) and grayish-black (N2) shale, brownish-gray portions calcareous; dipping nearly horizontal, basal contact gradational

$4073.8-4103.4$ 
USGS Lithologic Log (concluded)

[Color designations are from the Rock Color Chart (Goddard and others, 1948);

"no recovery" designates where core was lost during coring operations]

Lithologic description

Depth interval

Feet

Sandstone, light-olive-gray $(5 \gamma-5 / 2)$ to olive-gray $(5 \gamma-3 / 2)$, fine to medium

grained, porous, calcareous cement; upper $5 \mathrm{ft}$ and from 4114.6 to $4122.1 \mathrm{ft}$

lighter shades and contains wavy, very thin beds of olive-gray $(5 \gamma-3 / 2)$

siltstone; core broken during recovery at 4 intervals; measurements are as if

full recovery $(60.0 \mathrm{ft})$ plus $1.1 \mathrm{ft}$ of preceding core; basal contact gradational

$4103.4-4174.0$

Shale, dusky-yellowish-brown (10YR-2/2), calcareous, porous; pelecypod shells

$3 \mathrm{~mm}$ and smaller disseminated throughout unit; fairly horizontal bedding; basal

contact gradational

$4174.0-4182.8$

Sandstone, grayish-black (N2) and olive-gray $(5 \gamma-4 / 1)$, fine to medium grained, non-calcareous cement, very poorly cemented from about 4188 to $4204 \mathrm{ft}$ (this portion of core crumbled upon removal from barrel); discontinuous claystone in very thin beds; basal contact gradational

$4182.8-4218.2$

Shaley sandstone; olfve-gray (5Y-4/1) and medium-dark-gray (N4); unit not readily apparent (drilling time increase)

$4218.2-4219.0$

Sandstone, same as unit from 4182.8 to $4218.2 \mathrm{ft}$; dark-gray (N3) clay seams, $3 \mathrm{~mm}$ thick at $\mathbf{4 2 4 3 . 2}$ and $4244.9 \mathrm{ft}$; interval from 4244.9 to $4260.1 \mathrm{ft}$ slight ly coarser grained and poorly cemented; two very thin ( $<0.1 \mathrm{ft}$ thick) dark-gray (N3) clay seams $6 \mathrm{~mm}$ thick at $4260.1 \mathrm{ft}$; from about 4264.4 to $4264.8 \mathrm{ft}$ a fragmented mass of dark-gray (N3) clayey material was recovered; dark-gray (N3) clay seam $6 \mathrm{~mm}$ thick at $4264.4 \mathrm{ft}$

$4219.0-4265.0$

Sandstone, mostly grayish-black (N2) as in unit above, grades to dusky-yellowishbrown (5YR-4/1) from 4277.0 to 4288.0 and 4303.8 to $4325.0 \mathrm{ft}$; black (N1) shale $0.1 \mathrm{ft}$ thick at $4265.8,3 \mathrm{~mm}$ thick at $4270,4275.3,4300.9$, and $4301.9,6 \mathrm{~mm}$ thick at 4300.9 , and $9 \mathrm{~mm}$ thick at $4302.7 \mathrm{ft}$; shaley sandstone from 4270.2 to 4270.8; coarse to medium grained sandstone from 4275.3 to $4288.0 \mathrm{ft}$; soft sediment deformation structures at 4268.3 and $4288.9 \mathrm{ft}$; shale-sandstone contacts sharp and horizontal

$4265.0-4325.0$ 
DISTRIBUTION:

US Department of Energy (5)

Office of Civilian Radioactive Waste Management

Office of Geologic Repositories

Attn: Associate Director

W. J. Purcell, RW-20

Director, Repository Coordination Div.

T. H. Isaacs, RW-22

Director, Engineering \& Licensing

R. Stein, RW-23

Director, Geosciences \& Technology

R. Stein, Actg., RW-24

Director, Siting Division

E. Burton, RW-25

Forrestal Building

Washington, DC 20585

US Department of Energy (3)

Albuquerque Operations

Attn: R. G. Romatowski

D. L. Krenz

D. G. Jackson, Director, Public Affairs Division

PO Box 5400

Albuquerque, NM 87185

US Department of Energy (6)

Attn: J. Tillman

WIPP Project Office (Carlsbad) (2)

G. Pappas, WPO (Carlsbad)

A. Hunt, WPO (Carlsbad)

R. Eastmond, WPO (Carlsbad) (2)

PO Box 3090

Carlsbad, NM 88221

US Department of Energy, SRPO (4)

Office of Nuclear Waste Isolation

Attn: J. O. Neff

R. Wunderlich

G. Appel

J. Sherwin

505 King Avenue

Columbus, OH 43201

US Department of Energy (2)

Idaho Operations Office

Nuclear Fuel Cycle Division

Attn: R. M. Nelson

J. Whitsett

550 Second Street

Idaho Falls, ID 83401
US Department of Energy (2)

Savannah River Operations Office

Waste Management Project Office

Attn: S. Cowan

W. J. Brumley

PO Box A

Aiken, SC 29801

US Department of Energy (3)

Office of Defense Waste and

Transportation Management

Attn: J. E. Dieckhoner, DP-122

L. H. Harmon, DP-121

A. Follet, DP-121

Washington, DC 20545

US Department of Energy

Research \& Technical Support Division

Attn: D. E. Large

PO Box E

Oak Ridge, TN 37830

US Department of the Interior

Attn: E. Roedder

959 National Center

Geological Survey

Reston, VA 22092

US Nuclear Regulatory Commission (2)

Division of Waste Management

Attn: M. Bell

H. Miller

Mail Stop 623isS

Washington, I) 20555

US Geological Survey (2)

Special Projects

Attn: R. Snyder

G. M. Fairer

MS913, Box 25046

Denver Federal Center

Denver, CO 80225

US Geological Survey

Conservation Division

Attn: W. Melton

PO Box 1857

Roswell, NM 88201 
DISTRIBUTION (continued):

US Geological Survey

Water Resources Division

Attn: J. D. Bredehoeft

Western Region Hydrologist

345 Middlefield Road

Menlo Park, CA 94025

US Geological Survey (2)

Water Resources Division

Attn: H. L. Case

P. Davies

Western Bank Bldg.

505 Marquette NW, \#720

Albuquerque, NM 87102

State of New Mexico (3)

Environmental Evaluation Group

Attn: R. H. Neill, Director

320 Marcy Street

PO Box 968

Santa Fe, NM 87503

NM Department of Energy \& Minerals

Attn: K. LaPlante, Librarian

PO Box 2770

Santa Fe, NM 87501

New Mexico Bureau of Mines and Mineral Resources (2)

Attn: F. E. Kottolowski, Director

J. Hawley

Socorro, NM 87801

Battelle Pacific Northwest Laboratories

Attn: D. J. Bradley

Battelle Boulevard

Richland, WA 99352

Battelle Memorial Institute (13)

Project Management Division

Attn: W. Carbiener, General Manager (3)

J. Treadwell

T. Naymik

J. Kirchner

V. Adams

o. Swanson

A. Razem

S. Gupta

W. Newcomb

A. LaSala

ONWI Library

505 King Avenue

Columbus, OH 43201
Bechtel Inc. (2)

Attn: E. Weber M. Bethard

PO Box 3965

45-11-B34

San Francisco, CA 94119

IT Corporation (2)

Attn: W. E. Coons J. E. Zurkoff

2340 Alamo, SE

Suite 306

Albuquerque, NM 87106

IT Corporation (5)

Attn: W. Patrick

R. McKinney

D. Deal

D. Winstanley

D. W. Uhland

PO Box 2078

Carlsbad, NM 88221

INTERA Technologies, Inc. (5)

Attn: G. E. Grisak

G. J. Saulnier

G. E. Freeze

INTERA Library

6850 Austin Center Blvd., \#300

Austin, TX 78731

INTERA Technologies, Inc.

Attn: W. Stensrud

PO Box 2123

Carlsbad, NM 88221

Martin Marietta Energy Systems, Inc.

Oak Ridge National Laboratory

Attn: J. A. Carter

Box Y

Oak Ridge, TN 37830

Martin Marietta Energy Systems, Inc.

Oak Ridge National Laboratory

Environmental Science

Attn: E. Bondietti

X10 Area, Bldg. 1505, Rm. 322

Oak Ridge, TN 37831

RE/SPEC Inc.

Attn: P. Gnirk

PO 725

Rapid City, SD 57701 
DISTRIBUTION (continued):

RE/SPEC Inc.

Attn: S. W. Key

PO Box 14984

Albuquerque, NM 87191

Rockwell International

Atomics International Division

Rockwell Hanford Operations

Attn: W. W. Schultz

PO Box 800

Richland, WA 99352

Serata Geomechanics

Attn: S. Serata

4124 Lakeside Drive

Richmond, CA 94806-1941

G. O. Bachman

Star Route Box 1028

Corrales, NM 87048

Leonard Minerals Co.

Attn: B. Donegan

3202 Candelaria NE

Albuquerque, NM 87107

Peters Technology Transfer

Attn: L. Lantz

PO Box 216

Swarthmore, PA 19081

Stanford University

Department of Geology

Attn: K. B. Krauskopf

Stanford, CA 94305

Vanderbilt University

Department of Environmental and

Water Resources Engineering

Attn: F. L. Parker

Nashville, TN 37235

Oak Ridge National Laboratory

Attn: J. O. Blomeke

PO Box X

Oak Ridge, TN 37830

K. P. Cohen

928 N. California Avenue

Palo Alto, CA 94303
F. M. Ernsberger

1325 NW 10th Avenue

Gainesville, FL 32601

Johns Hopkins University

Department of Earth Sciences

Attn: H. P. Eugster

Baltimore, MD 21218

University of New Mexico (3)

Department of Geology

Attn: R. C. Ewirg

D. G. Brockins

Library

Albuquerque, NM 87131

University of Minnesota

Department of Geological Sciences

Attn: C. Fairhurst

Minneapolis, MN 55455

University of Texas at Austin

Department of Geological Sciences

Attn: W. R. Muehlberger

Austin, TX 78712

D. A. Shock

233 Virginia

Ponca City, OK 74601

National Acaderny of Sciences

Committee on Radioactive Waste Management

Attn: P. Meyers

2101 Constitution Avenue, NW

Washington, DC 20418

New Mexico Junior College

Pannell Library

Attn: R. Hill

Lovington High'way

Hobbs, NM 88240

New Mexico Tech

Martin Speere Memorial Library

Campus Street

Socorro, NM 87810

New Mexico State Library

Attn: I. Vollenhofer

PO Box 1629

Santa Fe, NM 87503 
DISTRIBUTION (continued):

University of New Mexico

Zimmerman Library

Attn: Z. Vivian

Albuquerque, NM 87131

Atomic Museum

WIPP Public Reading Room

Attn: G. Schreiner

Kirtland East AFB

Albuquerque, NM 87185

Carlsbad Municipal Library

WIPP Public Reading Room

Attn: L. Hubbard, Head Librarian

101 S. Hallagueno St.

Carlsbad, NM 88220

Thomas Brannigan Library

Attn: D. Dresp, Head Librarian

106 W. Hadley St.

Las Cruces, NM, 88001

Roswell Public Library

Attn: N. Langston

$301 \mathrm{~N}$. Pennsylvania Avenue

Roswell, NM 88201

University of Minnesota

Dept. of Energy and Materials Science

Attn: R. Oriani

151 Amundson Hall

421 Washington Ave SE

Minneapolis, MN 55455

Texas A\&M University

Center of Tectonophysics

Attn: J. Handin

College Station, TX 77840

University of Arizona (2)

Department of Nuclear Engineering

Attn: J. G. McCray

$$
\text { J. J. K. Daemen }
$$

Tucson, AZ 85721

University of Texas at El Paso

Department of Geological Sciences

Attn: D. W. Powers

El Paso, TX 79968
Princeton University

Department of Civil Engineering

Attn: G. Pinder

Princeton, NJ 08504

Netherlands Energy Research Foundation ECN (2)

Attn: T. Deboer, Mgr.

L. H. Vons

3 Westerduinweg

PO Box 1

1755 ZG Petten

THE NETHERLANDS

1540 W. C. Luth

6000 D. L. Hartley

6300 R W. Lynch

6310 T. O. Hunter

6311 L. W. Scully

6312 F. W. Bingham

6314 J. R. Tillerson

6330 W. D. Weart

6330 Sandia WIPP Central Files (700H IND) (2)

6331 A. R. Lappin

6331 R. L. Beauheim (2)

6331 D. J. Borns

6331 M. M. Gonzales

6331 A. L. Jensen

6331 S. J. Lambert

6331 K. L. Robinson

6331 C. L. Stein

6331 D. Tomasko

6332 L. D. Tyler

6332 F. G. Yost

6334 D. R. Anderson

6334 K. Brinster

6334 R. L. Hunter

6416 L. R. Shipers

6416 C. D. Updegraff

7100 C. D. Broyles

7120 M. J. Navratil

7125 R. L. Rutter

7130 J. D. Kennedy

7133 R. D. Statler

7133 J. W. Mercer (2)

7135 P. D. Seward

8024 P. W. Dean

3141 S. A. Landenberger (5)

3151 W. L. Garner (3)

3154-1 C. H. Dalin (28)

For DOE/OSTI (Unlimited Release) 


\section{FIGURE 3-2. LTTHOLOGIC AND GEOPHYSICAL LOGS OF DRILLHOLE DOE-2 --CONTINUED}

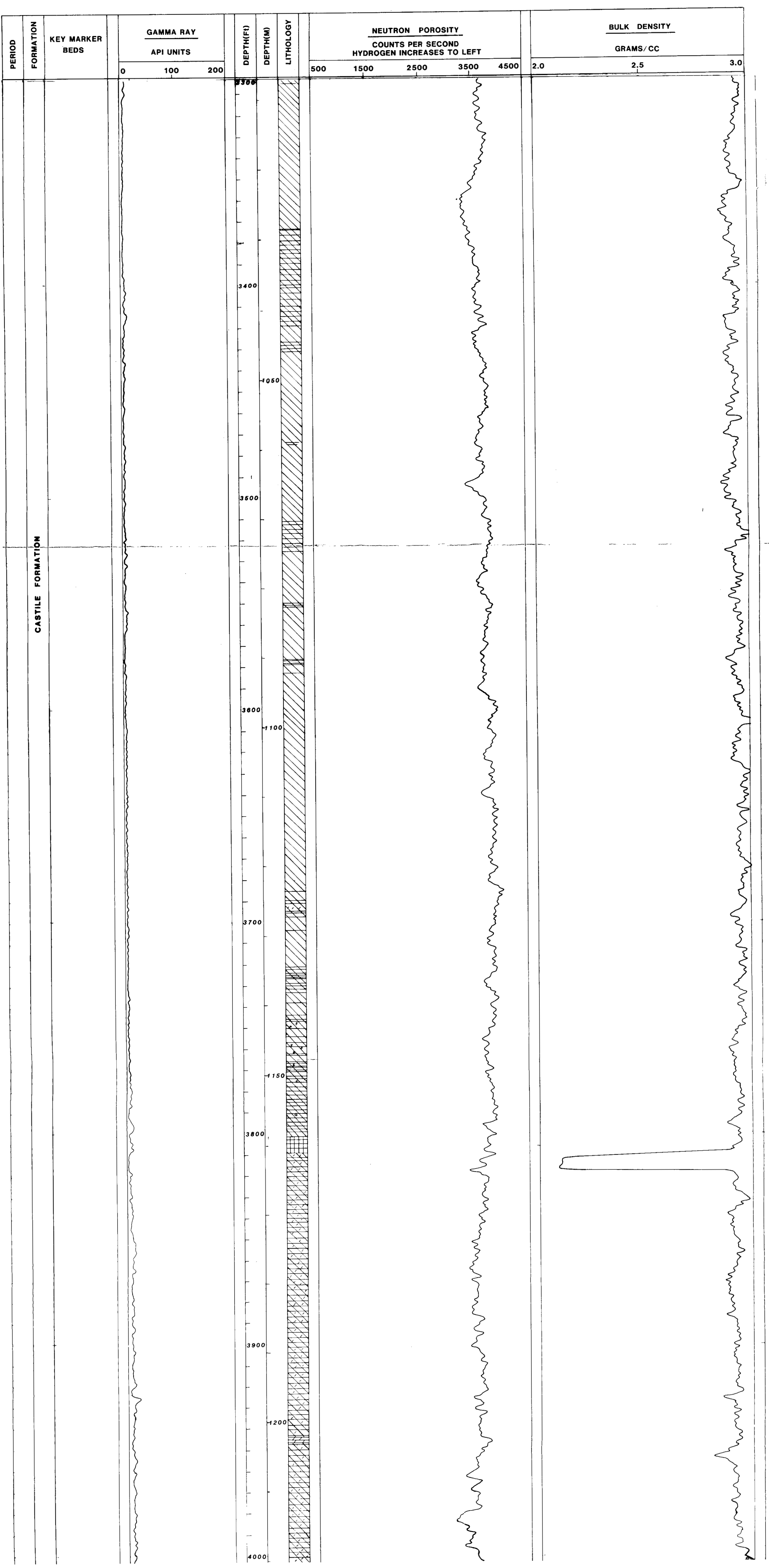




\section{FIGURE 3-2.LTHOLOGIC AND GEOPHYSICAL LOGS OF DRILLHOLE DOE-2 -- CONTINUED
(e) From $2600 \mathrm{ft}$ to $3300 \mathrm{ft}$ Underground}
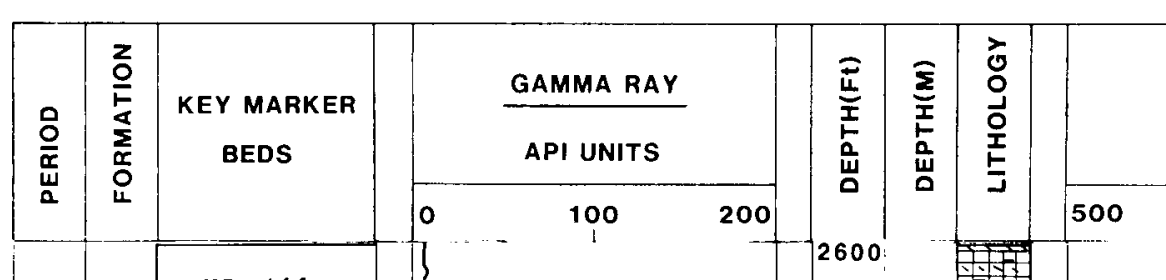

BULK DENSITY

m8 14 $-2600+500$ COUNTS PER SECOND
HYDROGEN INCREASES TO LEFT

$1500 \quad 2500 \quad 3500 \quad 4500 \quad 2.0$ 2,5 3.0
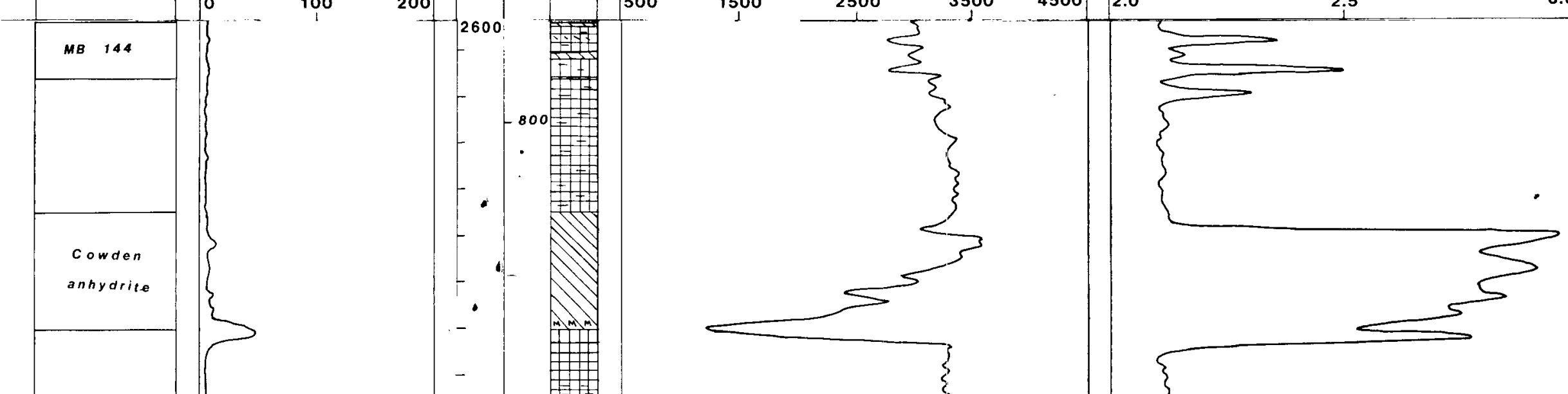

700

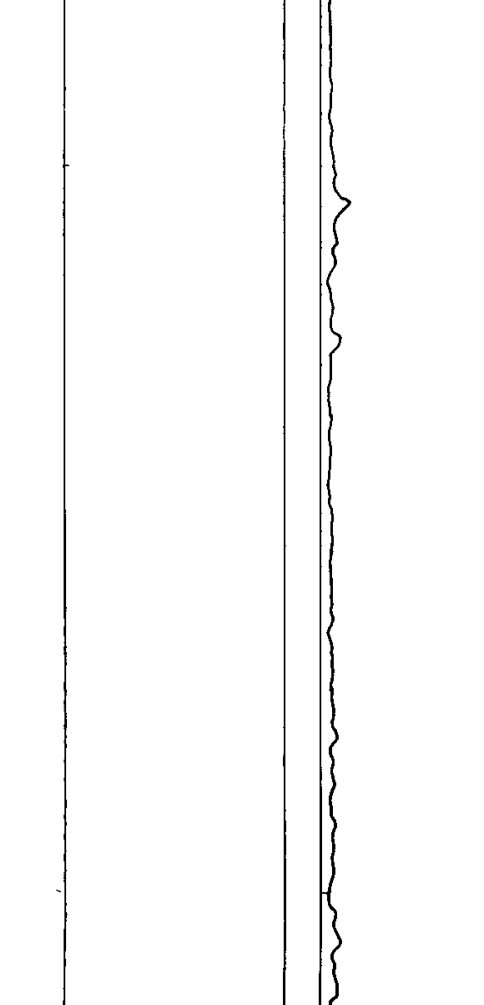

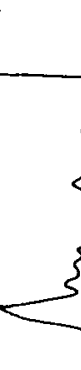
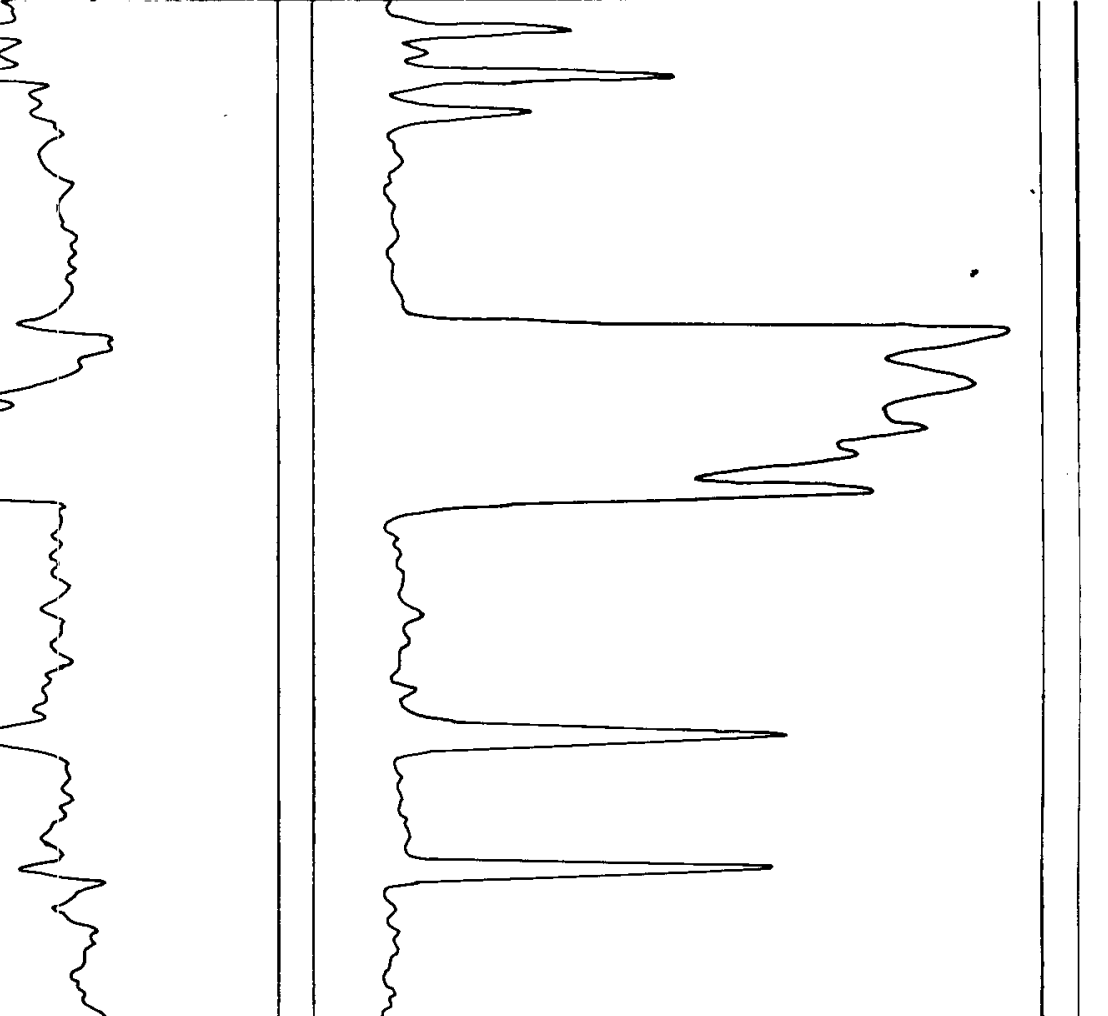


\section{FIGURE 3-2. LITHOLOGIC AND GEOPHYSICAL LOGS OF ORILLHOLE DOE-2 --CONTINUED
(d) From $1900 \mathrm{ft}$ to $2600 \mathrm{it}$ Underground}

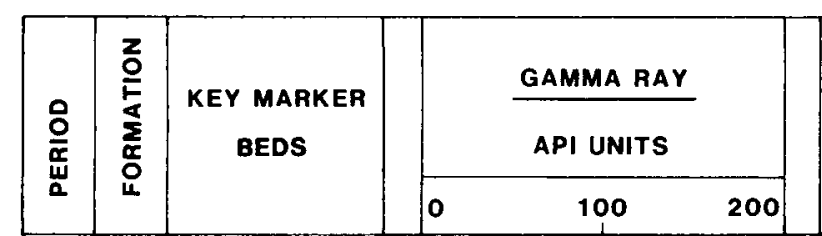

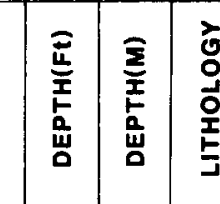
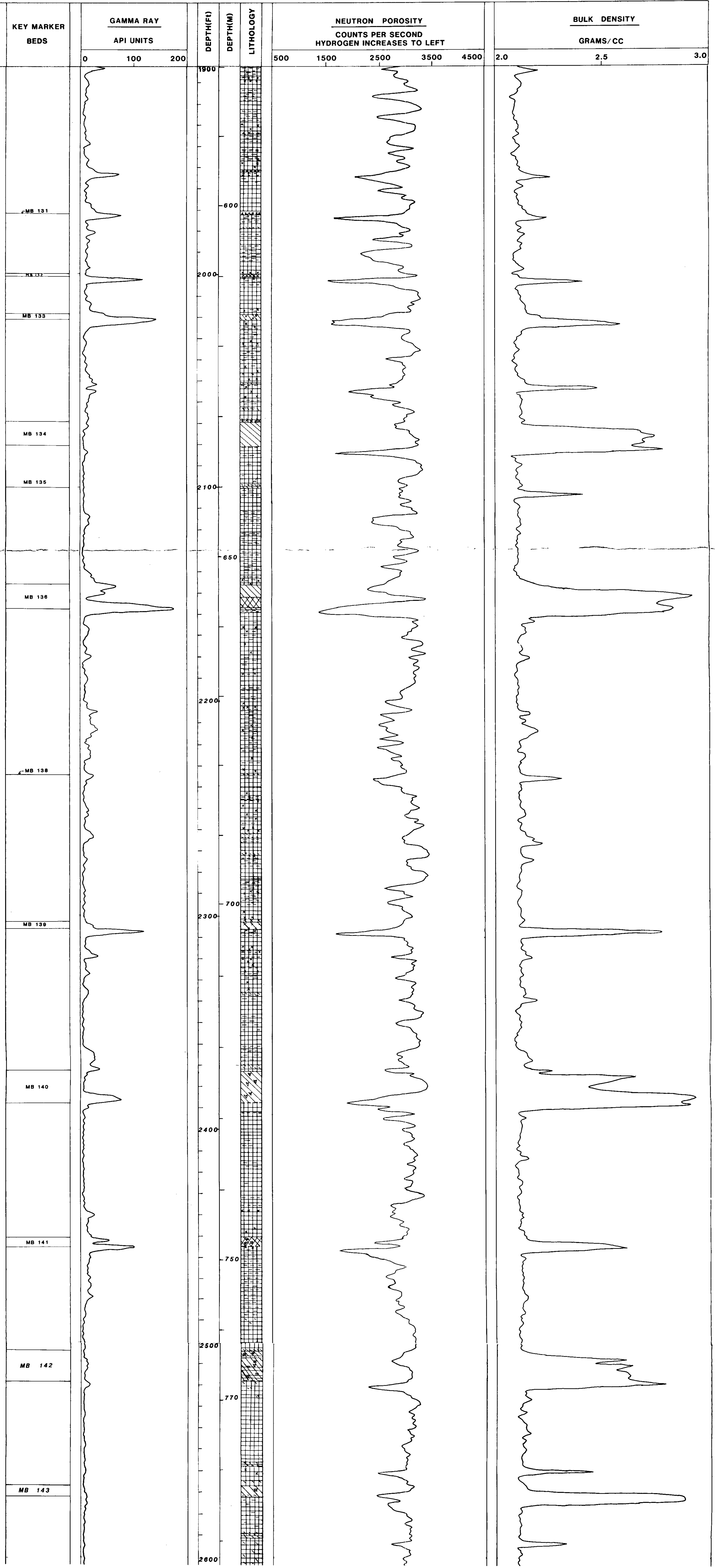
FIGURE 3-2. LITHOLOGIC AND GEOPHYSICAL LOGS OF DRILLHOLE DOE-2 --CONTINUED

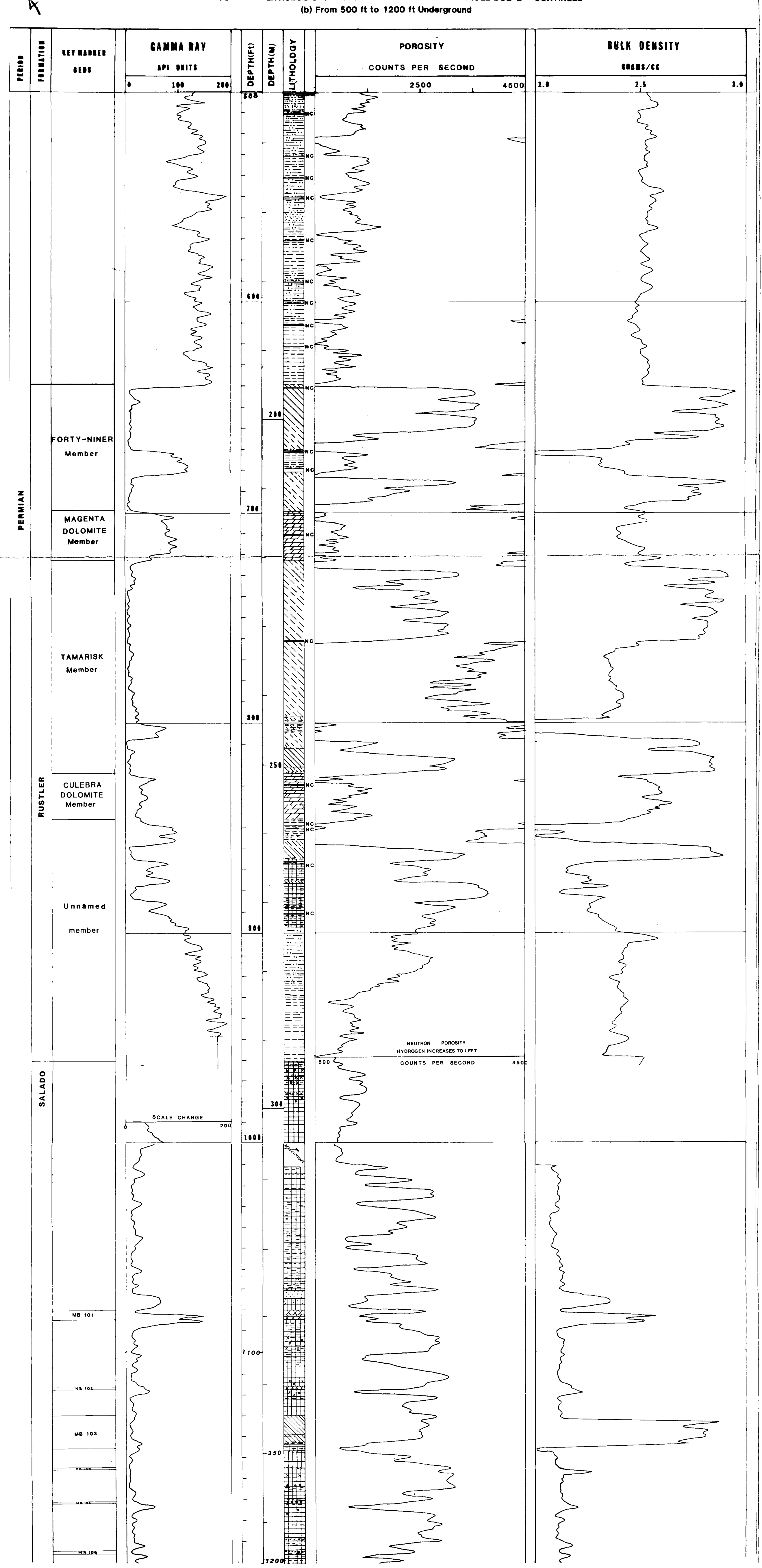




\section{$A$}

FIGURE 3-2. LITHOLOGIC AND GEOPHYSICAL LOGS OF DRILLHOLE DOE-2 (Parts a Through g) (a) Surface to a Depth of $500 \mathrm{f}$

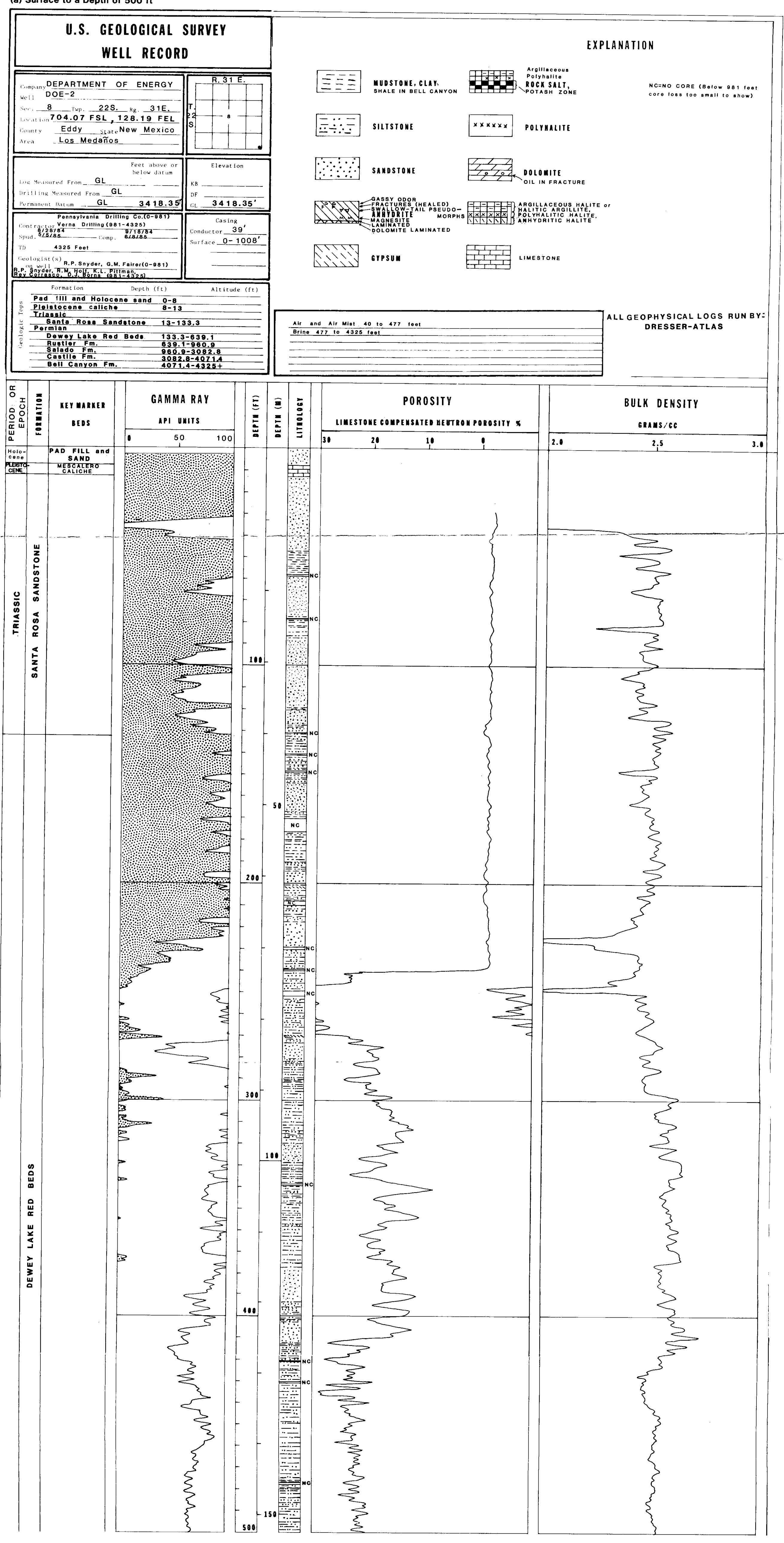

